\title{
ARICONIUM Herefordshire
}

An Iron Age Settlement and Romano-British 'Small Town'

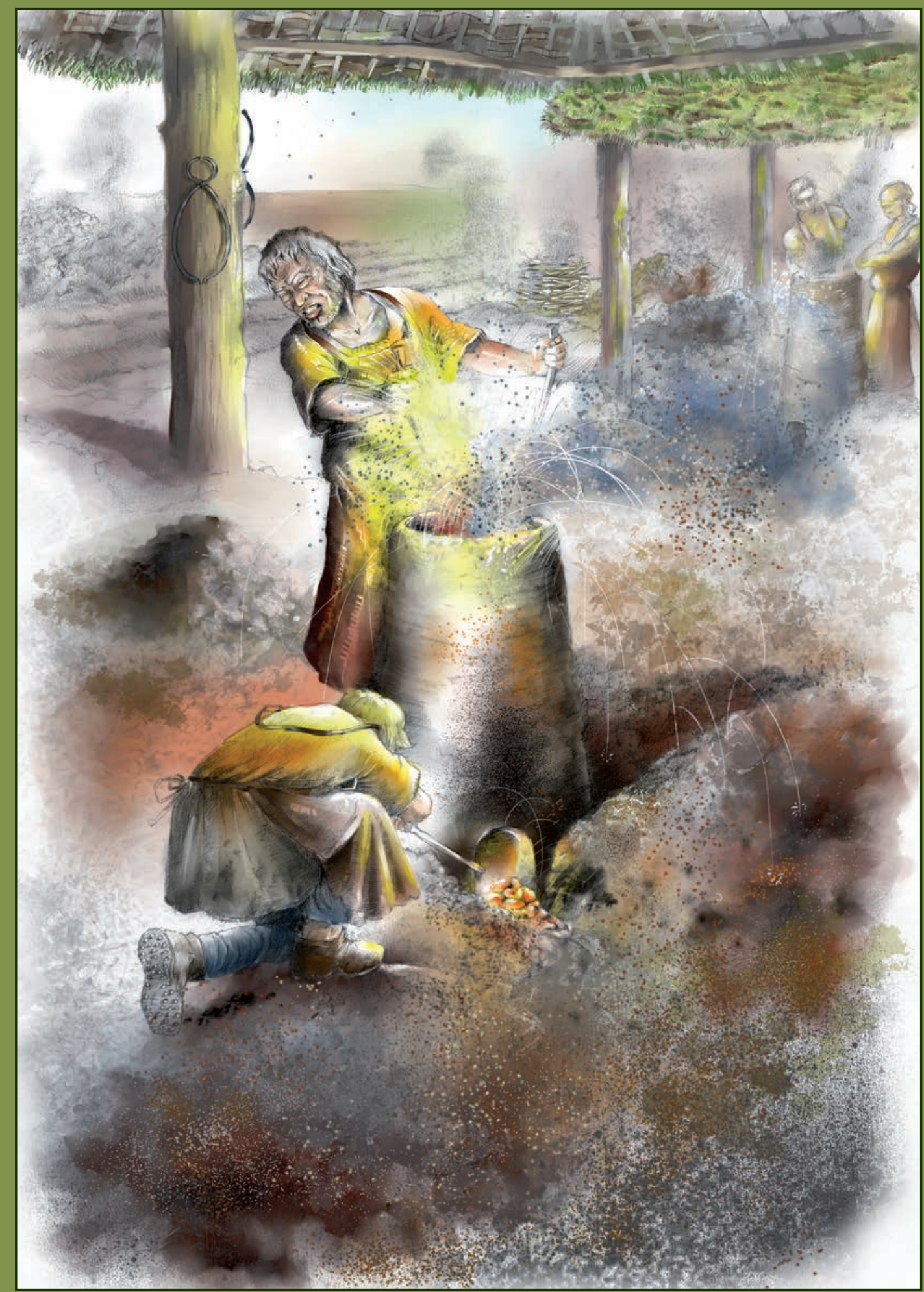

Robin Jackson 
Ariconium, Herefordshire An Iron Age Settlement and

Romano-British 'Small Town' 



\title{
Ariconium, Herefordshire An Iron Age Settlement and
}

Romano-British 'Small Town'

\author{
Robin Jackson
}

With contributions from Hilary Cool, Chris Cox, Rachel Edwards, Rowena Gale, Cathy King, Tony Lloyd, Donald Mackreth, Elizabeth Pearson, Fiona Roe,

Ruth Shaffrey, David Starley, Steven Willis and Tim Young Illustrated by Carolyn Hunt, Steve Rigby and Laura Templeton

\section{OXBOW BOOKS}

Oxford and Oakville 
(c) Oxbow Books, Humber Archaeology Partnership, Worcestershire County Council and the authors 2012

ISBN 978-1-84217-449-4

A CIP record for this book is available from the British Library

This book is published with the aid of a grant from English Heritage.

English Heritage is now Historic England

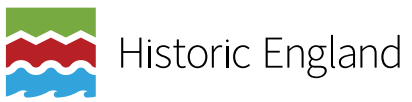

This book is available to download from

http://books.casematepublishing.com/Ariconium_Herefordshire.pdf

Front cover: Roman Iron Workers by Steve Rigby

Library of Congress Cataloging-in-Publication Data

Jackson, Robin.

Ariconium, Herefordshire : an Iron Age settlement and Romano-British "small town" / Robin Jackson ; with contributions from Hilary Cool ... [et al.] ; illustrated by Carolyn Hunt, Steve Rigby and Laura Templeton.

p. $\mathrm{cm}$.

Includes bibliographical references and index.

ISBN 978-1-84217-449-4

1. Herefordshire (England)--Antiquities. 2. Iron age--England--Herefordshire. 3. Great Britain--History--Roman period, 55 B.C.-449 A.D.--Antiquities. 4. Romans--Great Britain--Antiquities. I. Cool, H. E. M. II. Title.

DA670.H4J33 2012

936.2' $42--d c 23$ 
'In elder days, ere yet the Roman bands

Victorious, this our other world subdu'd,

A spacious City stood, with firmest walls

Sure mounded, and with num'rous turrets crown's,

Aerial spires, and citadels, the seat

Of Kings, and heroes resolute in war,

Fam'd Ariconium; uncontrol'd and free,

Till all-subduing Latin arms prevail'd.

Then also, tho' to foreign yoke submiss,

She undemolished stood; and ev'n till now,

Perhap, had stood, of ancient British art

A pleasing monument, not less admir'd

Than what from Attic or Etruscan hands

Arose, had not the Heav'nly pow'rs averse

Decreed her final doom;

Old Ariconium sinks, and all her tribes,

Heroes and senators, down to the realms

Of endless night. Meanwhile the loosen'd winds

Infuriate, molten rocks, and flaming globes,

Hurl'd high above the clouds, til, all their force

Consum'd, her ravenous jaws the earth satiate clos'd

Thus this fair City fell, of which the name

Survives alone; nor is there found a mark

Whereby the curious passenger may learn

Her ample site, save coins and mouldering urns,

And huge unweildy bones, lasting remains

Of that gigantic race, which, as he breaks

The clotted glebe, the ploughman haply finds,

Appall'd. Upon that treacherous tract of land

She whildom stood, now Ceres in her prime

Smiles fertile.

Philips (1676-1708) in his 'Poem on Cyder' 



\section{Contents}

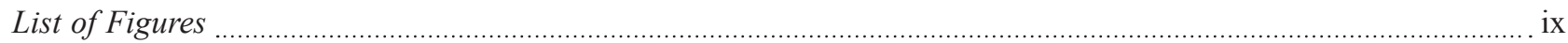

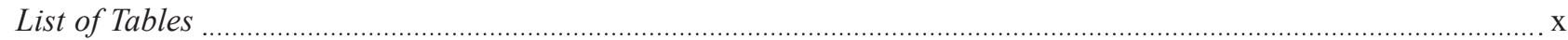

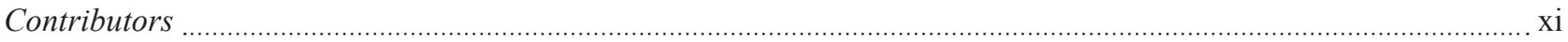

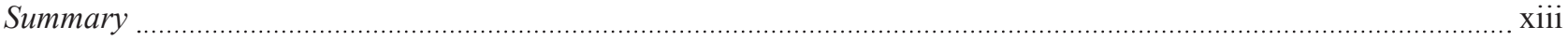

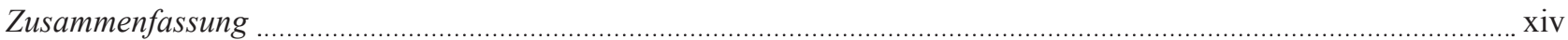

Résumé

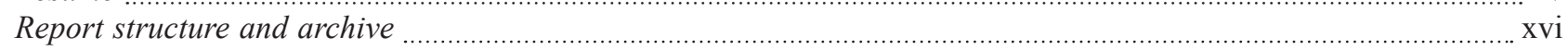

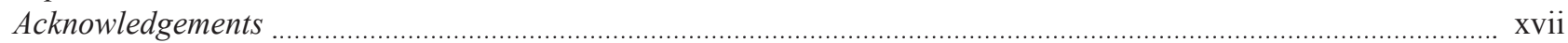

\section{SECTION 1. BACKGROUND}

Introduction

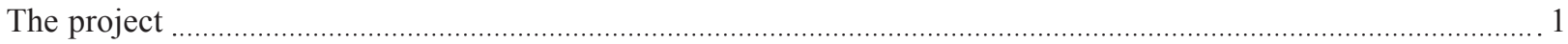

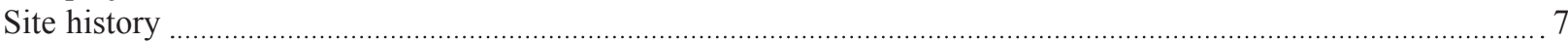

SECTION 2: ARCHAEOLOGICAL INVESTIGATIONS: SUMMARY AND ANALYSIS

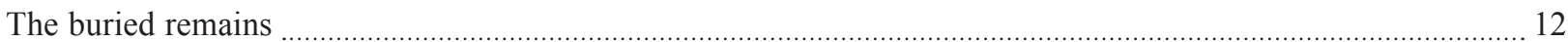

Fieldwalking and other sources

SECTION 3: EROSION AND DEPOSITION HISTORY

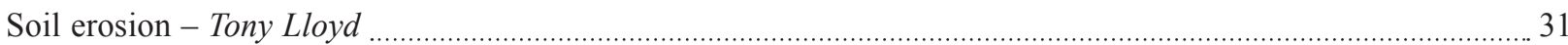

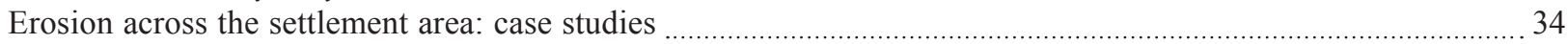

\section{SECTION 4: THE FINDS AND ENVIRONMENTAL EVIDENCE}

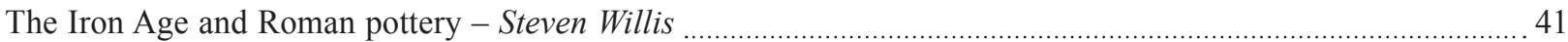

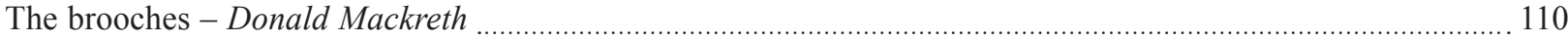

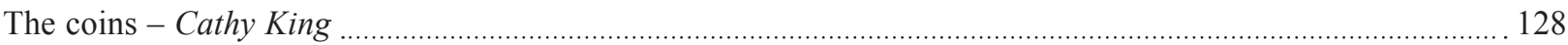

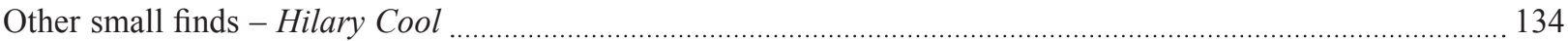

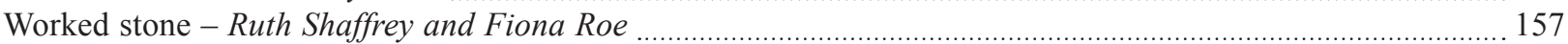

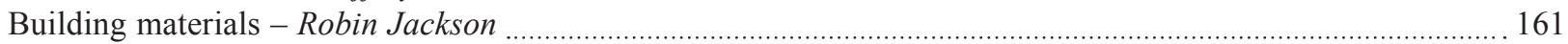

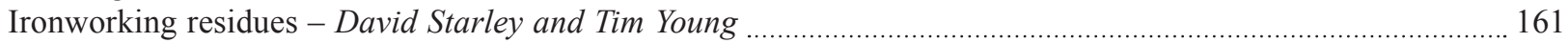

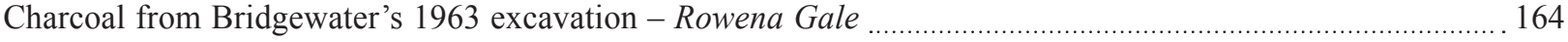

Environmental evidence - Elizabeth Pearson

\section{SECTION 5: ARCHAEOLOGICAL SYNTHESIS}

The character of the settlement $\quad 169$

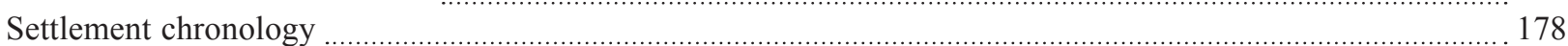

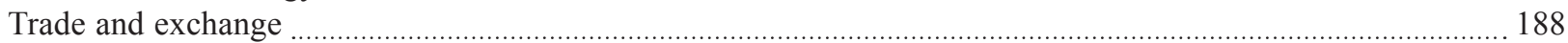

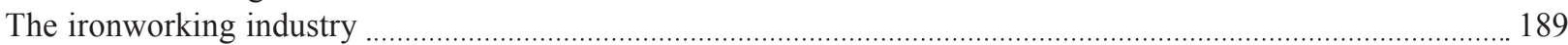

SECTION 6: MANAGEMENT, EROSION AND LANDUSE

Management, erosion and landuse 


\section{SECTION 7: CONCLUDING REMARKS}

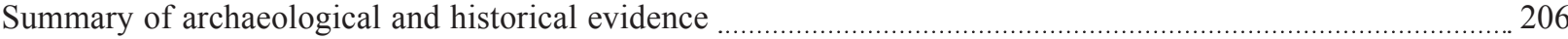

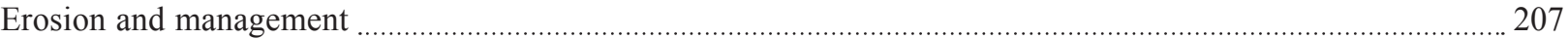

Areas for future research

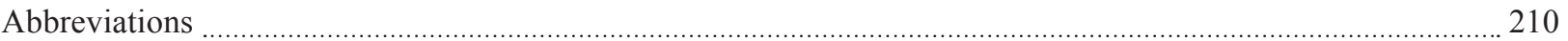

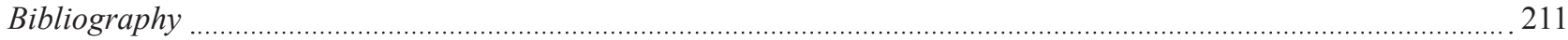

APPENDICES

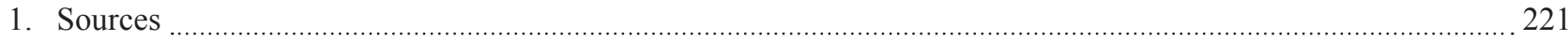

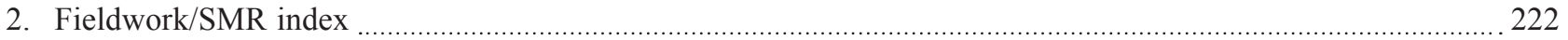

3. Aerial photographic assessment …

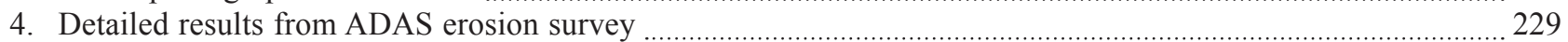

5. Concordance of pottery fabric codes used in the report with WAS fabric series codes ......................................... 236

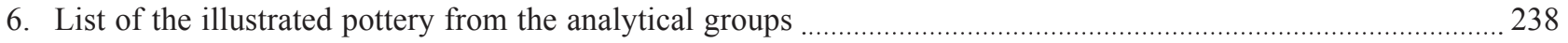

7. Samian catalogue

8. Coin catalogue

Index 


\section{List of Figures}

1.1. Location of Ariconium project study area

1.2. Study area showing CMHTS urban extents and scheduled area

1.3. Areas of trenching (salvage recording, evaluation and excavation)

1.4. Areas of surface collection (fieldwalking, metal detecting, spot finds)

1.5. Cropmark plot

2.1. The 'kitchen block' (HSM 16780; after Jack 1923)

2.2. Plan of ironworking features north of the scheduled area (after Bridgewater 1965)

2.3. Sections across ironworking features north of the scheduled area (after Bridgewater 1965)

2.4. Areas of 'black loam' and trench locations (Garrod and Moss 1967)

2.5. Garrod and Moss 1967, Trench CXX (HSM 23552)

2.6. Garrod and Moss 1967, Trench CI (HSM 23551)

2.7. Plan and section of trench at The Great Woulding (HSM 9071; after Walters and Walters 1989)

2.8. Trenches along the route of the Welsh Water pipeline (HSM 6097; Jackson, Hancocks and Pearson 1999)

2.9. Welsh Water pipeline 1993, Trench 3 (HSM 6097)

2.10. Welsh Water pipeline 1993, Trench 4 (HSM 6097)

2.11. Welsh Water pipeline 1993, Trenches 6 and 8/14 (HSM 6097)

2.12. Welsh Water pipeline 1993, Trenches 10 and 11 (HSM 6097)

2.13. Deposits to the south-east of Pond Cottage (HSM 12666; Jackson, Hancocks and Pearson 1999)

2.14. Plot of located metal detecting finds

3.1. Extents of the ADAS survey

3.2. Composite profile through deposits investigated on the Welsh Water pipeline

4.1. Pottery: Black burnished ware 1

4.2. Pottery: Limestone tempered ware

4.3. Pottery: Limestone tempered ware (cont.)

4.4. Pottery: Fine wares

4.5. Pottery: Malvernian metamorphic ware

4.6. Pottery: Mortaria

4.7. Pottery: Mortaria

4.8. Pottery: Severn Valley ware

4.9. Pottery: Severn Valley ware

4.10. Pottery: Severn Valley ware

4.11. Pottery: Severn Valley ware

4.12. Pottery: Severn Valley ware

4.13. Pottery: Severn Valley ware

4.14. Pottery: Severn Valley ware
4.15. Pottery: Severn Valley ware, Oxfordshire wares and other oxidised wares

4.16. Pottery: Unoxidised Severn Valley ware

4.17. Pottery: Unoxidised Severn Valley ware and Unoxidised ware

4.18. Pottery: Unoxidised wares

4.19. Pottery: Samian wares and samian stamps

4.20. Distribution of South Gaulish samian

4.21. Distribution of Central Gaulish samian

4.22. Distribution of East Gaulish samian

4.23. The relative frequency, by rim equivalent, of jars and storage jars within various pottery groups from Ariconium

4.24. The relative frequency, by rim equivalent, of bowls within various pottery groups from Ariconium

4.25. The relative frequency, by rim equivalent, of beakers within various pottery groups from Ariconium

4.26. The relative frequency, by rim equivalent, of tankards within various pottery groups from Ariconium

4.27. Distribution of Oxfordshire colour coated wares

4.28. Distribution of Limestone tempered ware

4.29. Distribution of Dressel 20 amphora

4.30 Scattergram showing percentages of jars within site groups from southern Britain plotted against percentages of bowls and dishes present.

4.31. Severn Valley ware: face pot

4.32. The brooches (Catalogue numbers 1-16)

4.33. The brooches (Catalogue numbers 17-34)

4.34. The brooches (Catalogue numbers 35-57)

4.35. The brooches (Catalogue numbers 59-75)

4.36. The brooches (Catalogue numbers 77 and 79)

4.37. Other small finds (Personal ornaments)

4.38. Other small finds (Personal ornaments and toilet equipment)

4.39. Other small finds (Household utensils, recreational equipment and surveying and measuring equipment)

4.40. Other small finds (Writing equipment, military equipment, religious items and keys/locks

4.41. Other small finds (Box fittings and studs, other fastenings and fittings and metalworking finds)

4.42. Quernstones/millstones

4.43. Quernstones/millstones

4.44. Other stone objects

5.1. Summary of buried remains

5.2. Sites in the region

5.3. The late Iron Age settlement

5.4. The early Roman settlement (c. AD 50 to 100) 
5.5. The Roman 'small town' (c. AD 100 to 250)

5.6. The Roman 'small town' (c. AD 250 to 400)

6.1. The changing composition of surface finds by phase

6.2. Cartographic evidence for field boundary removal
6.3. Decay profile for deposits at Ariconium (based upon MARS; Darvill and Fulton 1998)

6.4. Areas of potential erosion

\section{List of Tables}

1. Fields at Bollitree Farm (ADAS)

2. Summary of data on fields where erosion occurred

3. Probable reasons why certain fields suffered no erosion

4. The quantities of pottery surviving and analysed from the various fieldwork projects undertaken at Ariconium

5. Quantification by fabric of Analytical Group 1

6. Quantification by fabric of Analytical Group 3

7. Quantification by fabric of Analytical Group 4

8. Quantification by fabric of Analytical Group 5

9. Quantification by fabric of Analytical Group 6

10. Quantification by fabric of Analytical Group 7

11. Quantification by fabric of Analytical Group 8

12. Quantification by fabric of Analytical Group 9

13. Summary quantification by vessel form of Analytical Group 1

14. Quantification by vessel form and fabric of Analytical Group 1

15. The composition of Analytical Group 2 by vessel form and fabric

16. Summary quantification by vessel form of Analytical Group 3

17. Quantification by vessel form and fabric of Analytical Group 3

18. Summary quantification by vessel form of Analytical Group 4

19. Quantification by vessel form and fabric of Analytical Group 4

20. Summary quantification by vessel form of Analytical Group 5

21. Quantification by vessel form and fabric of Analytical Group 5

22. Summary quantification by vessel form of Analytical Group 6

23. Quantification by vessel form and fabric of Analytical Group 6

24. Summary quantification by vessel form of Analytical Group 7

25. Quantification by vessel form and fabric of Analytical Group 7

26. Summary quantification by vessel form of Analytical Group 8
27. Quantification by vessel form and fabric of Analytical Group 8

28. Summary quantification by vessel form of Analytical Group 9

29. Quantification by vessel form and fabric of Analytical Group 9

30. The chronology of the Bridgewater 1963 samian

31. The composition of the Bridgewater 1963 samian on the basis of rims

32. The composition of the surviving Garrod and Moss 1967 samian assemblage

33. The chronology of the samian collected by Bridgewater from the surface of field HSM 21376

34. The composition of the samian collected by Bridgewater from the surface of field HSM 21376

35. The chronology of the samian collected by DAG from the surface of field HSM 21376

36. The composition of the samian collected by DAG from the surface of field HSM 21376

37. The chronology of the samian collected by Bridgewater from the surface of field HSM 21378

38. The composition of the samian collected by Bridgewater from the surface of field HSM 21378

39. The proportions of beakers and tankards, and of cups within the analytical groups, as a percentage of each group as a whole

40. The average rim equivalent value for rim sherds in Oxidised Severn Valley ware within the analytical groups

41. The average rim equivalent value for rim sherds in Oxidised Severn Valley ware R21 within the analytical groups

42. The Iron Age coins

43. Summary of Roman coins

44. Distribution of Roman coins by period

45. Slag weight totals from the Welsh Water pipeline

46. Ironworking residues. List of examined material (iron slags)

47. Ironworking residues. Raw wholerock major element analyses by XRF

48. Charcoal from metal-working contexts 


\section{Contributors}

Robin Jackson, Elizabeth Pearson, Carolyn Hunt, Steve Rigby and Laura Templeton

Worcestershire County Council

Historic Environment and Archaeology Service

Woodbury

The Hive

Sawmill Walk

The Butts

Worcester WR1 3TD

Hilary CoOL

16 Lady Bay Road

West Bridgford

Nottingham NG2 5BJ

Chris Cox

Air Photo Services Ltd

Brinkworth House Business Centre

Brinkworth

Wiltshire SN15 5DF

RACHEL EDWARDS

Arboretum Archaeological Consultancy

4 Wood Terrace

Worcester WR1 1NY

Rowena Gale

Folley Cottage

Chut Cadley

Andover

Hampshire SP11 9EB

CATHY KING

Heberden Coin Room

The Ashmolean Museum

Oxford OX1 2PH

TONY LLOYD

29 Brighton Road

Redland

Bristol BS6 6NU
Donald Mackreth

126 London Road

Peterborough PE2 9BY

Fiona Roe

Blackthorn Cottage

Vicarage Lane

Hillesley

Wotton under Edge

Gloucestershire GL12 7RA

David Starley

75 Albert Road

Saltaire

Shipley

West Yorkshire BD18 4NS

Ruth SHAFFrey

Oxford Archaeology South

Janus House

Osney Mead

Oxford OX2 0ES

Steven Willis

School of European Culture and Languages (SECL)

Cornwallis Building NW

University of Kent

Canterbury CT2 7NF

TIM Young

GeoArch

Unit 6

Western Industrial Estate

Caerphilly CF83 1BQ 



\section{Summary}

The Ariconium Project was undertaken between 1998-2003 in response to the poor state of understanding of this nationally important, Roman industrial 'small town'.

The settlement had late pre-Roman Iron Age origins and enjoyed wide trading links and considerable status. It is argued that, through control of the production and distribution of Forest of Dean iron, it was able to develop as an important centre on the fringes of Dobunnic territory. There is a strong sense of continuity into the Roman period and the settlement maintained its comparatively high status into the early 2nd century. Ironworking again probably provided the basis for this position and the native population was clearly able to rapidly articulate with the new economic opportunities the Roman conquest brought.

In the early 2 nd century a domestic core emerged to the immediate west of a major Roman road junction and an extensive ironworking area developed to the north. During the 2nd and through into the 3rd century settlement reached its maximum extent. However, although Ariconium was a major iron production centre throughout this period, in comparison with its earlier importance its development was more typical of roadside 'small towns' elsewhere in southern England. From about the mid-3rd century onwards the settlement extent appears to have been declining; however, a new ironworking centre developed to the south-west, probably to replace the one to the north which was abandoned. This new area was active well into the 4 th century.

The economic basis for the Roman 'small town' was iron smelting and the site formed part of an extensive network of iron producing settlements distributed around the fringes of the Forest of Dean. Within this network, Ariconium was probably the most important production centre complementing a range of other settlements of varying size. In the absence of any evidence for imperial management, it is argued that the organisation of the industry was maintained by a civilian 'native' elite and was influenced by pre-Roman factors. It is also suggested that a primary determining factor in locating smelting centres may not have been the ore sources, but the supply of charcoal to fuel the furnaces.

The status of the later settlement is uncertain but artefactual evidence indicates that significant occupation continued until at least about AD 350. Only a handful of artefacts are dated later than this and it is evident that the site fell into a sharp decline in the later 4 th century. There is no excavated or artefactual evidence for 5th or 6th century occupation. It is, however, unlikely that the settlement was entirely deserted and the survival of the name Ariconium in the early medieval Welsh kingdom of Ergyng or Archenfield has been taken to imply some continuity of settlement at Ariconium itself, perhaps with political importance within an emerging subkingdom.

Apart from a thin scatter of medieval finds, there is no evidence for significant activity until the late 17th to 18th century. At this time, iron 'cinders' from Ariconium were probably amongst those extracted from Roman sites throughout the Forest of Dean for re-smelting at ironworks such as at nearby Linton. In the mid-18th century the site first came to antiquarian attention following clearance and enclosure of overgrown land that it occupied. Over the subsequent 250 years the area has provided a focus for collection of surface finds and latterly for a range of small-scale archaeological projects.

Throughout the period since its clearance the site has mostly been in arable use as reflected in numerous reports of surface finds. These reports allied to the undertaking of a survey by the Agricultural and Development Advisory Service (ADAS) have prompted a related element of the project which was to examine processes of erosion resulting from former and current landuse at the monument. This has demonstrated that changes in landuse have caused considerable damage to archaeological remains, damage which has clearly continued, and in some respects, accelerated since scheduling. After the initial impact of clearance and initial ploughing in the 18th century, damage was probably localised until the last 50 years when a major impact is liable to have resulted from a combination of plough damage and soil erosion arising from changing agricultural practice. Crop cycles and wider land management practices have been identified which will minimise the potential for such erosion. It is suggested that a management agreement should be sought to implement these practices across the monument, thus securing the long-term preservation of this nationally important site.

The two elements of the project are closely interrelated. Erosion of the site resulting from agricultural practice has resulted in the exposure of artefacts on the surface. These have led to the identification of the site and have prompted archaeological fieldwork which aided by the ADAS survey has resulted in the recognition, by archaeologists, of the problem of soil erosion at the site. This project has not only resulted in a new understanding of a nationally important Roman settlement but has also identified a problem which the site will face through the 21 st century. 


\section{Zusammenfassung}

Das Ariconium Projekt wurde von 1998 bis 2003 durchgeführt, um die unzureichende Kenntnis dieser national bedeutenden römischen „Industriekleinstadt" zu verbessern.

Die Siedlung hat vorrömische eisenzeitliche Ursprünge und besaß weiträumige Handelsbeziehungen und einen bemerkenswerten Status. Man kann davon ausgehen, dass sie durch die Kontrolle von Produktion und Distribution von Eisen des Forest of Dean Gebiets in der Lage war sich zu einem wichtigen Zentrum an den Rändern des Dobunnic Territoriums zu entwickeln. Die Kontinuität in die römische Epoche lässt sich deutlich erkennen, und die Siedlung behielt ihren vergleichsweise hohen Status bis ins frühe 2. Jahrhundert n.Chr. bei. Die Eisenverhüttung bildete sehr wahrscheinlich die Grundlage für diese Stellung; die einheimische Bevölkerung war offensichtlich in der Lage sich auf die neuen wirtschaftlichen Möglichkeiten einzustellen, die die römische Eroberung mit sich brachte.

Im frühen 2. Jahrhundert entstand eine Wohnsiedlung unmittelbar westlich einer römischen Straßenkreuzung und ein extensives Areal für Eisenverarbeitung entwickelte sich im Norden. Im Verlauf des 2. und bis ins 3. Jahrhundert erreichte die Besiedlung ihre maximale Ausdehnung. Doch obwohl Ariconium während dieser Zeit ein wichtiges Zentrum der Eisenproduktion war, entsprach seine Entwicklung im Vergleich mit seiner vorherigen Bedeutung eher der einer typischen südenglischen „Straßenkleinstadt“. Ab der Mitte des 3. Jahrhunderts scheint die Ausdehnung der Siedlung zu schrumpfen, während sich gleichzeitig ein Eisenverarbeitungszentrum im Südwesten entwickelte, vermutlich um jenes im Norden zu ersetzen, das verlassen wurde. Das neue Areal blieb bis weit ins 4. Jahrhundert in Gebrauch.

Die ökonomische Basis der römischen „Kleinstadt“ war die Eisenverhüttung und der Ort bildete einen Teil eines extensiven Netzwerks eisenverarbeitender Siedlungen, das sich um die Ränder des Forest of Dean erstreckte. Ariconium war wahrscheinlich das bedeutendste Produktionszentrum innerhalb dieses Netzwerks und komplettierte eine Reihe weiterer Siedlungen unterschiedlicher Größe. Mangels Hinweisen auf eine Leitung von kaiserlicher Seite wird davon ausgegangen, dass die Organisation des Gewerbes einer zivilen „einheimischen“ Elite oblag und von vorrömischen Faktoren beeinflusst wurde. Ein solcher ursprünglicher Faktor, so wird vorgeschlagen, durch den die Verhüttungsplätze hier angelegt wurden, waren nicht die Erzlagerstätten, sondern die Versorgung mit Holzkohle um die Schmelzöfen zu beheizen.

Der Status der späten Besiedlung ist unsicher, doch weisen Artefakte darauf hin, dass eine bedeutende Ansiedlung noch bis mindestens 350 n.Chr. bestand. Nur eine Handvoll Artefakte kann in noch spätere Zeit datiert werden, und es wird deutlich, dass der Ort im späten 4. Jahrhundert einem schnellen Niedergang unterlag. Es liegen weder Funde noch Befunde für eine Nutzung im 5. oder 6. Jahrhundert vor.
Jedoch ist es unwahrscheinlich, dass die Siedlung vollständig verlassen war, und das Überleben des Namens Ariconium im frühmittelalterlichen walisischen Königreich Ergyng oder Archenfield deutet offensichtlich auf eine Kontinuität der Besiedlung in Ariconium selbst, vielleicht mit politischem Gewicht innerhalb eines entstehenden Unterkönigreichs.

Abgesehen von einer geringen Streuung mittelalterlicher Funde gibt es keine Hinweise für größere Aktivitäten bis ins späte 17. und ins 18. Jahrhundert. Zu dieser Zeit wurden Eisenschlacken aus verschiedenen römischen Fundstellen im Forest of Dean geborgen, vermutlich auch aus Ariconium, um sie in Eisenhütten wie im nahegelegenen Linton erneut zu schmelzen. In der Mitte des 18. Jahrhunderts fiel der Fundplatz Ariconium der antiquarischen Forschung auf, nachdem das Gelände gerodet und erschlossen worden war. Während der folgenden 250 Jahre wurden auf dem Areal häufig Oberflächenfunde geborgen und in jüngerer Zeit mehrere kleine archäologische Projekte durchgeführt.

Seit der Erschließung des Geländes war der Fundplatz überwiegend agrarisch genutzt worden, was sich aus zahlreichen Fundberichten von Oberflächenfunden erkennen lässt. In Verbindung mit einem Survey des Agricultural and Development Advisory Service (ADAS) haben diese Berichte zu einem Bestandteil des Projekts geführt, der darauf ausgerichtet war, Erosionsprozesse zu untersuchen, die aus der früheren und gegenwärtigen Landnutzung des Areals resultieren. Diese Untersuchung zeigte, dass Veränderungen in der Landnutzung beträchtliche Schäden an den archäologischen Hinterlassenschaften bewirkt haben, und die Zerstörung hat sich fortgesetzt seit es als Historisches Denkmal (Scheduled Ancient Monument) eingetragen wurde - und teilweise sogar beschleunigt. Von den ersten Eingriffen durch Rodung und erstem Pflügen im 18. Jahrhundert bis vor etwa 50 Jahren waren die Schäden wohl nur lokal, bis eine Kombination der Schädigung durch Pflügen und Bodenerosion durch den Wechsel der Agrarmethoden zu massiven Auswirkungen führte. Fruchtwechsel und vielfältigere Landnutzungsmethoden werden als Möglichkeiten genannt, um diese Erosion verringern zu können. Es wird vorgeschlagen ein Abkommen zur Nutzung des Areals zu erarbeiten, durch das diese Praktiken implementiert werden, um die dauerhafte Erhaltung dieses national wichtigen Fundplatzes zu sichern.

Die beiden Bestandteile des Projekts sind eng miteinander verknüpft. Die Erosion des Geländes durch die bisherigen Agrarmethoden resultierte in der Freilegung von Funden an der Oberfläche. Diese führten zur Identifikation des Fundplatzes und zu archäologischen Untersuchungen, die, unterstützt durch den ADAS Survey, die Archäologen das Problem der Bodenerosion erkennen ließen. Dieses Projekt resultierte somit nicht nur in einer besseren Kenntnis einer national bedeutenden römischen Siedlung, sondern es offenbarte auch ein Problem, dem sich der Fundplatz im 21. Jahrhundert stellen muss. 


\section{Résumé}

Le projet Ariconium fut entrepris entre 1998 et 2003 en réaction au fait qu'on comprenait mal cette 'petite ville' industrielle romaine d'importance nationale.

L'occupation remontait à la fin de l'âge du fer pré-romain et jouissait de liens commerciaux étendus et d'un statut considérable. On argumente qu'en contrôlant et distribuant le fer de la forêt de Dean, elle a pu s'agrandir en un important centre en bordure du territoire des Dobunnic. Une forte impression de continuité se prolonge dans la période romaine et l'occupation a conservé son statut relativement élevé jusqu'au début du IIe siècle. A nouveau, c'était probablement sur la métallurgie que reposait la base de cette position et la population locale se montra, de toute évidence, capable d'assimiler rapidement les nouvelles opportunités économiques apportées par la conquête romaine.

Au début du IIe siècle émergea une unité domestique juste à l'ouest d'un important croisement de voies romaines et une zone extensive de métallurgie se développa au nord. Pendant le IIe et une partie du IIIe siècle l'occupation atteignit son étendue maximale. Cependant, bien qu'Ariconium fut un important centre de production de fer tout au long de cette période, une comparaison avec son importance antérieure montre que son évolution était plus typique des 'petites villes' de bord de route ailleurs dans le sud de l'Angleterre. A partir environ du milieu du IIIe siècle, il semble que l'étendue de l'occupation ait connu une période de déclin, cependant, un nouveau centre de métallurgie s'est développé au sud-ouest, probablement pour remplacer celui au nord qui avait été abandonné. Cette nouvelle zone continua d'être en activité pendant une bonne partie du IVe siècle.

La base de l'économie des 'petites villes' romaines était l'extraction du fer et le site faisait partie d'un réseau étendu d'occupations productrices de fer réparties autour de la lisière de la forêt de Dean. A l'intérieur de ce réseau, Ariconium constituait probablement le centre de production le plus important, venant compléter un nombre d'autres occupations de diverses tailles. En l'absence de toute preuve de directives impériales, on argumente qu'une élite civile indigène contrôlait l'organisation de cette industrie et était influencée par des facteurs pré-romains. On émet aussi l'idée qu'il se pourrait qu'un facteur primaire déterminant dans le choix des sites d'extraction n'ait pas été la présence de minerai mais la disponibilté de charbon de bois pour alimenter les fourneaux.

Nous ne sommes pas certains du statut de l'occupation par la suite mais les témoignages des objets manufacturés indiquent qu'une occupation significative s'y est maintenue au moins jusque vers 350 ap- J.-C. Seule une poignée d'objets présente une datation plus tardive et il est évident que le site avait décliné rapidement pendant la deuxième moitié du IVe siécle. Il n'existe aucun témoignage, reposant sur des fouilles ou des objets, concernant l'occupation au Ve et VIe siècles. Il est, cependant, improbable que le site ait été complètement abandonné et le fait que le nom Ariconium ait survécu au début du moyen-âge dans le royaume gallois d'Eryng ou Archenfield a été interprété comme impliquant une certaine continuité de l'occupation d'Ariconium même, peut-être avec une importance politique à l'intérieur d'un sous-royaume émergeant.

A part un petit nombre de trouvailles médiévales éparpillées, il n'existe aucun témoignage d'activité significative avant la fin du XVIIe et le XVIIIe siècles. A cette époque, des scories d'Ariconium se trouvaient probablement parmi celles extraites des sites romains de toute la forêt de Dean pour être refondues dans des fonderies proches telles que celle de Linton. Au milieu du XVIIIe siècle, le site attira pour la première fois l'attention des amateurs d'antiquités après qu'on eut débarrassé et clôturé le terrain en friche sur lequel il se trouvait. Au cours des 250 années qui suivirent la zone fut un lieu de prédilection pour la collecte de trouvailles en surface et plus récemment pour diverses campagnes archéologiques de petite envergure.

Tout au long de la période qui a suivi son défrichage le site a essentiellement été en terre labourable ce qui se reflète dans les nombreux répertoriages de trouvailles en surface. Ces répertoriages associés à l'entreprise d'une étude par le Service de Conseil à l'Agriculture et au Développement (ADAS) ont instigué un élémen, lié au projet, qui était d'examiner les procédés d'érosion résultant de l'utilisation des terres, autrefois et actuellement, sur le site du monument. Il a démontré que les changements dans les pratiques agricoles avaient causé des dégâts considérables aux vestiges archéologiques, dégâts qui ont, de toute évidence, continué, et dans certains cas, se sont accélérés depuis son classement. Après l'impact initial $\mathrm{du}$ défrichement et des premiers labours au XVIIIe siècle, les dégâts furent probablement limités jusqu'à ces cinquante dernières années, moment où un impact majeur est susceptible d'avoir résulté de la combinaison des dégâts causés par les labours et de l'érosion des sols provoquée par des changements dans les pratiques agricoles. On a identifié une rotation des cultures et des pratiques de gestion des terres sur une plus grande échelle pour minimiser le risque d'une telle érosion. On propose de chercher à obtenir l'accord de la direction pour mettre en place ces pratiques sur tout le monument, garantissant ainsi la conservation à long terme de ce site d'importance nationale.

Les deux éléments du projet sont étroitement liés. L'érosion du site causée par les méthodes agricoles a eu comme résultat l'exposition en surface des objets. Ce qui nous a conduits à l'identification du site et nous a poussé à effectuer une prospection archéologique qui, avec l'aide de l'étude de l'ADAS, a eu pour résultat la reconnaissance par les archéologues du problème de l'érosion du sol sur le site. Ce projet a non seulement résulté en une nouvelle compréhension d'une occupation romaine d'importance nationale mais a aussi identifié un problème auquel le site devra faire face au cours du XXIe siècle. 


\section{Report structure and archive}

This publication presents the results of a programme of analysis, discussion and reporting completed between 1998 and 2003 on behalf of English Heritage.

The report comprises seven sections. The first section provides an introduction to the site, the project and a summary of antiquarian, archaeological and other investigation. Section 2 provides summaries of fieldwork relating to the settlement while the third part covers issues of erosion and deposition history. Following this the artefactual and environmental evidence is presented in Section 4. The evidence is then drawn together in a synthetic section covering the character of the settlement, its origins and chronological development, economic activity and a consideration of Ariconium within a wider local, regional and national context. Issues relating to management and protection of the monument and the problems of soil erosion are then discussed in Section 6 which concludes with recommendations to support future management of the monument. Section 7 completes the report with summaries and potential avenues for future research.

The report also includes a series of specialist appendices incorporating the details of the sources consulted, catalogues, project datasets and Geographical Information System (GIS) plots which have formed the basis of the main report text.

The project archive has been deposited with Herefordshire Heritage Service, Herefordshire Museum and Art Gallery, Hereford, HR4 9AU and with the NMR. Copies of the report have also been deposited with Herefordshire Sites and Monuments Record.

Museum collections have been returned to their relevant sources. 


\section{Acknowledgements}

The existence of the Ariconium Project owes much to the Central Marches Historic Towns Survey (CMHTS) which highlighted the shortfalls in the understanding and protection of the monument. The development of the project arose through a series of discussions within the County Archaeological Service of Hereford and Worcester County Council (now Worcestershire County Council Historic Environment and Archaeology Service). In particular Duncan Brown, Hal Dalwood, Derek Hurst and Simon Woodiwiss contributed much advice and encouragement both during the development of the project and throughout its course.

Funding for the project has come from English Heritage from whom the Service would especially like to thank Tony Wilmott, Alex Gibson, Kathy Perrin and Helen Keeley who as project monitors have provided much advice and encouragement while Chris Scull provided invaluable help in refining the original Project Design. Three Ancient Monument Inspectors (Kate Clark, Sue Cole and Paul Stamper) also supported the project and its progress. The input of the anonymous English Heritage referee was invaluable in refining the report content.

Among staff of Herefordshire Council, the Service would like to thank Dr Keith Ray (County Archaeological Officer), Rebecca Roseff (Sites and Monuments Record Officer) and Judy Stephenson (Collections Officer of Human History) for their constant support and encouragement.

Above all, however, this project has only been possible as a result of the work and effort of numerous individuals, groups and organisations over many years.

The many members of the Dean Archaeological Group who have been involved at the site must be thanked for their great contribution over many years. In particular, I would like to single out the efforts of Bryan Walters who devoted many years of his life to the study of Ariconium and the Forest of Dean iron industry, and who during the course of the project sadly passed away. Special mention must also go to the late Alf Webb who along with Bryan Walters' son Mark gave the project a great deal of help in accessing much of the Group's fieldwalking collection, surface finds, newsletter extracts and aerial photograph collection as well as contacts and information from group members. Martin Sterry is also thanked for his kind cooperation providing information and access to metaldetecting finds.

I would also like to pass special thanks on to Patrick Garrod who very kindly made available for study both the archive from the unpublished excavations he undertook with Phillip Moss in 1967 and his own collection of surface finds.

A number of museum curators must be thanked for making their collections available and providing information including the staff of Gloucester City Museum and of Herefordshire City Museum and Art Gallery along with those from the National Museum Cardiff and the British Museum.

I would also like to acknowledge the contribution of all the Project Team whose hard work has made the report possible, and also the late Lady Gillian Braithwaite for commenting on the face pot.

Lastly, I would like to thank Annette Hancocks, Laura Griffin and Erica Darch whose work over the years managing and cataloguing all the finds and maintaining the artefactual databases has been invaluable.

Hilary Cool is most grateful to Rachel Atherton of Gloucester City Museum for making the material in the Palmer collection available, and to Ralph Jackson and Valery Rigby of the British Museum for their help with the terret No. 214. 



\section{Section 1. Background}

\section{Introduction}

\section{The site}

The Roman settlement at Weston-under-Penyard is located at NGR SO 645 240, a few miles to the east of Ross-onWye in south Herefordshire (Fig. 1.1). The site is generally recognised as the Roman 'small town' of Ariconium (Rivet 1970). Much of the former settlement is under regular arable cultivation although several minor roads cross it and its eastern side is affected by the small hamlet of Bromsash.

Ariconium is one of the most important Roman sites in Herefordshire and the region as a whole. Part of the settlement area is a scheduled ancient monument (County Monument number, Here. and Worc. 154; Fig. 1.2) and it has long been known as a major iron production centre. As such it has been identified as one of a group of specialised 'small towns' with an industrial function (Burnham and Wacher 1990). Of these Ariconium is probably one of the least well understood and, over the years, the general paucity of information has hindered synthetic studies (VCH I 1908; Crickmore 1984; Burnham and Wacher 1990; Dalwood 1994). The most recent of these was able to define an urban area (CMHTS; Dalwood 1994; Fig. 1.2). However, no details of the chronology, development or layout of the settlement could be identified.

The combination of poor understanding of the settlement allied to a threat from soil erosion mean that effective management and protection of the archaeological deposits has been identified as problematic (Jackson and Hancocks 1998).

The Arionium Project was consequently undertaken between 1998-2003 in response to this situation with the aim of assessing the current state of knowledge and establishing a framework for future research and management at the site.

\section{Topography and geology}

The focus of occupation lies between $85 \mathrm{~m}$ and $125 \mathrm{~m}$ OD on a fairly flat hilltop from which the ground falls away gently to the north and south (Fig. 1.2). A scarp forms the eastern side of the hill and slight promontories extend to the north and west. Drainage is predominantly westwards along three small streams. The focus of occupation lies on the western side of the hill with activity quite clearly extending down the hillsides towards the streams.

The solid geology consists of Breconian and Dittonian Old Red Sandstone (British Geological Survey 1990, $1: 250,000$ sheet $51^{\circ} \mathrm{N}-04^{\circ} \mathrm{W}$ ) giving rise to well drained easily cultivated soils typical of the Eardiston 1 association (Soil Survey of England and Wales, 1:250000, Sheet 3, Midland and Western England). These soils are subject to erosion especially on cultivated slopes, where sheet and gully erosion often occur following heavy storms (Ragg et al. 1984). At Ariconium erosion of this type has been noted during fieldwork by both the Service and the Agricultural and Development Advisory Service (ADAS).

\section{The project}

\section{Project design}

The project was designed in recognition of the poor level of understanding of this nationally important site and, particularly, to address specific problems identified by the CMHTS (Dalwood 1994). These were considered to relate to both management and research frameworks. In addition, hillslope erosion has been identified as a potentially significant threat to archaeological deposits and one of the principal aims of the project was to assess the impact and extent of this problem.

Data has been drawn from a study area based upon a $2 \mathrm{~km}^{2}$ centred on the scheduled area, thus covering the whole of the main cropmark complex and finds concentration as well as incorporating several areas of activity in the immediate hinterland (Figs 1.1 and 1.2). A wide range of sources have been consulted and reassessed, including aerial photographs, excavation and fieldwalking data, and museum collections. A significant amount of material has been available for study for the first time. In addition, data gathered from the area of the settlement by ADAS has been analysed and, in conjunction with archaeological evidence, has contributed to the development of an understanding of the nature, scale and causes of erosion at Ariconium. This has implications for the future management of this particular site as well as other sites in similar locations.

The project is seen as being particularly opportune, combining the study of both old and recently published evidence with analysis and incorporation of a large amount of data which had previously been unpublished. Assessment, analysis and discussion has lead to a synthetic overview of the archaeology of an important, but poorly understood, Roman industrial 'small town' and to an improved understanding of the impact of erosion on the site. This has led to the creation of a better and more focussed management and research framework for this nationally important site. 


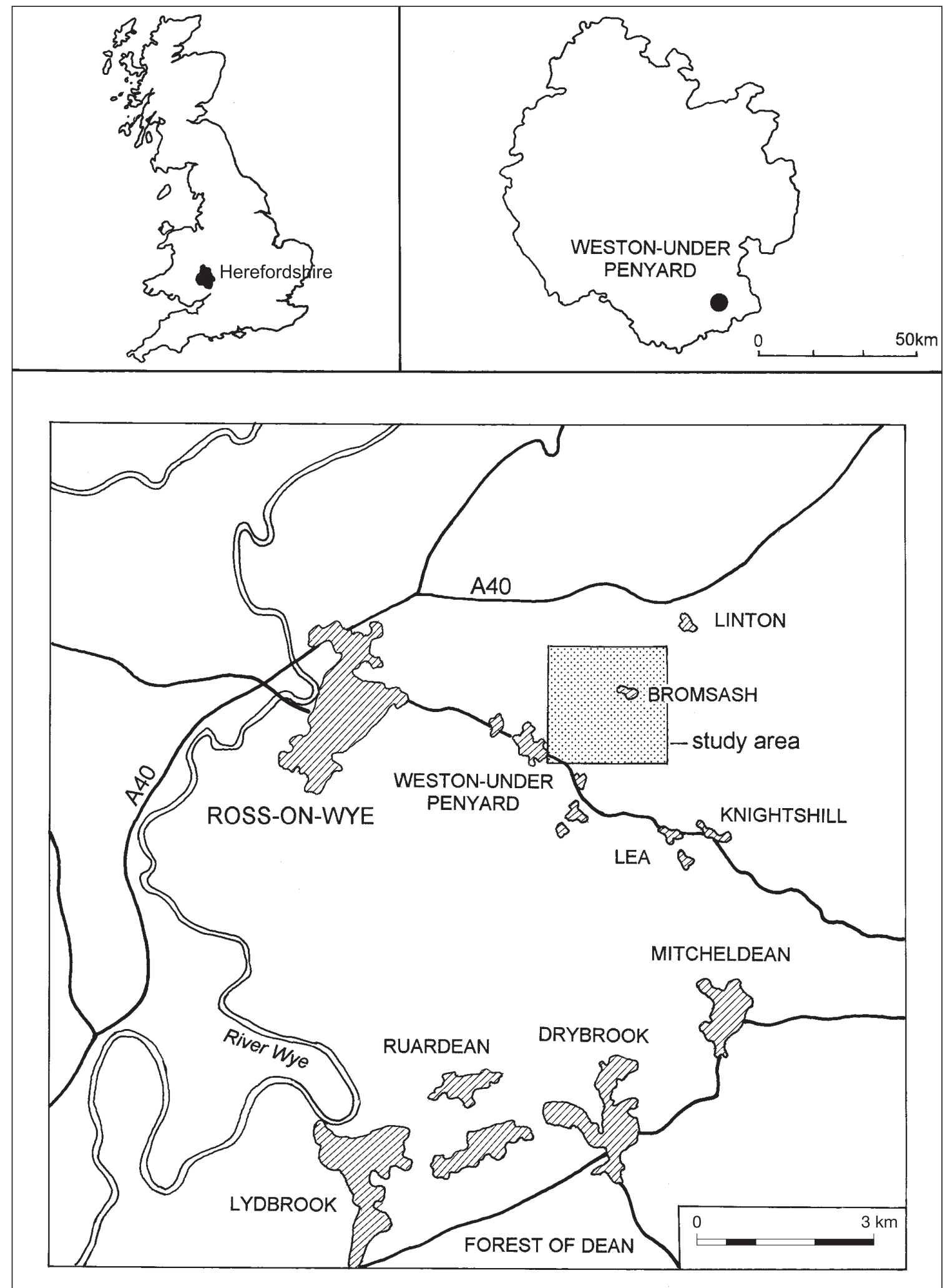

Figure 1.1. Location of Ariconium project study area. Reproduced by permission of Ordnance Survey on behalf of HMSO. (C) Crown Copyright 2011. All rights reserved. Ordnance Survey Licence number 100051813

\section{Aims and objectives}

The original aims and objectives (CAS 1995) remained little changed throughout the project, falling under two headings management and academic. These largely arose from the Central Marches Historic Towns Survey report (Dalwood 1995) and from the preparation of the Project Design (CAS 1995, sections 4 and 5.1). 


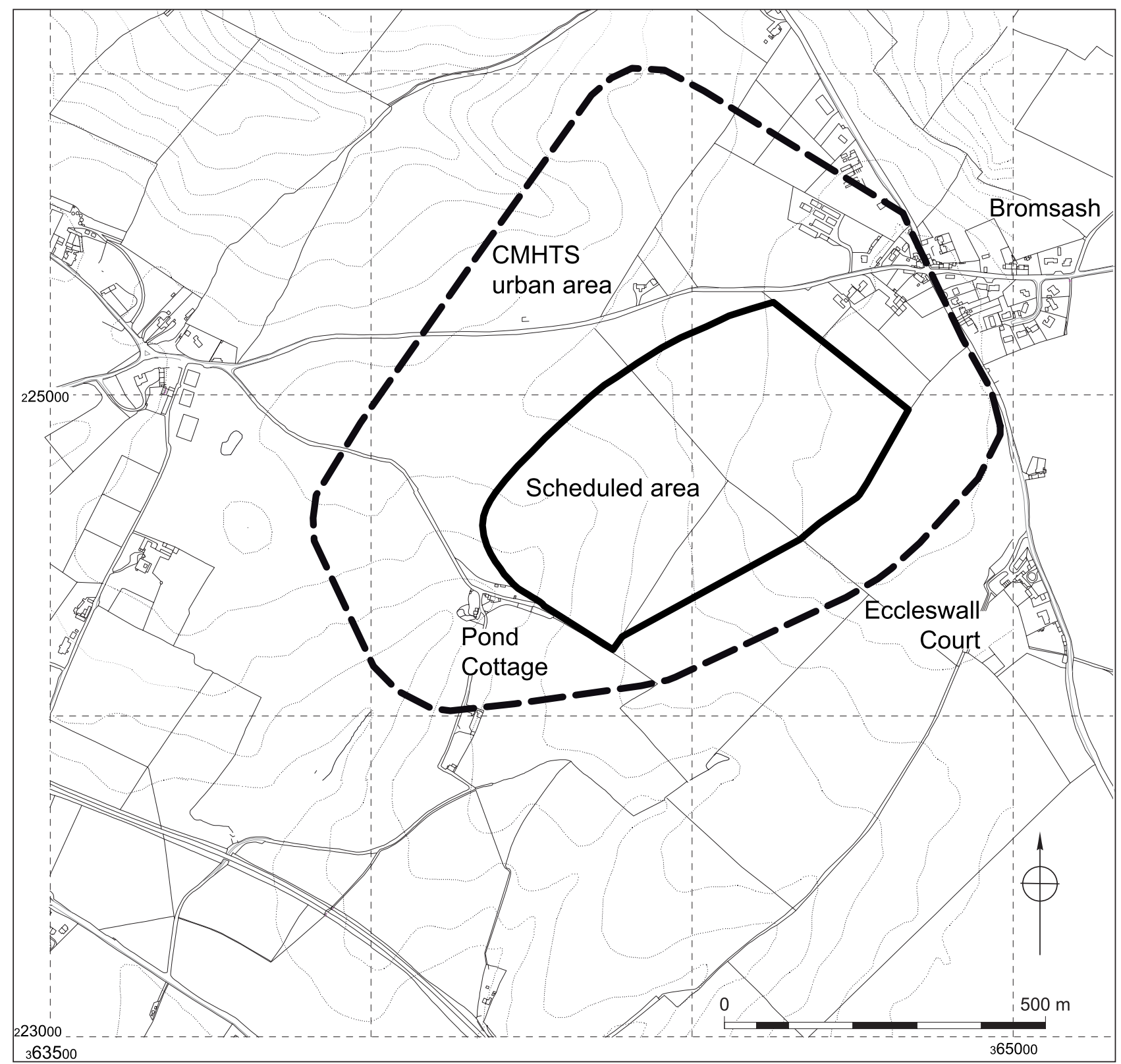

Figure 1.2. Study area showing CMHTS urban extents and scheduled area. Reproduced by permission of Ordnance Survey on behalf of HMSO. (C) Crown Copyright 2011. All rights reserved. Ordnance Survey Licence number 100051813

\section{Academic objectives}

These are grouped under five headings: character, development, morphology, economic activity and hinterland settlement. These were more specifically broken down as follows.

\section{Character (Section 5)}

1. What was the nature of pre-Roman occupation at the site?

2. What is character of the earliest Roman occupation?

3. Does the evidence support the suggestion of religious and military activity?

4. How does Ariconium compare with other RomanBritish industrial 'small towns' in the area such as Droitwich and Worcester, and with the town of
Kenchester? How can it contribute to the understanding of 'small towns'?

5. What was the nature of post-Roman activity at the site?

Morphology (Section 5)

1. Can an Iron Age occupation area be defined?

2. Can the area of the earliest Roman occupation be defined?

3. How was the settlement laid out in the Roman period and can roads and domestic and industrial zones be identified? Do these change through time? What implications do these have for the understanding of the settlement as a 'small town'?

4. Can areas of military and religious activity be defined? 
Development (Section 5)

1. Can Iron Age origins be demonstrated and how do these relate to the subsequent Roman activity? What are the implications for the understanding of the Iron Age to Roman transition period?

2. What is the date of the earliest Roman occupation at the site?

3. Can the chronological development of the Roman settlement be established?

4. Can a date for the decline and desertion of the Roman occupation be established?

ECONOMIC ACTIVITY (SECTION 5)

1. What was the nature of the Roman ironworking industry? What were its sources of supply, its technology and products? What can this information contribute to the understanding of this highly important regional and national industry?

2. What does the other evidence for the economic function of the settlement tell us about it in terms of other industrial activities, agricultural base, and the evidence of its trading network?

Hinterland Settlement (SECtion 5)

1. What was the nature of the other Roman settlements (farmsteads etc) known in the immediate hinterland (within the study area; Fig. 1.2) of the site? Can these be related to Ariconium and if so what was this relationship?

2. What is the potential for reconstructing the surrounding landscape before and during settlement of the site? What impact did settlement, industry and agriculture have on, for example, woodland cover and soil erosion?

Management objectives (Sections 3 And 6)

1. What impact has post-Roman activity had on Roman deposits?

2. What is the condition, survival and vulnerability of deposits and artefacts across the site?

3. How severe is hillslope erosion across the site and what are the factors which are causing it?

4. Can changes in the composition of the surface assemblage and visible cropmarks through time be detected and if so what contribution can they make to understanding the impact of erosion?

5. What are the effects of hillslope erosion and deposition on archaeological deposits and on approaches to identifying and interpreting them?

6. What is the role agricultural management plays in determining whether hillslope erosion occurs? What options are there for future management which would minimise the effects of such erosion?

7. What is the identifiable extent and potential impact of metal detecting in and around the scheduled area?

Focussing on these aspects of academic research and management has allowed the project to achieve the following:
- Contribute to the research framework and understanding of the site, with particular reference to its origins and chronological development.

- Revise definition of urban area and definition of components.

- Define immediate hinterland settlements and road network within study area.

- Contribute to the development of an effective site management framework.

- Contribute to the identification and understanding of the effects of hillslope erosion on archaeological sites.

- $\quad$ Enhance SMR and CMHTS.

- Disseminate the results through publication.

\section{Related work}

The project has been related to a number of other independently resourced areas of research, contributing to them and also drawing on them. Two particular areas of interest have been identified:

1. The information relating to erosion and its impact on a scheduled ancient monument is seen as having particular relevance to the long-term aims of the English Heritage funded Monuments At Risk Survey (MARS). Ariconium falls within one of the MARS field transects and it is envisaged that the project will provide information on causes and scale of the deterioration of preservation of deposits at this particular site over a period of time. This can potentially contribute to one of the key long-term focuses of investigation by the MARS project (Darvill and Fulton 1998).

2. Ongoing research as part of a PhD thesis and research programme being undertaken at Cardiff University into sourcing iron ores and products has fed into the project. Samples taken from Roman contexts and one potential Iron Age context at Ariconium on the Welsh Water pipeline were submitted for analysis as part of the University's research programme (Thomas and Young 1999a; 1999b). In conjunction with data from work undertaken by English Heritage (AML) on slag from Ariconium resulting from the same project this has supported discussion of the character and scope of the ironworking industry at Ariconium and in the Forest of Dean. In particular this data has supported the production of tentative estimates of the potential output of the iron industry at the site.

\section{Methodology}

\section{Sources}

An SMR and literature search of the study area was used to establish a basic index of all reported discoveries (Project Database 1). Principal sources comprised primary archives, excavation reports, other fieldwork reports and documented find spots. A full list of sources consulted is included in Appendix 1 while Appendix 2 provides an index to fieldwork and the sites registered on the Herefordshire County Sites and Monuments Record (SMR). 
Three further datasets have been created, one for buried remains (Project Database 2), one for all artefacts (Project Database 3) and one for the pottery (Project Database 4). A sub-set of the pottery database covering the more tightly dateable pottery fabrics has also been created (Project Database 4b). Subsets of the databases have been used in conjunction with a Geographical Information System (GIS).

The databases are briefly described below. Copies of the databases and detailed descriptions of their structures and fields are held in archive.

\section{Dating}

Wherever possible deposits, artefacts and other forms of evidence have been dated, either through stratigraphic analysis or through spot dates. A Terminus Post Quem (T.P.Q.) has been assigned wherever possible.

To simplify the dating two fields have been included in the databases and used in analysis, the first covering broad periods and the second a more specific sub-division of the Roman period. The following broad periods have been identified:

- $\quad$ Prehistoric (all pre-Iron Age finds)

- Iron Age (including some Roman Republican and early Empire material)

- Roman (AD 43-c. 400)

- Medieval (AD 1000 - 1650)

- Post-medieval (AD 1650+)

- Modern (post 1900)

More specific date ranges for the latest Iron Age and Roman periods are as follows:

- $\quad$ Phase 1. Iron Age/Transitional (up to c. AD 100)

- $\quad$ Phase 2. Early to Mid-Roman (c. AD 100 to 250)

- $\quad$ Phase 3. Later Roman (c. AD 250 to 400)

\section{Buried remains}

Analysis of buried remains has been undertaken at two levels, a site specific level and at a broader, settlement wide level.

Site specific analysis has been undertaken on two pieces of previously unpublished work. Firstly, the archive from the excavations undertaken in 1967 by Garrod and Moss has been analysed leading to the production of a phased structural sequence and site narrative with discussion of the associated artefactual and environmental remains (Jackson 2000). Secondly, analysis of a large collection of unanalysed pottery from Bridgewater's excavations in 1963 (Willis, this volume) has lead to refinement of the dating sequence and some reconsideration of selected deposits. The resultant information has been incorporated into the wider, whole site analyses.

Overall analysis and discussion of the evidence from buried remains has been based upon a re-examination and consideration of individual excavation reports and available archives. Each piece of fieldwork undertaken has been summarised and where necessary has been critically considered and re-interpreted (Section 2). The resultant information has contributed to map-based analyses undertaken using the GIS.

\section{Artefactual analysis}

Analysis of the Garrod and Moss and the Bridgewater ceramic assemblages has been undertaken as described above. Analysis has also included fieldwalking and other surface assemblages, including those collected by Garrod and Moss, by Bridgewater and the extensive DAG collections (Sections 2 and 4).

Several ceramic assemblages were not analysed, notably those from the Welsh Water pipeline (Jackson, Hancocks and Pearson 1999) and from the excavations on the 'military installation' to the north (Walters and Walters 1989). The latter were not available for study while the former had only recently been analysed. Both groups of material have, however, been considered in the pottery report (Section 4).

Apart from the ceramic analysis described above, a range of other specialist assessments have concentrated on classes of artefacts with the potential to contribute to the dating and characterisation of deposits and activities (brooches, small finds, coins, glass, mortaria, samian, stone and iron working residues). As with the pottery analysis, this work incorporated study of previously unanalysed material in conjunction with consideration of already published material and known collections. Details of the methods used by specialists are included in the individual reports presented below.

The completed artefactual data has been entered onto two further databases (Project Databases 3 and 4) the structures of which are described briefly below. Analysis has been undertaken in conjunction with other sources of data and using the GIS. Artefactual data has also been used to consider whether there is any evidence for changes in the composition (range, date and character) of fieldwalking assemblages through time. As anticipated, this has only been demonstrable on a very broad basis, as insufficient data from comparable areas is available for study. However, the information has supported consideration of the potential effects of soil erosion (Sections 3 and 6) and has identified the potential value of a systematic programme of fieldwalking (and subsequent comparison with existing evidence) in enabling the development of a greater understanding of the impact and effects of erosion.

\section{Environmental analysis}

Analysis and reporting of the charcoal samples from Bridgewater's excavations and of the animal bone from Garrod and Moss's excavations (Jackson 2000) has provided information which has contributed towards the wider analysis and discussion of environmental evidence.

Beyond this no further environmental analysis has been undertaken. However, the results of the environmental work undertaken on the Welsh Water pipeline and all other (albeit 
limited) data from the settlement have been used to update an earlier assessment undertaken as part of the CMHTS. An assessment has also been made of the environmental potential of the study area beyond the currently identified urban area.

Recommendations for future environmental research have been made which take into account paleoenvironmental techniques not previously used at this location (Section 7).

\section{Aerial photographic data}

Cropmarks showing on aerial photographs covering the study area have been plotted and an accompanying interpretative report has been produced (presenting and discussing the results of the mapping; Cox 1995). This is summarised here (Section 2 and Appendix 3) and the full report is held in archive. The cropmark plots have contributed to, and supported, analysis of other data sources and form part of the project archive. The mapping and interpretation of geological and soil features has facilitated the understanding and mapping of areas of erosion and deposition.

\section{Erosion and deposition data}

The ADAS data has been analysed and a report produced (Section 3 and Appendix 4). A range of further information on activities, which may potentially have affected rates of erosion of archaeological deposits, has been considered in conjunction with the ADAS report. These include information on previous landuse and cropping regimes, tithe maps and 1st edition Ordnance Survey maps (which allow identification of areas where field boundaries have been removed) and archaeological data relating to the survival of deposits (and any discernible erosion of deposits).

This information has formed the basis of a discussion of the past and potential future impact of erosion (and deposition) on archaeological deposits and the threat that they constitute (Section 6). The resultant data has been used to identify and map areas of potential erosion and this is hoped to be of considerable value in formulating any land management approaches developed for the site.

\section{Map based analysis}

\section{Rachel Edwards}

A significant element of the analytical work has involved spatial analysis of data through the use of a GIS. This was undertaken following all other analysis, specialist reporting and updating of the four project databases.

Only well located data sources were used. To this end, subsets of the four project databases were employed to produce distribution plots on a map base derived from Ordnance Survey digital vector mapping.

The GIS computer programme used was MapInfo. The spatial analysis was not complex, consisting of plotting two-dimensional distributions of subsets of the recorded data. The databases could be queried on any logical combination of the contents of their fields. Eighty-two distributions were plotted and printed out. Key plots have been reproduced within the report (Figs 4.20-22 and 4.27-29), the remainder are held within the archive.

Plots focussed on a number of themes:

1. Plots were undertaken using all sources of located data to define the extents of the main settlement as well as to identify any areas of activity in the immediate hinterland.

2. Data relating to the character of both finds and deposits was used to generate plots which identify areas (components) of industrial activity and domestic occupation as well as any areas associated with military or religious activity.

3. Dating evidence was used in conjunction with the data from the first two plot types to support development of an understanding of the early origins, chronological development and eventual abandonment of both the main settlement and other areas of activity within the study area. In conjunction with the plots of data relating to the character of various areas of the site this analysis allowed certain activities or areas of activity to be linked to particular periods of the settlement's development.

4. It was initially hoped that the data would allow more detailed consideration of patterns of erosion and deposition across the site. However, the relevant data were only recorded in the most recent excavations at Ariconium, so these distributions merely demonstrated the locations of recent fieldwork.

5. Plotting of metal detecting finds has allowed identification of those areas most affected allowing consideration of the potential threat, which this poses to the settlement, and associated areas of activity.

In considering these matters the overall understanding of the distribution of fieldwork across the monument and of the effects of erosion/deposition on distributions of data have been used to consider where such processes may have caused bias in these distributions.

\section{Synthesis and discussion}

Following completion of all analyses and GIS plotting, the resultant data and distribution plots have been used for synthesis and discussion (Sections 5 and 6). Through use of overlays of GIS plots, mapping of buried remains and cropmark plots in conjunction with the information from the specialist analyses it has been possible to generate a model for the chronological and morphological development as well as the character and status of the settlement and its associated iron industry. Other sources, in particular the ADAS report, have combined to enable assessment and discussion of the potential impact of erosion upon archaeological deposits. 


\section{The Ariconium databases}

\section{Rachel Edwards and Robin Jackson}

The databases referred to above were created during the course of the project to support analysis of various categories of information. Details are held in archive. Each database includes common fields such as County Sites and Monuments Record number and National Grid reference.

Project Database 1 provides a basic index for the site, cross-referencing sources (see also Appendix 2). Database 2 covers buried remains and includes data on excavation history, deposits and dating as well as interpretative information at a structural level (e.g. oven, pit, etc.) and a higher functional level (e.g. domestic or industrial). The third database relates to artefacts and includes contextual and interpretative information along with a range of fields to enable recording of different classes of artefact. Lastly two databases (Databases 4 and $4 b$ ) were created for the pottery data, one covering all pottery, the other a subset of particularly date sensitive material. These databases were used both within their own right and during GIS analysis.

\section{Site history}

\section{Antiquarian investigations}

The site has a long history of antiquarian and archaeological interest. This initially stemmed from its inclusion in the Antonine Itinerary (Itinerarium Antonini Augusti) in which Ariconium is listed on the Iter XIII as being 15 Roman miles from Gloucester (Clevo) and 11 from Monmouth (Blestio; Margary 1955).

The first known antiquarian reference is by William Camden in Britannia which was published in 1586. Both Camden and Stukeley, the 18th century antiquarian (1724) equated the site listed in the Itinerary with that at Kenchester (Magnis), near Hereford. They recorded that the site was reported to have been destroyed by an earthquake.

It was not until 1732 that it was realised that it was unlikely that the Itinerary was referring to Kenchester when John Horsley in his Britannia Romana calculated that Ariconium had to lie near Ross-on-Wye. The first references to Roman remains being uncovered at the site date from some 20 to 30 years later. At this time the land was apparently unenclosed and in a rough state, with heaps of rubbish overgrown with briars. The landowner, Mr. Thomas Hopkins Merrick of Bollitree, had this land levelled and enclosed. During the course of this work many finds were reported to have been uncovered. In 1785, in response to a request for more information, Mr. Merrick reported the remains in a letter:

'I received a note from Dr Matthews, of Hereford, requesting that I would inform you of what I knew relative to the Old Town, which formerly stood in this neighbourhood. I imagine it to be larger than the City of Gloucester. It covered a great part of the land I occupy at Bollitree, together with much more of the neighbouring lands; indeed, where the streets stood might almost be traced by the colour of the soil. I have never heard that the least ruin appeared above ground, though we often on ploughing strike against some of the old ruins underground, from which I have obtained vast quantities of stone, the walls lying on their sides from a foot to a yard and upwards under the surface. Some time since, being with my men at plough, I observed that the plough struck against a part of the ruins, and raised many large stones; upon examining with my stick I found a very deep cavity where my stick went in. I imagined it an arch or vaulted cellar, and called my men together with proper tools to dig, but found only one of the walls lying as above related. However, not discouraged, we proceeded to dig four or five feet further, when we came to a sound floor, and on it we found a quantity of wheat as perfect in shape as when newly threshed, but it had turned quite black, and vanished to dust by the touch or the least puff of air. Digging at another time a hedge about the depth of four feet we came to a very fine, smooth floor, the face of it being so hard and impenetrable that the spittle would not make the least impression. On this, I procured iron bars, pickaxes, etc, for raising it, but to my disappointment I found it to be nothing but sand - very fine sand, such as is used to shower over writing to dry up ink

This floor must have been a great curiosity, as having so hard a face that nothing less than pickaxes would touch it. We often find Roman, and sometimes British coins (but of the latter very rarely), besides images, fibulae, and other curiosities. Several of the coins that were pretty deep in the earth appear well preserved and as perfect as ever. Several gentlemen, lovers of antiquity, have visited this place, and from its distance from Gloucester, Monmouth, etc, say this is the Ariconium of the Romans'.

In 1788 a bronze statuette of Diana reputedly from the site was exhibited to the Society of Antiquaries (Archaeologia, ix, 368). The date of its exhibition suggests that this object, if correctly provenanced, may have been one of the images reported by Merrick. It has unfortunately been 'lost' but an engraving of the statue dated 1843 shows a figure 'about five inches high, of the usual type, apparently represented as drawing a bow' (VCH I 1908).

Early in the nineteenth century, these discoveries led to the first formal identification of the site of Ariconium as that at Weston-under-Penyard (Brayley and Britton 1805). They recorded that Merrick had found immense quantities of Roman coins and some British, along with fibulae, lares, lachrymatories, lamps, rings and fragments of tesselated pavements, pillars and 'stones with holes for the jambs of doors.' They also noted that the soil at the site was of an 'extremely dark hue' and that this covered several acres, while adjoining lands were strewn with 'scoria of iron ore'. Coins and innumerable pieces of grey and red pottery could apparently be picked up after ploughing. Coins included some of Constantine and Trajan, many of Tetricus and one of Antonius Pius. They also recorded that in 1804, during the course of widening a road across the site, several skeletons and a wall had been discovered. The wall was constructed from well-worked masonry and was considered to be the front of a building. Within what appeared to be the inside of this building, the soil was 
'extremely black and shining'. Pottery, bones (animal and human) and bits of iron were also recorded.

In 1821, in Ariconensia, Thomas Dudley Fosbroke recorded that a large bronze head with rams' horns had been found by Merrick, along with the remains of statues, heads, arms, etc. He also reported that the bronze and coins had been sold for $£ 15$, a sum which later reports suggest was a figure paid for it by weight (i.e. its scrap value). He described the site as a Roman Birmingham due to the quantities of cinders of ore.

Later writings through the 19th century add certain details to this information but tend to elaborate on it, perhaps a little unreliably (Wright 1844; Thompson Watkin 1877; Cooke 1882; and Haverfield 1896). A further development came in 1853 when James Davies in Archaeologia Cambrensis explored the possible links of the place-name Ariconium with what was then the present name of the surrounding district, 'Irchenfield.' He noted the name 'Yrcinga-field' in the Anglo-Saxon Chronicle and 'Arcenefelde' in Domesday and suggested that Ariconium might have been a district centre which survived, in name at least, in the post-Roman, British state of Ereinwg or Herging which lay in this vicinity.

By 1870, there was sufficient interest for the site to warrant a visit by the British Archaeological Association to whom a collection of finds was displayed by M. C. Palmer (Journal of the British Archaeological Association, XXVII). These included nine British coins, two of which were copper coins of Cunobelin. There were also 118 Roman coins dating from Claudius (AD 41) through to Magnentius (AD 353) and a wide range of small finds.

In 1882, Dr Bull recorded a visit of the British Archaeological Society in the Woolhope Transactions. He summarised knowledge relating to the site and remarked that the blackened soil extended over an area of nearly one hundred acres. He referred to it as the 'Merthyr Tidfil of the Romans' and indicated that Roman finds were still easily found.

These antiquarian reports and discoveries were summarised in 1908 in the Victoria County History for Herefordshire, however, it was concluded that:

'Ariconium is a conspicuous example of the utter inadequacy of the investigations into Roman sites hitherto carried out in Herefordshire'.

\section{Twentieth century investigations}

\section{Excavations}

Excavations and other archaeological fieldwork have been undertaken sporadically since 1922 . These are considered in more detail below (Section 2; Figs 1.3 and 1.4), however, are briefly summarised here as part of the general overview of the history of investigations at Ariconium.

The first excavations were undertaken in 1922 by G. H. Jack (Jack 1923) who opened six trial trenches and one larger excavation ('The Buildings'). A range of deposits was recorded notably in the main trench where remains indicative of a building of some status were recorded. These were published the following year.

In the summer of 1929, Jack returned to investigate the line of a road known from cropmarks. Three years later, two further roads were recorded by the Reverend E. R. Holland (Watkins 1932) while N. P. Bridgewater carried out further investigation of roads in the area in 1959.

During the 1960s more excavations were undertaken. The first, in 1963 by Bridgewater, lay to the north of the main settlement area in what he called 'New Ariconium' (Bridgewater 1963). This revealed the remains of six Roman furnaces and associated deposits. The second of the 1960s excavations, by Garrod and Moss (1967), comprised eight small trenches. One trench produced evidence of a partially robbed sandstone building which overlaid the remains of earlier ironworking structures. Other trenches produced further oven or hearth structures, metalled surfaces and occupation horizons. Only an interim report was published, however, Mr. Garrod has made the archive available and an archive report has now been produced (Jackson 2000). A summary of the results of this work is presented below (Section 2).

In 1989, Bryan Walters and Mark Walters undertook investigation of a cropmark site showing 'at least four overlapping enclosures' in a field known as the Great Woulding (Walters and Walters 1989). This lies some distance to the north of previous excavations and beyond the main settlement focus. A long trench across the cropmarks led to the identification of the site as representing 'Roman military installations'.

The most recent large-scale fieldwork occurred in 1992/3 during the construction of a sewage transfer pipeline across fields to the south-west of the scheduled area (Jackson, Hancocks and Pearson 1999). Extensive and well-preserved Roman deposits were revealed which were clearly associated with industrial activity and in particular ironworking. Limited stratified evidence for Iron Age activity was also recorded along with a 'satellite' settlement to the south-west in Bull Meadow. Still further to the south-west, a small-scale watching brief on Wigg Meadows (Topping 1993) confirmed the presence of one of the previously known roads (Bridgewater 1959; Wigg 3). An occupation layer was also identified and can probably be associated with previously identified activity at this location (Bridgewater 1959; Wigg 2). Further work in this area was undertaken two years later (Fagan and Hurst 1994; Napthan, Ratkai and Pearson 1995) during evaluation of the route of the proposed Ryeford Bypass. This recorded further evidence of the road line along with a ditch complex and adjacent metalled surfaces.

Finally, two small-scale pieces of work on the western fringes of the survey area have proved sterile, a trial pit (Walters 1988) and a watching brief undertaken during construction of a swimming pool at the Vicarage (Jackson 1996). 


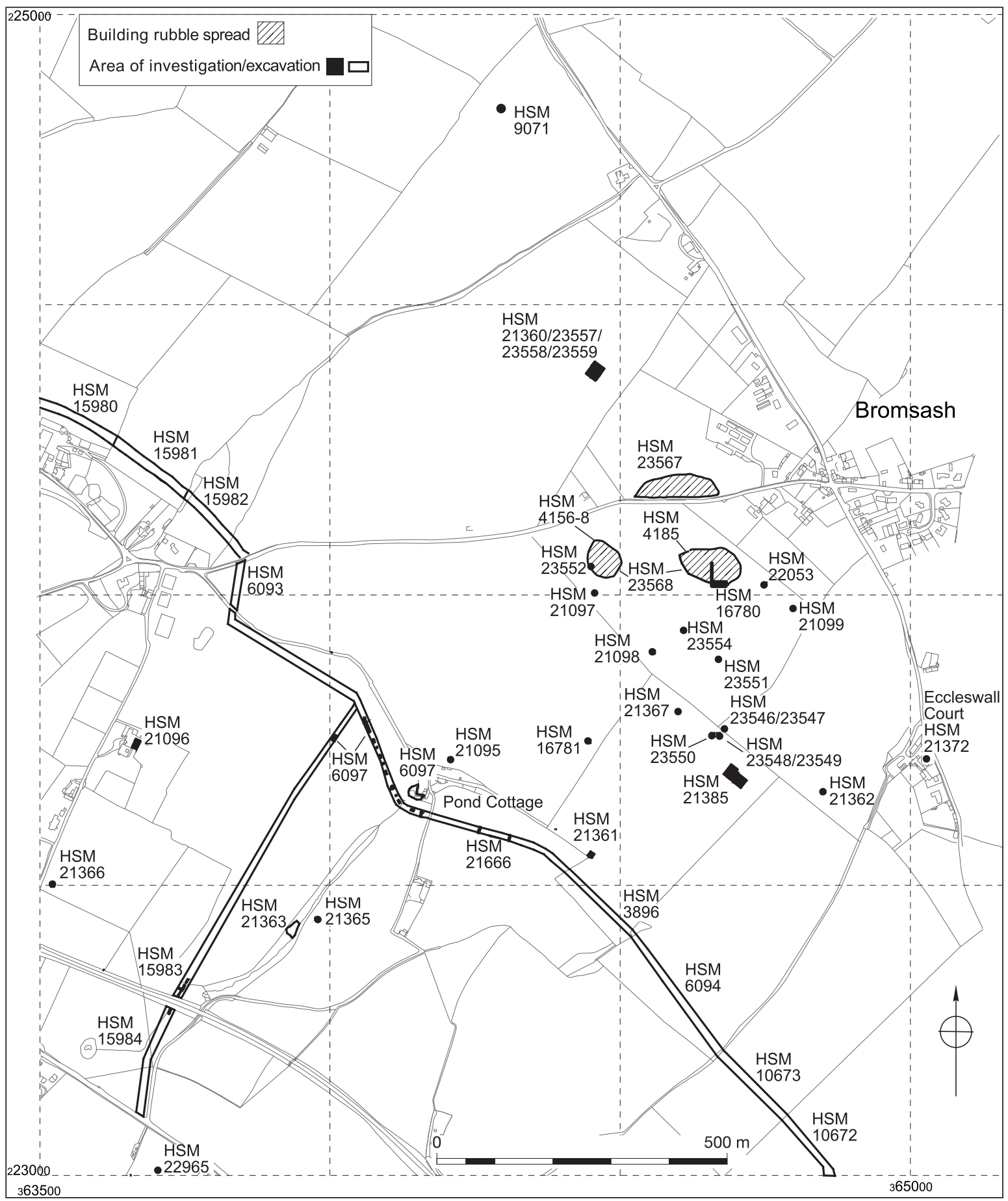

Figure 1.3. Areas of trenching (salvage recording, evaluation and excavation). Reproduced by permission of Ordnance Survey on behalf of HMSO. (C) Crown Copyright 2011. All rights reserved. Ordnance Survey Licence number 100051813

\section{Other fieldwork}

Apart from the excavation and investigation of buried remains, a wide range of other sources are available including fieldwalking, other surface finds, surface observations, metal detector finds, aerial photographic evidence and the results of a survey by ADAS.

Since the 1960s a number of fieldwalking projects and less formal (but relatively well-located) surface collections have been undertaken, both in their own right and accompanying excavation and salvage recording projects (Section 2; Figs 1.3 and 1.4). Such collections survive from both the Bridgewater and Garrod and Moss programmes of fieldwork during the 1960s. Other collections by Bridgewater and Garrod as well as several other individuals also survive and date from work between 1958 and 1971. 


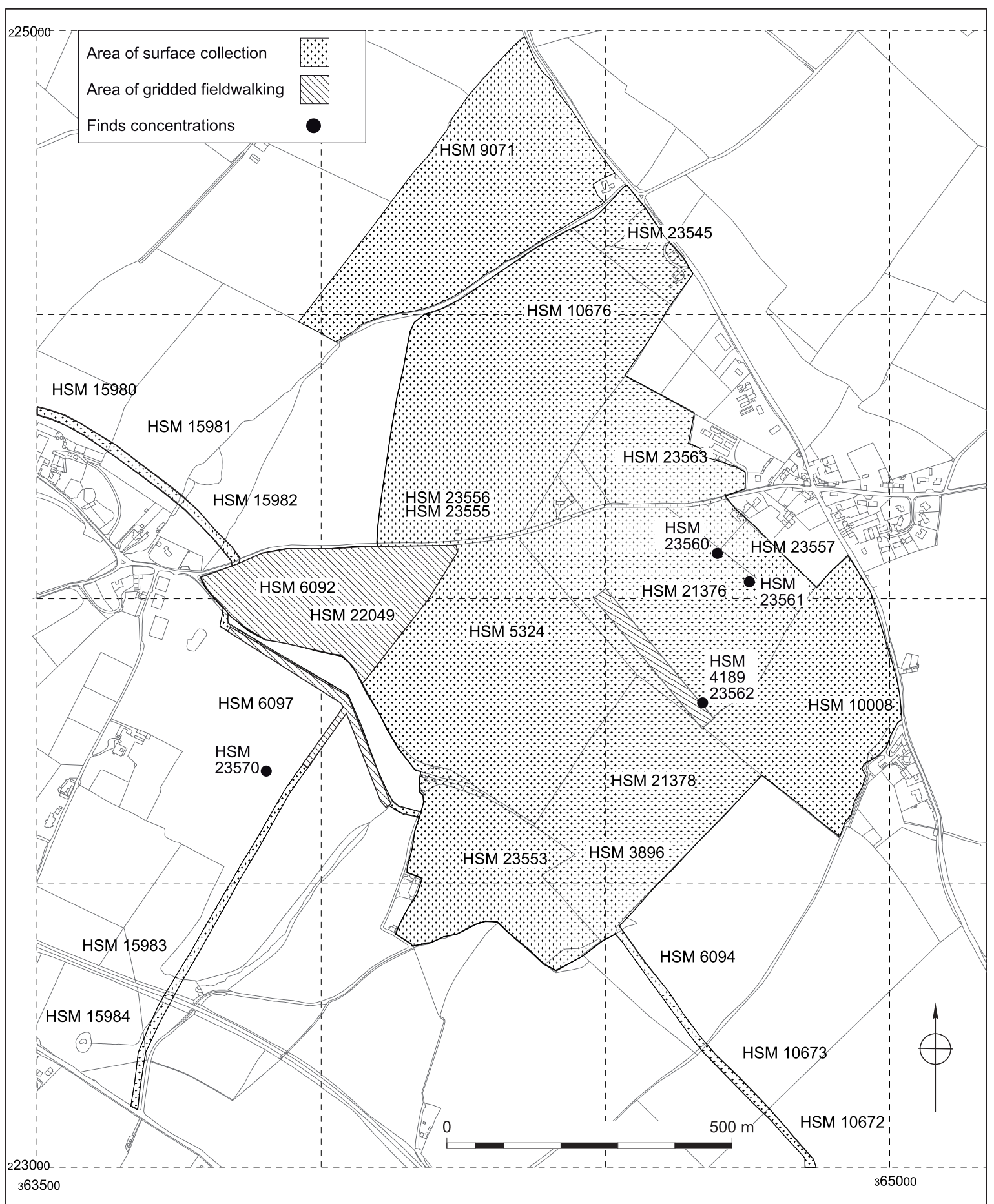

Figure 1.4. Areas of surface collection (fieldwalking, metal detecting, spot finds). Reproduced by permission of Ordnance Survey on behalf of HMSO. (C) Crown Copyright 2011. All rights reserved. Ordnance Survey Licence number 100051813

More significantly, over a period of five years from 19841989, the Dean Archaeological Group (DAG) carried out a number of well-recorded and located areas of fieldwalking. The South Worcestershire Archaeological Group (SWAG) carried out further gridded fieldwalking in 1986 and on part of the Welsh Water pipeline in 1993.

In addition to the more specifically located material, several concentrations of artefacts and building debris have been noted during the past 30 years. Further information derives from metal detecting which has affecting the site since the early 1990s and from various aerial photographs taken over a 45 year period from 1946 to 1992 which have been assessed and plotted (Cox 1995; Fig. 1.5).

Lastly data on erosion in the area was collected by ADAS over five winter periods, from autumn 1989/90 until late winter 1993/4 (Appendix 3). 


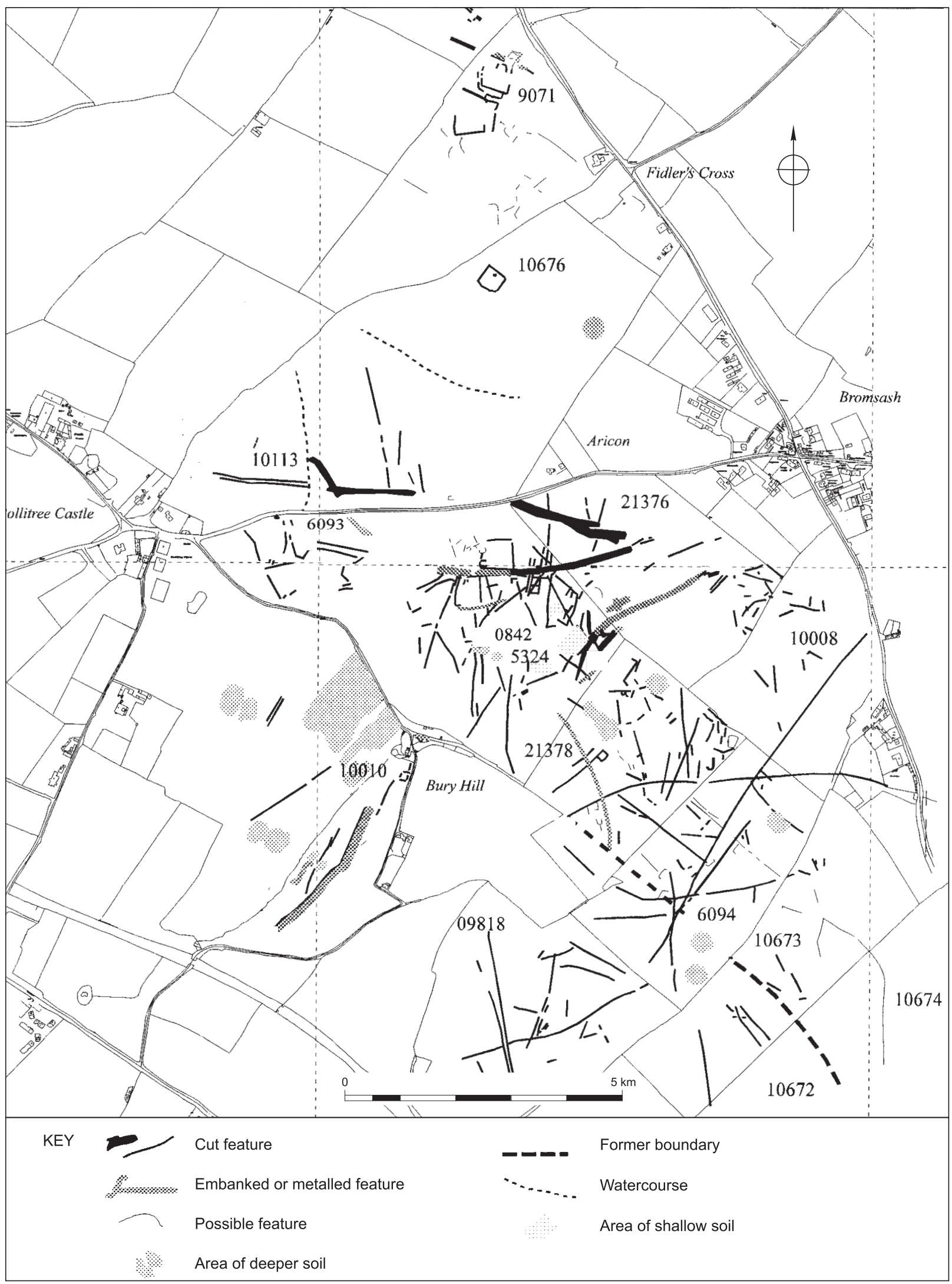

Figure 1.5. Cropmark plot. Reproduced by permission of Ordnance Survey on behalf of HMSO. C Crown Copyright 2011. All rights reserved. Ordnance Survey Licence number 100051813 


\section{Section 2. Archaeological investigations: summary and analysis}

\section{The buried remains}

\section{Introduction}

Within the study area a total of 40 archaeological trenches and test pits have been excavated (Fig. 1.3). In addition monitoring of topsoil stripping and trenching was undertaken during recent salvage recording for Welsh Water. Of these, all bar two, (HSM 21366, Walters 1988; HSM 21096, Jackson 1996), have produced evidence relating to the settlement and its hinterland. These are summarised below.

\section{Extent and integrity of sources}

The excavations and test pits, although all relatively small in scale, are mostly well located, although precise location of the Jack (1923) and Bridgewater (1963) excavations and some of the smaller trenches on Roman road alignments has not proved possible. Excavations cover less than $0.5 \%$ of the urban area as mapped by the CMHTS.

Although this represents a small sample, trenches are widely distributed thus providing detailed information from many locations across the main 'urban' area (Jack 1922; Garrod and Moss 1967; Bridgewater 1963; Welsh Water 1993). They also cover several settlements in the immediate hinterland and roads leading to and from the 'small town' (Bridgewater 1959, Walters and Walters 1989, Napthan, Ratkai and Pearson 1995 and Jackson, Hancocks and Pearson 1999).

The presence of sterile areas or those with limited activity have also been important, supporting definition the extents of the settlement.

The standard of excavation and reporting (where undertaken) has generally been high although inevitably there are limitations, especially from the earlier investigations. For instance, the excavations by Jack (1923) lack detailed stratigraphic information. In addition, data (or elements of the data) from several excavations has only been retrievable from published sources rather than the original site archives.

A couple of site specific limitations have been identified and addressed. Only partial analysis of the ceramic assemblage from Bridgewater's 1963 excavations had been undertaken and this has now been completed (Willis, Section 4). In addition, the results of the excavations by Garrod and Moss in 1967 had only been published in interim form. These have now been analysed and an archive report produced (Jackson 2000). Some reassessment has also been undertaken, notably of the 1989 excavations at the Great Wouldings (Walters and Walters 1989).

\section{Stratified artefactual assemblages}

Stratified artefactual assemblages have been recovered from the trenches of Jack (1923), Bridgewater (1959 and 1965), Garrod and Moss (1967), Waters and Waters (1989) and Welsh Water (1993). These are dominated by pottery and iron slag, but include a range of other finds including building materials, small finds, glass and bone. These are predominantly Roman in date, however, include significant quantities of later Iron Age material.

The bulk of the excavated artefacts come from wellstratified deposits. Analysis has been undertaken of the Bridgewater (1965) and Garrod and Moss (1967) ceramic assemblages (Willis, Section 4), while the other stratified assemblages have been reassessed. In addition, specialist analysis and re-assessment of other artefact classes has included those from these stratified contexts (Section 4).

These analyses have been particularly important in providing dating to support understanding of the chronological development of the settlement and for characterising areas of activity (Section 5 ).

\section{Sources of information}

Information has been drawn where possible from project archives, artefact collections and published reports, though some of the information is drawn from the SMR and personal recollections of individuals who have investigated the site. Well-located surface scatters of building debris have been included since they are likely to be directly related to sub-surface structures and do not fall readily into the information recorded on the artefactual database. Poorly recorded observations, especially antiquarian ones, have been omitted since they cannot be plotted and in certain cases may not be particularly reliable.

\section{Excavations by G. H. Jack (1922)}

\section{Introduction}

Excavations were undertaken in 1922 and published the following year in a report which included a wide range of specialist reports and a summary of existing information 


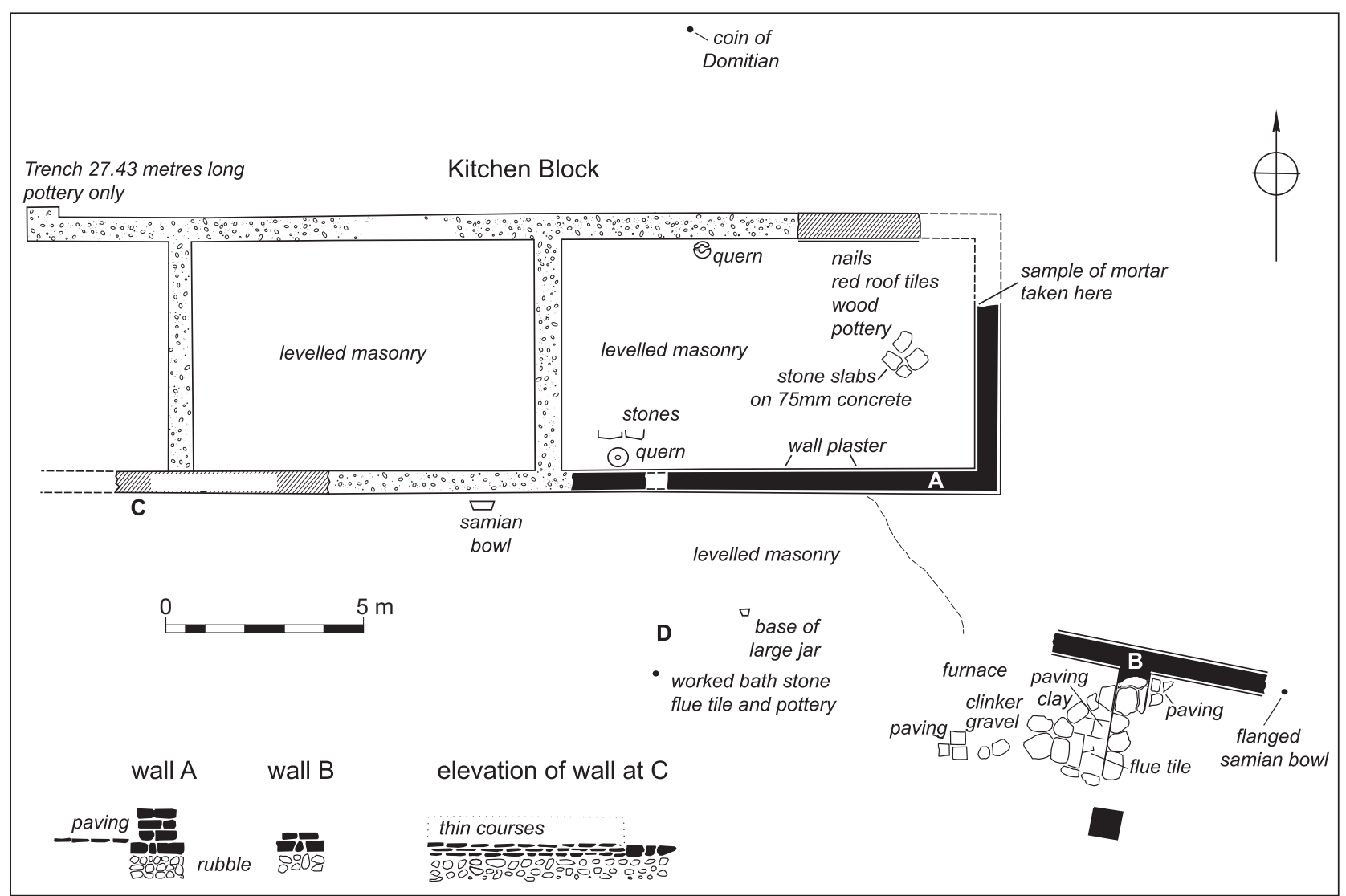

Figure 2.1. The 'kitchen block' (HSM 16780; after Jack 1923)

(Jack 1923). The report is to be admired for its thoroughness and the range of analytical techniques used.

Trenches were opened at seven locations (HSM 16780, 16781, 21095, 21097, 21098, 21099 and 22053; Fig. 1.3) largely within the currently scheduled area. One trench produced extensive evidence of Roman activity indicative of a domestic building of relatively high status. Of the other trenches only two produced Roman deposits. Associated artefacts provided evidence of dating and function.

For the purposes of this project, the published report formed the main source although some of the finds were available for analysis. The latter were loaned from Herefordshire Museum and it is evident that only part of the assemblage survives in this collection.

\section{Deposits}

The most significant remains, described as a 'kitchen block' and 'heated rooms', were located in the largest of the trenches (Fig. 2.1; HSM 16780; Jack 1923; plate 17). Photographs show that excavation followed the walls, typical practice at the time (Jack 1923; plate 1). This revealed the 'kitchen block' to comprise two compartments, one 34 feet by 19 feet, the other 28 feet by 19 feet $(10.20 \times$ $5.70 \mathrm{~m}$ and $8.40 \times 5.70 \mathrm{~m}$ respectively). A wider area (some $6 \mathrm{~m}^{2}$; Jack 1923; plate 2) seems to have been opened for the investigation of a further range of walls interpreted as 'heated rooms'. Associated material included plaster on the walls, stone footings and flagstone floors, evidence of a tiled roof, glazed windows and numerous finds. Together these indicate the presence of one or more buildings of considerable size and relatively high status.

A 'shapeless mass of masonry' and artefacts in a second trench (HSM 21097) indicated another building in the vicinity. The dimensions of this trench are not recorded in the report. The remaining five areas contained no comparable deposits. One (HSM 22053), a series of short trenches extending for some 100 feet (c. 30m) in an area to the south-west of the 'kitchen' block, contained an area of gravel and iron clinker bedded onto red clay. This may represent the continuation of a metalled road or track observed elsewhere through both cropmark and trench evidence (Fig. 1.5: Route F-E; Fig. 1.3, HSM 23554). Alternatively it could represent a yard.

No Roman deposits were identified in the other four trenches (HSM 16781, 21095, 21098 and 21099). Of these dimensions are only provided for one (HSM 21098), this being 18 yards long $(c .7 .5 \mathrm{~m})$. The other three are described as 'short'. With the exception of HSM 21099 which was excavated into 'reddish earth', all trenches were cut into a layer of 'black earth'. No artefacts were recorded from this layer in the trenches to the south (HSM 16781 and 21095) or from the 'reddish earth' in the easternmost trench (HSM 21099). 
Interestingly Jack's trenches did not reveal any industrial features and generally the character of his discoveries can be said to be domestic, however, 'iron clinker' and charcoal were recorded (in HSM 22053 and 16780).

Although stratigraphic recording is not evident from the published report, broad sequences of activity were described and artefacts assigned to structures and other deposits. Dimensions and depths were recorded, though not consistently.

\section{Artefacts}

Most of the surviving artefactual evidence has been located to the 'kitchen block' and 'heated rooms' (HSM 16780), with a single find located to Trench 1 (HSM 21097). Unfortunately it has been impossible to locate the finds from Trenches 2 (HSM 21098) and 6 (HSM 22053), the other trenches for which finds were reported.

Some 169 artefacts have been seen. The character of this material is essentially domestic. The ceramic assemblage comprised 67 sherds, weighing $2662 \mathrm{~g}$. The remaining material consists of small finds of bone, copper alloy, lead, glass and iron, many of which have been included within the specialist assessments (Section 4).

The standard of artefact recording was, on the whole very accurate, although the lack of stratigraphic evidence has limited detailed analysis. Jack did, however, take advantage of the scientific techniques available in 1922 and a number of samples of iron objects, slag and ore, as well as charcoal and coal were submitted for specialist analysis.

All the artefacts recovered are well-documented and identified in the publication, but it is unfortunate that only the finds that were considered worthy of illustrating have survived and that a substantial proportion of the assemblage has been 'lost'. This undoubtedly has affected the use of the information, limiting examination of residuality and contamination and providing only a broad date range of activity to the 2 nd through to the 4 th century. Nonetheless, for its time, the standard of the work should not be underestimated. The material has survived well, with the small finds having been well conserved and packaged by Herefordshire Museum. The ceramic material was somewhat confusingly organised and has been re-boxed and ordered by fabric and trench.

\section{Environmental remains}

Environmental sampling was not undertaken in 1922, but charcoal remains were identified and analysed to species level, along with a small number of animal bones.

\section{Investigations by G. H. Jack (1929)}

In the summer of 1929, Jack returned and recorded a cropmark immediately to the south of his 1922 site. This showed as 'a broad belt of corn, short and dried up, running in a south-westerly direction' (HSM 21367; Fig. 1.3; Jack 1929). 'Belts' of green corn, two feet wide, ran down either side and Jack surmised that this might be a road with drainage ditches.

Trenching revealed a 12 foot $(3.65 \mathrm{~m})$ wide surface metalled with iron slag. Some of the slag had fine clay adhering to it. This metalling lay about 2 feet $(0.60 \mathrm{~m})$ down and fragments of '4th century black-gritted ware' lay on its surface, however, no 'properly constructed drain' was located.

The location of this work is uncertain. Jack described the alignment as being some 700 feet $(c .210 \mathrm{~m})$ south-east of the Bromsash to Bollitree road. This suggests that the road in question may equate to one of those plotted from cropmarks (Fig. 1.5: Route C to D).

\section{Trenching by the Reverend E. R. Holland (1932)}

In 1932, Alfred Watkins reported the discovery of two roads by the Reverend Holland. The first, comprising a compact, 7-8 feet $(2.10-2.50 \mathrm{~m})$ wide slag and stone surface, was picked up about $1 \mathrm{~km}$ to the south-west of the settlement running across the Wigg Meadow towards the Forest of Dean (HSM 840). This was recorded at four locations tracing it for about five-eighths of a mile $(c .1 \mathrm{~km})$ heading in the direction of Hope Mansell. This route has also been investigated on several subsequent occasions (Bridgewater 1963, Wigg Meadows 1993 and Ryeford Bypass 1995).

The continuation of this route into Ariconium is probably represented by a second and similar, iron-slag-surfaced road, measuring 7 feet wide (2.10m; HSM 21365; Fig. 1.3). This was recorded running for over 70 feet $(c .21 \mathrm{~m})$ parallel to the small steam running west from Pond Cottage. The precise location is unclear since the surface is recorded as being above the lowest of three 'mill-ponds' along the stream and it is uncertain whether 'above' means to the south or north of the stream. Cropmark evidence (Fig. 1.5, Route $\mathrm{M}$ to $\mathrm{N})$ suggests that the south side is the more probable.

Two 'mill-ponds' were also recorded (HSM 21363 and 21364; Fig. 1.3). The first of these is shown on the 6' Ordnance survey as a pond, although it was dry in 1932 when surviving sandstone blocks of the pond dam were recorded, including two which had squared socket-holes (Anon 1932; facing page LXXXI). The second 'mill-pond' adjacent to Pond Cottage still had its dam in working order having a stone with a square socket-hole retaining the post of the sluice-gate. This pond still survives. The dating of these ponds is uncertain, however, they are potentially Roman in origin even if the sluice gates are of more recent date.

\section{Excavations by N. P. Bridgewater (1959)}

Further investigation of the road system was undertaken in 1959 and this revealed two stretches of iron-slag-metalled surfacing to the south and west of the settlement 'core'.

The first (HSM 21361; Fig. 1.3) focussed upon the route of the road to Gloucester, a route recorded on the Antonine Itinerary (Margary 1955; Route 611). Slightly over one foot below the groundsurface a slag and stone 


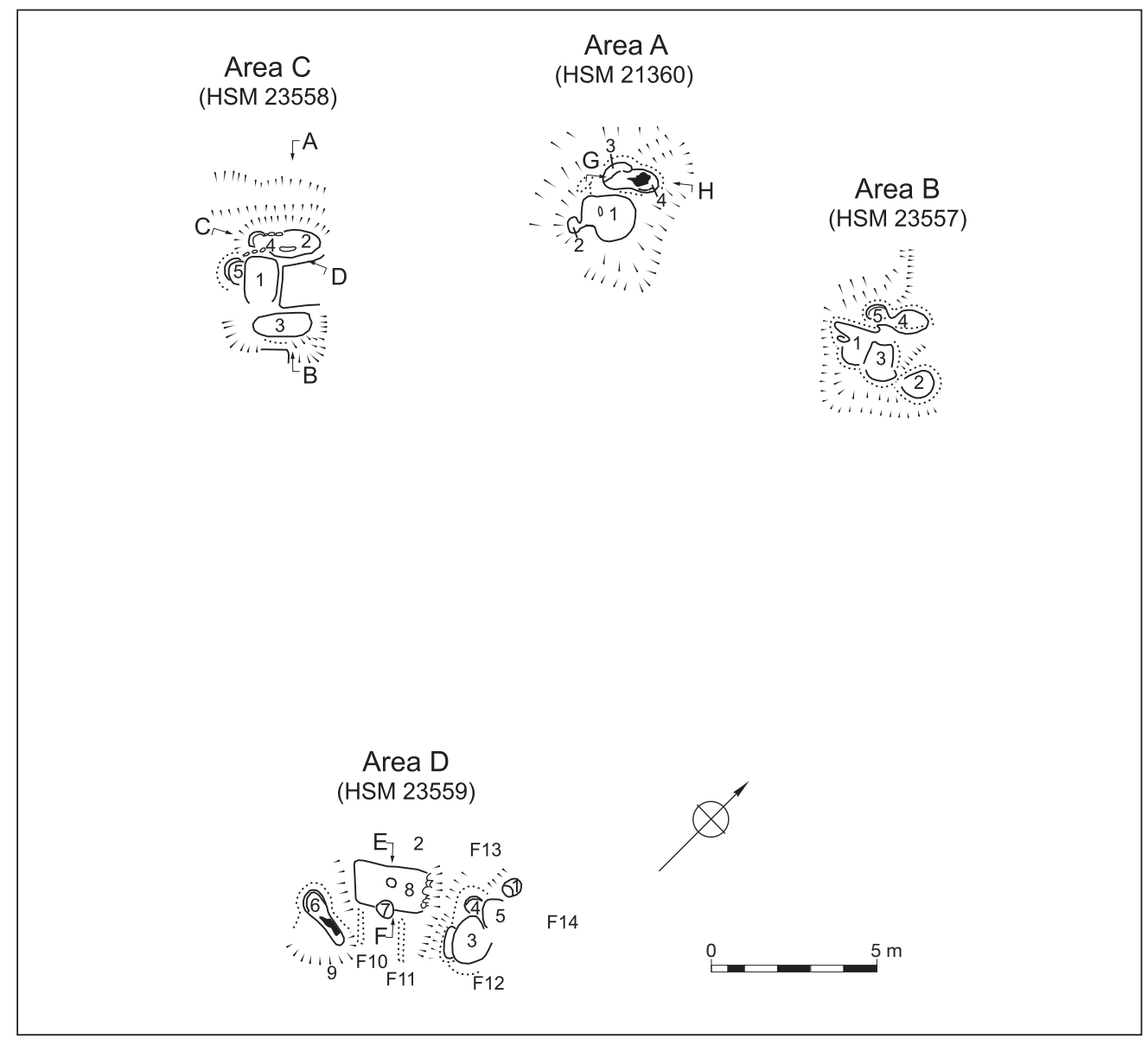

Figure 2.2. Plan of ironworking features north of the scheduled area (after Bridgewater 1965)

metalled surface was identified. This had a central, heavily compacted 'agger' measuring 4 foot 9 inches wide with a 3 foot wide grit and small stone surface down each side, providing an overall width of over 10 feet (c. $3 \mathrm{~m})$. A shallow gully ran down its southern side. To the north-west, this ran into a hollow-way and then a lane, past the cottages at Bury Hill and into the road running up to Bollitree. To the south-east the route was traced (by probing) running towards Goomstool. Here a second trench recorded a much disturbed stone and slag surface measuring 10 feet in width. No datable finds were found in either trench. The road follows field boundaries recorded on the 1838 tithe. These had been removed by the time of Bridgewater's investigations, although the route survived as a footpath.

In the first trench another similarly constructed road was recorded running towards Eccleswall Court. This was also investigated closer to the farm (HSM 21362; Fig. 1.3). This was a very well preserved 9 feet wide surface of compact iron slag. A clay pipe and two fragments of pottery dated this to the post-medieval period and Bridgewater surmised that this represented a road constructed to carry iron slag from Ariconium to Linton for resmelting during the 18th century, a documented practice. This survived as footpath into the 20th century and is shown on Ordnance Survey maps and is identifiable through a track and field boundaries shown on the 1838 tithe.

Bridgewater also undertook further work at four locations to the south, across the Wigg Meadow. These confirmed the route identified in 1932 (Watkins 1932). Construction was similar to that observed elsewhere with a 3 to 4 inch (0.07-0.10m) thick, compact, iron slag surface. At one location some $2 \mathrm{~km}$ distant from Ariconium, a $2 \mathrm{nd}$ to 4 th century roadside settlement was identified adjacent to the Whitbrook. Stone roof tile, flue brick and sandstone rubble indicated that there might have been a relatively substantial building at this location.

\section{Excavations by N. P. Bridgewater (1963)}

\section{Introduction}

Bridgewater undertook more extensive excavations in 1963, to the north of the scheduled area, on a site he referred to as 'New Ariconium'. A relatively large trench was opened $($ c. $22.00 \times 25.00 \mathrm{~m})$ in an area of finds rich, 'black soil'. Within this, four smaller areas were systematically investigated (Areas A, B, C and D; HSM 21360, 23557, 23558 and 23559 respectively; Bridgewater 1965, figs 1 and 2; Figs 2.2 and 2.3). Although much of the original 


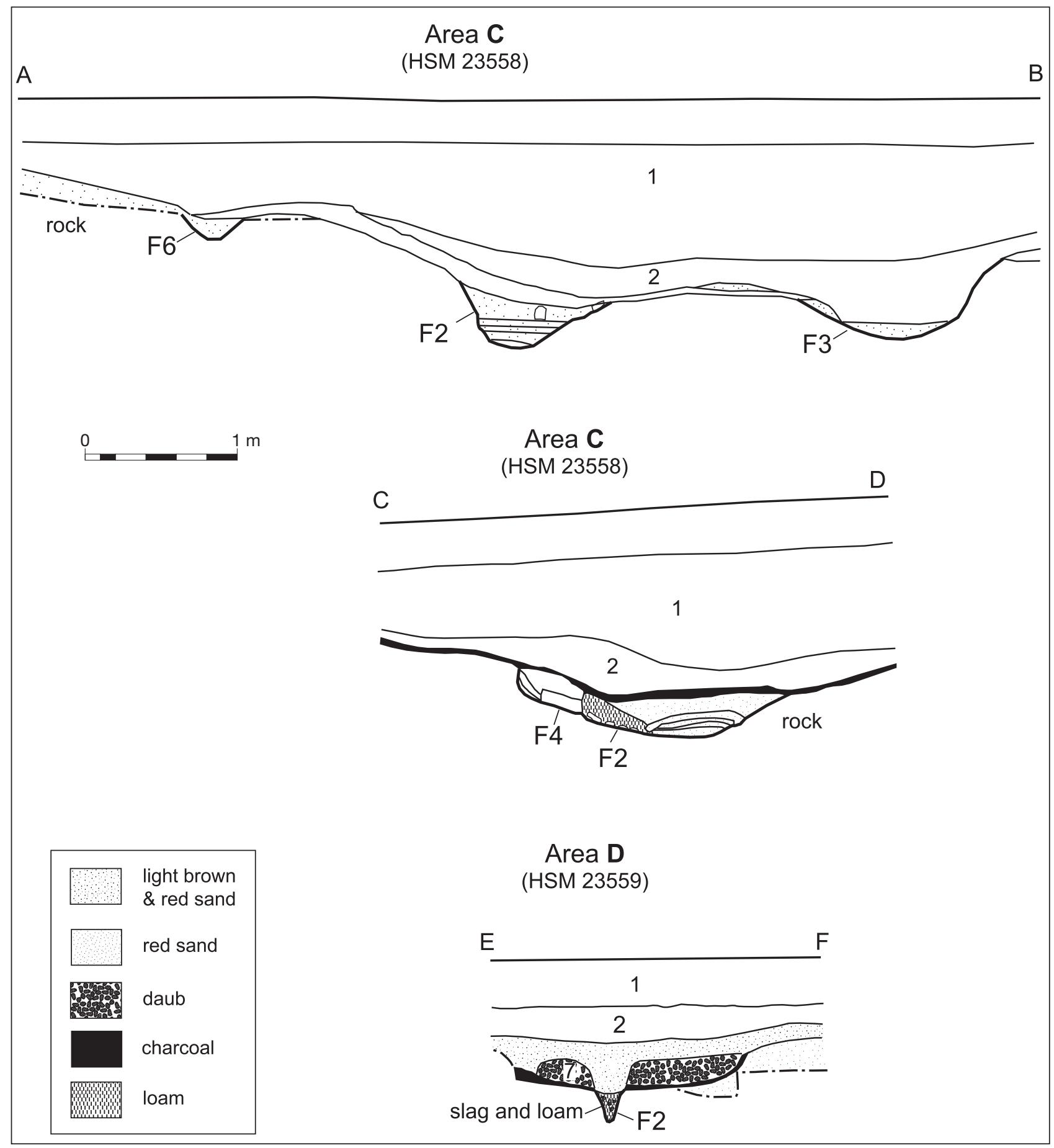

Figure 2.3. Sections across ironworking features north of the scheduled area (after Bridgewater 1965)

site archive has not been traced, both the finds notebooks and assemblage were available for analysis.

\section{Deposits}

Each of the four areas included the remains of ironworking structures. A total of six furnaces were identified along with associated working hollows, slag pits and other features.

In Area A (HSM 21360) a furnace and slag pit were associated with a working hollow and a small hollow (possibly a subsidiary furnace). These were sealed by demolition deposits and a compact soil accumulation, the latter of which had been disturbed during the 17th or 18th century. Areas B, C and D (HSM 23557-9) contained similar features and deposit sequences, with Area D notable for the presence of a structure interpreted as a 'charcoal store'. This comprised a rectangular hollow in the bedrock containing a 'complete bed of charcoal' and a layer of daub with wattle impressions. Extending from this were two parallel clay wall footings of an adjoining structure. 
The furnaces were interpreted as shaft furnaces and smelting was clearly represented, though evidence for smithing was poor, only comprising fragments of coal in some of the slag waste. No hammerscale was recorded. This activity dated to the 2 nd century after which ironworking appears to have ceased and 'the hollows and the surrounding slag heaps must have become rubbish dumps for the occupants of the houses at Ariconium'. The latter activity although not fully discussed by Bridgewater is represented by a sequence of layers filling over the furnaces and hollows reflecting a changed and datable use of this area of the settlement.

Finally the evidence of 17 th to 18 th century disturbance is believed to result from the excavation of Roman bloomery slag for re-smelting. Alternatively this could relate to Hopkins Merrick's land clearance in the latter half of the 18 th century.

\section{Artefacts}

The four investigated areas (A-D) have provided the bulk of the finds assemblage from these excavations (HSM 21357-21360; Figs 1.3 and 2.2). Other finds have been provenanced to the field in which the excavations took place (HSM 10676; Fig. 1.4) and to surrounding fields and specific locations within them (HSM 23560-23562, 21376, 21378 and 23544). Nearly all finds have been accurately located and nearly 1000 artefacts have been recorded.

Of this material the ceramic assemblage comprises some $80 \%$. This has been examined and reassessed by Steven Willis (this volume) providing good dating evidence for the ironworking phase of $c$. AD 135 to 230/250 and subsequent use of the area (for 'rubbish' disposal) into the 4th century.

The remaining finds, of building materials and slag primarily represent industrial activity. The original finds notebook was consulted during the assessment and proved to be of immense value. The material has survived well. Some re-ordering and re-boxing has been undertaken. It is not clear whether any conservation records or X-rays survive.

\section{Environmental remains}

Some soil samples were taken from the immediate vicinity of the furnaces. These may have been taken merely for reference, as no analytical work was ever commissioned. Unfortunately, they were in too poor a state to warrant analysis. However, well stratified charcoal remains were found in association with one of the furnaces (in HSM 21360). This was not studied for the original report but survived in excellent condition and consequently specialist analysis has now been undertaken (Gale, Section 4).

\section{Excavations by Garrod and Moss (1967)}

\section{Introduction}

Patrick Garrod and Phil Moss excavated eight small trenches in the late autumn and early winter of 1967.
The work, undertaken in advance of a national ploughing competition, reflected the concerns of the excavators about damage resulting from both the competition and annual ploughing of parts of the site.

Eight trenches were excavated and were numbered AI, AII, BI, BII, BIII, CI, CII and CXX. These have been allocated individual County Sites and Monuments Record numbers (HSM 23546-23552 and 23554 respectively; Fig. 1.3). These amounted to $c .60 \mathrm{~m}^{2}$ and were located in three different fields. The broad aim was to test the depth at which deposits survived and how much erosion had occurred. In addition a plan was recorded showing the extents of dark, charcoal stained soils around the site (Fig. 2.4).

Due to lack of resources, it was only possible to undertake some preliminary analysis and publish a short interim note at the time of excavation. However, as part of the Ariconium project, analysis has now been undertaken of the complete site archive which was kindly made available by Mr. Patrick Garrod. An archive report has also been produced (Jackson 2000).

\section{Summary of results}

Roman deposits were encountered in all eight trenches, the most significant being located on the north side of the scheduled area.

The largest of the trenches measuring some $4.90 \times 3.20 \mathrm{~m}$ (Trench CXX; HSM 23552; Fig. 2.5) focussed on an area where building debris including tesserae had been noted. Here, a robber trench and stone wall foundation, along with large quantities of roof tile and some wall plaster, indicated the presence of a substantial building. Dating evidence was poor but indicated a date range from the 2 nd century through to 4 th century $\mathrm{AD}$, with the robber dating to the late 3 rd or early 4 th century. The relationship of the robber trench and the stone wall foundation was somewhat ambiguous, however, suggested at least one rebuild. One possibility is that a well constructed building (represented by the robbed trench and the high status building debris) was demolished at the end of the 3rd century or early in the 4 th and was replaced by a less substantial rubblestonefounded building.

The wall truncated a series of furnace structures and associated hollows, which provided evidence of an early phase of ironworking. The structure and dimensions of three of these indicated that they represented the bases of shaft furnaces comparable to those excavated by Bridgewater in 1965. Another structure potentially represented a smithing hearth for working blooms or alternatively an ore-roasting hearth, while several hollows and other features can be interpreted as tapping pits and the remnants of associated structures.

A second trench (Trench CII; HSM 23554) was located to the south-east just above a break in the hillslope. This focussed on a flat area and bank and comprised three closely spaced narrow trenches $(0.38 \mathrm{~m})$, measuring $4.80,2.80$ and $1.80 \mathrm{~m}$ long. Here, a metalled surface and a wall footing can be interpreted as a road with a building fronting onto 


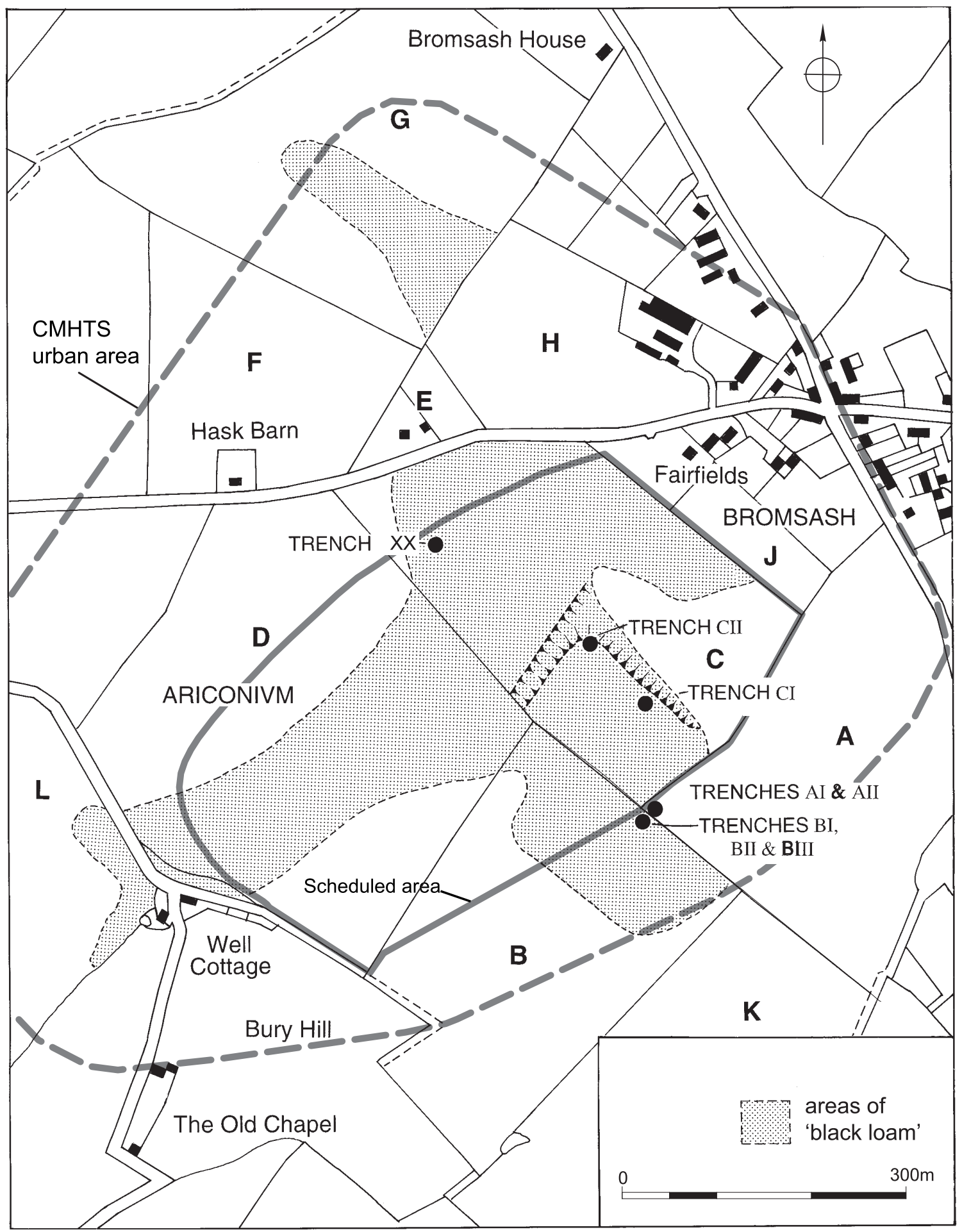

Figure 2.4. Areas of 'black loam' and trench locations (Garrod and Moss 1967)

it. The surface is located upon the line of a Roman road known to run into the settlement from the south-west.

The third trench in this field (CI; HSM 23551; Fig. 2.6) was a small test pit measuring $c .3 \mathrm{~m}^{2}$. This contained relatively complex deposits including $1 \mathrm{st}$ century curvilinear features, which may represent eavesdrip gullies and thus provide evidence for one or more roundhouses. Postholes and metalled areas were also present.
Five small trenches (c. $\left.3 \mathrm{~m}^{2}\right)$ lay to the south, just beyond the scheduled area and to either side of a field boundary (AI and AII, HSM 23546 and 23547; BI, BII and BIII, HSM 23548, 23549 and 23550; Fig. 2.4). This cluster of trenches revealed further furnace or hearth/oven structures of probable 1st century date AD. Overlying these were accumulations of soil incorporating significant quantities of occupation debris of predominantly 1 st and 2 nd century 


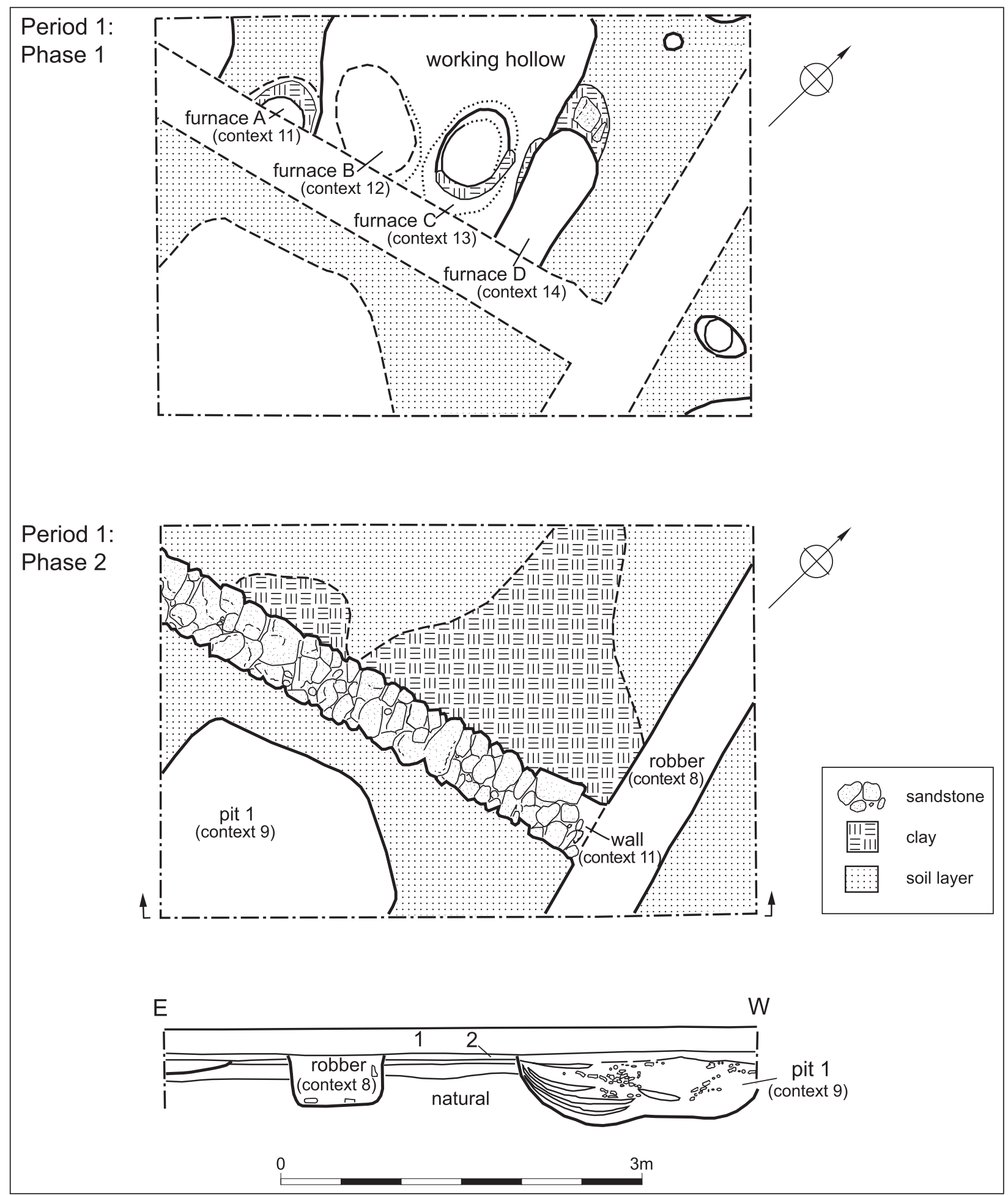

Figure 2.5. Garrod and Moss 1967, Trench CXX (HSM 23552)

date but also including material dating to the later Roman period (Willis, this volume: Section 4). These suggest that, although evidence for later structural remains or industrial activity were not present, there was continuing occupation in the vicinity and that this area was used for rubbish disposal, perhaps having formed small fields or garden plots adjacent to a settlement area. Significant quantities of late Iron Age/Transitional period material were also recovered from these trenches. This material forms a particularly interesting group and, although residual in later contexts, is strongly indicative of pre-Roman origins. Indeed the volume and range of material present here (and across the site as whole) leaves little doubt that there was significant occupation in the pre-Roman Iron Age. Some 


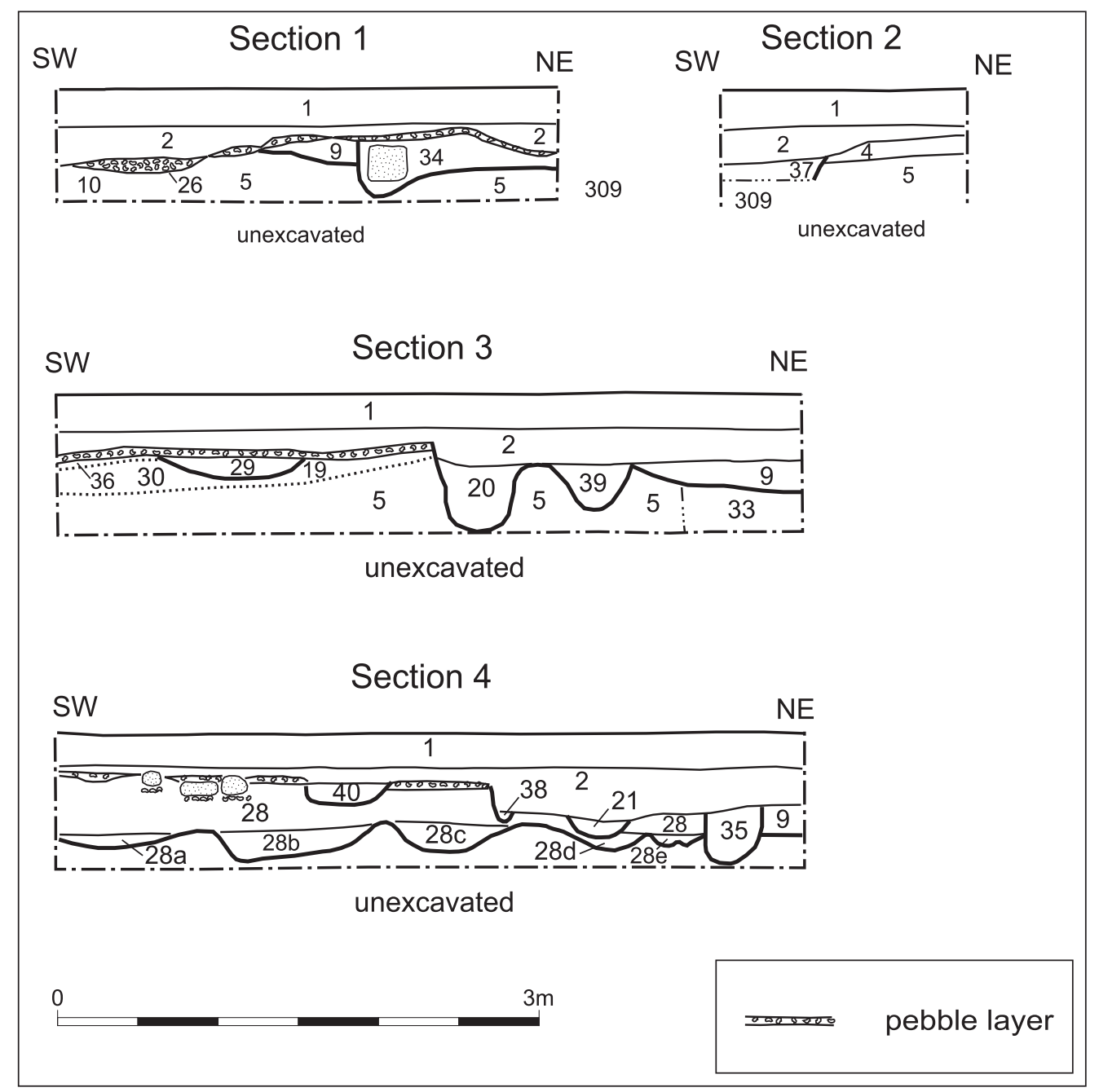

Figure 2.6. Garrod and Moss 1967, Trench CI (HSM 23551)

of the undated features, notably the furnaces in the main trench, may potentially be pre-Roman in origin although this cannot be demonstrated.

Although these results are limited by their small-scale, the integrity of the original project archive has generally proved to be good. Consequently, valuable information has been identified on the character, chronological development and survival of deposits at a number of locations across the settlement.

\section{Investigations by $B$. Walters and $M$. Walters at 'The Great Woulding' (1989)}

\section{Introduction}

In 1989, Bryan Walters and Mark Walters undertook an assessment of a site known as 'The Great Woulding' lying c. $1 \mathrm{~km}$ to the north of the scheduled area (HSM 9071; Fig. 1.3). Aerial survey, fieldwalking, geophysical survey and a trial trench were carried out and an interim report was produced (Walters and Walters 1989). Unfortunately, due to lack of resources, a full report was never completed.
Apart from a limited amount of additional analysis (Walters 1999), no further details were published. As a result of these factors, interpretations were only provisional. These are outlined below and then re-assessed by the current author in the light of additional information derived from analysis of some of the finds which were made available for analysis and from plotting of the cropmark evidence.

The site was identified from cropmarks showing the 'outlines of at least four squarish and rectangular ditched enclosures with rounded corners'. Provisional plotting and assessment of these showed a pair of overlapping, regular and square enclosures with a slightly less regular and rectilinear enclosure to their south, the latter extended or recut on the east. It was suggested that these might represent Roman 'military installations' which had long been suspected at or near Ariconium (Walters and Walters 1989).

\section{Summary of results}

Fieldwalking produced a large assemblage of Severn Valley Ware, entirely comprising early forms and fabrics 


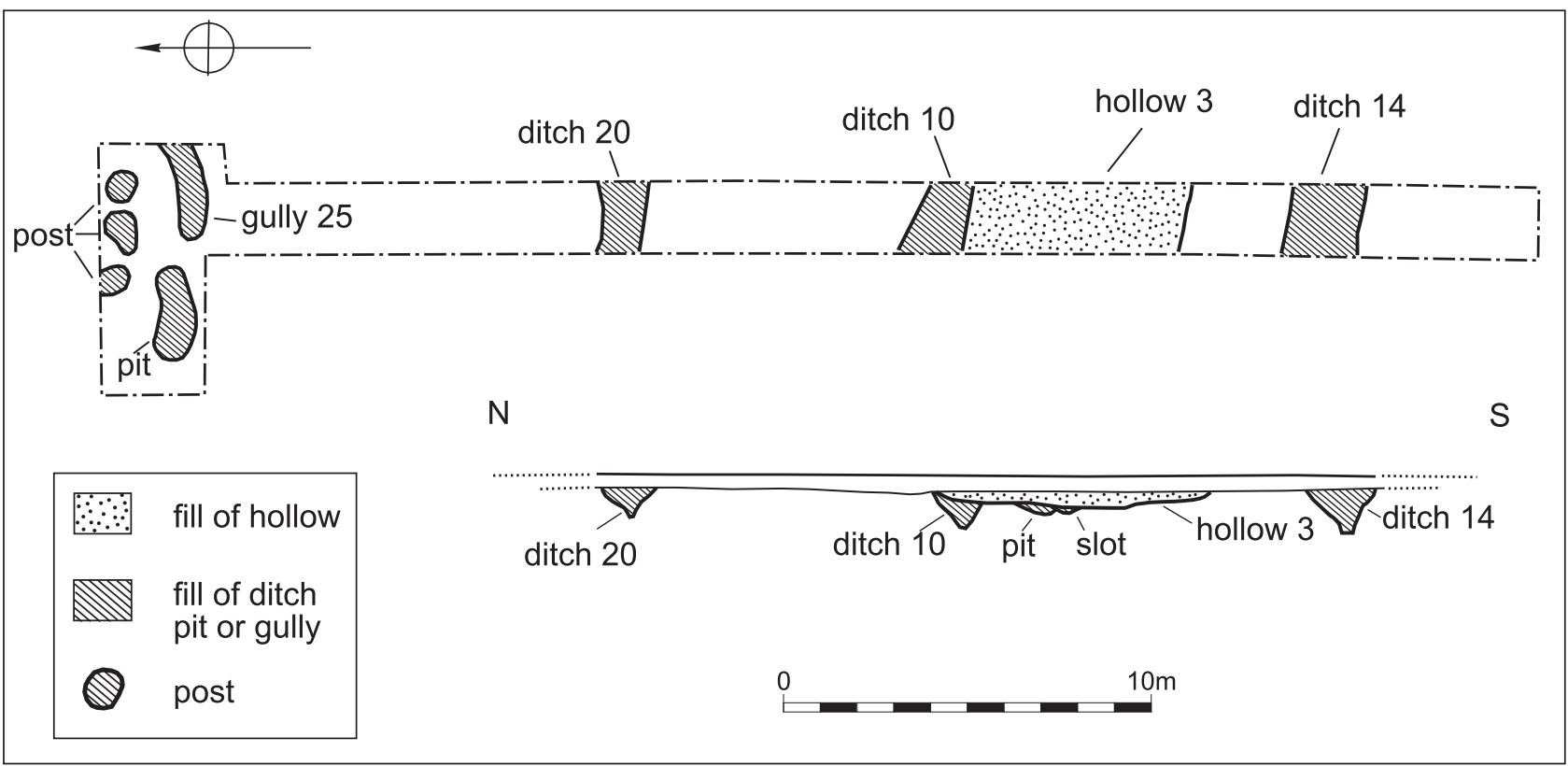

Figure 2.7. Plan and section of trench at The Great Woulding (HSM 9071; after Walters and Walters 1989)

suggestive of a 1 st century AD date. No other fabrics were recorded and the only other finds comprised iron slags and vitrified clay.

Subsequent to this, a north to south trench, $40 \mathrm{~m}$ long and $2 \mathrm{~m}$ wide, was excavated by members of the Dean Archaeological Group and the Woolhope Archaeological Section (HSM 9071; Fig. 1.3). This was located to intersect the southern ditches of the overlapping enclosures and the northern ditch of the southern enclosure(s). All three ditches (Fig. 2.7; ditches 10, 14 and 20) were identified along with a further broad 'ditch', truncating one of the northern enclosure ditches. Features were present in the base of this broad ditch and internally to the two enclosures.

The northernmost ditch (cut 20) measured $1.60 \mathrm{~m}$ across and $0.72 \mathrm{~m}$ deep and had a stepped profile. A single fill produced pottery, cattle bone, smithing slag and a large fragment of the upper part of a rotary quern. All of the pottery was described as 'native ware'.

The other ditch (cut 10) lay to the south and could be related to the northern enclosures. This had a small slot in its base, possibly indicating a recut. The fill included both Severn Valley ware and 'native ware', along with three whetstones and circular stone disc. This was suggested to be the earlier of the two ditches.

The third of the enclosure ditches investigated (cut 14) was the north side of the southern enclosure(s). This was $1.90 \mathrm{~m}$ across and $1.12 \mathrm{~m}$ deep and had apparently been recut. The main fill (13) produced only 'native ware' pottery, including a distinctive lugged cooking pot described as possibly deriving from 'the Durotrigan tradition'. Bloomery slag, smithing slag and vitrified clay were also present. The upper fill appeared to be a deliberate infill, including sandstone rubble possibly derived from levelling of an associated bank. Again only 'native ware' was present.

A fourth feature interpreted as a ditch (Fig. 2.7; hollow 3 ) was recorded between the enclosures. This was over $7 \mathrm{~m}$ wide yet no more than $0.45 \mathrm{~m}$ deep. It cut the fill one of the enclosure ditches (10) and appeared to have truncated a number of earlier features including a slot, a stakehole and a pit. The slot produced both 'native ware' and Severn Valley Ware, while the pit included Severn Valley Ware and shreds from a Dressel 20 amphora. The latter also produced iron slag fused to which was a broken 'iron spear/javelin tip of a socketed type'. The fills in this broad 'ditch' were complex and included lenses of slag. A base fill produced an 'Aucissa' type brooch (Mackreth: Catalogue No. 63, dated 1 st to early 2 nd century) and 'native wares'. The upper fill (2) included Black Burnished Ware, Central Gaulish Samian and Severn Ware.

Lastly, within the northern enclosures, a shallow curvilinear gully (25) and several postholes were recorded, none of which produced any finds.

The evidence led to a provisional identification as a 1 st century AD Roman military establishment comprising two overlapping fortlets of $c$. 0.6 acres with a major iron production area enclosed to the south (Walters and Walters 1989). It was argued that these fulfilled an administrative role, supervising or overlooking civilian production and distribution of iron and iron objects for the military advance into Wales.

\section{Re-assessment}

The conclusion reached by Walters and Walters is an attractive one given the military control exercised over the major iron industry of the Weald in southern England 
(Cleere 1974). However, the evidence is inconclusive and can be more readily equated with a civilian farmstead complex of Late Iron Age and early Roman date.

Firstly, the plotting of the cropmarks demonstrates that they are not as regular as first suggested (Fig. 1.5; HSM 9071). As Walters (1999) has pointed out they are small (50-70m across) for Roman military enclosures and on form alone they seem more likely to represent one or more farmstead enclosures.

Turning to the character and dating of the artefact assemblages examined, evidence is inconclusive for a military presence and again seems to point more strongly towards a civilian, native settlement. The absence of non-local fine wares is certainly inconsistent with the general pattern of Roman military use and although the predominance of local wares could be consistent with a general pattern of use of local wares by the Roman military, the evidence is at best equivocal (Willis, Section 4). Neither is conclusive and a general problem exists in that there is wide variability in the composition of Roman military site assemblages in western Britain. Similarly, the 'Aucissa' brooch whilst of a type often associated with early military sites is also known from a number of purely civilian ones (Mackreth, Section 4). This only leaves the few military items, the majority of which are of later date and from the main site (Cool, Section 4). Only the spearhead was a stratified find at The Great Woulding. Since this had a distorted socket, was fused to iron slag waste and derives from a site where there is abundant evidence of ironworking, this could simply be a scrap item brought for resmelting or a reject. Furthermore, as has recently been pointed out (Black 1994) the presence of a small number of military artefacts should not necessarily be taken to denote a military presence unless other evidence is present.

In the light of this absence of certain evidence for a military presence, an alternative site sequence and interpretation is offered. It is suggested that the southern enclosure represents a native farmstead of Iron Age date at which ironworking was undertaken. Although limited, the dating evidence from the infill of the ditch indicated that it probably went out of use prior to the end of the Iron Age. A second or possibly contemporaneous enclosure lay to the north and appears to also have ironworking associations. Internal features investigated within this enclosure may represent elements of a roundhouse as suggested by postholes and a short section of curvilinear gully (Fig. 2.7). The fill of the ditch indicated disuse of this enclosure at a Late Iron Age/Transitional date at which point the second of the northern enclosures may have been constructed. An association with ironworking is again evident. Pottery from the ditch fill suggests use until about the end of the 1st century. Lastly the broad feature truncating this enclosure ditch and several other features may be re-interpreted as a hollow-way running between the enclosures and linking them to the road to the east. This seems to have gone out of use in the early 2 nd century.

\section{Salvage recording on the Welsh Water pipeline (1993)}

\section{Introduction}

Salvage recording was undertaken in 1993 by the Hereford and Worcester County Archaeological Service (now Worcestershire Historic and Environment and Archaeology Service) alongside construction by Welsh Water of a pipeline known as the Lea and Weston-under-Penyard Sewage Transfer. Three areas of deposits were identified (HSM 6097; HSM 12666 and HSM 15983; Fig. 1.3) and an archive report was completed (Jackson, Hancocks and Pearson 1999). Post-excavation analysis was undertaken in such a manner as to be fully compatible with the Ariconium project, in order that the artefact and structural databases could be fully integrated into the wider project.

\section{Deposits at HSM 6097}

This area was first identified through fieldwalking which revealed a scatter of iron slag and Roman pottery. Topsoil stripping subsequently revealed complex and significant deposits within the southern half of the field, mostly concentrating along the main pipeline route, but also extending a short distance along a spur to the south-west.

Test trenching of this area revealed well preserved deposits extending along about $300 \mathrm{~m}$ of the pipeline. Trenches were restricted to $1.00 \mathrm{~m}$ in width (the width of the trench excavated for the pipe). Fourteen trenches were excavated, totalling $67.00 \mathrm{~m}$ in length (Fig. 2.8) representing approximately $22 \%$ of the area of maximum impact. In addition a number of small areas off the direct line of the pipe (but within the easement) were investigated.

Significant Roman deposits were recorded across most of this area, with the northern and western trenches (Trenches 8/14 and 6) reflecting the maximum extents of observed archaeological deposits. To the south, deposits were present in the field south-east of the road (HSM 12666, see below).

The best preserved deposits lay close to Pond Cottage (Trenches 3 and 9; Figs 2.8 and 2.9), where waterlogged remains including timbers were observed close to the stream. The latter were left in situ since they were not to be disturbed by the pipetrenching and extended beyond excavated limits. Extensive sampling for environmental analysis was undertaken (see below). These deposits lay in a near vertical sided cut (307; Fig. 2.9) interpreted as a water management feature such as a channel or leat, or alternatively as a specialist industrial feature such as a water storage tank. Infilling or slumping deposits over this feature indicated disuse in the later 3rd to 4th century AD.

Beyond this area, other trenches revealed well preserved deposits, with complex sequences of layers (groundsurfaces, metalled areas and soils) and features (furnaces, pits, postholes, walls, etc). These extended across a wide area and dated from the late 2 nd through to the 4th century.

The most significant deposits lay in Trenches 4 and 


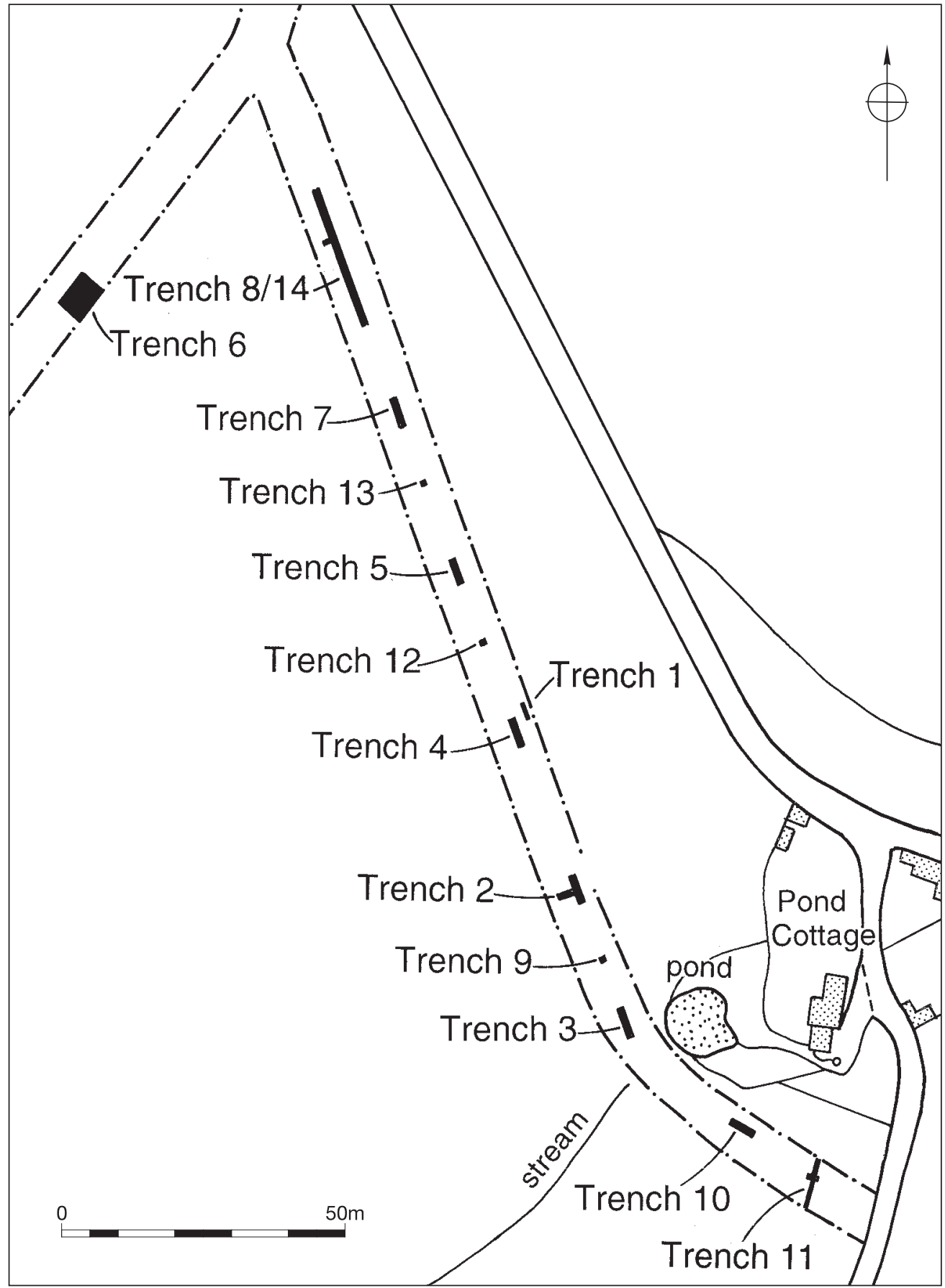

Figure 2.8. Trenches along the route of the Welsh Water pipeline (HSM 6097; Jackson, Hancocks and Pearson 1999)

8/14 and related to ironworking (Figs 2.10 and 2.11). The morphology of iron slag recovered was consistent with the use of tapped (shaft) furnaces and a group of bowl-shaped features in Trench 8/14 were considered likely to represent tapping pits (Fig. 2.11). Adjacent postholes represented the remains of a structure, possibly a workshop or shelter, while further postholes to the west (in Trench 6; Fig. 2.11) also probably represented associated timber buildings. To the south, in Trench 4 (Fig. 2.10), a potentially specialised industrial feature was investigated. The narrowness of the trench precluded any clear indication of its form or function; however, large quantities of iron slag and lengths of charcoal cut from coppiced wood indicated association with the ironworking activities (Gale 1995; Section 4). This activity dated from the 3 rd to 4 th century.

Two rubble wall footings, a dump of sandstone rubble (including a millstone) and postholes were also recorded to either side of the stream by Pond Cottage (Trenches 2, 10 and 11; Fig. 2.12). In addition, important information was recorded relating to the effect of topsoil erosion on 
archaeological deposits at the site. These are discussed in more detail in Sections 3 and 6 of the report.

\section{Deposits at HSM 12666}

Two north-east to south-west aligned ditches were recorded at this location (HSM 12666; Fig. 2.13; Jackson, Hancocks and Pearson 1999). Palaeozoic limestone tempered ware, organic briquetage and a small quantity of iron tap slag were recovered. These indicate a probable Late Iron Age date for the ditches, although one of them contained two very small sherds $(4 \mathrm{~g})$ of medieval pottery. These are believed to be intrusive and result from movement of heavy plant along the pipeline easement.

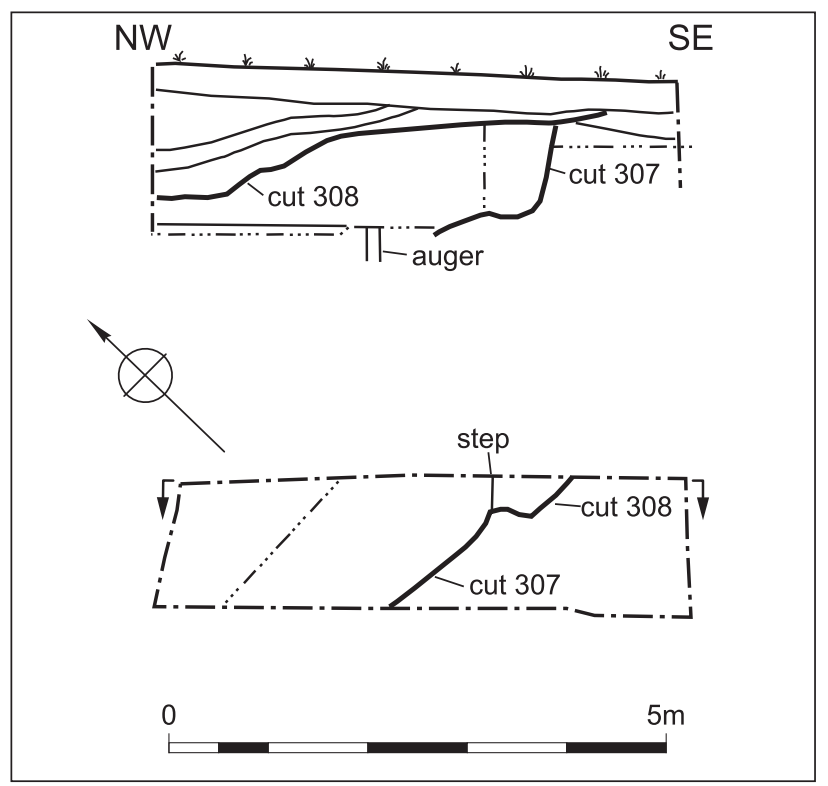

Figure 2.9. Welsh Water pipeline 1993, Trench 3 (HSM 6097)

\section{Deposits at HSM 15983: Bull Meadow}

Approximately half a kilometre south-west of Ariconium, a concentration of Roman pottery was observed and subsequent investigation revealed well preserved deposits (HSM 15983; Fig. 1.3; Jackson, Hancocks and Pearson 1999). These have been interpreted as the remains of a farmstead lying close to the Roman road running south across the Wigg Meadows towards Hope Mansell.

Structural features including a slot and possible wall line were associated with a large rubbish pit, a shallow ditch and dumped deposits. Dating indicated occupation during the $3 \mathrm{rd} / 4$ th century. A deposit incorporating debris from the demolition, or abandonment and collapse, of a substantial building sealed these.

\section{Artefacts}

Large assemblages of well stratified artefactual material were recovered from the excavated trenches at HSM 6097 and allowed phasing of Roman activity. In addition, fieldwalking recovered a substantial quantity of material. The character and nature of these assemblages is predominantly Roman, although amongst the fieldwalking there is inevitably a small amount of post-Roman material.

The total ceramic assemblage comprised c. 2500 sherds while large quantities of iron slag, some 4000+ fragments, were also recovered. Copper alloy slag and a partly melted vessel base (Mackreth: Catalogue No. 87) was also present. Other artefacts included jewellery, a coin, iron objects, glass beads and vessel fragments. Specialist analysis of the iron slag residues (Starley 1995) has been drawn upon for the purposes of this report while analysis of ceramics, worked stone and small finds has been incorporated into other relevant specialist assessments (Section 4).

These artefacts have made a valuable contribution to

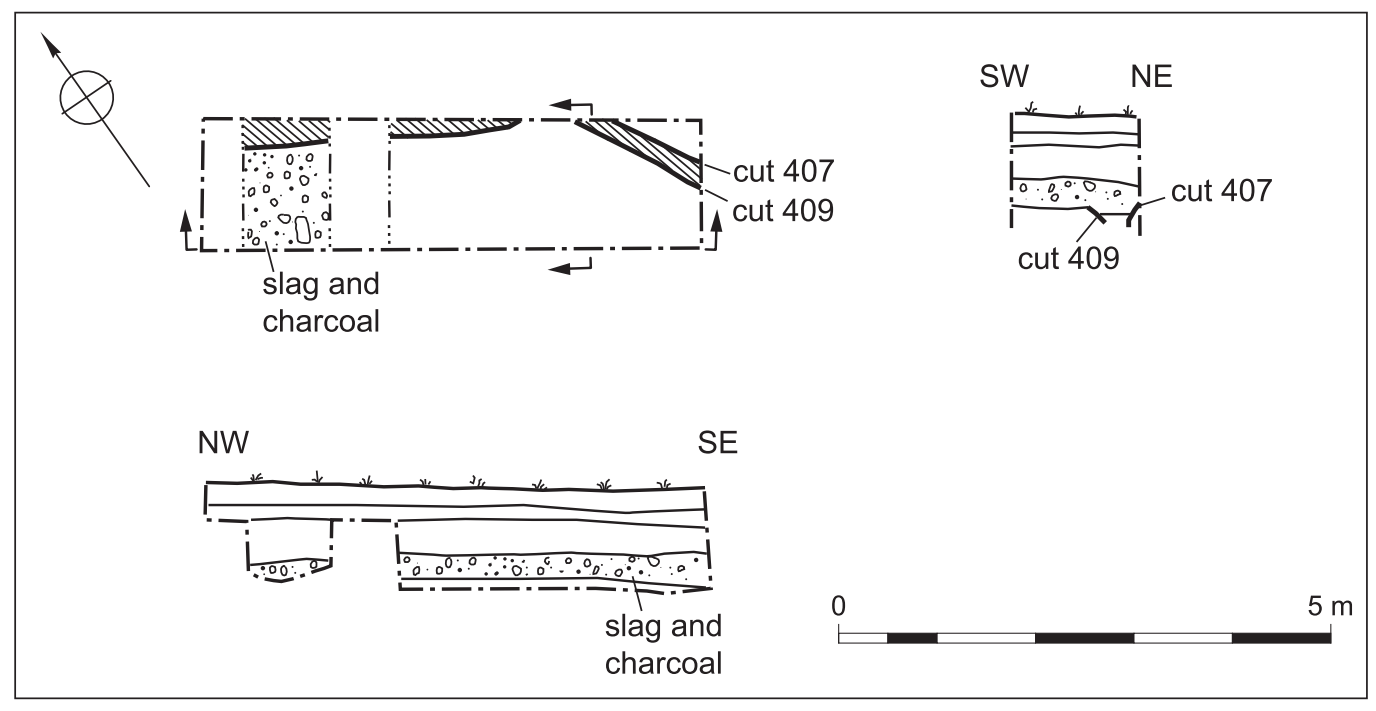

Figure 2.10. Welsh Water pipeline 1993, Trench 4 (HSM 6097) 


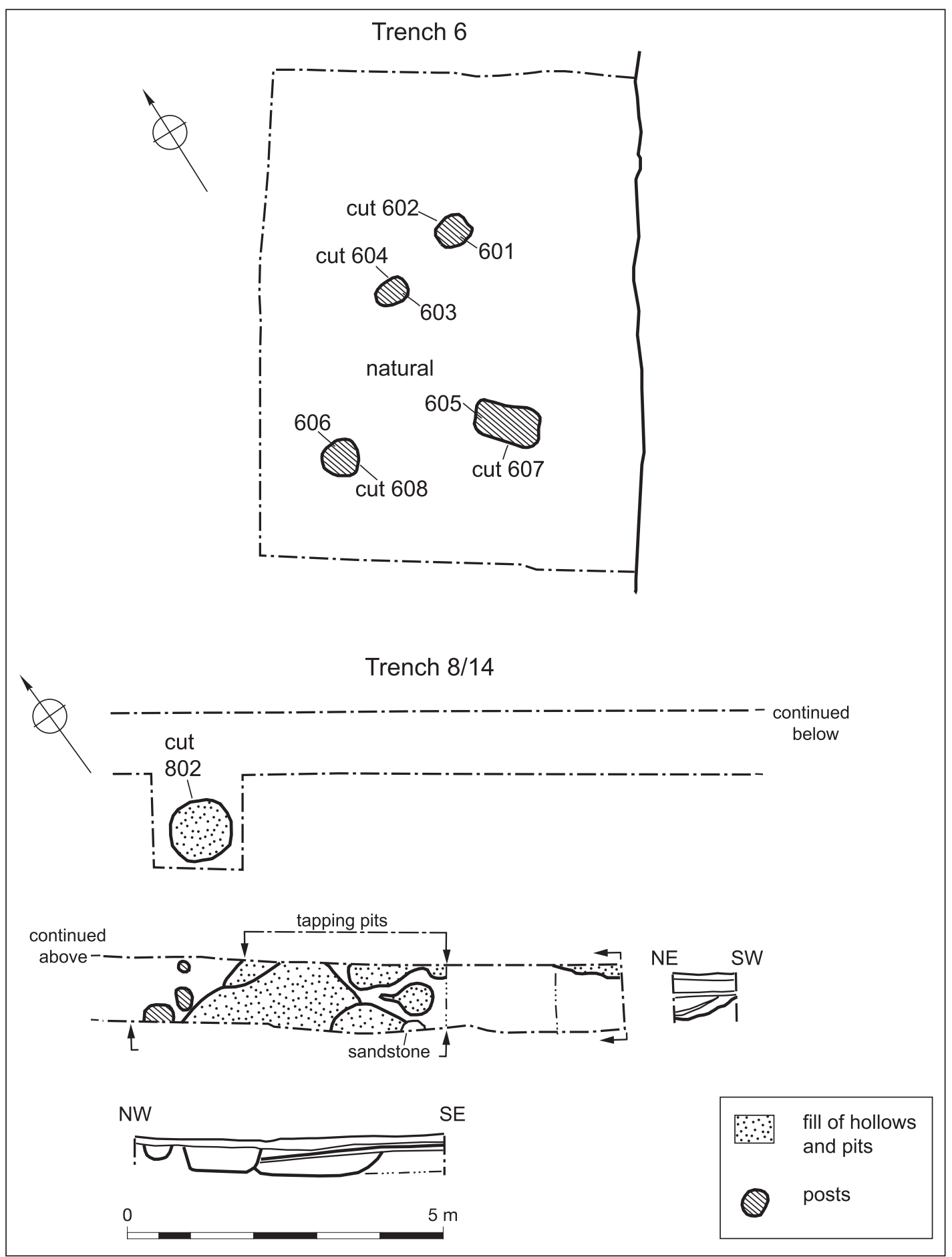

Figure 2.11. Welsh Water pipeline 1993, Trenches 6 and 8/14 (HSM 6097)

understanding the development of domestic and industrial activities. Dating suggested that the remains related to activity commencing in the late 2 nd century and extending through well into the 4th.

The artefactual assemblage from the Bull Meadow site (HSM 15983) comprised 254 sherds $(3,731 \mathrm{~g})$ of pottery, iron slag, copper alloy slag, ceramic mould, Roman building debris (brick and tile), a rotary quern fragment and vessel glass. These indicated a period of occupation dating to the later Roman period ( $3 \mathrm{rd} / 4$ th century). Smallscale bronze working was postulated as one activity at the site (Starley 1995).

\section{Environmental remains}

Charred plant remains consisted mainly of charcoal, much 


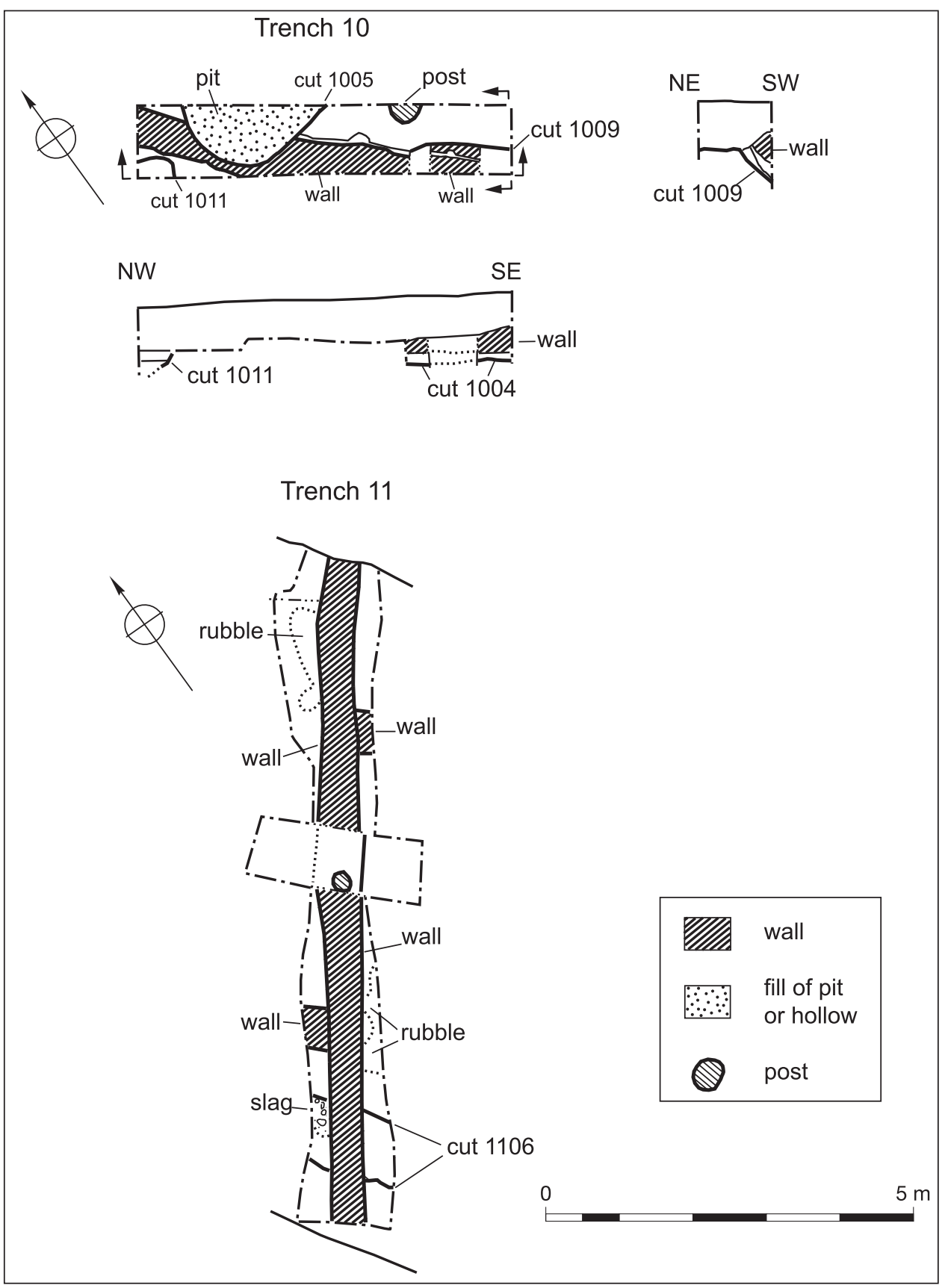

Figure 2.12. Welsh Water pipeline 1993, Trenches 10 and 11 (HSM 6097)

of which was considered to have derived from fuel used in iron smelting. These were mostly poorly preserved though a pit fill (from Trench 10) produced the remains of fine-sieving waste from processing of a spelt wheat crop while nine samples of well preserved charcoal were recovered from ironworking deposits and identified to species level. Species were comparable to those recovered by Jack (1923) and analysis confirmed that the wood was cut from rods or poles, indicating coppicing as a form of woodland management (Gale 1995; Gale, Section 4).

The most significant material came from late $3 \mathrm{rd} /$ early 4th century waterlogged samples recovered from Trench
3 close to Pond Cottage (Figs 2.8 and 2.9). These were remarkably rich in organic remains and included species likely to have grown around the nearby stream and in the surrounding area.

\section{Watching brief on Wigg Meadows (1993)}

In 1993 observation of small pits excavated for the erection of new power line poles provided further confirmation of the road running south towards Hope Mansell (HSM 840; Topping 1993). Box flue recovered from one pit close to the roadside settlement identified by Bridgewater (Wigg 3; 


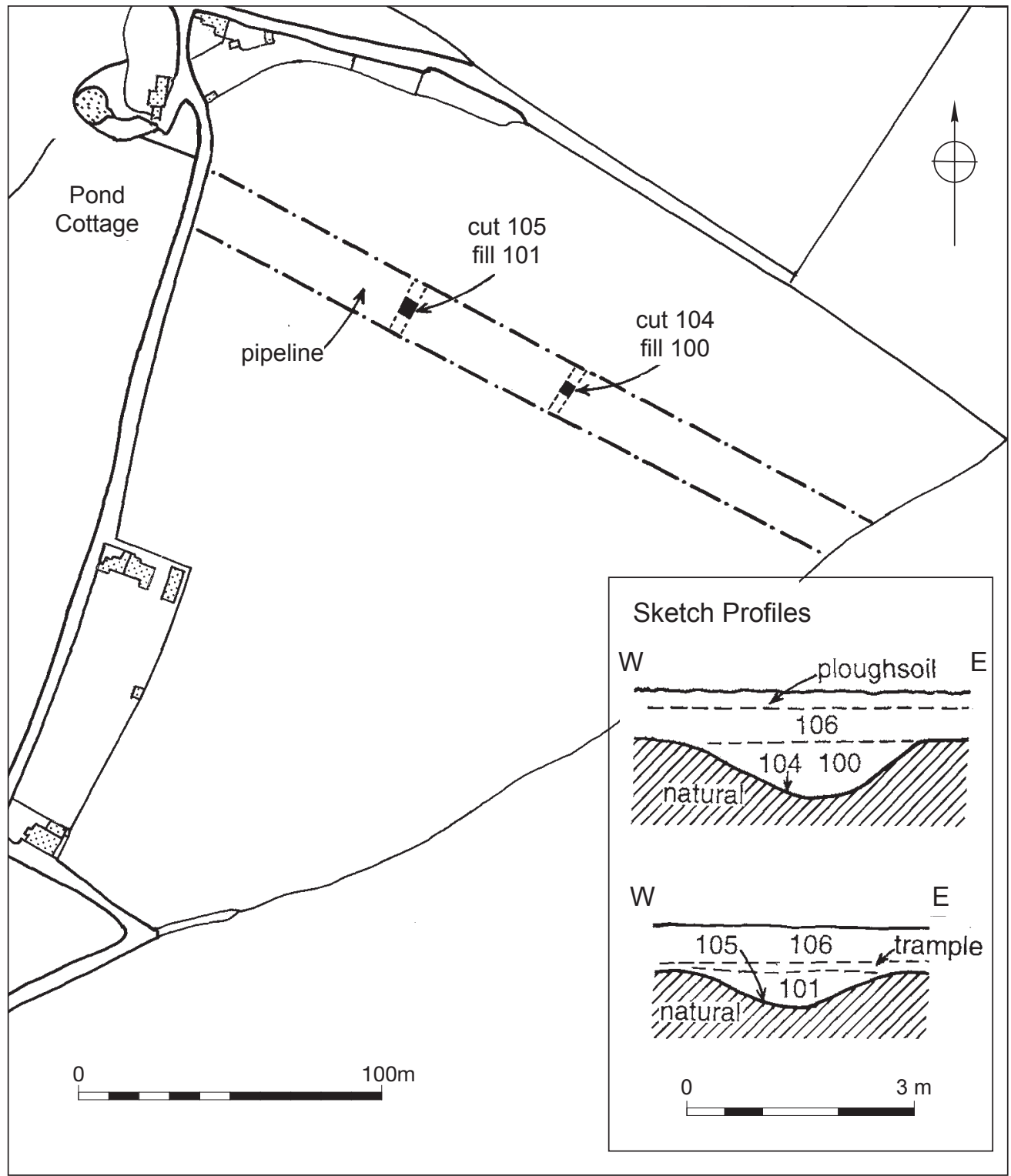

Figure 2.13. Deposits to the south-east of Pond Cottage (HSM 12666; Jackson, Hancocks and Pearson 1999)

1959) appears to support the identification of a romanised building near this location.

\section{Evaluation on the route of the proposed Ryeford Bypass (1995)}

Evaluation of the proposed Ryeford Bypass, south of Ariconium, revealed further evidence for the road running across Wigg Meadows. A metalled slag surface, c. 3.50$4.00 \mathrm{~m}$ wide, was associated with evidence of a roadside settlement comprising a ditch complex, yard surfaces and finds (HSM 22965; Fig. 1.3; Trench 11; Napthan, Ratkai and Pearson 1995). Pottery provided a broad date range of the Late Iron Age through to the later Roman period. A sherd of Palaeozoic Limestone tempered ware from the road surface indicated that this was of early construction, possibly having been an Iron Age route. However, most material was 3 rd to 4 th century suggesting that roadside settlement was of this date.

\section{Fieldwalking and other sources}

\section{Fieldwalking}

A number of the programmes of excavation and salvage recording have been accompanied by surface collection of unstratified material (Fig. 1.4). Such material survives from both the Bridgewater and Garrod and Moss fieldwork during the 1960s. Other collections by Bridgewater (HSM 10676, 21376, 21378, 23544, 23560, 23561 and 23562) and Garrod (HSM 5324 and 21376) as well as several other 
individuals (Anon: HSM 5324 and 10676; Harper: HSM 5324 and 21376; Kemp: HSM 5324) date from between 1958 and 1971. These are located at minimum to land parcel and often to more specific centres or points.

Further fieldwalking, over a period of five years from 1984-1989, by members of the Dean Archaeological Group (DAG) led to several well recorded and located collections (HSM 5324, 10008, 10676, 21376, 21378, 22049, 23545, 23553, 23555-56; 23563; Fig. 1.4). As a result of permission granted in 1989, this includes material from gridded surface collection within the scheduled area. The South Worcestershire Archaeological Group (SWAG) carried out gridded fieldwalking in 1986 (HSM 22049).

Fieldwalking was also carried out on the Welsh Water pipeline in 1993. The entire route was rapidly scanned and artefacts revealed at the surface and following topsoil stripping were recovered (HSM 3896, 6092-94, 6097, 10672-73, and 15980-15984). In one field (HSM 6097), where extensive Roman deposits were subsequently recorded, fieldwalking of the easement was undertaken locating material to the nearest $5 \mathrm{~m}$. Lastly, during a site visit made as part of the current project, a distinct concentration of artefacts was recorded to the west of the scheduled area (HSM 23570).

Thus fieldwalking has occurred in areas adjacent to, and within, the scheduled area. The amount and character of ceramic evidence in combination with many small finds recovered has been of especial use in identifying the extents of the core of Roman domestic occupation, the area of Iron Age settlement and areas of hinterland activity.

\section{Surface observations}

Concentrations of artefacts and building debris have been noted at several locations. In 1971, building debris was recorded within the scheduled area (HSM 4186-8; Fig. 1.3). A 'rubbish dump' (HSM 4189) and a stone spread (HSM 4185; letter from Alan Morriss in HAN 22) were also identified. The first of these concentrations was subsequently visible following ploughing in 1988 and 1996 (DAG; HSM 23568). These concentrations occur in the vicinity of buildings identified by Jack (1923) and Garrod and Moss (1967).

In addition, the co-operation of a metal detectorist (Martin Sterry) operating around the fringes of the scheduled area has resulted in the identification of an area of previously unknown activity (HSM 23567; Fig. 1.3). This was evidenced by a significant quantity of surface finds focussed on a scatter of building debris. This area of land has historically been under pasture thus preventing identification of activity through fieldwalking or cropmark evidence. It was only in relatively recent years that the field was ploughed and metal detecting permitted, thus revealing this area of activity.

\section{Metal detecting finds}

Since about 1990 the site has been affected by metal detecting. Some of this has been unreported and has occurred within the scheduled area despite the best efforts of the landowner. More positively, the known detectorists who regularly work in the area have largely avoided the scheduled area and have consistently reported finds through the Dean Archaeological Group (DAG 1991; 1993; 1994; 1995 and 1997).

Metal detecting has been identified within the study area from at least 1989 to the present (HSM 5324, 10676, $21376,21378,23544,23555,23563$ and 23567). With the co-operation of a couple of detectorists, and from finds reported through DAG newsletters and to the SMR, it has been possible to build up a catalogue of material held in selected private collections. This has enabled the scale of the potential loss of artefacts to be brought to light and at the same time drawn on the observations of these individuals in the field.

Brooches and coins, covering both the Iron Age and Roman periods form the majority of these assemblages. Most of the material has been accurately identified and some has been conserved. It is unfortunate that no record exists of exact findspots; however, it has been possible to locate them to specific fields through the finders' records and memories. The majority remains in private hands and as a result only a proportion have been included in the specialist finds analyses.

The distribution of the well-located finds has been plotted (Fig. 2.14) and supported discussion of the future management of the site.

\section{Aerial photographs}

Cropmark evidence prior to this project included reports of buildings, roads and enclosures; however, only limited information was available and none had been formally plotted. Examination, interpretation, plotting and reporting of all available and appropriate photographs within the project study area were undertaken. The full report (Cox 1995 ) is held in archive and individual area assessments are included in Appendix 3.

The main areas of soil change have been plotted, where they may prove to be of archaeological significance or may mask archaeological deposits which would otherwise show as cropmarks. The soil depth differences in the area caused problems during archaeological interpretation of the cropmark evidence and it was particularly difficult to differentiate natural features from areas of deeper or 'different' soils produced by localised industrial processes. The Roman town and its associated industrial and transportation features show as a superimposed series of very complex, and often amorphous, marks in growing crops (Fig. 1.5; Cox 1995). Several roads and trackways were recorded. Some of these retain evidence of existing buried metalling or other hard surfacing, whilst others have 


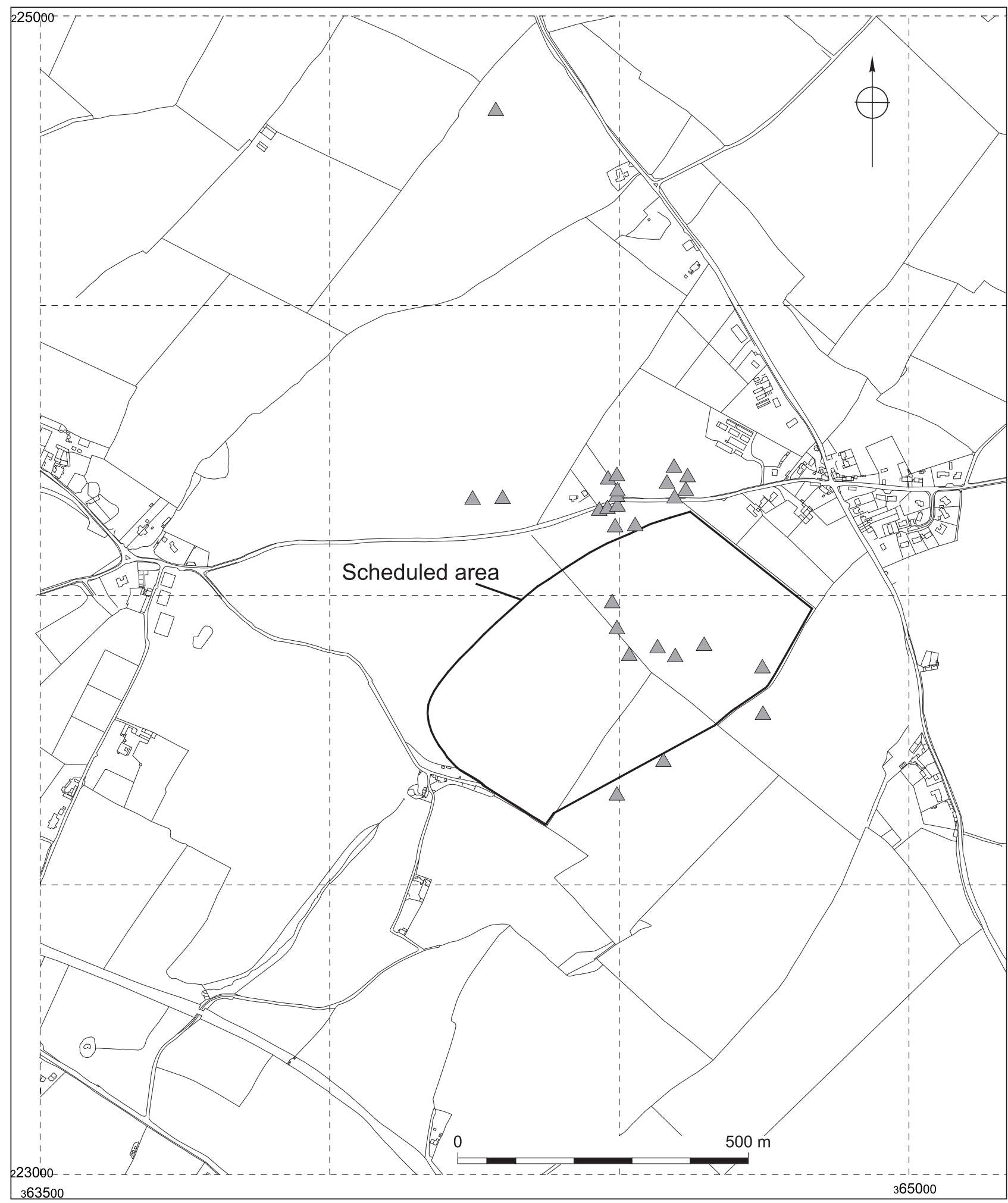

Figure 2.14. Plot of located metal detecting finds.Reproduced by permission of Ordnance Survey on behalf of HMSO. (C) Crown Copyright 2011. All rights reserved. Ordnance Survey Licence number 100051813

been robbed or degraded and show as negative features.

All the archaeological features are severely degraded and buried. These extend some considerable distance beyond the currently scheduled area. The 'roads' are bordered by complicated, and probably multi-period, remains of fragmentary, buried cut features representing associated settlement and industrial activity while the immediate environs of the scheduled site contain further settlement 
and industrial evidence in the form of enclosures, roads and possible industrial areas (Cox 1995).

Identifiable components of the Roman settlement such as the roads/tracks and enclosures have been used in conjunction with evidence from buried remains and GIS plots of artefact scatters to support the creation of a model for the morphological and chronological development of the settlement (Section 5).

Finally evidence of field boundary removal and areas of deeper soil accumulation have been considered in relation to other evidence for changes in landuse and erosion.

\section{Poorly located finds}

Antiquarian activity has been extensive (see above). Although finds are poorly located, they have been of importance in understanding the history of archaeological activity at the site and providing background information. The most important material is from the Palmer collection of 1870 (HSM 23571) which mainly comprises coins and brooches. No detailed locations are available, the finds only being provenanced to Ariconium.

The material has been collected by hand and ranges in date from the late Iron Age to the end of the Roman occupation. It is essentially domestic in character and has an obvious bias towards the aesthetically pleasing. Material has largely been well conserved, although it has not been possible to determine whether conservation records survive. The various artefact classes present in the collections have been analysed (Section 4) and have supported examination of dating, character and trade. In the absence of meaningful location evidence this material has not contributed to the GIS analyses.

\section{Place-name evidence}

The place-name Ariconium is recorded in the Antonine Itinerary (as Ariconio). This was first equated with the site at Weston-under-Penyard by Brayley and Britton (1805) and this identification has since been confirmed (Rivet 1970).

The name is formed from the British prefix are- (or ari-) meaning 'in front of' and conio- the meaning of which is unknown (Rivet and Smith 1979, 257-8). It has been observed that the prefix are- has usually been used in place-names of regions beside some natural feature such as a forest or a marsh (Rivet and Smith 1979, 258). At Ariconium, the association might therefore be of a place beside the forest (of Dean).

The other place-name of interest in the vicinity is that of Eccleswall (as in Eccleswall Court; HSM 21372; Fig. 1.3). This means 'spring of the Christian community' (Copplestone-Crow 1989, 130; Gelling 1992, 114) and is believed to refer to the Christianity of the early medieval Welsh kingdom of Ergyng (and variants thereof Ergyn, Ercic, Ergic, and Erging) or Archenfield, the name of which derives from Ariconium (Gelling 1992, 114-8).

Weston-under-Penyard is first recorded at Domesday (Thorn and Thorn 1983) as Westune meaning 'west settlement', with the form Weston sutbus Penyard first appearing in 1376 (Copplestone-Crow 1989, 202). 


\section{Section 3. Erosion and deposition history}

\section{Soil erosion (Tony Lloyd, ADAS)}

\section{Introduction}

Due to mounting concern about the effects of soil water erosion on farming in vulnerable areas, the Ministry of Agriculture, Fisheries and Food (MAFF; now DEFRA) commissioned ADAS to monitor regularly a number of erosion-susceptible arable catchments in England and Wales. The monitoring scheme was established on 13 sites, one of these being at Bollitree Farm which is also the site of the Romano-British town of Ariconium. This site was monitored over five winter periods, from autumn 1989/90 until late winter 1993/94.

Because of the potentially damaging effects of soil erosion, this survey was considered to provide useful information for the Ariconium project. Initially ADAS provided a scoping report on the survey (in January 1996), to outline the available information. This showed that the information would be useful in understanding the causes of erosion at Bollitree Farm and ADAS was commissioned, in May 1999, to present a full analysis of the data.

Three main objectives were identified:

- Summarise the erosion survey data collected by ADAS;

- Interpret the data in terms of the causes of the erosion events that occurred;

- Identify management options for controlling erosion in the future.

\section{Nature of Bollitree Farm}

\section{Cropping}

Bollitree Farm is a 143 ha holding which lies approximately $3.5 \mathrm{~km}$ to the east of Ross on Wye in Herefordshire. It is an arable farm in a predominantly grassland area and is operated as a satellite of another farm to the north of Ross on Wye. It consists of 10 large fields (with an average size of $13.6 \mathrm{ha}$ ) which at the time of reporting were cropped with cereals (mainly autumn sown), sugar beet and potatoes (Fig. 3.1; Table 1).

\section{Geology and soils}

The underlying geology is Devonian and Permo-Triassic reddish sandstone and the overlying soils are formed from the weathering of this material. However, in the past, the area has been glaciated and so igneous erratics can be found.
The soils have been mapped at a scale of 1:250,000 by the Soil Survey of England and Wales ('Soils and their use in South West England', 14, Harpenden). This shows that the soils belong to the Eardiston 1 soil association. These are defined as reddish well-drained coarse loamy and fine silty soils over hard sandstones, interbedded with thin siltstones and silty shales. The Eardiston soil association comprises a range of similar soil series and the predominant one in the survey fields at Bolitree farm is the North Newton series.

A representative profile description of this soil type is as follows:

0-350mm Reddish brown sandy loam; moderately developed, fine sub-angular structure; abundant fine pores; slightly stony (1\%) with few small rounded quartzite and sandstone pebbles.

$350+\mathrm{mm}$ Dark reddish brown sandy clay loam/ clay loam; compact, angular structure; few fine pores; slightly stony (1\%) with few small rounded sandstone pebbles.

As far as erosion potential is concerned, the main point of interest is the high proportion of medium- and fine-grained sand particles in the topsoil. The particle size distribution of the upper $150 \mathrm{~mm}$ of topsoil in field 1 showed that these accounted for $52 \%$ of the soil material:

Particle size distribution in the topsoil $(0-150 \mathrm{~mm}$ depth):

$\begin{array}{ccc}\text { Coarse sand } & \text { Medium sand } & \text { Fine sand } \\ 5 \% & 32 \% & 20 \% \\ \text { Coarse silt } & \text { Silt } & \text { Clay } \\ 11 \% & 17 \% & 15 \%\end{array}$

\section{Methods}

The soil physical characteristics (\% sand, silt, clay; organic matter content; stone content; bulk density) and slope forms of most fields were measured, to indicate the soil and land characteristics likely to affect erosion potential.

For each winter period, monitoring was restricted to those fields where erosion was considered likely. Each of the selected fields was visited on a monthly basis or following rainfall events of $20 \mathrm{~mm}$ or more in 24 hours from late summer (usually September) until the following 


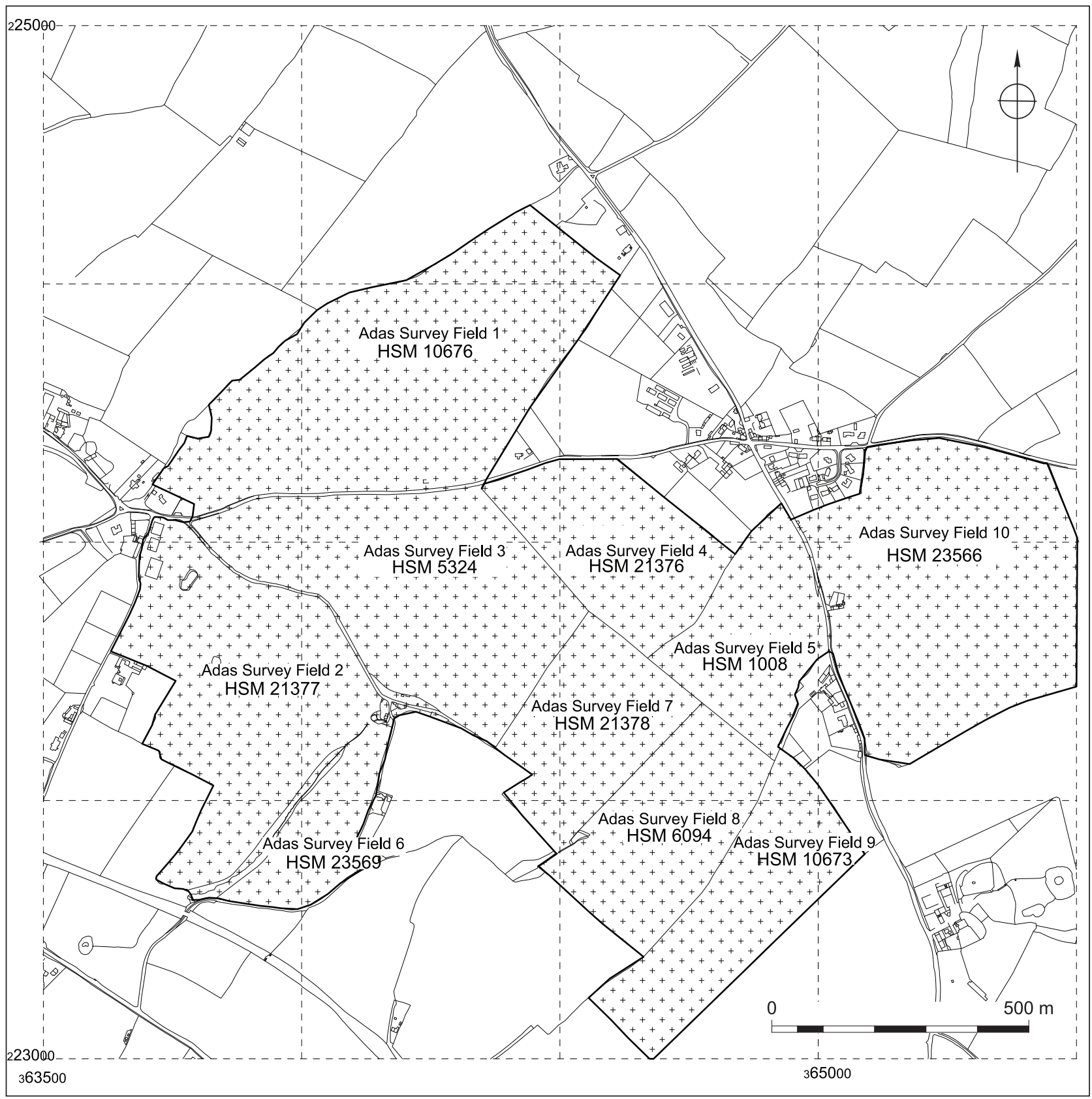

Figure 3.1. Extents of the ADAS survey. Reproduced by permission of Ordnance Survey on behalf of HMSO. C) Crown Copyright 2011. All rights reserved. Ordnance Survey Licence number 100051813

Table 1. Fields at Bollitree Farm (ADAS)

\begin{tabular}{|c|l|l|c|}
\hline $\begin{array}{c}\text { Survey } \\
\text { Field No }\end{array}$ & $\begin{array}{l}\text { OS Field } \\
\text { No }\end{array}$ & Field Name & $\begin{array}{l}\text { Area } \\
(\text { ha })\end{array}$ \\
\hline 1 & $0025 / 3846$ & Hask & 27.2 \\
\hline 2 & 7700 & Bollitree & 18.9 \\
\hline 3 & $0001 / 3100$ & Ariconium & 20.2 \\
\hline 4 & 6000 & Bromsash & 10.1 \\
\hline 5 & 9100 & Eccleswall & 8.7 \\
\hline 6 & 7700 & Bridgets & 4.9 \\
\hline 7 & 5764 & Middle & 9.4 \\
\hline 8 & 7043 & Pond & 10.6 \\
\hline 9 & 9338 & Clutterbuck & 6.7 \\
\hline 10 & $0005 / 0900 / 2000 /$ & Linton & 26.6 \\
& $3500 / 4600 / 3180 /$ & & \\
\hline & 1571 & & \\
\hline
\end{tabular}


spring (usually April). The monitoring period was extended to early summer (usually June) where spring crops were sown. Thus for any one monitoring period (e.g. 1991/92), erosion observations could have extended from September of one year to early June of the next year.

For each field, details on cropping (such as species and crop cover) and cultivations (such as date of drilling, whether the field was rolled, the presence of tramlines and their direction in relation to field slopes) were recorded throughout the monitoring period.

Erosion events were mapped in the field and the dimension of each rill/gully estimated by surveying crosssections at 5-10 metre intervals. For severely eroded slopes, traverses along the contour were made, recording the crosssectional area of each rill/gully at 20-50 metre intervals.

Depositional fan volumes were measured from measuring their area and estimating their depth at several locations with auger probes. Following erosion events in one or two fields, the particle size distribution and nutrient content of soil eroded down the slope were measured.

An automatic recording rain gauge was installed at Bollitree farm to record the intensity and duration of rainfall events.

\section{Presentation of data}

Although a wide range of data was collected over the five year period, not all of this is presented in this report. Because this was a research project, a range of measurements were taken to see if they gave meaningful results and some of these were found not to be useful - an example is shear strength measurements. Consequently, the data presented is that which is useful to the objectives of this report; including other results would only serve to confuse rather than enlighten.

Appendix 4 details the measurements taken from the various fields throughout the five year period.

In this report, 'rills' are defined as small continuous channels that can be removed by ploughing. The term 'gully' refers to wider, deeper, more permanent features.

\section{Results of survey}

\section{Fields where erosion occurred}

Table 2 summarises the data from these fields.

Over the five year monitoring period, erosion occurred in ten fields, Fields 1, 2, 4, 6 and 10 being affected. Field 1 was affected in four out of the five years. There is a 1900 map showing field boundaries in the present area of Field 1 at that time; one part of the field, that regularly floods, was in those days a plantation. There was also a field boundary, probably a hedge, across the top of the valley slope on the northern side which would have cut off the water before it flowed down the steeper slope. The positions of the old boundaries can be seen in aerial photographs.

Most erosion occurred as 'rills' which were fairly shallow (usually up to $0.10 \mathrm{~m}$ deep) although some were deeper than that and one event in 1989 led to a deep gully

Table 2. Summary of data on fields where erosion occurred

\begin{tabular}{|c|c|c|c|c|c|c|c|c|c|}
\hline $\begin{array}{l}\text { Season/ } \\
\text { Field No }\end{array}$ & $\begin{array}{l}\text { Date of } \\
\text { erosion }\end{array}$ & $\begin{array}{c}\text { Volume }(\mathrm{mm}) \\
\text { and duration } \\
\text { of rainfall }\end{array}$ & $\begin{array}{c}\text { Rainfall } \\
\text { maximum } \\
\text { intensity } \\
(\mathrm{mm} / \mathrm{hr})\end{array}$ & $\begin{array}{c}\text { Slope } \\
\left({ }^{o}\right)\end{array}$ & Crop & $\begin{array}{c}\text { Crop } \\
\text { cover } \\
(\%)\end{array}$ & $\begin{array}{l}\text { Nature of } \\
\text { erosion }\end{array}$ & $\begin{array}{l}\text { Volume } \\
\text { soil } \\
\text { eroded } \\
\left(\mathrm{m}^{3}\right)\end{array}$ & $\begin{array}{l}\text { Field factors associated } \\
\text { with erosion }\end{array}$ \\
\hline \multicolumn{10}{|l|}{$1989 / 90$} \\
\hline 1 & $8-10$ Nov & 45 in 3 days & 7.0 & $7-24$ & Wheat & $<5$ & $\begin{array}{l}81 \text { rills } \\
1 \text { gulley }\end{array}$ & $\begin{array}{l}18\} 84 \\
66\}\end{array}$ & $\begin{array}{l}\text { Wheelings; slope; crop } \\
\text { cover } \\
\text { Adjacent field runoff }\end{array}$ \\
\hline 4 & $8-10$ Nov & 45 in 3 days & 7.0 & $5-7$ & Potatoes & - & Surface runoff & 20 & $\begin{array}{l}\text { Compaction during } \\
\text { harvest }\end{array}$ \\
\hline \multicolumn{10}{|l|}{$1990 / 91$} \\
\hline 1 & $24-30$ Oct & 51 in 7 days & 5.0 & $7-24$ & Rape & $<5$ & 15 rills & 11 & $\begin{array}{l}\text { Adjacent road runoff; } \\
\text { crop cover; tramlines }\end{array}$ \\
\hline 4 & 3-9 Apr & 36 in 6 days & 3.6 & 2 & S Beet & 0 & 2 rills & 7 & $\begin{array}{l}\text { Wheelings/headlands; } \\
\text { crop cover }\end{array}$ \\
\hline 10 & $24-30$ Oct & 51 in 7 days & 5.0 & $2-12$ & Wheat & 0 & 226 rills & 79 & Crop cover; slope \\
\hline \multicolumn{10}{|l|}{ 1991/92 } \\
\hline 1 & $\begin{array}{l}31 \text { Oct } \\
-3 \text { Nov } \\
8-9 \text { Jan }\end{array}$ & $\begin{array}{l}42 \text { in } 4 \text { days } \\
74 \text { in } 2 \text { days }\end{array}$ & $\begin{array}{l}8.0 \\
5.6 \\
\end{array}$ & $\begin{array}{l}7-24 \\
7-24 \\
\end{array}$ & $\begin{array}{l}\text { Wheat } \\
\text { Wheat }\end{array}$ & $\begin{array}{c}0 \\
15 \\
\end{array}$ & $\begin{array}{l}\text { \}228 rills } \\
\text { \} }\end{array}$ & $\begin{array}{l}29\} 39 \\
10)\end{array}$ & Slope; crop cover \\
\hline 10 & $\begin{array}{l}28 \text { May } \\
-1 \text { Jun }\end{array}$ & 22 in 4 days & 4.4 & $7-12$ & S Beet & 90 & 8 rills & 35 & Slope, wheelings \\
\hline \multicolumn{10}{|l|}{$1992 / 93$} \\
\hline 2 & $\begin{array}{l}\text { 24-25 Nov } \\
13 \text { Jan }\end{array}$ & $\begin{array}{l}30 \text { in } 2 \text { days } \\
24 \text { in } 1 \text { day }\end{array}$ & $\begin{array}{l}5.2 \\
5.4\end{array}$ & $\begin{array}{l}7 \\
7\end{array}$ & $\begin{array}{l}\text { Wheat } \\
\text { Wheat }\end{array}$ & $\begin{array}{l}0 \\
5\end{array}$ & $\begin{array}{l}\text { \}30 rills } \\
\}\end{array}$ & $\begin{array}{l}6\} 27 \\
21\}\end{array}$ & $\begin{array}{l}\text { Slope; crop cover } \\
\text { Slope; crop cover }\end{array}$ \\
\hline 6 & $\begin{array}{l}\text { 24-25 Nov } \\
13 \text { Jan }\end{array}$ & $\begin{array}{l}30 \text { in } 2 \text { days } \\
24 \text { in } 1 \text { day }\end{array}$ & $\begin{array}{l}5.2 \\
5.4\end{array}$ & $\begin{array}{l}10 \\
10\end{array}$ & $\begin{array}{l}\text { Wheat } \\
\text { Wheat }\end{array}$ & $\begin{array}{l}0 \\
5\end{array}$ & $\begin{array}{l}\text { \} } 7 \text { rills } \\
\text { \} }\end{array}$ & $\begin{array}{l}9\} 20 \\
11\}\end{array}$ & $\begin{array}{l}\text { Slope; crop cover } \\
\text { Slope; crop cover }\end{array}$ \\
\hline \multicolumn{10}{|l|}{$1993 / 94$} \\
\hline 1 & $\begin{array}{l}10-13 \text { Oct } \\
13 \text { Jan } \\
\end{array}$ & $\begin{array}{l}54 \text { in } 4 \text { days } \\
29 \text { in } 7 \text { days }\end{array}$ & $\begin{array}{l}5.6 \\
4.0\end{array}$ & $\begin{array}{l}7-24 \\
7-24\end{array}$ & $\begin{array}{l}\text { Wheat } \\
\text { Wheat }\end{array}$ & $\begin{array}{l}0 \\
5 \\
\end{array}$ & $\begin{array}{l}\text { \} } 210 \text { rills } \\
\text { \} }\end{array}$ & $\begin{array}{l}79\} \\
131 \\
52\} \\
\end{array}$ & $\begin{array}{l}\text { Slope; crop cover } \\
\text { Slope; crop cover }\end{array}$ \\
\hline
\end{tabular}


being formed in Field 1. The volume of soil eroded in any one field ranged from $7-131 \mathrm{~m}^{3}$ (approximately $12-220$ tons soil). In some instances, the eroded soil could be accounted for as deposition fans down slope in the field but, after some events, soil was washed out of the field either onto the road or into an adjacent stream/ditch or into a neighbouring field.

Most ( 8 out of 10) erosion events occurred in the winter period from October to January and on fields with little crop cover. This was usually associated with autumn sown wheat or rape crops, often following late harvested potatoes or sugar beet. In one instance, erosion occurred during the lifting of potatoes, prior to sowing with wheat.

Two erosion events occurred in spring/early summer. One of these, in early April 1991, followed the sowing of a sugar beet crop but before it had emerged. The other, in late May 1992, occurred in a crop of sugar beet with $90 \%$ ground cover; although one might not have expected erosion in this situation, compaction and slope led to the problem.

In most situations, slope was a factor in permitting run-off although in one instance (Field 4 in early April 1992 ) erosion did occur on a slope of only $2^{\circ}$.

Rainfall, that was considered to have initiated erosion, was recorded. Of course this does not give the whole picture because often rainfall over a much longer period will have also contributed to wetting the soil in the first instance. However rainfall immediately prior to the time of erosion (from 1-7 days) ranged from 22 to $45 \mathrm{~mm}$ and the maximum intensity of rainfall during that period ranged from 3.6 to $7.0 \mathrm{~mm}$ /hour. Sometimes erosion continued after the first event but with no particular rainfall being responsible - it would appear that the eroded area is susceptible to further erosion. However at four fields there were definite and separate erosion events, the second being directly attributable to a specific period of rain.
The other main factors associated with erosion events were compact wheelings, headlands or tramlines. The compact soil surface decreased water infiltration rates and allowed water run off to neighbouring non compact areas, so leading to soil particles being washed down the slope. Such effects were more noticeable where compact tramlines led down slope and, it is interesting to note that, where tramlines went across the slope (Field 10 in 1991/92) run-off was decreased but only on slopes less than $7^{\circ}$.

\section{Fields where no noticeable erosion occurred}

Table 3 summarises the data from monitored fields that showed no signs of erosion.

For most of these fields, the main reason for lack of erosion was a dense ground cover (either wheat stubble or sugar beet tops). This held the soil together and also minimised the impact of rainfall hitting the soil surface during periods of rain when other fields did suffer erosion.

In several fields there was minimal ground cover, during the period of rain that initiated erosion in other fields, but it appears that the slope was insufficient for significant runoff to occur. In two fields ( 3 and 4) in 1993/94, there may also have been an added effect from the lack of tramlines during the period of heavy rain; tramline formation was delayed until February 1994, after which rainfall was insufficient to cause problems.

\section{Erosion across the settlement area: case studies}

It is possible through use of documentary sources allied to the ADAS report and other sources to present a model for the pattern of erosion and potential impact on archaeological deposits within most of the fields within the former settlement area.

Table 3. Probable reasons why certain fields suffered no erosion

\begin{tabular}{|c|c|}
\hline $\begin{array}{l}\text { Season/ } \\
\text { Field No. }\end{array}$ & Probable reason for lack of erosion \\
\hline \multicolumn{2}{|l|}{$1989 / 90$} \\
\hline 2,6 & Wheat stubble until spring; insufficient rain after that \\
\hline 3 & Sugar beet tops ( $100 \%$ ground cover) until early Dec ' 89 ; insufficient rain after cultivations \\
\hline 5 & Shallow slopes (up to $3^{\circ}$ ) although only small ground cover during high rainfall period \\
\hline \multicolumn{2}{|r|}{ D. } \\
\hline 3 & Wheat stubble left over winter and tramlines cultivated to relieve compaction \\
\hline \multicolumn{2}{|l|}{$1991 / 92$} \\
\hline 2 & Sugar beet tops on surface until ploughed in Feb '92; insufficient rain after that \\
\hline $3,7,8$ & Shallow slopes (up to $3^{\circ}$ ) although only small ground cover during high rainfall period \\
\hline \multicolumn{2}{|l|}{$1992 / 93$} \\
\hline $1,3,4,5,7,8$ & Wheat stubble until March'93 \\
\hline 10 & Sugar beet tops on surface until cultivated at end Jan ' 93 ; insufficient rain after that \\
\hline \multicolumn{2}{|r|}{ ow } \\
\hline 3,4 & Shallow slope $\left(3^{\circ}\right)$ and no tramlines until Feb '94 \\
\hline $2,6,10$ & Wheat stubble until March '94 \\
\hline 7,8 & Sugar beet tops on surface until early Dec '94; insufficient rain after that \\
\hline
\end{tabular}




\section{HSM 10176/23564 (ADAS Field 1)}

This large field was in arable use at the time of the survey with wheat, potatoes and rape being grown in rotation. Steep slopes ranging from $7-24^{\circ}$ have a complex pattern but basically drain to the north-east. The 1838 tithe shows this as five fields, a situation which persisted until as late as 1965. By 1967 two boundaries had been removed reducing it to three fields and by 1989 the remaining boundaries had been removed.

The ADAS survey has indicated that the removal of a northern boundary across the top of the valley slope is likely to have been a particular factor in leading to erosion recorded in four out of the five years of their survey. In two years, two erosion events were recorded whilst the other two years only featured single events. The worst single erosion feature was a gully $200 \mathrm{~m}$ long, $0.50 \mathrm{~m}$ to $3.00 \mathrm{~m}$ wide and $0.20 \mathrm{~m}$ to $1.20 \mathrm{~m}$ deep. This is estimated to have caused a loss of $66 \mathrm{~m}^{3}$ of topsoil from the affected area. Most erosion was, however, in the form of rills which varied in depth from $0.05 \mathrm{~m}$ to $0.25 \mathrm{~m}$. Up to $80 \%$ of the field was affected (1993/4). Much of the eroded material was redeposited in the form of fans at the base of slopes. Where measurable, between about 65 and $80 \%$ was of the eroded material was redeposited on the field surface, the remainder washing into a neighbouring field. One fan covered an area of $740 \mathrm{~m}^{2}$ and averaged $0.10 \mathrm{~m}$ thick.

Within this field, only one area has been excavated (Bridgewater 1963). This demonstrated the survival of significant remains of Roman ironworking furnaces at four closely located sites (HSM 21360, 23557, 23558 and 23559). The depth of material overlying these varied between 0.40 and $1.00 \mathrm{~m}$, with the best preserved remains surviving in hollows cut into the underlying bedrock. Some of the overlying layers are also of some significance since they may relate to 17 th and 18 th century mining of slag. These layers were not described in detail in the original report, but have now been shown to contain significant ceramic assemblages (Willis, Section 4). In addition, this field contains cropmarks showing a small enclosure (HSM 10676) and two parallel ditches marking the course of a road (HSM 10113).

It is clear therefore that the documented erosion events will have had considerable impact on deposits in this field. A single erosion feature such as that cutting to a depth of $1.20 \mathrm{~m}$ will have had an impact in its own right. On a wider and probably ultimately more damaging basis, the almost annual removal of large volumes of material downslope and into the neighbouring field (to the north-east) will have resulted in topsoil depths reducing and thus ploughing continually cutting into previously undisturbed deposits.

In conclusion, this field is considered according to MAFF criteria to be at high to very high risk of erosion when in arable cultivation (MAFF 1999). Such erosion can potentially have a direct effect on surviving archaeological deposits and in the long term has a strong potential to lead to significant further damage to any surviving deposits.

\section{HSM 21377 (ADAS Field 2)}

This is a large field to the south-west of the monument. In 1838 the tithe map shows this as four fields, part of one of which is now incorporated in a separate field (HSM 23569; ADAS 6). By 1923 further sub-division had occurred, and, since then other boundaries have been removed to produce one large field. It was in arable use at the time of the survey with a rotation of wheat, sugar beet and potatoes; however, was a meadow in 1932 (Anon 1932). The field drains to the south and south-east into a stream on its southern boundary. This at one time had a series of ponds strung along its length. The slope is variable, with virtually no slope to the north but an increasing drop towards the stream with a maximum slope of $18^{\circ}$.

The field was monitored in four of the five years of the ADAS survey and erosion was only recorded during one of these (1992/3). A combination of slope, heavy rain and absence of ground cover in December $(0 \%)$ through to February (only 10\%) led to two separate erosion events during which rilling affected up to $50 \%$ of the field. A total of $27.2 \mathrm{~m}^{3}$ of soil was eroded, some of which was redeposited in the field, but over half of which was deposited into the stream. The years in which no erosion occurred were ones in which the crop rotation was at a stage whereby crop cover remained during the winter months in the form of beet tops or wheat stubble. However, further erosion events are likely to occur whenever late sown crops follow late harvested ones (for instance wheat following potatoes) leaving the surface of the field exposed during the winter months.

Archaeological investigations undertaken in advance of pipelaying by Welsh Water identified extensive deposits along the eastern side of the field (Jackson, Hancocks and Pearson 1999). Ironworking features (furnaces), pits, ditches, postholes and other structural remains of Roman date survived in varying degrees of complexity and at widely varying depths below the modern groundsurface.

In upslope areas only the increasingly shallow bases of natural cut features survived buried directly below the modern ploughsoil. Plough-scoring of the surface of the natural and feature fills was also recorded. Concentrations of unstratified artefacts within the ploughsoil extended for some $75 \mathrm{~m}$ beyond the northernmost surviving features and suggested that Roman deposits had had been completely eroded in this area.

In contrast, in downslope areas complex stratigraphy survived beneath increasingly deep accumulations of colluvial material (i.e. redeposited eroded material) and topsoil which in places measured over $0.75 \mathrm{~m}$ deep. Closest to the stream these included waterlogged remains. Analysis of the deposits along the length of the pipetrench enabled reconstruction of a profile through surviving deposits across this area (Jackson, Hancocks and Pearson 1999; Fig. 3.2). In addition to these excavations, earlier investigations by Rev. E. Holland (Anon 1932) recorded three 'mill-ponds' including one with a stone dam (HSM 21364) and a second 


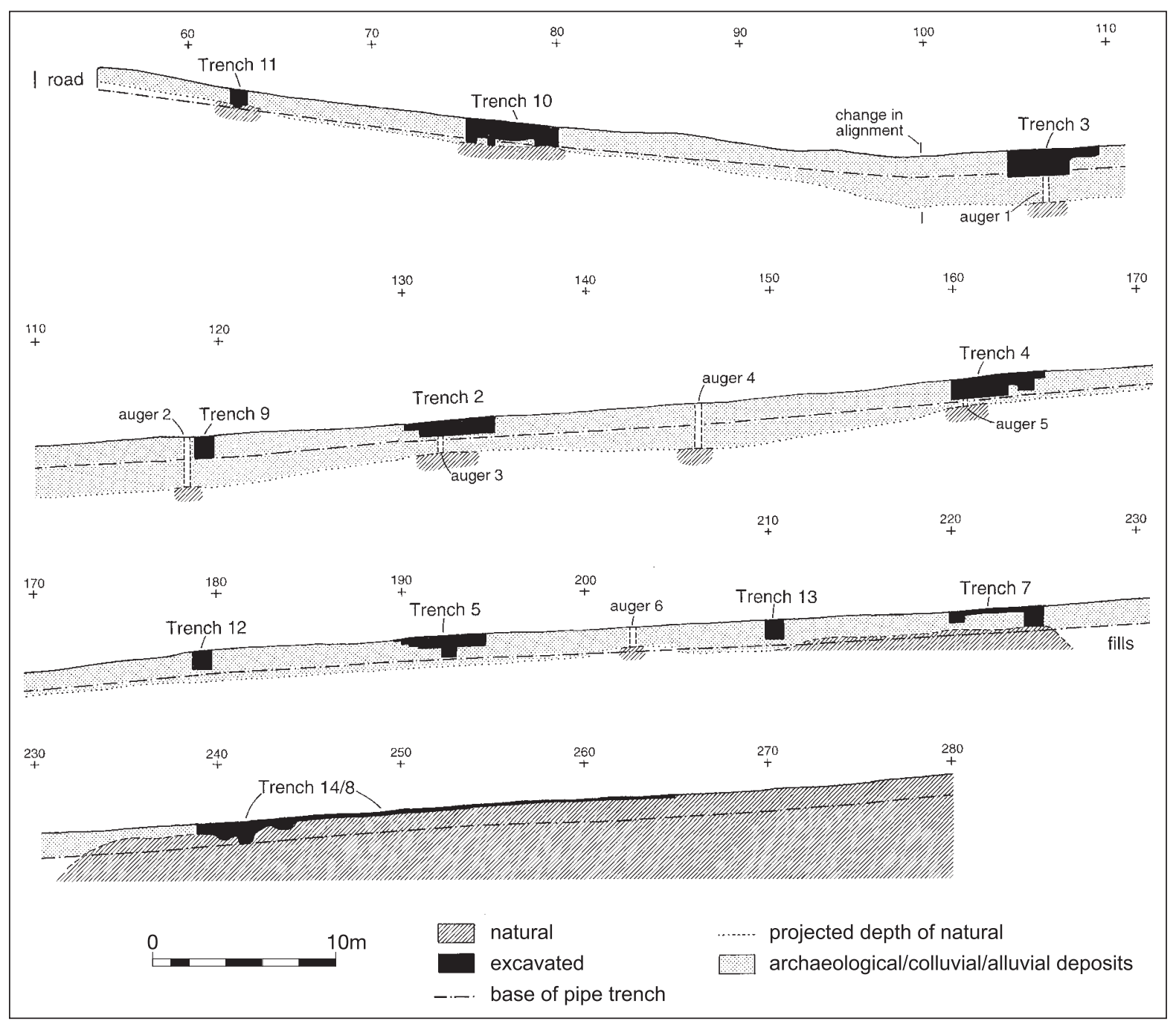

Figure 3.2. Composite profile through deposits investigated on the Welsh Water pipeline

with further stonework (HSM 21363). Slight cropmarks and many surface finds have also been recorded.

The Welsh Water pipeline data clearly demonstrates that erosion has had a considerable impact on surviving and significant deposits. The depths of accumulated overburden recorded suggest that erosion and subsequent deposition has occurred to a considerable degree and perhaps over a fairly long period of time, while the ADAS data demonstrates that this is an ongoing process. The date at which such erosion started is uncertain since it is not known when the area was first ploughed and thus began to be susceptible to erosion. However, it is known that the lower part of the field, alongside the stream, remained as a meadow until at least 1932 and so ploughing of this area might be a relatively recent phenomenon. One factor, which has probably contributed to erosion, is the removal of two former field boundaries which ran in a north-easterly to south-westerly direction across the line of the slope.

It was felt at the time of recording on the pipeline, that whilst upslope areas had suffered considerably, that downslope areas had been protected by colluvial deposits and were in a stable state in which erosion was unlikely to affect them. However, in the light of the ADAS report this assumption may need questioning. The recorded deposition of eroded soil into the stream suggests that erosion will continue moving downslope until such a time as the slope into the valley has reached a point of equilibrium where it is no longer steep enough for downslope erosion to continue. At this point, only those deposits in the valley base will survive and even they may be susceptible to erosion by a combination of ploughsoil erosion allied to the action of the stream. The absence of deep colluvial deposits in the pipeline trenches immediately adjacent to the stream provides evidence that the stream is indeed removing colluvial deposits from the base of the slope.

In conclusion, this field is considered according to MAFF criteria to be at moderate to high risk of erosion when in arable cultivation (MAFF1999). Any such erosion is considered to have a strong potential to lead to further damage to surviving archaeological deposits. 


\section{HSM 5324/22049 (ADAS Field 3)}

This large field is one of the three fields covered by the scheduled area. The tithe map indicates that in 1838 this was divided into three, one cross slope boundary having been removed by 1923 and one downslope boundary since 1986. Records from 1980 report regular ploughing to a depth of 9 to 10 inches $(0.20-0.25 \mathrm{~m})$ associated with a crop rotation of rape, barley and wheat. The field was in arable use at the time of the survey with crops including wheat, sugar and peas. The field drains to the south-west and has gentle slopes mostly in the region of $2-3^{\circ}$, although slopes of up to $10^{\circ}$ are present.

Monitoring for erosion was undertaken throughout the five year period of the ADAS survey, however, none was recorded. Where possible the farmer left stubble over winter, ploughed across the slope and cultivated tramlines and headlands to reduce compaction. However, it seems that the shallowness of the slopes was the key factor in preventing erosion, since even in periods of heavy rainfall onto soil surfaces with no crop cover (i.e. stubble) no discernible erosion occurred.

Archaeological investigations within this field have been very limited (Jack 1923; Trenches 4 and 5; HSM 16781 and 21095). These only recorded 'black earth' with no finds overlying sandstone. However, both cropmarks and finds scatters suggest that considerable Roman activity occurred in some of the area covered. Cropmarks include two east-west aligned roads (HSM 0842 and 6093; Cox 1995; routes E-F and C-D) with metalling and side ditches. Small lengths of further metalled surfaces, ditches and a clearly defined enclosure abutting the north side of one of the roads (HSM 6093) have also been identified.

Reports from DAG record surface finds indicative of disturbance of Roman deposits in both 1993 and 1994 (DAG Newsletter 24, June 1994) and these and earlier surface finds are fairly extensive (HSM 5324). The presence of significant Roman deposits in excavations to the east and west (see HSM 21376 and 21377) would also strongly suggest that similarly important remains are likely to be present. On the other hand, fieldwalking by SWAG in 1986 of the western end of this field (at a time when it was still a separate field) produced only small quantities of Roman material (HSM 22049). Intensive activity may therefore not have extended this far west.

In the absence of evidence for soil erosion, allied to the lack of excavation and uncertainties about extent of former activity within this field, it is difficult to assess the potential degree of damage to any significant deposits which might have been present. It is likely that this is one of the areas cleared and enclosed by Merrick in the 18 th century and thus wall footings may well have been robbed from this area. Arable cultivation since the land was cleared is also liable to have caused some degradation of archaeological deposits, and initially this is likely to have been quite severe given the fact that the land does not seem to have been ploughed previously. Recently recorded plough depths of $0.20-0.25 \mathrm{~m}$ in 1980 give some indication of the sort of depths ploughing can effect, while the recording of surface finds from the 1960s onwards and as recently as the mid-1990s suggests that there is still fresh disturbance occurring. This may result from the use of heavier machinery or from deeper ploughing such as that reported for potato cropping (DAG Newsletter 14, June 1991). However, generally reports of freshly disturbed material seem much less common than from the field to the north-east (HSM 21376) and it is possible that preservation of deposits is considerably better than in many of the surrounding fields. Alternatively it may be that less Roman activity occurred in this area or that a bias exists in the reporting of surface finds towards the areas where building remains are known.

In conclusion, this field was considered according to MAFF criteria to be at low risk of erosion at the time of the survey (MAFF 1999); however, any increase in ploughing depth or use of heavier machinery would be liable to lead to increased damage to surviving deposits.

\section{HSM 21376 (ADAS Field 4)}

This is the second of the three fields covered by the scheduling. It has been a single field since at least 1923, although the 1838 tithe shows it divided in two. Records from 1980 reported regular ploughing of the whole area of the monument to a depth of 9 to 10 inches $(0.20-0.25 \mathrm{~m})$ and a crop rotation of rape, barley and wheat. It was only in the late 1980s that new ownership led to cultivation of potatoes as part of a crop cycle also including wheat and sugar beet (Lloyd 1999; DAG Newsletter 14, June 1991). The field has some steep slopes of up to $10^{\circ}$ but mostly comprises gentle slopes of $2^{\circ}-3^{\circ}$ which drain the field to the west.

The ADAS survey recorded two instances of erosion in the four years that this field was monitored. As with the field to the south-west (HSM 5324/22049), it was found that the generally shallow slopes were insufficient for erosion to occur if combined with crop cover or absence of compacted areas. However, in this instance compaction and wheelings triggered erosion on two occasions. In the worst instance, in 1989/90, an estimated $20 \mathrm{~m}^{3}$ of soil was washed away and redeposited either in the field opposite or on the road. Run-off water also contributed to the severe erosion recorded in the opposite field (HSM 10176/23564).

This field has probably the most extensive evidence for the presence of significant archaeological remains within the whole settlement area. Five of Jack's excavation trenches were located here (Jack 1923; HSM 16780, 21097, 21098, 21099 and 22053) revealing significant Roman deposits including evidence of a well-preserved, substantial, stone-founded building, further stone rubble footings and yard surfaces. In 1967, three further trenches (Garrod and Moss 1967; HSM 23551, 23552 and 23554) also produced evidence of yards and a substantial building. These deposits occurred at varying depths below the contemporary 
groundsurfaces, from as little as $0.18 \mathrm{~m}$ to as much as $0.85-0.90 \mathrm{~m}$, however, were generally in the lower part of that depth range. Other reports indicate the presence of buildings in the form of disturbed debris including morticed stones and other stone rubble, spreads of plaster (red, bluegreen and white) and tesserae (HSM 4185-8 and 23568; HAN 22 1971; DAG Newsletter 20, April 1993). Many reports have also been made of surface finds (HSM 4189 and 21376; HAN 22 1971; Sindrey 1990; DAG Newsletter 14, June 1991; DAG Newsletter 20, April 1993). Finally, this field also forms an apparent focus for several roads known through cropmark evidence (Cox 1995; routes A-B, C-D and E-F). Some ditch complexes, possibly representing enclosures are also visible on cropmark plots and appear to concentrate towards the eastern end of the field.

It is clear from the regular reports of newly disturbed material that ploughing has damaged and was continuing to damage significant archaeological deposits in this field at the time of the survey. As with the field to the southwest, this is believed to be within the area cleared during in the 18th century. Indeed, given the recorded presence of building remains, this was most probably the focus of Merrick's discoveries and the robbing of a wall recorded in one of the excavated areas (HSM 23552) may date to this period. Subsequent arable cultivation is initially likely to have caused quite considerable damage to remains in an area which seems not to have been ploughed previously. Again the plough depths of $0.20-0.25 \mathrm{~m}$ recorded in 1980 give some indication of the depths which can be affected. It is, however, clear that in the 1920s and even as recently as 1967 that significant deposits including substantial stone structures had survived over 200 years of ploughing.

ADAS data suggests that cereal cropping, especially before the advent of heavy machinery, is unlikely to have caused significant erosion of topsoil due to the shallow slopes present. Consequently the condition of the site may until recently have been fairly stable. Unfortunately, the recording of freshly disturbed material since the 1960s suggests that the introduction of heavier machinery has had an adverse impact on deposit survival. In particular the introduction of deeper ploughing for potato cropping reported in the early 1990s in this field (DAG Newsletter 14, June 1991; DAG Newsletter 20, April 1993) is known to have brought large volumes of newly disturbed surface finds and building debris to the surface. The machines in use also gather and grade all the topsoil and some subsoil, redepositing material (including disturbed finds) several meters along the field from their original location. This will have a considerable detriment on the effectiveness of future fieldwalking, since clearly artefacts are now being moved far greater distances from their original source than had previously been the case. Significantly it has also been demonstrated that the use of heavy machinery and the introduction of a late harvested crop (potatoes) have created conditions in which topsoil erosion occurs, thus thinning potentially protective soils and bringing new areas into the reach of plough damage.
In conclusion, this field is considered according to MAFF criteria to be at only moderate risk of erosion (MAFF1999). Although such erosion may potentially lead to increased damage to surviving archaeological deposits, the effects are likely to be limited and significant damage to any surviving deposits is considered more likely to arise as a result of any increase in ploughing depth or use of heavier machinery.

\section{HSM 10008 (ADAS Field 5)}

This field is located to the east of the settlement, outside of the scheduled site. In 1838 the tithe recorded this as having been two fields, but by 1923 these had been amalgamated. Cropping at the time of the survey included potatoes, sugar beet and wheat. The field drains to the south-east on a gentle slope of not more than $3^{\circ}$.

The ADAS survey only included this field in two out of five years of its study and no erosion was identified. This was due to the shallow slopes involved which meant even where other conditions were present which caused erosion elsewhere at the site, none occurred in this field.

The archaeological record indicates low levels of activity. Three trenches have been excavated all near the south boundary (HSM 21362, 23546 and 23547; Bridgewater 1959; Garrod and Moss 1967). The first recorded the remains of a post-medieval slag road some $0.30 \mathrm{~m}$ below the field surface; however, the 1967 trenches recorded no features, only a deep accumulation up to $1.15 \mathrm{~m}$ thick above the natural. Some slight downslope soil movement might be indicated by these deep accumulations; but the trench locations, in the corner of the field, adjacent to the hedge and at the base of a slope may reflect better preservation or headland accumulation rather than any significant erosion. A small number of metalwork finds have also been recorded while aerial photographs have revealed a number of ditches extending from the adjacent field and possibly representing enclosures.

The present condition of any Roman deposits is hard to assess given the lack of significant remains recorded in the trenches excavated to date. The numbers of finds recorded in the 1967 trenches, allied to surface collected material and cropmark evidence, suggest that the settlement area does extend this far. Ploughing, typically recorded to a depth of $0.20-0.30 \mathrm{~m}$ is likely to have had an impact on any such deposits at first; however, after the initial impact of the first ploughing (the date of which is not known) the topsoil and subsoil depths are liable to have stabilised and erosion is likely to have been minimal.

In conclusion this field was considered according to MAFF criteria to be at low risk of erosion from the cultivation regime practiced at the time of the survey (MAFF1999); however, any increase in ploughing depth or use of heavier machinery can be identified as liable to lead to increased damage to surviving deposits. 


\section{HSM 23569 (ADAS Field 6)}

This is a long narrow field to the south of the main settlement. In 1838 the tithe shows this as being included in one of the fields later amalgamated to form a field to the north. The point at which this became a separately identified field is uncertain, however, it is likely to have always been physically separate due to the stream running along its northern edge. The field drains into this stream with quite short steep slopes of up to $12^{\circ}$. Crop rotation at the time of the survey comprised sugar beet, potatoes and wheat. Although recently in arable cultivation, it was a meadow in 1932 (Anon 1932).

The field was included in three of the five years of the ADAS survey and during this period in 1992/3 two erosion events were recorded. During these rills up to $0.05 \mathrm{~m}$ wide and $0.30 \mathrm{~m}$ deep affected up to $15 \%$ of the field resulting in the loss of a total of $19.6 \mathrm{~m}^{3}$ of topsoil which was washed into the stream.

Archaeological deposits were recorded here along the Welsh Water pipeline (Jackson, Hancocks and Pearson 1999). As with the field to the north, significant Roman deposits were buried at variable depths below an accumulation of topsoil and colluvial material. The composite section created (Jackson, Hancocks and Pearson 1999; Fig. 3.2) shows that the accumulation sealing significant deposits increases downslope towards the stream (just beyond Trench 3) but that their depth is minimal towards the top of the slope, close to the road. Stone wall footings, a pit and several postholes were recorded here. In addition, trial pits excavated in 1932 revealed a slag surfaced road which seems to run through this field (HSM 21365; Anon 1932). At the time of recording this was buried about $0.30 \mathrm{~m}$ below the field surface. This may be the road known from cropmarks in this location (Cox 1995; route $\mathrm{M}-\mathrm{N}$ ) or a further cropmark which lies between the road and the stream.

In conclusion, it seems that similar erosion and deposition processes to those recorded in the field to the north were occurring at the time of the survey. This may have been a relatively recent development since this field does not seem to have come into arable use until after 1932. However, there is clearly a considerable impact in this area with fairly severe erosion evidenced both in the ADAS survey and pipeline trenches, while depths at which buried deposits have been recorded are within the range of a single ploughing to a depth of $0.30 \mathrm{~m}$ or more.

In conclusion this field was considered according to MAFF criteria to be at moderate to high risk of erosion at the time of the survey (MAFF1999). Any such erosion is considered to have a potential to lead to further damage to surviving archaeological deposits.

\section{HSM 21378 (ADAS Field 7)}

This is the third of the three fields covered by the scheduled area. It is formed from two fields shown on 1838 tithe along with parts of two further fields (the other parts of which now form elements of HSM 22050). Considerable remodelling of field boundaries had occurred here by 1923 at which time the boundaries were on their current alignments. In 1980 it was recorded that the whole monument area was in arable cultivation being ploughed to a depth of $0.20-0.25 \mathrm{~m}$ for rape, barley and wheat crops. In 1983 deeper plough damage was recorded to a depth of $0.30-0.40 \mathrm{~m}$. Crops at the time of the survey included wheat and sugar beet. A gentle slope of about $3^{\circ}$ drains this field to the south-west.

This field was within the area monitored by ADAS, however no erosion was recorded in the three years that the field was included in the survey. Although conditions were recorded in which erosion was triggered in other fields, the shallow slope prevented erosion occurring.

Excavations in 1959 in this field recorded two slag road surfaces, one of which is believed to be Roman in origin (HSM 21371) and the other is of post-medieval construction (HSM 21361; Bridgewater 1959). Three further trenches were excavated in 1967 (HSM 23548, 23549 and 23550; Garrod and Moss 1967) and recorded two Roman hearths, a pit and a posthole buried beneath about $0.45 \mathrm{~m}$ and $0.70 \mathrm{~m}$ of accumulated topsoil and colluvial material. A trench excavated in 1983 produced no remains (HSM 3896) and no Roman deposits were identified in the section of the pipeline which crossed the south-western end of this field (HSM 6094; Jackson, Hancocks and Pearson 1999). Cropmarks in this field include a former boundary on the line of a Roman road (Cox 1995; route K-L) and a complex of ditches and soils, while large quantities of surface finds have been recovered by Bridgewater.

The archaeological data indicates that significant Roman deposits are present. The ADAS survey suggests that topsoil erosion is not likely to have been a significant factor in affecting their preservation. As with the other two fields within the scheduled area, it is possible that this is one of the areas cleared in the 18th century and thus wall footings may well have been robbed out from this location. Subsequent cultivation is initially likely to have caused quite severe damage but in the probable absence of topsoil erosion on the shallow slopes of this field, the ploughsoil cover is liable to have stabilised and plough damage reduced to a minimum except where cropping changed or heavier ploughing was introduced. Recently recorded plough depths of $0.20-0.25 \mathrm{~m}$ in 1980 give some indication of the sort of depths ploughing can effect, while the recording of surface finds from the 1960s onwards suggests that there is still fresh disturbance occurring. This may result from the use of heavier machinery, however, reports of freshly disturbed material are not especially common and conditions of preservation of any deposits are liable to be relatively stable.

In conclusion, this field was considered according to MAFF criteria to be at low risk of erosion at the time of the survey (MAFF1999); however, any increase in ploughing depth or use of heavier machinery is liable to lead to increased damage to surviving deposits. 


\section{HSM 22050 (ADAS Field 8)}

This field is situated to the south-east of the monument. The boundaries have been considerably remodelled with one field and part of two others shown on the 1823 tithe having been amalgamated to form this field by 1923 . Crops at the time of the survey included wheat and sugar beet. The field drains to the south-west on a gentle slope of no more than $3^{\circ}$.

This field was in the ADAS survey area and no erosion was recorded in the three years in which it was included. Although heavy rainfall combined with low crop cover was recorded, erosion was not triggered due to the gentle slope of the field.

Archaeological records for the field are not extensive. Although cropmarks extend into this area, few finds have been recorded and where the route of the Welsh Water pipeline crossed the south-west end of the field no deposits or artefacts were recovered. Any deposits present are liable to have been affected by ploughing which is typically in the region of $0.25 \mathrm{~m}$. According to MAFF criteria and the ADAS data this field can be identified as being at low risk of erosion (MAFF 1999). As result the ploughsoil is liable to be stable and thus after any initial damage to deposits when first ploughed, the preservation of any surviving deposits is also liable to be stable. Any increase in ploughing depth or use of heavier machinery is, however, liable to lead to increased damage.

\section{HSM 23565 and 23566 (ADAS Fields 9 and 10)}

These two fields lay beyond areas where complex Roman settlement remains are potentially present, although cropmarks are present (HSM 10673). As with other areas of the survey, these fields have been created from more than one earlier field as shown on the 1838 tithe. In particular HSM 23566 is a recent creation from at least five or six smaller ones. The southernmost field (HSM 23565) has only gentle slopes in the region of $2^{\circ}-3^{\circ}$, however, the eastern field (HSM 23566) has slopes as steep as $12^{\circ}$. Cropping at the time of the survey included cultivation of sugar beet, wheat and potatoes.

The ADAS survey area covered both of these fields, however, in the event only one was studied (HSM 23566) where erosion events were recorded in two out of four years. Up to $80 \%$ of the field was affected by rills with an estimated $79 \mathrm{~m}^{3}$ of soil lost, of which just over half was redeposited in fans. Here the steepness of the slope combined with other factors has led to erosion and according to MAFF criteria the field was assessed as being at high to very high risk of erosion at the time of the survey (MAFF 1999).

The other field, although not studied is considered to be at low risk of erosion due to having only a shallow slope. In neither case are significant archaeological deposits considered to be under threat.

\section{HSM 9071, 9818 and 23563}

These three fields lie outside of the ADAS survey area; however, are considered here since they were under arable cultivation at the time of the survey and contain or potentially contain significant deposits which are liable to be under threat from erosion.

The first field, lying some way north of the main settlement site (HSM 9071), has moderate to steep slopes at its south-west end but only shallow ones at the north-eastern end. Erosion risk is probably high on the steep slopes, but is probably low on the shallow slopes. Significant archaeological deposits are known from cropmarks, surface finds and excavations (Walters and Walters 1989). Significant deposits were buried beneath about $0.45-0.50 \mathrm{~m}$ of topsoil and subsoil. These deposits relate to a group of Roman enclosures, probably a farm, which lies at the north-eastern end of the field. Since these are situated on the relatively level land in this field, topsoil erosion is not liable to be significant factor affecting deposits. Ploughing will have had an impact from whatever date it started, especially initially, but in the absence of topsoil erosion conditions are liable to have stabilised except where deeper ploughing or heavier machinery have upset the balance as may have occurred recently.

The second of these three fields (HSM 9818) has gentle to moderate slopes and a narrow valley draining to the south-west. Erosion risk is probably low to moderate on these slopes, with the highest risk on the sides and floor of the shallow valley. Archaeological deposits have not been investigated in this field and no surface finds have been reported; but although the field lies away from areas which have usually been considered cropmarks suggest the presence of areas of former activity.

The last of these fields (HSM 23563) lies immediately to the north of the scheduled area. Gentle slopes drain it to the west. This field appears from aerial photographic evidence to have been under grass for a considerable period of time. In 1993 it was ploughed for first time in over 10 years and a cereal crop was planted followed by a potato crop in 1994 (DAG Newsletter 24, June 1994). The field has since reverted to pasture, however, this period of ploughing disturbed large quantities of iron slag, a ballista bolt (bronze), other artefacts and a spread of building debris including painted plaster (HSM 23567). Although no excavations have taken place here and discoveries are limited to this brief period of arable use, it is evident that ploughing has the potential to cause damage to significant surviving deposits and structures. Due to the gentle slopes present topsoil erosion is unlikely to be a significant factor. 


\section{Section 4. The finds and environmental evidence}

\section{The Iron Age and Roman pottery}

\section{Steven Willis}

\section{Introduction}

This report presents the Iron Age and Roman pottery from Ariconium. It covers the assemblages arising from Bridgewater's excavations in 1963, the trial trenching conducted by Garrod and Moss in 1967 and the various surface collections undertaken during the later decades of the 20th century, as well as material from other interventions in and around the scheduled area. These exercises have yielded what is in sum a sizeable assemblage of Iron Age and Roman pottery, though the extant collections from the major investigations are not ideal groups as quantities of body sherds were discarded. Hence the core dataset of the report comprises a little over 2100 sherds (Table 4). Fortunately the surviving sherds from the excavations are highly diagnostic, comprising mainly of rims.

From Bridgewater's work the pottery recovered was middle Roman in date, while the material from Garrod and Moss' trenches included much typologically late Iron Age and Transitional pottery, but extended to the later Roman period. The bulk of the surface collected pottery is of Roman date, covering the whole of the occupation period. Quantitative data relating to all three of these sources of material is produced below, along with detailed presentation of the fabrics and forms represented. The evidence of these sizeable collections is considered, with particular regard to the light they can shed on the chronology, nature, status and identity of the site during the late Iron Age and Roman periods. The taphonomy of the assemblages is examined in an endeavour to elucidate site formation processes. Pottery data from other significant work at or near to the site is, appropriately, incorporated in this synthesis. In particular, the pottery arising from the trial trenching undertaken by Jack in the 1920s (Jack 1923) is considered, as is the collection from the excavations undertaken by Walters and Walters to the north of the known core of the complex in the 1980s. The recent works in advance of development projects south-west of the scheduled area (i.e. Trench 11 of the Ryeford Bypass evaluation and fieldwork preceding the transfer pipeline for Welsh Water (see below)) have also yielded important collections, which constitute key material which is drawn upon in the discussion sections below.

Jeremy Evans, Derek Hurst and Robin Jackson kindly read an earlier version of this report and the present text incorporates many of their observations, for which the writer is grateful.

\section{The assemblages}

The assemblages and groups of pottery arising from the various episodes of fieldwork have themselves experienced differing histories since being unearthed. The Bridgewater, Garrod and Moss and surface collected assemblages have not, of course, been previously published. The assemblages do not form ideal datasets but the extant excavated material is spatially and stratigraphically located, while much of the surface collected pottery can be located to specific parts of the site, in many cases via eight figure grid references.

Table 4. The quantities of pottery surviving and analysed from the various fieldwork projects undertaken at Ariconium

\begin{tabular}{|l|l|l|r|}
\hline Fieldwork & $\begin{array}{l}\text { Quantity of IA and } \\
\text { Roman pottery examined } \\
\text { at assessment }\end{array}$ & $\begin{array}{l}\text { Quantity of IA and Roman pottery } \\
\text { (in sherds) analysed for this report }\end{array}$ & \\
\hline 1. Jack 1922 & 67 & & 67 \\
\hline 2. Bridgewater 1963 & 970 & $\begin{array}{l}\text { On database from excavations: } \\
\text { On database from surface collections: } \\
\text { Coded from surface collections: }\end{array}$ & 894 \\
\hline $\begin{array}{l}\text { 3. Garrod and Moss } \\
\text { surface collection }\end{array}$ & 814 & $\begin{array}{l}\text { On database from excavations: } \\
\text { Coded from surface collections: }\end{array}$ & 379 \\
\hline $\begin{array}{l}\text { 4. DAG/other } \\
\text { surface collections }\end{array}$ & $\begin{array}{l}\text { (1600 artefacts, including } \\
\text { medieval and post- } \\
\text { medieval finds) }\end{array}$ & $\begin{array}{l}\text { On database from surface collections: } \\
\text { Coded from surface collections: }\end{array}$ & 669 \\
\hline
\end{tabular}


Bridgewater's report upon his 1963 excavations (Bridgewater 1965) does include a list and illustrations of a modest number of significant pottery vessels; though no detailed pottery report was commissioned and there is no analysis. This is typical of reports of the period, though Bridgewater's main thrust in reporting the work was focused upon the important metalworking evidence that his investigations had revealed (Jackson and Hancocks 1998). Neither the Garrod and Moss nor the surface collected assemblages have previously been studied. A report specifically upon the former material has been produced by the writer, under the auspices of the present exercise, and this has been incorporated within the archive excavation report generated for that fieldwork (Jackson, Hancocks and Pearson 1999).

The pottery arising from Jack's excavations (Jack 1923 ) is referred to in the course of the present report. Only a small proportion of the recovered assemblage now survives and hence it was not possible to study this material in an analytical manner. Nonetheless this assemblage is significant for any discussion of pottery consumption at Ariconium. The pottery was published in a largely exemplary fashion by the standards of the time (Hayter 1923). The published pottery items were accurately identified and well documented, and it is advantageous that the diagnostic illustrated material has survived. One drawback however is the fact that the exact find locations of most of the items are not given, although the great majority of pieces were clearly recovered from the field identified here as HSM 21376 (Fig. 1.4). Data from the assemblage has been collated and included in the GIS database of the present project. In sum, this assemblage adds detail to the picture of the development of the site.

The Bridgewater and Garrod and Moss collections have been subject to a degree of selective retention, with some sherds having evidently been discarded or lost at a stage prior to 1999 (when the material was catalogued for this report). Fortunately all of the rim and base sherds of the Bridgewater assemblage have, apparently, been retained. The collection from the Garrod and Moss fieldwork appears to have been subject to a more severe selection procedure at some point in time, though rim sherds from stratified deposits have been retained to the extent that the extant groups should constitute reliable samples. In consequence the only avenue available for quantitative analysis is the EVE method (Orton 1982a; 1982b; 1989) using rim equivalents (RE); propitiously this method is theoretically the best measure of the relative frequency of pottery types (Orton 1989).

The pottery collection from the systematic fieldwalking exercises on the other hand is, evidently, intact.

Considering the quality of the material, the pottery from the Bridgewater and Garrod and Moss excavations, as well as that from the fieldwalking, has been well-collected in so far as details of the spatial and stratigraphic provenance of sherds have been recorded, and the sherds are marked. The apparently selective retention of the Bridgewater and
Garrod and Moss assemblages means that they are biased towards rims and other diagnostic items and hence sherds are comparatively large. Generally the ceramics are in good condition having experienced comparatively little abrasion and weathering. The surfaces of the samian fragments, for instance, are well preserved, while calcareous inclusions in fabrics have been subject to very limited leaching. The surfaces of the Severn Valley ware types are typically dull and powdery and in this case original surfaces may have been lost, though to what extent is uncertain.

An important aspect of the quality of the material relates to the spatial location of the interventions and fieldwork reported here. The majority of the Iron Age and Roman pottery recovered comes from the north-eastern half of the scheduled area and the area immediately to its southeast (see Fig. 1.3); essentially this is the field identified as HSM 21376 and a small area to its south-east. This was the main focus of Jack's work, was the location of the Garrod and Moss excavations, and has been a magnet for repeated surface collection. In consequence there is a bias amongst the collections emphasising the area of the apparent 'core' of the settlement, with the various collections from this vicinity displaying (unsurprisingly) a consistent chronology and character. This bias is off-set in part by the Bridgewater assemblage derived from a location some $300 \mathrm{~m}$ to the north of the scheduled 'core', and by the collection of sherds from the surface of field HSM 5324 (to the south of HSM 21376, but also largely within the scheduled area) gathered by Patrick Garrod. In addition several important groups of Iron Age and Roman pottery exist from various other exercises in the immediate hinterland of the scheduled area. These collections are useful in elaborating the ceramic picture, particularly spatially.

These groups include the pottery from the excavations of Walters and Walters to the north (1989; HSM 9071), together with that from Trench 11 of the evaluation in advance of the Ryeford Bypass (Napthan, Ratkai and Pearson 1995; HSM 22965) and the fieldwork preceding the laying of the Lea and Weston-under-Penyard sewage transfer pipeline for Welsh Water (Jackson, Hancocks and Pearson 1999; HSM 6097, 12666 and 15983), both southwest of Ariconium (Fig. 1.3). These groups have not been studied for presentation as part of the current work, rather they are considered from a comparative perspective. The ceramic material from the pipeline works is of especial importance for it is a sizeable collection, recovered using modern recording techniques, and includes Late Iron Age, Roman and later Roman pottery types which shed significant light on the chronology, character and extent of the site. Similarly the excavations of Walters and Walters recovered an important collection of 1 st century AD pottery, potentially including late Iron Age groups (see below).

The quantities of pottery are documented in Table 4 . All of the pottery from the Bridgewater and Garrod and Moss excavations and the systematic surface collections has been fully examined and is published here. The less 
closely provenanced surface collected pottery has all been examined and the more instructive samples are also published. All of the pottery amongst the collections has been scanned in some detail, and diagnostic pieces illustrated or otherwise documented for reference in the present text.

The chronology of the assemblages is clear. All of the assemblages deriving from the scheduled area and its immediate vicinity include late Iron Age and 1st century AD pottery types, as well as Roman types which continue through to the late Roman period. These assemblages comprise those arising from the excavations conducted by Jack (1922) and Garrod and Moss (1967), as well as Garrod's surface collection, the Dean Archaeological Group's various collections and other surface collections from this area. In contrast Bridgewater's 1963 excavations yielded pottery of a mid to late Roman emphasis with late Iron Age and early Roman pottery essentially absent.

The methodology adopted in the processing and analysis of these pottery collections is outlined below. The typology of the pottery (fabrics and forms) is then documented. The pottery is then examined by phase, using quantified data. The subsequent sections are more analytical, regarding the pottery from Ariconium from the point of view of vessel function, the taphonomy of the assemblages, site chronology and supply and trade. The report concludes by discussing the nature and status of the site as viewed from the evidence of the ceramics, thereby placing the site within a regional, and national perspective.

The collections reported here are curated by the Hereford and Gloucester City Museums.

\section{Methodology}

The late Iron Age and Roman pottery has been classified into exact fabrics following established principles ( $c f$. Peacock 1977a; Orton et al. 1993; PCRG 1995). All sherds were clipped to produce a fresh break and examined using a $\times 20$ binocular microscope with light source. As might be expected a number of common and familiar traded fabrics are present, having well defined characteristics, and these could be identified with confidence. A range of other wares are, of course, also present for which the source is less certain or uncertain. All of the fabric types present are documented below. In the case of the familiar traded wares and other well-defined types only their code, type name and a reference are, generally, listed. The wares from an uncertain or less certain source, etc., are accordingly described in some detail below. The majority of the latter seem very likely to be local products or from the region. When examining fabrics two recently published volumes giving details of fabrics and types were found to be useful references (Tyers 1996; Tomber and Dore 1998), in addition to the regionally important Droitwich volume (Woodiwiss 1992). Dr Jeremy Evans and Derek Hurst both kindly give advice on regional fabrics.

The different fabrics present have been categorised using a system analogous to that employed by the Warwickshire Museum, Oxford Archaeology (OA) and Dr Jeremy Evans (Booth 1996). This approach offers a practical means of organising an arbitrary number system such that it is hierarchical and thus amenable to interrogation. This system divides the material into broad generic ware classes, with an appropriate leading character specified as a prefix to the code. The Warwickshire Museum/OA system divides all Iron Age and Roman fabrics into 13 ware classes: A: amphorae, B: Black burnished wares, C: shell-tempered and heavily calcareously tempered wares, $\mathrm{E}$ : early grog tempered wares (i.e. 'Belgic' wares), $\mathrm{F}$ : non-samian finer fabrics, G: heavily tempered Roman fabrics (often handmade), M: mortaria fabrics, O: oxidised fabrics, P: handmade Iron Age and Iron Age tradition material, Q: white-slipped flagon fabrics, R: unoxidized/ greyware fabrics, $\mathrm{S}$ : samian fabrics and $\mathrm{W}$ : whitewares. Of these categories, 9 are used for the current report, with categories E, P, Q and W not employed. (Fabrics associated with medieval and later pottery have not been characterised or studied for the current report). The identified fabrics are listed below. Not surprisingly there is a close overlap between the fabrics present amongst the different assemblages reported here.

For a number of years pottery from sites in Herefordshire and Worcestershire excavated by what is now Worcestershire Historic Environment and Archaeology Service has been processed and published using a robust regional fabric type series which was initially based upon the large range of pottery from investigations in Droitwich (Woodiwiss 1992; Rees and Hurst 1992; Hurst 1999). This series was not used for the present report as the author was more familiar with the Warwickshire Museum/OA system; however, a concordance of the fabric codes used in this report with those of the Worcestershire Historic Environment and Archaeology Service series is produced in Appendix 5. Where there is a correspondence the fabric numbers of the Worcestershire series are also noted at the end of each fabric description below, as 'WHEAS F' numbers.

Once the sherds had been sorted into fabrics their attributes (i.e. fabric, form, quantity, surface finish, decoration, etc.) were recorded on a proforma sheet for entry into an Access database. All sherds from the Bridgewater and Garrod and Moss excavations and the systematic surface collections have been quantified by sherd count and the EVE method, using Rim Equivalent (RE; see Introduction, above). The latter measures the percentage of any extant rim represented on a sherd, where an RE of 1.00 would represent a complete circumference and an RE of $0.10,10 \%$ (see Introduction, above). Where possible rim and base diameters were also measured as an index of vessel size. In this way a full database catalogue of the extant pottery from these works, by context, fabric and form, has been produced in order to assist analysis. This database forms part of the project archive. Diagnostic items were selected for illustration and appear in Figures 4.1-4.19. 


\section{Fabric codes and descriptions}

Around 70 different discrete fabrics were identified in the course of the processing of the material and these categories are listed in this section. By far the majority of these fabrics are associated with Roman pottery, rather than Iron Age or Transitional types. The range of fabrics present is fairly wide, being boosted by small quantities of early imported wares of the 1 st and 2 nd centuries, plus later Oxfordshire ware types.

Only fabrics for which no published definition exists are described at length here, otherwise, for the well-known (confidently identified) fabrics represented, existing corpora are referenced, where descriptions may be found. An estimate of the date-range (currency) of each fabric at Ariconium is given in terms of calendar years (this being the date range of deposits with which like pieces are normally associated). This estimate is based upon the known chronology of certain wares (e.g. South-east Dorset Black burnished ware 1), the evidence of the form types in which the fabrics occur, and, to some extent the stratified occurrence of the wares at the site.

\section{Amphorae}

A11 Baetican amphora fabric, associated principally with the Dressel 20 form type, but also employed for the production of amphorae of Haltern 70 class, ( $c f$. Peacock and Williams 1986, 136-40; Tyers 1996, 87); c. AD 30-275. There are numerous sherds from Dressel 20 form amphorae amongst the collections from Ariconium. There is only one sherd present from a Haltern 70, coming from a rim; (though sherds from the two types occur in identical fabric they are usually readily distinguishable since the Dressel 20 has a much thicker wall and gentler body curvature). WHEAS F 42.1 .

A12 Southern Spanish amphora fabric, possibly from the Cadiz region, associated with the Beltrán I/Dressel 7-11 form range, ( $c f$. Sealey 1985, 77-85; Tyers 1996, 98-9; Tomber and Dore 1998, 87, 107); c. AD 30-130. (There is only one example of this fabric amongst the surviving assemblages examined here. This item is a body fragment recovered during fieldwalking by the Dean Archaeological Group; unfortunately its find-spot is not known). WHEAS F 42.5.

A13 Off-white amphora fabric, probably Southern Gaulish and associated with the Gauloise 4/Pélichet 47 form, ( $c f$. Tyers 1996, 94-6; cf. Tomber and Dore 1998, 93-4); c. AD 70-230. (As with A12 there is only one example of this fabric amongst the surviving examined assemblages, this being a body sherd recovered during systematic fieldwalking by the Dean Archaeological Group in field HSM 21376, specifically from SO 6457 2392). WHEAS F 42.3.

\section{Black burnished wares}

B11 (South-east Dorset) Black Burnished Ware 1, (cf. Tomber and Dore 1998, 127); c. AD 110-400. WHEAS F 22.

\section{Heavily calcareous tempered wares}

C11 Palaeozoic Limestone tempered ware, (cf. Peacock 1968, 421-2, Group B1; Morris 1983, 120-2; Hurst and Rees 1992, 201, fabric 4.1; Buteux and Evans 2004); at Ariconium perhaps c. $70 \mathrm{BC}-\mathrm{AD} 75 / 100$. At Ariconium this fabric occurs in jar, medium mouthed jar (perhaps barrel shaped), slack profiled jar, storage jar, hemispherical cup, small necked bowl, very large bowl and lid forms. Vessels produced in this fabric were predominantly handmade; surfaces are invariably well finished to a smooth feel (despite the size of the temper inclusions in the fabric). Overall vessels in this fabric were produced to a consistently good standard. WHEAS F 4.1.

\section{Finer fabrics}

F11 Oxfordshire red/brown colour-coated ware, (cf. Young 1977, 123); c. AD 240-400. WHEAS F 29.

F13 Central Gaulish black slipped ware, standard fabric, ( $c f$. Tyers 1996, 137; Tomber and Dore 1998, 50); c. AD 150-230. Cf. WHEAS F 44.

F15 Lower Rhineland (Cologne) colour-coated ware, ( $c f$. Tyers 1996, 146-8; Tomber and Dore 1998, 57); c. AD 40-260. $C f$. WHEAS F 45.

F16 Central Gaulish black slipped ware, grey fabric, (cf. Tyers 1996, 137); c. AD 150-230. Cf. WHEAS F 44.

F17 Nene Valley colour-coated ware, ( $c f$. Tyers 1996, 173); c. AD 150-400. WHEAS F 28.

F18 Central Gaulish glazed ware, (cf. Greene 1979, 86-103; Tyers 1996, 140); c. AD 30-80/100. WHEAS F 102.

F19 North Gaulish sandy white ware, ( $c f$. Tomber and Dore 1998, 24).; c. AD 1-80.

F20 North Gaulish Terra Nigra (cf. Rigby 1991, 76); c. 15/10 BC-AD 70. WHEAS F 25.

F21 Fine-grained sandstone/siltstone tempered greyware, with dark grey highly burnished surfaces; a local fabric, which may be an attempted emulation of F20; probably $c$. AD $50-100 / 250$.

F22 Oxfordshire brown colour-coated ware (cf. Young 1977, 123), a dark brown variant of F11; c. AD 240-400. WHEAS F 29.

F23 Very pale brown fine fabric, with sparse fine grog and calcareous inclusions; probably an early Severn Valley ware fine variant; $c$. AD 30-100. WHEAS F 12.

\section{Heavily tempered Roman fabric (handmade)}

G11 Malvernian metamorphic ware, (cf. Peacock 1967, 15-8; Hurst and Rees 1992, 201, fabric 3; Lee et al. 1994, 4-5; Tomber and Dore 1998, 147; Buteux and Evans 2004); c. AD 1-400 (probably with a main floruit $c$. AD 1-200). WHEAS F 3.

\section{Mortaria fabrics}

M01 North Gaulish (Noyon) mortarium fabric, (cf. Hartley 1977; 1998; Tomber and Dore 1998, 75; Tyers 1996, 125); c. AD 55-100. WHEAS F 36.

M10 Verulamium Region white ware mortarium fabric, ( $c f$. Davies et al.. 1994, 41; Tyers 1996, 132); c. AD 50-200. WHEAS F 35. 
M21 Oxfordshire parchment ware mortarium fabric, $(c f$. Young 1977, 81); c. AD 240-400. WHEAS F 40.

M22 Oxfordshire white colour-coated mortarium fabric, ( $c f$. Young 1977, 117); c. AD 240-400. WHEAS F 30.

M23 Oxfordshire red/brown colour-coated mortarium fabric, (cf. Young 1977, 123); c. AD 240-400. WHEAS F 29.

M25 Oxfordshire white ware mortarium fabric, ( $c f$. Young 1977, 56); c. AD 100-400. WHEAS F 38.

M30 Mancetter-Hartshill mortarium fabric, (cf. Tyers 1996, 123); c. AD 100-350. WHEAS F 32.

M40 Caerleon ware mortarium fabric, (cf. Zienkiewicz 1992, 92); c. AD 75-190. WHEAS F 110.

M50 Probable Cotswold/Gloucester mortarium fabric The fabric is pale pink/light brown throughout and hard with a roughish feel and fairly hackly fractures. Well-sorted, rounded quartz grains, mainly translucent and up to $0.5 \mathrm{~mm}$ are common. Very rare black specks, perhaps ferrous, c. $0.3 \mathrm{~mm}$ are also present. Ill-sorted rounded and subrounded rosy quartz fragments up to $3 \mathrm{~mm}$ occur sparsely over the rim and flange of the only example of this fabric and may relate to trituration grit. These characteristics are similar to those of fabric TF 9S (a) (and possibly TF 9Q) at Kingsholm, Gloucester, which is believed to be a fabric type local to Gloucester (Hurst 1985, 81-4); c. AD 60-100.

\section{Oxidized fabrics}

O10-O24 are Oxidized Severn Valley wares (Webster 1976). Invariably forms in these fabrics are wheelmade. The chronology of this ware class has remained vague due largely to its evidently slow rate of typological change, together with the fact that there is a lack of published well-dated groups and of kiln groups ( $c f$. Booth and Willis 1997, 53). Timby has suggested that the tradition appears shortly before the Roman conquest (Timby 1990). The present writer finds no reason to question this hypothesis and so an approximate date of $c$. AD 30 for the debut of the pottery of this tradition is proposed here as a heuristic solution.

O10 Severn Valley ware (SVW); c. AD 30-400. This is a general code identifying oxidized Severn Valley ware sherds, where these have not been otherwise allocated to a specific SVW fabric type (i.e. Fabrics O11-24, below); in particular it is employed in the analysis of the pottery from surface collections. For general descriptions of Severn Valley ware see Webster 1976 and Tomber and Dore 1998, 148-50. The fine-grained sandstone/siltstone (or possibly mudstone) pellets present within several of the below fabrics occur in a variety of colours, with variation often visible between closely adjacent pellets, however, it is common for these inclusions to appear matrix coloured or near matrix coloured. Sandstones such as Old Red Sandstone can occur in fine grained varieties qualitatively similar to the rock type(s) occurring in these fabrics. A local source within Herefordshire, or possible west Gloucestershire, therefore seems likely. WHEAS F 12.

O11 Severn Valley ware. Yellowish-brown fine fabric with medium grey core; hard with regular fractures and a soapy feel; fine/very fine white specks and fine-grained sandstone/siltstone pellets are sparse to moderate, while elongated voids occur; c. AD 30-300. WHEAS F 12.

O12 Severn Valley ware. Yellowish-brown fabric with, often, a mid-grey core; this fabric type can be soft and has a soapy or powdery feel; the clay matrix is silty, while very fine quartz grains are sparse, as are fine-grained sandstone/siltstone pellets; red-brown ferrous pellets, $c$. 2mm, are also present; $c$. AD 30-400. WHEAS F 12.

O13 Severn Valley ware. Yellowish-brown fabric; fairly hard with regular fractures and a smooth feel; the clay matrix is fine and silty; very fine sandstone/siltstone and/or possibly grog can be sparse to moderate; fine quartz grains are sparse to rare; c. AD 30-400. WHEAS F 12.

O14 Severn Valley ware Yellowish-brown fine fabric; soft, with regular fractures and a smooth feel; the clay matrix is fine and silty and the only inclusions visible at $\times 20$ magnification are rare fine quartz grains and equally rare very fine mica plates; $c$. AD 30-400. WHEAS F 12.

O15 Severn Valley ware. Yellowish-brown fabric with medium grey core; somewhat soft with regular fractures and a soapy feel; the clay matrix is fine and silty and contains a range of inclusion types: fine-grained sandstone/siltstone pellets up to $0.8 \mathrm{~mm}$ and charcoal fragments up to $c .1 \mathrm{~mm}$ occur, both in sparse frequency; red/brown ferrous pellets are rare; rhomboid voids up to $3 \mathrm{~mm}$ are also present, in sparse frequency, perhaps indicting the former presence of calcareous inclusions; c. AD 30-400. WHEAS F 12.

O16 Severn Valley ware. Reddish-brown fabric; fairly hard with regular fractures and a slightly rough feel; the clay matrix is fine and silty and contains fine-grained sandstone/siltstone pellets up to $1.2 \mathrm{~mm}$ in moderate to common frequency; red/brown ferrous pellets are rare, while mica is likewise rare; c. AD 30-400. WHEAS F 12.

O17 Severn Valley ware. Reddish-brown fabric with, occasionally a medium grey core; comparatively soft with regular fractures and a soapy feel; the clay matrix is fine and silty and is similar to that of O14, though in this case sub-rounded red/brown ferrous pellets up to $c$. $2 \mathrm{~mm}$, and generally c. $1 \mathrm{~mm}$, occur in sparse frequency; c. AD 30-400. WHEAS F 12.

O18 Severn Valley ware. Reddish-brown fabric with, typically, a medium grey core; the fabric is normally hard or fairly hard with regular fractures and a slightly rough feel; the clay matrix contains sub-rounded to sub-angular finegrained sandstone/siltstone pellets in common frequency, generally these inclusions are $1 \mathrm{~mm}$ or less but much larger pellets up to $5 \mathrm{~mm}$ can occur, many of the smaller pellets are off-white and give rise to a distinctive speckled appearance; charcoal fragments $c .1 \mathrm{~mm}$ in length are present but rare; some fine irregular splitting within vessel walls is present, perhaps the result of gases expanding during firing; this fabric is associated with thick walled vessels, especially storage jars; c. AD 30-400. WHEAS F 12.

O19 Severn Valley ware. Yellowish-brown distinctive fabric. This fabric is hard with a rough feel and somewhat irregular fractures; the clay matrix is rather granular and contains fine rounded quartz grains in common frequency; red ferrous pellets also occur in sparse to rare frequency; surfaces have fine pit marks where quartz grains have been dislodged; $c$. AD 120-400. WHEAS F 12.

O20 Severn Valley ware. Reddish-brown fabric, occasionally 
with a mid-light grey core; the fabric is hard with regular fractures and a smooth feel; fine rounded to sub-rounded fine-grained pale brown to red sandstone/siltstone pellets are sparse, while fine elongated voids are sparse to moderate; very fine mica is also present but rare; a cream slip may be present on interior and exterior surfaces; $c$. AD 55-100/110. WHEAS F 12.

O21 Severn Valley ware. Yellowish-brown fabric; this is a fairly hard fabric with regular fractures and a soapy feel; the clay matrix is silty and contains fine and very fine fine-grained pale brown to red sandstone/siltstone pellets in moderate frequency and similar sized (apparent) calcareous specks which are sparse; numerous fine voids are also visible under x20 magnification; c. AD 30-100. WHEAS F 12.

O22 Severn Valley ware. Adull yellowish-brown, comparatively coarse fabric; this variety is hard with regular fractures and a smooth feel; the clay matrix is again silty; it contains a variety of inclusions, principal amongst which are fine to coarse sub-angular fine-grained sandstone/siltstone pellets in common frequency; fine charcoal flecks are rare to sparse; red/brown ferrous pellets are rare; some fine irregular splitting within vessel walls is present, perhaps the result of gases expanding during firing; c. AD 30-400. WHEAS F 12.

O23 Severn Valley ware. A yellowish-brown to red fabric, with a grey core; the fabric is hard with regular fractures; sub-rounded and sub-angular quartz grains (mainly white) c. $0.5 \mathrm{~mm}$ are moderate in frequency, while numerous extremely fine irregular splits occur within vessel walls, perhaps the result of gases expanding during firing; $c$. AD 30-200. WHEAS F 12.

O24 Severn Valley ware. The fabric is yellowish-brown and is fairly soft with regular fractures and a smooth feel. The clay matrix is very fine and inclusions comprise very fine quartz grains which are sparse, together with mica and red ferrous pellets which are both rare; c. AD 140-400. WHEAS F 12.

\section{O30-O37 are Oxidized Oxfordshire wares}

O30 Oxfordshire coarse white ware variant with rare to sparse translucent quartz grains, (cf. Young 1977, 93); c. AD 100-400. WHEAS F 38.

O31 Oxfordshire coarse white ware, (cf. Young 1977, 93, Type 2); c. AD 40-400. WHEAS F 38.

O32 Oxfordshire white colour-coated ware, (cf. Young 1977, 117); c. AD 200-400. WHEAS F 30

O34 Oxfordshire parchment ware, (cf. Young 1977, 81); $c$. AD 240-400. WHEAS F 40.

O35 Oxfordshire fine white ware, (cf. Young 1977, 93, Type 1); c. AD 40-400. WHEAS F 38.

O36 Oxfordshire coarse red ware, (cf. Young 1977, 185, Type 2); c. AD 40-400.

O37 Red fabric with common quartz grain inclusions and a cream slip; a coarse Oxfordshire white colour-coated ware type (cf. Young 1977, 117) or possibly a Severn Valley ware variant; $c$. AD 50-400.

O38 Other Oxidized wares. Probable early Severn Valley ware variant. Yellowish-brown to pale grey fabric which is hard with regular fractures and a smooth or burnished surface; the matrix is silty and contains sub-angular to sub-rounded fine-grained sandstone/siltstone pellets, generally up to
$1.2 \mathrm{~mm}$, and these are moderate in frequency; very fine white specks are present but rare; fine irregular splitting within vessel walls is frequent, perhaps the result of gases expanding during firing; $c$. AD 30-120. WHEAS F 12.

\section{Greyware fabrics}

Fabrics R20-R22 are described here as 'Unoxidized Severn Valley wares'. Severn Valley wares are, of course, typically yellow-brown or reddish-orange, but unoxidized wares also occur ( $c f$. Tyers 1996, 197; Rees and Hurst 1992). Indeed the same kilns were used to produce both oxidized and unoxidized wares (Webster 1976). As regards the Ariconium pottery, Fabrics R20-R22 share similar qualities to Fabrics $\mathrm{O} 10-\mathrm{O} 24$ in terms of fabric, temper, surface treatment and powdery touch. The prominent occurrence of fine-grained sandstone/siltstone pellets in particular links Fabrics R20-R22 with many of the fabrics of the O10-O24 range, indicating that they come from the same sources or general area. R20 and R21 were employed in the production of distinct form types (Figs 4.6 and 4.7) but many of these forms are actually closely paralleled amongst the $\mathrm{O} 10$ to $\mathrm{O} 24$ series, as reference to the illustrated pottery demonstrates.

R20 'Unoxidized Severn Valley ware'. The fabric is mid to light grey, hard, with regular fractures and a smooth/soapy feel; the clay matrix is silty and contains common ill-sorted fine-grained sandstone/siltstone inclusions ranging up to c. $2 \mathrm{~mm}$; red/brown ferrous pellets are present but rare, while very fine white specks also occur; sub-angular voids, up to $c .2 \mathrm{~mm}$ occur at surfaces with moderate frequency and evidently represent the former presence of weathered or missing sandstone/siltstone inclusions, though some may relate to leached calcareous inclusions; (there is no evidence of organic tempering); some fine irregular splitting within vessel walls is present, perhaps the result of gases expanding during firing; $c$. AD 30-400. Evidently this is a local or regional fabric type. WHEAS F 12R.

R21 'Unoxidized Severn Valley ware'. The fabric is mid to light grey (with often a 'sandwich' appearance at breaks), hard, with regular fractures and a slightly rough feel; the clay matrix is silty and contains fine well sorted fine-grained sandstone/siltstone inclusions $c .0 .1-0.3 \mathrm{~mm}$, though very rare larger pellets can occur; exterior surfaces may be burnished; in essence this fabric appears to be a finer version of R20, while it is also characteristically similar to R32; ? c. AD 30-400. WHEAS F 12R; somewhat similar to WHEAS F 14.

R22 'Unoxidized Severn Valley ware'. Surfaces are typically dark grey ('black'), while cortices and margins are red and cores grey; this variety is again hard, with regular fractures and a smooth feel; the clay matrix is silty and contains moderate to common ill-sorted fine-grained sandstone/siltstone pellets ranging up to $c$. $2 \mathrm{~mm}$, but generally less than $1 \mathrm{~mm}$; red/brown ferrous pellets, of similar size, are also present; exterior surfaces may be burnished; R22 appears to be a variant of R20, with a closely similar fabric, though the two have been finished and fired differently; ? c. AD 30-400. WHEAS F 12R.

R23 Gritty micaceous grey ware. The fabric ranges from 
light to dark grey; it is hard with irregular fractures and a rough feel; the clay matrix is silty and contains fine rounded quartz grains, similar sized fine-grained sandstone/siltstone pellets, gold mica, $c .1 \mathrm{~mm}$, and black grains, also $c$. $1 \mathrm{~mm}$, all in moderate frequency; also represented are rare to sparse white angular fragments, c. $1 \mathrm{~mm}$, probably feldspar, and red/brown ferrous pellets, of similar size but rare; ? c. AD 30-400.

R24 Unoxidized fabric, comparatively finer, possibly a Severn Valley ware variant. Grey to yellowish-brown fabric, fairly soft with regular fractures and a smooth feel; the clay matrix is silty and contains moderate to common well-sorted black (and occasionally red) grains which are very fine; fine red/brown ferrous pellets are rare, while fine muscovite is sparse; surfaces may be burnished; ? c. AD 30-400. ? WHEAS F 12R.

R25 Coarse fabric with grey-brown surfaces and a red core. This is a hard fabric with irregular fractures and a very slightly rough feel; the clay matrix is silty and contains some very fine mica flecks; the main inclusion represented takes the form of ill-sorted sub-angular fine-grained sandstone/siltstone pellets, up to $2.2 \mathrm{~mm}$, which are common; angular quartz fragments $c .1 .5 \mathrm{~mm}$ are rare; fine red/brown ferrous pellets are rare; ? c. AD 30-100/120. $C f$. WHEAS F 8.

R26 Distinctive coarse unoxidized ware, with burnished surface and a markedly soapy feel. This fabric has dark grey surfaces and a grey core; lighter semi-oxidized margins are frequently present. This a hard fabric; fractures are largely regular while surfaces have a highly soapy feel. Once again the clay matrix is silty; fine fine-grained sandstone/siltstone pellets are moderate to common in frequency; very fine black inclusions occur in rare to sparse frequency; charcoal streaks and fine/very fine fragments are likewise sparse to rare; this ware is similar to R29; c. 40 BC-AD 100. R26 is evidently of late Iron Age/early Roman date being closely associated with necked and carinated bowls; the fabric was also used to produce beakers. Some similarity to WHEAS F 7, 8 and 12.3 .

R27 Finer fabric with pale grey surfaces and fine-grained sandstone/siltstone inclusions. The surfaces and core of this fabric are pale grey, while the margins are red; again this is a hard fabric with regular fractures and a smooth/soapy feel; the main inclusion type comprises fine sub-rounded fine-grained sandstone/siltstone which occurs in moderate frequency; very fine white specks are notable, though sparse; red/brown ferrous pellets are rare; c. AD 30-75.

R28 Unoxidized fabric with fine-grained sandstone/siltstone inclusions, similar to R26/R29. This fabric has dark grey surfaces and a light to mid grey core; it is hard with fairly irregular fractures and where not burnished is somewhat rough to feel; the clay matrix is silty and contains fine finegrained sandstone/siltstone pellets which are common; also represented are distinctive rounded white/translucent quartz grains somewhat larger than the fine-grained sandstone/siltstone, and these occur in rare frequency; exterior surfaces are, typically, burnished; c. $20 \mathrm{BC}-\mathrm{AD}$ 400. This fabric occurs in necked jar and beaker forms. WHEAS F 7.

R29 Distinctive coarse unoxidized ware, with burnished surfaces and a markedly soapy feel. This fabric has dark grey surfaces and a grey core, while margins are frequently oxidized red. This is a hard fabric; fractures are largely irregular and the ware has a soapy feel; surfaces can be highly burnished. The clay matrix is silty; fine fine-grained sandstone/siltstone pellets are moderate to common in frequency; this ware is similar to R26; c. 50 $\mathrm{BC}-\mathrm{AD}$ 140. Barrel and medium mouthed jars occur in this fabric, though it was particularly employed in manufacturing carinated bowls. $C f$. WHEAS F 8 .

R30 Unoxidized ware. The fabric is hard with a smooth feel; fractures may be regular or irregular. The fabric matrix is silty and contains angular sandstone/siltstone fragments $c$. $1 \mathrm{~mm}$ and less which are sparse to moderate in frequency; quartz grains are present but rare; irregular voids within sherd walls are visible at breaks, and evidently indicate expanding gases during firing, perhaps through the presence of organic matter. Surfaces are generally very dark grey and are characteristically burnished or very smooth; cores are dark to light grey. This fabric is associated with comparatively fine vessel forms; $c$. 50 BC-AD 70. This fabric occurs in beaker and bowl forms. Cf. WHEAS F 8.

R31 Unoxidized coarse fabric with fine-grained sandstone/ siltstone inclusions, similar to R26/R29. This fabric has dark grey to brown surfaces and a grey core, while margins are frequently oxidized red. It is fairly hard with semi-hackly/irregular fractures and a soapy feel; surfaces may be burnished. The clay matrix is silty; fine (under $1 \mathrm{~mm}$ ) ill-sorted fine-grained sandstone/siltstone pellets are moderate to common in frequency; very fine black inclusions occur in rare to sparse frequency; rare to sparse tiny voids and white specks suggest very fine calcareous inclusions; this ware is similar to R29, of which it may be a variant; $c$. AD 1-100. Cf. WHEAS F 8.

R32 Unoxidized coarse fabric, superficially similar to R26/R29 but with quartz grain temper. This fabric has dark grey surfaces and may have a grey core, while margins are typically oxidized red. This is a hard fabric; fractures are largely irregular and the ware has a soapy feel; surfaces can be highly burnished. The clay matrix is somewhat silty; well-sorted fine rounded and sub-rounded quartz grains are common in frequency; c. AD 30-100. Cf. WHEAS F 8.

R33 Pale grey coarse fabric. The fabric is mid to light grey throughout; it is hard with regular fractures and a smooth feel. Sub-rounded matrix coloured fine-grained sandstone/ siltstone (? and grog) pellets are common to abundant, up to $2 \mathrm{~mm}$; very fine black specks occur in some frequency with an occasional larger fragment also $c$. $2 \mathrm{~mm} ; c$. AD 120-250. ? WHEAS F 12R.

R34 Distinctive unoxidized coarse ware with abundant inclusions. The fabric has light to mid-grey surfaces and margins and the core is dark grey; it is hard with irregular fractures and a smooth feel; coarse fine-grained sandstone/ siltstone pellets are abundant, while charcoal flecks up to $2 \mathrm{~mm}$ are sparse; fine white specks occur, possibly calcareous, while fine black inclusions are also present (apparently not charcoal), both the latter are sparse; fine irregular splits within vessel walls are common, perhaps the result of gases expanding during firing; $c$. AD 50-200. Some similarity to WHEAS F 12.3 . 


\section{Samian (Terra Sigillata) fabrics}

S01 South Gaulish samian from La Graufesenque, ( $c f$. Tomber and Dore 1998, 28); c. AD 40-110. WHEAS F 43.

S02 Central Gaulish samian from Les Martres-de-Veyre, ( $c f$. Tomber and Dore 1998, 30); c. AD 100-130. WHEAS F 43.

S03 Central Gaulish samian from Lezoux, (cf. Tomber and Dore 1998, 32); c. AD 120-200. WHEAS F 43.

S04 East Gaulish samian; c. AD 140-260. WHEAS F 43.

S05 East Gaulish samian from Trier, (cf. Tyers 1996, 113; $c f$. Tomber and Dore 1998, 41); c. AD 150-260. WHEAS F 43.

S06 East Gaulish samian from Rheinzabern, (cf. Tyers 1996, 113-4; cf. Tomber and Dore 1998, 39); c. AD 150-260. WHEAS F 43.

S07 East Gaulish samian from Argonne, (cf. Tomber and Dore 1998, 34-5); c. AD 140-260. WHEAS F 43.

S08 South Gaulish samian from Montans, (cf. Tomber and Dore 1998, 29); c. AD 50-200. WHEAS F 43.

\section{Post Roman pottery}

Post-Roman pottery was identified in the processing with the following code: X99 - Medieval and Post-Medieval.

\section{Catalogue of the Illustrated Pottery}

The illustrated pottery items are ordered in the following manner. The primary division is by pottery Fabric, following the codes employed for the report (e.g. B11, C11, etc.) in alphabetic sequence, and within this, by numeric sequence. For each Fabric type all the drawn examples of that fabric are arranged together by form class, with the form classes following the order established elsewhere in the report, that is moving from the more closed to the more open forms. In some cases the drawings are also ordered chronologically within form classes (for example, as with the jars in B11).

The descriptive details adhere to a consistent format. Items are listed under their Fabric type: the illustration number is followed by the fabric code and a short description of the item; hand manufacture is invariably recorded, while wheel manufacture is noted when this is of significance (for instance, with late Iron Age or Transitional types). The context of the item is then listed. A date range for the item is then given, this being the date range of deposits in which other examples of the type modest frequently occur, or, alternatively, an estimate of the date range on typological grounds. Where there is more than one sherd illustrated this is noted in brackets. Finally, an illustrated parallel(s) for the form may be referenced.

\section{Figure 4.1. B11, Black Burnished Ware 1}

1. B11. Jar; burnished exterior and rim. Garrod and Moss 1967, Trench AI, context 2; c. AD 120-160. cf. Gillam 1968, no. 119.

2. B11. Rim and shoulder from a miniature necked jar; burnished exterior surface and rim. From HSM 21376 but precise findspot not known; ?c. AD 120-200. No close parallel in Gillam 1976.

3. B11. Jar. Bridgewater 1963, Area C, context 2; c. AD 120-200.

4. B11. Small jar. Bridgewater 1963, Area A, context 1; c. AD 120-200.

5. B11. Jar. Bridgewater 1963, Area C, context 1; c. AD 120-200.

6. B11. Jar. Bridgewater 1963, Area C, context 2; c. AD 160-200.

7. B11. Jar, traces of carbonized residue on exterior. Bridgewater 1963, Area C, HSM 10676, 'TH1'; c. AD 200-250. (2). cf. Gillam 1968, no. 139.

8. B11. Jar, unusually large for this form type; traces of soot or carbonized residue on exterior, below rim. Bridgewater 1963, Area C, context 1; c. AD 200-250/300.

9. B11. Jar; highly burnished exterior and rim; wavy burnished line on underside of rim. Bridgewater 1963, Area D, context 1; ?c. AD 200-300, possibly c. AD 250300.

10. B11. Rim and upper wall from a jar with short everted rim; burnished on exterior surface and rim. DAG fieldwalking. HSM 21376, precise findspot not known; probably c. AD 240-300. cf. Gillam 1976, fig. 3, nos 30-33.

11. B11. Rim and upper wall from a jar with flaring rim; burnished on exterior surface and rim. DAG fieldwalking. HSM 21376, precise findspot not known; $c$. AD 270-360. cf. Gillam 1976, fig. 2, nos 10-14.

12. B11. Flange rimmed bowl. Bridgewater 1963, Area A, context 1; probably c. AD 160/80-230.

13. B11. Flange rimmed bowl. Bridgewater 1963, Area A, context 2; probably c. AD 160/80-230.

14. B11. Rim and wall from a bowl with short flat flange rim; burnished all over; exterior decorated with overlapping sequences of intersecting arcs. DAG fieldwalking. HSM 21376, precise findspot not known; probably $c$. AD 170-200. cf. Gillam 1976, fig. 3, nos 40-41.

15. B11. Rim and upper wall from a bowl with flange rim; burnished all over; exterior decorated with intersecting arcs. DAG fieldwalking. HSM 21376, precise findspot not known; probably c. AD 170-200. cf. Gillam 1976, fig. 3 , no. 40.

16. B11. Rim and upper wall from a flanged bowl with bead rim; burnished all over. DAG fieldwalking. HSM 21376, precise findspot not known; c. AD 200-400.

17. B11. Bowl with flange. Bridgewater 1963, Area C. Probably HSM 10676, surface find; c. AD 260-400.

18. B11. Rim and upper wall from a bowl with a short flange; burnished all over; one drilled hole for repair. DAG fieldwalking. HSM 21376, precise findspot not known; c. AD 270-360. cf. Gillam 1976, fig. 4, nos 46-49.

19. B11. Rim from a flanged bowl; burnished all over. DAG fieldwalking. HSM 21376, SO 6470 2390; c. AD 270-400. cf. Gillam 1976, fig. 4, nos 45-49.

20. B11. Flange rimmed dish. Bridgewater 1963, Area C, context 1; c. AD 120-200. (2).

21. B11. Straight sided dish with slight groove below rim on exterior. Bridgewater 1963, Area D, context $1 ; c$. AD 120-400.

22. B11. Flange rimmed dish. Bridgewater 1963, Area C, context 1; c. AD 160/80-230. (2). 

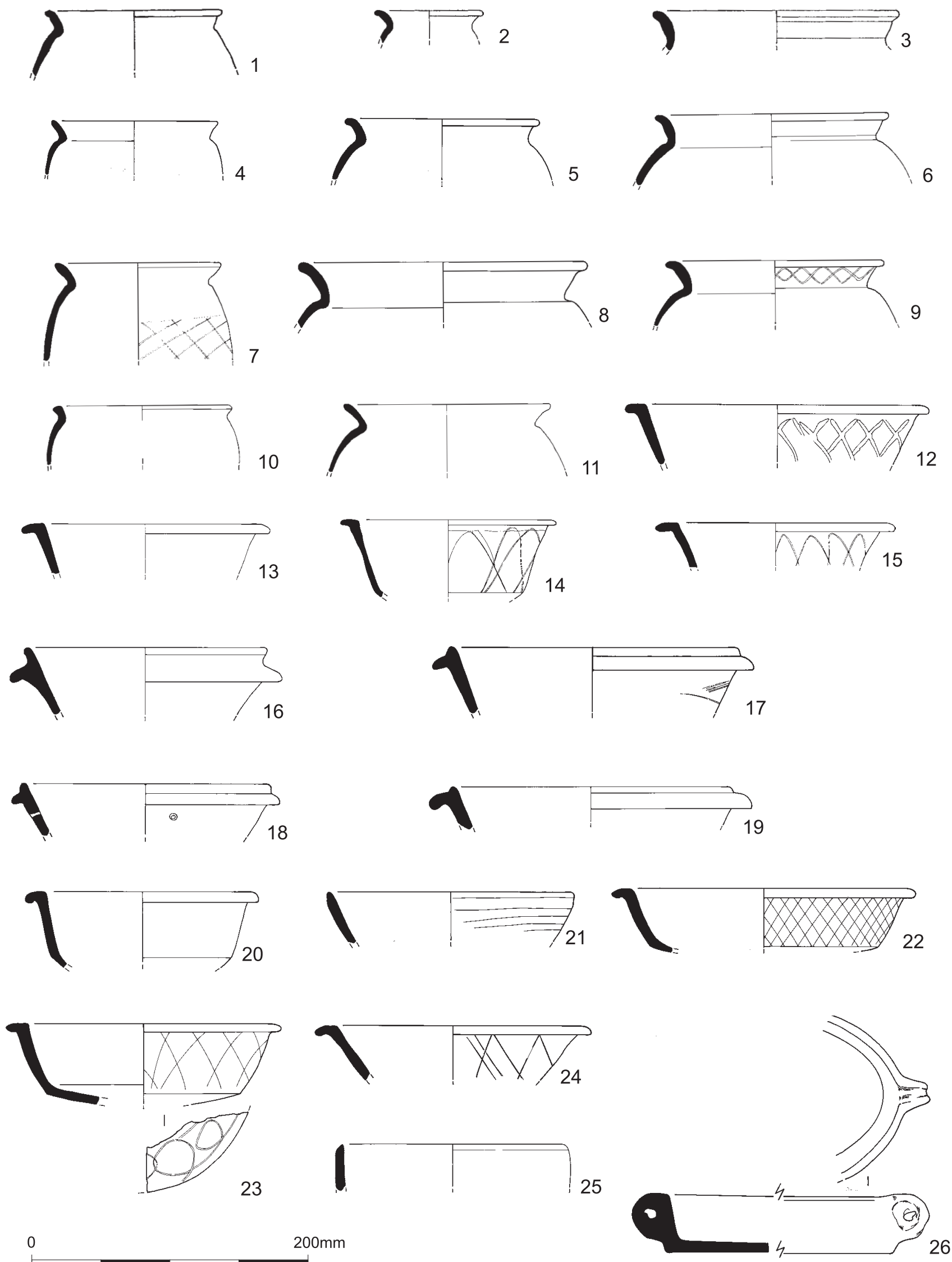

Figure 4.1. Pottery: Black burnished ware 1 
23. B11. Flange rimmed dish; traces of carbonized residue on the exterior below the rim. Bridgewater 1963, Area C, context 1; c. AD 160/80-230.

24. B11. Flange rimmed dish, upper two thirds fully oxidized light red. Bridgewater 1963, Area D, context 2; c. AD 160/80-230.

25. B11. Rim and wall from a small plain rimmed dish; burnished all over. DAG fieldwalking. HSM 21376, SO 6470 2380; c. AD 170-230. cf. Gillam 1976, fig. 5, no. 78.

26. B11. Oval handled dish, a so-called 'fish dish', with a flat base; burnished all over; no decoration. Garrod Collection, surface find; $c$. AD 270-400. cf. Gillam 1976, 77-8, no. 85 .

\section{Figure 4.2. C11, Limestone Tempered Ware}

1. C11. Jar with everted rim and band of decoration on shoulder; burnished exterior surface and rim; handmade. Garrod Collection, surface find, SO 645 241; c. 70 BC-AD 75.

2. C11. Rim and shoulder from a necked jar with decorated shoulder and everted rim; burnished exterior and rim; handmade. Garrod Collection, surface find, SO 645 241; c. 70 BC-AD 75.

3. C11. Jar, with decorated shoulder; handmade. Garrod Collection, surface find, SO 645 241; c. 70 BC-AD 75.

4. C11. Jar, with bead rim; very smooth exterior surface and rim; handmade. Garrod Collection, surface find; c. 70 BC-AD 75. (2). cf. Hawkesand Hull 1947, pl. 52, Cam 249A.

5. C11. Rim and upper body from a jar; very smooth exterior surface and rim; handmade. Garrod and Moss 1967, Trench BII, context 3; c. 70 BC-AD 75. (2).

6. C11. Rim from a medium mouthed jar, perhaps barrel shaped in form; the rim is everted; very smooth exterior surface and rim; handmade. Garrod and Moss 1967, Trench BI, context 2B; c. 70 BC-AD 75.

7. C11. Rim and upper wall from a medium mouthed jar with everted rim; very smooth surfaces all over; handmade. Garrod and Moss 1967, Trench AI, context 3; c. 70 BC-AD 75.

8. C11. Rim and upper wall from a medium mouthed jar with everted rim; very smooth surfaces all over; handmade. Garrod and Moss 1967, Trench AI, context 3; c. 70 BC-AD 75.

9. C11. Rim and upper body from a jar; very smooth exterior surface and rim; handmade. Garrod and Moss 1967, Trench BI, context 2A; c. 70 BC-AD 75.

10. C11. Jar (medium mouthed); handmade. Garrod and Moss 1967, Trench AI, context 3; c. 70 BC-AD 75.

11. C11. Rim and upper body from a jar; very smooth exterior surface and rim; handmade. Garrod and Moss 1967, Trench BI, context 2A; c. 70 BC-AD 75.

12. C11. Rim and upper body from a slack profiled jar; very smooth interior and exterior surfaces and rim; handmade. Garrod and Moss 1967, Trench BI, context 2A; c. 70 BC-AD 75.

13. C11. Rim and upper body from a medium mouthed jar, perhaps barrel shaped in form; the rim is everted; burnished exterior surface and rim; probably handmade. Garrod and Moss 1967, Trench BI, context 2B; c. 70 BC-AD 75.

14. C11. Rim and upper body from a jar; very smooth exterior surface and rim; handmade. Garrod and Moss 1967, Trench BII, context 3; c. 70 BC-AD 75.

15. C11. Rim and upper body from a jar; very smooth exterior surface and rim; handmade. Garrod and Moss 1967, Trench BI, context 2A; c. 70 BC-AD 75. (2).

16. C11. Rim and upper wall from a jar with everted rim; exterior weathered, interior and rim very smooth; handmade. Walters and Walters 1989, HSM 9071, context 8, c. 70 BC-AD 75.

17. C11. Rim and upper wall from a jar with everted rim; very smooth surfaces; handmade. Walters and Walters 1989, HSM 9071, context 8, c. 70 BC-AD 75.

18. C11. Jar rim; handmade. Bridgewater 1963, Area C, HSM 21378, surface find; c. 70 BC-AD 75.

19. C11. Base from a jar with a central drilled hole, fashioned after firing; exterior surface very smooth; handmade. Garrod and Moss 1967, Trench BIII, context 4; c. 70 BC-AD 75.

20. C11. Rim from storage jar; the rim is everted and there is a slight corrugation on the shoulder; very smooth exterior surface and rim; wheelmade. Garrod and Moss 1967, Trench BI, context 2B; c. AD 1-70.

21. C11. Rim from storage jar; very smooth exterior surface and rim; wheelmade. Garrod and Moss 1967, Trench BI, context 3 ; c. AD 1-70.

22. C11. Jar rim; handmade. Bridgewater 1963, Area C, HSM 21378, surface find; c. 70 BC-AD 75.

23. C11. Rim from storage jar; very smooth exterior surface; wheelmade. Garrod and Moss 1967, Trench BI, context 2B; c. AD 1-70.

24. C11. Jar rim and shoulder with $\mathrm{x}$-hatch marking; handmade. Bridgewater 1963, Area C, HSM 21378, surface find; c. $70 \mathrm{BC}-\mathrm{AD} 75$.

\section{Figure 4.3. C11, Limestone Tempered Ware (continued)}

1. C11. Jar/storage jar rim; handmade. Bridgewater 1963, Area C, HSM 21378, surface find; c. 70 BC-AD 75.

2. C11. Rim and shoulder from a storage jar; very smooth exterior surface and rim; handmade. Garrod and Moss 1967, Trench BII, context 2; c. 70 BC-AD 75.

3. C11. Rim and shoulder from a storage jar; very smooth exterior surface and rim; handmade. Garrod and Moss 1967, Trench BIII, context 2; c. 70 BC-AD 75.

4. C11. Rim and shoulder from a storage jar; very smooth exterior surface and rim; handmade. Garrod and Moss 1967, Trench CI, context 28; c. 70 BC-AD 75.

5. C11. Rim from a hemispherical cup; very smooth interior and exterior surfaces and rim; handmade. Garrod and Moss 1967, Trench BI, context 2A; c. 70 BC-AD 75.

6. C11. Small necked bowl with decorated shoulder; burnished exterior and rim; this item is pale yellowish-brown throughout which is unusual for examples of Fabric C11; handmade. Garrod Collection, surface find, SO 645 241; c. 70 BC-AD 75.

7. C11. Small necked bowl with out-turned and flattened rim with two grooves on the upper surface; the exterior surface and rim have an exceptionally high burnish, while the interior is also burnished; handmade. Garrod Collection, surface find, SO 645241 ; c. 70 BC-AD 75. (2).

8. C11. Part profile from a small necked bowl; very smooth 


$$
\begin{array}{lll}
1,1 & 1 \\
1 & 1 & 1 \\
1 & 1 & 1 \\
1 & 1 & 1 \\
1 & 1 & 1 \\
1 & 1 & 1 \\
2,1 & 1 \\
1 & 1
\end{array}
$$



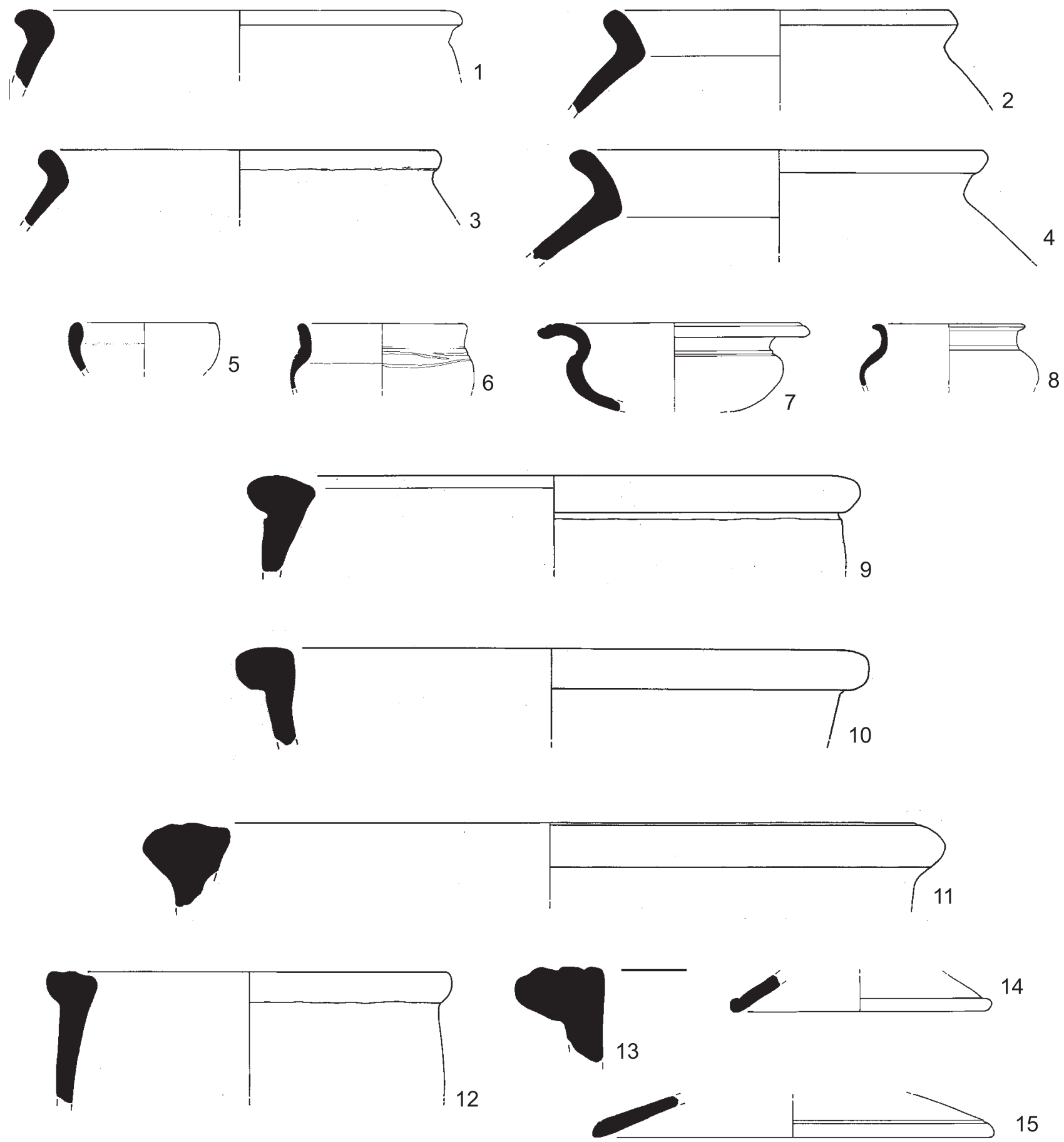

14

0

$200 \mathrm{~mm}$

Figure 4.3. Pottery: Limestone tempered ware (cont)

exterior surface and rim; handmade. Garrod and Moss 1967, Trench BIII, context 2; c. 70 BC-AD 75. (5).

9. C11. Very large bowl; two faint grooves on the upper surface of the rim; very smooth exterior and interior surfaces; handmade. Garrod Collection, surface find; c. 70 BC-AD 75. cf. Kenyon 1954, fig. 19.

10. C11. Very large bowl; handmade. Garrod and Moss 1967, Trench AI, context 3; c. 70 BC-AD 75. (2). cf. Kenyon 1954, fig. 19.
11. C11. Rim from very large bowl; handmade. Garrod and Moss 1967, Trench AI, context 2A; c. 70 BC-AD 75. cf. Kenyon 1954, fig. 19.

12. C11. Rim from very large bowl; two grooves on the upper surface of the rim; handmade. Garrod and Moss 1967, Trench AI, context 2A; c. 70 BC-AD 75. cf. Kenyon 1954, fig. 19.

13. C11. Very large bowl; three grooves on the upper surface of the rim; very smooth exterior and interior surfaces; 


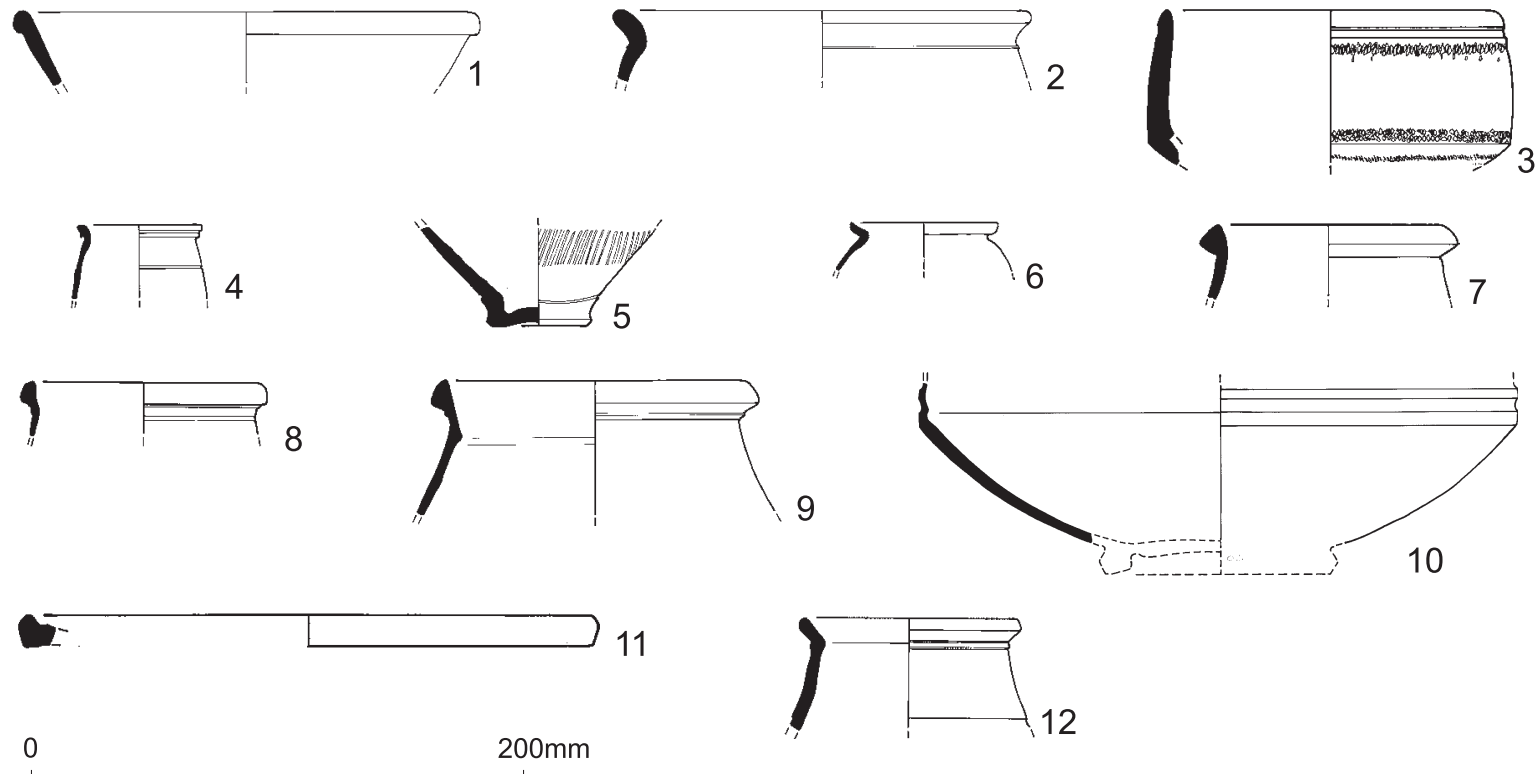

4.4. Pottery: Fine wares

handmade. Garrod Collection, surface find; c. 70 BC-AD 75. cf. Kenyon 1954, fig. 19.

14. C11. Lid fragment, with beaded circumference; upper surface and rim very smooth; handmade. Garrod and Moss 1967, Trench BIII, context 5; c. 70 BC-AD 75.

15. C11. Lid; handmade. Bridgewater 1963, Area C, HSM 21378, surface find; c. $70 \mathrm{BC}-\mathrm{AD} 75$.

\section{Figure 4.4. F11-F23, Fine Wares}

1. F11. Oxfordshire Red/Brown Colour-Coated Ware. Rim from a shallow bowl, imitating the samian form Drag 31 . Bridgewater 1963, Area C, context 1; c. AD 270-400. cf. Young 1977, Type C.45 or 46.

2. F11. Oxfordshire Red/Brown Colour-Coated Ware. Rim and upper wall from a curving sided bowl with everted rim; colour-coated all over; wheelmade. DAG fieldwalking. HSM 21376, SO 6452 2401, c. AD 270-400. cf. Young 1977, C.18.

3. F11. Oxfordshire Red/Brown Colour-Coated Ware. Rim and upper wall from a carinated bowl; colour-coated interior and exterior surfaces; bands of rouletting on exterior; wheelmade. Garrod Collection, surface find; c. AD 300-400. cf. Young 1977, C. 81.

4. F13. Central Gaulish Black Slipped Ware. Beaker. Bridgewater 1963, Area C, context 1; c. AD 150-230.

5. F15. Lower Rhineland (Cologne) Colour-Coated Ware. Lower portion of a beaker, evidently trimmed round for reuse. Bridgewater 1963, Area D, context 2; c. AD $140-250$.

6. F18. Central Gaulish Glazed Ware. Small globular beaker; green glazed over all surfaces; wheelmade. Garrod and Moss 1967, Trench AI, context 2A; c. AD 40-80/100. cf. Greene 1979, Type 13/14.

7. F19. North Gaulish Sandy White Ware. Rim from a butt beaker; burnished exterior and rim; wheelmade. Garrod Collection, surface find; $c$. AD 1-80. cf. Hawkesand Hull 1947, pl. 57, Cam 113.
8. F19. North Gaulish Sandy White Ware. Butt beaker; wheelmade. Garrod and Moss 1967, Trench AII, context 3; c. AD 1-70. cf. Hawkes and Hull 1947, pl. 57, Cam 113.

9. F19. North Gaulish Sandy White Ware. Rim and upper profile from a butt beaker; burnished exterior and rim; wheelmade. Garrod Collection, surface find; $c$. AD 1-80. cf. Hawkes and Hull 1947, pl, 57, Cam 113.

10. F20. Terra Nigra. Body sherd from a bowl. Garrod and Moss 1967, Trench BI, context 2A; c. 15/10 BC-AD 50. cf. Deru 1996, fig. 26 B6, fig. 27 B15 or fig. 32 B45.

11. F20. Terra Nigra. Rim from a platter; burnished. Garrod Collection, surface find; c. 15/10 BC-AD 60. $c f$. Hawkesand Hull 1947, pl. 49, Cam 5.

12. F23. (Probably) Severn Valley Ware, early fine ware variant. Butt beaker; very smooth exterior and rim; probably wheelmade. Garrod Collection, surface find; $c$. AD 30-80. cf. Hawkesand Hull 1947, pl. 57, Cam 113; cf. Timby 1990, fig. 4, nos 48-9.

\section{Figure 4.5. G11, Malvernian Metamorphic Ware}

1. G11. Barrel shaped jar, a so-called 'tubby cooking pot'; not decorated. Bridgewater 1963, Area A-D, context 1; ?c. AD 1-130. cf. Peacock 1968, no. 16; Lee et al. 1994, fig. 5 , no. 75 .

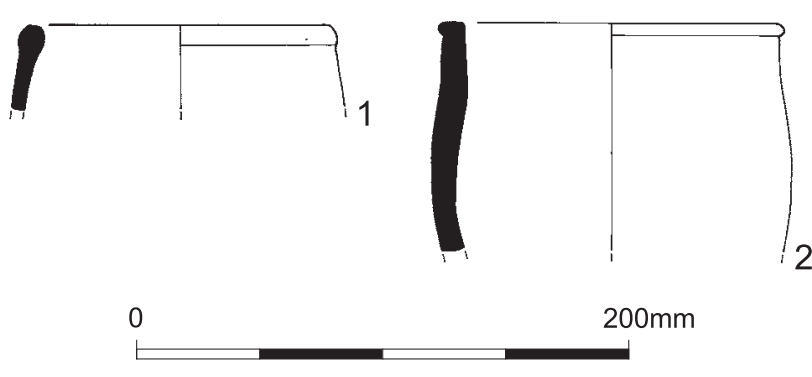

Figure 4.5. Pottery: Malvernian metamorphic ware 


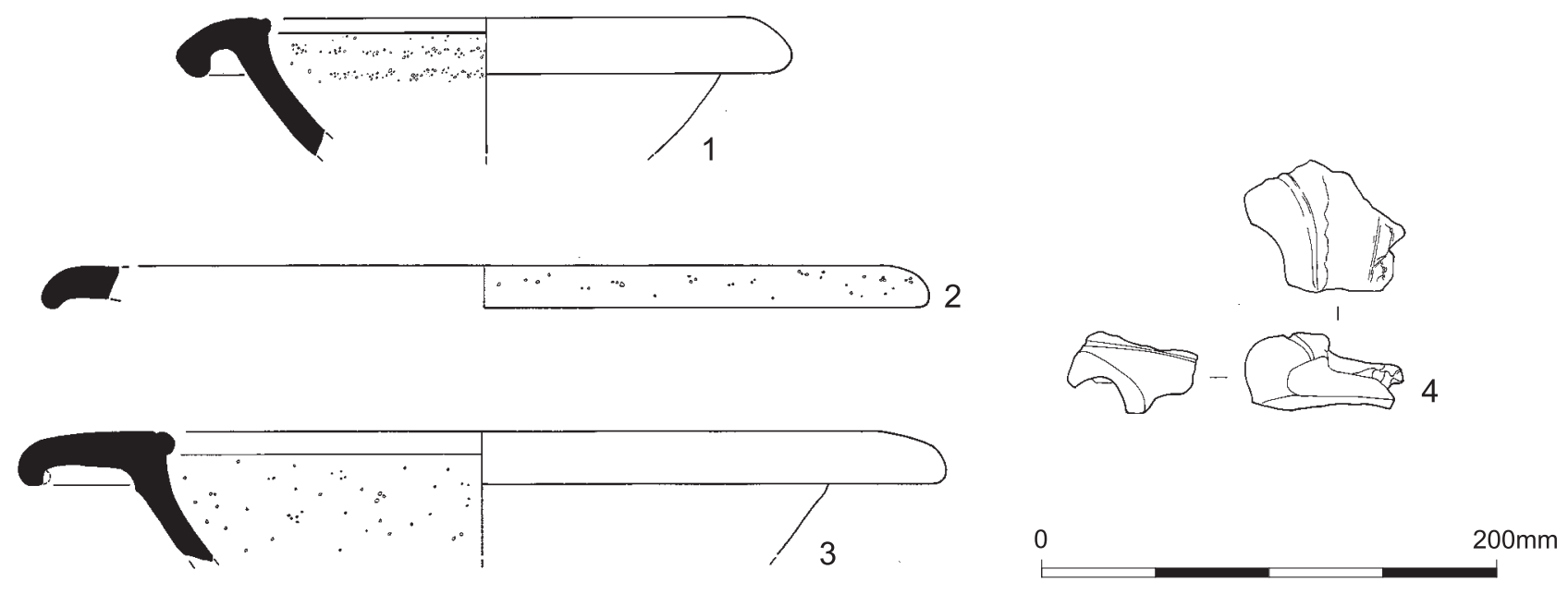

Figure 4.6. Pottery: Mortaria

2. G11. Rim and upper profile from a barrel shaped jar with upstanding rim and slight beading, a so-called 'tubby cooking pot'; not decorated; burnished all over; handmade. Garrod Collection, surface find; c. AD $120-200$.

\section{Figure 4.6. M01 and M10, Mortaria}

1. M01. North Gaulish (Noyon) Mortarium fabric. Rim from a small Gillam 238 mortarium. Unstratified, findspot not known; c. AD 55-100.

2. M01. North Gaulish (Noyon) mortarium fabric. Fragment from mortarium flange. Bridgewater 1963, Area C, HSM 21376, SO 6470 2407; c. AD 55-100. cf. Gillam 1968, no. 238.

3. M01. North Gaulish (Noyon) Mortarium fabric. Rim from a Gillam 238 mortarium. Bridgewater 1963, Area C, HSM 21376, surface find; $c$. AD 55-100.

4. M10. Verulamium Region White Ware. Fragment from the spout of a mortarium. Bridgewater 1963, Area D, context 1 ; c. AD 55-125.

\section{Figure 4.7. M23, M25 and M30, Mortaria}

1. M23. Oxfordshire Red Colour-Coated Ware Mortaria fabric. Rim with flange. HSM 21376, SO 6460 2400, surface find; c. AD 300-400. cf. Young 1977, Type C. 100.

2. M23. Oxfordshire Red Colour-Coated Ware Mortaria fabric. Rim with flange. Work in advance of the Welsh Water pipeline, 1993/4, HSM 6097; c. AD 300-400.cf. Young 1977, Type C. 100.

3. M25. Oxfordshire White Ware Mortaria fabric. Upper wall and rim with damaged flange. Garrod and Moss 1967, Trench AI, context 2; c. AD 100-170. cf. Young 1977, Type M2.1 / M2.2.

4. M25. Oxfordshire White Ware Mortaria fabric. Mortarium rim with damaged flange; sub-rounded quartz trituration grits. Bridgewater 1963, Area D, context 2; c. AD 180-240. cf. Young 1977, Type M.10.3.

5. M25. Oxfordshire White Ware Mortaria fabric. Rim with flange and spout. Work in advance of the Welsh Water pipeline, 1993/4, HSM 15983, c. AD 240-400. cf. Young 1977, Type M.22.

6. M25. Oxfordshire White Ware Mortaria fabric. Mortarium with upstanding rim and short square flange. Bridgewater 1963, Area A-D, context 1; ?c. AD 240-400. cf. Young 1977, Type M.22.

7. M30. Mancetter-Hartshill Mortarium fabric. Rim and upper body from a hammer-head type mortarium. Unstratified, findspot not known; c. AD 200-(?)320.

\section{Figure 4.8. O11, O12 and O13, Severn Valley}

Wares

1. O11. Jar, exterior yellowish brown slip and highly polished appearance. Bridgewater 1963, Area A-D, context 1; c. AD 30-200.

2. O11. Rim from narrow necked jar, apparently copying a BB1 form; exterior burnished; wheelmade. Garrod and Moss 1967, Trench AI, context 2; c. AD 120-200.

3. O11. Large bead rimmed jar. Bridgewater 1963, Area A, context 2; c. AD 100-300. cf. Webster 1976, fig. 2, no. 7.

4. O11. Butt beaker; wheelmade. Bridgewater 1963, Area C, HSM 21378, surface find; $c$. AD 30-75. Derivative of Hawkes and Hull 1947, pl. 57, Cam 113.

5. O11. Rim and upper body from a butt beaker; burnished exterior surface and rim; probably wheelmade. Garrod and Moss 1967, Trench CI, context 9; c. AD 30-70. (4). $c f$. Timby 1990, fig. 4 , no. 49.

6. O11. Pedestalled base, presumably from a beaker; exterior surface very smooth; wheelmade. Garrod and Moss 1967, Trench BIII, unstratified; c. AD 30-90. cf. Oswald 1974, fig. 11, no. 9.

7. O11. Carinated cup; wheelmade. Bridgewater 1963, Area C, HSM 21378, surface find; $c$. AD 30-120. cf. Timby 1990, fig. 4, no. 44.

8. O11. Tankard. Bridgewater 1963, Area C, context 1; c. AD 30-200.

9. O11. Tankard; wheelmade. Bridgewater 1963, Area A, context 1 ; probably $c$. AD 30-100.

10. O11. Flange rimmed bowl. Bridgewater 1963, Area C, context 2; c. AD 100-300. cf. Webster 1976, fig. 8. 

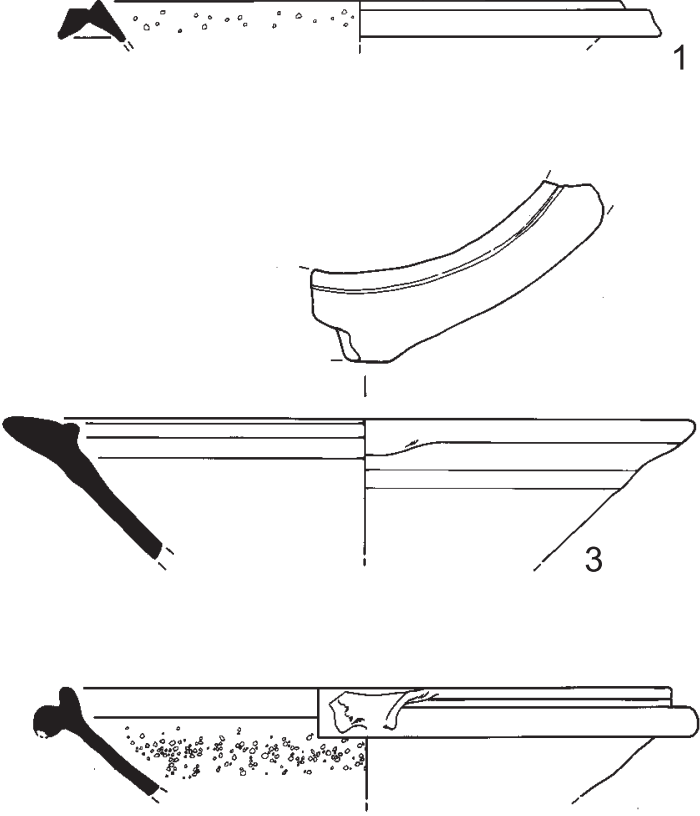

5

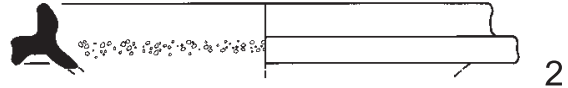

2
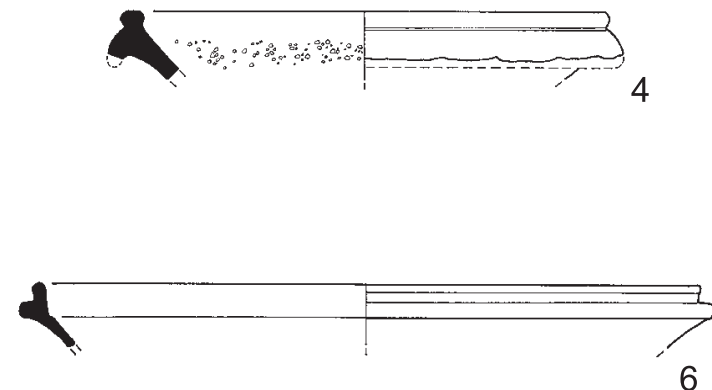

6
0

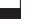

Figure 4.7. Pottery: Mortaria

11. O11. Rim and upper body from a necked bowl; very smooth exterior surface; wheelmade. Garrod and Moss 1967, Trench BI, context 2A; c. AD 30-100.

12. O11. Rim and upper wall from a carinated bowl; wheelmade. Garrod and Moss 1967, Trench AI, context 2; c. AD 30-100. cf. Timby 1990, fig. 4, no. 43.

13. O12. Globular jar with bead rim, originally slipped. Garrod and Moss 1967, Trench AI, context 3; c. AD 30-200.

14. O12. Jar rim; wheelmade. Bridgewater 1963, Area A, context 1; c. AD 30-400.

15. O12. Wide mouthed jar; some burnishing on interior of rim; wheelmade. Bridgewater 1963, Area A, context 1; $c$. AD 100-300.

16. O12. Storage jar, exterior yellowish brown slip. Bridgewater 1963, Area A-D, context 1; c. AD 100-400.

17. O12. Wide mouthed jar or bowl. Bridgewater 1963, Area A-D, context 1; c. AD 30-100, possibly c. AD 30/200.

18. O12. Butt beaker; wheelmade. Bridgewater 1963, Area C, HSM 21378, surface find; c. AD 30-75.

19. O12. Butt beaker; burnished exterior; faint traces of thin white slip on both interior and exterior; wheelmade. Garrod and Moss 1967, Trench AI, context 2A; c. AD 30-75. cf. Hawkes and Hull 1947, pl. 57, Cam 113.

20. O12. Beaker with zone of combing. Bridgewater 1963, Area $\mathrm{D}$, context $3 \mathrm{~A}$ or 4 ; probably $c$. AD 100-200, though might be earlier.

21. O12. Tankard. Bridgewater 1963, Area C, context 1; probably c. AD 100-300.
22. O12. Platter; wheelmade. Bridgewater 1963, Area C, HSM 21378, surface find; c. AD 30-100. cf. Webster 1976, fig. 10, no. 69; Hawkes and Hull 1947, pl. 50, Cam 24.

23. O13. Narrow mouthed jar; some burnishing extant on interior and exterior of rim. Bridgewater 1963, Area A, context 2; c. AD 30-400.

24. O13. Tankard with bead rim. Bridgewater 1963, Area A, context 2; c. AD 30-400.

\section{Figure 4.9. O14, Severn Valley Ware}

1. O14. Flagon. Bridgewater 1963, Area C, context 1; c. AD 100-400.

2. O14. Flagon handle. Garrod and Moss 1967, Trench AI, context 2A; c. AD 50-250.

3. O14. Rim and upper body from a small jar; wheelmade. Garrod and Moss 1967, Trench BI, context 2A; c. AD 30-120. cf. Timby 1990, fig. 4, no. 57.

4. O14. Rim and upper body from a small jar, perhaps copying a BB1 form; wheelmade. Garrod and Moss 1967, Trench BI, context 2A; c. AD 120-200.

5. O14. Storage jar. Bridgewater 1963, Area A-D, context 1; ?c. AD 100-400.

6. O14. Rim and corrugated shoulder from a bowl or jar; wheelmade. Garrod and Moss 1967, Trench BI, context 2A; c. AD 30-100. cf. Hawkes and Hull 1947, pl. 81, Cam 252. 

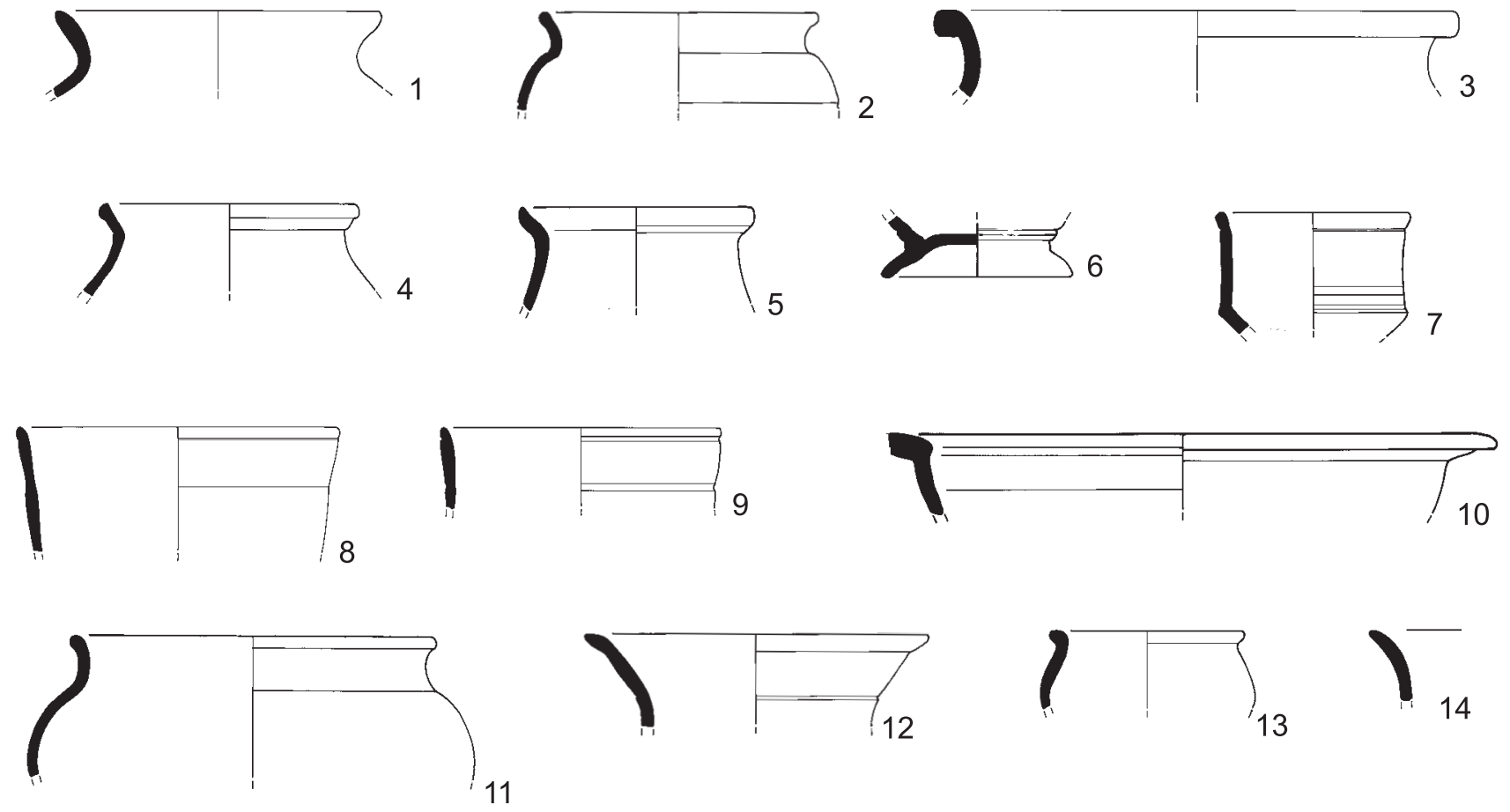
11
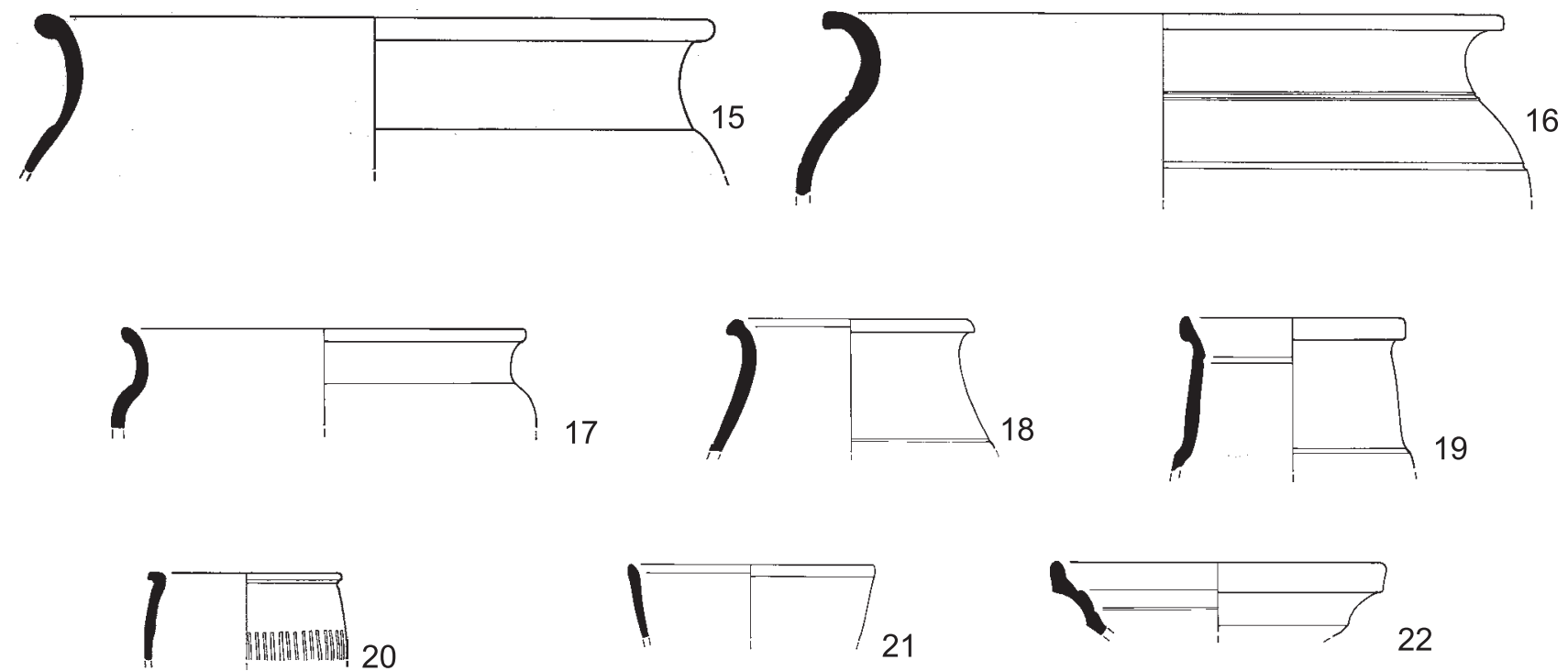

22

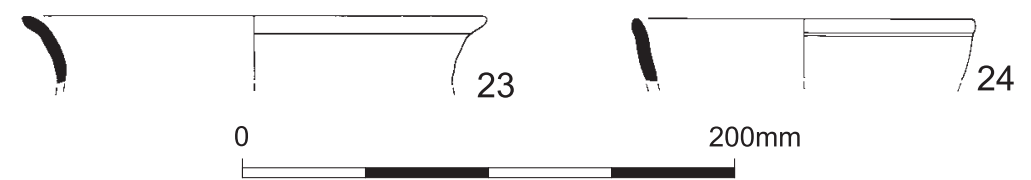

Figure 4.8. Pottery: Severn Valley ware

7. O14. Jar rim. Bridgewater 1963, Area C, context 1; c. AD 100-400.

8. O14. Rim and upper profile from a beaker, which is cordoned with a plain upstanding rim; very smooth exterior and rim; wheelmade. Garrod Collection, surface find; $c$. AD 30-80. cf. Hawkes and Hull 1947, pl. 54, Cam 78.

9. O14. Small beaker with corrugated shoulder; wheelmade.
Bridgewater 1963, Area C, HSM 21378, surface find; perhaps $c$. AD 50-160.

10. O14. Rim and upper wall from a carinated bowl; wheelmade. Garrod and Moss 1967, Trench AI, context 2; c. AD 30-75. The form is reminiscent of the pedestal beakers and bowls illustrated by Hawkes and Hull 1947, pl. 54.

11. O14. Butt beaker, cordon at neck; wheelmade. Garrod and 

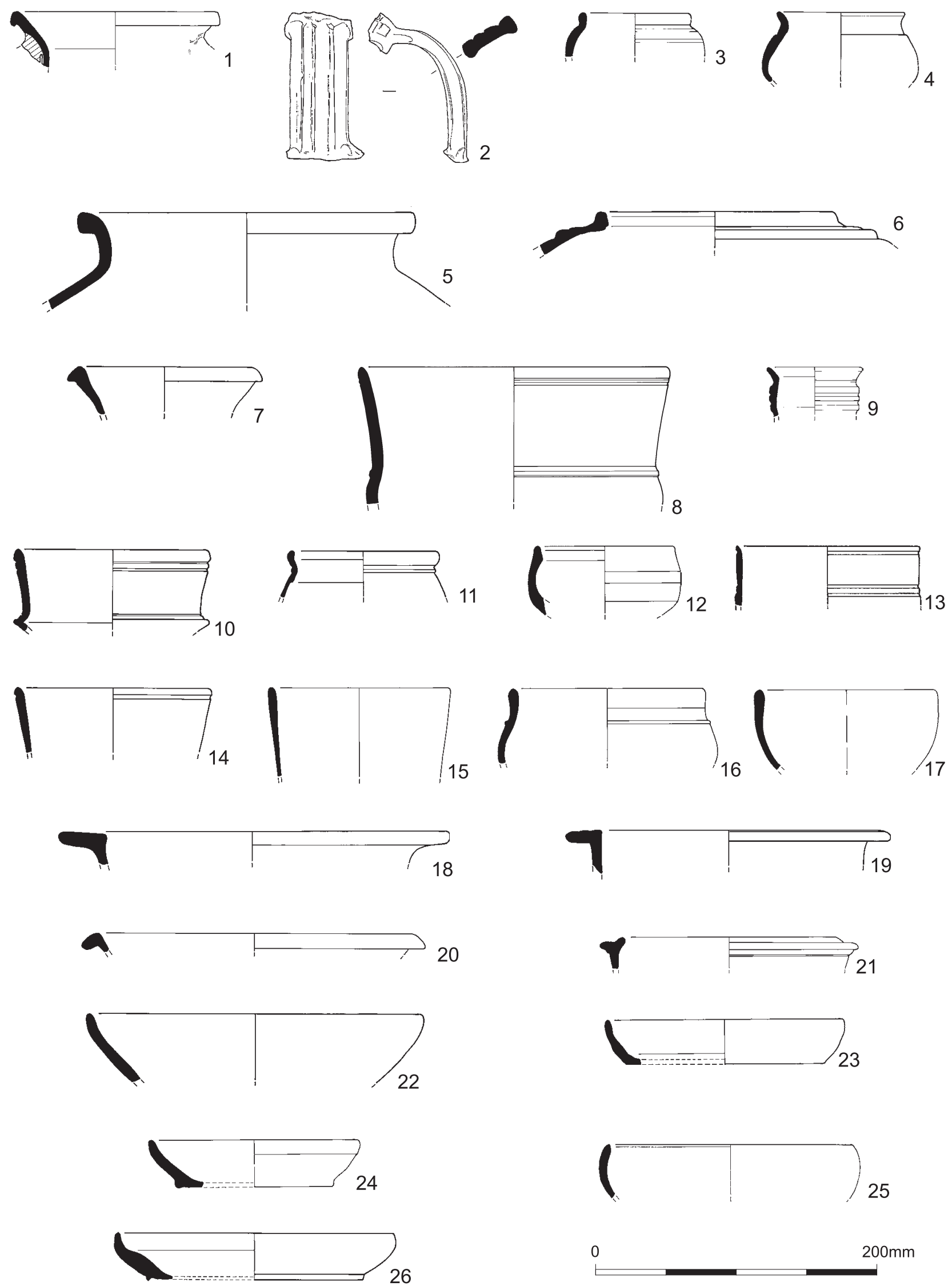

Figure 4.9. Pottery: Severn Valley ware 

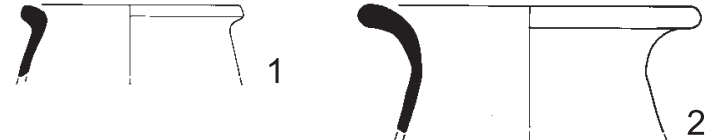

2

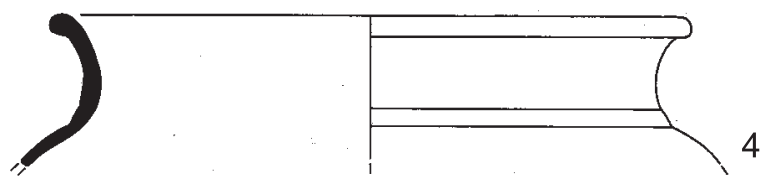

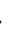

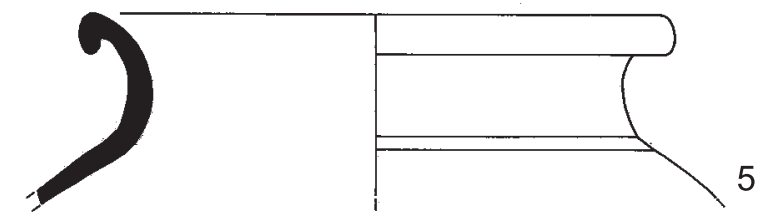

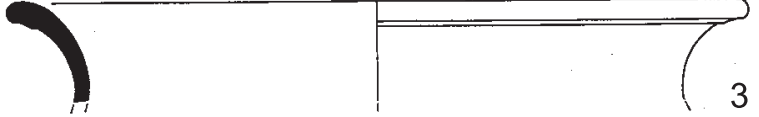

3

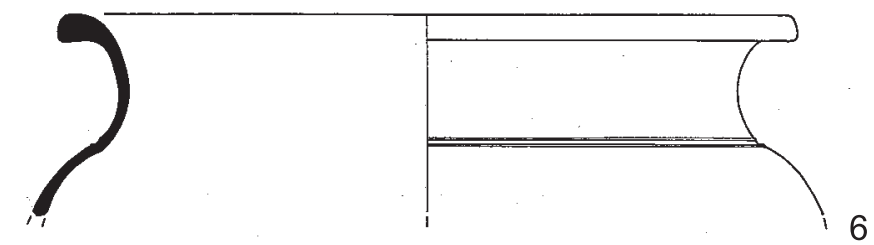

6
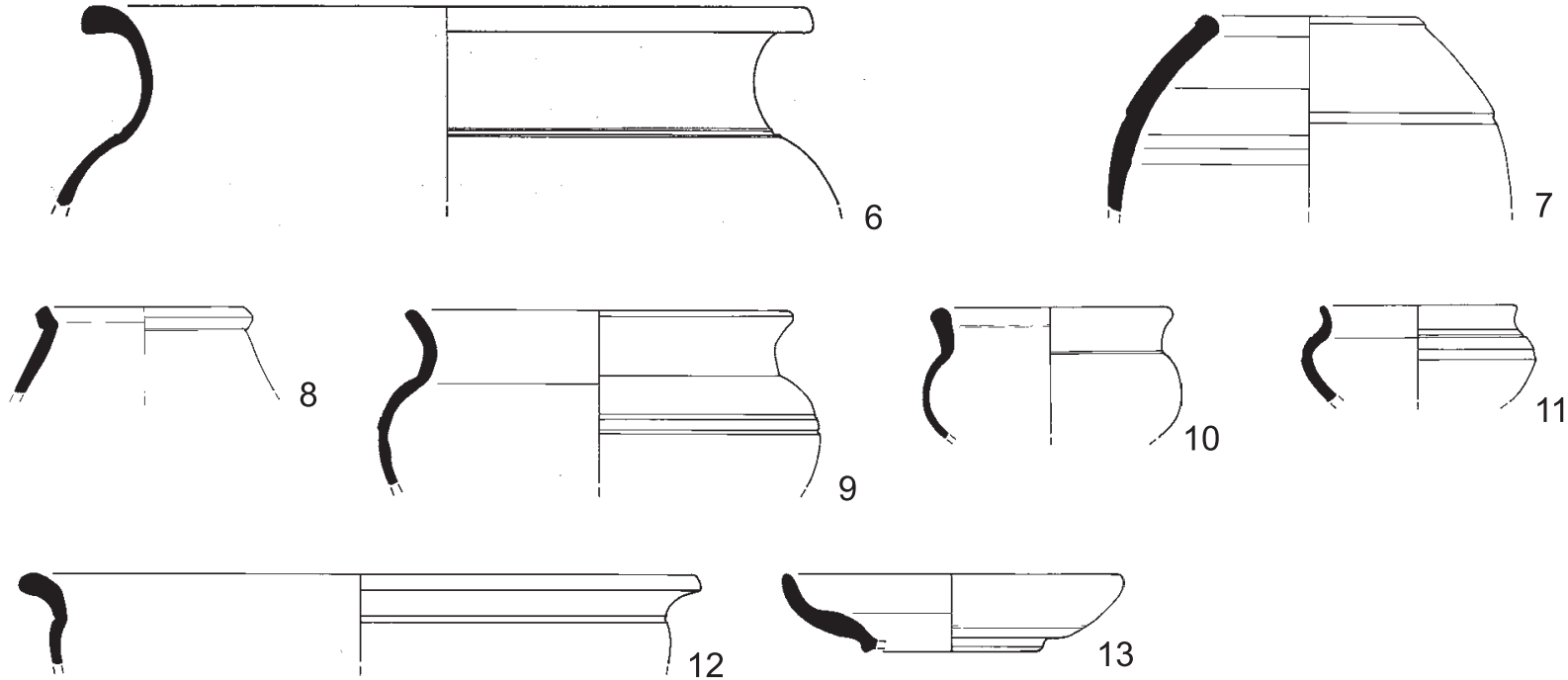

0

$200 \mathrm{~mm}$

Figure 4.10. Pottery: Severn Valley ware

Moss 1967, Trench AI, context 2A; c. AD 30-75. cf. Timby 1990, fig. 4, nos 48 and 49.

12. O14. Part profile of a cup; wheelmade. DAG fieldwalking. HSM 21376, SO 6470 2390; probably c. AD 30-100.

13. O14. Tankard. Bridgewater 1963, Area A-D, context $1 ; c$. AD 30-200.

14. O14. Tankard. Bridgewater 1963, Area C, context 1; c. AD 100-300.

15. O14. Tankard. Bridgewater 1963, Area C, context $1 ; c$. AD 100-300.

16. O14. Rim and upper body from a bowl with cordon and upstanding rim; burnished exterior; wheelmade. DAG fieldwalking. HSM 21376, SO 6470 2390; c. AD 30-100.

17. O14. Curving sided bowl; wheelmade. Garrod and Moss 1967, Trench AI, context 2A; c. AD 30-400. cf. Timby 1990, fig. 4 , no. 54.

18. O14. Rim from a large flange rimmed bowl; wheelmade. Garrod and Moss 1967, Trench AII, context 2; c. AD 30-300. cf. Webster 1976, fig. 8, nos 45-47.

19. O14. Bowl with reeded flange at rim; wheelmade. Bridgewater 1963, Area C, HSM 21378, surface find; c. AD 70-135. cf. Webster 1976, fig. 9, no. 54 .

20. O14. Bowl or dish, perhaps copying a BB1 form. Bridgewater
1963, Area A-D, context 1; ?c. AD 120-200.

21. O14. Flanged bowl. Bridgewater 1963, Area C, context 1; c. AD 200-300. cf. Webster 1976, fig. 9, no. 57.

22. O14. Dish with curving wall; burnt. Bridgewater 1963, Area C, context 1; c. AD 30-100. cf. Webster 1976, fig. 10, no. 73 .

23. O14. Dish with curving wall and grooved base. Garrod and Moss 1967, Trench AI, context 2; c. AD 40-100. cf. Hawkes and Hull 1947, pl. 49, Cam 16.

24. O14. Dish, variably oxidized; wheelmade. Garrod and Moss 1967, Trench AI, context 2A; c. AD 40-80. cf. Webster 1976, fig. 10, nos 71 and 73 .

25. O14. Dish. Bridgewater 1963, Area A-D, context 1; probably c. AD 40-100. cf. Hawkes and Hull 1947, pl. 49, Cam 16.

26. O14. Dish with curving wall and footring. Garrod and Moss 1967, Trench AI, context 2; c. AD 30-100. Derived from Gallo-Belgic forms $c f$. Hawkes and Hull 1947, pls 49 and 50.

Figure 4.10. O15, Severn Valley Ware

1. O15. Small barrel jar. Bridgewater 1963, Area C, context 1; ?c. $\mathrm{AD} 30-400$. 

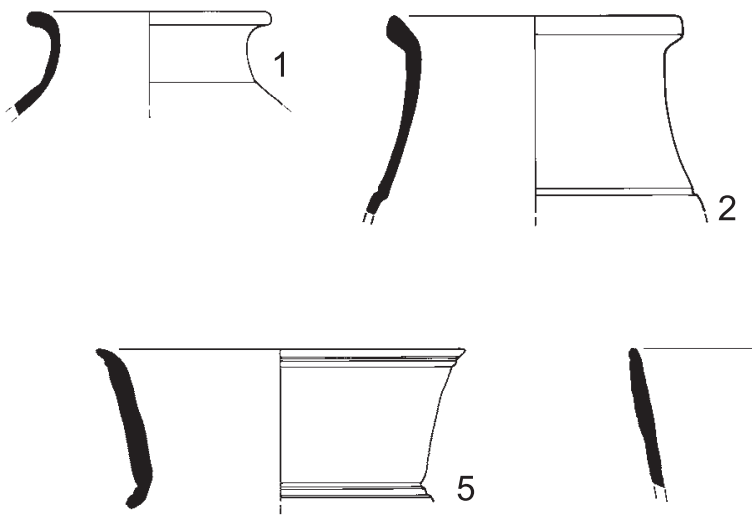

5
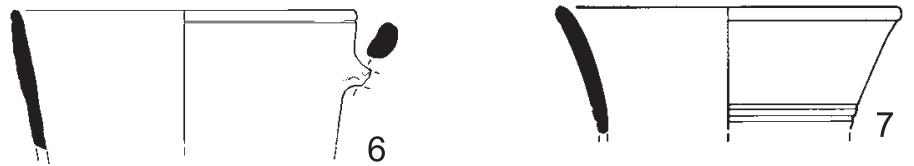
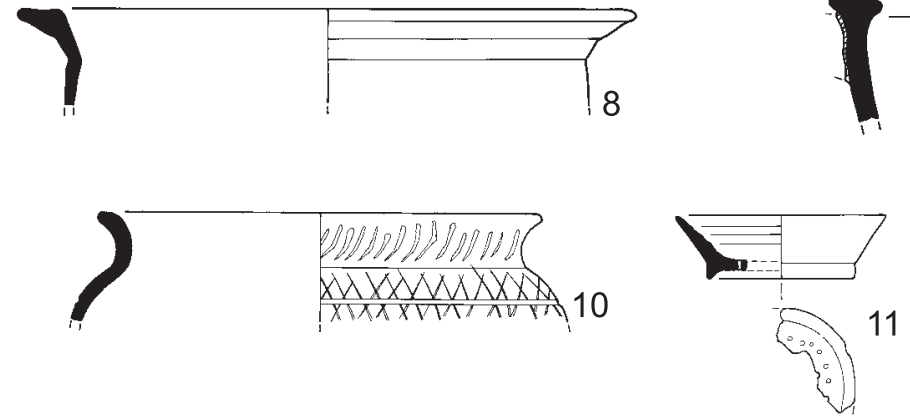

11
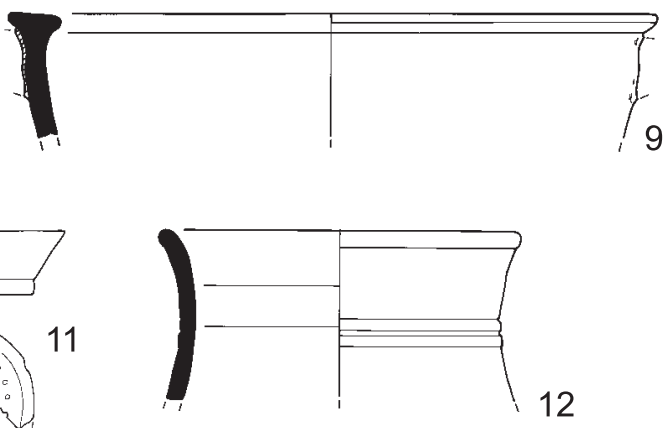

12
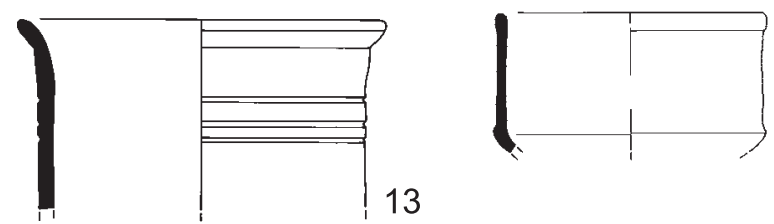

14

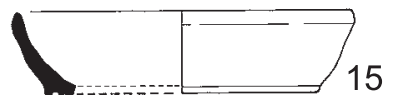

0

$200 \mathrm{~mm}$

Figure 4.11. Pottery: Severn Valley ware

2. O15. Large jar. Bridgewater 1963, Area B, context 4; probably c. AD 100-300. cf. Webster 1976, fig. 2, no. 7.

3. O15. Storage jar. Bridgewater 1963, Area C, context 1; $c$. AD 100-300.

4. O15. Storage jar. Bridgewater 1963, Area C, context 1; $c$. AD 100-300.

5. O15. Storage jar; yellowish brown slip all-over. Bridgewater 1963, Area D, context 2; perhaps $c$. AD 200-300.

6. O15. Storage jar; yellowish brown slip all-over; burnished on shoulder. Bridgewater 1963, Area D, context 2; $c$. AD 30-400.

7. O15. Rim and upper profile from a beaker; very smooth exterior and rim; a wide band around the girth has faint vertical decorative markings; wheelmade. Garrod Collection, surface find; $c$. AD 30-80. cf. Hawkes and Hull 1947, pl. 58, Cam 117.

8. O15. Butt beaker; burnished exterior; faint traces of thin white slip on exterior; wheelmade. Garrod and Moss 1967, Trench AI, context 2A; c. AD 30-75. cf. Timby 1990, fig. 4, no. 48 .

9. O15. Rim and upper body from a necked bowl/wide mouthed jar; smooth exterior surface; wheelmade. Garrod and Moss 1967, Trench AI, context 2A; c. AD 70-200.

10. O15. Small necked bowl with bead rim; wheelmade.
Garrod and Moss 1967, Trench AII, context 5; c. AD 30-200.

11. O15. Miniature necked bowl with corrugated shoulder; burnished exterior and rim; wheelmade. Garrod Collection, surface find; c. AD 30-80. cf. Timby 1990, fig. 4, no. 53.

12. O15. Necked bowl. Bridgewater 1963, Area D, context 1; ? c. AD 30-200.

13. O15. Dish with curving wall and grooved base. Garrod and Moss 1967, Trench AII, context 6; c. AD 40-100. cf. Hawkes and Hull 1947, pl. 49, Cam 16.

\section{Figure 4.11. O16, Severn Valley Ware}

1. O16. Narrow mouthed jar. Bridgewater 1963, Area C, context 1; possibly c. AD 30-250.

2. O16. Butt beaker, very smooth exterior; wheelmade. Garrod and Moss 1967, Trench AI, context 3; c. AD 30-75. (3).

3. O16. Rim and upper profile from a butt beaker; burnished neck, below which is a band of faint rouletting; wheelmade. Garrod Collection, surface find; $c$. AD 30-80. cf. Hawkes and Hull 1947, pl. 57, Cam 113; cf. Timby 1990 fig. 4, no. 48. 

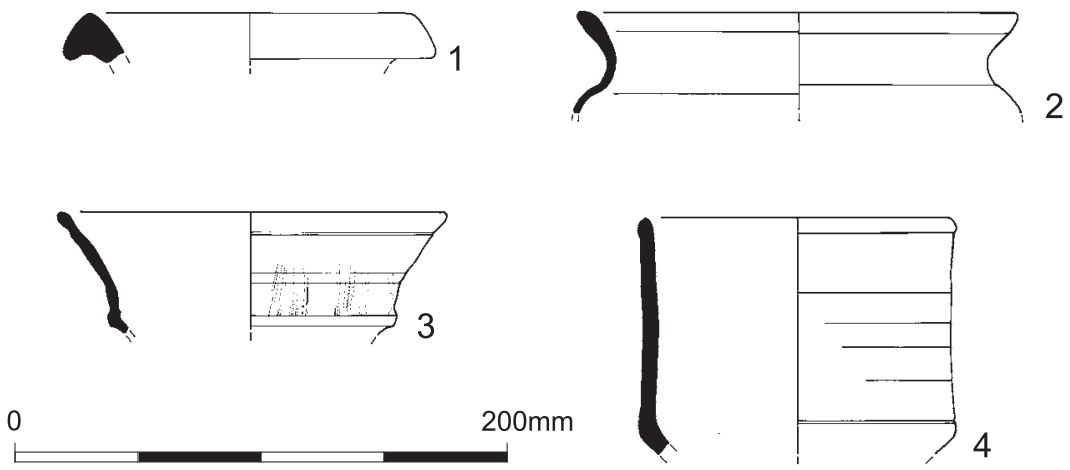

Figure 4.12. Pottery: Severn Valley ware

4. O16. Butt beaker; wheelmade. Garrod and Moss 1967, Trench AII, context 3; c. AD 30-70. cf. Hawkes and Hull 1947, pl. 57, Cam 113.

5. O16. Beaker; wheelmade. Bridgewater 1963, Area C, HSM 21378, surface find; c. AD 30-150. cf. Timby 1990, fig. 4 , no. 47.

6. O16. Tankard. Bridgewater 1963, Area A-D, context 1; $c$. AD 100-300. (2).

7. O16. Rim and upper body from a tankard with bead rim and horizontal grooves; wheelmade. Garrod and Moss 1967, Trench BI, context 2A; c. AD 30-300.

8. O16. Rim, from bowl or wide-mouthed jar; wheelmade. Bridgewater C, 1963, probably HSM 10676, surface find; probably c. AD 200-400.

9. O16. Rim and upper body from a flanged bowl with internal lip; there is a handle scar on the exterior; wheelmade. DAG fieldwalking. HSM 21376, SO 6470 2390; c. AD 30-200. cf. Webster 1976, fig. 8, no. 45.

10. O16. Necked bowl; x-hatch design on shoulder, which is grooved, and diagonal lines on neck; wheelmade; the fabric is unusually hard with a grey core. Garrod and Moss 1967, Trench AI, context 2; perhaps $c$. AD 70-230.

11. O16. Colander/strainer bowl base; wheelmade. Bridgewater 1963, Area C, HSM 21378, surface find; c. AD 100-300.

12. O16. Rim and upper body from a carinated bowl, with bead rim and constricted girth; probably finished on a turning board or slow wheel. Garrod and Moss 1967, Trench BI, context 1; c. AD 30-100. cf. Timby 1990, fig. 4, no. 43.

13. O16. Carinated bowl; burnished exterior and rim, with grooves on upper wall; wheelmade. Garrod Collection, surface find; c. AD 30-75.

14. O16. Small bowl (or cup), with straight, vertical wall, bead rim and carination; wheelmade. Garrod and Moss 1967, AI context 2A; c. AD 30-200. cf. Timby 1990, fig. 4, no. 44.

15. O16. Dish with curving wall and grooved base; the wall is burnt. Garrod and Moss 1967, AI context 2; c. AD 30-100. cf. Hawkes and Hull 1947, pl. 49, Cam 16.

Figure 4.12. O17, Severn Valley Ware

1. O17. Narrow mouthed jar. Bridgewater 1963, Area C, context $1 ;$ ? c. AD 100-300.
2. O17. Jar. Bridgewater 1963, Area C, context 1; ?c. AD 30-400.

3. O17. Rim and body from a carinated bowl with bead rim, and cordon with irregular faint vertical comb marks above cordon; wheelmade. Garrod and Moss 1967, Trench BIII, context 5; c. AD 30-75.

4. O17. Bowl, with straight, vertical wall, bead rim and carination; wheelmade. Garrod and Moss 1967, Trench AI, context 3; c. AD 30-200.

\section{Figure 4.13. O18, Severn Valley Ware}

1. O18. Storage jar. Bridgewater 1963, Area D, context 2A; $c$. AD 100-300.

2. O18. Storage jar; wheelmade. Bridgewater 1963, Area C, HSM 21378, surface find; probably c. AD 100-300.

3. O18. Storage jar. Bridgewater 1963, Area A-D, context 1; c. AD 30-400.

4. O18. Storage jar; wheelmade. Bridgewater 1963, Area C, HSM 21378, surface find; probably $c$. AD 100-300.

5. O18. Storage jar; wheelmade. Garrod and Moss 1967, Trench AI, context 2A; c. AD 30-200. (2).

6. O18. Flange rimmed bowl with handle. Bridgewater 1963, Area C, context 1; ? c. AD 30-200. cf. Webster 1976, fig. 8 .

7. O18. Large bowl; wheelmade. Bridgewater 1963, Area C, HSM 21378, surface find; probably c. AD 30-100. (2).

8. O18. Dish. Bridgewater 1963, Area C, context 1; c. AD 30-120. Similar to Webster 1976, fig. 10, no. 73.

\section{Figure 4.14. O19, O20 and O21, Severn Valley}

Wares

1. O19. Small jar, apparently imitating BB1 form; some extant burnishing on interior and exterior surfaces. Bridgewater 1963, Area D, context 2A; c. AD 120-200.

2. O19. Bowl. Bridgewater 1963, Area A-D, context 1; c. AD 300-400, possibly earlier.

3. O20. Large ring-necked flagon, with cream slip on interior and exterior surfaces now only partially coating the form; wheelmade. Bridgewater 1963, Area C, HSM 21378, surface find; $c$. AD 55-100/110.

4. O21. Jar rim; wheelmade. Bridgewater 1963, Area C, HSM 10676, 'TH1'; c. AD 30-100. 

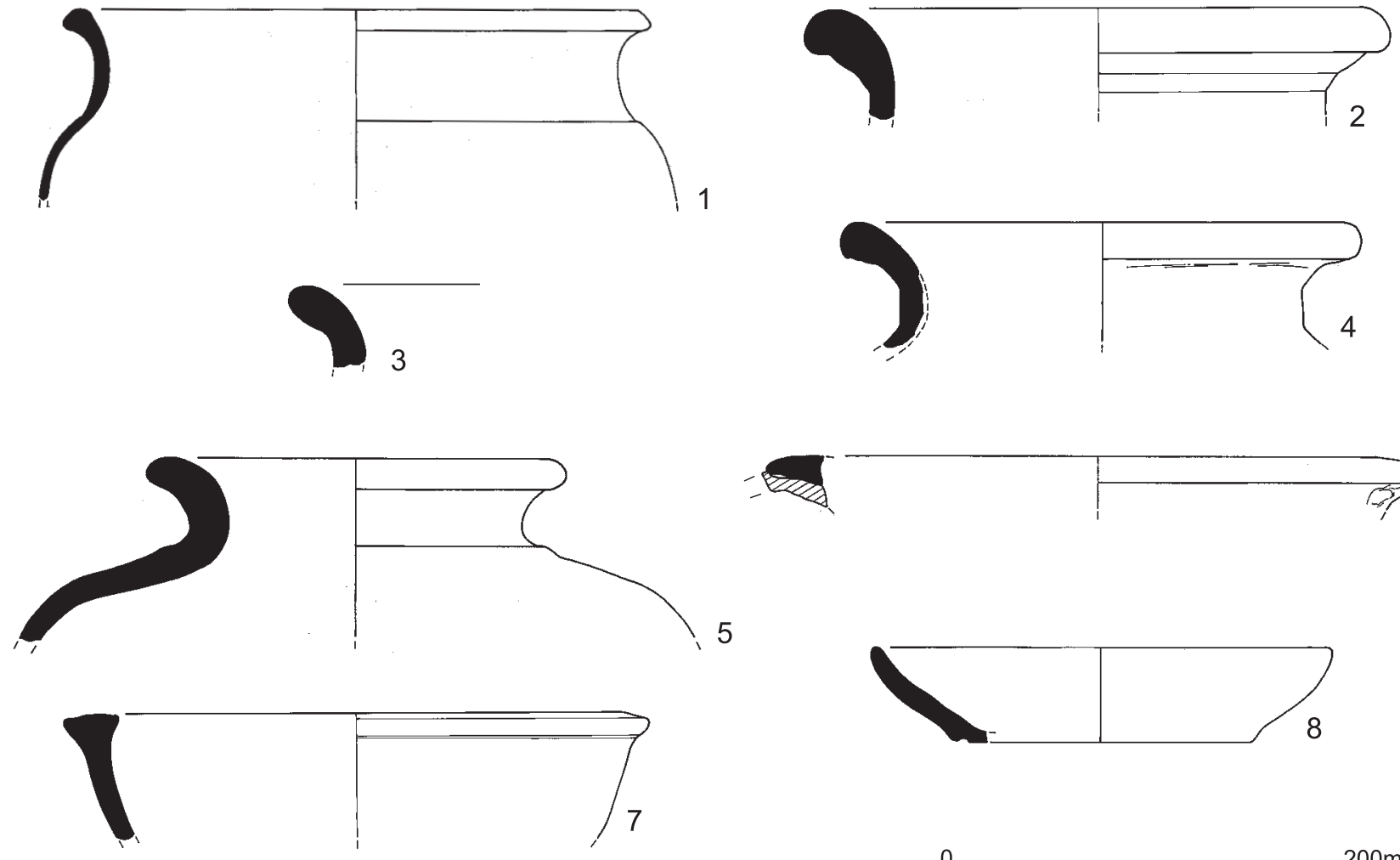

1

5

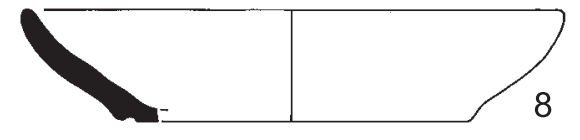

0 $200 \mathrm{~mm}$
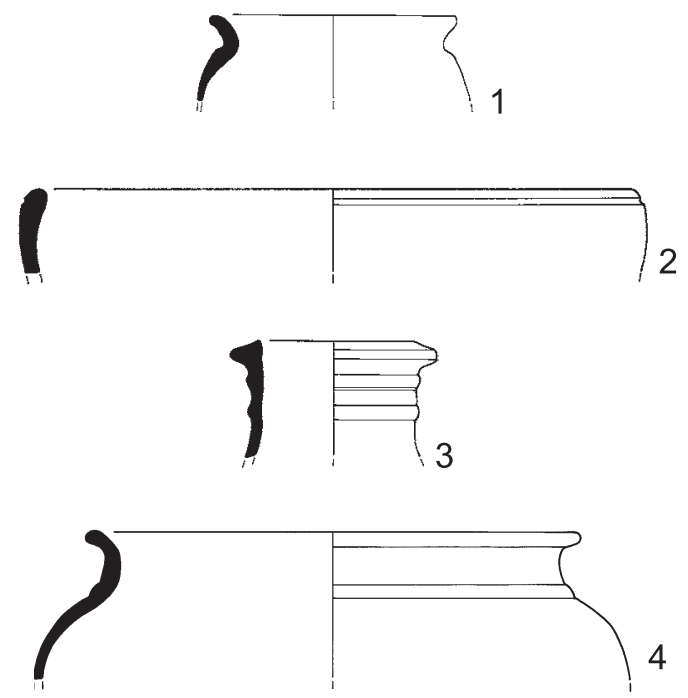

0

$200 \mathrm{~mm}$

Figure 4.14. Pottery: Severn Valley ware
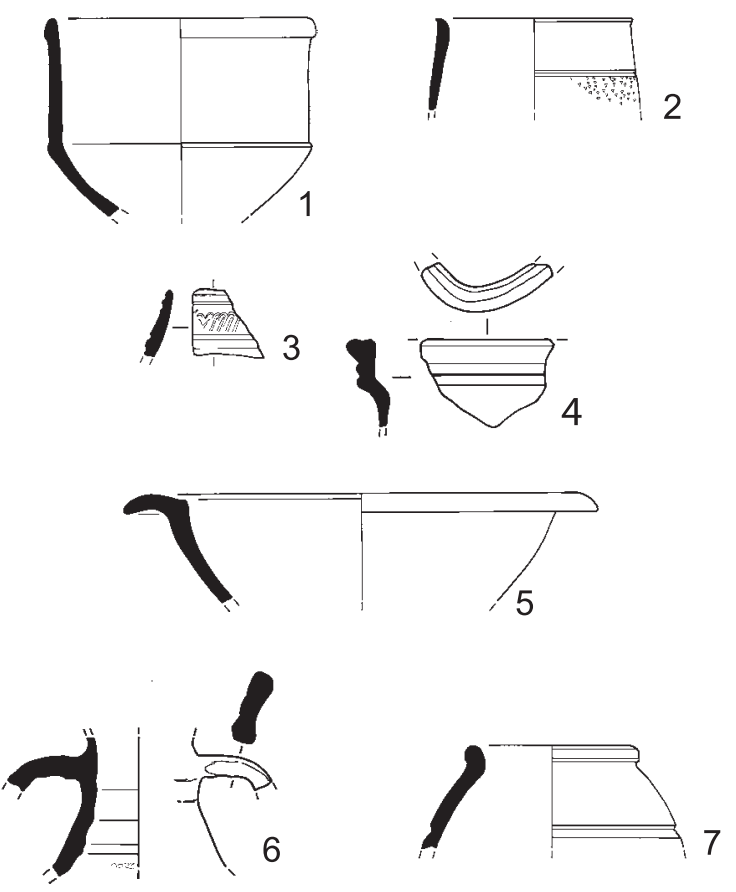

0 $200 \mathrm{~mm}$

Figure 4.15. Pottery: Severn Valley ware, Oxfordshire wares and other oxidised wares 

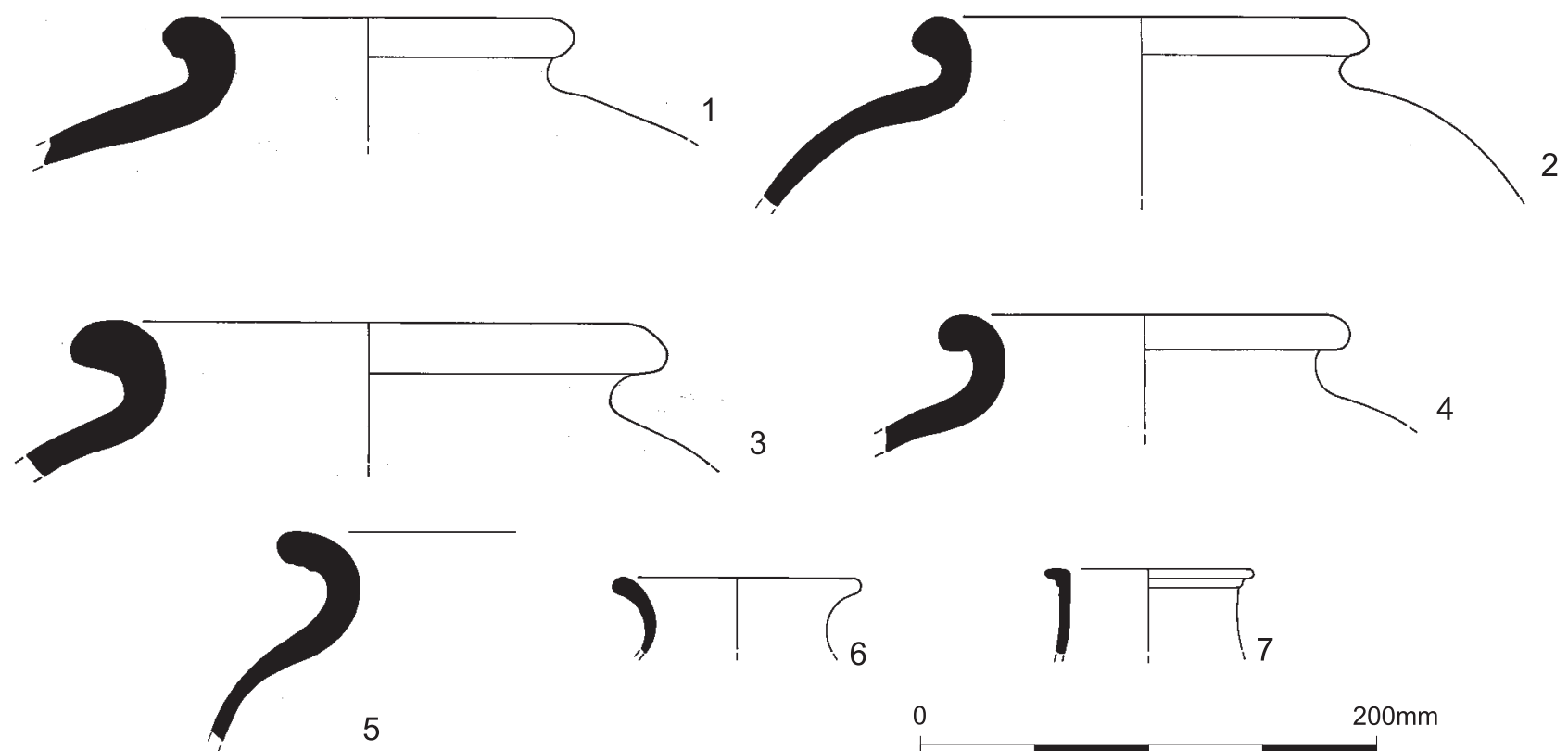

3
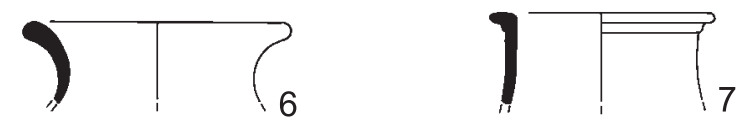

0

$200 \mathrm{~mm}$

Figure 4.16. Pottery: Unoxidised Severn Valley ware

Figure 4.15. O23 and O24, Severn Valley Wares; 030 and 036, Oxfordshire Wares; 037 and O38, other Oxidised Wares

1. O23 Severn Valley Ware. Bowl, with straight, vertical wall, bead rim and carination; wheelmade. Garrod and Moss 1967, Trench AI, context 2A; c. AD 30-200. cf. Timby 1990, fig. 4, no. 44.

2. O23 Severn Valley Ware. Rim and upper wall from a beaker with exterior lip and a band of rouletted decoration; wheelmade. DAG fieldwalking. HSM 21376, SO 6467 2377; probably c. AD 100-200.

3. O24 Severn Valley Ware. Beaker fragment, from just below rim. Bridgewater 1963, Area C, context 1; c. AD 140-400.

4. O30 Oxfordshire White Ware. Trefoil-lipped flagon with expanded bead rim; wheelmade. Garrod Collection, surface find; $c$. AD 240-400.

5. O36 Oxfordshire Ware. Flange rimmed bowl with curving wall; cream exterior and pale red interior. Garrod and Moss 1967, Trench AI, context 2A; c. AD 70-150. (2). cf. Young 1977, Type O.39.

6. O37 Red fabric with cream slip, possibly Severn Valley Ware or Oxfordshire White Colour-Coated Ware. Neck and part of the handle of a flagon (minus the rim); this may well be a ring-necked flagon; vestiges of cream slip are present on interior and exterior surfaces. DAG fieldwalking. HSM 21376, SO 6460 2400; c. AD 50-250.

7. O38 (Probably) Severn Valley Ware. Small beaker with bead rim; exterior surface burnished; wheelmade. Garrod Collection, surface find; $c$. AD 30-120).

Figure 4.16. R20, 'Unoxidized Severn Valley Ware'

1. R20. Storage jar; very smooth exterior; wheelmade. Garrod and Moss 1967, Trench AI, context 3; c. AD 30-200.
2. R20. Storage jar; very smooth exterior; wheelmade. Garrod and Moss 1967, Trench AI, context 2A; c. AD 30-400. cf. Lee 1994, fig. 4 R.61.

3. R20. Storage jar with everted rim; very smooth exterior surface; wheelmade. Garrod and Moss 1967, Trench AII, context 5; c. AD 30-400. cf. Lee 1994, fig. 4 R.61.

4. R20. Storage jar; very smooth exterior surface; wheelmade. Garrod and Moss 1967, Trench AII, context 2; c. AD 30-400. cf. Lee 1994, fig. 4 R.61.

5. R20. Storage jar. Bridgewater 1963, Area D, context 2; c. AD 30-200.

6. R20. Narrow mouthed jar. Bridgewater 1963, Area C, context 2; c. AD 30-200.

7. R20. Flagon rim; wheelmade. DAG fieldwalking. HSM 21376, SO 6465 2379; perhaps c. AD 100-200.

Figure 4.17. R21, 'Unoxidized Severn Valley Ware'; R26, Unoxidized Ware

1. R21. Jar with everted rim. Garrod and Moss 1967, Trench AI, context 2; c. AD 50-120.

2. R21. Necked jar with everted rim; wheelmade; possibly a waster. Garrod and Moss 1967, Trench AII, context 5; c. AD 30-400.

3. R21. Narrow necked jar with groove at junction of neck and shoulder; wheelmade. Garrod and Moss 1967, Trench AII, context 6; c. AD 100-400.

4. R21. Jar, copying BB1 form. Bridgewater 1963, Area B, context 2; c. AD 100-200.

5. R21. Rim and shoulder from a fine necked bowl; very smooth exterior surface and rim; wheelmade. Garrod and Moss 1967, BIII, context 2; c. AD 1-100. cf. Timby 1990 fig. 4 , no. 53 .

6. R21. Jar, copying BB1 form. Bridgewater 1963, Area A, context 1; probably c. AD 120-200.

7. R21. Rim and shoulder from a jar evidently copying a BB1 

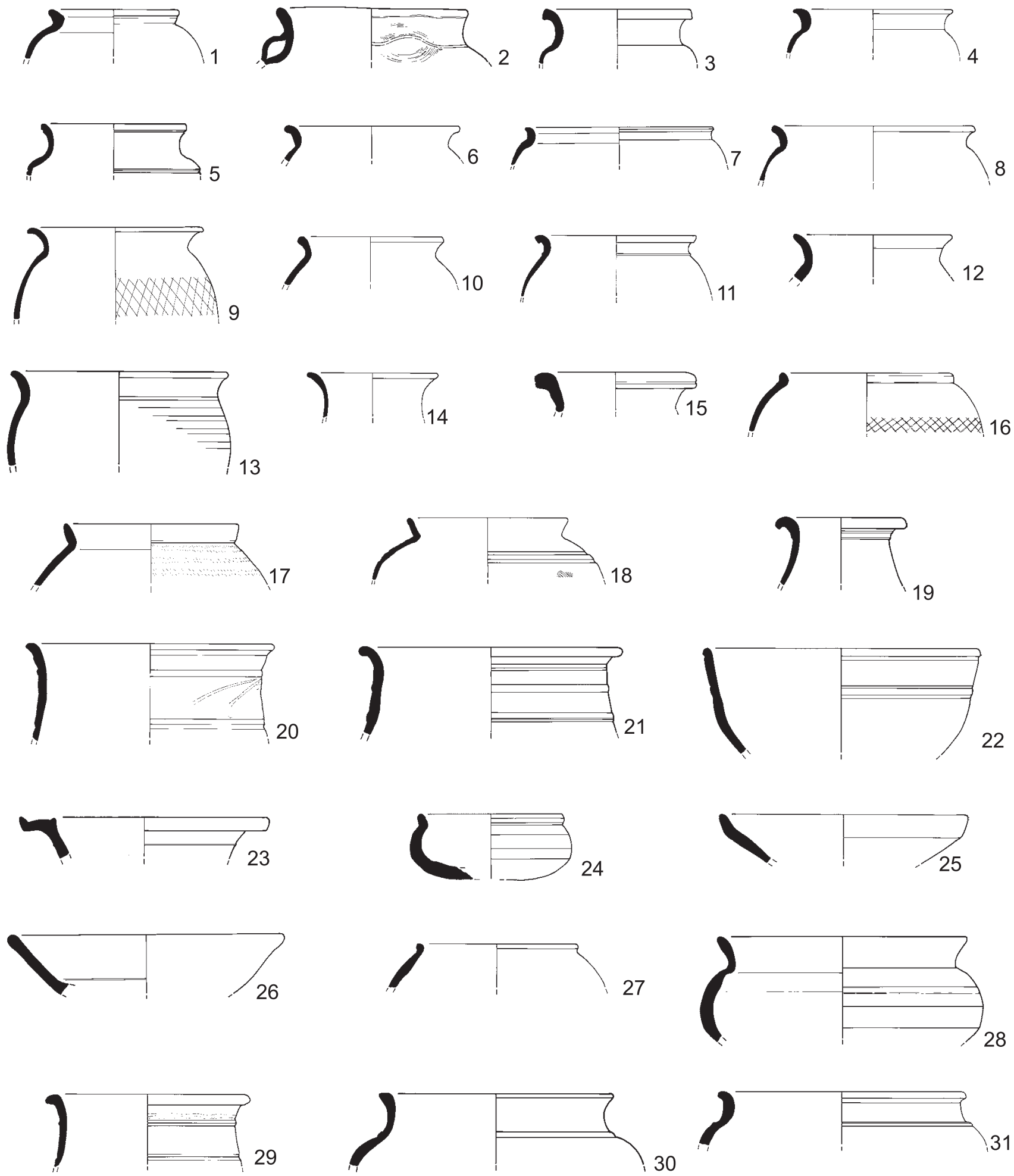

0 $200 \mathrm{~mm}$

Figure 4.17. Pottery: Unoxidised Severn Valley ware and Unoxidised ware

form (i.e. Gillam 1976, fig. 1, no. 2); wheelmade. DAG fieldwalking. HSM 21376, SO 6470 2390; c. AD 120-250.

8. R21. Jar, copying BB1 form. Bridgewater 1963, Area A, context 1; probably c. AD 120-200.

9. R21. Jar, copying BB1 form; burnished exterior below rim. Bridgewater 1963, Area C, context 2; c. AD 120-200. 
10. R21. Jar. Bridgewater 1963, Area C, context H; possibly $c$. AD 100-200.

11. R21. Narrow mouthed jar. Bridgewater 1963, Area C, context 2; c. AD 30-200/250.

12. R21. Small jar, copying BB1 form; possible soot or carbonized residue on exterior of shoulder. Bridgewater 1963, Area D, context 2; c. AD 120-200.

13. R21. Jar, slipped and burnished exterior. Bridgewater 1963, Area C, context 11 F2; c. AD 30-200.

14. R21. Narrow mouthed jar. Bridgewater 1963, Area A, context 2; ? c. AD 30-400.

15. R21. Narrow mouthed jar. Bridgewater 1963, Area A, context $1 ;$ ? c. AD 30-250.

16. R21. Jar rim and shoulder with lattice decoration and burnishing on the shoulder; wheelmade. Bridgewater 1963, Area C, HSM 10676, 'TH1'; c. AD 120-200. cf. Webster 1976, fig. 4, no. 15.

17. R21. Globular beaker with everted rim and rouletted decoration below neck; wheelmade. Garrod and Moss 1967, Trench AI, context 2; c. AD 40-120. (2).

18. R21. Globular beaker; the surfaces are not burnished and indeed have a slightly rough feel; line of wavy combing occurs below the shoulder; wheelmade. Garrod and Moss 1967, Trench AI, context 2A; c. AD 40-100. (4).

19. R21. Butt beaker; wheelmade. Garrod and Moss 1967, Trench AII, context 6; c. AD 30-80.

20. R21. Bowl rim; wheelmade. Bridgewater 1963, Area C, HSM 21378, surface find; c. AD 1-80. cf. Timby 1990, fig. 4, no. 46.

21. R21. Bowl rim; wheelmade. Bridgewater 1963, Area C, HSM 21378, surface find; c. AD 1-80. cf. Timby 1990, fig. 4, no. 46.

22. R21. Hemispherical bowl with bead rim and cordon, a close copy of the samian bowl form Drag. 37; wheelmade. Garrod and Moss 1967, Trench AI, context 2; c. AD 70-250. (2).

23. R21. Flange rimmed bowl; wheelmade. Garrod and Moss 1967, Trench AI, context 2; c. AD 70-160.

24. R21. Much of the profile from a small bowl or cup with upstanding rim; probably wheelmade. Findspot not known; c. AD 30-100. cf. Timby 1990, fig. 4, nos 55-56.

25. R21. Dish. Bridgewater 1963, Area C context 1; c. AD 30-100. cf. Webster 1976, fig. 10, no. 69-70.

26. R21. Dish, slipped and burnished on interior and exterior; perhaps a derivative of Hawkes and Hull 1947, 149, Cam 16, or an imitation of samian form Drag 18/31R. Bridgewater 1963, Area A-D, context 1; ?c. AD 40-200.

27. R26. Rim from a beaker with bead rim; burnished exterior surface and rim. DAG fieldwalking. HSM 21376, SO 6470 2390; c. AD 1-100.

28. R26. Rim and upper profile of a necked bowl; burnished exterior surface and rim; probably handmade. Garrod Collection, surface find; c. 20 BC-AD 70.

29. R26. Rim and upper wall from a carinated bowl with bead rim and cordons on upper wall; well burnished exterior surface and rim; probably wheelmade. Garrod and Moss 1967, Trench BIII, unstratified; c. 40 BC-AD 70. $c f$. Timby 1990, fig. 4, no. 46.

30. R26. Rim and shoulder from a necked bowl with cordon at junction of neck and shoulder; very dark grey burnished exterior and rim; wheelmade. Garrod and Moss 1967,
Trench BI, context 2A; c. $50 \mathrm{BC}-\mathrm{AD} 70$.

31. R26. Rim and shoulder from a necked bowl with bead rim and cordon; highly burnished interior and exterior surfaces; apparently wheelmade. DAG fieldwalking. HSM 21376, SO 6470 2380; c. BC 40-AD 80.

Figure 4.18. R27, R28, R29, R30, R31, R33 and

\section{R34, Unoxidized Wares}

1. R27. Pale grey fine ware. Butt beaker, rouletted and cordoned; wheelmade. Garrod and Moss 1967, Trench AI, context 3; c. AD 30-75. (8). cf. Timby 1990, fig. 4 , nos 48-49.

2. R28. Unoxidized fabric Narrow mouthed necked jar with grooves at the base of the shoulder; semi-burnish on exterior; wheelmade. Garrod and Moss 1967, Trench AII, context 4; c. AD 30-400.

3. R28. Unoxidized ware. Rim from a necked jar, perhaps copying a BB1 form; wheelmade. Garrod and Moss 1967, Trench BIII, context 5; c. AD 60-200.

4. R28. Unoxidized ware. Rim and upper body from a bead rimmed beaker; semi-burnished exterior and rim; method of manufacture uncertain. Garrod and Moss 1967, Trench BII, context 2; c. 20 BC-AD 70. cf. Timby 1990, fig. 4, no. 50 .

5. R29. Unoxidized ware. Rim from barrel jar; very smooth exterior surface and rim; traces of carbonized residues on exterior; probably handmade. Garrod and Moss 1967, Trench AI, context 2; c. AD 1-80.

6. R29. Unoxidized ware. Rim from barrel jar; very smooth rim; probably wheelmade. Garrod and Moss 1967, Trench AI, context 2; c. AD 1-100.

7. R29. Unoxidized ware. Rim and shoulder from a medium mouthed jar; very smooth exterior surface and rim; hand-formed, probably finished on a turning board or slow wheel. Garrod and Moss 1967, Trench BIII, context 2; c. 50 BC-AD 80. (2).

8. R29. Unoxidized ware. Rim and upper profile from a carinated bowl with bead rim and cordons; burnished exterior and rim; wheelmade. Garrod Collection, surface find; c. 40 BC-AD 70. cf. Hawkes and Hull 1947, pl. 75, Cam 211.

9. R29. Unoxidized ware. Rim and upper body from a carinated bowl with horizontal grooves; very dark grey burnished exterior and rim; wheelmade. Garrod and Moss 1967, Trench BI, context 2A; c. 40 BC-AD 70. cf. Timby 1990, fig. 4, no. 43.

10. R29. Unoxidized ware. Rim and upper body from a straight sided bowl, presumably carinated; very dark grey burnished exterior and rim; wheelmade. Garrod and Moss 1967, Trench BI, context 2A; c. 40 BC-AD 70. cf. Timby 1990, fig. 4, nos 42-43.

11. R29. Unoxidized ware. Rim and upper body of a necked and carinated bowl; burnished exterior surface and rim; wheelmade. Garrod and Moss 1967, Trench BI, context 2B; c. 50 BC-AD 140. cf. Timby 1990, fig. 4, no. 52 .

12. R29. Unoxidized ware. Full profile of a necked and carinated bowl; semi-burnished exterior surface and rim; wheelmade. Garrod and Moss 1967, Trench BI, context 2B; c. 50 BC-AD 140. (8; a further sherd was recovered from Trench BI, context 2A). cf. Timby 1990, fig. 4 , no. 52 . 

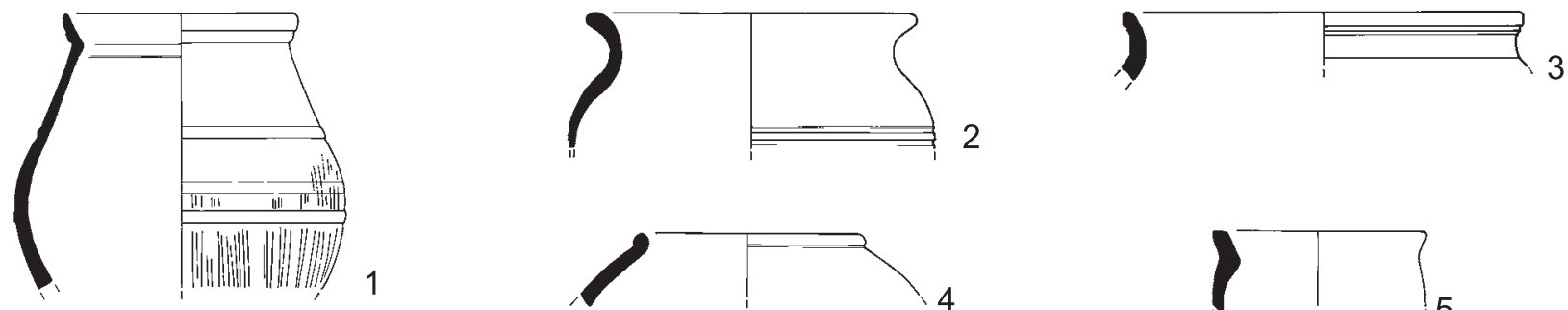

2
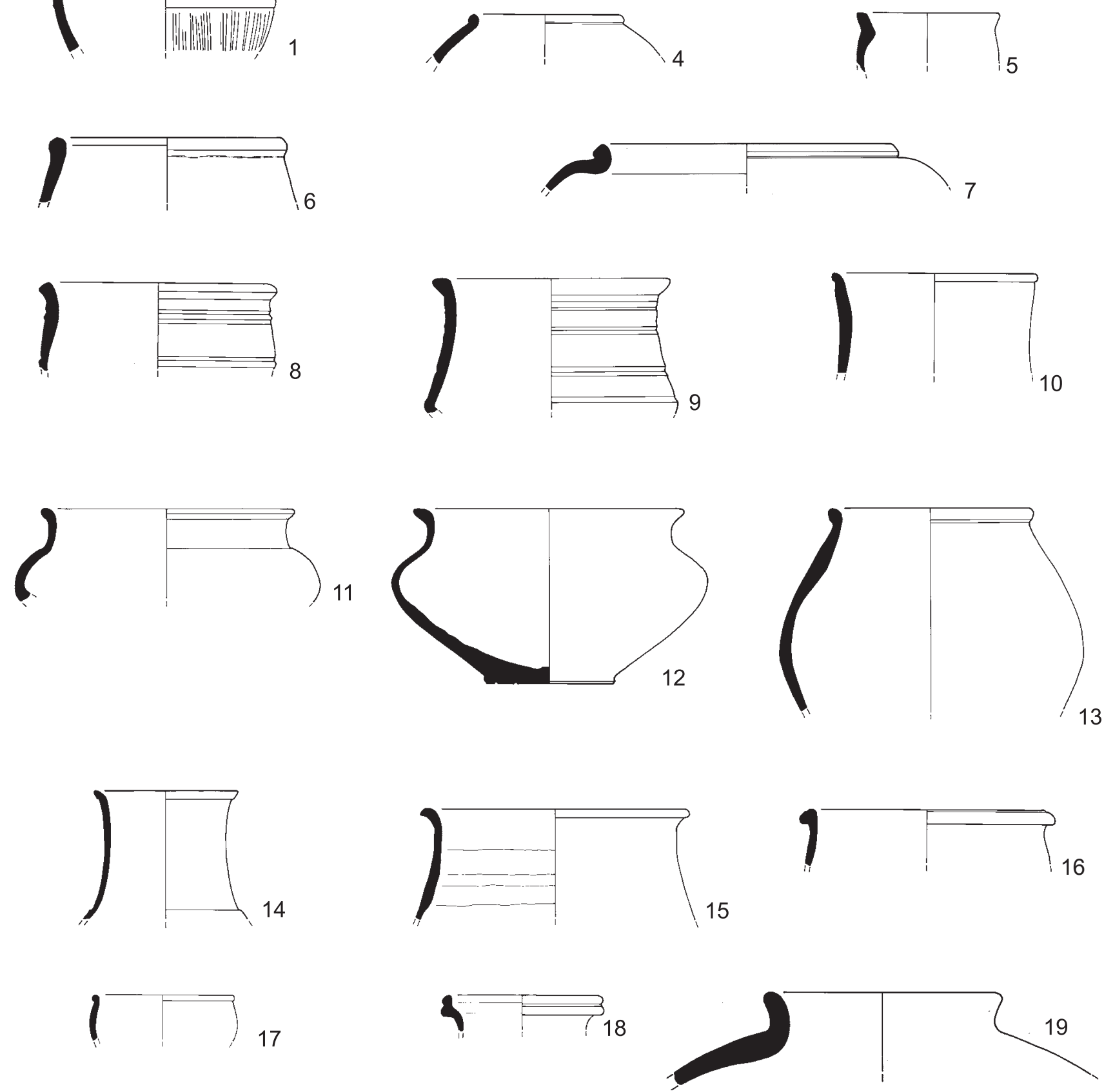

19

0

$200 \mathrm{~mm}$

Figure 4.18. Pottery: Unoxidised wares

13. R30. Unoxidized ware. Rim and upper body from a large butt beaker; very smooth exterior with faint horizontal burnish lines at girth; wheelmade. Garrod and Moss 1967, Trench BI, context 2B; c. AD 1-70. (3). cf. Timby 1990, fig. 4, no. 50 .

14. R30. Unoxidized ware. Rim and upper body from a beaker; very dark grey highly burnished exterior and rim; apparently wheelmade. Garrod and Moss 1967, Trench BI, context 2A; c. AD 1-70.

15. R30. Unoxidized ware. Rim and upper body from a bead rimmed bowl; burnished exterior surface; darkened rim possibly due to burning rather than original firing; 
wheelmade. Garrod and Moss 1967, Trench BII, context 2; c. AD 1-70. cf. Timby 1990, fig. 4, no. 42.

16. R30. Unoxidized ware. Rim from a bowl with a bead rim and groove on the upper surface of the rim; very smooth surfaces all over; probably wheelmade. Garrod and Moss 1967, Trench BI, context 2B; c. 50 BC-AD 70.

17. R31. Unoxidized limestone tempered ware. Rim and upper body from a bead rimmed hemispherical cup; probably wheelmade. Garrod and Moss 1967, Trench BI, context 2A; c. AD 1-100. The form parallels Timby 1990, fig. 4, no. 55 , though this item is not Severn Valley Ware.

18. R33. Unoxidized ware. Rim from a flagon; burnished exterior and rim; wheelmade. Garrod and Moss 1967, Trench BIII, unstratified; c. AD 120-250. cf. Gillam 1968, no. 16.

19. R34. Unoxidized ware. Rim and shoulder from a storage jar; probably wheelmade. Garrod and Moss 1967, Trench CXX, context 2; c. AD 50-200.

\section{Figure 4.19. S01, S02 and S03, Samian Wares and Samian Stamps}

1. S01. South Gaulish La Graufesenque ware. Drag. 29. Garrod and Moss 1967, Trench CI, context 1; c. AD 55-70.

2. S01. South Gaulish La Graufesenque ware. Drag. 30. Garrod and Moss 1967, Trench AII, context 6; c. AD 70-100.

3. S01. South Gaulish La Graufesenque ware. Drag. 37. Garrod and Moss 1967, Trench CI, context 1; c. AD 70-100.

4. S01. South Gaulish La Graufesenque ware. Drag 37. Garrod and Moss 1967, Trench AI, context 1; c. AD 80-100.

5. S01. South Gaulish La Graufesenque ware. Drag. 37. Garrod and Moss 1967 or Garrod collection, unstratified; $c$. AD 70-100.

6. S01. South Gaulish La Graufesenque ware. Drag. 37. Garrod and Moss 1967, Trench BIII, context 5 (the pit); c. AD 70-100.

7. S01. South Gaulish La Graufesenque ware. Drag. 37. Garrod and Moss 1967 or Garrod collection, unstratified; $c$. AD $80-100$.

8. S01. South Gaulish La Graufesenque ware. Drag 37. Bridgewater 1963, Area C, HSM 21378, surface find; c. AD 70-110. Burnt.

9. S02. Central Gaulish Les Martres-de-Veyre ware. Drag. 37. Garrod and Moss 1967, or Garrod collection, unstratified; c. AD 100-130. (2).

10. S02. Central Gaulish Les Martres-de-Veyre ware. Drag. 30. Garrod and Moss 1967, Trench CXX, context 1; c. AD 100-130.

11. S02. Central Gaulish Les Martres-de-Veyre ware. Drag. 37. Garrod and Moss 1967, Trench AI, context 2; c. AD $100-130$

12. S02. Central Gaulish Les Martres-de-Veyre ware. Drag. 37. Garrod and Moss 1967, Trench CI, context 1; c. AD 100-130.

13. S02. Central Gaulish Les Martres-de-Veyre ware. Drag. 37R dish (rather than a bowl) with rouletting. Garrod and Moss 1967, Trench AII, context 5; c. 100-130.

14. S03. Central Gaulish Lezoux ware. Drag. 37. Garrod and Moss 1967, Trench CI, context 1; c. AD 120-140.
15. S03. Central Gaulish Lezoux ware. Drag. 30. Garrod and Moss 1967, Trench CII, context 1; c. AD 120-140.

16. S03. Central Gaulish Lezoux ware. Drag. 37. Garrod and Moss 1967, Trench BIII, unstratified; c. AD 140200.

17. S03. Central Gaulish Lezoux ware. Drag 37 in the style of MERCATOR. Bridgewater excavations 1963, Area D, context 9; c. AD 160-200. Three conjoining sherds plus a further conjoining rim sherd from Area D, context 7, all burnt.

18. S01. South Gaulish La Graufesenque ware. Stamped ']SECV[', form not identifiable. Garrod and Moss 1967, Trench CII, context 1; c. AD 55-70.

19. S02. Central Gaulish Les Martres-de-Veyre ware. Stamped 'LVCINIOF', Drag. 33. Garrod and Moss 1967, Trench CXX, context 1 ; c. AD 100-130.

20. S03. Central Gaulish Lezoux ware. Stamped ']AVTPIRR[', form not identifiable. Garrod and Moss 1967 or Garrod collection, unstratified; c. AD 120-200. (Two conjoining sherds, though only 1 has the stamp fragment).

21. S03. Central Gaulish Lezoux ware. Stamped 'MALLIACI. M', being the product of MALLIACVS, Drag. 18/31R. Bridgewater 1963, Area C, HSM 21378, surface find; c. AD 135-150.

22. S03. Central Gaulish Lezoux ware. Stamped 'DONTIOIIIC', from a cup. Garrod and Moss 1967 or Garrod collection, unstratified; c. AD 130-160. Burnt.

\section{Vessel forms}

The Ariconium pottery has been classified into vessel forms on the basis of shape, size, rim type and surface treatment. The different form varieties present were categorised and coded using a system similar to that used by the Warwickshire Museum and OA, so that they could be entered onto the computerised database. As with the categorisation of fabrics the system has a hierarchic element: major vessel form classes were identified by a letter code, with each class allocated a letter code in strict alphabetical sequence running from narrow to wide-mouthed types. Further letters were then used for subdivisions of the major classes, where appropriate.

There are 12 major categories represented: amphorae, flagons, jars, jars/bowls, beakers, cups, tankards, bowls, very large bowls, dishes and platters, mortaria, and lids (for definitions see Evans 1993, 95-6, excepting the category 'very large bowls' which are a specific regional type of cauldron size and shape, for which see Kenyan 1954). Rim types were also recorded per individual rim sherd. These were classified by allocating three figure codes to each differing type, within form classes. The vessels are illustrated in Figs 4.1-4.19.

\section{Amphorae}

These occur in fabrics A11, A12 and A13. No items are illustrated. There are 14 securely located amphora sherds surviving from Bridgewater's excavations, plus three more sherds from his work in field HSM 10676 in 1963. All of 

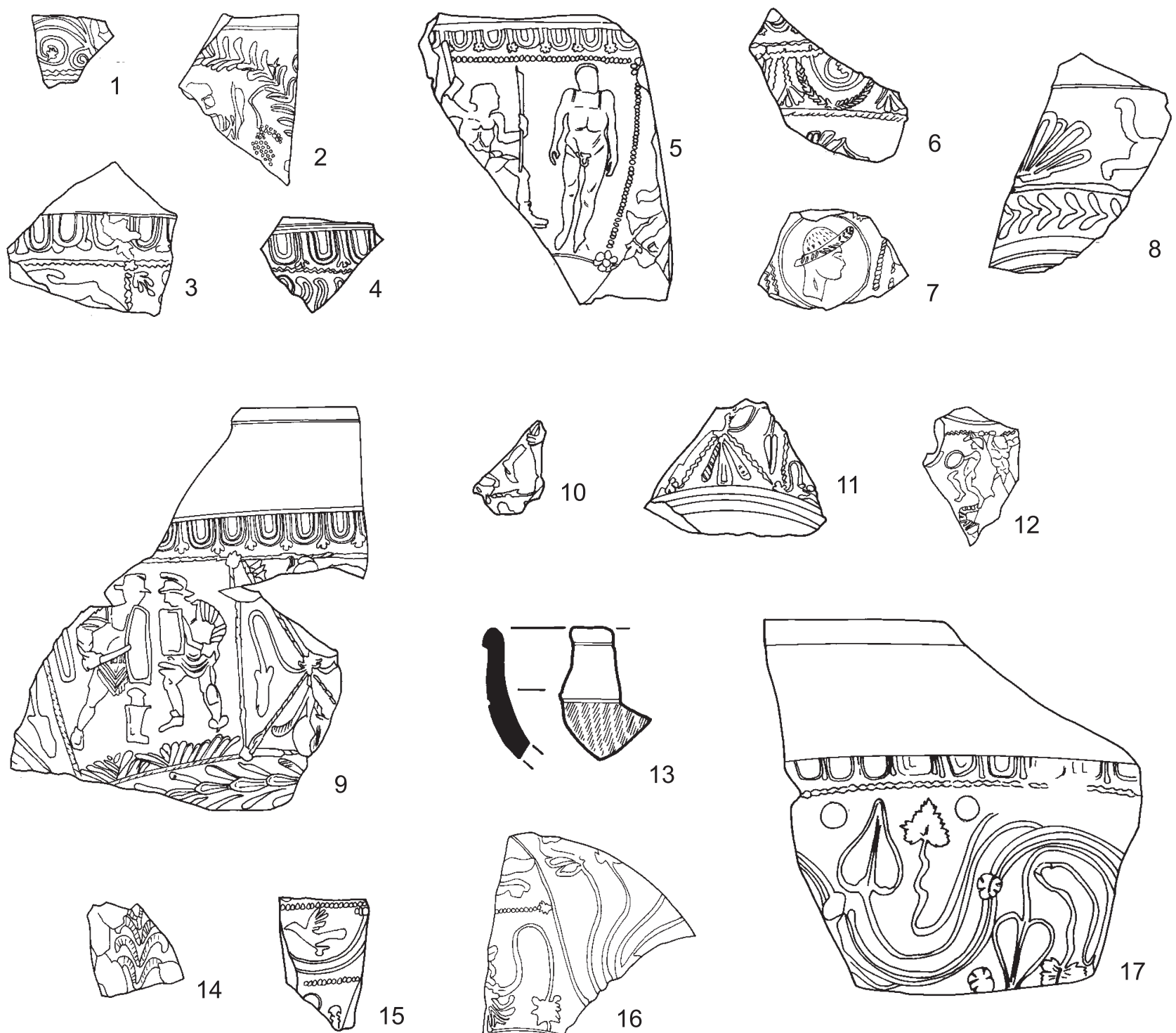

15
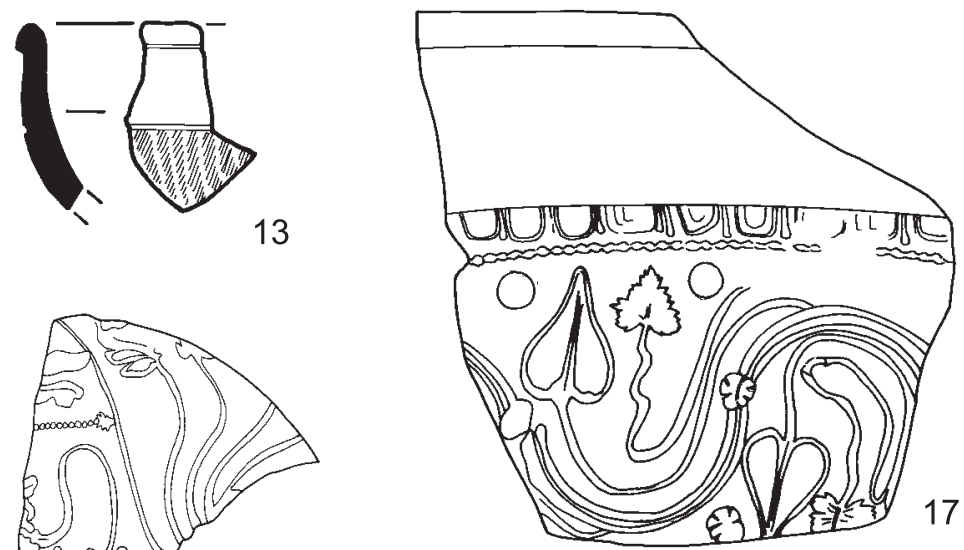

0

$100 \mathrm{~mm}$

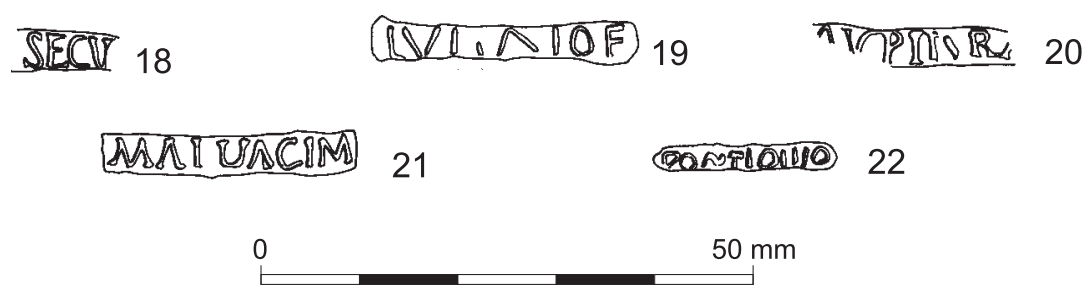

Figure 4.19. Pottery: Samian wares and samian stamps

the latter are examples of A11. There are no surviving amphora sherds from Garrod and Moss' excavations. A tally of c. 40 amphora sherds (the great majority in A11) are entered on the database from surface collections, in addition to the Bridgewater finds in HSM 10676. The sherds from the surface collections come from a wide number of specific locations.

Fragments from Dressel 20 amphorae were recovered 
during Jack's 1922 excavations and were reported by Hayter (Hayter 1923, 23). Sherds from Dressel 20 amphorae were also recovered during the work in advance of the Welsh Water pipeline: 2 sherds came from HSM 6097, one from surface collection, the other from Trench 7, while one sherd came from HSM 15983, where it was recovered unstratified.

Four amphora form types are represented amongst the present collections. There are single sherds from the Haltern 70, Beltrán I/Dressel 7-11 and Gauloise 4 forms, with there being many examples of Dressel 20. Sherds from Dressel 20 type amphorae have been found at many points across the site of Ariconium. There is however a complete (and conspicuous) absence of such sherds amongst the Garrod and Moss collection, despite the fact that examples have been recovered from the near vicinity of the Garrod and Moss trenches. This absolute absence of amphora sherds from amongst the Garrod and Moss assemblage must be the result of their discard. It is possible too that body sherds from amphorae were discarded from the Bridgwater excavated assemblage. The amphorae from the site are considered below in the discussion section of the report on the pottery.

\section{Flagons/jugs}

These occur in oxidized Severn Valley ware fabrics O10, O13, O14 and O20, Oxfordshire White Ware O30, the oxidized ware $\mathrm{O} 37$ which is possibly Severn Valley ware or Oxfordshire White Colour-Coated Ware, Unoxidized ware R33 and 'Unoxidized Severn Valley ware' R20. There are 3 securely located flagon sherds from Bridgewater's excavations, 7 from Garrod and Moss' excavations (mainly rims) and 4 (3 rims, 1 handle, all different vessels) entered on the database from surface collections. Rim types represented: ring-necked (O20, O37), Hofheim-type (O14), grooved (O14), bead (O10, O14, R20), trefoil-lipped (O30) and pulley-wheel (R33).

The absolute numbers represented may seem comparatively small, though this has to be viewed within a regional context: flagons are less common forms amongst assemblages from the West Midlands region generally (see below). The types represented span the Roman period. The illustrated rims (Fig. 4.14.3 in O20; Fig. 4.15.6 in O37) have a cream slip on interior and exterior surfaces.

\section{Jars}

Jars occur in Oxidized Severn Valley ware fabrics O11, O12, O13, O14, O15, O16, O17, O19 and O21, 'Unoxidized Severn Valley wares' R20 and R21, Unoxidized wares R28 and R29, Black burnished ware, B11, and the 'local' fabrics G11 and C11; storage jars are dealt with separately below.

There are 94 securely located jar sherds from Bridgewater's excavations (mainly rims), 191 (mainly rims) from Garrod and Moss' excavations and 150 sherds from
150 jars entered on the database from surface collections; other sherds from jars are coded and recorded.

The earliest jars at Ariconium include items in fabrics C11 and R29. Jars in C11, Limestone tempered ware, are prominent amongst the assemblages from in and around the scheduled area, though essentially absent from Bridgewater's 1963 collection. These handmade vessels should date to the 1 st centuries BC and AD. They tend to be medium to large vessels with some variety of form. Rims though, are typically of short, everted type, and often there is no neck; a standard example is that shown in Fig. 4.2.16 from The Great Woulding (HSM 9071). Decoration does occur, though rarely (e.g. Fig. 4.2.3). Jars in the Unoxidized ware R29 are of interest (e.g. Fig. 4.18.5-7) being of late Iron Age/1st century AD date and occurring in barrel and globular jar forms, with very smooth exterior and rim surfaces. They appear to straddle a transition from hand to wheel manufacture.

A variety of jar forms occur in Oxidized Severn Valley wares, though jars in these fabrics are not prolific amongst the assemblages from Ariconium. Evidently no particular Oxidized Severn Valley ware fabric or fabrics was especially employed in the production of jars. The jar forms represented correspond well with the range published by Webster (Webster 1976); chronologically they span the Roman period. Several items in Oxidized Severn Valley ware fabrics amongst these assemblages appear to copy Black Burnished Ware 1 forms (e.g. Fig. 4.9.4 and Fig. 4.14.1).

Many jars at Ariconium occur in the 'Unoxidized Severn Valley ware' R21. The fabric was used to produce a circumscribed range of forms which evidently span the early to middle Roman period, continuing into the 3rd century at least (cf. Fig. 4.17.1-26). Copies of Black Burnished Ware 1 type jar forms are common in this fabric (e.g. Fig. 4.17.4 and 4.17.8), and in cases where sherd surfaces are well preserved lattice decoration and burnishing are visible (e.g. Fig. 4.17 .9 and 28.16). Narrow necked jars and jars without necks but with everted rims also occur.

Black Burnished Ware 1 jars are reasonably well represented at Ariconium. A range of forms are represented with the bulk of the examples being 2 nd and 3rd century. It may well be that their abundant quartz grain tempering and highly burnished surfaces gave these vessels a competitive advantage over local grey/cooking wares in so far as they may have proved more enduring items upon repeated exposure to the temperature changes associated with cooking. Their burnished surfaces are likely to have been less permeable than with other fabrics, though their function may not have been to contain liquids over time. If this were the aim one would expect their interiors to have been burnished as well.

So-called 'tubby cooking pots' with black and burnished surfaces in Malvernian metamorphic ware (G11) are also present (e.g. Fig. 4.5.1 and 4.5.2), albeit in modest numbers (that is, forming less than $1 \%$ of the overall assemblage reported here). 
Significantly, there are no rusticated jars amongst these assemblages from Ariconium. This suggests a lack of Roman military influence amongst the assemblage (Jeremy Evans, pers comm.).

\section{Storage jars}

Jars of storage scale proportion form a distinct sub-set of vessels. Storage jars occur in a discrete range of fabrics: C11, the Oxidized Severn Valley ware fabrics O12, O14, O15 and O18, the 'Unoxidized Severn Valley ware' fabric R20 and the grey ware R34.

This class of vessels is well represented at Ariconium. The source, or sources, will lie within the region. There are 23 securely located storage jar sherds (mainly rims) from Bridgewater's excavations, 74 (mainly rims) from Garrod and Moss' excavations (principally in fabrics C11 and R20) and 52 sherds from 52 storage jars entered on the database from surface collections; other sherds from storage jars are coded and recorded. Storage jars in Oxidized Severn Valley wares were particularly associated with the Bridgwater assemblage. Typically these vessels have high shoulders and a curving neck which forms a continuous curve to the rim terminal (e.g. Fig. 4.10.4); the terminal often ends in a bead or slight swelling. There are subtle variations of detail within this general form.

Contrastingly there is a close consistency of form and fabric in the case of the 'Unoxidized Severn Valley ware' R20. Storage jars in this fabric again have a high shoulder, though the neck is short and straight with a thick out-turned bead rim. Four of the five illustrated storage jars in R20 are of this type, as is the illustrated vessel in R34 (Fig. 4.18.19), a fabric which is also evidently local. Since two further storage jars in the Limestone Tempered Fabric C11 also occur in this form (Fig. 4.2.21 and 4.2.23) the suspicion must be that the form is comparatively early in date, and has its origins in the late Iron Age. This possibility is supported by the fact that the four aforementioned vessels in R20 came from Garrod and Moss' excavations which also produced much other late Iron Age and early Roman pottery. The remaining vessel in R20 (Fig. 4.16.5) came from Bridgewater's excavations which investigated deposits of middle to late Roman date; this item is similar in form to the vessels in Oxidized Severn Valley ware. The remaining illustrated storage jars in $\mathrm{C} 11$ (Fig. 4.2.20; Fig. 4.3.2, 3 and 4) have everted rims and are not necked.

Following the Webster typology (Webster 1976) the storage jars in Oxidized Severn Valley wares essentially span the Roman period. One example (Fig. 4.13.5 in O18) seems likely to be of earlier date, perhaps 1 st century and no later than $c$. AD 200.

\section{Jars/bowls}

This category covers items where insufficient of the vessel is represented to enable a reliable estimate of the height: diameter ratio and so the pieces could be either from jars or bowls. It also includes borderline wide-mouthed jars/bowls. Items falling into this category occur in $\mathrm{C} 11$ and Oxidized Severn Valley ware fabrics O10, O12, O14, O15, O16 and O17.

There are 2 securely located examples of this category from Bridgewater's excavations, 23 sherds (essentially rims) from Garrod and Moss' excavations and 3 sherds from 3 vessels entered on the database from surface collections.

\section{Beakers}

Beakers occur in a very wide range of fabrics: fine wares F13, F15, F16, F17, F18, F19, F23, Oxidized Severn Valley ware fabrics $\mathrm{O} 11, \mathrm{O} 12, \mathrm{O} 14, \mathrm{O} 15, \mathrm{O} 16, \mathrm{O} 23, \mathrm{O} 24$ and $\mathrm{O} 38$, the characteristically similar Unoxidized wares R26, R27, R28 and R30 and 'Unoxidized Severn Valley ware' R21.

There are 13 securely located beaker sherds from Bridgewater's excavations, 61 sherds (mainly rims) from Garrod and Moss' excavations, and 22 sherds from 22 vessels entered on the database from surface collections; other sherds from beakers are coded and recorded. The majority of these vessels are butt beakers, whilst globular, barrel and other types are represented. Various rim types are present including: cornice (F13), bead (e.g. O12), everted (e.g. O11, R21, R27) and 'lid-seated' (O14, O15).

The great majority of the beakers are of 1 st century $\mathrm{AD}$ date, with the imported Cam 113 type (Hawkes and Hull 1947), and especially copies of the form in Severn Valley wares, being prominent from across the scheduled area, including Garrod and Moss' trial trenches. Close or derived copies of the Cam 113 in Severn Valley ware fabrics indicate that this form was of significance; several of the Severn Valley ware items have traces of white slip, indicating that efforts had been made to imitate the white/buff appearance of the prototype. These copies are not associated with a particular ware variety, but they do occur in a select range of oxidized Severn Valley ware fabrics: O11, O12, O14, O15, O16 and F23.

There are a small number of beakers present of later date which come from extra-regional sources, including Central Gaulish Black Slipped Ware (F13, F16), Nene Valley Colour-Coated Ware (F17), and, potentially later, Lower Rhineland (Cologne) Colour-Coated Ware (F15).

Of particular interest are the illustrated vessels comprising a small beaker with corrugated shoulder $(\mathrm{O} 14$, Fig. 4.9.9) and two others (O16, Fig. 4.11.5, and O14, Fig. 4.9.8) which are similar to the Cam 78 beaker (Hawkes and Hull 1947, pl. 54; cf. Timby 1990, fig. 4, no. 47).

\section{Cups}

As is normal with late Iron Age and Roman period pottery assemblages, cups are rare amongst collections under study here. The majority of such vessels present appear in the samian wares, S01, S02, S03, S04 and S06. The cups in non-samian fabrics occur in the following: Oxidized Severn 
Valley ware fabrics O11 and O14, Unoxidized wares R21 and R31, and Limestone tempered ware, C11.

There are 3 securely located cup fragments from Bridgewater's excavations, 8 sherds (mainly rims) from Garrod and Moss' excavations, and 5 sherds from 5 vessels entered on the database from surface collections.

The paucity of cups from amongst assemblages from Ariconium is probably related, in part, to the presence and evident popularity of tankard forms, which may have fulfilled similar functions to cups. Cups were relatively more frequent in Britain during the early Roman period rather than later.

The cups in samian ware occur in the standard range of forms; there are no copies of these forms, however, in non-samian fabrics. The few non-samian cups represented are essentially 'singletons'. It is perhaps worth noting that the two Oxidized Severn Valley ware fabrics in which cups occur - namely $\mathrm{O} 11$ and $\mathrm{O} 14$ - were also both used for producing beakers. The carinated cup in $\mathrm{O} 11$ (Fig. 4.8.7) is a small version of a type ( $c f$. Timby 1990, fig. 4, no. 44) which also occurs in a larger guise at Ariconium and elsewhere. In its larger manifestation it must be defined as a bowl. The item in 'Unoxidized Severn Valley ware' R21 (Fig. 4.17.24) is a small bowl or cup with upstanding rim, and of early date (cf. Timby 1990, fig. 4, nos 55-56).

The cup in C11 (Fig. 4.3.5) is a rare example in this fabric type. Presumably this particular item dates to the late Iron Age/1st century AD. Cups are unusual amongst assemblages of late Iron Age date, though simple hemispherical cups of this type are known from some sites, for instance, Dragonby, North Lincolnshire (May 1996) and Sleaford, Lincolnshire (Elsdon 1997, fig. 75 no. 340).

Jack's 1922 excavations recovered at least two cups in, apparently, Oxidized Severn Valley ware (Hayter 1923, 21, E and pl. 9 fig. 7), one 'nearly globular', the other with a carination and lip. From his work too came a Central Gaulish Black Slipped Ware (fabric F13) cup in Drag 40 form (Hayter 1923, 18 (e), pl. 9, fig. 6).

\section{Tankards}

As at many other sites in western England the tankard form at Ariconium is closely associated with Oxidized Severn Valley wares. It appears in the following fabrics: Oxidized Severn Valley ware fabrics O10, O11, O12, O13, $\mathrm{O} 14$ and $\mathrm{O} 16$; there is an apparent example in $\mathrm{C} 11$ from Analytical Group 3.

There are 33 securely located tankard sherds from Bridgewater's excavations (mainly rims, but also handles), 22 sherds from Garrod and Moss' excavations, and 39 sherds from 38 vessels entered on the database from surface collections; other sherds from tankards are coded and recorded. The form types represented are consistent with those published by Webster (Webster 1976). The majority of the vessels have a slight groove below the rim on the exterior; walls are straight sided and either vertical or slightly angled outwards. Whilst the range of types present essentially spans the Roman period the later types with more flaring rims ( $c f$. Webster 1976, fig. 7, nos 43 and 44) are rare in this case. The range of fabric variants employed to produce the form is limited and it is of considerable interest that there are no examples of tankards in 'Unoxidized Severn Valley ware', though this emphasis is apparent elsewhere (e.g. Lee et al. 1994, 10). Bridgewater's 1963 excavations yielded a useful sample of the class, mainly of 2 nd to 3 rd century date.

\section{Bowls}

Bowls occur in a very wide range of fabrics: Oxfordshire red/brown colour-coated ware F11, Oxidized Severn Valley ware fabrics O10, O11, O14, O15, O16, O17, O18, O19, O23 and O38, 'Unoxidized Severn Valley ware' R21, the characteristically similar Unoxidized wares R26, R29 and R30, as well as Black Burnished Ware 1 (B11) and Limestone tempered ware C11. Samian ware bowls occur in: S01, S02, S03, S06. Note that 'Very Large Bowls' are dealt with separately below.

There are 34 securely located sherds (mainly rims) from bowls surviving from Bridgewater's excavations, there are 168 sherds (principally rims) from Garrod and Moss' excavations and 48 sherds from 47 vessels entered on the database from surface collections; other sherds from bowls have been coded and recorded.

A large proportion (c. 40-45\%) of the bowls from Ariconium appear in Oxidized Severn Valley ware fabrics. These vessels occur in a very wide variety of form types, there being no particular correlation between a specific fabric variety and a particular vessel form. The types span the Roman period, though there is again an emphasis towards types of early and mid Roman date (particularly with regard to Fabric O16).

The bowls in Black Burnished Ware 1 occur in familiar types, comprising, essentially, of flange rimmed bowls or bowls with an exterior flange below a bead rim ( $c f$. Gillam 1976, nos 40-1, 45-49). Examples date from the mid to late 2 nd century through to the end of the fourth.

Bowls in the 'Unoxidized Severn Valley ware' R21 are of interest. Whereas many of the jars that occur in this ware imitate Black Burnished Ware 1 (B11) forms, this trend does not extend to bowls which appear in distinct non-B11 type forms. However, there is a fine example of a copy of the samian bowl form Drag 37 in this ware (Fig. 4.17.22). Of likely earlier date are two cordoned bowls of Aylesford affinity (Fig. 4.17.20 and 21) and a necked bowl (Fig. 4.17.5), testifying to the currency of this ware during the mid 1 st century $\mathrm{AD}$, if not earlier. Items in the related black-surfaced wares R26, R29 and R30, occur in analogous forms of likewise early date. Occurring in R26 are necked bowls (Fig. 4.17.28, 30, and 31), of late Iron Age to mid 1st century AD date, and a carinated bowl with bead rim, cordons and burnishing (Fig. 4.17.29; cf. Timby 1990, fig. 4, no. 46) of similar date.

R29 occurs in a circumscribed range of bowls, all, 
similarly dating to the late Iron Age/early Roman period. Again, the fabric was employed to produce carinated bowls with cordons (Fig. 4.18.8, 9 and 10; cf. Hawkes and Hull 1947, pl. 75, Cam 211; Timby 1990, fig. 4, no. 43), as well as necked shallow bowls (Fig. 4.18 .11 and 12; $c f$. Timby 1990, fig. 4, no. 52).

There are a few bowls in C11, a fabric which was much more commonly used in making jars and very large bowls. The vessels are handmade and again date to the late Iron Age/mid 1st century AD. One (Fig. 4.3.6) has a simple rim and a somewhat carinated profile; a second (Fig. 4.3.8) is a small necked bowl; and another (Fig. 4.3.7) is a vessel of outstanding quality being a small necked bowl with out-turned and flattened rim with an exceptionally high burnish giving the appearance of polished marble. The great majority of these early bowls came from Garrod and Moss' excavations.

\section{Very large bowls}

Very large bowls are a distinct category of huge container vessels that only appear in Limestone tempered ware, C11 (see Fig. 4.3.9, 10, 11, 12 and 13).

There are no examples of very large bowls present amongst the surviving excavated Bridgewater assemblage. There are three rim sherds from 3 vessels surviving from Garrod and Moss' excavations, and there is one rim sherd entered on the database from surface collections; other sherds from very large bowls have been coded and recorded.

The vessels are handmade with thickened out-turned rims, often with faint concentric grooves incised in the upper surface of the rim. These vessels should date to the late Iron Age/mid 1st century AD. The type is known from elsewhere in the wider region, for instance at Sutton Walls (Kenyon 1954, fig. 19).

\section{Dishes and platters}

Dishes and platters occur in a range of fabrics: Terra Nigra F20, Oxidized Severn Valley ware fabrics O12, O14, O15, O16 and O18, 'Unoxidized Severn Valley ware' R21, and Black Burnished Ware 1, B11, as well as in samian wares: S01, S02, S03, and S06.

There are 43 securely located sherds from dishes and platters surviving from Bridgewater's excavations, while there are 13 items from Garrod and Moss' excavations, and 15 sherds from 14 vessels entered on the database from surface collections; other dish and platter sherds are coded and recorded.

Oxidized Severn Valley ware fabrics and R21 were employed to produce similar forms, familiar from the Webster (Webster 1976) typology; on the whole they are mid-1st century AD to early Roman. There are essentially two vessel types in these wares: curving walled dishes or platters, sometimes with a groove on the base near to the spring point of the wall and suggesting a footring (e.g.
Fig. 4.13.8). This form is reminiscent of the Cam 16 dish (Hawkes and Hull 1947, pl. 49) or of 'Pompeian Red' Ware forms ( $c f$. Webster 1976, fig. 10, no. 73). The other form has a step in the wall and may also be derived from Gallo-Belgic forms for it resembles Cam $24 \mathrm{Ca}$ (Hawkes and Hull 1947, pl. 50, itself probably a development of the Cam 12-14 platter series); in Webster's series these forms are nos 69-70. The majority of dishes/platters in Oxidized Severn Valley ware fabrics are in O14.

It is of note that there are no platters or dishes in the characteristically similar grey wares R26, R27, R28 and R30, although they are of contemporary date.

The Black Burnished Ware 1 dishes span the period $c$. AD 120-400 and include an example of an oval, handled, so-called 'fish dish' (Fig. 4.1.26; Gillam 1976, 77-8, no. 85 ), as well as plain forms (Fig. 4.1.21 and 25; Gillam 1976, fig. 5, no. 78).

\section{Mortaria}

A modest sample of mortaria are represented amongst the extant collections reported here. The fabrics present are listed above and a range of examples are illustrated (Figs 4.6 and 4.7).

There are 3 securely located mortaria sherds from Bridgewater's excavations and 3 from Garrod and Moss' excavations; 6 sherds from 6 vessels are entered on the database from surface collections; other sherds of mortaria from across the site have been coded and recorded.

A small number of vessels are present which indicate supply during the early Roman period: these include imports from Northern Gaul (Fabric M01; Fig. 4.6.1 and 3) and a Verulamium region vessel (Fabric M10; Fig. 4.6.4). The supply during the middle Roman period seems paltry, represented by rare Mancetter-Hartshill vessels (M30) and early Oxfordshire arrivals (Fabric M25; Fig. 4.7.3 and 4). Caerleon ware mortaria (M40) are represented, dating from the later 1 st to the later 2 nd centuries AD. The majority of the mortaria from the site are from Oxfordshire and date to the period from $c$. AD 240. Mortaria supply is discussed further, below.

\section{Lids}

Lids are present in small numbers, appearing in the following fabrics: Oxfordshire red/brown colour-coated ware, F11, 'Unoxidized Severn Valley ware' R21 and Limestone tempered ware C11. Two items are illustrated (Fig. 4.3.14 and 15).

There are no lid sherds amongst the surviving excavated Bridgewater assemblage. There is 1 sherd from the circumference of a lid from Garrod and Moss' excavations and there are three lid fragments entered on the database from surface collections; other fragments from lids are coded and recorded. Forms are simple; some have a bead terminal. The finds in C11 came from the area of the scheduled monument or its immediate vicinity. 


\section{Summary typology of the Severn Valley ware from Ariconium}

There is a reasonably strong correspondence between fabric variety and form in the case of the Severn Valley ware from the site. The forms in which the fabric variants occur are summarised here for convenience (see Figs 4.8-4.15):

O11: This fabric occurs in a range of forms including jar, narrow necked jar, butt beaker, carinated cup, tankard, flange rimmed bowl, carinated bowl and necked bowl forms.

O12: This fabric was employed in the manufacture of a variety of forms including jar, globular jar, storage jar, wide mouthed jar, beaker, tankard and platter forms.

O13: Flagon, jar and tankard forms occur in this fabric variety. O14: This fabric occurs in a range of forms including flagon, storage jar, small beaker, butt beaker, cup, tankard, bowl, carinated bowl, flanged bowl and dish forms.

O15: This fabric occurs in large jar, storage jar, small barrel jar, butt beaker, tankard, necked bowl, miniature necked bowl and dish forms.

O16: This fabric was employed to make narrow mouthed jar, beaker, tankard, small bowl, carinated bowl, colander/strainer bowl, flanged bowl and dish forms.

O17: Appears in narrow mouthed jar and bowl forms.

O18: This variety was used in the production of large robust vessels, especially storage jars and large bowls, including a flange rimmed bowl with handle ( $c f$. Webster 1976, fig. 8), plus dish forms.

O19: Jar and bowl forms occur in this fabric.

O20: A flagon occurs in this fabric.

O21: A bowl occurs in this variant.

O22: This fabric is associated with thick walled vessels, especially storage jars.

O23: O23 occurs in beaker and bowl forms.

O24: A beaker occurs in this fabric variety.

\section{Summary typology of selected greyware fabrics from Ariconium}

The forms in which the fabrics occur are summarised here for convenience (see Figs 4.16-4.18):

R20: This fabric was employed in particular for the production of storage jars, though narrow mouthed jar and flagon forms also occur in this fabric. R20 is a characteristically similar fabric to O18, though unoxidized. Likewise the forms in which it occurs are reminiscent of those for which $\mathrm{O} 18$ was employed, as the illustrated material demonstrates.

R21: Although evidently a local or regional fabric with the general appearance of being an 'Unoxidized Severn Valley ware' this fabric does not occur in a standard range of Severn Valley ware forms. However, it is a feature of several of the Ariconium oxidized Severn Valley ware tradition fabric variants that they occur in certain specific form types.

A high proportion of the forms in fabric R21 are 'imitations' of those occurring in other fabrics, especially Black Burnished Ware 1 (B11) jars of so-called cooking pot type. Similar 'imitations' of Black Burnished Ware 1 jars do occur in oxidized Severn Valley ware (see illustrations) though they are not frequent. It may be that an unoxidized ware was considered appropriate for the production of these imitative forms since the originals were themselves unoxidized. R21 was also used in emulating other forms such as butt and globular beaker forms, as well as bowls copying the samian Drag 37 form; flange rimmed bowl and dish forms also occur.

R26: This fabric is associated with necked and carinated bowls, and was also used to produce beakers.

R28: This fabric occurs in necked jar and beaker forms.

R29: Barrel and medium mouthed jars occur in this fabric, though it was particularly employed in manufacturing carinated bowls.

R30: This fabric is associated with comparatively fine vessel forms, occurring in beaker and bowl forms.

\section{The pottery groups: quantification by fabric}

In this section a series of tables and other data are produced which present basic details of the stratified and surface collected assemblages by provenance, phase and fabric. EVE data by Rim Equivalent are used in all cases for reasons outlined in the introduction. The data show the changing nature of the occurrence of fabric types through time at Ariconium, and from area to area. The data are presented in broad chronological order, excepting the surface collected samples which are considered together at the end of the section.

Analysis is only feasible for samples of some size, and this criteria has determined which groups are examined here. Garrod and Moss' trial trenches CI, CII and CXX (HSM 23551, 23554 and 23552), for instance, have only very small quantities of pottery associated with context and phase groups and are thus not amenable to an analytical approach. Nine Groups are analysed here, their date of deposition is specified in each case.

\section{Analytical Group 1. Date range (i.e. likely date of deposition) c. AD 50/70-100. Garrod and Moss excavations, Layer: Trench AI context 3 and Trench AII context 6}

These contexts are described in Jackson's report upon Garrod and Moss' excavations ( $c f$. above) and have been assigned by him to a 'Period 1' covering these two trenches. Evidently they comprised parts of the same stratified layer.

The pottery from these two contexts is consistent and comprises a small sample of 45 sherds, 35 of which are rim sherds, with an RE of 3.88. Including all sherds, thirteen different fabrics are represented: $\mathrm{C} 11, \mathrm{O} 11, \mathrm{O} 12, \mathrm{O} 14, \mathrm{O} 15$, O16, O17, O22, R20, R21, R26, R27 and S01. A number of items from this Group are illustrated (these items are listed by fabric and form in Appendix 6). The pottery is essentially of 1 st century AD date. Some of the types have date-ranges that could carry the date of the deposit into the 2 nd century, but the two certain latest pieces are sherds from Flavian samian bowls (c. AD 70-100). Hence it seems likely that the deposit was laid down in the period c. AD 50/70-100. 
Table 5. Quantification by fabric of Analytical Group 1. Garrod and Moss excavations, Trench AI context 3 and Trench AII context 6

\begin{tabular}{|l|c|c|}
\hline Fabric & RE Total & \% \\
\hline C11 - Limestone tempered ware & 0.61 & $\mathbf{1 5 . 7}$ \\
\hline O11, O12, O14, O15, O16, O17 - Oxidized Severn Valley wares & 1.33 & $\mathbf{3 4 . 3}$ \\
\hline R20 - Coarse 'Unoxidized Severn Valley ware' & 0.43 & $\mathbf{1 1 . 1}$ \\
\hline R21 - Finer 'Unoxidized Severn Valley ware' & 0.74 & $\mathbf{1 9 . 1}$ \\
\hline R27 - 'Fine' regional ware & 0.77 & $\mathbf{1 9 . 8}$ \\
\hline Totals & $\mathbf{3 . 8 8}$ & 100.0 \\
\hline
\end{tabular}

The composition of the Group by RE is shown in Table 5. Although the RE aggregate is low it is based upon 35 rims and so should be a reasonable guide to the nature of the Group. Oxidized Severn Valley wares have a good showing amongst the group, but this is not surprising since they appear to have been established by the mid 1st century AD. The darker surfaced wares collectively comprise half the group by RE.

\section{Analytical Group 2. Date range (i.e. likely date of deposition) c. AD 50/70-100. Garrod and Moss excavations, Pit fill: Trench BIII context 5}

Several deposits encountered in Garrod and Moss' trial trenches BI, BII and BIII (HSM 23548, 23549 and 23550) have been assigned by Jackson to a Period 1 for this area ( $c f$. above). However, only one of these contexts, BIII context 5 , which is a pit fill, has more than a couple of sherds associated.

Fourteen sherds of late Iron Age and Roman pottery survive from the pit, context 5, with an RE of just 0.70 . Nine fabrics are represented: C11, O14, O17, O20, O38, R20, R21, R28, S01. Sherds from four vessels within this Group are illustrated (these items are listed by fabric and form in Appendix 6).

The group is composed of mid to late 1 st century AD types with the potential exception of a rim in the sandy greyware, R28 (Fig. 4.18.3) which might be an imitation of a BB1 jar form, though which nonetheless has a date bracket of $c$. AD 60-200. Although the sample is small, the composition of the group is similar in character to that of Group 1 and includes Flavian samian (c. AD 70-100). A comparable date is implied, $c$. AD 50/70-100.

\section{Analytical Group 3. Date range (1.e. likely date of deposition) c. AD 50-100. Garrod and Moss excavations, Layer: Trench BI contexts $2 a$ and 2b, Trench BII contexts 2 and 3, and Trench BIII context 2}

These contexts are grouped by Jackson in his report upon Garrod and Moss' excavations ( $c f$. above) and have been assigned by him to a 'Period 2' for these three trenches. Seemingly they comprised parts of essentially the same sandy loam layer. In Trench BI, layer 2 was excavated in two spits, the upper designated as BI $2 \mathrm{a}$ and the lower
$2 b$; the nature of the deposit was characteristically similar throughout and it appeared to be a single stratigraphic unit. Context 1a in Trench BIII is also part of this horizon but there is no pottery from this context amongst the surviving assemblage.

A total of 86 sherds (47 rims) of late Iron Age and Roman pottery survive from context BI 2a. Fourteen fabrics are represented: C11, F20, O11, O14, O16, O17, O22, R20, R25, R26, R27, R29, R30, R31. Sixteen items from this context are illustrated (these items being listed by fabric and form in Appendix 6). There are also 86 sherds (only 21 rims) of late Iron Age and Roman pottery from context BI 2b; (a differing degree of retention seems to have been exercised between these two groups). Seven fabrics are represented: C11, O16, R21, R27, R29, R30, R31. Eight items from this context are illustrated (see Appendix 6).

From BII contexts 2 and 3 totals of 28 sherds (19 rims) and 26 sherds (13 rims) respectively of late Iron Age and Roman pottery survive. Fabrics present in BII context 2 comprise: C11, F20, O16, O38, R28, R29, R30 and S03, with three items illustrated (Appendix 6). In BII context 3 the following Fabrics are present: C11, O14, O20, O38, R26, R29 and R32, with two items illustrated (Appendix 6). Finally, BIII 2 has a total of 34 sherds (19 rims) surviving, in fabrics C11, O18, R21, R29 R31, S01 and S03. Four items are illustrated from this context (Appendix 6).

Overall the surviving pottery from these contexts presents a consistent picture and indicates the deposit(s) was laid down $c$. AD 50-100. A date-range of $c$. AD 30-100 though is possible. There are a number of aspects of the Group which complicate the dating. The pottery from the stratigraphically lower contexts of this Group in Trenches $\mathrm{BI}$ and BII, specifically BI context $2 \mathrm{~b}$ and BII context 3 , appears marginally older than that from the contexts above (i.e. Trench BI context $2 \mathrm{a}$ and BII context 2) with which it is grouped. The pottery from Trench BI context 2a, for instance, has more Oxidized Severn Valley ware present than do the other contexts in the group, suggesting it may be slightly later in date. Whatever, this contrast is marginal. Trench BII (contexts 2 and 3) contained very similar pottery types.

A further consideration though relates to the large proportion of the Group formed by the late Iron Age and Transitional fabrics (C11, R25, R26, R28, R29, R30, R31 and $\mathrm{O} 38$ ) as demonstrated by Table 6 . The proportions of these wares present are much higher than with Group 1. 
Table 6. Quantification by fabric of Analytical Group 3. Garrod and Moss excavations, Trench BI contexts $2 a$ and $2 b$, Trench BII contexts 2 and 3, and Trench BIII context 2

\begin{tabular}{|l|r|r|}
\hline Fabric & RE Total & \% \\
\hline C11 - Limestone tempered ware & 6.91 & $\mathbf{5 0 . 7}$ \\
\hline O11, O14, O16, O22 - Oxidized Severn Valley wares & 1.99 & $\mathbf{1 4 . 6}$ \\
\hline O38 - Early Severn Valley ware variant & 0.14 & $\mathbf{1 . 0}$ \\
\hline R20 - Coarse 'Unoxidized Severn Valley ware' & 0.29 & $\mathbf{2 . 1}$ \\
\hline R21 - Finer 'Unoxidized Severn Valley ware' & 0.54 & $\mathbf{4 . 0}$ \\
\hline R25, R26, R29, R31 - Dark surfaced Transitional wares & 2.64 & $\mathbf{1 9 . 3}$ \\
\hline R28 - Distinctive dark surfaced Transitional ware & 0.13 & $\mathbf{1 . 0}$ \\
\hline R30 - Dark surfaced Transitional ware & 0.99 & $\mathbf{7 . 3}$ \\
\hline Totals & $\mathbf{1 3 . 6 3}$ & 100.0 \\
\hline (Excluded, two S03 (Lezoux samian) rims) & 0.10 & \\
\hline
\end{tabular}

Evidently this was an area of intense activity during the late Iron Age/mid 1st century AD and perhaps some, at least, of the deposits of Group 3 began forming during that time. Nonetheless the dating suggested above remains valid.

The other chronological problem is the seemingly incongruous occurrence of three small samian sherds of 2nd century date amongst the group, namely two Hadrianic to Antonine pieces (from BII 2, with a date range $c$. AD 120-200) and a fragment from a Drag 45 samian mortarium dating to $c$. AD 170-200 (BIII 2). Since there is apparently no other 2 nd century (or later) pottery present, the occurrence of these sherds is difficult to explain; they may be intrusive from the overlying ploughsoil, but then there is no other material of this status present. It remains possible that they reflect the actual date of the deposit with the great bulk of the pottery being residual material, though this is not the interpretation preferred here.

The group is dominated by typologically late Iron Age and Transitional vessels, including beakers and carinated bowls, in Fabrics C11 and R29, etc. The dark surfaced wares with fine-grained sandstone/siltstone tempering, R25, R26, R29 and R31 are typologically similar and are combined for analysis.

Amongst the body sherds of this group are a fragment from a Flavian South Gaulish samian bowl (Drag 37, c. AD 70-100) and two sherds of North Gaulish Terra Nigra (F20) from contexts BI 2a and BII 2 which are perhaps from the same vessel (Fig. 4.4.10). The latter is evidently a carinated bowl form (cf. Deru 1996, fig. 26 B6, fig. 27 B15 or fig. 32 B45), which is an unusual type to occur in Terra Nigra in Britain.

\section{Analytical Group 4. Date range (1.e. likely date of deposition) c. AD 100-200/250. Garrod and Moss excavations, Layer: Trench AI, context 2 and $2 a$, and Trench AII, contexts 3, 4 and 5}

These contexts are described in Jackson's report upon Garrod and Moss' excavations ( $c f$. above) and evidently formed parts of the same layer which was excavated in spits, two in AI and three in AII. These contexts have been assigned by Jackson to a 'Period 2' covering the two trenches.

The pottery from these contexts has a consistent character. Some 209 sherds of late Iron Age and Roman pottery survive from these contexts, of which 134 are rim sherds with an RE of 17.07. Twenty six different fabrics are represented: B11, C11, F18, F19, M25, O11, O12, O14, O15, O16, O17, O18, O22, O23, O36, O37, R20, R21, R22, R24, R26, R28, R29, S01, S02, and S03 (Table 7). Some 39 items are illustrated (Appendix 6).

The date range of the pottery potentially extends from the early 1 st century AD to the 4th century. However, the bulk of the pottery is of 1 st and 2 nd century date and perhaps mainly pre- $c$. AD 150 . The only necessarily 4 th century item is a rim from a flanged bowl in Black Burnished Ware 1 (B11; cf. Gillam 1976, types 45-9) and hence there is necessary suspicion that this item is intrusive. It is possible that the deposit began accumulating before the end of the 1 st century AD, which would explain the presence of a number of diagnostic 1st century fragments amongst the group; more likely perhaps, is the probability that the latter material is residual and that the date range for the laying down of the deposit is $c$. AD 100-200/250.

The illustrated pottery includes some items of note: a $1 \mathrm{st}$ century Green Glazed rim from Central Gaul (Fig. 4.4.6; cf. Greene 1979, Type 13/14); a Trajanic-early Hadrianic Drag 37R dish (c AD 100-130; Fig. 4.19.13); and a likely waster in the form of a jar in R21 (Fig. 4.17.2).

Oxidized Severn Valley wares form the majority of the pottery group. A further third of the group is composed of 'Unoxidized Severn Valley wares'(R20-22), amongst which the relatively fine fabric R21, employed to produce 'copies' of Black burnished ware 1 and other common forms, is dominant. The overall picture is of a group with very few extra-regional products. The later include early Oxfordshire traded products (in $\mathrm{O} 36$ and M25). The low proportion formed by B11 is surprising for this date. Similarly, the proportion formed by the samian (S01-3) is low, especially as the S01 sherds are likely to be residual. In fact a distinct residual 'tail' is identifiable including S01, F18, F19 and $\mathrm{C} 11$ (all fabrics which will have been contemporary with the preceding horizon, that is, Groups 1-3). 
Table 7. Quantification by fabric of Analytical Group 4. Garrod and Moss excavations, Trench AI contexts 2 and 2 a and Trench AII contexts 3, 4 and 5

\begin{tabular}{|l|r|r|}
\hline Fabric & RE Total & \% \\
\hline C11 - Limestone tempered ware & 0.88 & $\mathbf{5 . 2}$ \\
\hline B11 - Black Burnished Ware 1 & 0.13 & $\mathbf{0 . 8}$ \\
\hline F18 - Central Gaulish glazed ware & 0.07 & $\mathbf{0 . 4}$ \\
\hline F19 - North Gaulish sandy white ware & 0.07 & $\mathbf{0 . 4}$ \\
\hline M25 - Oxfordshire white ware mortaria fabric & 0.15 & $\mathbf{0 . 9}$ \\
\hline O11, O12, O14, O15, O16, O18, O22, O23 - Oxid. Severn Valley wares & 9.06 & $\mathbf{5 3 . 6}$ \\
\hline O36 - Oxfordshire coarse red ware & 0.30 & $\mathbf{1 . 8}$ \\
\hline R20 - Coarse 'Unoxidized Severn Valley ware' & 0.80 & $\mathbf{4 . 7}$ \\
\hline R21 - Finer 'Unoxidized Severn Valley ware' & 4.34 & $\mathbf{2 5 . 7}$ \\
\hline R22 - 'Unoxidized Severn Valley ware' variant & 0.16 & $\mathbf{0 . 9}$ \\
\hline R24 - Unoxidized ware, possible 'Unoxid. Severn Valley ware' variant & 0.29 & $\mathbf{1 . 7}$ \\
\hline R28 - Distinctive dark surfaced transitional ware & 0.18 & $\mathbf{1 . 1}$ \\
\hline R29 - Dark surfaced transitional ware & 0.18 & $\mathbf{1 . 1}$ \\
\hline S01 - South Gaulish La Graufesenque samian & 0.19 & $\mathbf{1 . 1}$ \\
\hline S02 - Central Gaulish Les Martres samian & 0.03 & $\mathbf{0 . 2}$ \\
\hline S03 - Central Gaulish Lezoux samian & 0.07 & $\mathbf{0 . 4}$ \\
\hline Totals & $\mathbf{1 6 . 9 0}$ & 100.00 \\
\hline (Excluded, 1 B11 rim) & 0.17 & \\
\hline
\end{tabular}

Analytical Group 5. Date range (i.e. likely date of deposition): c. AD 135-230/250. Bridgewater excavations 1963, ironworking activity: all contexts pre-dating layer 2

Bridgewater's excavations in field HSM 10676 investigated a rectangular area $c .25 \mathrm{~m}$ by $22 \mathrm{~m}$ in which four specific areas (A-D) were excavated to natural (Bridgewater 1965). The earliest activity was represented by a series of furnaces and working hollows and related deposits dating to the Roman period. The latter were in all cases sealed by a loam layer referred to by Bridgewater as context 'Layer 2', and this in turn was overlain by a further layer (Bridgewater's 'Layer 1') which underlay sub and ploughsoil horizons. The deposits sealed by Layer 2 seem all to have been of modest size in terms of volume, judging from the published sections (Bridgewater 1965).

There are only very small numbers of sherds, in the surviving assemblage, from these contexts, while a number of contexts have no associated pottery. The pottery from the contexts relating to the period of furnace activity is grouped together here for analytical purposes; the group evidently comprising material of broadly contemporary date.

Some 64 sherds of late Iron Age and Roman pottery survive from these contexts, with an RE total of 2.75. The sherds come from 15 contexts (Area A: 8F1, 8F2; Area B: 4; Area C: 6, 7, 11F2, H; Area D: 3, 4, 4 or 3a, 5, 7, 9 , 11, 14). Thirteen fabrics are represented: A11, B11, O11, O12, O14, O15, O16, O17, O18, R20, R21, R23, S03; there are three modern/medieval sherds present (X99), 2 conjoining, which are presumably intrusive. Five items from this Group are illustrated (Appendix 6).

The pottery points to a start date for these activities during the 2 nd century, perhaps $c$. AD 135 . There is a general absence of Iron Age and pre-Hadrianic pottery (i.e. pre-c. $\mathrm{AD} 120)$ amongst Bridgewater's assemblage, indicating that there was no occupation at this location prior to the onset of this industrial period. There is nothing amongst the pottery from these pre-Layer 2 contexts which is 4th century and no Oxfordshire ware or later Black Burnished Ware. Unless all later deposits of this type were eroded (see below), it seems that the industrial period ended (here) in the early to mid 3rd century. These dates are suggested on the basis of the surviving pottery. They are in good agreement with the dating pointers noted in Bridgewater's report (1965) which was produced immediately after the excavation. They appear therefore to be valid. The only potential discrepancy is Bridgewater's record of 'some 4th century coarse pottery' from F2 in Area A; this material could not be found in 1999).

The composition of the group by RE is presented in Table 8 . The absolute size of the sample is very small, but these data are nonetheless presented since, with the probable exception of Group 6, this is the only genuinely stratified pottery from Bridgewater's work. Oxidized Severn Valley wares form the principal ware type present. A further fifth of the group is composed of 'Unoxidized Severn Valley wares' (R20 and 21). As elsewhere the comparatively fine Fabric R21, employed to produce 'copies' of Black Burnished Ware 1 and other common forms, is the more prominent of these fabrics. As with Group 4 the impression is of a group with very few extra-regional products. Black Burnished Ware 1 is represented, though as with Group 4 the proportion formed by this ware is modest. Lezoux samian (S03) dating to $c$. AD 120-200 is the only samian present. Amongst Group 5 it forms $29 \%$ of the group which is a surprisingly high percentage, especially in the context of this particular site with its industrial function at this time. It is quite possible that this figure has been inflated by the discard of coarse wares from the group. 
Table 8. Quantification by fabric of Analytical Group 5. Bridgewater excavations 1963, all contexts pre-dating context (Layer) 2

\begin{tabular}{|l|c|r|}
\hline Fabric & RE Total & \multicolumn{1}{|c|}{} \\
\hline B11 - Black Burnished Ware 1 & 0.20 & $\mathbf{7 . 3}$ \\
\hline O11, O12, O15, O16 - Oxidized Severn Valley wares & 1.20 & $\mathbf{4 3 . 6}$ \\
\hline R20 - Coarse 'Unoxidized Severn Valley ware' & 0.16 & $\mathbf{5 . 8}$ \\
\hline R21 - Finer 'Unoxidized Severn Valley ware' & 0.39 & $\mathbf{1 4 . 2}$ \\
\hline S03 - Central Gaulish Lezoux samian & 0.80 & $\mathbf{2 9 . 1}$ \\
\hline Totals & $\mathbf{2 . 7 5}$ & 100.00 \\
\hline
\end{tabular}

Table 9. Quantification by fabric of Analytical Group 6. Bridgewater excavations 1963, context (Layer) 2

\begin{tabular}{|l|c|c|}
\hline Fabric & RE Total & \% \\
\hline B11 - Black Burnished Ware 1 & 0.47 & $\mathbf{1 0 . 7}$ \\
\hline M25 - Oxfordshire white ware mortaria fabric & 0.07 & $\mathbf{1 . 6}$ \\
\hline O11, O13, O14, O15, O17 - Oxidized Severn Valley wares & 2.42 & $\mathbf{5 5 . 0}$ \\
\hline R20 - Coarse 'Unoxidized Severn Valley ware' & 0.13 & $\mathbf{3 . 0}$ \\
\hline R21 - Finer 'Unoxidized Severn Valley ware' & 0.68 & $\mathbf{1 5 . 4}$ \\
\hline R22 - 'Unoxidized Severn Valley ware' & 0.12 & $\mathbf{2 . 7}$ \\
\hline S03 - Central Gaulish Lezoux samian & 0.51 & $\mathbf{1 1 . 6}$ \\
\hline Totals & $\mathbf{4 . 4 0}$ & 100.00 \\
\hline
\end{tabular}

An alternative possibility that should not be ignored is that samian was deliberately selected for deposition, the ritual connotation being that samian, as material of 'value', was suitable as an offering to a Smith-God, perhaps with deposition occurring as the metal-working reached a cessation. No other extra-regional fine wares are present. Fabrics associated with Iron Age/1st century AD types (such as C11, R26 and R29) are absent from this Group as well as others arising from Bridgewater's excavations.

The group includes 12 amphora body sherds from the large globular Dressel 20 form (A11). The latter may have been brought to this area of the site as a useful commodity in themselves, having a number of potential uses in the ironworking process whether whole or otherwise. As whole or trimmed vessels they could be employed for their storage and transport functions, and this would include use as water containers; in fragments, Dressel 20 is particularly useful as their form can give rise to large pieces suitable for 'pre-fabricated' small structures and for lining pits etc.; their 'sandy' fabric also makes Dressel 20 sherds suitable as hones and rubbers for finishing and polishing metal ( $c f$. Willis 1998a, 331).

\section{Analytical Group 6. Date range (i.e. likely date of deposition): c. AD 230/250-300. Bridgewater excavations 1963, post-ironworking horizon: Layer 2}

The deposits forming Group 5 were overlain by a compact soil layer, containing furnace debris and much slag, referred to by Bridgewater as 'Layer 2'. The pottery from this deposit forms Analytical Group 6. This thick horizon evidently extended across the whole of the area investigated. In Area $\mathrm{C}$ Bridgewater found a clay tobacco pipe fragment in Layer 2 and suggested that at this point Layer 2 must have been deposited in the 17 th or 18 th century. However, for the other areas the implication is that Layer 2 had accumulated during the Roman period (Bridgewater 1965). Two further clay tobacco pipe fragments, from Area D, are also ascribed to Layer 2; however, there are no post Roman pottery fragments from any part of this layer, nor other post-Roman finds. The 3 pipe stem fragments suggest some (? isolated) disturbance or contamination of the context.

A total of 81 sherds survive from context 2. All are Roman. Half of the sherds are rim fragments and the RE figure is 4.40. Twenty-two fabrics are present: A11, B11, F11, F15, G11, M25, M30, O11, O12, O13, O14, O15, O16, O17, O18, O34, O35, R20, R21, R22, S02, S03. Nineteen items of pottery from this Group are illustrated (Appendix 6 ). The pottery types represented are of middle to late Roman date. The latest pottery types present (including a Black Burnished Ware 1 dish, Oxfordshire parchment ware and Oxfordshire red/brown colour-coated ware) date from the mid 3rd century, c. AD 240.

The range of fabrics present in Group 6 includes virtually all of those present in Group 5, together with rarer fabrics at Ariconium (e.g. F15 and M30) and others which have a comparatively late debut (e.g. F11 and O34). The composition of the group by RE is presented in Table 9; the RE total is small but is drawn from a sample of $c .40$ rim sherds and should therefore constitute a reliable index. Oxidized Severn Valley wares form the majority of the pottery of this group, with the 'Unoxidized Severn Valley wares' R20 and R21 comprising very similar proportions amongst the group as in Group 5. Again R21 is the most prominent of the 'Unoxidized Severn Valley wares'. Extraregional products occur with moderate frequency. B11 is slightly more frequent than amongst the preceding period (Group 5). Lezoux samian (S03) is less prominent than with Group 5, but still accounts for c. $11.6 \%$ of the RE total. The Lezoux samian will have been manufactured 
Table 10. Quantification by fabric of Analytical Group 7. Bridgewater excavations 1963, context (Layer) 1

\begin{tabular}{|l|r|r|}
\hline Fabric & RE Total & \% \\
\hline B11 - Black Burnished Ware 1 & 2.49 & $\mathbf{2 1 . 4}$ \\
\hline F11 - Oxfordshire red/brown colour-coated ware & 0.10 & $\mathbf{0 . 9}$ \\
\hline F13 - Central Gaulish black slipped ware & 0.12 & $\mathbf{1 . 0}$ \\
\hline G11 - Malvernian metamorphic ware & 0.07 & $\mathbf{0 . 6}$ \\
\hline M25 - Oxfordshire white ware mortaria fabric & 0.13 & $\mathbf{1 . 1}$ \\
\hline O11, O12, O14, O15, O16, O17, O18, O19, O24 - Oxidized Severn & 6.54 & $\mathbf{5 6 . 1}$ \\
Valley wares & & \\
\hline R20 - Coarse 'Unoxidized Severn Valley ware' & 0.07 & $\mathbf{0 . 6}$ \\
\hline R21 - Finer 'Unoxidized Severn Valley ware' & 1.53 & $\mathbf{1 3 . 1}$ \\
\hline R24 - Unoxidized, possible 'Unoxidized Severn Valley ware' variant & 0.04 & $\mathbf{0 . 3}$ \\
\hline S01 - South Gaulish La Graufesenque samian & 0.05 & $\mathbf{0 . 4}$ \\
\hline S03 - Central Gaulish Lezoux samian & 0.48 & $\mathbf{4 . 1}$ \\
\hline S04 - East Gaulish samian & 0.04 & $\mathbf{0 . 3}$ \\
\hline Totals & $\mathbf{1 1 . 6 6}$ & 100.00 \\
\hline
\end{tabular}

during the 2 nd century, but presumably a proportion of vessels will have remained in use into the 3rd century. (The large majority of these sherds in Group 6 date from after $c$. AD 150 in any case). There is no East Gaulish samian present.

\section{Analytical Group 7. Date range of pottery (disturbed deposit) c. AD 230/250-300/350. Bridgewater excavations 1963, Layer 1}

Bridgewater's 'Layer 2' underlay a disturbed soil, 'Layer 1 ', which lacked large slag fragments and contained clay tobacco pipe stems and post-medieval pottery in addition to Roman pottery. From Bridgewater's account Layer 1 seemingly represents a 17 th/18th century disturbance of Layer 2 (Group 6) together perhaps with a levelling of deposits at this time (Bridgewater 1965, 128 and 132). Hence it is not a secure stratified Roman deposit, though it underlies modern subsoil and ploughsoil horizons. With this proviso, it nonetheless provides a further indication of the pottery in use at Ariconium in the later Roman period.

There are 220 surviving Roman sherds from context 1 , together with 7 medieval/post medieval sherds. The total includes 125 rim sherds from Roman vessels with an RE value of 11.66 (Table 10). The following Roman fabrics are present: A11, B11, F11, F13, F16, G11, M10, M25, O11, O12, O13, O14, O15, O16, O17, O18, O19, O24, O30, O31, O32, O34, O35, R20, R21, R24, S01, S03, S04. Some 50 items are illustrated (Appendix 6). As with Group 6 the pottery types are of middle to late Roman date. The latest pottery types present largely date from the mid to late 3rd century, $c$. AD 250/270, and include a series of Oxfordshire ware items (e.g. Oxfordshire red/brown colour-coated ware, White ware mortaria and Parchment ware), plus Black Burnished Ware. These items, together with some not closely dateable Severn Valley ware types (such as the bowl of Webster type 72; Webster 1976; fig. 14.2) could actually be 4th century. In sum it would seem that there is nothing present that is necessarily later than c. AD 325. The range of fabrics present is similar to the character of Groups 5 and 6.
Oxidized Severn Valley wares again dominate the group, forming the same proportion of the Group as in the case of Group 6. Similarly R21 is a significant group component, forming a near identical proportion of this group as it does in Group 6. B11, however, registers more strongly, probably for chronological reasons: elsewhere in the West Midlands the supply of Black Burnished Ware 1 becomes most important in the late 3 rd and 4th centuries, as for instance at Alcester ( $c f$. Evans 1994, 144). Overall the composition of Group 7 is not greatly different from that of Group 4 from Garrod and Moss' excavations, despite the fact that the latter is earlier in date and from a different part of the site.

\section{Analytical Group 8. Maximum potential date} range: c. $70 B C-A D$ 400. Surface collected assemblage from field HSM 21376: systematic gridded collection by Dean Archaeological Group, October 1986 ('AR100')

Between 1984 and 1989 Dean Archaeological Group carried out a series of fieldwalking exercises at Ariconium, walking fields both within and without the scheduled area (Jackson and Hancocks 1998). In the autumn of 1986 DAG conducted a gridded collection within the scheduled part of Field HSM 21376, along a line running just within, and parallel to, the south-western boundary of this field. The south-eastern terminal of this line lay at the boundary of the scheduled area on its eastern side; from this point a series of 12 contiguous squares measuring $25 \mathrm{~m}$ by $25 \mathrm{~mm}$ and running SE-NW was laid out and walked (Fig. 1.4). In effect, the surface collection covers a $c .300 \mathrm{~m}$ transect SE-NW across the known core area of the Iron Age and Roman occupation and hence constitutes a potentially valuable sample of material surviving in topsoil. The 12 squares of the transect were prefixed AR 100, and finds bagged separately per square.

For this analysis the material from the 12 squares is combined in order to attain a reasonably sized sample. The collection includes rim sherds from 90 Iron Age and Roman vessels with a low RE value of 6.10 . The fabrics 
Table 11. Quantification by fabric of Analytical Group 8. Surface collected assemblage from Field HSM 21376, collected by Dean Archaeology Group, October 1986 ('AR 100')

\begin{tabular}{|l|c|c|}
\hline Fabric & RE Total & \% \\
\hline B11 - Black Burnished Ware 1 & 0.12 & $\mathbf{2 . 0}$ \\
\hline C11 - Limestone tempered ware & 0.05 & $\mathbf{0 . 8}$ \\
\hline F11 - Oxfordshire red/brown colour-coated ware & 0.23 & $\mathbf{3 . 8}$ \\
\hline M25 - Oxfordshire white ware mortaria fabric & 0.16 & $\mathbf{2 . 6}$ \\
\hline $\begin{array}{l}\text { O11, O12, O14, O15, O16, O17, O18, O23 - Oxidized Severn Valley } \\
\text { wares }\end{array}$ & 4.35 & $\mathbf{7 1 . 3}$ \\
\hline R20 - Coarse 'Unoxidized Severn Valley ware' & 0.35 & $\mathbf{5 . 7}$ \\
\hline R21 - Finer 'Unoxidized Severn Valley ware' & 0.21 & $\mathbf{3 . 5}$ \\
\hline R24 - Unoxidized, possible 'Unoxidized Severn Valley ware' variant & 0.14 & $\mathbf{2 . 3}$ \\
\hline R34 - 'Unoxidized Severn Valley ware' variant & 0.19 & $\mathbf{3 . 1}$ \\
\hline S01 - South Gaulish La Graufesenque samian & 0.05 & $\mathbf{0 . 8}$ \\
\hline S03 - Central Gaulish Lezoux samian & 0.25 & $\mathbf{4 . 1}$ \\
\hline Totals & $\mathbf{6 . 1 0}$ & 100.00 \\
\hline
\end{tabular}

present are: B11, C11, F11, M25, O11, O12, O14, O15, O16, O17, O18, O23, R20, R21, R24, R34, S01, S03. Three vessels are illustrated (Appendix 6).

The pottery types cover the late Iron Age to the late Roman era. The potential date range is $c .70 \mathrm{BC}$ to $\mathrm{AD} 400$. A series of items come from types with a late $3 \mathrm{rd}$ to 4 th century date range, including several Oxfordshire vessels. A bowl of Young type C68, which should be exclusively 4th century is present. Overall there is nothing present which necessarily pre-dates $c$. AD 1 or post-dates $c$. AD 330. The composition of the Group as a whole is shown in Table 11.

\section{Analytical Group 9. Maximum potential date range: c. $70 B C-A D$ 400. Surface collected assemblage from Field HSM 21376: collection by Dean Archaeological Group, 1980s}

Group 8 is evidently the only systematic collection undertaken by DAG which survives as an integral unit. An area to the east of the scheduled area was walked on a systematic basis by the South Worcestershire Archaeological Group in 1986, HSM 22049 (Jackson and Hancocks 1998), but recovered mainly post-medieval pottery and less than a dozen Iron Age and Roman sherds. There is a further DAG surface collected group from Field HSM 21376, covering the northern half of the scheduled area which forms a useful comparison with other Ariconium groups. It is uncertain how this particular collection was organised or managed, nor whether the material is from the whole or part of the field; hence there are necessary reservations attached to any interpretation of these data. However, in the absence of well-collected and recorded samples it is necessary to examine collections such as Group 9.

This collection includes 176 rim sherds from Iron Age and Roman vessels with an RE value of 13.23. The fabrics represented by rims are: A11, B11, C11, F11, G11, M25, O10, O14, O16, O18, R20, R21, R22, R26, R28, S02, S03. (Fabric A13 is represented by a body sherd). Six vessels are illustrated (Appendix 6). Again the types cover the late Iron Age to the late Roman era and the potential date range is $c .70 \mathrm{BC}$ to $\mathrm{AD} 400$. A considerable number of items come from types with a late 3 rd to 4 th century date range. A probable 4th century tankard is represented. Strictly stated, there is nothing amongst the group which need pre-date $c$. AD 1 or post-dates $c$. AD 330. Group composition is shown in Table 12.

Groups 8 and 9 clearly present a consistent picture. Both are dominated by Oxidized Severn Valley wares which in both cases account for nearly three quarters of the recovered RE. Black Burnished Ware (B11) is present in quite modest proportions, as is R21, a fabric which in some of the stratified groups registers much more strongly. R20 is also present in small proportions. These comparatively low levels of B11, R20 and R21 might be explained by the fact that as dark fabrics they may have been less visible to fieldwalkers against a dark soil background than sherds of Oxidized Severn Valley ware. Second century Lezoux ware is the most frequent samian type in both groups. On the whole extra-regional wares, and fine wares generally, are comparatively rare, as are mortaria. Limestone tempered ware is present amongst both samples. This is not surprising since the various excavations in this field and its vicinity have yielded many examples. The quantity of this ware amongst Groups 8 and 9 might seem low given its showing amongst stratified levels. Two possibilities arise: either examples of the fabric are sealed in early deposits which have not been incorporated into the topsoil, or sherds of the fabric which are incorporated into the topsoil have broken down due to weathering. Group 9 also includes examples of early dark surfaced wares (R26 and R28).

\section{Residuality}

Residuality, namely the presence of old, perhaps reworked, sherds in more recent deposits does not appear to be a particular problem with these Ariconium groups. Generally, contexts have evidently relatively low levels of residual material present.

In the case of the early Groups 1-3 residual pottery is not identifiable (if present) since the date ranges (or currency) of the pottery types present fall wholly, or in part, within the date-range for the deposition of the group. 
Table 12. Quantification by fabric of Analytical Group 9. Surface collected assemblage from Field HSM 21376, collected by Dean Archaeology Group, 1980 s

\begin{tabular}{|l|r|r|}
\hline Fabric & RE Total & \% \\
\hline A11 - Dressel 20 amphora & 0.14 & $\mathbf{1 . 0}$ \\
\hline B11 - Black Burnished Ware 1 & 0.75 & $\mathbf{5 . 7}$ \\
\hline C11 - Limestone tempered ware & 0.62 & $\mathbf{4 . 7}$ \\
\hline F11 - Oxfordshire red/brown colour-coated ware & 0.13 & $\mathbf{1 . 0}$ \\
\hline G11 - Malvernian metamorphic ware & 0.06 & $\mathbf{0 . 4}$ \\
\hline M25 - Oxfordshire white ware mortaria fabric & 0.12 & $\mathbf{0 . 9}$ \\
\hline O10, O14, O16, O18 - Oxidized Severn Valley wares & 9.91 & $\mathbf{7 4 . 9}$ \\
\hline R20 - Coarse 'Unoxidized Severn Valley ware' & 0.39 & $\mathbf{2 . 9}$ \\
\hline R21 - Finer 'Unoxidized Severn Valley ware' & 0.47 & $\mathbf{3 . 5}$ \\
\hline R22 - 'Unoxidized Severn Valley ware' variant & 0.04 & $\mathbf{0 . 3}$ \\
\hline R26 - Distinctive dark surfaced transitional ware & 0.14 & $\mathbf{1 . 1}$ \\
\hline R28 - Distinctive dark surfaced transitional ware & 0.07 & $\mathbf{0 . 5}$ \\
\hline S02 - Central Gaulish Les Martres samian & 0.05 & $\mathbf{0 . 4}$ \\
\hline S03 - Central Gaulish Lezoux samian & 0.34 & $\mathbf{2 . 6}$ \\
\hline Totals & $\mathbf{1 3 . 2 3}$ & 100.00 \\
\hline
\end{tabular}

The degree of residual material within Group 4 is noted under the discussion of the fabric composition of that group (above); the level is indicated by the proportion of C11 present, a fabric type which should have passed out of use by the time of the period of the deposition of this group. The figures presented in Table 7 suggest that the level of residual pottery amongst Group 4 is probably $c$. $10-15 \%$. In Group 6 the level of residual pottery seems likely to be low; whereas Group 5 relates to an initial phase of activity in a previously unused location.

The frequency of samian types, which are well-dated, can often provide a useful guide to the level of residual pottery in a site context, phase or period. In Group 4, for instance, which will have been deposited $c$. AD 100-200/250, most if not all of the South Gaulish samian should be residual; it forms $c .1 .1 \%$ of the group by RE. An endemic complication, however, resides in the types which are less diagnostic of date, and this is the case particularly with Oxidized Severn Valley wares. The Oxidized Severn Valley wares at Ariconium occur in a series of fabric variants many of which are clearly long-lived, and which endure through much if not all of the Roman period. This lack of chronological distinctiveness amongst the fabrics is exacerbated by the fact that many of the forms in which Oxidized Severn Valley wares occur show longevity and continuity through time (cf. Webster 1976). The situation is assisted to a degree in the case of the present assemblages by the fact that such a high proportion of these sherds are rims, that is to say, from the most chronologically indicative part of a vessel.

\section{The pottery groups: quantification by vessel form}

The Fulford and Huddleston review of Roman pottery studies (1991) noted the importance of documenting the occurrence of pottery forms amongst groups and assemblages via quantified information. In this section tables and other data are produced showing details of the incidence of vessel forms amongst the stratified and surface collected assemblages from Ariconium, by phase and provenance. Again EVE data by Rim Equivalent are used in all cases for the reasons outlined in the Introduction. The pottery groups are the same as those scrutinised above, where group composition by fabric was examined. As with the examination of fabric, analysis is only appropriate for samples of some size and this determines which groups can be examined.

\section{Analytical Group 1. Date: c. AD 50/70-100.} Garrod and Moss excavations, Trench AI context 3 and Trench AII context 6

Details of this group have been outlined above, where its composition by fabric was presented. The group is sufficiently large to yield reliable results (Jeremy Evans, pers comm.), including 35 rim sherds with an RE of 3.88. Table 13 shows a wide range of functional types represented, with beakers the dominant type. The latter occur in a range of fabrics, though their tally is rather inflated by the presence of much of a single beaker in R27 (Table 14). It is of interest that beakers are present in Severn Valley ware, as examples of the ware in this form are rare for this period (i.e. the mid-1st century AD); they parallel the beakers known from Kingsholm, Gloucester (Hurst 1985), with which they may be contemporary (or of even earlier manufacture). Jars are well represented, but bowls form a surprisingly low proportion of the Group. Oxidized Severn Valley wares occur in a wide range of forms; the tankard has made its debut.

\section{Analytical Group 2. Date: c. AD 50/70-100. Garrod and Moss excavations, Trench BIII context 5}

There is only a very small quantity of pottery associated with the early pit fill, BIII context 5 , with an RE of 0.70 . This quantity is too small to permit analysis but its composition (in absolute RE figures) is recorded in Table 15. 
Table 13. Summary quantification by vessel form of Analytical Group 1. Garrod and Moss excavations, Trench AI context 3 and Trench AII context 6

\begin{tabular}{|l|c|r|}
\hline & $\boldsymbol{R E}$ Total & \multicolumn{1}{c|}{$\%$} \\
\hline Jars & 1.20 & $\mathbf{3 0 . 9}$ \\
\hline Storage jars & 0.43 & $\mathbf{1 1 . 1}$ \\
\hline Jars/bowls & 0.04 & $\mathbf{1 . 0}$ \\
\hline Beakers & 1.68 & $\mathbf{4 3 . 3}$ \\
\hline Tankards & 0.13 & $\mathbf{3 . 4}$ \\
\hline Bowls & 0.18 & $\mathbf{4 . 6}$ \\
\hline Very large bowls & 0.09 & $\mathbf{2 . 3}$ \\
\hline Dishes/platters & 0.13 & $\mathbf{3 . 4}$ \\
\hline Totals: & $\mathbf{3 . 8 8}$ & 100.00 \\
\hline
\end{tabular}

Table 14. Quantification by vessel form and fabric of Analytical Group 1. Figures expressed as percentages. (*SVW $=$ Severn Valley ware)

\begin{tabular}{|l|r|r|r|r|c|}
\hline & $\boldsymbol{C 1 1}$ & $\begin{array}{c}\text { Oxidized } \\
\text { SVW* }\end{array}$ & $\boldsymbol{R 2 0}$ & $\boldsymbol{R 2 1}$ & $\boldsymbol{R 2 7}$ \\
\hline Jars & 13.4 & 8.5 & & 9.0 & \\
\hline Storage jars & & & 11.0 & & \\
\hline Jars/bowls & & 1.0 & & & \\
\hline Beakers & & 13.4 & & 10.0 & 19.8 \\
\hline Tankards & & 3.4 & & & \\
\hline Bowls & & 4.6 & & & \\
\hline Very large bowls & 2.3 & & & & \\
\hline Dishes/platters & & 3.4 & & & \\
\hline \% of Group: & $\mathbf{1 5 . 7}$ & $\mathbf{3 4 . 3}$ & $\mathbf{1 1 . 0}$ & $\mathbf{1 9 . 0}$ & $\mathbf{1 9 . 8}$ \\
\hline
\end{tabular}

Table 15. The composition of Analytical Group 2 by vessel form and fabric. Garrod and Moss excavations, Trench BIII context 5. Figures expressed as absolute RE values

\begin{tabular}{|l|c|c|c|c|}
\hline & C11 & $\begin{array}{c}\text { Oxidized } \\
\text { SVW }\end{array}$ & $\boldsymbol{R 2 1}$ & $\boldsymbol{R 2 8}$ \\
\hline Jars & 0.19 & & 0.15 & 0.06 \\
\hline Jars/Bowls & 0.07 & & & \\
\hline Bowls & & 0.13 & & \\
\hline Lids & 0.10 & & & \\
\hline
\end{tabular}

Analytical Group 3. Date: c. AD 50-100. Garrod and Moss excavations, Trench BI contexts $2 a$ and $2 b$, Trench BII contexts 2 and 3 , and Trench BIII context 2

This group has been outlined above, where its composition by fabric was presented. Some 119 rim sherds of late Iron Age and Roman pottery survive amounting to an RE total of 13.63 (Tables 16 and 17). The group is dominated by typologically late Iron Age and Transitional vessels in Fabrics C11 and R29, etc. The dark surfaced wares with fine-grained sandstone/siltstone tempering, R25, R26, R29 and R31 are typologically similar and are combined for analysis.

By form, beakers are much less important amongst this group than is the case with Group 1. Jars and storage jars (as with Group 1) form large proportions of the group while bowls account for about a quarter of the group and are particularly associated with Dark surfaced Transitional wares. There is a rim sherd in $\mathrm{C} 11$ which appears to be from a tankard.

Analytical Group 4. Date: c. AD 100-200/250. Garrod and Moss excavations, Trench AI, contexts 2 and $2 a$, and Trench AII, contexts 3, 4 and 5

Group 4 includes 134 rim sherds from Iron Age and Roman pottery vessels with an RE of 17.07. The composition of the group by basic form type is recorded in Table 18. This shows a similar picture to the earlier group, Group 3 , with a wide range of forms present. Jars and storage jars occur in proportions that mirror their importance in
Group 3. Jars appear in a range of fabrics (Table 19). Bowls are somewhat less prominent than amongst Group 3 ; nonetheless they are the second most frequent form type (as in Group 3).

Oxidized Severn Valley wares form the majority of the pottery by fabric and, as Table 19 confirms, were employed in the manufacture of almost all basic vessel classes by this time. This pattern is also apparent with the 'Unoxidized Severn Valley ware' type, R21.

Analytical Group 5. Date: c. AD 135-230/250. Bridgewater excavations 1963, all contexts predating context 2

Group 5 is of very modest size, amounting to 64 sherds of late Iron Age and Roman pottery and an RE total of 2.75. Tables 20 and 21 show the composition of the group by form. Jars and bowls are the most common forms in that order; there are no examples of storage jars, though this is probably a function of small group size. Beakers form only a very modest proportion of the Group which foreshadows their infrequency amongst Groups 6 and 7.

Analytical Group 6. Date: c. AD 230/250-400. Bridgewater excavations 1963, context 2

Group 6 has been discussed above from the point of view of fabric composition. The 81 sherds surviving from this context have a RE figure of 4.40 . The constitution of the group by form is presented in Tables 22 and 23. 
Table 16. Summary quantification by vessel form of Analytical Group 3. Garrod and Moss excavations, Trench BI contexts 2 a and $2 b$, Trench BII contexts 2 and 3, and Trench BIII context 2

\begin{tabular}{|l|r|r|}
\hline & RE Total & \% \\
\hline Jars & 5.80 & $\mathbf{4 2 . 6}$ \\
\hline Storage jars & 2.45 & $\mathbf{1 8 . 0}$ \\
\hline Jars/bowls & 0.51 & $\mathbf{3 . 7}$ \\
\hline Beakers & 0.59 & $\mathbf{4 . 3}$ \\
\hline Cups & 0.25 & $\mathbf{1 . 8}$ \\
\hline Tankards & 0.63 & $\mathbf{4 . 6}$ \\
\hline Bowls & 3.27 & $\mathbf{2 4 . 0}$ \\
\hline Uncertain & 0.13 & $\mathbf{0 . 9}$ \\
\hline Totals & $\mathbf{1 3 . 6 3}$ & 100.00 \\
\hline Excluded, three S03 (Lezoux samian) rims: intrusive & 0.10 & \\
\hline
\end{tabular}

Table 17. Quantification by vessel form and fabric of Analytical Group 3. Figures expressed as percentages

\begin{tabular}{|l|c|c|c|c|c|c|c|}
\hline & $\boldsymbol{C 1 1}$ & $\begin{array}{c}\text { Oxidized } \\
\mathbf{S V W}\end{array}$ & $\boldsymbol{R 2 0}$ & $\boldsymbol{R 2 1}$ & $\begin{array}{c}\boldsymbol{R 2 5}, \\
\boldsymbol{R 2 6 ,} \\
\boldsymbol{R 2 9 ,} \boldsymbol{R 3 1}\end{array}$ & $\boldsymbol{R 2 8}$ & $\boldsymbol{R 3 0}$ \\
\hline Jars & 33.4 & 6.2 & 0.8 & & 2.2 & & \\
\hline Storage jars & 13.7 & & 0.6 & & 3.7 & & \\
\hline Jars/bowls & 1.6 & 1.3 & & & 0.8 & & \\
\hline Beakers & & & & & & 1.0 & 3.4 \\
\hline Cups & 1.0 & & & & 0.8 & & \\
\hline Tankards & 0.4 & 4.2 & & & & & 3.9 \\
\hline Bowls & 0.6 & 3.4 & 0.7 & 4.0 & 11.4 & & \\
\hline Uncertain & & 0.5 & & & 0.4 & & $\mathbf{7 . 3}$ \\
\hline \% of Group: & $\mathbf{5 0 . 7}$ & $\mathbf{1 5 . 6}$ & $\mathbf{2 . 1}$ & $\mathbf{4 . 0}$ & $\mathbf{1 9 . 3}$ & $\mathbf{1 . 0}$ & \\
\hline
\end{tabular}

Table 18. Summary quantification by vessel form of Analytical Group 4. Garrod and Moss excavations, Trench AI contexts 2 and $2 a$ and Trench AII contexts 3, 4 and 5

\begin{tabular}{|l|r|r|}
\hline & RE Total & \multicolumn{1}{|c|}{ \% } \\
\hline Jars & 6.94 & $\mathbf{4 1 . 1}$ \\
\hline Storage jars & 2.49 & $\mathbf{1 4 . 7}$ \\
\hline Jars/bowls & 0.26 & $\mathbf{1 . 5}$ \\
\hline Beakers & 1.88 & $\mathbf{1 1 . 1}$ \\
\hline Cups & 0.25 & $\mathbf{1 . 5}$ \\
\hline Tankards & 1.09 & $\mathbf{6 . 5}$ \\
\hline Bowls & 2.84 & $\mathbf{1 6 . 8}$ \\
\hline Very large bowls & 0.18 & $\mathbf{1 . 1}$ \\
\hline Dishes/platters & 0.75 & $\mathbf{4 . 4}$ \\
\hline Mortaria & 0.15 & $\mathbf{0 . 9}$ \\
\hline Uncertain & 0.07 & $\mathbf{0 . 4}$ \\
\hline Totals & $\mathbf{1 6 . 9 0}$ & 100.00 \\
\hline (Excluded late B11 rim) & 0.17 & \\
\hline
\end{tabular}

Table 19. Quantification by vessel form and fabric of Analytical Group 4. Figures expressed as percentages; F18, F19, and M25 (1.8\%) not included

\begin{tabular}{|l|c|c|c|c|c|c|c|c|c|c|}
\hline & C11 & B11 & $\begin{array}{c}\text { Oxid'd } \\
\text { SVW }\end{array}$ & O36 & R20 & R21 & R22 & R24 & $\begin{array}{c}\text { R28, } \\
\text { R29 }\end{array}$ & $\begin{array}{c}\text { S01, } \\
\text { S02, } \\
\text { S03 }\end{array}$ \\
\hline Jars & 4.1 & 0.8 & 14.1 & & & 17.9 & 0.9 & 1.7 & 1.5 & \\
\hline Storage jars & & & 10.0 & & 4.7 & & & & & \\
\hline Jars/bowls & & & 0.8 & & & 0.8 & & & & \\
\hline Beakers & & & 5.4 & & & 4.3 & & & 0.7 & \\
\hline Cups & & & 0.7 & & & & & & & 0.8 \\
\hline Tankards & & & 6.4 & & & & & & & \\
\hline Bowls & & & 12.5 & 1.8 & & 2.2 & & & & 0.2 \\
\hline V. large bowls & 1.1 & & & & & & & & & \\
\hline Dishes/platters & & & 3.3 & & & 0.5 & & & & 0.7 \\
\hline Uncertain & & & 0.4 & & & & & & & \\
\hline \% of Group: & $\mathbf{5 . 2}$ & $\mathbf{0 . 8}$ & $\mathbf{5 3 . 6}$ & $\mathbf{1 . 8}$ & $\mathbf{4 . 7}$ & $\mathbf{2 5 . 7}$ & $\mathbf{0 . 9}$ & $\mathbf{1 . 7}$ & $\mathbf{2 . 2}$ & $\mathbf{1 . 7}$ \\
\hline
\end{tabular}


Table 20. Summary quantification by vessel form of Analytical Group 5. Bridgewater excavations 1963, all contexts pre-dating context (Layer) 2

\begin{tabular}{|l|c|c|}
\hline & $\boldsymbol{R E}$ Total & \multicolumn{1}{|c|}{} \\
\hline Jars & 1.59 & $\mathbf{5 7 . 8}$ \\
\hline Beakers & 0.14 & $\mathbf{5 . 1}$ \\
\hline Cups & 0.05 & $\mathbf{1 . 8}$ \\
\hline Bowls & 0.68 & $\mathbf{2 4 . 7}$ \\
\hline Dishes/platters & 0.29 & $\mathbf{1 0 . 6}$ \\
\hline Totals & $\mathbf{2 . 7 5}$ & 100.00 \\
\hline
\end{tabular}

Table 21. Quantification by vessel form and fabric of Analytical Group 5. Figures expressed as percentages

\begin{tabular}{|l|r|r|r|r|r|}
\hline & $\boldsymbol{B 1 1}$ & $\begin{array}{c}\text { Oxid'd } \\
\text { SVW }\end{array}$ & $\boldsymbol{R 2 0}$ & $\boldsymbol{R 2 1}$ & $\boldsymbol{S 0 3}$ \\
\hline Jars & 2.2 & 35.6 & 5.8 & 14.2 & \\
\hline Beakers & & 5.1 & & & \\
\hline Cups & & & & & 1.8 \\
\hline Bowls & 5.1 & 2.9 & & & 16.7 \\
\hline Dishes/platters & & & & & 10.6 \\
\hline \% of Group: & $\mathbf{7 . 3}$ & $\mathbf{4 3 . 6}$ & $\mathbf{5 . 8}$ & $\mathbf{1 4 . 2}$ & $\mathbf{2 9 . 1}$ \\
\hline
\end{tabular}

Table 22. Summary quantification by vessel form of Analytical Group 6. Bridgewater excavations 1963, context (Layer) 2

\begin{tabular}{|l|c|r|}
\hline & RE Total & \multicolumn{1}{|c|}{ \% } \\
\hline Jars & 1.69 & $\mathbf{3 8 . 4}$ \\
\hline Storage jars & 1.25 & $\mathbf{2 8 . 4}$ \\
\hline Jars/bowls & 0.08 & $\mathbf{1 . 8}$ \\
\hline Cups & 0.18 & $\mathbf{4 . 1}$ \\
\hline Tankards & 0.31 & $\mathbf{7 . 1}$ \\
\hline Bowls & 0.49 & $\mathbf{1 1 . 1}$ \\
\hline Dishes/platters & 0.33 & $\mathbf{7 . 5}$ \\
\hline Mortaria & 0.07 & $\mathbf{1 . 6}$ \\
\hline Totals & $\mathbf{4 . 4 0}$ & 100.00 \\
\hline
\end{tabular}

Table 23. Quantification by vessel form and fabric of Analytical Group 6. Figures expressed as percentages

\begin{tabular}{|l|c|c|c|c|c|c|c|}
\hline & B11 & M25 & $\begin{array}{c}\text { Oxid'd } \\
\text { SVW }\end{array}$ & R20 & R21 & R22 & S03 \\
\hline Jars & 6.1 & & 11.6 & 2.5 & 15.4 & 2.7 & \\
\hline Storage jars & & & 27.9 & 0.5 & & & \\
\hline Jars/bowls & & & 1.8 & & & & \\
\hline Cups & & & & & & & 4.1 \\
\hline Tankards & & & 7.0 & & & & \\
\hline Bowls & 4.5 & & 6.6 & & & & \\
\hline Dishes/platters & & & & & & & 7.5 \\
\hline Mortaria & & 1.6 & & & & & \\
\hline \% of Group: & $\mathbf{1 0 . 7}$ & $\mathbf{1 . 6}$ & $\mathbf{5 5 . 0}$ & $\mathbf{3 . 0 0}$ & $\mathbf{1 5 . 4}$ & $\mathbf{2 . 7}$ & $\mathbf{1 1 . 6}$ \\
\hline
\end{tabular}

Analytical Group 7. Date: (disturbed) c. AD 230/250400. Bridgewater excavations 1963, context 1

Group 7 includes 125 rim sherds from Roman vessels with an RE value of 11.66. As noted above it is not a secure stratified Roman deposit, though it provides further indication of the pottery being consumed at Ariconium in the later Roman period. Jars remain the most important form. Tankards are comparatively well represented, while dishes, present in a range of fabrics, are more frequent than in Groups 5 and 6 (Tables 24 and 25).
Analytical Group 8: Date: c. 70 BC-AD 400. Surface collected assemblage from Field HSM 21376: systematic gridded collection by Dean Archaeological Group, October 1986 ('AR100')

The collection strategy behind Group 8 has been outlined above. The collection includes (rather fragmentary) rim sherds from 90 Iron Age and Roman vessels with a RE value of 6.10; Oxidized Severn Valley wares are preeminent. The composition of the group by form is shown in Tables 26 and 27. There is a clear consistency between the composition of this group (by form) and the excavated 
Table 24. Summary quantification by vessel form of Analytical Group 7. Bridgewater excavations 1963, context (Layer) 1

\begin{tabular}{|l|r|r|}
\hline & RE Total & \multicolumn{1}{|c|}{$\%$} \\
\hline Flagons/jugs & 0.13 & $\mathbf{1 . 1}$ \\
\hline Jars & 5.11 & $\mathbf{4 3 . 8}$ \\
\hline Storage jars & 1.11 & $\mathbf{9 . 5}$ \\
\hline Beakers & 0.16 & $\mathbf{1 . 4}$ \\
\hline Cups & 0.23 & $\mathbf{2 . 0}$ \\
\hline Tankards & 2.08 & $\mathbf{1 7 . 8}$ \\
\hline Bowls & 0.96 & $\mathbf{8 . 2}$ \\
\hline Bowls/dishes & 0.07 & $\mathbf{0 . 6}$ \\
\hline Dishes/platters & 1.68 & $\mathbf{1 4 . 4}$ \\
\hline Mortaria & 0.13 & $\mathbf{1 . 1}$ \\
\hline Totals & $\mathbf{1 1 . 6 6}$ & 100.00 \\
\hline
\end{tabular}

Table 25. Quantification by vessel form and fabric of Analytical Group 7.Figures expressed as percentages

\begin{tabular}{|c|c|c|c|c|c|c|c|c|c|c|c|c|}
\hline & B11 & $F 11$ & $F 13$ & G11 & $M 25$ & $\begin{array}{c}\text { Oxid2 } \\
d S V W\end{array}$ & $R 20$ & $R 21$ & $R 24$ & S01 & S03 & S04 \\
\hline $\begin{array}{l}\text { Flagons/ } \\
\text { jugs }\end{array}$ & & & & & & 1.1 & & & & & & \\
\hline Jars & 12.6 & & & 0.6 & & 23.3 & 0.6 & 6.7 & & & & \\
\hline Storage jars & & & & & & 5.0 & & 4.4 & & & & \\
\hline Beakers & & & 1.0 & & & 0.4 & & & & & & \\
\hline Cups & & & & & & & & & & & 2.0 & \\
\hline Tankards & & & & & & 17.5 & & & 0.3 & & & \\
\hline Bowls & 1.1 & 0.9 & & & & 6.30 & & & & & & \\
\hline $\begin{array}{l}\text { Bowls/ } \\
\text { dishes }\end{array}$ & & & & & & & & & & & 0.6 & \\
\hline $\begin{array}{l}\text { Dishes/ } \\
\text { platters }\end{array}$ & 7.7 & & & & & 2.5 & & 2.0 & & 0.4 & 1.5 & 0.3 \\
\hline Mortaria & & & & & 1.1 & & & & & & & \\
\hline$\%$ of Group: & 21.4 & 0.9 & 1.0 & 0.6 & 1.1 & 56.1 & 0.6 & 13.1 & 0.3 & 0.4 & 4.1 & 0.3 \\
\hline
\end{tabular}

groups examined here ( $c f$. Table 18, Group 4, with its near identical composition).

Analytical Group 9: Date: c. 70 BC-AD 400. Surface collected assemblage from Field HSM 21376: collection by Dean Archaeological Group, $1980 \mathrm{~s}$

The collection policy behind Group 9 is described above. The 176 rim sherds from Iron Age and Roman vessels of this Group amount to an RE value of 13.23. Group 9 has jars and storage jars in similar proportion to Group 8 (Tables 28 and 29). However, beakers are less frequent than in Group 8, while tankards and bowls are both twice as more frequent than in that group. This difference is due essentially to the varying composition of the Severn Valley ware components in both groups ( $c f$. Tables 27 and 29). Dishes/platters are poorly represented in both. Overall the make-up of Group 9 by form is very similar to that of the stratified Group 4.

\section{The mortaria}

A range of mortaria fabrics and forms occur amongst the present assemblages from Ariconium. Most of these are
Table 26. Summary quantification by vessel form of Analytical Group 8. Surface collected assemblage from Field HSM 21376 : systematic gridded collection by Dean Archaeological Group, October 1986

\begin{tabular}{|l|c|r|}
\hline & RE Total & \multicolumn{1}{|c|}{ \% } \\
\hline Amphorae & 0.14 & $\mathbf{1 . 0}$ \\
\hline Flagons/jugs & 0.12 & $\mathbf{0 . 9}$ \\
\hline Jars & 5.66 & $\mathbf{4 2 . 8}$ \\
\hline Storage jars & 2.28 & $\mathbf{1 7 . 2}$ \\
\hline Jars/bowls & 0.13 & $\mathbf{1 . 0}$ \\
\hline Beakers & 0.59 & $\mathbf{4 . 5}$ \\
\hline Cups & 0.20 & $\mathbf{1 . 5}$ \\
\hline Tankards & 1.52 & $\mathbf{1 1 . 5}$ \\
\hline Bowls & 2.06 & $\mathbf{1 5 . 6}$ \\
\hline Bowls/dishes & 0.16 & $\mathbf{1 . 2}$ \\
\hline Dishes/platters & 0.22 & $\mathbf{1 . 7}$ \\
\hline Mortaria & 0.12 & $\mathbf{0 . 9}$ \\
\hline Uncertain & 0.03 & $\mathbf{0 . 2}$ \\
\hline Totals & $\mathbf{1 3 . 2 3}$ & 100.00 \\
\hline
\end{tabular}

familiar traded types. There are no examples of mortaria in Severn Valley ware nor in the buff-cream ware of the type sometimes referred to as West Midlands mortaria (Hurst and Rees 1992, fabric 34). There are no stamps present. 
Table 27. Quantification by vessel form and fabric of Analytical Group 8. Figures expressed as percentages

\begin{tabular}{|l|c|c|c|c|c|c|c|c|c|c|}
\hline & B11 & $\boldsymbol{C 1 1}$ & $\boldsymbol{F 1 1}$ & $\mathbf{M 2 5}$ & $\begin{array}{c}\text { Oxid'd } \\
\text { SVW }\end{array}$ & $\boldsymbol{R 2 0}$ & $\boldsymbol{R 2 1}$ & $\boldsymbol{R 2 4}$ & $\boldsymbol{R} 34$ & $\begin{array}{c}\text { S01, } \\
\text { S03 }\end{array}$ \\
\hline Flagons/jugs & & & & & 1.7 & 3.4 & & & & \\
\hline Jars & 1.0 & 0.8 & & & 36.5 & & & 2.3 & & \\
\hline Storage jars & & & & & 10.8 & 2.3 & & & 3.1 & \\
\hline Jars/bowls & & & & & 1.3 & & & & & \\
\hline Beakers & & & & & 10.0 & & & & & \\
\hline Cups & & & & & & & & & & 2.4 \\
\hline Tankards & & & & & 5.7 & & & & & \\
\hline Bowls & & 3.0 & & 5.3 & & & & & 0.5 \\
\hline Bowls/dishes & & & & & & & 0.7 & & & \\
\hline Dishes/platters & & & & & & & & & & 2.0 \\
\hline Mortaria & & & & 2.6 & & & & & & \\
\hline Lids & 1.0 & & 0.8 & & & & 2.8 & & & \\
\hline \% of Group: & $\mathbf{2 . 0}$ & $\mathbf{0 . 8}$ & $\mathbf{3 . 8}$ & $\mathbf{2 . 6}$ & $\mathbf{7 1 . 3}$ & $\mathbf{5 . 7}$ & $\mathbf{3 . 5}$ & $\mathbf{2 . 3}$ & $\mathbf{3 . 1}$ & $\mathbf{4 . 9}$ \\
\hline
\end{tabular}

Table 28. Summary quantification by vessel form of Analytical Group 9. Surface collected assemblage from Field HSM 21376: collection by Dean Archaeological Group, 1980 s

\begin{tabular}{|l|c|r|}
\hline & RE Total & \multicolumn{1}{|c|}{$\%$} \\
\hline Amphorae & 0.14 & $\mathbf{1 . 0}$ \\
\hline Flagons/jugs & 0.12 & $\mathbf{0 . 9}$ \\
\hline Jars & 5.66 & $\mathbf{4 2 . 8}$ \\
\hline Storage jars & 2.28 & $\mathbf{1 7 . 2}$ \\
\hline Jars/bowls & 0.13 & $\mathbf{1 . 0}$ \\
\hline Beakers & 0.59 & $\mathbf{4 . 5}$ \\
\hline Cups & 0.20 & $\mathbf{1 . 5}$ \\
\hline Tankards & 1.52 & $\mathbf{1 1 . 5}$ \\
\hline Bowls & 2.06 & $\mathbf{1 5 . 6}$ \\
\hline Bowls/dishes & 0.16 & $\mathbf{1 . 2}$ \\
\hline Dishes/platters & 0.22 & $\mathbf{1 . 7}$ \\
\hline Mortaria & 0.12 & $\mathbf{0 . 9}$ \\
\hline Uncertain & 0.03 & $\mathbf{0 . 2}$ \\
\hline Totals & $\mathbf{1 3 . 2 3}$ & 100.00 \\
\hline
\end{tabular}

Table 29. Quantification by vessel form and fabric of Analytical Group 9. Figures expressed as percentages

\begin{tabular}{|c|c|c|c|c|c|c|c|c|c|c|c|c|c|}
\hline & A11 & B11 & $C 11$ & F11 & G11 & $M 25$ & $\begin{array}{c}\text { Oxid'd } \\
\text { SVW }\end{array}$ & $R 20$ & $R 21$ & $R 22$ & $R 26$ & $R 28$ & $\begin{array}{l}S 02, \\
S 03\end{array}$ \\
\hline Amphorae & 1.0 & & & & & & & & & & & & \\
\hline Flagons/jugs & & & & & & & 0.9 & & & & & & \\
\hline Jars & & 3.4 & 3.3 & & 0.4 & & 31.7 & & 3.5 & 0.3 & & & \\
\hline Storage jars & & & 0.8 & & & & 13.7 & 2.2 & & & & 0.5 & \\
\hline Jars/bowls & & & & & & & 1.0 & & & & & & \\
\hline Beakers & & & & & & & 3.4 & & & & 1.1 & & \\
\hline Cups & & & & & & & 1.5 & & & & & & \\
\hline Tankards & & & & & & & 11.5 & & & & & & \\
\hline Bowls & & 1.7 & 0.5 & 1.0 & & & 11.2 & 0.7 & & & & & 0.4 \\
\hline Bowls/dishes & & & & & & & & & & & & & 1.2 \\
\hline Dishes/platters & & 0.5 & & & & & & & & & & & 1.2 \\
\hline Mortaria & & & & & & 0.9 & & & & & & & \\
\hline Lids & & & & & & & & & & & & & 0.2 \\
\hline$\%$ of Group: & 1.0 & 5.7 & 4.7 & 1.0 & 0.4 & 0.9 & 74.9 & 2.9 & 3.5 & 0.3 & 1.1 & 0.5 & 3.0 \\
\hline
\end{tabular}

The total sample of mortaria from amongst the present assemblages is small; there are only a modest number of stratified fragments, though numbers are boosted by unstratified and surface finds. This does not necessarily mean that mortaria were unpopular with the inhabitants of the site. Mortaria occur amongst the quantified Groups examined above with some regularity, even if the proportion that they represent is very small. Moreover, there is some reason to believe that mortaria are generally rare at smaller centres such as Ariconium before the later Roman period.

The sequence of mortaria supply to Ariconium is clear. There are a small number of vessels from Northern Gaul, probably made at Noyon, Oise, (Fabric M01) dating to 
the second half of the 1st century AD (e.g. from HSM 21376; examples: from SO 6450 2393, recovered during fieldwalking by DAG in 1989; from SO 64712407 , recovered by Bridgewater as a surface find; plus another Bridgewater surface find from this field). A rim from a mortarium in Fabric M50 seems likely to be of a similar date as its form resembles Gillam 238; this item occurs in a ware which is likely to be from the Cotswolds region, possibly Gloucester (from fieldwalking in 1987 by DAG in Field HSM 21376, SO 6470 2390). Verulamium region vessels (M10) are present which will be later 1st or possibly 2nd century in date. Of similar date-range are two Caerleon mortaria (M40), one item being a base recovered from SO 64702390 (HSM 21376) during fieldwalking by DAG in 1987, while the second example is a rim and spout fragment from SO 64552375 (HSM 21378), also recovered by DAG. The supply during the middle Roman period is represented by a small number of early Oxfordshire products (in M25; as occur in Group 4) and by several Mancetter-Hartshill vessels (M30). The latter come from various locations (e.g. HSM 10676, 23559). To these can be added several Central and East Gaulish samian mortaria, which date to the period c. AD 170-260 (examples from: HSM 21376, from SO 64602400 recovered during fieldwalking by DAG and from SO 6465 2385, surface find recovered by Bridgwater; HSM 21378, surface find made by Bridgewater; HSM 23550, SO 64662376 from Garrod and Moss' Trench B III, Context 2; and HSM 23551, SO 64672389 Garrod and Moss' Trench C I, Context 1).

The majority of the mortaria from the site are later Oxfordshire products (in M21, M22, M23 and M25) dating from c. AD 240. This pattern reflects two wider trends. Firstly, away from military sites and major administrative centres, mortaria appear to become a more frequent site find at 'small towns', roadside settlements and rural sites only during the later Roman period (cf. Rush 1997). Secondly, products from the Oxfordshire industry came to dominant mortaria assemblages at many sites in southern Britain from the mid 3rd century (cf. Young 1977; Rush 1997; Hartley 1985). At Ariconium these later Oxfordshire products have been recovered from across the whole area of the known site (e.g. HSM 5324, 6097, 10676, 15983, 21376, 21378, 23544, 23559), and are not particularly concentrated in any one area. A further example came from Trench 11 of the evaluation in advance of the proposed Ryeford Bypass, HSM 22965 (Napthan, Ratkai and Pearson 1995).

Noyon products ( $c f$. Hartley 1977; 1998; Tyers 1996, 125-7) achieved a wide distribution in Britain and are well attested at early Roman military sites in the Gloucestershire and south-east Wales region (Hartley 1998, fig. 2). Hence their occurrence at Ariconium is not surprising, especially as these vessels may have arrived in the region from France directly, via the Bristol Channel. Hartley 1998 notes a stamped mortarium of Q. Valerius Veranius from the site, which is perhaps likely to be from Noyon, though this item is not amongst the present collections. Similarly
Verulamium region wares are known from the lower Severn hinterland (Tyers 1996, fig. 139). Oxfordshire mortaria are also well precedented in this area, with many examples documented (Tyers 1996, fig. 129). Mancetter-Hartshill mortaria are less well attested in the south-west Midlands; the great bulk of the output of this centre stayed in the central and north Midlands or moved north to the Northern Frontier. Caerleon Ware mortaria are known at other sites in the region, for example, at Thornwell Farm, Chepstow (Evans 1996), Kenchester (Hartley 1985) and Leintwardine (Hartley 1996). As at Ariconium they occur at these sites in very small numbers.

Mortaria are an infrequent find amongst the pottery groups from Ariconium. They are not represented amongst the surviving pottery forming the three early Analytical Groups 1-3 (c. AD 50-100). Where present they are only manifest in the form of an occasional sherd. M25 is the only fabric type to occur with any regularity amongst the quantified groups. It appears amongst the mid and later Roman Groups, including the material from the surface collections, being present in Groups 4, 6, 7, 8 and 9. However, it occurs at a consistently low relative frequency of between 0.9 and $2.6 \%$ by RE. This is a normal frequency for mortaria at sites of the scale of Roman Ariconium (that is to say, of middle rank order).

\section{The samian pottery}

Assemblages of samian pottery survive from both the excavations of Bridgewater and Garrod and Moss. In addition there are sizeable groups of samian from various surface collection exercises, in particular those of the Dean Archaeological Group. The distribution of samian pottery within the Ariconium study area is wide, with specific concentrations (Figs 4.20-4.22). Analysis of this material is of considerable importance for characterising the site. In the following section the Bridgewater and Garrod and Moss samian assemblages are examined, before turning to the surface collected groups. The samian from Jack's excavations has been published (Hayter 1923).

The catalogues (Appendix 7) list all surviving samian sherds from the excavations and fieldwalking, with the exception of pieces for which there is no recorded findlocation. The catalogues adhere to a consistent format with the following data given: the number of sherds and their type (i.e. whether a sherd is from the rim, base (footring) or body of a vessel), the source of the item (South Gaulish is abbreviated to $\mathrm{SG}$, Central Gaulish to $\mathrm{CG}$ and East Gaulish to EG), the vessel form (where identifiable), the percentage of any extant rim (i.e. the RE figure, where 1.00 would represent a complete circumference), and an estimate of the date of the sherd in terms of calendar years (this being the date range of deposits with which like pieces are normally associated). For brevity any extant decoration is not described. The presence of other features, such as burning and rivet and cleat holes for repair, is also noted. 


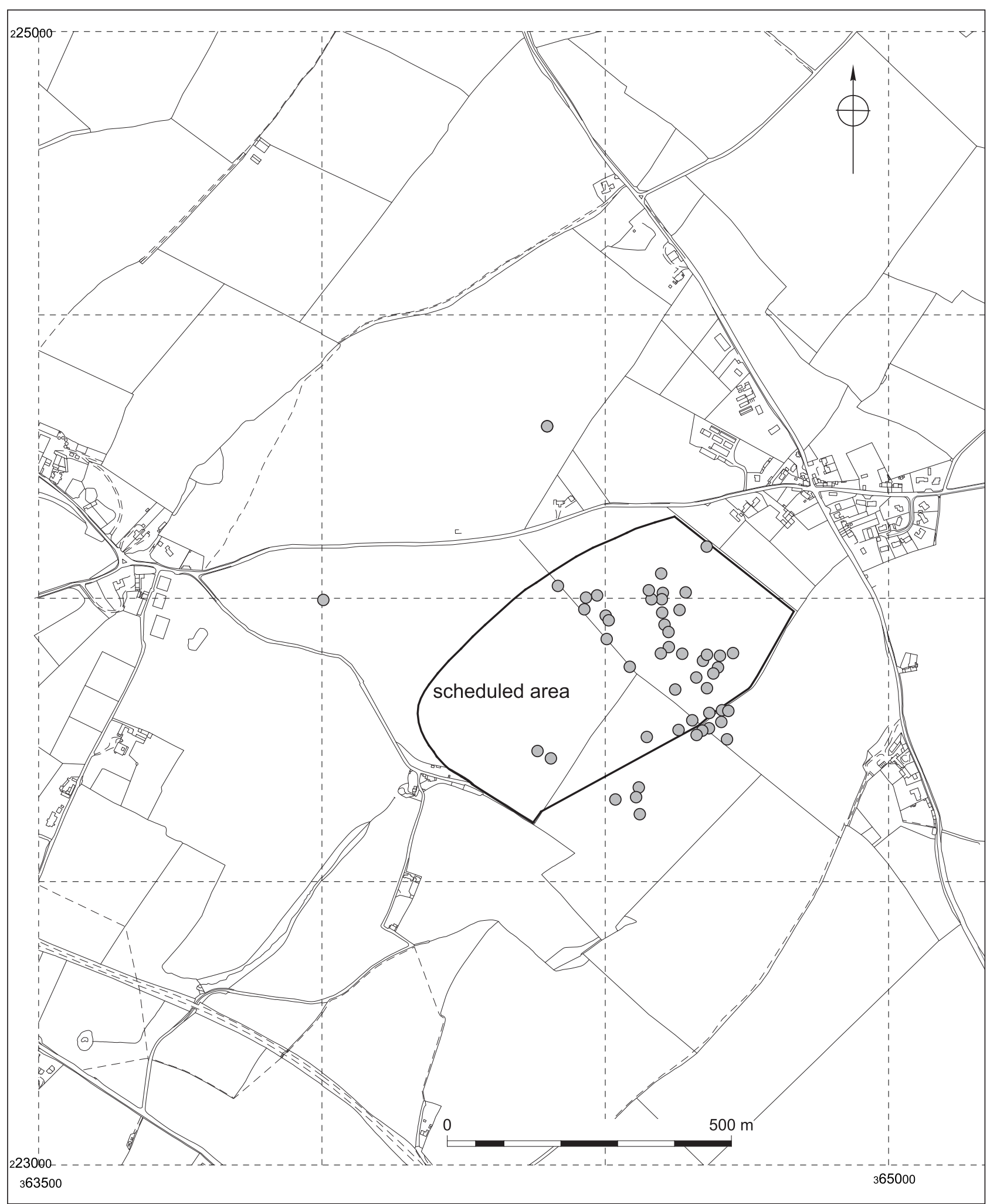

Figure 4.20. Distribution of South Gaulish samian. Reproduced by permission of Ordnance Survey on behalf of HMSO. (C) Crown Copyright 2011. All rights reserved. Ordnance Survey Licence number 100051813 


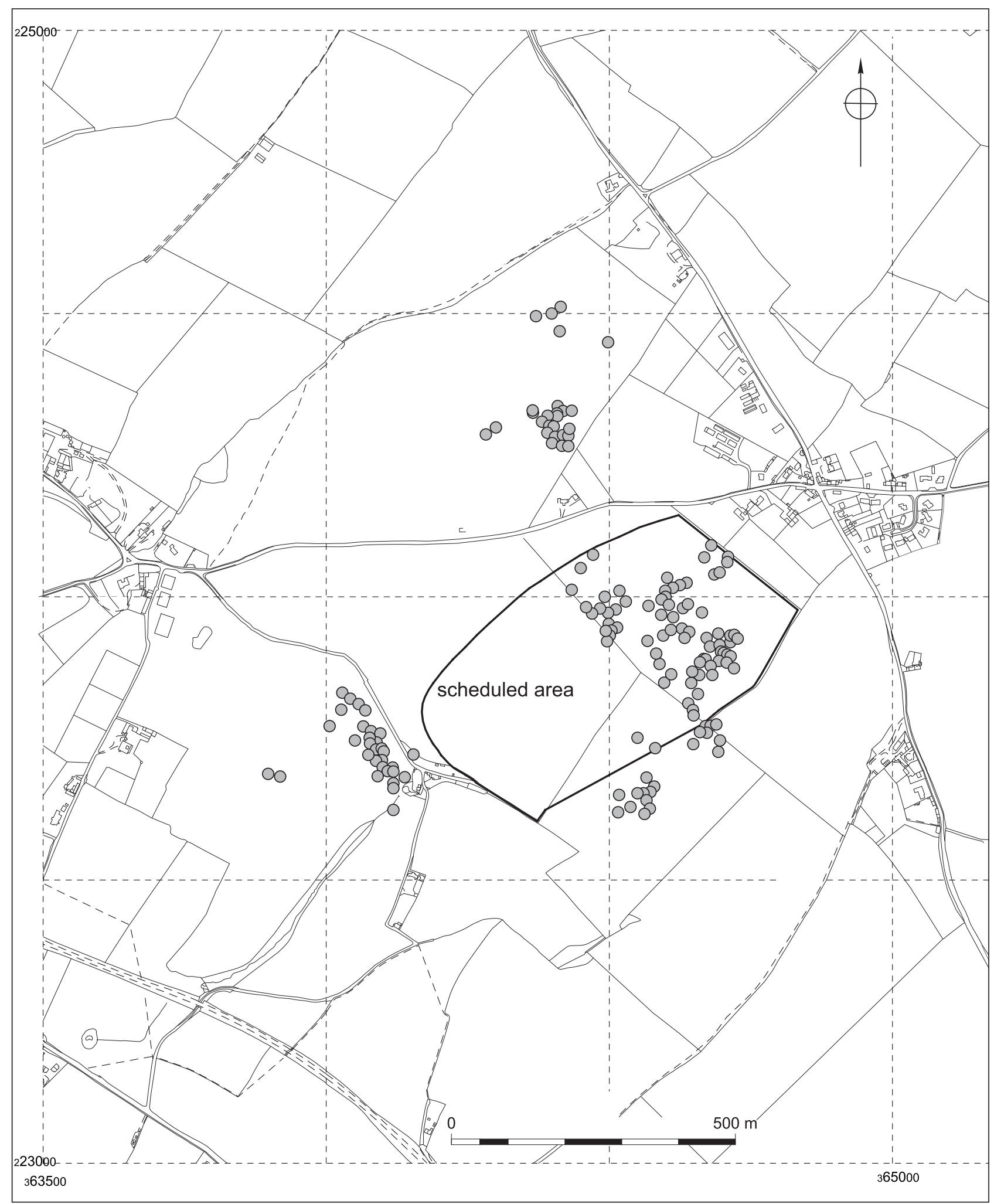

Figure 4.21. Distribution of Central Gaulish samian. Reproduced by permission of Ordnance Survey on behalf of HMSO. C Crown Copyright 2011. All rights reserved. Ordnance Survey Licence number 100051813 


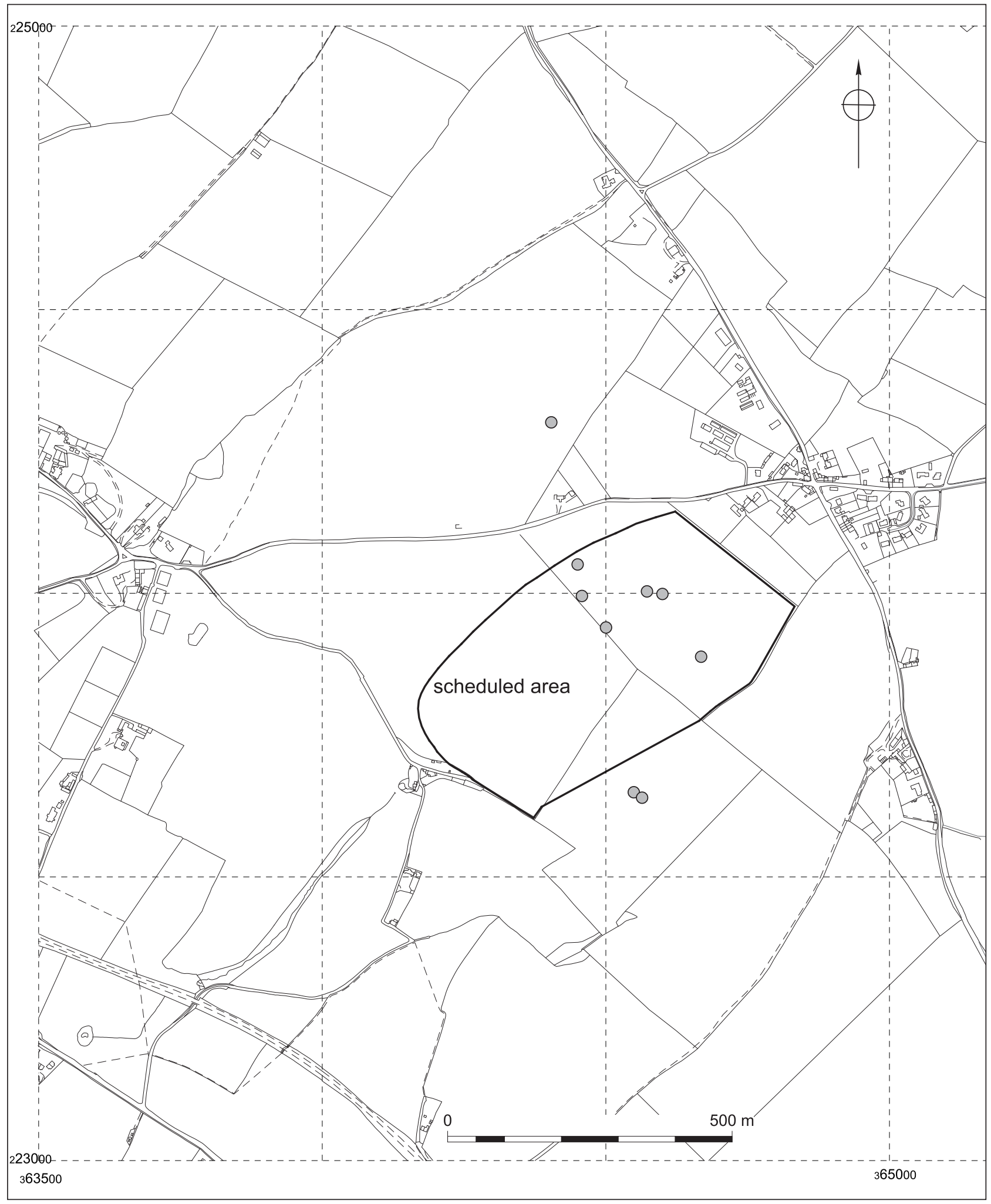

Figure 4.22. Distribution of East Gaulish samian. Reproduced by permission of Ordnance Survey on behalf of HMSO. (C) Crown Copyright 2011. All rights reserved. Ordnance Survey Licence number 100051813 


\section{Discussion of the samian pottery from Bridgewater's excavations 1963}

As with the coarse wares from Bridgewater's excavations it seems certain that the samian pottery has been 'weeded' for there are very few body sherds present. The surviving collection comprises rims, bases and decorated and featured sherds with very few body fragments present (Appendix 7: Catalogue). This not withstanding, the extant assemblage should be a fair guide to the character of samian from this area of Ariconium since rims have evidently been retained.

The stratigraphically earliest samian from Bridgewater's excavations came from several deposits underlying his 'Layer 2' associated with iron-working. These sherds are part of Analytical Group 5 in the present report (see above). Group 5 dates to $c$. AD 135-230/250 and therefore covers the middle and later period of samian importation to
Britain. Contexts belonging to this group which have samian associated are Area $\mathrm{C}$ contexts 6 and ' $\mathrm{H}$ ' and Area D contexts 5, 7 and 9 (see catalogue). Sherds from 7 samian vessels are represented, all of which are Central Gaulish Lezoux products dating to between $c$. AD 120-200. The samian from overlying deposits, that is his Layers 2 (Analytical Group 6) and 1 (Analytical Group 7) will be residual.

Collectively the samian from Bridgewater's 1963 trench can be amalgamated to provide a 'snapshot' of samian consumption at this part of the site. This is a less than ideal approach but gives an order of magnitude impression of the composition of this material which is justified given the circumstances. Since all rim sherds seem to have been retained they provide the best means of establishing this snapshot, hence they form the basis for Tables 30 and 31 (with any surviving body and base sherds discounted for this exercise). Table 30 shows an unequivocal pattern, confirming that the samian from this

Table 30. The chronology of the Bridgewater 1963 samian

\begin{tabular}{|l|l|c|}
\hline Period & Date & $\begin{array}{c}\text { Number of } \\
\text { vessels } \\
\text { represented } \\
\text { (on basis of rims) }\end{array}$ \\
\hline Neronian-early Flavian & c. AD 55-80 & 1 \\
\hline Hadrianic & c. AD 120-140 & 1 \\
\hline Hadrianic-early Antonine & c. AD 120-160 & 3 \\
\hline Hadrianic-Antonine & c. AD 120-200 & 3 \\
\hline Early Antonine & c. AD 140-160 & 1 \\
\hline Antonine & c. AD 140-200 & 5 \\
\hline Mid Antonine & c. AD 150-180 & 1 \\
\hline Mid-late Antonine & c. AD 160-200 & 4 \\
\hline Mid Antonine-mid 3rd century & c. AD 160-230 & 1 \\
\hline
\end{tabular}

Table 31. The composition of the Bridgewater 1963 samian on the basis of rims (identifiable generic forms only)

\begin{tabular}{|c|c|c|c|}
\hline Form type/source & $\begin{array}{c}\text { South } \\
\text { Gaulish }\end{array}$ & $\begin{array}{c}\text { Central } \\
\text { Gaulish- } \\
\text { Lezoux }\end{array}$ & $\begin{array}{c}\text { East } \\
\text { Gaulish }\end{array}$ \\
\hline \multicolumn{4}{|l|}{ Cups: } \\
\hline Drag 33 & & 4 & \\
\hline Unidentified form & & 1 & \\
\hline \multicolumn{4}{|l|}{ Decorated bowls: } \\
\hline Drag 37 & & 2 & \\
\hline \multicolumn{4}{|l|}{ Plain bowls: } \\
\hline Drag 31R & & 3 & \\
\hline Drag 38 & & 1 & \\
\hline \multicolumn{4}{|l|}{ Bowls or dishes: } \\
\hline Drag 31 or $31 \mathrm{R}$ & & 1 & 1 \\
\hline Unidentified form & & 2 & \\
\hline \multicolumn{4}{|l|}{ Dishes: } \\
\hline Drag 15/31 & & 1 & \\
\hline Drag $18 / 31$ & & 1 & \\
\hline Drag 18/31R & & 1 & \\
\hline Drag 31 & & 1 & \\
\hline \multicolumn{4}{|l|}{ Platters: } \\
\hline Drag 18 & 1 & & \\
\hline Totals: & 1 & 18 & 1 \\
\hline
\end{tabular}


intervention is strongly 2 nd century with clear Antonine emphasis (c. AD 140-200). This pattern is consistent with the date of the coarse wares from the excavation. There is only one 1st century sherd of samian amongst the entire collection and this was residual in Layer 1. Equally there is only one East Gaulish item.

Table 31 shows the composition of this samian assemblage by fabric, form and functional class. Despite the fact that the sample is small the range of types present is wide. This diversity is actually typical of excavated site samian assemblages. Overall the composition of the group is as might be expected for a middle order Roman settlement; decorated bowls account for a very low proportion of the group which may be related to the function and status of this particular part of the site.

\section{Discussion of the samian pottery from Garrod and Moss' excavations 1967}

The samian assemblage from Garrod and Moss' excavations has, unfortunately, been subject to severe selective retention (much more so than with the Bridgewater assemblage). Clearly only a fraction of the samian originally excavated is present. The surviving collection from the excavation amounts to 40 samian sherds from 40 vessels. The assemblage consists of 10 rims, one stamped base and 29 body sherds (Appendix 7: Catalogue). The fact that 24 of the latter are from decorated vessels is telling; the other body sherds include a fragment of a stamp, and pieces from 'unusual' forms such as a Drag 45 mortarium, Curle 11 and an East Gaulish Drag 31R. Self-evidently decorated pieces, items of intrinsic interest, stamps and some rims have been retained and base and plain body sherds and so forth discarded or mislaid (see catalogue). Hence the extant assemblage reveals only limited information as to the character of samian from this part of the core of Ariconium. It can provide chronological data and an indication of trends in the supply of decorated ware.

The stratigraphically earliest samian from Garrod and Moss' trial trenches was recovered from deposits which form Analytical Groups 1-3, dating to the 1st century AD. There are 2 sherds from Group 1 and 2 from Group 2 (see catalogue); all four items are Flavian (c. AD 70-100) and therefore consistent with the date of these Groups. However, as noted and discussed above, there are three items of samian amongst Group 3 which seem certain to be intrusive for they are Hadrianic or later (i.e. dating after c. AD 120).

Half of the 40 vessels represented are South Gaulish items dating to the second half of the 1 st century. Independent of what may or may not have been discarded, this seems strong evidence for samian consumption across this part of the site from a comparatively early date and forms a marked contrast with the area investigated by Bridgewater in 1963 from where only one 1 st century piece is recorded (cf. above). This material firmly suggests that Ariconium was a site of some status during this period, with consumers able to acquire plain and decorated samian which would have been of some 'value' at this time (cf. Willis 1997). The majority (16) of the South Gaulish vessels from Garrod and Moss' trenches are Flavian (c. AD 70-100). It is typical for non-military sites in Britain which have South Gaulish ware present to show a Flavian peak; generally this seems to be a function of increased supply to Britain

Table 32. The composition of the surviving Garrod and Moss 1967 samian assemblage (identifiable generic forms only)

\begin{tabular}{|c|c|c|c|c|}
\hline Form type/source & $\begin{array}{c}\text { South } \\
\text { Gaulish }\end{array}$ & $\begin{array}{c}\text { Central Gaulish } \\
\text { - Les Martres }\end{array}$ & $\begin{array}{c}\text { Central Gaulish } \\
\text { - Lezoux }\end{array}$ & $\begin{array}{c}\text { East } \\
\text { Gaulish }\end{array}$ \\
\hline \multicolumn{5}{|l|}{ Cups: } \\
\hline Drag $24 / 25$ & 1 & & & \\
\hline Drag 27 & 1 & & & \\
\hline Drag 33 & & 1 & 1 & \\
\hline \multicolumn{5}{|l|}{ Decorated bowls: } \\
\hline Drag 29 & 2 & & & \\
\hline Drag 30 & 1 & 1 & 1 & \\
\hline Drag 37 & 11 & 4 & 6 & \\
\hline \multicolumn{5}{|l|}{ Plain bowls: } \\
\hline Drag 31R & & & & 1 \\
\hline Curle 11 & & 1 & & \\
\hline \multicolumn{5}{|l|}{ Bowls or dishes: } \\
\hline Unidentified form & 1 & & & \\
\hline \multicolumn{5}{|l|}{ Dishes: } \\
\hline Drag 37R & & 1 & & \\
\hline Curle 15 & & & 1 & \\
\hline \multicolumn{5}{|l|}{ Platters: } \\
\hline Drag 18 & 2 & & & \\
\hline \multicolumn{5}{|l|}{ Mortaria: } \\
\hline Drag 45 & & & 1 & 1 \\
\hline Totals: & 19 & 8 & 10 & 2 \\
\hline
\end{tabular}


Table 33. The chronology of the samian collected by Bridgewater from the surface of Field HSM 21376

\begin{tabular}{|l|c|c|}
\hline Period & Date & $\begin{array}{c}\text { Number of } \\
\text { vessels } \\
\text { represented }\end{array}$ \\
\hline Claudian-Neronian & $c$. AD 40-70 & 1 \\
\hline Neronian-early Flavian & $c$. AD 55-80 & 1 \\
\hline Neronian-Flavian & $c$. AD 55-100 & 3 \\
\hline Flavian & $c$. AD 70-100 & 2 \\
\hline Late Flavian-early Trajanic & $c$. AD 90-110 & 2 \\
\hline Trajanic-early Hadrianic & $c$. AD 100-130 & 1 \\
\hline Hadrianic & $c$. AD 120-140 & 3 \\
\hline Hadrianic-early Antonine & $c$. AD 120-160 & 3 \\
\hline Hadrianic-Antonine & $c$. AD 120-200 & 6 \\
\hline Antonine & $c$. AD 140-200 & 15 \\
\hline Mid-late Antonine & $c$. AD 160-200 & 5 \\
\hline Mid Antonine-early 3rd century & $c$. AD 160-225 & 1 \\
\hline Late Antonine & $c$. AD 170-200 & 1 \\
\hline
\end{tabular}

at this time ( $c f$. Marsh 1981). Four of the South Gaulish vessels are, however, Neronian or Neronian-early Flavian (c AD 55-70/80). That there are 8 Les Martres vessels (c. AD 100-130) present is of interest as this indicates a sustained access to samian at Ariconium despite the general decline in its importation during the early decades of the 2nd century ( $c f$. Marsh 1981). There is one Trier vessel and one from Rheinzabern, demonstrating some level of supply from East Gaulish workshops, despite the fact that East Gaulish samain has generally been assumed to be comparatively rare away from eastern Britain and the northern frontier ( $c f$. Tyers 1996). Table 32 summarises the surviving samian.

\section{The samian pottery from surface collections at Ariconium}

There are several collections of samian from surface collections undertaken during the 1960s, 1970s and 1980s. Some of these collections (especially those by DAG) are well-recovered and remain complete; others represent surviving 'selected' material. Much of the Bridgewater material and that collected by the DAG can be located to precise locations within fields, while most sherds are locatable to specific fields. Where known, precise locations are recorded here, but in order to make sense of the general trends in this pottery each field is taken as the basic unit for analysis and in some cases collections are grouped.

The absolute total of samian gathered from field surfaces is surprisingly large, especially given the fact that some of the site lies under pasture or within gardens and not all the gathered samian was available for the present study. Moreover the material listed here excludes the considerable amount of samian that is not well located. The sheer quantity of surface gathered samian firmly implies that deposits have been eroded and incorporated into the ploughsoil ( $c f$. Haselgrove 1985). Deposits therefore remain vulnerable to further erosion as discussed in detail in Section 3. Field HSM 21376, which covers the north- eastern half of the known core area of the site, has evidently been subject to sustained surface collections. There is more surface collected samian from this field than any other.

Field HSM 21376: SAMian SURFACE FINDS COLLECTED By BRIDGEWATER: DISCUSSION

There are 44 vessels represented amongst this collection which consists: 15 rims, 24 body sherds and 7 bases (Appendix 7: Catalogue). This material appears, firmly, to be a well-collected ensemble which has not been subject to selection; hence it should be a reliable guide to samian in the topsoil within this field. Table 33 demonstrates that 1 st century samian is reasonably well represented $(20.5 \%$ of the group), but that 2 nd century items are more frequent, especially those dating to the later 2 nd century. This emphasis is in fact a normal trend seen amongst samian assemblages from 'small towns' and roadside settlements in Britain (cf. Willis 1998b). There is an evident chronological contrast between this surface collected assemblage and that surviving from Garrod and Moss' excavations which took place in this area. The latter had a much stronger showing by 1st century (La Graufesenque) samian and that of Les Martres. This difference seems likely to be connected with the fact that Garrod and Moss investigated early stratified Roman deposits, whereas topsoil assemblages typically have a later emphasis simply because they are more likely to have a disproportionate amount of later site deposits incorporated within them ( $c f$. Haselgrove 1985). Table 34 verifies that a wide range of forms are present. Decorated vessels, in this case, are not prominent, forming c. $13.8 \%$ of the group on the basis of identifiable generic forms.

FIELD HSM 21376: SAMIAN SURFACE FINDS FROM SYSTEMATIC GRIDDED FIELDWALKING BY THE DAG, OCTOBER 1986: DISCUSSION

The samian from this fieldwalking forms part of Analytical Group 8. The organisation of this collection, which formed a transect across the known core of the site, has been outlined above. This small group is evidently a reliable 
Table 34. The composition of the samian collected by Bridgewater from the surface of Field HSM 21376 (identifiable generic forms only)

\begin{tabular}{|c|c|c|c|}
\hline Form type/source & $\begin{array}{c}\text { South } \\
\text { Gaulish }\end{array}$ & $\begin{array}{c}\text { Central } \\
\text { Gaulish } \\
\text { - Lezoux }\end{array}$ & $\begin{array}{c}\text { East } \\
\text { Gaulish }\end{array}$ \\
\hline \multicolumn{4}{|l|}{ Cups: } \\
\hline Drag 24/25 & 1 & & \\
\hline Drag 27 & 1 & 1 & \\
\hline Drag 33 & & 1 & \\
\hline Unidentified form & 1 & 1 & \\
\hline \multicolumn{4}{|l|}{ Decorated bowls: } \\
\hline Drag 30 & & 1 & \\
\hline Drag 30 or 37 & & 1 & \\
\hline Drag 37 & 1 & 1 & \\
\hline \multicolumn{4}{|l|}{ Decorated beakers: } \\
\hline Déch 67 & 1 & & \\
\hline \multicolumn{4}{|l|}{ Plain bowls: } \\
\hline Drag 31R & & 3 & \\
\hline Unidentified form & & 4 & \\
\hline \multicolumn{4}{|l|}{ Bowls or dishes: } \\
\hline Drag 31 or $31 \mathrm{R}$ & & 2 & \\
\hline Drag 38 or Curle 23 & & 1 & \\
\hline Unidentified form & & 3 & \\
\hline \multicolumn{4}{|l|}{ Dishes: } \\
\hline Drag 18/31 & 1 & 1 & \\
\hline Drag 18/31R & & 3 & \\
\hline Drag 31 & & 2 & \\
\hline Curle 23 & & 1 & \\
\hline \multicolumn{4}{|l|}{ Platters: } \\
\hline Drag 15/17 & 1 & & \\
\hline Drag 18 & 1 & & \\
\hline Walters 79 & & & 1 \\
\hline Unidentified form & 1 & & \\
\hline \multicolumn{4}{|l|}{ Mortaria: } \\
\hline Drag 45 & & 1 & \\
\hline Totals: & 9 & 27 & 1 \\
\hline
\end{tabular}

sample comprising small sherds, a high proportion of body fragments and with decorated items not 'over-represented'; it has been well-collected and curated (Appendix 7: Catalogue). The composition of the group is consistent with the Bridgewater sample from this field examined above. First century items form $28.6 \%$ of the group, Les Martres $9.5 \%$, and 2nd century Lezoux wares $61.9 \%$. Decorated vessels form $14.3 \%$ of this small group, a figure which is closely similar to their frequency amongst the Bridgewater collection $(13.8 \%)$.

FIELD HSM 21376: SAMIAN SURFACE FINDS FROM VARIOUS FIELDWALKING EXERCISES BY THE DAG: DISCUSSION

A total of 74 vessels are represented amongst this group which again has been well-collected and curated (Appendix 7: Catalogue). The chronological spread of the group is summarised in Table 35 . South Gaulish 1st century vessels represent $16.2 \%$ of the group; this is a smaller proportion than amongst the Bridgewater and DAG systematic collections, but not grossly so. Les Martres vessels account for $8.1 \%$ and Lezoux items $66.2 \%$ of the sample (Table 36). These figures are both very close to the frequency of these wares amongst the systematically collected group. Several East Gaulish items occur, suggesting that samian may have continued to arrive at Ariconium into the 3rd century. The small size of many of the sherds of this collection means that in many cases $(55 \%)$ the form represented cannot be identified.

FiEld HSM 21378: SAMian SURfaCe FINDS COLleCted BY BRIDGEWATER AND DAG: DISCUSSION

In addition to field HSM 21376, Bridgewater collected sherds from the surface of the field immediately to the south, HSM 21378, the north-western side of which lies within the scheduled area. The group includes sherds from

Table 35. The chronology of the samian collected by DAG from the surface of Field HSM 21376 during various fieldwalking exercises

\begin{tabular}{|l|c|c|}
\hline Period & Date & $\begin{array}{c}\text { Number of } \\
\text { vessels } \\
\text { represented }\end{array}$ \\
\hline Claudian-Neronian & $c$. AD 40-70 & 1 \\
\hline Claudian-Flavian & $c$. AD 40-100 & 2 \\
\hline Neronian-Flavian & $c$. AD 55-100 & 1 \\
\hline Flavian & $c$. AD 70-100 & 8 \\
\hline Trajanic-early Hadrianic & $c$. AD 100-130 & 6 \\
\hline Hadrianic & $c$. AD 120-140 & 2 \\
\hline Hadrianic-early Antonine & $c$. AD 120-160 & 3 \\
\hline Hadrianic-Antonine & $c$. AD 120-200 & 31 \\
\hline Antonine & $c$. AD 140-200 & 10 \\
\hline Antonine-early 3rd century & $c$. AD 140-230 & 1 \\
\hline Antonine-mid 3rd century & $c$. AD 140-260 & 1 \\
\hline Mid Antonine-early 3rd century & $c$. AD 150-230 & 4 \\
\hline Mid-late Antonine & $c$. AD 160-200 & 3 \\
\hline Late Antonine-early 3rd century & $c$. AD 170-230 & 1 \\
\hline
\end{tabular}


33 vessels. There are comparatively few undiagnostic pieces, whilst sherds from decorated items appear to be 'over-represented' (comprising $42.8 \%$ of the group). Hence it seems likely that some selective retention of this samian has occurred. Some $26.6 \%$ of the vessels represented amongst the surviving sherds are South Gaulish and $63.6 \%$ are Lezoux 2nd century wares. Two East Gaulish vessels are represented. Again vessels dating to the late 1 st century are comparatively well represented, though the majority of items are Hadrianic-Antonine (cf. Table 37, c. AD 120-200). The composition of the group therefore closely reflects the pattern of the adjacent field (HSM 21376), as one might expect, though it should be borne in mind that selective retention of pieces seems to have occurred (Table 38).

There are five accessioned sherds of samian collected by DAG from the surface of this field, all from that part of the field lying within the scheduled area. They testify

Table 36. The composition of the samian collected by DAG from the surface of Field HSM 21376 during various fieldwalking exercises (identifiable generic forms only)

\begin{tabular}{|c|c|c|c|c|}
\hline Form type/source & $\begin{array}{c}\text { South } \\
\text { Gaulish }\end{array}$ & $\begin{array}{c}\text { Central } \\
\text { Gaulish - } \\
\text { Les Martres }\end{array}$ & $\begin{array}{c}\text { Central } \\
\text { Gaulish - } \\
\text { Lezoux } \\
\end{array}$ & $\begin{array}{c}\text { East } \\
\text { Gaulish }\end{array}$ \\
\hline \multicolumn{5}{|l|}{ Cups: } \\
\hline Drag 27 & & & 1 & \\
\hline Drag 33 & & & 2 & 1 \\
\hline Unidentified form & & & 1 & \\
\hline \multicolumn{5}{|l|}{ Decorated bowls: } \\
\hline Drag 29 or 37 & 2 & & & \\
\hline Drag 30 & & 2 & & \\
\hline Drag 30 or 37 & & 1 & & \\
\hline Drag 37 & 1 & & 3 & \\
\hline \multicolumn{5}{|l|}{ Plain bowls: } \\
\hline Drag 31R & & & & 1 \\
\hline Drag 38 & & & 1 & \\
\hline Drag 38 or 44 & & & 1 & \\
\hline \multicolumn{5}{|l|}{ Bowls or dishes: } \\
\hline Drag $18 / 31 \mathrm{R}$ or $31 \mathrm{R}$ & & & 2 & \\
\hline Drag $18 / 31 \mathrm{R}, 31$ or $31 \mathrm{R}$ & & & 1 & \\
\hline Drag 31 or $31 \mathrm{R}$ & & & 1 & 1 \\
\hline Unidentified form & & & 2 & \\
\hline \multicolumn{5}{|l|}{ Dishes: } \\
\hline Drag $15 / 31$ & & & 1 & \\
\hline Drag 18/31 & & 1 & & \\
\hline Drag $18 / 31 \mathrm{R}$ or 31 & & & 1 & \\
\hline Drag 31 & & & 2 & \\
\hline \multicolumn{5}{|l|}{ Platters: } \\
\hline Drag 15/17 & 1 & & & \\
\hline Walters 79 & & & 2 & \\
\hline \multicolumn{5}{|l|}{ Mortaria: } \\
\hline Drag 45 & & & & 1 \\
\hline Totals: & 4 & 4 & 21 & 4 \\
\hline
\end{tabular}

Table 37. The chronology of the samian collected by Bridgewater from the surface of Field HSM 21378

\begin{tabular}{|l|c|c|}
\hline Period & Date & $\begin{array}{c}\text { Number of } \\
\text { vessels } \\
\text { represented }\end{array}$ \\
\hline Neronian-early Flavian & $c$. AD 55-80/85 & 3 \\
\hline Flavian & $c$. AD 70-100 & 4 \\
\hline Late Flavian-early Trajanic & $c$. AD 90-110 & 1 \\
\hline Trajanic-early Hadrianic & $c$. AD 100-130 & 2 \\
\hline Hadrianic & $c$. AD 120-140 & 4 \\
\hline Hadrianic-early Antonine & $c$. AD 120-160 & 4 \\
\hline Hadrianic-Antonine & $c$. AD 120-200 & 6 \\
\hline Antonine & $c$. AD 140-200 & 4 \\
\hline Mid Antonine-mid 3rd century & $c$. AD 150-260 & 2 \\
\hline Mid-late Antonine & $c$. AD 160-200 & 3 \\
\hline
\end{tabular}


Table 38. The composition of the samian collected by Bridgewater from the surface of Field HSM 21378 (identifiable generic forms only)

\begin{tabular}{|c|c|c|c|c|}
\hline Form type/source & $\begin{array}{c}\text { South } \\
\text { Gaulish }\end{array}$ & $\begin{array}{c}\text { Central } \\
\text { Gaulish - } \\
\text { Les Martres }\end{array}$ & $\begin{array}{c}\text { Central } \\
\text { Gaulish - } \\
\text { Lezoux }\end{array}$ & $\begin{array}{c}\text { East } \\
\text { Gaulish }\end{array}$ \\
\hline \multicolumn{5}{|l|}{ Cups: } \\
\hline Drag 33 & & 1 & & 1 \\
\hline \multicolumn{5}{|l|}{ Decorated bowls: } \\
\hline Drag 29 & 2 & & & \\
\hline Drag 30 & & & 2 & \\
\hline Drag 37 & 3 & 1 & 4 & \\
\hline \multicolumn{5}{|l|}{ Decorated beakers: } \\
\hline Drag 54 & & & & 1 \\
\hline Unidentified form & & & 1 & \\
\hline \multicolumn{5}{|l|}{ Plain bowls: } \\
\hline Ritt. 12 or Curle 11 & 1 & & & \\
\hline Curle 11 & & & 1 & \\
\hline Drag 31R & & & 1 & \\
\hline Unidentified form & & & 1 & \\
\hline \multicolumn{5}{|l|}{ Bowls or dishes: } \\
\hline Drag 31 or $31 \mathrm{R}$ & & & 1 & \\
\hline Unidentified form & & & 2 & \\
\hline \multicolumn{5}{|l|}{ Dishes: } \\
\hline Drag 18/31R & & & 1 & \\
\hline Drag 42 & & & 1 & \\
\hline \multicolumn{5}{|l|}{ Platters: } \\
\hline Drag 18 & 1 & & & \\
\hline Walters 79 & & & 1 & \\
\hline \multicolumn{5}{|l|}{ Mortaria: } \\
\hline Drag 45 & & & 1 & \\
\hline Totals: & 7 & 2 & 17 & 2 \\
\hline
\end{tabular}

to the consumption of samian at this part of the site during the early Roman period. The samian finds from surface collections in Field HSM 21378 are catalogued in Appendix 7.

Field HSM 10676: SAmian SuRface Finds COllected By BRIDGEWATER: DISCUSSION

There are 6 samian sherds collected by Bridgewater from the surface of Field HSM 10676, the field in which he conducted his excavation in 1963 (Appendix 7: Catalogue). The types represented all lie within the Hadrianic-Antonine bracket (c. AD 120-200), reflecting the date of the samian recovered from his excavation ( $c f$. above). In addition to these items a body sherd from a Central Gaulish Lezoux Drag 37 bowl, c. AD 100-130, was recovered by DAG from SO 6450 2445, to the north-east of Bridgewater's trench.

SAMIAN SURFACE FINDS FROM OTHER FIELDS

Amongst the material available for study there are few sherds of samian from other fields. There are a few fragments from the field south-west of HSM 21376 and west of HSM 21378, namely HSM 5324, much of which lies within the scheduled land. These items comprise the rim from a South Gaulish (La Graufesenque) Drag 36, c. AD 65-100, a rim, from a South Gaulish (La Graufesenque) Déch 67 beaker, $c$. AD 70-100 and a rim from a Central Gaulish (Lezoux) Drag 33, c. AD 120-160. All have the findspot SO 64402372 and were collected by DAG.

To the west of HSM 5324 an intensive systematic fieldwalking exercise was conducted by South Worcestershire Archaeological Group (SWAG) in the area of HSM 22049. Only one sherd of samian was recovered, a body sherd from a South Gaulish (La Graufesenque) vessel (form not identifiable) dated $c$. AD 40-100. The find spot was SO 6400 2400. This work provides a strong indication of a low level of activity in this area during the early to mid Roman period.

Notably Bridgewater recovered two surface finds of samian within field HSM 23544 to the north of HSM 10676. This is the field within which Walters and Walters undertook their trial excavation upon the site of a putative early Roman military installation (Walters and Walters 1989; see below). The two sherds were both rims from Central Gaulish (Lezoux) vessels, one a Drag 33 cup, dated $c$. AD 120-200, the other from a platter, dated $c$. 
AD 160-200. Walters and Walters also recovered: 'a few fragments of Central Gaulish samian' (ibid., 37) from a fill deposit that they excavated in the course of their work; these items are presumably 2nd century. No 1st century samian is recorded from their work, nor from this field and these are potentially significant 'absences'.

As part of the salvage recording on the Lea and Westonunder-Penyard sewage transfer a programme of systematic fieldwalking was undertaken in Field HSM 6097 south of the scheduled area (Jackson, Hancocks and Pearson 1999). Twenty-three samian sherds were recovered of which twenty-one were from Central Gaulish Hadrianic or Antonine vessels (c. AD 120-200), reflecting the pattern elsewhere at Ariconium of a later 2 nd century peak in supply.

\section{Briquetage: containers for the storage and transport of salt}

Finds of briquetage (that is to say, fragments from ceramic salt containers) are well attested from sites of Iron Age and Roman date in the hinterland region of the Lower Severn Valley (Morris 1985). There are, however, no fragments of briquetage amongst the pottery collections from Ariconium reported here. This absence is extraordinary given the date and regional location of the site, together with the size of the extant collections. Given the circumstances the conclusion must be that some amount of this material was probably encountered during the various fieldwork operations undertaken at Ariconium and reported here but was either not collected or not retained. The fact that these vessels were roughly fashioned and that fragments can, to the inexperienced eye, superficially look like burnt daub or undiagnostic fired clay to will not have assisted their recognition.
Significantly, pieces of Droitwich briquetage and fragments possibly from organically tempered briquetage (Worcestershire Historic Environment and Archaeology Service, Fabrics 1 and 2 respectively) were present within the fills of two ditches examined south-east of Pond Cottage during works in advance of the Welsh Water pipeline (cf. above and below; Jackson, Hancocks and Pearson 1999).

\section{Discussion of the Ariconium Iron Age and Roman pottery}

\section{Functional types, fine wares and pottery function}

A striking aspect of the pottery groups from Ariconium is the broad continuity they show in terms of form types over time. Analytical Groups 3-9 are most usefully employed in examining the formal composition of the Ariconium pottery through time (Group 1 is of considerable interest but is somewhat skewed by the presence of a large proportion of a single beaker within what is a comparatively small sample; Group 2 is a very small group). Changes in the relative frequency of different form types within groups are not particularly marked (cf. Figs 4.23-4.26). Jars, for instance, remain a major form type accounting for between $38-43 \%$ of all vessels within 6 of the 7 analytical groups examined ( $c f$. Fig. 4.23, and section on quantification by form, above). Jars and storage jars combined account for a sustained $53-64 \%$ of vessels within the 7 groups. In other words the Ariconium groups do not conform to the standard southern British pattern of a steady decline in the proportion of jars through the Roman period from a very high point in the 1st century AD (cf. Booth and Willis 1997, 56). Jar proportions at Ariconium are broadly similar to those at Neatham and, at least for the later period, Segontium, as

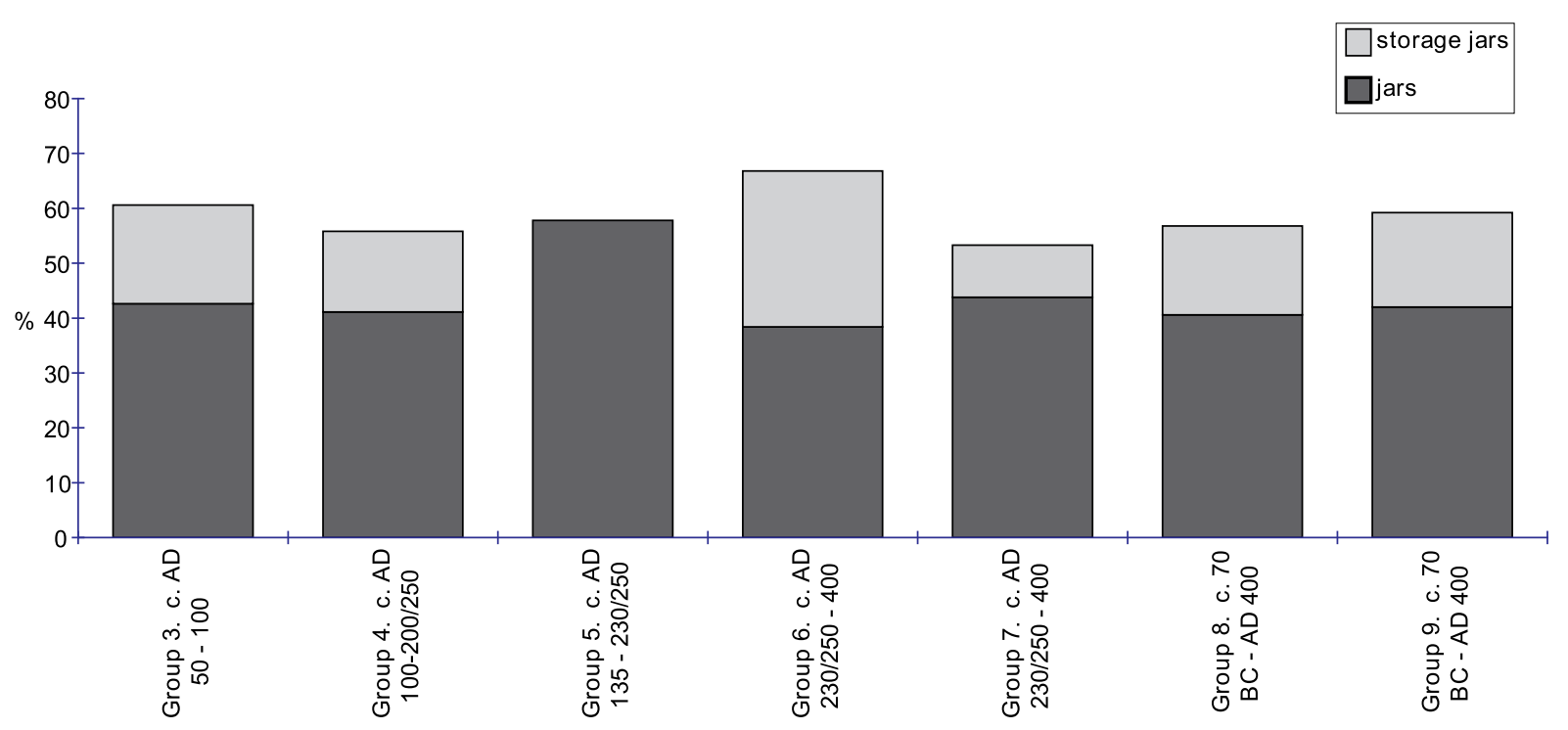

Figure 4.23. The relative frequency, by rim equivalent, of jars and storage jars within various pottery groups from Ariconium 


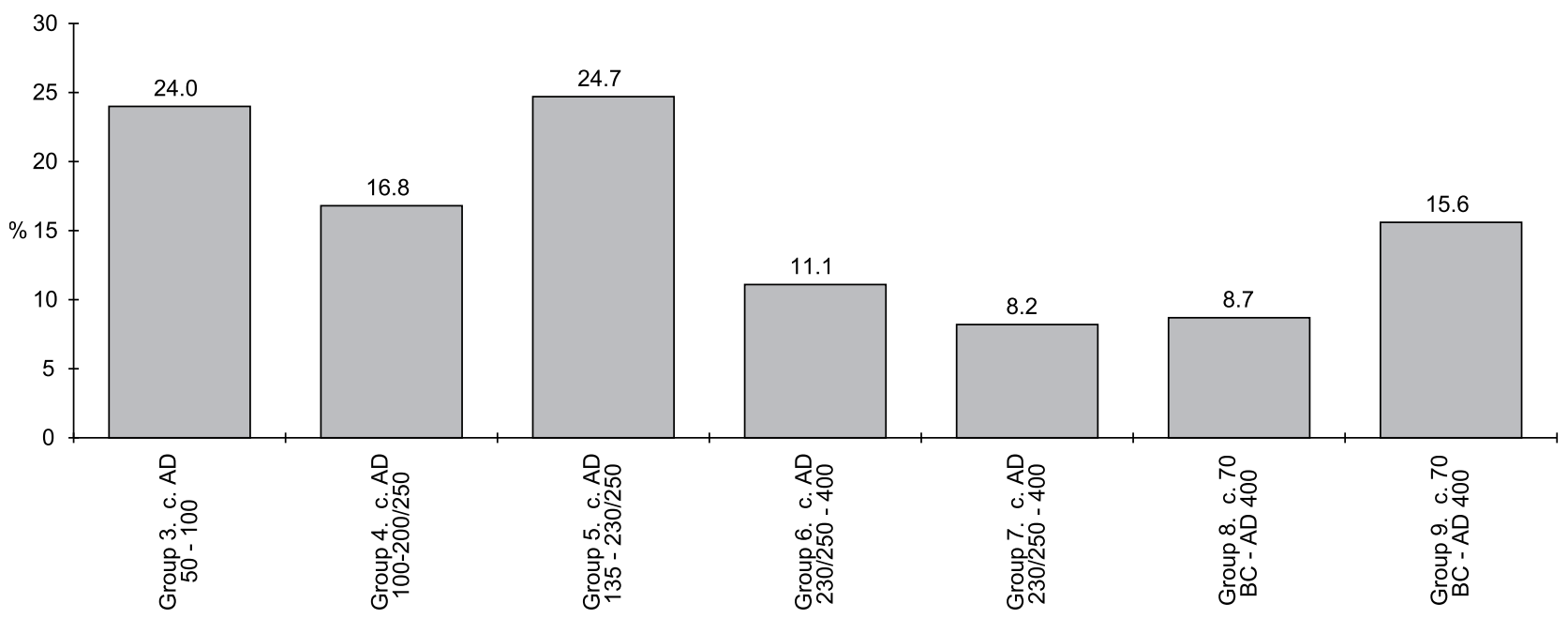

Figure 4.24. The relative frequency, by rim equivalent, of bowls within various pottery groups from Ariconium

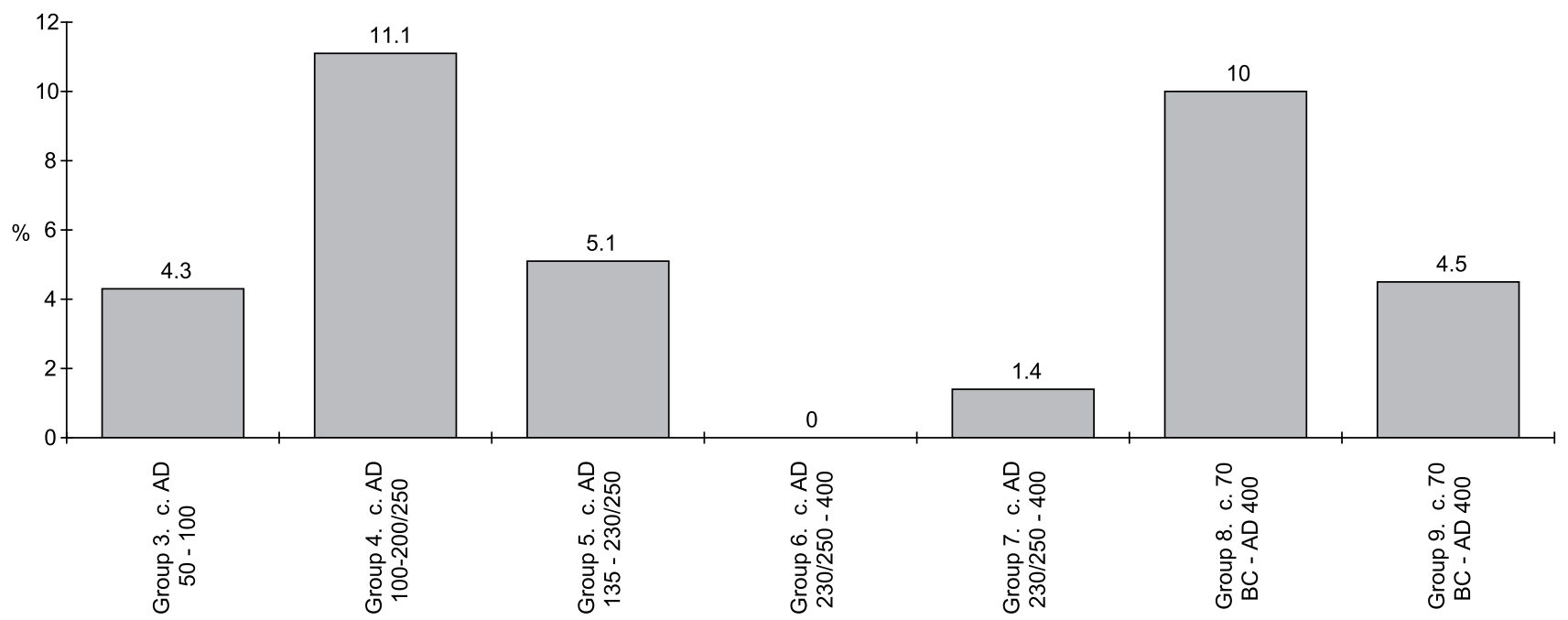

Figure 4.25. The relative frequency, by rim equivalent, of beakers within various pottery groups from Ariconium

a comparison with the data assembled by Jeremy Evans clearly demonstrates (Evans 1993, figs 2 and 5).

Bowls show some evidence of a decline from the mid to late Roman period, as Figure 4.24 demonstrates. During the late Iron Age and early Roman period they are comparatively common items (c. 24\% of Group 3 for instance) in C11 and the Transitional black-surfaced wares, though they are clearly less prominent than at some other sites in the region. Amongst, for instance, the pottery from the late Iron Age and early Roman deposits at Ditches near Bagendon (Trow 1988) bowls account for $57.7 \%$ of the assemblage. At Ariconium and elsewhere, bowls become a familiar form type in Oxidized Severn Valley wares. An apparent decline in the frequency of bowls at Ariconium during the later Roman period contrasts with their increasing popularity amongst assemblages from other southern British sites, such as Neatham (Millett and Graham 1986) and Thornwell Farm, Chepstow (Evans 1996).
The frequency of beakers amongst the Ariconium groups is summarised in Figure 4.25. This chart demonstrates a sustained presence of the class at the site. Late Iron Age and mid-1st century types, including Gallo-Belgic butt beakers and local 'copies' occur in stratified early groups at Ariconium, while sherds from 1st century AD beaker types are not infrequent amongst the unstratified finds collected by Garrod and others. Beakers comprise a major component of Analytical Group 1, dating from the mid-1st century AD, in which they account for some $43 \%$ of the Group by form class ( $c f$. above). There is some distortion here, though, effected by the presence of a very large proportion of a single vessel. Significantly, high proportions of beakers typify pottery groups of the early and mid-1st century AD at major centres in southeast England (such as Silchester). Hence, whilst some qualification is necessary, the nature of Group 1 has an affinity with pottery from such sites at this time. Some of 


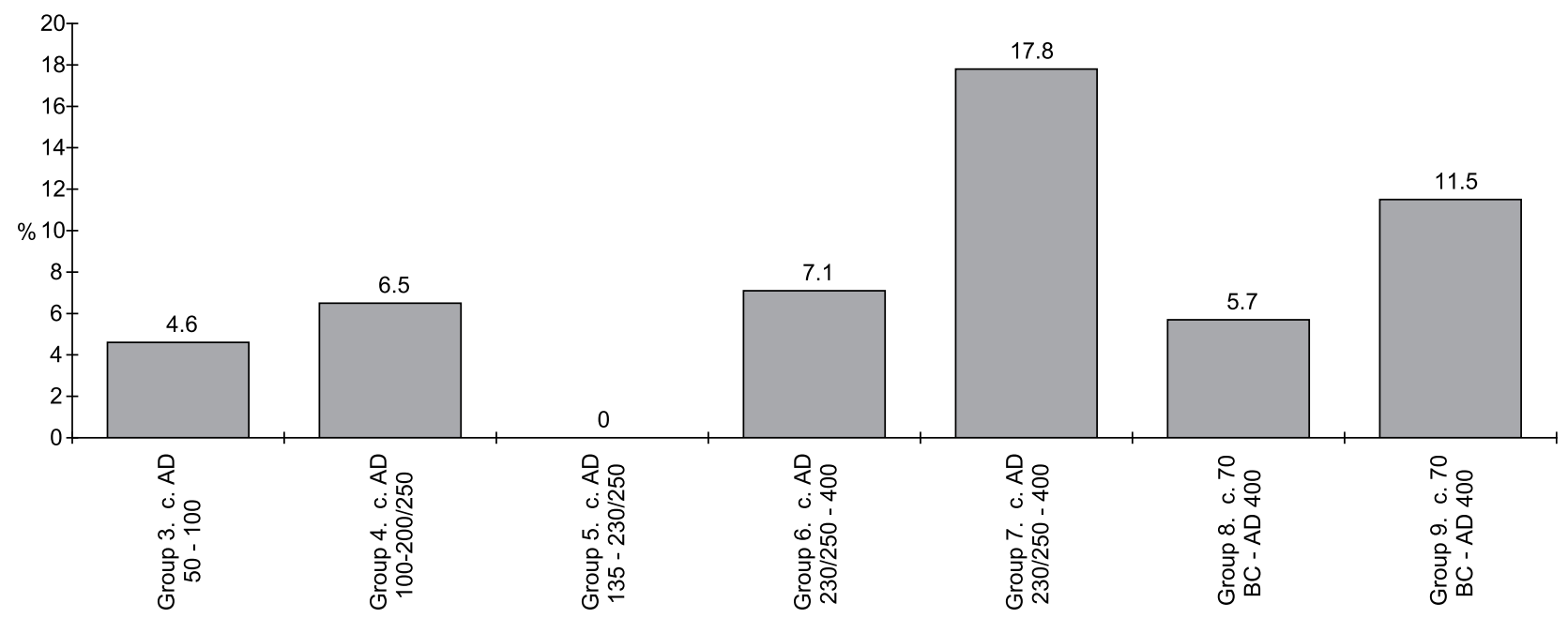

Figure 4.26. The relative frequency, by rim equivalent, of tankards within various pottery groups from Ariconium

Table 39. The proportions of beakers and tankards, and of cups within the analytical groups, as a percentage of each group as a whole (measurement via Rim Equivalent; Analytical Group 2 excluded)

\begin{tabular}{|l|c|c|c|c|c|c|c|c|}
\hline Analytical Group & $\mathbf{1}$ & $\mathbf{3}$ & $\mathbf{4}$ & $\mathbf{5}$ & $\mathbf{6}$ & $\mathbf{7}$ & $\boldsymbol{8}$ & $\mathbf{9}$ \\
\hline Beakers and Tankards Combined & 46.7 & 8.9 & 17.6 & 5.1 & 7.1 & 19.2 & 15.7 & 16.0 \\
\hline Cups & 0.0 & 1.8 & 1.5 & 1.8 & 4.1 & 2.0 & 2.5 & 1.5 \\
\hline
\end{tabular}

the beaker sherds in the later groups are doubtless residual items. Evidently the site received beakers from continental and extra-regional sources (for example, from Oxfordshire and the Nene Valley) throughout the Roman period, albeit at a low level compared with the earlier period.

Tankards are a form type which is distinctive of the region during the Roman era, and such vessels will have been an alternative drinking vessel to the beaker. Examples of the form are present in the early stratified groups from the excavations of Garrod and Moss. The form, for instance, is present in Analytical Groups 1 and 3 (cf. above), dating to the second half of the 1st century AD. Figure 4.26 summarises the presence of the tankard form within the 7 groups (Groups 3-9). Again there is a general continuity in the proportions that it forms within these groups, albeit with some fluctuation. These data suggest a slight increase in its relative importance with time from its debut around the mid-1st century AD. Cups comprise the other drinking receptacle at the site. As Table 39 indicates they are consistently present amongst the analytical groups wherein they constitute small proportions of the repertoire.

The proportions of beakers and tankards within the analytical groups are combined in Table 39. The combined proportions for Groups 4, 7, 8 and 9 are consistent, falling between c. 16-19\%. The levels for Groups 5 and 6 are noticeably low and this seems likely to reflect the functional status of their find-spot, since they come from the lower contexts in the industrial area investigated by Bridgewater (cf. above).

Generally the levels of fine ware pottery at Ariconium seem modest to low. In absolute terms a comparatively large sample of samian has been recovered from the site, though this arises from a considerable amount of fieldwork input (the sample would of course be larger had not the 'weeding' of some collections taken place). Amongst Analytical Groups 4, 8 and 9 samian forms only small percentages; its high percentage total in Group 5 seems anomalous. The non-samian fine ware includes some notable 'surprises'. These include several North Gaulish butt beakers dating to the early to mid 1st century AD, Gallo-Belgic Terra Nigra vessels of similar date, and a beaker in Central Gaulish green glazed ware (Fig. 4.4.6); such vessels are rare, though a Central Gaulish glazed beaker from Blackwardine has been published (Rees 1990). 'Copies' of 1st century AD Gallo-Belgic beakers, mainly in Oxidized Severn Valley ware, are more common than the originals at Ariconium. This phenomenon, namely for 'copies' of these butt beakers to be more frequent than the imitated proto-type is something of a widespread pattern, seen elsewhere at this time ( $c f$. Willis 1994); presumably this indicates that the form was keenly adopted and 'required' as an accoutrement in drinking and feasting events which appear to have been a vital part of cultural life at this time (Hill 1995, 80-2).

A small number of extra-regional fine wares dating to the mid Roman period are represented (e.g. Central Gaulish black slipped ware, Lower Rhineland (Cologne) colour-coated ware, and Nene Valley colour-coated ware). However, these wares do not achieve the prominence of Oxfordshire red/brown colour-coated ware during the late Roman period. Examples of the latter fine ware have been 


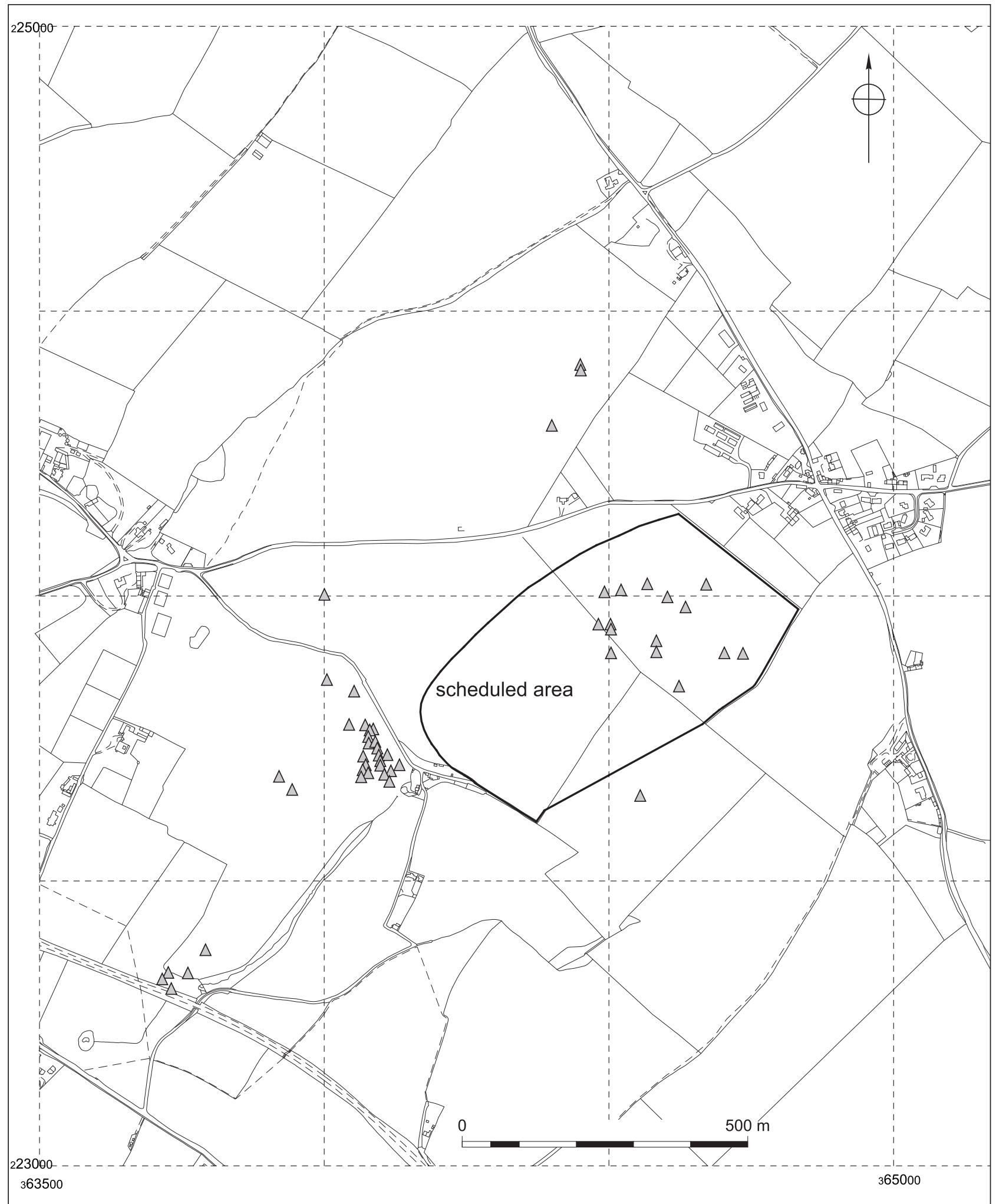

Figure 4.27. Distribution of Oxfordshire colour coated wares. Reproduced by permission of Ordnance Survey on behalf of HMSO. (C) Crown Copyright 2011. All rights reserved. Ordnance Survey Licence number 100051813

recovered from across the site (Fig. 4.27) and the ware is represented amongst the analytical groups of later date, albeit is small proportions.

As noted above cups, excepting samian examples, are altogether rare amongst the Ariconium assemblages. Similarly beakers in local fabrics are infrequent after the 1 st century AD. Copies of Gallo-Belgic style dishes ( $c f$. Cam from 16, etc) or derivative forms, in local fabrics, are 
present, dating to the early Roman period. These mirror examples from Gloucester and Kingsholm (Webster 1976; Timby 1990). In sum the picture verifies a modest level of fine ware use at the site, with samian and then, to a lesser degree Oxfordshire red/brown colour-coats, the main fine ware types present. It would seem that as with mortaria, the Oxfordshire industry was the main supplier of fine ware to the site during the later Roman era. This is the case with other West Midlands sites such as Alcester (Evans 1994, 148) and the villa at Huntsham (Webster 1995). At Droitwich, Oxfordshire was the main supplier of fine ware, though mortaria from Mancetter-Hartshill were more frequent than their Oxfordshire equivalents (Rees 1992, 55-6). There is a lack of genuine fine ware in Severn Valley ware fabrics, but this, of course, is a wider phenomenon. It might be borne in mind though that, notoriously, Severn Valley wares as recovered from fieldwork frequently seem to lack their original surfaces; more vessels may once have been burnished than now appears to be the case.

There is no particular indication from the context of the pottery finds dealt with here as to their specific functions.

The presence of soot/carbonised and calcareous residues and of burning can provide some insight as to the manner in which vessels were used and thereby of patterns in cultural activity. Most of the main coarse (and fine ware) fabrics present at Ariconium include sherds with burning. However, it is often difficult to determine what this represents. It may be due to over-firing in the kiln, the result of vessel use over fires or accidental exposure to heat. Typically in the case of sherds from Ariconium it could not be established whether burning pre or post-dated the breakage of the vessel. Proportionally more sherds from Bridgewater's excavations display evidence of burning than do those from the Garrod and Moss trial trenches (e.g. compare the samian catalogue lists for these exercises). Presumably this reflects the industrial activities undertaken in the area investigated by Bridgewater. There are no examples of calcareous deposits amongst the Bridgewater and Garrod and Moss excavated assemblages, these residues normally suggesting the boiling of liquids. In this case their absence may relate to local water chemistry, for this is a soft water area (R. Bond, pers comm.).

Soot or carbonised residues are a guide to vessel use. Often such traces are vestigial (and fragile) and unaided discrimination between soot and a carbonised residue, which may represent burnt food remains, is not always reliable. Consequently such evidence is grouped together here. Taking the rim sherds from both the Bridgewater and Garrod and Moss excavations as a sample, of the coarse wares, remarkably, only two fabric types are associated with such remains: C11 and B11. Only 3 rim sherds of C11, Limestone tempered ware, have traces of soot/carbonized remains (in each case on the exterior of the rim). This amounts to a mere $2.8 \%$ of the total number of rims in this ware. Evidently this common late Iron Age/1st century AD ware was not regularly used for food preparation involving heat. Contrastingly $35.3 \%$ of B11, Black Burnished Ware 1 , rims display soot/carbonised residue. In all cases these remains occur on the exterior. There are no examples of such traces on Oxidized and 'Unoxidized Severn Valley wares', despite the fact that wares such as R21 were used to copy B11 forms. It may be that if such wares have lost their original surfaces such traces have been lost with them. However, the pattern seems too absolute not to be indicative of a genuine trend in the use of Severn Valley wares.

\section{Taphonomy}

The quality and character of the sherds within an assemblage can often shed light upon site activities and deposit formation processes ( $c f$. Evans and Millett 1992). Sherd abrasion, for instance, can indicate the degree to which sherds have been trampled, disturbed and deposits re-worked; it can also be a sign of a malign soil environment. In fact the assemblages from Ariconium consist of comparatively unabraded pottery and, generally, sherds are in a good state of preservation. Some original surfaces may have been lost from Oxidized Severn Valley ware fabrics.

A good measure of the state of sherds and of the processes they may have been exposed to is the average sherd weight per fabric. Unfortunately since both the Bridgewater and Garrod and Moss excavation assemblages have been sorted to some degree this is not an appropriate method for this particular material. An alternative approach is to establish the average Rim Equivalent (RE) value of rim sherds per fabric within site phases. Data of this type are presented in Tables 40 and 41 using the analytical groups as the unit of assessment.

Table 40 shows the average RE values for Oxidized Severn Valley wares within the analytical groups. In the case of Groups 1 and 3-6, comprising stratified finds, there is apparent consistency with averages lying within a close range. Groups 8 and 9 have markedly lower averages, but this is to be expected as the sherds in question were recovered from topsoil and will have been subject to a series of attritional processes. Group 7 also shows a comparatively low average, and this evidently reflects the status of the context in question (Layer 1 within Bridgewater's excavation), specifically a disturbed layer sandwiched between topsoil layers and undisturbed archaeological deposits. Table 41 shows matching data for fabric R21. Rim sherds of this fabric within the early deposits comprising Groups 1 and 3 are clearly relatively unbroken. However, amongst the middle to late Roman Groups 4-7 a similar degree of brokenness is evident to that of the Oxidized Severn Valley wares. This trend amongst the later groups may well be an indicator of the presence of a proportion of residual material. Again the averages for Groups 8 and 9 are, by comparison, low.

An aspect of the assemblages dealt with in this report is the small quantity of pottery associated with discrete 
Table 40. The average rim equivalent value for rim sherds in Oxidised Severn Valley ware within the Analytical Groups

\begin{tabular}{|l|c|}
\hline Oxidized Severn Valley ware fabrics & $\begin{array}{c}\text { Average RE value, } \\
\text { for rim sherds } \\
\text { within Group }\end{array}$ \\
\hline $\begin{array}{l}\text { Group 1. From excavation; } \\
\text { date of Group } c \text {. AD 50/70-100 }\end{array}$ & 0.12 \\
\hline $\begin{array}{l}\text { Group 3. From excavation; } \\
\text { date of Group } c \text {. AD 50-100 }\end{array}$ & 0.13 \\
\hline $\begin{array}{l}\text { Group 4. From excavation; } \\
\text { date of Group } c \text {. AD 100-200/250 }\end{array}$ & 0.14 \\
\hline $\begin{array}{l}\text { Group 5. From excavation; } \\
\text { date of Group } c \text {. AD 135-230/250 }\end{array}$ & 0.15 \\
\hline $\begin{array}{l}\text { Group 6. From excavation; } \\
\text { date of Group } c \text {. AD 230/250-400 }\end{array}$ & 0.12 \\
\hline $\begin{array}{l}\text { Group 7. From excavation; } \\
\text { date of Group } c \text {. AD 230/250-400 }\end{array}$ & 0.09 \\
\hline $\begin{array}{l}\text { Group 8. From systematic surface collection; } \\
\text { date of Group } c .70 \text { BC-AD 400 }\end{array}$ & 0.06 \\
\hline $\begin{array}{l}\text { Group 9. From surface collection; } \\
\text { date of Group } c .70 \text { BC-AD 400 }\end{array}$ & 0.08 \\
\hline
\end{tabular}

Table 41. The average rim equivalent value for rim sherds in Oxidised Severn Valley ware R21 within the Analytical Groups

\begin{tabular}{|l|c|}
\hline 'Unoxidized Severn Valley ware' fabric R21 & $\begin{array}{c}\text { Average RE value, } \\
\text { for rim sherds } \\
\text { within Group }\end{array}$ \\
\hline $\begin{array}{l}\text { Group 1. From excavation; } \\
\text { date of Group } c \text {. AD 50/70-100 }\end{array}$ & 0.25 \\
\hline $\begin{array}{l}\text { Group 3. From excavation; } \\
\text { date of Group } c \text {. AD 50-100 }\end{array}$ & 0.27 \\
\hline $\begin{array}{l}\text { Group 4. From excavation; } \\
\text { date of Group } c \text {. AD 100-200/250 }\end{array}$ & 0.14 \\
\hline $\begin{array}{l}\text { Group 5. From excavation; } \\
\text { date of Group } c \text {. AD 135-230/250 }\end{array}$ & 0.13 \\
\hline $\begin{array}{l}\text { Group 6. From excavation; } \\
\text { date of Group } c \text {. AD 230/250-300 }\end{array}$ & 0.11 \\
\hline $\begin{array}{l}\text { Group 7. From excavation; } \\
\text { date of Group } c \text {. AD 230/250-300/350 }\end{array}$ & 0.11 \\
\hline $\begin{array}{l}\text { Group 8. From systematic surface collection; } \\
\text { date of Group } c .70 \text { BC-AD 400 }\end{array}$ & 0.11 \\
\hline $\begin{array}{l}\text { Group 9. From surface collection; } \\
\text { date of Group } c \text {. 70 BC-AD 400 }\end{array}$ & 0.08 \\
\hline
\end{tabular}

features. This is lamentable as pottery groups from features are often closely dateable, comparatively well-preserved and particularly amenable to analytical approaches.

\section{Pottery and site chronology}

The project had a series of aims and objectives, cast as questions, which it was anticipated that study would be able to address (Section 1; Jackson and Hancocks 1998). A central aim was to establish the history of the development of the site. Examination of the pottery evidence has established some well-defined chronological perimeters and a number of key trends which can assist in defining the chronology of the site. As verified above the pottery assemblages available fall short of being ideal samples. Nonetheless they constitute an effective body of data for addressing many queries concerned with chronology. In this sphere, complementary information from other work in the immediate vicinity is provided by samples from evaluation work in advance of the Ryeford Bypass (HSM 22965; Napthan, Ratkai and Pearson 1995) and the fieldwork preceding the Lea and Weston-under-Penyard (Welsh Water) transfer pipeline (HSM 6097, 12666 and 15983; Jackson, Hancocks and Pearson 1999).

The pottery evidence - as with the brooch assemblage - points firmly to there being occupation at the site during the pre-Roman Iron Age. This cannot be proven from the existing excavated stratigraphic or structural evidence from the known core area of the site nor from the pottery. However, the typological composition of Analytical Groups 1-3, and indeed the sheer volume of late Iron Age/Transitional pottery amongst the Garrod and Moss 
assemblage, can leave little doubt that there was significant occupation at the site during the earlier 1st century AD ( $c f$. especially Group 3 above). The start date for this occupation is obscure. In this respect the chronology of C11 and the siltstone/fine-grained sandstone tempered black surfaced wares is a significant factor; their distribution constitutes something of an index of late Iron Age and/or mid 1st century AD activity. Vessel and rim forms in $\mathrm{C} 11$ are not chronologically distinct and the ware has a long Iron Age pedigree. Similarly the debut of the black surfaced wares is not known. At Ariconium these wares appear in characteristic late Iron Age forms of Aylesford affinity (i.e. in forms which used to be referred to as 'Belgic'). Traditionally such wares would be dated in this region to the first half of the 1 st century $\mathrm{AD}$, though without there being fixed chronological anchors for such a dating ( $c f$. Saville 1984, 159). Haselgrove has plausibly suggested in a recent article (Haselgrove 1997) that the ascribed dating of such wares in southern Britain has been too late, and that there are good reasons for pushing their date back into the mid 1 st century BC. Hence these types at Ariconium might be indicators of occupation in the mid to late 1st century BC. Any fieldwork at Ariconium in the future should aim to address this matter, especially via the investigation of early stratified deposits and the recovery of associated pottery, supported, crucially, by accelerator dating.

Two ditches examined in section south-east of Pond Cottage during the works conducted in advance of the Welsh Water pipeline ( $c f$. above) have been tentatively interpreted by the excavator as being of Late Iron Age date (Jackson, Hancocks and Pearson 1999). Only limited archaeological detail was recovered. One ditch contained several sherds of Palaeozoic Limestone tempered ware (C11) and fragments possibly from organically tempered briquetage. The other yielded five pieces of Droitwich briquetage. No Roman sherds came from these features. The identification of these features adds further support to the thesis that the Ariconium complex is of Iron Age origin.

Vessels in C11 are also firmly represented amongst the assemblage from the excavations conducted by Walters and Walters to the north-west of the scheduled area (HSM 9071; see above). Again their presence can be interpreted as implying that there was occupation at this location during the late Iron Age.

Overall, the pottery evidence suggests a 'seamless' continuity in pottery consumption and occupation at Ariconium through the 1 st century AD, the period of the Roman conquest and after. As elsewhere ( $c f$. Pollard 1988; Willis 1996) the conquest cannot be discerned in terms of an abrupt change in the ceramics at this site, and it is unlikely that further excavation will reveal a sudden stratified change, as this seems not to be the case at sites with pre-conquest indigenous occupation. Instead there is an apparent first wave of ceramic change, which might a few years ago have been cast as an initial phase of 'Romanisation', with the arrival of North Gaulish (Gallo-
Belgic) imports and the appearance of copies of such types in local Severn Valley wares. This event had occurred almost certainly by $c$. AD 50, if, indeed, not before. These local copies or emulations mirror types identified by Timby (1990). Both these copies of Gallo-Belgic forms, as well as the copies of Aylesford style forms (e.g. the carinated bowls) in Severn Valley ware fabrics, may potentially pre-date the Roman conquest; this possibility is in line with Timby's suggestion that the tradition emerges prior to the conquest (Timby 1990). At approximately this time there is little samian ware arriving at the site; the earliest samian at Ariconium may well all post-date the conquest, appearing here after $c$. AD 50.

This initial wave of ceramic change has been described by Jeremy Evans as Gallic or Gallo-Roman in character (Evans 1997) rather than being genuinely (metropolitan) Roman or Romano-British. By the early Flavian period (c. AD 70-80/85) a second wave of change begins to define and a difference can be seen in the ceramics at Ariconium at around this date. During the Flavian period (c. AD 70-100) the ceramics in use become more obviously Roman/Romano-British. From this time, for instance, samian vessels are present in some quantity. The composition of groups by fabric changes with the disappearance of Gallo-Belgic types and copies of such, and the decline of wares such as C11 and R29. Forms and typological characteristics too become more typical of Roman assemblages. This is a pattern identifiable elsewhere at similar sized contemporary centres with indigenous roots (Willis 1996; Evans 1997).

The pottery from the area examined by Bridgewater in 1963 demonstrates that activity did not begin in this particular location until the later Hadrianic period (from c. AD 135). Positioned north-west of the scheduled site, this location was evidently virgin ground chosen (or cleared) for industrial activity (activities of an industrial nature often being placed in a liminal location with regard to Roman settlements). The pottery suggests that the deposits associated with iron-working (Group 5) cover a late Hadrianic to early/mid 3rd century date-span (c. AD 135-230/250). Whilst it is unclear quite what site formation processes account for the layers overlying Group 5 they clearly include later Roman pottery types.

The pottery from the scheduled area and its immediate vicinity presents reliable evidence for the continued occupation of this 'core' area through the early and middle Roman period. What is less certain though is the level of occupation and activity during the 4 th century. Clearly there is no shortage of 2 nd and earlier 3rd century Roman pottery as the evidence documented above demonstrates. Further, though the excavations reported here did not encounter good stratified later 3rd and 4th century pottery groups there is in sum sufficient later Roman pottery amongst the various collections to be confident that occupation of the site continued during the later 3rd century. There are, for example, a number of Black Burnished Ware 1 (B11) vessels that date to the later 3rd or 4th century (Fig. 
4.1.11, 17-19 and 26). Similarly there is a wide range of Oxfordshire products dating to after $c$. AD 240 (e.g. Fig. 4.15). Unfortunately little amongst the later Oxfordshire material from the site can be dated more precisely than to within the $c$. AD 240-400+ range. An amount of the Oxidized and 'Unoxidized Severn Valley ware' items might also date to the 4 th century. The assemblage recovered by Jack also includes a number of evidently late, potentially 4th century, items (Hayter 1923). The stone structures which he partially uncovered may have been in use in the 4th century, though they lack directly associated pottery and thus firm dating evidence.

In sum it is possible to interpret the existing ceramic evidence as indicating that occupation within the scheduled area was in marked decline in the 4th century. The absence of late Roman South Midlands shell gritted ware ( $c f$. Worcestershire Historic Environment and Archaeology Service Fabric 23; Tyers 1996, 192-3) from amongst the collections may be significant. This ware, perhaps from Harrold (Bedfordshire) or the Harrold area, is present at many sites in the Midlands and Wales during the 4th century, particularly after $c$. AD 350. The fact that the areas investigated via excavation and fieldwalking in and around the scheduled 'core' have been subject to disturbance, some landscaping (in the case of the field wherein Bridgewater undertook excavation), erosion and concerted ploughing must be borne in mind in any assessment of the 'absence' of later Roman pottery groups and of later Roman activity generally. Inevitably, and normally, the latest deposits at any archaeological site are the first to be denuded by such processes (cf. Haselgrove 1985), and the incorporation on pot sherds into topsoils exposes them to a deleterious environment.

Work in advance of the Lea and Weston-under-Penyard Welsh Water pipeline, south-west of the scheduled area produced an assemblage which included a strong proportion of later Roman pottery (Jackson, Hancocks and Pearson 1999). In particular sherds from Trench 4, and items gathered during fieldwalking, plus unstratified finds, include Oxfordshire colour-coated ware, Oxfordshire mortaria, Oxfordshire white ware, Black burnished ware, Nene Valley colour coated ware and Shell gritted ware (the latter perhaps dating from after $c$. AD 350). These finds are comparatively densely concentrated and seem firmly to indicate late Roman activity at this location. It may well be that the topography of this particular area has aided in the survival of later Roman evidence.

To summarise, the area in and around the scheduled core appears to have been heavily used at least until the end of the 3rd century. The date at which this area ceased to be a place of significant occupation and activity is not clear, however, from the present pottery samples. Seemingly, this was at some stage in the 4th century. Any further work undertaken at the site should, in particular, prioritise the recovery of stratified later Roman pottery groups.

\section{Pottery Supply and Trade}

Ariconium lies in an area covering south Herefordshire and west Gloucestershire which has seen limited fieldwork at late Iron Age and Roman period sites. Hence there is a dearth of pottery samples from the hinterland of the site which might be used to help characterise the nature of pottery supply on a wider basis. Significantly the site was positioned on an important Roman (and presumably Iron Age) road and lies near to the Severn Estuary and Wye Valley. These elements, in addition to its function in the production of iron, will have had a strong bearing upon its articulation with exchange systems involving pottery.

The major late Iron Age ware at the site is the Limestone tempered ware $\mathrm{C} 11$ which is a frequent find from the scheduled area and elsewhere within the Ariconium study area (Fig. 4.28). As noted above the fabric was used to manufacture jars and bowls, together with small numbers of cups and very large bowls. Few items from Ariconium are decorated; this is a notable aspect. Previous publications of Iron Age tradition pottery types in the region have tended to focus upon and illustrate decorated items and it has not always been clear what proportion of wares are decorated or other wise. The source of the ware is believed to be the Woolhope area (Morris 1983), some $11 \mathrm{~km}$ north-east of Ariconium. There are other potential sources though these too lie nearby. Hence the ware is very local. More than one manufacturing centre may have been involved in supplying Ariconium, though with the product outcome being characteristically identical pottery. If Woolhope is the source then one might envisage a rather dispersed industry here with multiple foci and perhaps of peripatetic character, analogous to some of the later Roman pottery industries in this manner. Clearly the $\mathrm{C} 11$ industry was a major producer by the late Iron Age, and conquest period phases at Beckford are dominated by items in this ware (Ford and Rees 1984; cf. Buteux and Evans 2004). At both Beckford and Ariconium the ware declines dramatically in frequency by the late 1st century (Ford and Rees 1984; $c$. Buteux and Evans 2004). At Alcester it is fairly common in deposits of $c$. AD 60, but is probably in decline from $c$. AD 70 (Jeremy Evans, pers comm.). The end date of the ware is not securely established but it seems improbable that it was produced in any quantity beyond $c$. AD 100 .

The black surfaced wares R25-31 seem certain to be local or regional products. They occur in a series of fabric variants but share several key characteristics: (generally) siltstone/fine-grained sandstone tempering, unoxidized (black) surfaces and similarity in the forms in which they occur. Typically they are associated with a variety of bowl forms such as necked and carinated bowls as well as necked jars and beakers. The forms are characteristic of the late Iron Age/1st century AD, though some examples appear to date to the early 2 nd century $\mathrm{AD}$. In terms of forms and fabrics these types may be described as Transitional (lying in typological and qualitative terms between typical Iron Age and typical Roman styles). In the past such items 


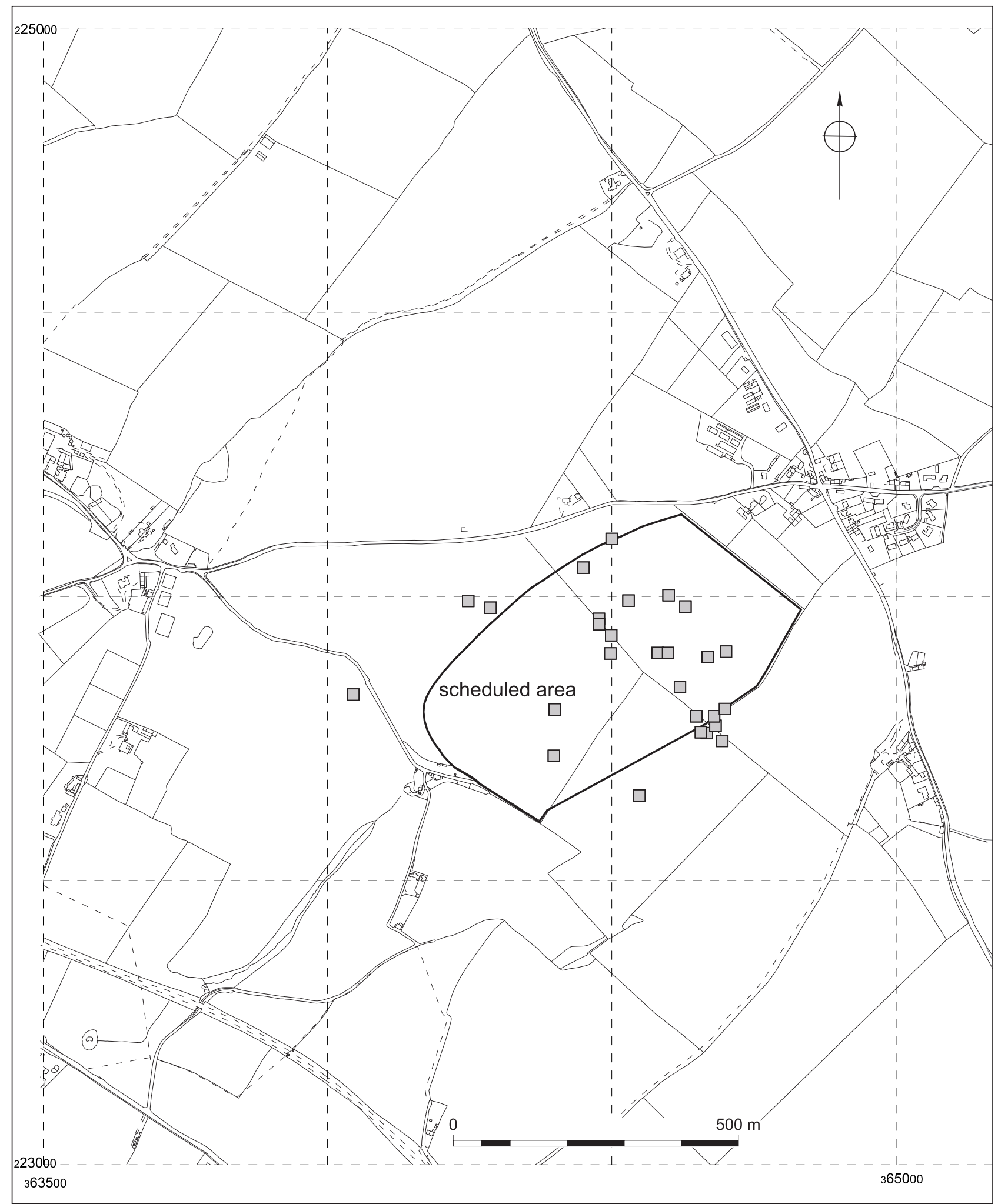

Figure 4.28. Distribution of Limestone tempered ware. Reproduced by permission of Ordnance Survey on behalf of HMSO. C Crown Copyright 2011. All rights reserved. Ordnance Survey Licence number 100051813

were referred to as 'Belgic'. Their prominence amongst the early pottery from Ariconium (e.g. Group 3) is highly significant for whilst examples of such types are known from the Avon and Upper Thames Valleys and in much of
Gloucestershire and Wiltshire they have not been found in any quantity in Herefordshire, South Wales or more westerly parts of Gloucestershire ( $c f$. Booth and Willis 1997, 54). In terms both of tempering and form these dark 
surfaced wares are related to early Oxidized Severn Valley wares.

The Roman pottery from Ariconium is dominated by Severn Valley ware, reflecting a pattern seen across the whole of the lower Severn Valley basin ( $c f$. Rees 1990; 1992; Darlington and Evans 1992; Evans 1994; Jackson, Hancocks and Pearson 1999). The majority of these vessels are Oxidized types, though Unoxidized wares are also important. The percentages of Severn Valley ware amongst the analytical groups examined above are consistent with the frequency of this pottery amongst the assemblage recovered during works in advance of the Welsh Water pipeline, south-west of the scheduled area. Severn Valley ware comprised some $65 \%$ of the pottery (by sherd count) from phase 1 deposits encountered during the latter works, which were of later 2 nd century to 4th century date (HSM 6097 and 12666; Jackson, Hancocks and Pearson 1999).

The principal temper in the case of these Ariconium examples of Severn Valley ware is siltstone/fine-grained sandstone, which was evidently employed throughout the life of the tradition. This is a temper recorded elsewhere amongst Severn Valley ware assemblages, but its prolific use in the case of the Ariconium assemblages is distinctive when compared to examples of this pottery from the wider region. This distinctiveness in itself implies a potential local source, and this possibility is sustained by the nature of the local geology, which is similarly reflected by the frequent presence of siltstone in the composition of medieval pottery commonly found in Herefordshire (Derek Hurst, pers comm.). How typical these fabric varieties may be vis-àvis the pottery in use in the locality of Ariconium is not known due to the lack of available pottery samples from the area, and because where such samples are available there has been little proper attention to fabric.

The formal range of the Oxidized Severn Valley wares at the site is wide, beginning with the important repertoire of 1 st century forms which mirror the early types recognised by Timby from eastern Gloucestershire (1990, fig. 4). Early Severn Valley ware types of 1 st century AD date are also reported from the area investigated by Walters and Walters (HSM 9071; Walters and Walters 1989, 33; see below). A number of these early forms are similar to vessels known from Kingsholm (Hurst 1985). Many of the later vessels in Severn Valley ware from Ariconium are paralleled amongst Webster's form series (1976). Overall, there is a correlation between fabric variety and form, especially in the case of the 'Unoxidized Severn Valley wares' such as R20 and R21. Flagons do occur in these wares, albeit rarely. There are no examples of mortaria in Severn Valley ware. Very few production sites of Severn Valley wares are known in the West Midlands ( $c f$. Evans, Jones and Ellis 2000) and the source(s) of these wares at Ariconium remain to be established. A local/near regional origin seems highly probable, especially given the sheer quantity of pottery involved. That more than one specific source location is involved is entirely possible, especially given that there is some degree of fabric variation amongst the Ariconium collection. Overall though there is a remarkable continuity of form, in fabrics and in supply of Severn Valley wares to the site.

Mortaria represent an interesting contrast to the Severn Valley wares for in this case the source of supply is extraregional. A potential explanation for this phenomenon is Rush's thesis that the long distance source and trade in mortaria had symbolic importance for consumers (Rush 1997). A series of major industries supplied Ariconium with mortaria throughout the Roman period. That the sources of supply changed was due in most cases simply to the chronology of the various industries, not to consumer preference. At variance to this pattern is the case of the Mancetter-Hartshill mortarium industry, the products of which will have been available from the 2 nd to 4 th centuries. Whilst there are a few examples of mortaria from this source at Ariconium they are numerically much surpassed by contemporary Oxfordshire products from c. AD 240. Both production centres (i.e. Oxfordshire and Mancetter-Hartshill) are a comparable distance from Ariconium. Mancetter-Hartshill mortaria were distributed in large quantities to the north midlands and northern England via the road network, and are rather infrequent at sites in south-west Britain. Contrastingly Oxfordshire mortaria are well-attested in the south-west Midlands and Bristol Channel hinterland ( $c f$. Tyers 1996), and in this case water transport was probably highly significant. Hence the imbalance in the mortaria from these two centres at Ariconium is typical of the region generally. Minor industries, with the exception of Caerleon and possibly a Cotswold/Gloucester source, are not represented.

Black Burnished Ware 1 is a frequent type amongst the collections, appearing, as elsewhere, from the early 2nd century. At Ariconium, this fabric occurs in jar, small jar, miniature necked jar, 'cooking pot', flange rimmed bowl, flange rimmed dish, straight sided dish and oval handled 'fish dish' forms. The proportion of Black Burnished Ware 1 amongst the pottery from the salvage recording on the Lea and Weston-under-Penyard Welsh Water pipeline south-west of the scheduled area (Jackson, Hancocks and Pearson 1999) is, overall, comparable to its frequency amongst the analytical groups from elsewhere at Ariconium examined above. The level of supply of this extra-regional coarse ware is not dramatic though and whether the percentages formed by this ware are low for a site of this scale and status in this region is a somewhat open question at present. At Blackwardine and Thornwell Farm, Chepstow, the frequency of the ware is similar to that at Ariconium (Rees 1990; Evans 1996), but the ware is more prominent at Sidbury, Worcester, at least before the 4th century (Darlington and Evans 1992). It is typical for the proportion of Black Burnished Ware 1 present in assemblages from Herefordshire, Worcestershire, western Gloucestershire and south Monmouthshire to vary ( $c f$. Allen and Fulford 1996). Doubtless the distribution was influenced by the nature of communication routes, but site status, identity and exchange relationships were clearly also major factors ( $c f$. Allen and Fulford 1996; Fulford and Allen 1992). 
Jars of the Malvernian industry (in G11) are represented amongst the assemblages, and sherds are also recorded from Trench 11 of the evaluation in advance of the proposed Ryeford Bypass, HSM 22965 (Napthan, Ratkai and Pearson 1995). Overall, however, they are very few in number and seem remarkably infrequent for a ware produced in quantity only c. $30 \mathrm{~km}$ from Ariconium. Jars in this ware are common at sites to the east and north-east of The Malverns, across Worcestershire (cf. Peacock 1967; Rees 1992; Buteux and Evans 2004). At Alcester, which is a similar distance from the source as Ariconium (though of course to the east), they are represented in comparatively modest numbers (Lee et al. 1994, 4-5, group 3, forming c. 3\% of the site assemblage); nonetheless they are significantly more common than at Ariconium.

There are two evident possibilities accounting for this low frequency of Malvernian products at Ariconium. The first is economic. It may be that locally produced jars, together with some mass produced Black Burnished Ware (B11), dominated the Ariconium market to such an extent as to close it to Malvernian jars. It is not surprising that jars in Palaeozoic limestone predominate during the early and middle 1 st century $\mathrm{AD}$, at least, as they were seemingly manufactured very near to the site. This tradition of the use of locally produced utilitarian vessels may have been an enduring pattern. The possibility that some type of social restriction or cultural preference was in operation to the disadvantage of Malvernian products might be borne in mind. The existence of such factors with regard to pottery distribution has been observed in East Yorkshire during the Roman period (Evans 1988). The virtual absence of Malvernian pottery from the assemblage is certainly a notable aspect of the ceramic identity of the site. It may well, moreover, be an indicator of a cultural distinctiveness, differentiating the site and perhaps the wider Forest of Dean area from the other regions of Dobunnic territory.

Oxfordshire products are well represented amongst the collections from Ariconium examined in detail here, and also occur in a range of types amongst the assemblage from the works in advance of the Welsh Water pipeline (Jackson, Hancocks and Pearson 1999). Amongst the surface collected and unstratified Roman pottery from the latter works some $4 \%$ (by count) was Oxfordshire colour-coated ware. Not surprisingly most of these items at Ariconium date from c. AD 240, though there are some earlier products. The Oxfordshire industry was the main supplier of mortaria to the site in the later Roman period, and seems also to have been the main source of the later fine wares. Ariconium lies on the western margin of the main distribution area of Oxfordshire products ( $c f$. Tyers 1996, figs 129 and 221). The frequency of Oxfordshire vessels seems comparatively high for a site west of the Severn. This presumably reflects both the importance of the site and the fact that it had good communications and exchange links in the 3 rd and perhaps 4th centuries. Oxfordshire items are well-attested along the north bank of the Severn estuary in western Gloucestershire and south Monmouthshire (cf. Young 1977; Allen and Fulford 1996, fig. 14 (e)).
An accurate picture of amphora supply to Ariconium is hindered by the loss of amphora sherds from the Garrod and Moss excavations. This partly explains why only four types are represented amongst the collections: examples of the Dressel 20 are numerous but the three other types are represented by single sherds: Haltern 70, Beltrán I/Dressel 7-11 and Gauloise 4/Pélichet 47. In contrast Droitwich, Sidbury (Worcester) and Kenchester, for example, have more diverse ranges ( $c f$. Woodiwiss 1992; Darlington and Evans 1992; Tomber 1985), with more examples of the non-Dressel 20 forms. The same is true, of course for Kingsholm (Hurst 1985, table 11), though this sample relates directly to military occupation.

From Ariconium there are 17 surviving Dressel 20 sherds amongst the assemblage from Bridgewater's work in field HSM 10676, plus a considerable number of Dressel 20 fragments collected from a wide number of locations across the site (Fig. 4.29). In addition a number of diagnostic Dressel 20 fragments were recovered by Jack from his work in field HSM 21376 (this work having the specific HSM code 16780). Further examples of the type were recovered both from work along the main course of the Welsh Water pipeline (HSM 6097) and from the salvage recording at HSM 15983, on the spur of the pipeline (Jackson, Hancocks and Pearson 1999). The Dressel 20 amphora is the most frequently encountered amphora type on Roman period sites in Britain, though away from military sites and major towns it is less common than is often imagined. The normal contents of this amphora type consisted of olive oil from Southern Spain which had a range of potential uses. Typically Haltern 70 was used to convey defrutum, a fruit sauce, or olives in fruit sauce; Beltrán I/Dressel 7-11 was normally used to transport fish sauce; and Gauloise 4/Pélichet 47 was a wine container. The virtual absence of wine amphorae from the Ariconium assemblage is at first glance striking, and might be considered a significant indicator of site status but for the fact that some uncertainty must exist as to the degree to which the available sample presents a reliable picture of amphora consumption. In addition to the loss of amphora sherds from the work undertaken by Garrod and Moss, sherds may not have been collected or retained in some other instances as well. It might also be borne in mind that amphora body sherds often appear undiagnostic, prior to close examination, or superficially similar to tile fragments.

It should be borne in mind though that amphorae were commodities in themselves and will have travelled and been used after their original contents had been consumed. The extant evidence points to a comparatively high level of amphora supply/use at Ariconium, at least in the case of the Dressel 20 type, especially when set alongside the evidence for these vessels at rural sites and sites of middlerank scale ( $c f$. Booth 1991). The recorded find-spots are centred on the scheduled area, but the wide occurrence of examples across the complex is striking (Fig. 4.29). It is possible that at this particular site these containers had a 'second' use in the storage and movement of water around the complex associated with the production of iron. Their 


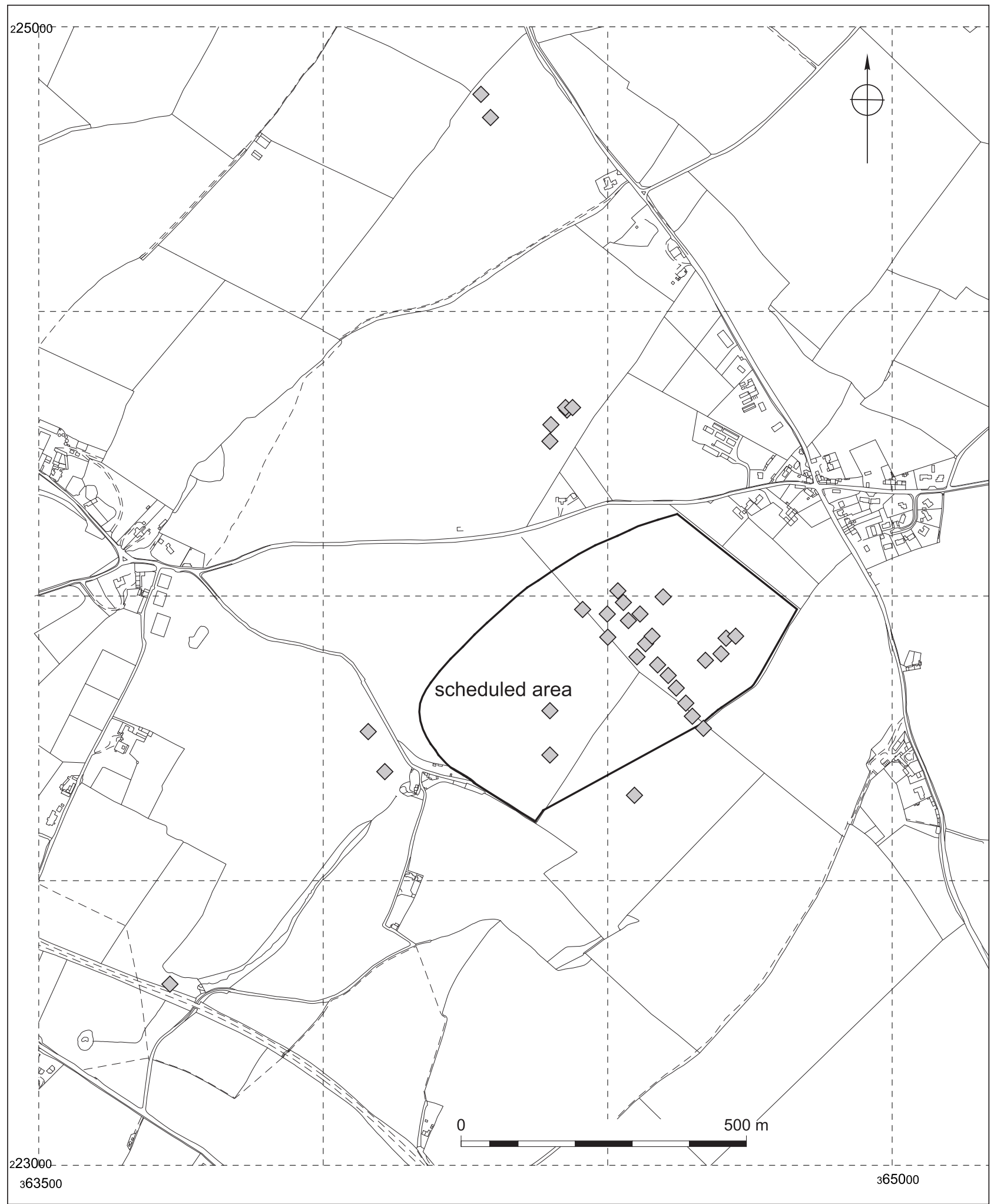

Figure 4.29. Distribution of Dressel 20 amphora. Reproduced by permission of Ordnance Survey on behalf of HMSO. (C) Crown Copyright 2011. All rights reserved. Ordnance Survey Licence number 100051813

standard capacity was 66-76 litres (Sealey 1985, 73). Sherds of Dressel 20 are recorded from the site of the Huntsham villa, Herefordshire (Webster 1995, 254).

There can be little doubt that at all times the pottery consumed at Ariconium was predominantly of local origin; this is clear from the analytical groups examined above, and is apparently the case with the samples from the Welsh Water pipeline (Jackson, Hancocks and Pearson 1999). Yet during the late Iron Age and Roman periods the site remained networked with sophisticated exchange systems 
and a range of extra-regional products occur, notably amphorae, samian, other fine wares, mortaria and Dorset Black Burnished Ware. The presence of Gallo-Belgic pottery is especially noteworthy for it is not otherwise recorded west of the Severn (excepting later Terra Nigra from military sites in South Wales). The large quantity of samian recovered from fieldwalking and the (small-scale) excavations at the site are testimony to a strong level of supply indicating a centripetal site.

\section{Site status, character and identity: the pottery evidence}

A range of ceramic evidence points to the fact that the site at Ariconium was of significant status within its region, for much of the period examined here.

The considerable quantities of typologically late Iron Age and Transitional pottery amongst the assemblages examined leave little doubt that there was extensive activity at the site during the late Iron Age. The pottery evidence does not provide a precise indicator of the start date of the occupation (on the basis of the currently available samples). The date of the Palaeozoic Limestone tempered vessels is important in this respect. Though this ware is current in the middle Iron Age there is nothing amongst the collections reported here which is necessarily typologically middle Iron Age.

The large majority of this pottery comes from the scheduled area, and its immediate vicinity, being recovered from both excavation and surface collections. This implies that the core of late Iron Age occupation is broadly contiguous with the current scheduled area. However, the spatial distribution of the recorded late Iron Age and Transitional pottery from the site may simply reflect the pattern of archaeological investigations which have been overly concerned with the scheduled area, and foremost one particular field (HSM 21376). The aerial photographic plot suggests a wider area of activity at the site and there are several find-spots of $\mathrm{C} 11$ away from the scheduled area (e.g. from SO 6445 2339, SO 64632454 and SO 6428 2488; Fig. 4.28), as well as from Trench 11 of the evaluation in advance of the proposed Ryeford Bypass, HSM 22965 (Napthan, Ratkai and Pearson 1995) and from south-east of Pond Cottage, HSM 12666 (Jackson, Hancocks and Pearson 1999) where probable Iron Age deposits were identified. One of the few systematic fieldwalking exercises away from the scheduled area provides the only certain evidence of an absence of late Iron Age and Transitional pottery from topsoil deposits, namely the work by SWAG in Field HSM 22049.

Unfortunately a late Iron Age phase (other than at HSM 12666 , cf. above) is not demonstrable in terms of the occurrence of late Iron Age pottery groups within discrete stratified contexts. Excavations at Ariconium have been limited in scope and a high proportion have not investigated the earliest levels to any extent. In particular the Garrod and Moss trial trenches yielded mixed results. The trenches with the simplest sequences tended to be those with the sizeable pottery groups, including much typologically late Iron Age and Transitional pottery (e.g. Group 3), but this material came from layers deposited after $c$. AD 50. Trenches with longer sequences, including features, had little or no associated pottery from their earliest deposits (e.g. Trenches CI and CXX; HSM 23551 and 23552), and some early deposits included Oxidized Severn Valley ware sherds. On balance a late Iron Age phase is denoted by proxy.

From the presence of this pottery several aspects of the site in the late Iron Age / mid first century era can be deduced. Firstly, the pottery in use was of local origin. It comprised unelaborated Limestone tempered ware (C11) in practical jar and bowl forms (not beakers) and these were not normally used in food preparation processes involving direct exposure to fires. In addition a range of dark surfaced wares are present representing a distinct late Iron Age 'Aylesford-affinity' ceramic phase. These items were contemporary with the $\mathrm{C} 11$ types. Elaborated beakers, jars and bowls occur in these dark-surfaced wares and represent a rare example of this style (in quantity) in the western territory of the Dobunni. Importantly, this occurrence indicates a site of some status, articulated with and receptive to cultural developments in Gloucestershire and the southeast of England. This is not surprising given the trading status of the site implied by its iron working activities.

Given this connection it is appropriate that the Ariconium collections include examples of early to mid 1 st century Gallo-Belgic fine ware imports (e.g. Fig. 4.4.7, 8, 9, 10 and 11) of the type known from Bagendon and its hinterland (Clifford 1961; Rigby 1988) but otherwise rare in Dobunnic territory, especially west of the Severn. These extant finds may well be an element of what was a large ensemble of these early imported finewares reaching the site. The significance of these items and their origin had seemingly not been appreciated prior to the present review. They represent a clear index of the status of Ariconium at this time: it was evidently a site of some standing within the settlement structure.

The ceramics provide no reason to believe that the area of occupation and industrial activity during the early Roman period differed from that of the late Iron Age.

Malvernian wares did not reach the site in any significant quantity at any time. During the early period this was because the prolific $\mathrm{C} 11$ industry was much more local, and its products were evidently preferred. Later, within the Roman period their virtual exclusion seems likewise due to more local production, though by this time the locally produced wares were oxidized and unoxidized vessels of Severn Valley ware tradition. The latter occur in predominantly siltstone/sandstone tempered fabrics which superficially mirror the Severn Valley ware fabrics represented at Droitwich and Alcester but which on any concerted inspection are highly distinctive. This clear preference for locally produced wares, evidently manufactured on the west side of the Malverns, may reflect marketing and economic factors and/or cultural factors (partiality, perhaps, in favour of local material culture).

The work conducted c. $1 \mathrm{~km}$ north of Ariconium has raised the interesting question as to whether there was an 
early military phase in the vicinity of the site (HSM 9071; Walters and Walters 1989). Walters and Walters examined a pair of small rectangular enclosures and associated features via evaluation trenches. An amount of 1 st century AD pottery was recovered. The excavators believed this to be a Roman military site comprising two fortlets. Pottery finds consisted of early (i.e. 1st century) Severn Valley ware, 'native wares' including Limestone tempered ware and sherds of Dressel 20 amphorae. However, the range of recovered pottery cannot be taken as diagnostic of an early Roman military presence. It does not, for instance, seem very different from the samples collected by Garrod and Moss from the early layers they encountered in their trenches. Moreover, there is no regional template a propos early military pottery assemblages. Darling's study of pottery from early military sites in western Britain has demonstrated how greatly assemblages differed site to site (Darling 1977). In addition the nature of the garrison, the specific function of the site and the functional area from which the pottery comes from, within a military site, will be key variables determining assemblage make-up. The predominance of evidently local wares is, however, not inconsistent with a military interpretation since at this time the Roman army used locally produced pottery wherever it was available in sufficient quantity and quality ( $c f$. Darling

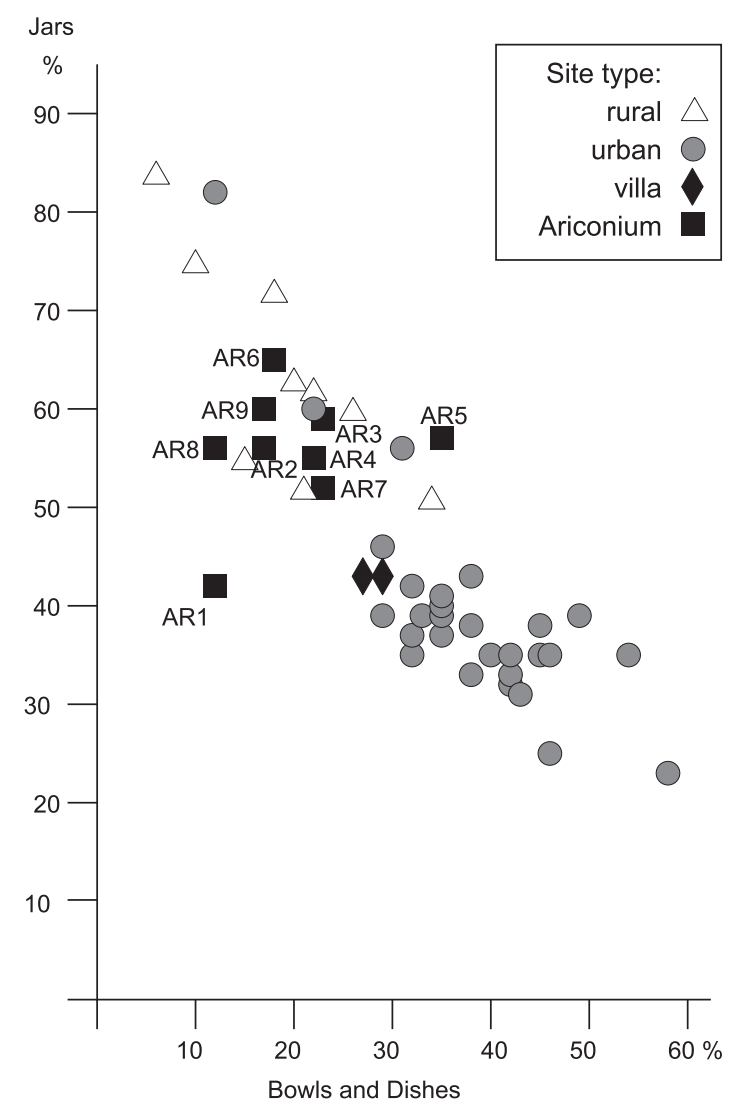

Figure 4.30 Scattergram showing percentages of jars within site groups from southern Britain plotted against percentages of bowls and dishes present.
1977, 60). The absence of non-local fine wares, samian, mortaria, rusticated jars, and (apparently) flagons seems to provide evidence against a military presence as these types might be expected with army personnel. However, sizeable assemblages from the fills of the ditches outside the early fort at Ancaster, Lincolnshire, lacked such exotic items, being composed almost entirely of typologically Iron Age pottery (Willis 1996).

Dressel 20 amphorae are particularly associated with Roman military sites during the 1 st century, but contemporary 'higher status' sites with no military connection such as Dragonby, North Lincolnshire, RedcliffNorth Ferriby, East Yorkshire and Stanwick and Melsonby, both North Yorkshire, have likewise yielded Dressel 20 sherds from stratified 1st century deposits (Willis 1993; Fitts et al. 1999). Indeed, all four of these sites have yielded stratified pre-conquest examples of this amphora type, and it must be possible that the amphora represented at this particular location at Ariconium was a pre-conquest arrival. Significantly no 1 st century samian is known from anywhere in this field. In sum the case for or against a military presence is not proven either way by the pottery recovered, though one might say there is no necessary reason to believe, from the ceramics, that this was a site of military activity.

During the early Roman period Ariconium evidently remained a centre of importance judging from the sheer amount of samian pottery recovered. In particular there is much 1st century South Gaulish La Graufesenque ware, including a number of pre-Flavian vessels (i.e. pre-dating c. AD 70), with no paucity of decorated vessels. Whilst the quantity recovered is in part a function of sustained collection and excavation, at Ariconium the overall impression is that there is an unusual frequency to these finds, when compared to other middle-rank settlements of the early Roman period ( $c f$. Willis 1997; 1998b). There are a minimum of 12 different vessel form types present in South Gaulish La Graufesenque ware. This is a high figure by any comparison ( $c f$. Willis 1997, table 3 ) and represents a higher tally than is presently recorded for the middlerank settlements of Dragonby, Nettleton (Lincolnshire) and Droitwich. Again the bulk of the early samian is from the scheduled area and its immediate vicinity.

Looking at the pattern of samian supply overall it is readily apparent that the majority of the material is Antonine (c. AD 140-200); it is typical of sites of middlerank order to show a peak in samian supply during this period, as at Droitwich (Dickinson 1992a, 58) and Sidbury, Worcester (Dickinson 1992b).

Figure 4.30 is a scattergram plotting the proportions of jars as against bowls and dishes within stratified pottery groups from a series of rural, urban and villa sites in southern Britain (the source being Evans 2001). The sample includes Alcester, Alchester and Silchester, and sites in the Arrow valley, Warwickshire, amongst others. Equivalent figures for the nine analytical groups from Ariconium examined here have been added to the plot (note that for these groups platters are also included with the bowls 
and dishes, as dishes and platters were combined in the analysis above). The plot discriminates Analytical Group 1 as being at variance with the other constituents of the sample. The difference arises from the strong presence of beakers within this group ( $c f$. above). Its position in the scatter plot, and general composition, are consistent with samples from 'oppida' type sites in the south-east of England (Jeremy Evans, pers comm.). The eight other Ariconium groups cluster reasonably closely together, independent of their chronology, emphasising continuity over time. Compared with the other constituent groups in the sample, these Ariconium groups fall amongst those from rural sites. The impression is striking and suggests ostensibly that the ceramics consumed at the site conform to the pattern of rural practice. How this evidence is best interpreted is not straight forward.

Ariconium was clearly neither an urban site, nor a rural site in the conventional senses. It might be better to interpret the scatterplot as indicating a non-urban pattern of pottery consumption. It is unlikely that the plot is simply a consequence of the typology of Severn Valley ware, the main ware class present within the groups, as consumers will have had a choice in the functional types they used, and, besides Severn Valley ware is a component of many of the other groups in the sample. It might be that the plot identifies a difference in the nature of ceramic use amongst the western Dobunni, but there is, to date, no other evidence for this (though it should be borne in mind that very few sites of the period in this region west of the Severn have been investigated or published). It is more likely that the plot identifies a specific industrial-roadside settlement identity, within a rural context. The pottery assemblage recovered from an area on the fringe of the 'small town' at Asthall, Oxfordshire, investigated recently, has a similar 'rural' composition (Booth 1997). Jeremy Evans (pers comm.) has pointed out that peripheral areas of urban sites may appear 'rural' in terms of their pottery assemblages due to the nature of the activities undertaken at such locations. Clearly Bridgewater's excavations were undertaken in what was a liminal milieu at Ariconium. This might also be true for the areas investigated by Garrod and Moss which yielded Analytical Groups 1-4 (see above), located as they are in an area of the site that sees no direct occupation or activity from the end of the early Roman era. Groups 8 and 9 , however, which should be representative samples from the core of the site, share the same area of the plot. This might be because the core of the site, as indicated by stone founded buildings, tesserae, etc., appears not to have been large. Percentages of fine ware types at the site, as noted above, are not, however, particularly low, as would be expected of a typical rural assemblage.

Levels of decorated samian ware are also a good guide to the status of a site and its type (Willis 1998b). Decorated bowls seem to have been more highly valued than plain samian wares and so, in principal, higher percentages of decorated vessels should provide an index of supply connections, wealth and status. Unfortunately the proportion of decorated ware amongst the sample from the
Garrod and Moss excavations cannot be established due to the erstwhile discard of some material ( $c f$. above).

The best (though not ideal) guide to the proportion of decorated samian vessels present lies in grouping the samian surface finds collected by Bridgewater and DAG from Field HSM 21376, all of which appear to be integral ( $c f$. above). This results in a sample of 83 vessels identifiable to generic form; the decorated proportion amounts to $23.8 \%$ ( $c f$. above). This proportion compares well with other samples from major Roman civil centres, 'small towns' and roadside settlements (Willis 1998b, table 6) and in fact the proportion is similar to levels in some samples from Cirencester and Verulamium. However, this general percentage figure for decorated samian (from HSM 21376) masks a striking bipartite chronological difference. Of the samian from La Graufesenque and Les Martres (c. AD 40-120/130), some $40 \%$ is decorated which is an exceptionally high figure by any comparison ( $c f$. Willis $1998 \mathrm{~b}$ ), while only $c .16 \%$ of the Lezoux vessels represented (c. AD 120-200) are decorated. Although the trend is for there to be somewhat less decorated vessels in the mid to late 2 nd century generally, relative to plain wares ( $c f$. Marsh 1981), these data seem to be a strong indicator of a change in site status from a high status centre in the 1 st century $\mathrm{AD} /$ early Roman period, to a more ordinary 'small town'/roadside settlement in the 2nd century. Indeed the percentage of decorated samian for the period $c$. AD 120-200, at 16\%, accords well with the $17 \%$ average percentage for decorated samian at both 'small towns' and roadside settlements, and rural sites, in Britain (Willis 1998b; the provincial average for major civil sites being $26.6 \%$ ). It is noteworthy that the proportion of decorated vessels amongst the samian assemblage from Bridgewater's excavation in an industrial zone, which is essentially 2 nd century in date, is $10 \%$. This somewhat lower proportion to the figure for the area to the south (HSM 21376) may be explained by the industrial function of this area, which may have been positioned away from any higher status occupation. In contrast a building of some pretension at Kenchester produced an excavated sample of samian dating to the Antonine period (site Period 2c, c. AD $140 / 150-180 / 200$ ), amongst which $20.7 \%$ of the vessels were decorated (Building AJ; Wilmott and Rahtz 1985).

Amphorae are also quite sensitive indicators of site type and status (Booth 1991; Evans 2002; Evans forthcoming). Normally they are not common finds at rural and middlerank Roman sites. As observed above sherds of Dressel 20 amphorae are both widespread and fairly frequent finds amongst the Ariconium assemblages (Fig. 4.29). This pattern is consistent with the samian evidence in suggesting a site of some considerable regional standing, especially during the 1 st century $\mathrm{AD} /$ early Roman period. There are no sherds with graffiti present amongst the collections.

Generally the range of pottery types represented is what might be expected of a settlement of some significant regional status (? high status) during the late Iron Age and 1 st century AD in central Britain, and which develops into a 'small town/roadside settlement' during the Roman period. The analytical groups show considerable consistency 
in composition both in terms of fabrics and forms, and between the different areas of the site from which the samples derive. Though there is a significant range of later Roman pottery amongst the various collections there is a conspicuous lack of securely stratified late Roman pottery groups. Largely for this reason the status and character of the site are less clear during the later Roman period from the evidence of ceramics. Any future intervention at the site which recovered stratified late Roman pottery would be advantageous for developing our knowledge of the site.

\section{A face pot \\ Robin Jackson}

One further pottery sherd of interest known from the site is of a fragment of a face pot (Fig. 4.31) from the surface collection of Martin Sterry (HSM 23563). The sherd is of a Severn Valley ware fabric (Worcestershire Historic Environment and Archaeology Service Fabric 12), a fabric which has rarely been associated with face pots (Gillian Braithwaite, pers comm.). Their distribution is restricted to a few early examples as at Gloucester and Kingsholm and later ones as at Wroxeter and Blackfriars, Worcester. However, the features on the example from Ariconium have little in common with any of these, any affinity seeming to be more with examples from eastern Britain (Gillian Braithwaite, pers. comm.).

Face pots are of some considerable interest, almost certainly having ritual associations with the faces representing either local or familiar protective deities (Braithwaite 1984; Halkon 1992). Associations with the Celtic smith god and his Roman counterpart Vulcan have also been suggested on the basis of smith's tools on several face pots as well as associations of face pots with smith pots (Braithwaite 1984; Webster 1989). Thus an association with both religious activity and ironworking can be suggested for these items. The sherd from Ariconium supports this association since the site is a well documented ironworking centre and since other finds from this immediate area can be taken to be indicative of the presence of a temple or shrine in the vicinity.

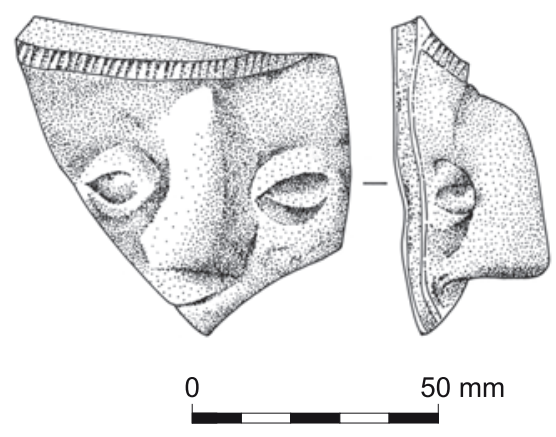

Figure 4.31. Severn Valley ware: face pot

\section{The brooches}

\section{Donald Mackreth}

\section{Introduction}

The following report deals essentially with a group of brooches seen by the author. After each main section is a list of those which were not examined by the author, but which have been classified by others. For these, the basic assignment to particular types has not been checked and, in the absence of any detailed information, especially on how the pin is mounted, no real comment has been made about them. They are designated by letters of the alphabet. At the very end are those brooches in the list which cannot be usefully attributed to a particular type. Fragments of pins not seen are not listed here.

The only exception covers items in Gloucester Museum recorded by Dr Hilary Cool and identified by reference to Hattatt 1989. These have been incorporated into the numbered sequence. They have the prefix 'Glos' to ensure that there is no confusion and should be taken to be covered in the discussion sections which follow. The description of each is essentially a préçis of her text.

All brooches are made from a copper alloy. Those selected for illustration are shown on Figures 4.32-4.36.

The following catalogue describes each of the brooches in turn and provides discussion of them in groups. Each brooch entry gives the source, museum accession (if relevant) and an SMR reference (prefixed HSM). The SMR numbers generally relate to individual fields or excavation trenches except for those from the Palmer collection which have a general number (HSM 23571) but cannot be located more specifically than to Ariconium. Where a more specific location is available in the form of excavation trench number, context number, or specific grid reference (e.g. for surface finds) this is also given.

\section{Catalogue and detailed discussion \\ (Figs 4.32-4.36)}

\section{Colchesters}

All of the Colchester brooches listed have integral bilateral springs, the external chord being held by a forward-facing hook.

The first example (Brooch 1) is a continental form, as the very short hook and the thin section of the bow show. There is nothing to stop such brooches from being imported at any time during their floruit on the Continent. However, the British style deriving from items such as this probably became too dominant to allow this and lasted longer than the type in its original homeland. The only site allowing an insight into developing brooch styles before the conquest is the King Harry Lane cemetery, St Albans (Stead and Rigby 1989). The incidence of continental Colchesters in the four phases into which the cemetery was divided is: phase 1, g 270.3; phase 2, g 231.6. The date range for 
these is at most (see after Brooch 8 for the revision of the dating of the King Harry Lane cemetery) 15 BC-AD 30 for phase 1 and 20-40 for phase 2. In reality, none needs be later than AD 25 and the signs are that the type had evolved by the end of the 1 st century BC.

Brooches 2-4 have almost straight profiles and relatively short hooks, and in this are closer to the continental parent than the bulk of British examples represented by Brooches $5-7$. The best place to see the distinction between the two is the King Harry Lane cemetery (Stead and Rigby 1989) and the occurrence of brooches like Brooches 2 and 3 at least, as Brooch 4 has lost its catch-plate, is: phase 1, g 296.3, g 312.4; phase 2, g 238.3, g 339.5. Note however, that $\mathrm{g} 312$ also has two Colchesters with standard profiles, as does $\mathrm{g} 339$ from phase 2 where a new catch-plate made from sheet metal had been fitted in antiquity. In other words, their occurrence matches that of Brooch 1, and the same date range may also be proposed, bearing in mind the worn and repaired state of one of those in a phase 2 burial.

The standard British Colchester was forged from a cast blank (e.g. Brooch 9). These begin early in the 1st century $\mathrm{AD}$ and are still in use at the conquest, by which time they are no longer made, even the later, cast, stages had ceased to be made by AD 40/45 and the Derivatives forms have evolved. In detail, Brooches 5 and 6 are carefully made with a well formed section and may well have ceased being made by $30 / 35$. However, the section of Brooch 7 has a bow section which is less well made which may mean that is was made between c. 10 and 35/40. These may seem to be fine divisions within a period where conventional dating is largely lacking, but Brooch 8 is a late Colchester and its size is a good enough guide even if its condition leaves a lot to be desired. For the first time, brooches were being made in standard sizes, a product of the manufacturing process, they being all cast in moulds.

The occurrence of late Colchesters in the King Harry Lane cemetery makes the point: phase 1, none, phase 2, none, phase 3, g 233.2, g 450.5; phase 4, g 28.5, g 431.2-3; unphased, g 306.6. The giant Rosette in grave 306 is very heavily worn, next to nothing surviving of the gilding and the Colchester in grave 450 of phase 3 shows something of the Derivative forms. In other words, it is only really at the end of the use of the cemetery that these brooches appear. They were still to be seen in use in the $50 \mathrm{~s}$ but it may be doubted that any were still in the $60 \mathrm{~s}$. This makes it appropriate to talk of the end-date of Colchesters in general. At best, early brooches such as Brooches 1-3, were probably only rarely seen in use by AD 40/45, while the later ones represented by Brooches 4-7 would have been seen through most of the 50s and only a very few indeed might have been seen in the $60 \mathrm{~s}$.

Now is the time to discuss the dating of the phases in the cemetery as this is relevant to more than one type of brooch represented at Ariconium for the astute reader will have realised that dating used here does not conform with that published in the excavation report. The authors of the report acknowledge that the cemetery may have begun as early as 15 BC, but preferred to use AD 1 (Stead and Rigby 1989, 83). This has had a knock-on effect on the dating of phases 2 and 3 leading to what this writer considers to be an unacceptably late date of AD 40-60 for phase 3 . The crux of the matter lies in presences and absences. If phase 3 has to date 40-60, where are the brooches which mark that period, the Colchester Derivatives and the Hod Hills? There is one Colchester Derivative, phase 3, grave 316.4 , and that would be counted as being an early one, a date of $c$. AD 40/5 being appropriate. There is no proper Hod Hill, a type which arrives in AD 43 fully developed and in great numbers. Both types were in use in the town scarcely $500 \mathrm{~m}$ away. There is also a lack of appropriate samian (ibid. 113). If the possible start date of $15 \mathrm{BC}$ is used, the consequent adjustment backwards of the four phases would be: phase 1, $15 \mathrm{BC}$ to $\mathrm{AD} 30$; phase 2, $\mathrm{AD}$ 20-40; phase 3, AD 35-55*; phase 4, AD 45+. This leaves the relative chronology intact and removes the problems created by the absences. Phase 3 has an asterisk to indicate that the brooches in the cemetery, which may all have been deposited by $45 / 50$, actually had, in the outside world, a different life, they all having the potential to continue in use and to pass into the archaeological record in a normal fashion, a cemetery being a specialised environment. In the discussions which occur below it is this revised dating which is used, but the terminal dates used for British types are based upon ordinary site dating.

Lastly, turning to the unfinished casting (Brooch 9), the study of the Colchester type shows that the vast majority were forged into their final form, even if the basic brooch was cast as a blank (Stead 1975). That this was not a standard blank being worked up is shown by the comment that the chevron was cast, earlier practice was to hand form it by using a punch alternately on either side of a ridge which may or may not have been part of the cast blank. The date should be that of Brooches 5-7.

1. $58.5 \mathrm{~mm}$ long. The wings are short with slight diagonal steps next to the bow being probably products of the manufacturing process rather than being intentional decoration. The hook is short with a knob at the end. The plain bow is thin with a slightly taper to a squared-off foot. The damaged catch-plate was narrow in proportion to its height and had two openings separated by a bar. HSM 5324; Garrod Coll. L260.

2. $84 \mathrm{~mm}$ long. The wings are plain and the hook fairly short. The plain bow is thin with a chamfer down each side and has a flat back. The catch-plate is more than twice as long as it is wide. It has two piercings separated by a dog-leg bar with an additional point up and down. The upper hole has a triangular intrusion at the top. Heref. Mus. 7639/21; HSM 16780; SO64672405; Jack 1922; Jack 1923, 8 and 24, pl. 12, fig. 1.

3. Now $75 \mathrm{~mm}$ long, it had been at least $85 / 90 \mathrm{~mm}$ long. The wings and hook are like those on Brooch 2. The bow has a stout octagonal section and has lost its foot. The catchplate was pierced like the last, only the triangular intrusion touches the upper of two bars with projections separating 

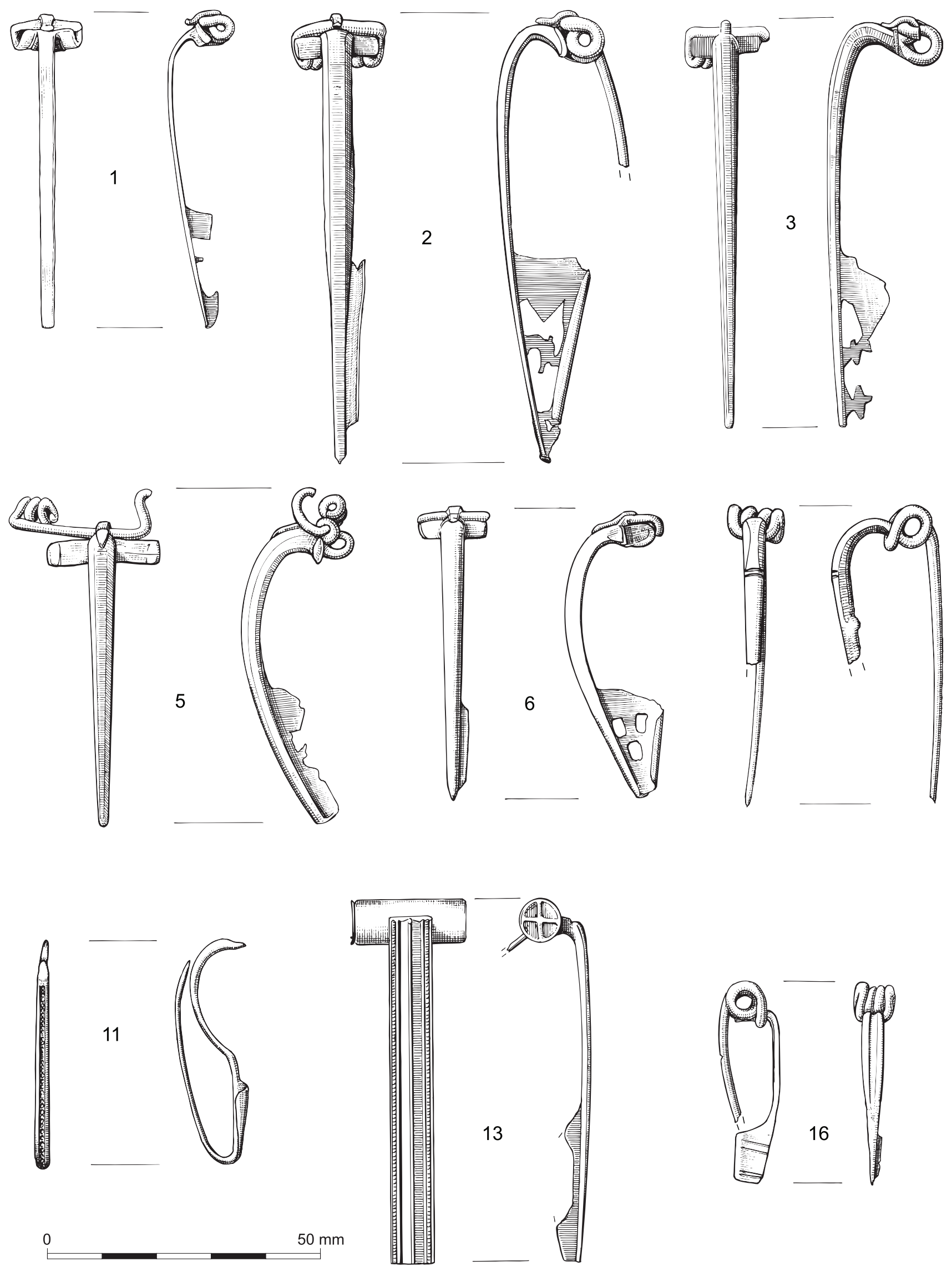

Figure 4.32. The brooches (Catalogue numbers 1-16) 
the original three tiers of openings. HSM 23549; SO 64672376; Tr. BII, context 2, sf. 15; Garrod 1967.

4. The very short wings are plain. The corrosion accretions hide whether the hook is broken or, more likely, very short, barely reaching the head of the bow. The bow is relatively thin and has a hexagonal section. The lower part with the catch-plate is missing. HSM 21376; SO 6449/2399 [5]; DAG Fieldwalking 1984-9. Not illustrated.

5. $60 \mathrm{~mm}$ long. The hook is moderately long as are the wings, each having vertical flutes. The bow is stout and has an octagonal section. The remains of the catch-plate, with signs of a series of piercings, was wide in proportion to its depth. HSM 5324; surface find; Garrod 1967.

6. $55 \mathrm{~mm}$ long. The hook has an average length, the wings are plain and the bow probably has an octagonal section. The length of the catch-plate is less than twice its width and has three piercings whose dividing bars have some signs of fretting. HSM 23571; Heref. Mus. A9379/6; Ritchie 1970.

7. Once more than $71 \mathrm{~mm}$ long. The hook is about average in length. The surviving wing is plain. The section of the bow seems to be rounded on the front and chamfered behind with a flat back. The catch-plate is largely missing but once had several piercings. HSM 10008; SO 6475/2375; DAG Fieldwalking 1984-9. Not illustrated.

8. $20 \mathrm{~mm}$ long without the catch-plate. Now corroded so that all of the original surface is lost. HSM 23571; Glos. Mus. A1694; 1870 Palmer Coll. Not illustrated.

9. Unfinished casting, $66 \mathrm{~mm}$ long and $16 \mathrm{~mm}$ across the wings which are flat stumps, unformed forward-facing hook. Stump for the spring, possibly incompletely cast. Bow has a D-section and a line of sunken chevron cast down the middle. Catch-plate incompletely cast with a down-gate running off on one side. HSM 5324; Glos. Mus. A6282; Surface find; Garrod 1960. Not illustrated.

\section{Late La Tène}

Brooches 10-17 all have or had four-coil-internal-chord springs.

\section{LA TÈNE II}

The first of these (Brooch 10) has a close parallel from Rotherley, Wilts (Pitt Rivers 1888, 122, pl. 99.4) which has a framed catch-plate. Both betray a relationship with La Tène II brooches in that the place where a collar would have been is marked by some ornament derived from the mouldings found on that. The group is diverse running as it does from those with framed catch-plates and external chords (e.g. Bulleid and Gray 1911, 192, fig. 42.3 with simple mouldings) to complex moulded items with solid catch-plates and internal chords (e.g. Salford, Beds, Dawson 2005). Although almost all these can be placed before the conquest, this cannot be guaranteed for while any found in 2 nd century or later contexts must have been residual in their contexts, this is less easy to assert when they fall in the 1st century: e.g. Weekley, mid-late 1 st century (Jackson and Dix 1987, M87, fig. 22.1); Baldock, 70-90 (Stead and Rigby 1986, 109, fig. 40.14). However, the high arch at the head of the bow suggests that, in this instance, a pre-conquest date should be appropriate and, if the catch-plate had been framed, it would have been earlier than c. $25 \mathrm{BC}$.

A surprising number of published brooches of the type represented by Brooches 11-13 are illustrated in side views only, thus making it difficult to tell how many may or may not have had decoration like that on the foot of Brooch 11. This is also true, of course, for Brooches 12 and 13 which have been placed here on the basis of a side view on a slide, and Hilary Cool's specific likening of Glos. L173 to one published by the writer. It should be assumed that none of these brooches is properly related to a real La Tène, this version being a curious hang-over possibly favoured by the Roman Army and its immediate entourage in parts of Germany, bearing in mind the origin of parts of the army of invasion.

However, there another possibility: this is Feugère's Type 3 (Feugère 1985, 190, fig. 8), and he shows that it also has a home in southern Gaul near the Pyrenees, but can be found thinly over much of the rest of Gaul. However, the dating in Gaul favours the earlier or first part of the 1st century $\mathrm{BC}$ which one might have expected in any case for late La Tène II brooches. He distinguishes a variant, 3b1, which seems not to occur before the end of the reign of Augustus and may have appeared about 10/15 AD (ibid., 196), but he is unable to put a term to it. The distribution in Britain reveals that those with decorated collars, like the ones here, may be confined to the strip of counties along the southern coast but access to the best crossings of the Severn being important. Those with plain collars seem to spread much further and those at Wroxeter should not have arrived there much before AD 55/60 with those at Chester being unlikely to be much earlier than $65 / 70$.

This should show that the association between the type and Roman sites, largely military ones, that these brooches, in Britain, will be of the conquest period and a few decades after. Dated examples of any variety are rare: Richborough, with Flavian and pre-Flavian pottery (Bushe-Fox 1949, 107, pl. 25.2), before AD 85 (ibid., pl. 25.1); Caernarvon, Hadrianic-late 3rd century (Casey and Davies 1993, 165, fig. 18.1, 3). The probability is that the type, as far as Britain is concerned, had ceased to be made by the $60 \mathrm{~s}$, if not before, and that few were to be seen as late as 65/70.

10. Only the high-arched upper bow survives. The beginning of the arch is marked by two cross-grooves and on the curve above are two arcs rising from the sides. HSM 5324; surface find; Garrod 1967.

11. The spring is missing. The bow proper has a basically circular section, the catch-plate is beaten out of the straight foot with is turned up and was once bound to the bow by a collar, now largely missing, formed most probably by folding flaps on the foot round the bow. The turned up foot has a deep and wide flute down it with a line of punched dots along it. HSM 21376; SO 6465/2392 [6]; DAG Fieldwalking 1984-9.

12. (Described from a slide). Only the side view can be seen. Again the spring is missing, the wrap-round is in position and two cross-grooves at its base can be seen. The foot 
is much shorter than that on Brooch 10 giving a greater prominence to the bow proper. HSM 21376; Sterry 1994. Not illustrated.

13. Described as being like Brooch 2 in booklet for Salisbury Museum (Mackreth 1973), this is of the same type as the two preceding examples. May be Hull's 8717, in which case there is minimal decoration on the collar. HSM 5324; Glos. Mus. L173; Surface find; Garrod 1960. Not illustrated.

\section{NAUHEIM}

Both Neuheims present (Brooches 14 and 15) have four-coil-internal-chord springs. The description of the decorated bows and the framed catch-plates make it certain that the identification as Nauheims is correct. It is safer to assume that they had had internal chords and the dating of these is: Glastonbury, Late Pre-Roman Iron Age, two examples (Bulleid and Gray 1911, 199, pl. 40.E79, E93; 201, pl. 40.E185); Skeleton Green, c. AD 25 to 41/54?+ (Partridge 1979, 35, f6.5); Weekley, mid/late 1st century (Jackson and Dix 1987, M79, fig. 24.23); Canterbury 70/80-100/120, two examples (Blockley et al. 1995, 965-6 f405.32 and Not illustrated.); Chichester, late 3rd-4th century (Down 1989, 186, Not illustrated.). Those with narrow bows are dated: Maiden Castle, 25-50 (Wheeler 1943, 258, fig. 83.13); Canterbury, Late pre-Roman Iron Age (Watson 1963, 186, fig. 14.9); Chichester, late 3rd-mid 4th century (Down 1974, 123, fig. 54.2).

The roll-call of sites is heavily biased towards those with prominent Late Pre-Roman Iron Age occupation in one form or other. In the case of Canterbury, although actual occupation deposits have been hard to find, the overall Late Pre-Roman Iron Age spectrum has been discussed and the conclusion, albeit tentative, was that there was good evidence for middle and later 1st century BC occupation (Mackreth 1995, 955-6). The difficulty is, as the details of dating given above show, that most are obviously residual, which of course leaves their actual date a little in limbo. Feugère $(1985,224-6)$, in reviewing the dating evidence available to him, concluded that while the type had appeared before $100 \mathrm{BC}$, which would accord well with those brooches having external chords, perhaps its greatest floruit was 70/60-30/20 BC. When it comes to Britain, all that need be noted here is that there is not one Nauheim in the King Harry Lane cemetery (Stead and Rigby 1989) and that the earliest reasonable date for the beginning of that is $15 \mathrm{BC}$ (see above). Therefore, all the Nauheims which one finds here ought to have passed from use very much as Feugère determined.

14. The front of the upper bow which tapers has a groove down each side. The lower part is missing but enough of the catch-plate survived to show that there was the squared top of a large piercing. HSM 5324; Glos. Mus. A6284; Surface find; Garrod 1960. Not illustrated.

15. $48 \mathrm{~mm}$ (surviving?) length. Tapering elongated bow with a bordering groove on each side of the front and a line of walked graver decoration down the middle and a perforated catch-plate. The length of $48 \mathrm{~mm}$ is puzzling, unless this was the surviving length. HSM 5324; Glos. Mus. A6269; Surface find; Garrod 1960. Not illustrated.

Nauheim Derivatives

The basic feature of these brooches is that they have decorated bows. As it happens this is not as frequent as one might think, and there is always a temptation to see in the decoration some immediate, typological, relationship with the parent type, rather than just all with solid catch-plates being later, usually post conquest. At best, the definition of a Derivative is that it lacks the framed catch-plate, to some extent this might even be a function of size. The oldest Derivative known to the writer comes from Foxholes Farm, 80-20 BC (Partridge 1989, 132, fig. 76.5), but the main Derivatives are plainly later, the difficulty is to determine how late.

Looking at Derivatives which are decorated and narrow like the two examppes from Ariconium, the dating evidence is: Verulamium, King Harry Lane cemetery phase 1, 15 BC-AD 30 (Stead and Rigby 1989, 354, fig. 154, g 317.4); Durrington Walls, Late Pre-Roman Iron Age (Wainwright 1971, 324, fig. 105.2); Hengistbury Head Late pre-Roman Iron Age to before 100 (Cunliffe 1987, 147, fig. 08.7); Verulamium, pre-Flavian (Stead and Rigby 1989, 14, fig. 10.1); Gussage All Saints before 65/75 (Wainwright 1979 , 111 f 86.3014); Chichester, 2nd century (Down 1989, 186, Not illustrated.);, Chichester 3rd-4th century? (ibid., Not illustrated.). The nett result is that, unlike the vast majority of badly executed and plain Derivative forms, these have a definite chronological horizon, they truly follow the Nauheim and run on to $c$. AD 70/75 at the latest.

Two further possible examples of this type derive from Ariconium but were not avalailable for examination. The first, is described from a slide and was not sufficiently shown for any detailed comment to be made; however it may date as late as the last two decades of the 1st century (Brooch A; HSM 21376, Sterry 1994. Not illustrated.). The second, also not seen, has been described elsewhere as a "Nauheim Derivative" (Brooch B; HSM 21376, Mark Walters 1989. Not illustrated.).

16. The bow down to the top of the catch-plate has a flute with a line of walked chisel decoration along it. The back of the solid catch-plate has two pairs of grooves across it. HSM 23571; Glos. Mus. A1600; 1870 Palmer Coll.

17. The bow is narrow with a flute down the upper part which is stopped at its bottom by two cross-grooves. The bow ends in a point and the catch-plate is solid. HSM 21378; Mark Walters 1989.

\section{Rosette}

The typological development of the Rosette from the middle of the 1 st century $\mathrm{BC}$, from a type which includes the so-called fibula of Criciro (Allen 1972), to the latest forms which have hinged pins and have been reduced to flat plates with a key-hole shape of the 2nd quarter of the 1 st century AD is well-known. However, the dating of 

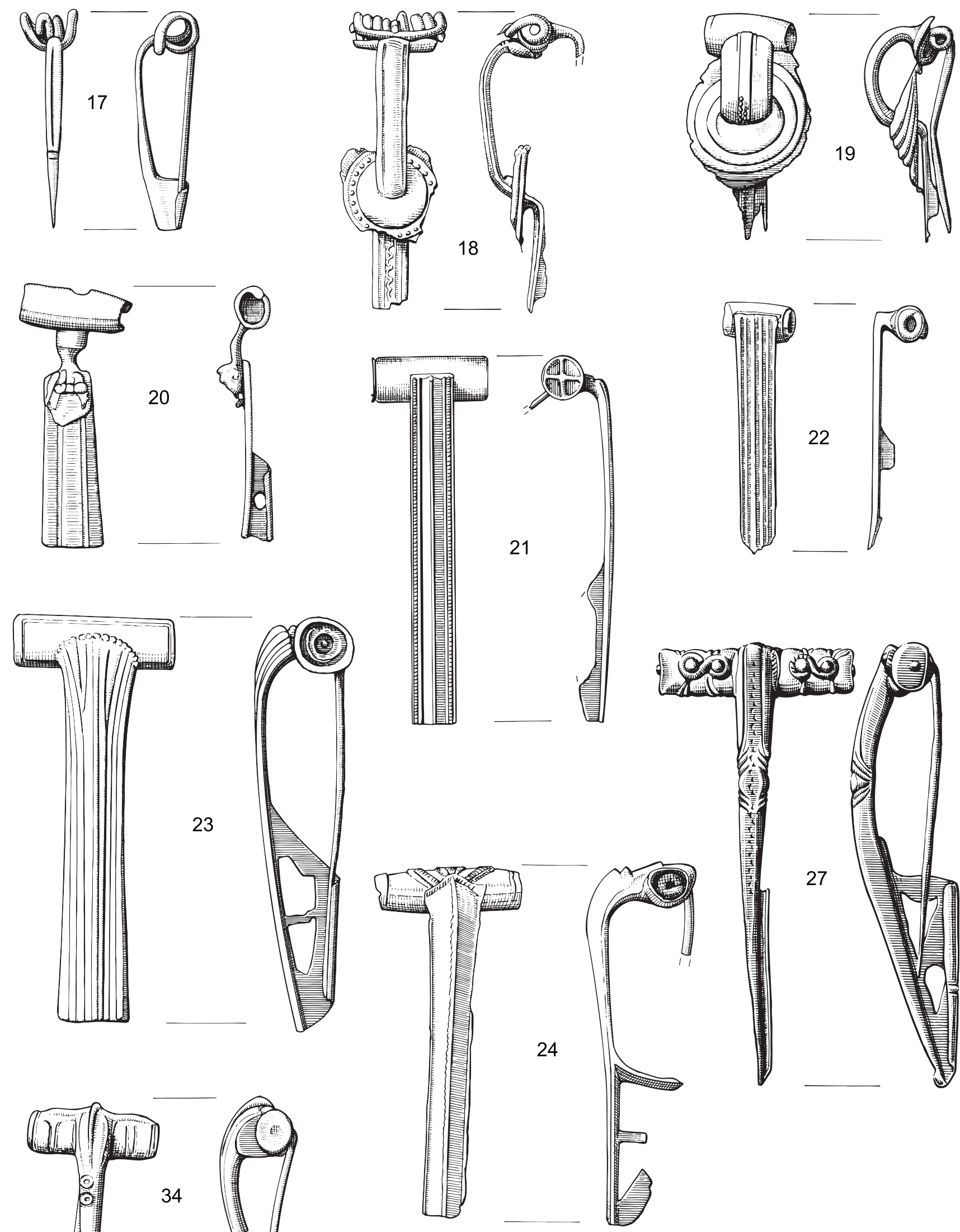

27
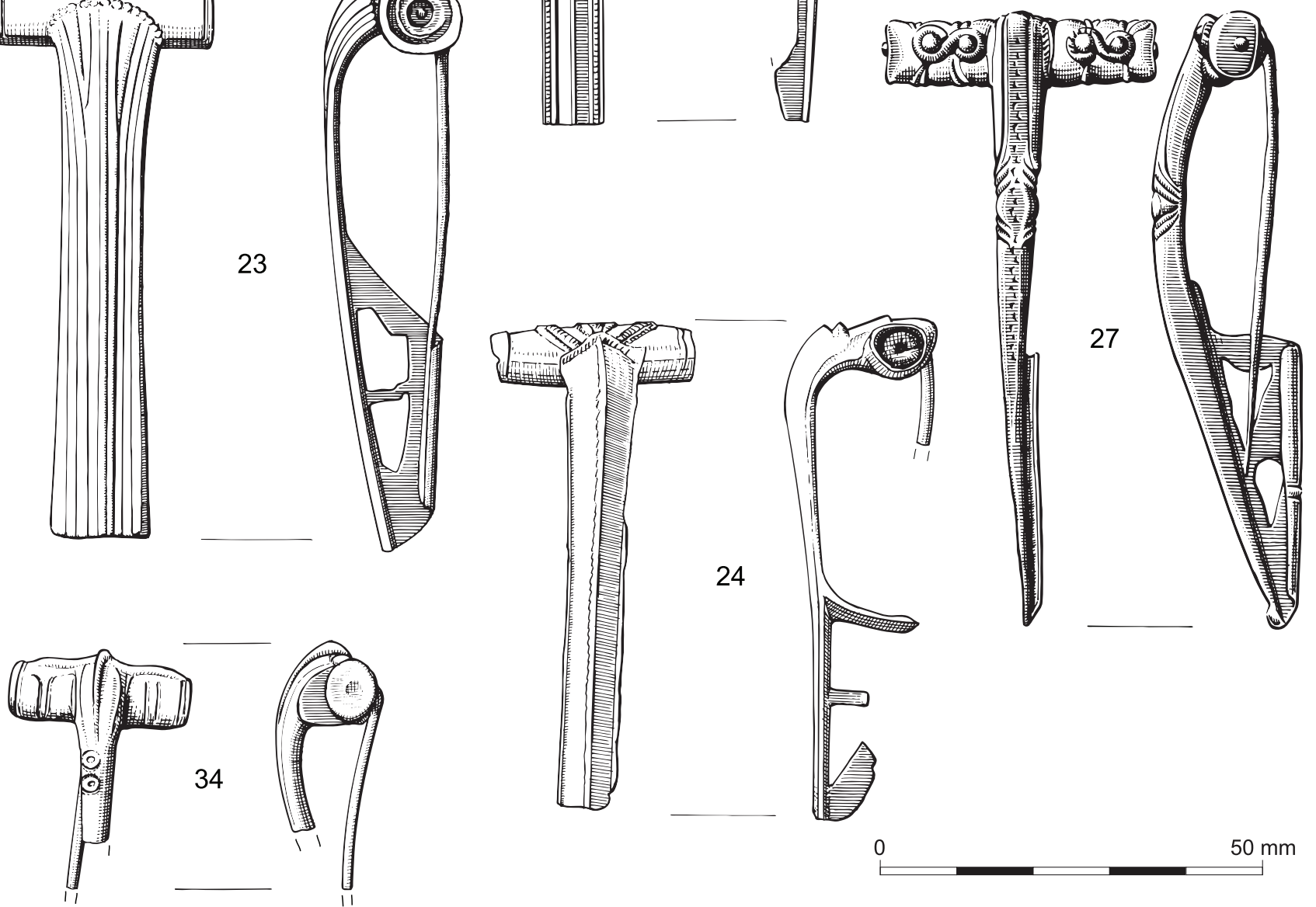

0 $50 \mathrm{~mm}$

Figure 4.33. The brooches (Catalogue numbers 17-34) 
the various stages is not so well established. The King Harry Lane cemetery lacks any Rosettes of form of Brooch 18, the spring being integral and with only the most rudimentary of cases for it. This places the present brooch securely before $c .15 \mathrm{BC}$ and it may date to any time in the previous 30 years.

The distinctive form of Brooch 19, with its stepped and slightly eccentric disc, has a profile that it is very closely related to Brooch 18 . However, it shows a slightly different development while keeping the same basic form. An example from Silchester (Reading Museum, Duke of Wellington Collection, 03163) shows that the foot can be cast in with the disc while the spring-case retains much of its early form. This style emanates from a different workshop tradition from that which produced the standard sequence of Rosettes. The changes in detail show that the traditions were parallel in part and this one seems to have got as far as having the foot cast in with the base of the disc and for the spring-case to have almost completely developed before disappearing. However, neither the form represented in the present example, nor of the later developments, appear in the King Harry Lane cemetery; although the absence of the later ones may be accidental, examples being so much less common than the standard Rosette. The basic dating for the present example has to be same as for Brooch 18 .

Brooches 20-25 have separately-made springs housed in cases formed by folding two flaps cast on the head of the bow round them.

The first of these, Brooch 20, is a Léontomorphe. In this instance, the form of the lion is clear although it is showing signs of devolving towards the simplified form which looks like a bow tie worn sideways (e.g. Down 1989, 188, fig. 16.1, 66), or worse. Their occurrence in the King Harry Lane cemetery is: phase 2, g 66.2, g 218.3, 4; unphased, $g$ 188.3, g 306.3. None is of the very devolved type and the phase 2 indications are that brooches such as Brooch 20 here ought to date to AD 20-40 (see after Brooch 8 ), with the latter date being very close to the actual end of the floruit. A further possible example described as a "Rosette" was not seen by the author and no image was available (Brooch C; HSM 21376, Sterry 1994. Not illustrated.).

18. The wings and integral spring are like those found on the Colchester. The rest of the bow was cast straight with a disc in the middle, and then bent to form the usual profile with a bow above the forward-facing disc and with a straight foot below. The bow betrays signs of heavy wear and the spring had been broken and repaired in antiquity by inserting a hinged pin. The traces of decoration on the bow point to it having the same kind as that preserved on the foot: a bordering ridge with a flute between that and the centre down which ran a sunken wavy ridge formed by punching alternately on each side of a straight ridge. HSM 23571; Glos. Mus. A1618; 1870 Palmer Coll.

19. (Described from a drawing). The spring is integral with the body of the brooch and housed behind wings whose ends are bent back to enclose each end of the spring. The bow is broad, and was moulded, all that can be seen is a central raised band and a suggestion of there having been a narrow element on each side. The bow ends below in a raised semicircular area which lies at the centre of a series of eccentric steps, certainly three with a trace of either another at the bottom or of a rim. All the complete edges seem to have been either cross-cut or beaded. The foot emerges from the back of the disc and was once moulded but was too damaged for the scheme to be determined. HSM 21378; Mark Walters 1989.

20. (Described from a drawing). The spring is housed in a case formed by folding two cast flaps on the head of the bow round it. The bow is in the stylized form of a lion whose hind quarters have been subsumed into the case leaving the body as the main arch of the bow, the head and outstretched paws are schematically shown and this end is riveted through the remains of a disc to the top of the foot. This has three flutes divided by a ridge one from another. HSM 21378; Metal detecting find (Terry James); DAG Fieldwalking 1984-9.

\section{Langton Down}

Langton Downs such as Brooch 22 and 23 with a squared top of the bow and parallel sides are a distinct type. In the King Harry Lane cemetery they occur in this manner: phase 1, g 202.8, g 287.6; phase 2, g 289.3; phase 3, g 117.5. The emphasis is definitely towards the earlier periods and the one from the phase 3 burial is not like the others which are the equivalents of the two here. In terms of the revised dating (see discussion above), a terminal date of AD 35/40 would be appropriate. In case it might seem that too much reliance is being placed on a reinterpreted dating of a single site, the following are dated: Canterbury, c. 20 BC-AD 70/80 (Blockley et al. 1995, 973, fig. 407.88); Skeleton Green, c. 10 BC-AD 20 (Partridge 1981, 133-4, fig. 71.43) and AD 15-25 (ibid., 139, fig. 71.46); Colchester, 49-61 (Hawkes and Hull 1947, 318, pl. 94.89); Baldock, 70-90 (Stead and Rigby 1986, 113, fig. 45.95). There is a clear break in this sequence and the bias in the dating is, if anything, to a slightly earlier floruit than the King Harry Lane cemetery suggests; and it should be noted that the other sites all have material of the appropriate early period.

Returning yet again to the King Harry Lane cemetery, Brooch 23 can be described as a standard Langton Down, but the style of the drawing is against any beading showing. It is assumed that there is none and therefore the dating is: phase 1, g 72.3,4 and g 413.3*, $4^{*}$; phase 3, g 156.3*, 4* and $g$ 184.2*; unphased, g 465.3*. There is a problem in that the style of drawing in the publication does not aid the recognition of beading and the writer has not checked all of them against the originals, those that remain unchecked have * next to them. There is a further difficulty: some of the brooches in the cemetery, Langton Downs as well as Rosettes, show that there had been enamelling in wide flutes and some of this had undoubtedly been beaded. Therefore, in the list above, the phase 1 brooches not marked by * may once have had this type of decoration. That this is likely is 
suggested by the absence of any unbeaded ones in phase 2 and then their reappearance in phase 3. On the whole, unbeaded reeded Langton Downs are later than 25 and some undoubtedly ran on in use beyond the conquest.

Brooch 25 is a Nertomarus, named after the commonest name found on the type. Only one came from the King Harry Lane cemetery: unphased g.234.2. The rest of the evidence suggests that this was also to be seen in use after the conquest: Bagendon, 43/45-47/52 (Clifford 1961, 176, fig. 35.5); Fishbourne, 43-c. 75 (Cunliffe 1971, 100, fig. 38.28); Witham, Essex, mid 4th century-early 5th (Turner 1999, 78, not illustrated.). Not an impressive list, but pointing, however, to the conquest period. One feature which is exclusive to the Nertomarus amongst Langton Downs, and which obviously was to be seen often enough for it to be taken up by more than one variety of Colchester Derivative, is the flange across the top of the catch-plate, usually on each side.

A further possible example of this type which was not available for study and for which no drawing or image could be traced is a metal detecting find described as "Langton Down" (Brooch D; HSM 21376. Sterry 1994. Not illustrated).

21. The spring-case is plain. The bow is straight-sided, squared-off top and bottom, and is offset from the springcase by a step. The face of the bow has three ridges down each side, the middle one beaded, and a flute at the junction of two inclined planes. The corrosion on the surface of the bow has preserved an applied bead-row (enamel?) down this central flute. The catch-plate is damaged, but had one large piercing. HSM 23548; SO 64672376; Tr. BI, context 2A, sf. 2; Garrod 1967.

22. Essentially the same as the last brooch, it is slighter and has a damaged foot and two steps on the offset. There is no trace of any applied decoration. HSM 21376; SO 6770/2390; DAG Fieldwalking 1984-9 (Found by M. Swaffield).

23. (Described from a drawing). The spring case has lines across the top and down the sides forming a panel from which rises the bow, separated from the case by a crossmoulding. The bow has three sets of triple mouldings with an extra single one in the spaces formed by the splayed head. There is no indication on the drawing either of diagonal lines in the panel or of any beading on the bow. The catch-plate has a large piercing divided by a dog-leg bar. HSM 21378; DAG Fieldwalking 1984-9 (Metal detecting find by R. James).

24. The spring-case has a buried ridge at each end and three decorative features in relief in the middle rising from the beaded cross-moulding dividing the bow from the case. The central feature is a truncated triangle with three depressions with crudely beaded borders, the ones to each side are a devolution from a beaded stem curled over at the end. The bow has a ridge down each side and one in the middle set along the arris formed by two inclined faces. The central ridge was relieved on each side which has a line of walked chisel decoration. The catch-plate is more triangular than is usual on the Langton Down type and had two large piercings divided by a simple bar. HSM 5324; Surface find; Garrod 1967.
25. Described by Hilary Cool as a Langton Down. Spring-case and upper bow only. No comment on decoration of the former and the latter has three ribs down the front. Not enough to fit into any discussion. HSM 5324; Glos. Mus. A6279; Surface find; Garrod 1960. Not illustrated.

\section{Colchester Derivatives}

The ' $S$ ' decoration on the wings of Brooch 27 has an interesting parallel on a brooch from Walsingham, Norfolk, where the feature was made separately and secured to the wings in the same manner. That brooch was a Rearhook and as such can hardly date after AD 60/65. Now the technique of making brooches in parts and riveting them together is essentially undated, except by its place in a tight typology and then running that back from a dated horizon. The Walsingham example is the first time that it can be married to a brooch whose terminal date is fixed by its presence in the land of the Iceni where the Rearhook was the special mark of the tribe and ceased to be made at the suppression of the Boudiccan Rebellion.

There are other indications amongst the Colchester Derivatives which show some familiarity with the brooches of the Iceni and the question has to be raised as to whether the connection, which cannot be fortuitous, is the result of migration before the rebellion, or the transfer of slave labour afterwards. The Iceni were master craftsmen in metal and it would not be surprising to see their influence under either of these conditions. Brooch 27 is very elaborate and would have been placed before AD 75 in any case because of the piercings and decoration of the catch-plate, and the treatment of the wings and bow. The treatment of the sides of the bow is found on a brooch from Nettleton (Wedlake 1982, 123, fig. 52.36).

It is Brooch 26 which stands as the start of a typological development, and while one might feel that this ought to go back to brooches made in parts, none of the examples (like Brooch 26) has yet been proved to have been made in this manner. The sections of these brooches are very thin and, if all cast, save for bending the ends of the wings back, are very fine examples of craftsmanship of the whitesmiths. It is surprising that only one brooch, from Castleford, has been closely dated within the general period 1 st century BC and the earlier 2 nd century AD: c. 80-86. The next stage in the development is for the sections to become thicker and the shape of the brooch to begin to approximate that of Brooch 28. The two earliest of these are: Bagendon, 50-60 (Clifford 1961, 173, fig. 31.5); Baginton, The Lunt, before 75 (Hobley 1973, 66, fig. 19.7). Therefore Brooches 26 and 27 find their horizon, despite detailed dating. As for Brooch 28, the dot-and-circles decoration is found on other examples of the general group: Kingsholm (unpublished), Wroxeter (Atkinson 1942, 204, fig. 36, H105). The enddate of the group is given by the initial date of the Dolphin type which evolves from it: c. $75 / 80$.

Brooches 28-46 inclusive have their sprung pins mounted in the Polden Hill manner: an axis bar through the coils is held in pierced plates at the ends of the wings, the 
chord being secured by either a rearward-facing hook or a pierced crest on the head of the bow, usually the former.

Brooches 30-34 represent a well-known type with very minor variations - changes to the decoration on the ends of the wings and the style of the piercing in the catchplate - found basically in the Lower Severn Valley with a possible extension up the Avon. The dating is surprisingly varied: Kingscote, 1 st century BC-c. AD130/140 (Timby 1998, 118, fig. 65.18); Gloucester, 1st century (Garrod and Heighway 1984, 93, fig. 63.3); Dorchester, 75-120 (Woodward et al. 1993, 123, fig. 61.28); Leicester, earlymid 2nd century (Clay and Pollard 1994, 145, fig. 74.22); Prestatyn, late 3rd-early 4th century (Blockley 1989, 88, fig. 36.2); Wilcote, 300-360 (Hands 1998, 49, fig. 18.34). Despite the lack of emphasis in the range of dates, the presence of a pierced catch-plate should rule out a 2 nd century date.

Brooch 35 has a parallel from East Anglia (Hattatt 1989, 70, fig. 33.1510), however, the connection with the east is stronger than might appear from a single likeness. The bead-and-reel moulded wings are most frequently found on the Rearhook and on the hinged-pin brooches deriving from that on the western edge of the Fens: they do occur on the contemporary Harlow or Dolphin Brooches and their predecessors save in the rarest of circumstances. The decorative lobes on the sides of the bow are a feature of another group of brooches which also belong to the western edge of the Fens. There should be little doubt that this brooch was either made on the eastern side of England, or its maker came from there.

Unfortunately, the whole series is poorly dated. The connection with the Rearhook, whose terminal date in its homeland is $\mathrm{AD} 60 / 65$, takes the origin back to 50 at least. Another feature which brooches with the lobed decoration have in common with the Rearhook is the frequent use of diagonal decoration on the front face of the wings. Unfortunately very few are published and there is no set of useful dates: the example just cited was dated to $140-180$, but the tenor of the relationships points to a general date-range of $c$. 50-75/100.

To some extent, Brooch 36 belongs to the same group discussed under Brooch 35. The decorative elements are at home in the eastern parts of England, specifically Norfolk, the western edge of the Fens and spreading up into Lincolnshire and into the East Midlands generally. Dating is largely lacking, but the whole ensemble points to the 1 st century and possibly to before AD $75 / 80$.

Brooches 37-40 form a discrete group with the first (Brooch 37) showing a relationship with those discussed after Brooch 31, the chief feature which marks a different family is the moulding springing from the wings and masking the sides of the head of the bow. Essentially, the head of the bow is more bulbous than in practically any other group in the Polden Hills and rides over the wings in a way which recalled to R. G. Collingwood the dolphin and it is to this family that the writer confines the name. The manufacturing centres, for there must be at least two, lay somewhere in the Severn Valley, but probably not north of Wroxeter, with another centre in the Southern Pennines which used a hinged pin.

The varieties are fairly well represented here in their range from the plain one, Brooch 40 , to the highly decorated Brooch 36 . The dating has fairly recently been discussed and the conclusion was that the date-range was from the last quarter of the 1 st century to $c$. $150 / 75$ (Jackson and Potter 1996, 300-1, fig. 93.8).

Turning to Brooches 42-44, there are surprisingly few brooches with this spring system which are completely plain. The pierced catch-plate of Brooch 42 ought to indicate the 1st century. As for Brooches 43 and 44, there is the ridge down the bow on the first and the decorated wings on the second, but again such simplicity is equally rare and there is even less to help with a date: ?c. 60-125/150.

Brooch 45 is a difficult brooch to deal with. It is a Polden Hill, but the wings and the prominence given to the rearward-facing hook suggest the Rearhook. On the other hand, the decoration and the profile of the bow suggest a relationship with brooches of the deep south-west which have an almost semicircular profile (e.g. Hattatt 1989, 74, fig. 5.1517). In addition, as some of these had applied plates on the upper bow which are actually separately-made rearward-facing hooks and show a relationship with a kind of Headstud, the present brooch is likely to be 1st century and probably before $75 / 80$.

Brooch 46 has moulded decoration on the wing which might suggest Norfolk and the area west running up the west side of the Fens, the pierced crest for the chord of the spring projecting so high above the head points to the south-west. This is not a true Polden Hill in the sense that the pierced plates for the axis bar are set in from the ends of the wings. As there are no useful parallels, there are no dates available. In general terms, the date range is likely to be later 1 st century to the middle of the 2 nd.

By a long extension, principally because of the decoration, Brooch 47 is related to the Dolphin (see Brooches 37-41); few are known and they spread from Kent to Hadrian's Wall and, as is common with groups having few members, is not really dated, save, that is, for its apparent relations. This brooch is most probably $2 \mathrm{nd}$ century, but possibly not much after 175 .

Five examples of brooches described as 'Polden Hills' were not seen by the writer and no images were available to check their designation (Brooch E, HSM 5324, Surface find; Garrod 1967; Brooch F, HSM 5324, Sterry 1994; Brooches G, H and I, HSM 21376, Sterry 1994).

Lastly, Brooch 48 is a Colchester Derivative by courtesy only. Many of the brooches in this group are large with head-plates as here, the main characteristic being the broad upper bow with mouldings. Choosing only those which are relatively close to the present specimen, the dating is: Catsgore, 1st-4th century, two examples (Leech 1982, 105, fig. 77.13, 14); Dorchester, late 1st into 2nd century (Green 1987, fig. 66.2); Camerton, 90-200 (Wedlake 1958, 225, fig. 52.23); Halstock, up to c. 120? (Lucas 1993, 77, 

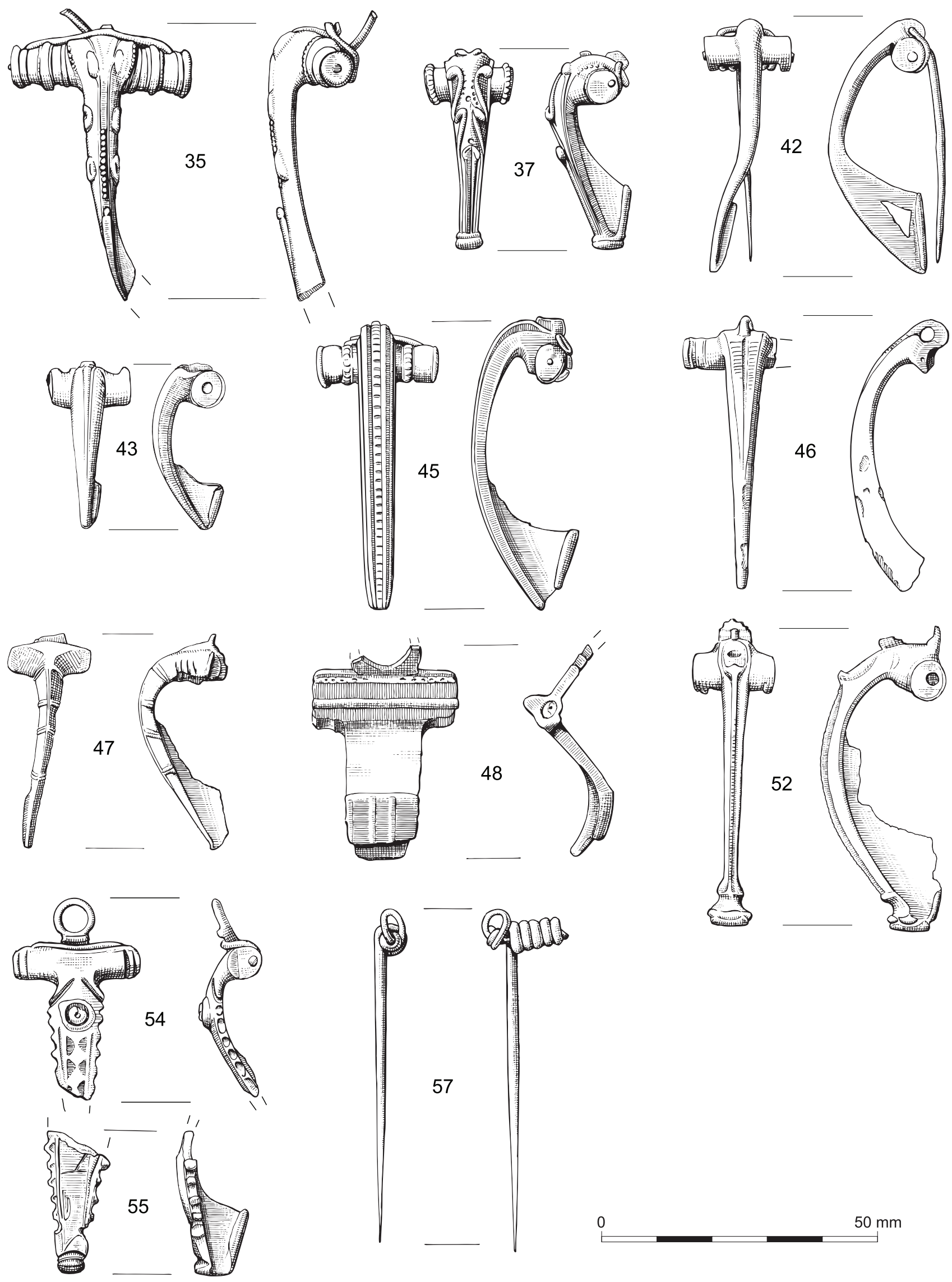

Figure 4.34. The brooches (Catalogue numbers 35-57) 
fig. 14.7); Chew, 2nd century (Rahtz and Greenfield 1977, fig. 114.12); and Chichester, late 4th century? (Down 1989, 185, fig. 26.1, 13). The indicated range is late 1 st to somewhere probably late in the 2nd century: British brooches of the general Colchester Derivative ceased to be made in the period 150/75.

26. This has a beaten out spring cover, broad rear-ward facing hook for the chord of the spring mounted in the Polden Hill manner (see Brooch 27). The spring has 15/16 coils. Each wing has three vertical lines of walked graver decoration. The bow has an oval section with a step at the top back to the wings. The catch-plate had been pierced. HSM 5324; Glos. Mus. A6271; Surface find; Garrod 1960. Not illustrated.

27. The spring housing and the bow were made separately and then riveted together. The spring is trapped inside a case made from folded and forged sheet metal, the ends being turned in and pierced to hold the axis bar of the spring, and the top and bottom turned to hold the spring firmly. There is no separate fixing for the chord. The front of the case forms the wings each of which has a pair of rivets through it which secure a length of beaded wire bent to form an $\mathrm{S}$ wound round their shanks. On the main are pairs of ridges placed diagonally, as it were radiating from the rivets. The top of the bow, which was forged and not cast, has extra beaded moulding on each side. Down the centre face, as far as the top of the catchplate where it dies out, is a wavy line formed by using a punch alternately on each side of a ridge. At the top there is an extra groove bordering each side which runs a quarter of the way down and then turns down the side. This forms the top part of a series of mouldings which are in effect a repeat of those on each wing. The lower bow is plain except for a small forward-facing projection at the foot. The catch-plate has two piercings, basically a triangle above a tear-drop. The back of the catch-plate has a groove down the beginning of the return, which has two pairs of grooves across it, and a line of walked chisel decoration along the three edges. HSM 23546; SO 64682377; Tr. AI, context 2, sf. 8; Garrod 1967.

28. Each wing has a moulding at its end. The bow is humped over the wings and separated from them on each side by a curved moulding rising from the wing. On the upper bow is a beaded ridge simulating the hook on the Colchester. The rest of the bow is plain and the foot is lost. Heref. Mus. 7639/22; HSM 16780; SO 64672405; Jack 1922; Jack 1923, 24, fibulae b. Not illustrated. (see Hattatt 1982, 70, fig. 23b.25).

29. Each wing has a sunken beaded ridge at its end and other half way along. The hook for the chord is carried over the top of the head as a skeuomorph of the hook on a Colchester, has diagonal cross-cuts and dies out into the bow. There is a step down each side of the bow which has a pointed foot. The catch-plate has a large piercing divided by a dog-leg bar, a line incised along its top border and the return has sunken ridges. This is also of the same general group as Brooch 28, but is different in the sense that there is a step on each side of the bow and the mouldings on the wings are more plastic than on the other examples described. The decorated return of the catch-plate and the fine piercing on that also point to a date in the period before AD 75. HSM 5324; Glos. Mus. A24321; Surface find; Garrod 1960. Not illustrated. (see Cracknell 1990, 201, fig. 8).

30. Each wing has a sunken beaded ridge at its end. The hook for the chord is carried over the head as a beaded ridge which dies out and simulates the hook on a Colchester. The bow tapers to a pointed foot and the catch-plate has a large triangular hole. HSM 23571; Glos. Mus. A1602; 1870 Palmer Coll. Not illustrated.

31. A repeat of the last, but without beading on the ridges on the wing and with the hole in the catch-plate divided by a dogleg bar. HSM 23571; Glos. Mus. A1601; 1870 Palmer Coll. Not illustrated.

32. A close repeat of Brooch 17, the wings are plain, the beaded ridge longer and chord was held by a pierced crest. The foot is missing. HSM 23571; Glos. Mus. A1603; 1870 Palmer Coll. Not illustrated.

33. Another close repeat, the better preserved wing has a buried ridge at its end, the ridge on the bow is relieved on each side and there is a pierced crest for the chord. There is a small projecting foot and the catch-plate is solid. HSM 21376; SO 6445/2400; DAG Fieldwalking 1984-9. Not illustrated.

34. Each wing has a buried ridge at the end and in the middle. The hook behind the head runs over the top for a short distance and is replaced by an arris down the rest of the bow as it survives. The catch-plate and foot are missing. On one side near the top is a pair of dot-and-circle stamps, and they were probably repeated on the other side under the accretion. Heref. Mus. 7639/23; unlocated; (?) Jack 1922. Not illustrated.

35. (Described from a drawing). The chord of the spring is held by a forward-facing hook. Each wing has bead and reel ornament, the beads themselves being beaded. The bow is set off from the wings by a curved moulding rising from the wings and has a beaded ridge down the middle dividing at the top into two with a plain ridge between. The sides of the bow had, at the top a small boss on each side and below these, two larger ones each with a ridge in the centre. The foot with most of the catch-plate is missing. HSM 21378; DAG 1990 (Pollard).

36. There is a possibility that this is a variety of Rearhook in which the hook faces forward. The bow has three narrow ribs down the middle and the wings are basically beadand-real, the bead being replaced by a raised wavy line. The example cited, Hattatt 1989, fig. 157.884, suggests that the bow is of the kind to be found in Norfolk and the immediately surrounding areas. HSM 5324; Glos. Mus. A6272; Surface find; Garrod 1960. Not illustrated.

37. Each wing has a beaded moulding at its end. The bow is again humped over the wings and the mouldings on each side are beaded. The bow is elaborately moulded in relief with a series of lenticular bosses rising from stems. On the top is a V arrangement from which rises the hook for the chord. On the upper bow are two circular stamps with, next to the upper one, a line of punched dots outlining the stems there. The lower bow has two stems in the middle and a step on each side. The foot-knob has a cross-moulding around the top. HSM 23571; Glos. Mus. A1610; 1870 Palmer Coll.

38. A simplified version of the last, the moulding at the end of each wing is plain. There is a pair of stems with the 
bosses reversed where one would find a skeuomorph of the Colchester's hook. The foot has a knob. HSM 23571; Glos. Mus. A1607; 1870 Palmer Coll. Not illustrated. (see Kenyon 1940, 222, fig. 15.1).

39. The wings are as before, the decoration on the head of the bow is, here, like a raised palm-leaf. The lower bow and catch-plate are missing. HSM 21376; SO 6449/2396; DAG Fieldwalking 1984-9. Not illustrated. (see Williams et al. 1995, 103, fig. 56.4).

40. A denuded fragment, the ends of the wings are missing, the bow is plain, but has the mouldings on each side of the type. HSM 10008; SO 6475/2375; DAG Fieldwalking 1984-9. Not illustrated. (see Dool et al. 1985, 283, fig. 123.5).

41. (Described from a drawing). There may have been a ridge at the end of the left hand wing, otherwise this is a sturdier version of the last and, like that, has lost the lower bow. HSM 5324; Glos. Mus. A24293; Surface find; Garrod 1960. Not illustrated.

42. The wings and bow are plain. The head of the bow rises well above the wings. The catch-plate has a fairly small triangular piercing. HSM 23571; Glos. Mus. A1605; 1870 Palmer Coll.

43. One wing has a ridge at its end, the bow has a ridge down the middle. The foot is plain. HSM 23571; Glos. Mus. A1606; 1870 Palmer Coll.

44. Each wing has a pair of mouldings at its end. The bow is plain and has a pointed foot. The pierced crest for the chord rises above all. The catch-plate is solid. HSM 23571; Glos. Mus. A1608; 1870 Palmer Coll. Not illustrated.

45. Each wing is boldly moulded with a bead with a beaded ridge on each side. The bow rises over the wings, has a concave surface on each side and a buried beaded ridge down the middle. The catch-plate is solid. HSM 23551; SO 64672389; Tr. CI, u/s, sf. 6; Garrod 1967.

46. The surviving wing has a moulded reel on it. There is a prominent pierced crest for the chord. The bow is broad at the top and tapered to what was probably a pointed foot, but this and most of the catch-plate is missing. The top of the bow has a groove down each side and the middle at the upper end stopped by a pair of cross-grooves. The two long panels so formed are cross-cut. HSM 23571; Glos. Mus. A1604; 1870 Palmer Coll.

47. The spring was held in a version of the Polden Hill method, here the plates for the axis bar through the coils are set away from the ends of the wings. These are short and largely replaced by the wide splayed head of the bow whose sides are stepped. On the head are the remains of a cast-on loop and collar. The bow has a very narrow front face and strongly chamfered sides each if which has four pairs of ridges. The catch-plate is solid. HSM 23571; Glos. Mus. A1614; 1870 Palmer Coll.

48. The axis bar of the hinged pin was housed in a semicircular projection at the base of the head-plate. There are the remains of a cast-on loop at the top and the main face has a sunken bead-row across the top and a beaded step at the bottom. The bow is wide and had a plain angled top. Most of the bow with its decoration is lost. The surviving part has a ridge on each side and a raised strip in the middle with a flute down it. HSM 23552; SO 64452405; Tr. CXX, u/s, sf. 20; Garrod 1967.

\section{Unclassified}

Brooch 49 is an example of the type now generally known as the Wroxeter as it was plainly the centre for what seem to have been the earliest of the family. The dating for those like the present specimen is: Dating: Colchester 60/1-c. 150 (Crummy 1983, 13, fig. 9.66); 5646-7 Prestatyn 70s-160, two examples (Blockley 1989, 88, fig. 36.3, 4); 5635 Wall, Hadrianic-Antonine (Gould 1967, 15, fig. 7.5). At the most, the type dates from $c .75$ to the Antonine period.

49. The bow divides into two parts. The upper bow has three vertical recesses each filled with enamel. The outer ones have alternating light and dark green, in the centre is dark blue and light green. The bow joins a head-plate, with a rounded lower edge, at the top on which is either a cast-on loop or a wire one lacking its collar seated in a bilateral spring mounted on a pierced plate behind the head. The lower end is rounded and has a recessed annulus and central dot, the enamel is missing. The lower bow is narrower and tapers to a bulbous foot-knob. HSM 5324; Glos. Mus. A6283; Surface find; Garrod 1960. Not illustrated.

\section{Durotrigan}

Very simple to make, these brooches, in copper alloy, are found mainly in the lands of the Durotriges. Plain ones are uncommon and, despite the lack of any decoration, this is derived from the Nauheim. All the Durotrigan brooches are poorly dated, and this is no exception: Maiden Castle, AD 43-70 (Wheeler 1943, fig. 84.17); Poundbury, mid 1st century (Richardson 1940, 441, fig. 4.1); Dorchester, 150 250 (Woodward et al. 1993, 123, fig. 61.34); Shakenoak Farm, Oxon, late 3rd-4th century (Brodribb et al. 1973, 115, fig. 53.178).

50. A simple strip with a thin rectangular section tapering to a point, the head is rolled under to house the axis bar of the hinged pin. HSM 5324; Glos. Mus. A6280; Surface find; Garrod 1960. Not illustrated.

\section{Headstud and Related}

Whatever the origin of the Headstud, there is no doubt that the earliest forms had sprung pins, and the earliest stage of enamelling on the main series was the use of square or rectangular cells as here. The standard triangles and lozenges, however, come first on the type to which Brooches 53 and 54 belong. The dating of the present type is: Prestatyn, before the 70s? (Blockley 1989, 93, fig. 30.15); Corbridge, 75-90/5 (Henson et al. 1993, 32, fig. 4.3); Castleford, 86-95?; Tripontium, 2nd century (Cameron and Lucas, 1973, 134, fig. 23b.8); Wilcote, Oxon, 150-175 (Hands 1998, 51, fig. 18.38); Whitton, before 160 (Jarrett and Wrathmell 1981, 171, fig. 69.15). The form should have evolved by $75 / 80$ at least and the poor dating after 100 should indicate a short life.

There is no established group to which Brooch 52 can be assigned: the sprung-pin Headstuds have the springs 
mounted on a single loop, and thereafter there are the hinged pin brooches. This has the Polden Hill system. In all respects it ought to be a relatively mainstream Headstud, save for that and the petalled foot. The very few brooches which have the former belong as might be expected to the western parts of Britain, south of the Dee and only one has a date: Upton St. Leonards, possibly late 1st-mid 2nd century (Rawes 1984, 58, fig. 11.1).

Brooch 53 provides an example of one of the main varieties of the standard type called the "Sawfish" by the late M R Hull. The standard dating is: Kinvaston, 55-70 (Webster 1955, 102, fig. 2.B); Wall, Staffs, with Neronian rubbish (Gould 1967, 15, fig. 7.2); Baginton, Warks, pit 86 with four examples, before $c .75$ (Hobley 1973, $66 \mathrm{f} \mathrm{19.1,} \mathrm{4,}$ 6 and Not illustrated.); Wroxeter, 75?-100 (Atkinson 1942, 203, fig. 36.H16); Harlow temple, before 80 (France and Gobel 1985, 79, fig. 41.69); Newstead, 80-c. 200 (Curle 1911, 323, pl. 86.23); Crundale, Kent, probably later 1st century (Hume 1863, 64, and fig.); Carlisle, late 1st century (McCarthy 1990, 107, fig. 100.3); Verulamium, 105 - 115 (Frere 1972, 116, fig. 30.12) and before 115-30 (ibid., fig. 29.11); Marshfield, 4th century (Blockley 1985, 142, fig. 45.20); Derby, late 4th century (Dool et al., 1985, $287 \mathrm{f}$ 126.21). There is a hint that the type was passing out of use in the earliest 2 nd century: the complete lack of any dating for the middle of the 2 nd century right up to the 4 th may mean that the actual period of use had come to an end by 100 .

Lastly in this group, Brooches 54 and 55 are obviously related to Brooch 53, but in the same way that Brooch 52 is related to Brooch 51; these are south-western versions of the main variety, and should strictly speaking be roughly contemporary.

51. The separately-made spring was mounted on a loop behind the head of the bow, the chord being held by a forward-facing hook which was cast as a spike and then bent forward. The front of each wing is stepped up to the bow. The stud has an annular recess with a trace of red enamel. Below the stud there is a step on each side of the bow and a line of rectangular cells for enamel, now missing, between. The foot and most of the catchplate are missing. HSM 21376; SO 6455/2400 [2]; DAG Fieldwalking 1984-9. Not illustrated. (see Cameron and Lucas 1973, 134, fig. 23b.8).

52. The spring was mounted in the Polden Hill manner, see Brooch 17 above. The wings are plain. There are the remains of a cast-on loop and collar on the head. The stud is elongated with the lower edge rising to a point, and a step around the inside with a cell for enamel in the middle. Above the stud is a short crest. The rest of the bow is very narrow with a ridge from the stud down to a moulded foot-knob which has a cross-moulding above a flute and a petalled base. HSM 23571; Glos. Mus. A1609; 1870 Palmer Coll.

53. The wings are like Hattatt 1989, fig. 163.937: flat fronted each with a circular setting for an enamelled ornament. The bow like Hattatt 30 on the same figure: teeth down each side, a stud at the top below which is a line of reserved lozenges marked out by triangles, and at the foot a forward-facing foot-knob. There is an unpierced tab on the head. HSM 5324; Glos. Mus. A6270; Surface find; Garrod 1960. Not illustrated.

54. The pin is sprung and is mounted in a version of the Polden Hill manner, see Brooch 17 above. The plates holding the axis bar are set away from the ends of the wings and the chord runs round the front of a cast-on loop and is held in place by a stop above it. Each wing has a buried ridge at each end. The bow has a waist at the top and diagonal grooves above the stud which contains a deep blue glass bead. The rest of the bow as it survives, the foot and catch-plate are missing, has a series of projection on each side, a groove down each side of the main face and a series if reserved lozenges between triangular cells for enamel, now discoloured. HSM 23571; Glos. Mus. A1613; 1870 Palmer Coll.

55. The head of the bow and wings are missing. The surviving bow has projections and bordering grooves like the last, but has incised triangles instead of cells for enamel. The foot has two cross-mouldings, the lower one being beaded. HSM 23571; Glos. Mus. A1695; 1870 Palmer Coll.

\section{Unclassified}

Brooch 56 provides an example of a relative of the Augenfibel, though lacking the eyes. The dating in Britain is: Rushden, Northants, 45-60 (Woods and Hastings 1984, 108, fig. 10.1, 5); Colchester, 49-61, two examples (Hawkes and Hull 1947, 321 pl. 96. 120-1); Haddon, late 1st-early 2nd century (French 1994, 133-4, fig. 72.7); Towcester, c. 100 (Lambrick 1980, 60, fig. 12.3); Baldock, 180-220, two examples (Stead and Rigby 1986, 112, fig. 42.47-8); Peterborough, Orton Hall Farm, 225/250300/325 (Mackreth 1996, 95, fig. 61.13); Haddon, Cambs, 4th century (French 1994, 133-4, fig. 72.8). Despite the many examples from the later 1 st century onwards, the true floruit is almost certainly before 75 : none of the sites producing the later dated specimens lacks an Iron Age or early Roman component.

56. The integral spring is arranged as that on the Colchester Type, see above. The wings are short. Only the upper bow is present. It has a ridge down each side and a buried bead-row down the middle. HSM 5324; SO 6452/2390; DAG Fieldwalking 1984-9. Not illustrated. (see Hattatt 1982, 62, fig. 19.16a)

\section{Alésia-Hod Hill Sequence}

The axis bar of the hinged pin of these is housed in the rolled-over head of the bow. Brooches 57 and 58 are Aucissas proper, even if the name is missing (e.g. Cracknell and Mahany 1994, 168, fig. 80.66), while Brooch 59 is a transitional one between the Aucissa and its chief progeny, the Hod Hill. The Aucissa was the end of a development, which began in the 1 st century $\mathrm{BC}$ with the Alésia (Duval 1974), which gave way to the bewildering variety shown by the designs of the Hod Hill family. The dating of this change is before the conquest as the Hod Hill arrives fully developed then. The parent also comes in but as a survivor-in-use. 

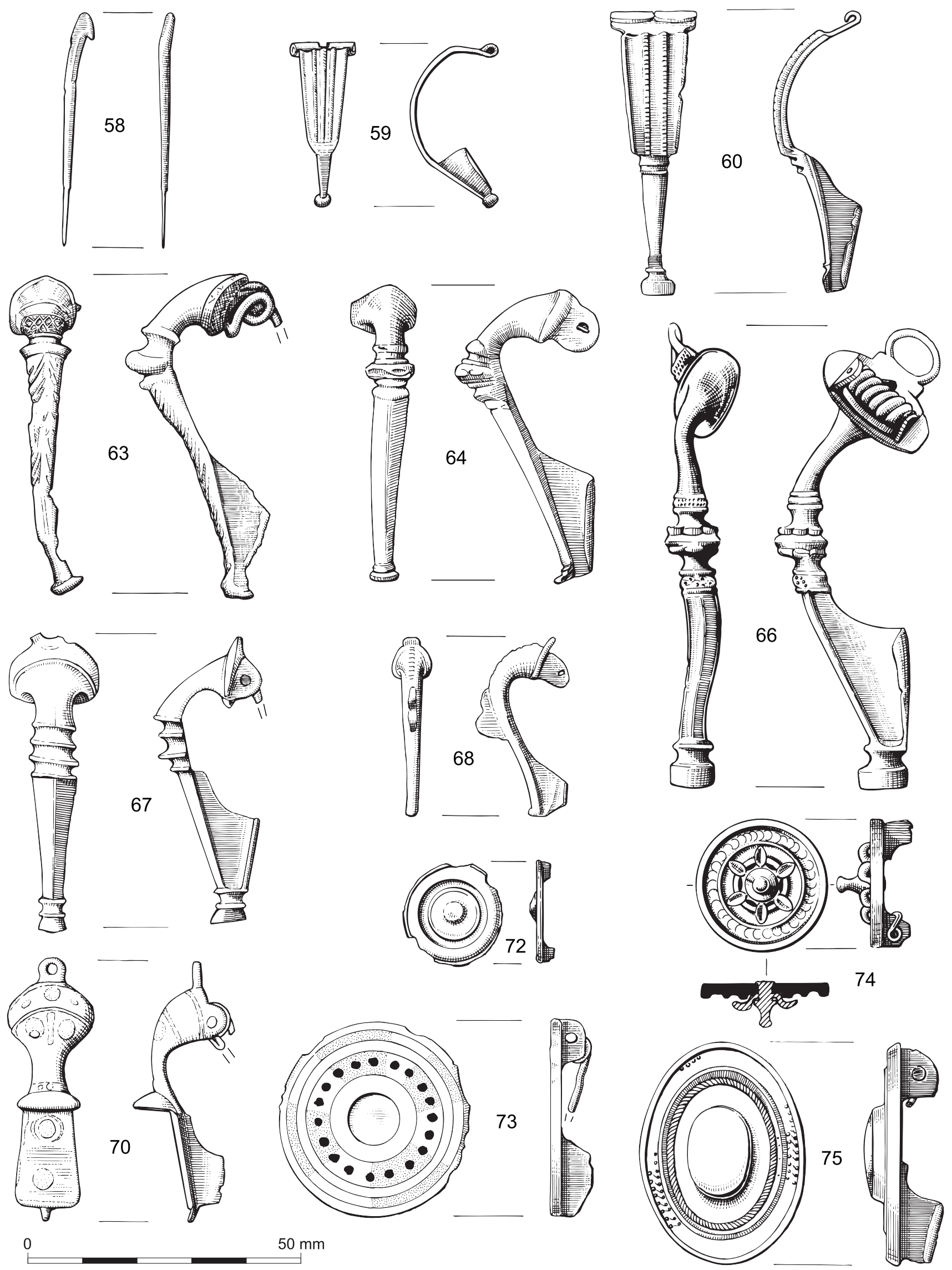

Figure 4.35. The brooches (Catalogue numbers 59-75) 
The dating in Britain is: Gorhambury, before c. 45 (Neal et al. 1990, 118, fig. 121.18); Hod Hill, before 50 (Brailsford 1962, 8, fig. 8.C46-48, and C50-52); Colchester, 43/44-46 (Hawkes and Hull 1947, 322, pl. 96.129); King Harry Lane, St Albans, unphased (Stead and Rigby 1989, 366, fig. 163, g 362.2); Colchester, 43/4-61 (Hawkes and Hull 1947, 322, pl. 96.134); Longthorpe, 43-60/65 (Frere and St Joseph 1974, 44, fig. 23.7); Waddon Hill, Dorset 50-60 (Webster 1960, 97, fig. 7.2, 6-7); Wilcote, Oxon, Claudian (Hands 1993, 33, fig. 25.20); Verulamium, 50-75 (Wheeler and Wheeler 1936, 206, fig. 43.12); Broxtowe, Nottingham, before 70/75 (Campion 1938; Braughing, 55-100 (Partridge 1981, 139, fig. 71.51); Colchester, 61-c 65 (Hawkes and Hull 1947, 322, pl. 96.131); Kelvedon, before 65 (Rodwell 1988, 57, fig. 45.25); Harlow temple, before 80 (France and Gobel 1985, 76, fig. 39.20); Wavendon Gate (Williams et al. 1995, 124, fig. 57.9) and Gorhambury, 1st century (Neal et al. 1990, 118, fig. 121.17); Alcester, 1st-early 2nd century (Cracknell and Mahany 1994, 168, fig. 80.66); Verulamium, 80-150 (Wheeler and Wheeler 1936, 206, fig. 43.13); Wroxeter, 80-120 (Bushe-Fox 1913, 24, fig. 9.5); Camerton, 90-200 (Wedlake 1958, 226, fig. 52.28, fig. 55.28A); Chichester, early 2nd century (Down 1978, 282, fig. 10.27, 32); Norden, 2nd century (Sunter and Woodward 1987, M7, fig. 26.3); Amersham, 225-50 (Yeoman and Stewart 1992, 156, fig. 28.3); Rudston, before late 2nd century (Stead 1980, 95, fig. 59.2); Alcester, 3rd century? (Cracknell and Mahany 1994, 168, fig. 88.65); Baldock, late 3rd century (Stead and Rigby 1986, 113, fig. 46.104); Catsgore, after late 4th century (Leech 1982, 105, fig. 76.1).

This shows, if the initial dates of each range are looked at, the typical dating curve of brooches in which the task of the interpreter is to find the point at which the particular brooch type had ceased to be even a survivor-in-use. Effectively, there is a discontinuity at c. 80 and this can be refined to not later than 65 . Most of those sites which produced later dates are known to have mid-1st century occupation and so the items should be regarded as being residual in their contexts. When it comes to Brooch 59 there is much less evidence of date, but that is less of a problem for transitional brooches such as this are relatively uncommon and, like the parent, had ceased to be made by the conquest and should be seen as, in Britain, sharing the same terminal date.

Both Brooches 60 and 62 can be put into one major category whose dating is: Colchester, 43- 48? (Hawkes and Hull 1947, 32-4, pl. 97.145); Dragonby, Lincs, mid 1st century (May 1996, 249, fig. 11.7, 77; Silchester, 45-65 (Cotton 1947, 144, fig. 7.8); Margidunum, Claudian ditch (Oswald 1952, pl. 4.10); Verulamium, 55-75 (Frere 1984, 27, fig. 8.38); Canterbury, Neronian-early Flavian (Williams 1948, 31, fig. 15.3); Lincoln, 60-70? (Petch 1960, 66, fig. 10.1); Wilcote, Oxon, 2nd century (Hands 1993, 33, fig. 25.23); Leicester, before 125/30 (Kenyon 1948, 251, fig. 80.13); Verulamium, 170-225 (Frere 1984, 27, fig. 8.39); Nettleton, 4th century (Wedlake 1982, 120, fig. 50.9). Here, the break in the curve is at Wilcote, and the end-date is fairly convincingly no later than 70-75 which is what would be expected of a type which is excessively rare north of the Humber-Dee line. So little survives of Brooch 62 that one would hesitate to give any specific date.

57. One knob survives on the axis bar. The head-plate has a buried bead-row on either side of a cross-flute which has a small curved cut out at each end. The bow proper has a bordering ridge and a buried bead-row down the middle of the swelled front. The lower bow is short and chamfered on each side under two cross-mouldings. The separately-made foot-knob has a cross-moulding round the top. HSM 4324; surface find; Garrod 1967. Not illustrated.

58. In many small pieces, this is a very small version of the last. HSM 9071; SO 364295/224840; context 17; Walters and Walters 1989. Not illustrated.

59. A version of Brooch 57 in which the head-plate has disappeared and the bow has become wider and flatter with a flute between the border and the buried bead-row. The lower bow is a simple flat face and the separatelymade foot-knob just a bead. HSM 23571; Heref. Mus. 9379/5; Ritchie 1970.

60. The upper bow has four ridges, the two middle ones beaded, separated by flutes. The lower bow has, under two cross-mouldings, a curved front running down to a two-part foot-knob recalling that on Brooch 39. HSM 23547; SO64682377; Tr. AII, context 4, sf. 4; Garrod 1967.

61. Only the upper bow really survives, this has a slight splay outwards towards the bottom, five vertical ridges and the remains of a wing on a lower corner. HSM 23571; Glos. Mus. A1689; 1870 Palmer Coll. Not illustrated.

62. The upper panel has a series of vertical ridges, a wing at each lower corner, the lower bow is broken across about halfway down. HSM 5324; Glos. Mus. A24300; surface find; Garrod 64-6. Not illustrated.

\section{Trumpets}

The condition of Brooch 63 was probably poor thus making identification of a precise variety from the available drawing a little difficult, especially when trying to reduce the decoration on the central moulding to a standard form. The following may be suggested as likely parallels: Chilgrove, West Sussex (Down 1979, 147, fig. 48.6); Gloucester (Hurst 1986, 39, fig. 22.2); Leicester, Causeway Lane (to be published); Caerleon (Hull 6945).

Brooches 64 and 65 are of the same style and the dating for all three is: Tewkesbury, 50-140 (Hannan 1993, 66, fig. 19.9); Whitton, 70-95 (Jarrett and Wrathmell 1981, 175, fig. 70.24); Castleford, 75-86; Caerleon, 80-100 (Zienkiewitz 1986, 170, fig. 54.3); Leicester, late 1st century (Clay and Pollard 1994, 145, fig. 74.24); Castleford, 90-95/105; Whitton, before 135 (Jarrett and Wrathmell 1981, 174, fig. 70.22); Silchester, with Hadrianic-Antonine pottery (Boon 1969, 47, fig. 6.7); Manchester 160-earliest 3rd century (Bryant et al. 1986, 67, fig. 5.5, 3194); Caerleon, 160-230 (Zienkiewitz 1986, 170, fig. 55.11); Chilgrove, late? 3rd-early 4th century (see above); Whittington Court, 
mid 4th century $+\left(\mathrm{O}^{\prime}\right.$ Neil 1952, 77, fig. 12.1); Nettleton, 4th century (Wedlake 1982, 127, fig. 53.53).

The upshot is that there is heavy weighting towards the period from before 75 to the earliest 2 nd century. Six examples covering 50 years at the outside and seven for the rest of the Roman period, suggest that the weakening of the dating after $c$. $125 / 135$ marks a proper term to the real floruit. What is marked is that the distributions show that Gloucestershire and South Wales lie at the heart of these particular varieties of Trumpets.

Trumpets like Brooch 66 with petalled knops and with this way of mounting the spring are uncommon, so much so that there is no adequate dating or significant distribution. The probability is that this example will date to the 2 nd century.

The core area of the distribution of brooches like Brooch 67 is around Derbyshire with others being traded to the south-west, none apparently going to the deep south or south-east. The dating is very limited: Wroxeter, 110-130 (Bushe-Fox 1913, 26, fig. 10.8); Derby, 150-175 (Dool et al.. 1985, 291, fig. 128.31) and Derby 4th century (ibid.., fig. 128.32). Hardly an impressive list, but the absence of any in the first century may represent the truth.

Unlikely as it may seem, Brooch 68 is a derivative of the Birdlip type and is the commonest as well as the simplest form of the Derivatives. The distribution is centred on Gloucestershire extending mainly into South Wales and up the Severn Valley into Shropshire. None is dated, but none is likely to be later than the 2 nd century.

Although Brooch 69 is strictly a Trumpet brooch, it is only the upper part which qualifies it for inclusion in that type. The evident intention to represent an insect closely resembling a fly is enough to move it into the category of Zoomorphic brooches. This particular design was to be seen in all parts of Roman Britain. The dating is weak: Caerleon, 160-230 (Zinkiewietz 1986, 172, f55.13). It is the use of silver appliqué, which all these brooches once had, which gives the proper date-range: c. 125-225.

63. (Described from a drawing). The spring is mounted on a loop behind the head of the bow. The narrow head is damaged, but may have had side mouldings at the top. The Knop is made of cross-mouldings, a single one top and bottom separated from a set of three in the middle by flutes. The central moulding is bigger than the others and is shown with some kind of diamond decoration. The lower bow is wasted by corrosion and may have had inverted ' $V$ ' markings at the top. HSM 9071; SO 64292484; surface find; Walters and Walters 1989.

64. The separately made spring was once mounted on a pierced loop behind the head of the bow. The trumpet head is emaciated and has a slight extension on each side. The knop is a triple moulding with a single one above and below. The lower bow has a central arris and the footknob is a simple two-part one. HSM 23571; Glos. Mus. A1612; 1870 Palmer Coll.

65. The same as the last, but smaller. HSM 23571; Glos. Mus. A1616; 1870 Palmer Coll. Not illustrated.

66. The spring has an internal chord and is mounted between two pierced plates. On the head of the trumpet is a cast-on loop and pedestal. The trumpet has a groove around its periphery. The knop is of the usual petalled form with a triple moulding above and below whose central element is beaded. The lower bow has a groove down each side and an arris down the middle. The foot-knob is petalled and lies under a flute and cross-moulding. HSM 23551; SO 64672389; Tr. CI, context 1, sf. 5; Garrod 1967.

67. The spring is mounted like that on Brooch 66. The upper bow is plain and ends in a head-plate with a cast-on loop. The knop is made up of four cross-mouldings separated by flutes. The lower bow has a central arris and tapers to two cross-mouldings separated by a flute all above a conical foot-knob. HSM 23571; Glos. Mus. A1617; 1870 Palmer Coll.

68. The spring was mounted as that on Brooch 45. The trumpet is exiguous with a slight head-plate surmounted by an unpierced tab. The knop has been replaced by a vertical crest mounted on the front of the otherwise plain bow. The crest is essentially an arc in profile with a curved cut-out. There is a projecting foot. HSM 23571; Glos. Mus. A1615; 1870 Palmer Coll.

69. (Described from a slide) In the form of a fly, the body is a trumpet which has a small unpierced tab on top. The wings are two semicircles filled with a blue enamel, a break in one suggested that it had been bedded down on a red base. At the bottom is a crude head with bulbous eyes and a narrow snout. The space between the semicircles and the knob has a small inverted cell for enamel in which all that can be seen is a touch of red at the bottom. HSM 21376; Sterry 1994. Not illustrated.

\section{Almgren 101}

Essentially a British type, the decoration of thin silver sheet soldered on is again almost exclusively British. The dating of the actual type is weak: Chichester, late 1 st to mid late 2nd century (Down 1989, 188, Not illustrated.), and Newstead, 80-c. 200 (Curle 1911, 311, pl. 85.2). However, if one turns to the use of the applied decoration as a whole precision of a sort comes into play: basically 125-225 AD.

70. The spring was mounted as that on Brooch 44. The design falls into three parts. At the top is a trumpet head with a cast-on loop. In the middle is a projecting, almost horizontal semicircular plate. The lower part is a flat plate tapering outwards towards the bottom which has a straight bottom edge and rounded corners. Traces exist of the once extensive applied silver trim: zones at the top and middle of the trumpet with rosettes of some form, another series around the top of the projecting plate, and two large circular features on the foot set within a raised border. HSM 23571; Glos. Mus. A1619; 1870 Palmer Coll.

71. Example cited as a parallel, Hattatt 1989, fig. 190.1540. Shows that this is another example No. 70. HSM 5324; Glos. Mus. A24301; surface find; Garrod 1960. Not illustrated. 


\section{Plate}

Brooch 72 is not a member of any well-defined group but is listed here. It is hard even to find any close relatives and certainly none of which has a date. The lack of British parallels, coupled with the use of a hinged pin, point to it having been made on the continent. The likely date-range is from the mid 1 st century into the 2 nd century, perhaps as far as 200 .

Brooch 73 is a member of a common British general type of which this particular variety is poorly dated: Watercrook, 120-200, (Potter 1979, 211, fig. 84.15). However, like most of its kin, the period of use for the silver appliqué with which it was once decorated is the best indicator of date and that is $c$. 125-225. The distribution of this pattern is in the west and the North of England, there being none at the moment south of Norfolk or west of Wiltshire. There are several from Hadrian's Wall.

Brooches 74 and 75 are British, even if some of the best dating evidence is from the Continent, the weight of examples known from Britain far outweighs this. The basic brooch may be either round or oval and the common form of decoration is best represented by Brooch 75, even if the commonest form of imitation gem is as an oval cone. The dating is: Wierden, Netherlands, with pottery of the 2nd half of the 2nd century and the 3rd (van Es and Verlinde 1977, 80, fig. 28.28); Manchester, c. 160-earliest 3rd century (Bryant et al. 1985, 65, fig. 5.5, 3102); Hockwoldcum-Wilton, Norfolk, late 2nd century and later (Gurney 1986, 64, fig. 40.8); Dorchester-on-Thames, post Antonine? (Frere 1962, 137, fig. 27.8); Esch, Netherlands, two examples, 200-250, but possibly 225-250 (van den Hurk 1977, 108, fig. 25-6, pl. 4.3); Inworth, Essex, 250/260-370 (Going 1987, 81, fig. 40.2); Saalburg and Zugmantel, two examples, before 260 (Böhme 1972, 110, Taf. 29.1132 and 1133 Not illustrated.); Brancaster, with 3rd century pottery (Hinchliffe and Green 1985, 44, fig. 28.5); Augst, with 3rd century pottery (Riha 1979, Taf. 13.309); Maxey, Cambs, late 3rd and 4th century (Crummy 1985, 164, fig. 111.6); Fishbourne, c. 280/290-early/mid 4th century (Cunliffe 1971, 106, fig. 40.43); Nettleton, 360-70 (Wedlake 1982, 148, fig. 63.5). The floruit for this type is therefore clearly from the last decades of the 2 nd century to about the middle of the 3 rd.

72. A circular plate once fitted with a hinged pin. On the front is a moulding with a convex section between bordering ridges, then a space around a dished centre which once had a stud riveted through it. HSM 23571; Glos. Mus. A1697; 1870 Palmer Coll.

73. (Described from drawing) The spring is mounted between two pierced lugs. The plate is circular and has an empty cell in the middle. Around that are two annular cells for enamel. The outer has two colours, one blue, alternating. The inner has enamel in which dots in a contrasting colour have been set. HSM 23571; Glos. Mus. A1634; 1870 Palmer Coll.

74. The bilateral spring is mounted on a single pierced lug. The front of the circular brooch is heavily gilded, The raised border is cross cut and immediately inside is a band of crescent shaped stamps. In the middle is a raised annulus with a flute round the top. In the centre is a stud whose top is damaged and whose base is a cone with a concave profile which holds in place a separately-made ring from which sprout six equally spaced projections each with an arched profile and a fluted top. HSM 23550; SO 64662376; Tr. BIII, context 1, sf. 1; Garrod 1967.

75. (Described from drawing). The plate is oval and gilded. In the centre is a single cell containing a glass/enamel cabochon jewel. Around that there are two zones. The inner is the narrower and has in its base a ridge with a cabled appearance. The outer zone has the remains of a series of S stamps radiating from the centre. HSM 5324; Glos. Mus. A6267; surface find; Garrod 1960.

\section{Penannulars}

In the case of penannular brooches such as Brooches 76 and 77 , there can, at times, be some difficulty in deciding how many grooves there are; these brooches were easy to make and very few indeed show much evidence for care in their manufacture. Assuming that the number of grooves may be two or three, the dating is: Bagendon, 43/45-47/52 (Clifford 1961, 184, fig. 36.9); Wilcote, Oxon, Claudian (Hands 1993, 34, fig. 25.26); Longthorpe, Claudian-Neronian (Dannell and Wild 1987, 87, fig. 21.12), and another from the same site is earlier than 60 (Frere and St Joseph 1974, 46, fig. 24.14) and another before $c$. 65 (ibid., 46, fig. 24.15); Waddon Hill, c. 50-60, three examples (Webster 1960, 97, fig. 7.21-2, and 1981, 62, fig. 59.13); Halstock, either before 60 or after 110/120 (Lucas 1993, 79, fig. 14.22); Prestatyn, 70-160 (Blockley 1989, 98 f40.28); Verulamium, 80-150 (Wheeler and Wheeler 1936, 98, fig. 40.28); Carlisle, late 1st century-110 (McCarthy 1990, 113.28); Leicester, early-mid 2nd century (Clay and Pollard 1994, 143, fig. 74.18); Caerleon, with HadrianicAntonine pottery (Wheeler and Wheeler 1928, 166, fig. 14.23); Tewkesbury, 140-60 (Hannan 1993, 68, fig. 19.12); Leicester, early 3rd century (Clay and Pollard 1994, 145, fig. 75.28); Shakenoak Farm, Wilcote, later 3rd century (Brodribb et al. 1971, 110, fig. 47.71; Somerton (Leech 1991, 214, fig. 16.7) and Nettleton 4th century (Wedlake 1982, 133, fig. 55.81); Bancroft, mid-4th to early 5th century (Williams and Zeepvat 1994, 296, fig. 134.37). The floruit probably begins before the conquest and is basically over by $c$. $75 / 85$ at the outside. The distribution is overwhelmingly England south of the Pennines.

Examples like Brooch 78 can be dated as follows: Bagendon, 20/25-43/45 (Clifford 1961, 184, fig. 36.10); Hod Hill, before 50 (Brailsford 1962, 13, fig. 11.E17); Waddon Hill, 50-60 (Webster 1981, 62, fig. 25.11); Longthorpe, before c. 65 (Frere and St. Joseph 1974, 46, fig. 24.13); Prestatyn, 70-160 (Blockley 1989, 98, fig. 40.267); Dorchester, 75-120 (Woodward et al. 1993, 123, fig. 62.47); Whitton, before 160 (Jarrett and Wrathmell 1981, 177, fig. 71.29); Alcester, Antonine into the 3rd century (Cracknell and Mahany 1994, 169; Not illustrated.). 
Anything with features that might be described as being zoomorphic, as in the case of Brooches 79 and 80 , tends to raise aesthetic emotions which have no place here. A complete analysis has been undertaken elsewhere of all which have any pretences to be included in this category (Mackreth forthcoming). The type of terminal, the presence or absence of grooves on the ring in groups or continuously, the degree of arc in the pin, the length of pin in relation to the diameter of the ring, even the size of the rings have all been looked at. The tentative conclusions arrived at have no place here. The pin is also a diagnostic feature for a reason other than its length: the style of the wrap-round. In the present instance, this is simple, but with the development towards the 'Dark Age' zoomorphic penannular, the wrap-round is replaced, visually, by a tube which becomes elongated and develops ridges at its ends and a hump in the middle. Any brooch with a pin which has any suggestion of these later forms is disregarded.

The sad truth is the writer has no dated parallel for Brooch 79 and very few other examples in any case. There are two from South Cadbury, but they are unpublished and their contexts are unknown, another from Norfolk was found with a metal-detector. It is perhaps the very lack of what may be called developed features of terminal, ring and pin which might be the best guide to the date of this piece. It is not of the 2nd half of the 4th century or later, but how much before 350 it might be is beyond present speculation.

76. The ring has a circular section. Each terminal is returned along the top of the ring and has two cross-flutes, although the presence of a ridge at the fold could be taken to mean that here was the intention to make three flutes. The pin is nearly straight. HSM 23571; Glos. Mus. A1620; 1870 Palmer Coll. Not illustrated.

77. The same form as the previous one, but with three definite flutes across each terminal. There is a slight bow in the pin. HSM 23571; Glos. Mus. A1621; 18701870 Palmer Coll.

78. (Described from a slide) The section of the ring is circular and each terminal is folded back along the ring. The complete terminal has a bulbous end at the fold over then two ridges with a wide flute between. HSM 21376; Sterry 1994. Not illustrated.

79. The ring has a circular section. Each terminal is returned along the top of the ring. The form of the terminals is almost zoomorphic. The cross-cuts in the form of an X at the opening end represent eyes, then there is a flute forming the top of the snout and at the end of the terminal has a V in crosscuts representing the nostrils. The pin has a more pronounced bow than the previous one, and the pin was once longer than is usual. HSM 23552; SO64452405; Tr. CXX, context 3B, sf. 23; Garrod 1967.

80. (Described from a slide). The terminals have been bent so far back that they now face in opposite directions. The one terminal which shows relatively clearly seems to have zoomorphic characteristics, but this is not used in the following discussion as it is not distinct enough to be of much use. HSM 21376; Sterry 1994. Not illustrated.
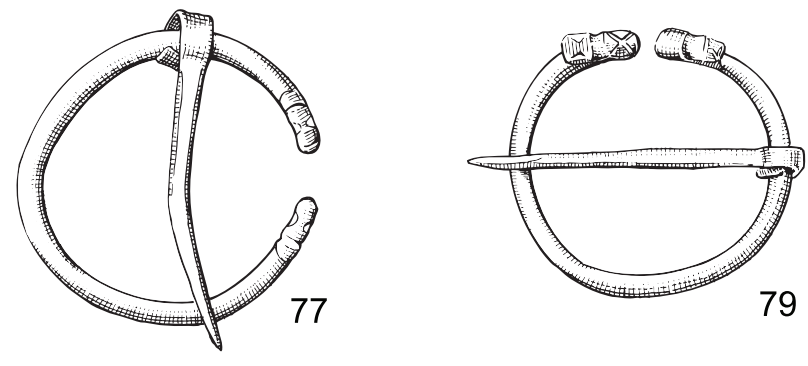

0 $50 \mathrm{~mm}$

Figure 4.36. The brooches (Catalogue numbers 77 and 79)

\section{Fragments and other objects}

81. The foot of a brooch with a thin border on each side and a pair of ribs down the middle. The face on each side of the latter has traces of widely spaced grooves. Possibly from a Colchester Derivative. HSM 5324; Glos. Mus. L260; surface find; Garrod 1960. Not illustrated.

82. Complete bilateral spring and pin from a Colchester Derivative. HSM 23546; SO 64682377; Tr. AI, context 3, sf. 14; Garrod 1967. Not illustrated.

83. Half a bilateral spring and pin most likely from a Colchester Derivative. HSM 23546; SO 64682377; Tr. AI, context 2A, sf. 9; Garrod 1967. Not illustrated.

84. A hinged pin. HSM 23546; SO 64682377; Tr. AI, context 2A, sf. 11; Garrod 1967. Not illustrated.

85. A pin with the upper end bent to fit round an axis bar with the end tucked under a wing to provide the necessary seating to flex the pin when that was released: almost certainly a repair and probably from a Colchester Derivative. HSM 21376; SO 6450/2400 (4); DAG Fieldwalking 1984-9. Not illustrated.

86. A pin from a brooch. HSM 23547; So 64682377; Tr. AII, context 5, sf. 6; Garrod 1967. Not illustrated.

87. Part melted, the object may have been part of a flat base for a vessel, the upstanding border having a flute around its outer surface. HSM 15983; Tr. 1, context 105; Welsh Water 1993; Jackson, Hancocks and Pearson 1999. Not illustrated.

88. A length of cast copper alloy with a uniform triangular section bent to form part of an involute curve. There is no feature which suggests that it must have be part of a brooch and the constant section is against this. HSM 23571; Glos. Mus. A1700; 1870 Palmer Coll. Not illustrated.

89. Fragment of spring. Glos. Mus. A6212. Not illustrated.

\section{Early Iron Age?}

This, if correctly identified from the drawing available, would be a member of Hull and Hawkes (1987) Group A or perhaps more likely Group $\mathrm{G}$ and so would apparently date between the late 8 th and 5 th centuries BC.

90. (Described from a drawing). A length of wire coiled into a spiral of at least five coils. The drawing shows the outer strand as bent and then tucked under the flat plane of coils, and what may be the other end issuing forth from 
under almost at the point where the distortion occurs in the mainly spiral. HSM 23547; SO 64682377; Tr. AII, context 8, sf. 7; Garrod 1967. Not illustrated.

\section{Unidentifiable}

O Not seen. No designation. HSM 5324; A24300HOD; surface find; Garrod 1960. Not illustrated.

P Not seen. No designation. HSM 23563; Sterry 1994. Not illustrated.

Q Not seen by author but listed as "complete". HSM 21376; Sterry 1994. Not illustrated.

R Not seen by author but listed as having "enamel". HSM 21376; Sterry 1994. Not illustrated.

S Not seen by author but listed as having "pin missing". HSM 21376; Sterry 1994. Not illustrated.

T Not seen. No designation. HSM 21376; Sterry 1994. Not illustrated.

U Not seen. No designation. HSM 21376; Sterry 1994. Not illustrated.

V Not seen. No designation. HSM 21376; Sterry 1994. Not illustrated.

W Not seen. No designation. HSM 21376; Sterry 1994. Not illustrated.

X Not seen. No designation. HSM 21376; Sterry 1994. Not illustrated.

Y Not seen but listed as "Glass centre boss missing". HSM 21376; Sterry 1994. Not illustrated.

Z Not seen. No designation. HSM 23569; Morrion 1970. Not illustrated.

AA No designation. HSM 23571; Glos. Mus. A6011; 1870 Palmer Coll. Not illustrated.

AB Not seen. Listed as "fragments". HSM 21376; Sterry 1994. Not illustrated.

AC Not seen. No designation. HSM 21376; Sterry 1994. Not illustrated.

AD Not seen but listed as fragments of S and pin. HSM 23571; Glos. Mus. A1696 and A1698-9; 1870 Palmer Coll. Not illustrated.

\section{Summary discussion}

There is strong evidence for the use of brooches on this site from at least the middle of the 1st century BC (Brooches 14, 15 and perhaps 10; Fig. 4.32) with the introduction of brooches certainly made on the continent before the end of that century (Brooches 18, 20 and possibly 19; Fig. 4.33) and strongly through the pre-conquest period (Brooches $1-4,21-2$, possibly 16 and 17; Figs 4.32 and 4.33).

Of particular interest in the assemblage is Brooch 9 which provides evidence that the Colchester was being made here far away from its core area, but possibly near the end of its manufacturing life anyway.

The question of possible a military presence is often asked and, whereas the answer is usually that brooches themselves do not declare this, Brooches 11-13 (Fig. 4.33) should not be expected on an ordinary civilian site. On the other hand, there are perhaps fewer Aucissa Hod Hills than might be expected on a site producing three examples of that kind of La Tène II.
Brooches 27 and 35-6 (Figs 4.33 and 4.34) throw up one intriguing detail. There is a hint here of a connection with that eastern part of England which was influenced by the styles of brooches used in Norfolk before the suppression of Boudicca's Rebellion. What it may mean is unknown, but is alluded to under Brooch 27.

\section{The coins \\ Cathy King}

\section{The material}

The coin assemblages derive from a number of sources including excavations, fieldwalking, personal collections and metal detecting. Altogether they total 437 pieces but only 180 were available for re-examination for this report. Of the 257 pieces recorded on the database that were not seen, records of most of the Iron Age material exist in the Celtic Coin Index (CCI) in Oxford. Consequently a more-or-less complete list of Ariconium finds of these coins could be compiled (Table 42). However, the vast majority of the Roman pieces that were not re-examined do not have even a provisional identification and the analysis below of the pattern of Roman coin loss is largely confined to those coins for which a reasonably secure attribution could be established. In order to clarify the nature of the available evidence and its reliability, a series of lists were compiled of the coins actually seen and catalogued for this report together with an additional list of coins arranged by HSM unique site numbers of the coins unavailable for examination (Appendix 8).

\section{The collections}

\section{The Palmer Collection (HSM 23571; HSM $5327=$} 1 coin)

In 1914 T. G. Barnett presented a group of coins to Gloucester Museum consisting of Iron Age and Roman pieces found at Ariconium before 1871, many and possibly all of which had apparently been acquired from Charles Palmer (Grinsell et al. 1973). The integrity of this collection and the degree to which a large number of the coins can be securely attributed by date and provenance to it are questionable. The coins currently in the museum and attributed to the Palmer Collection consist of 15 Iron Age pieces and 114 Roman ones. Ninety-one coins were reexamined, re-catalogued, and in some cases re-attributed for this report. The remaining 38 pieces, which were not sent by the museum, included fourteen Iron Age coins (twelve of which were published in the Sylloge of Coins in the Bristol and Gloucester Museums), five Roman coins on display (Palmer nos 472, 686, 703, 705, and 597), and one not included for unspecified reasons (Grinsell et al. 1973).

The attributions of the published Iron Age coins 
are secure since they include photographs and thus preclude any need for re-examination. The accuracy of the attributions of the Roman coins on display is less certain, while that of the coins which cannot be located cannot be considered reliable for purposes of quantitative analysis. Moreover, on the basis of the envelopes in which the coins are housed there seems to be some doubt whether many of the coins donated by Barnett did in fact come from Bollitree, Weston-under-Penyard. Of the 91 examined, 17 are securely assigned to Bollitree, 52 are designated as probably from Bollitree, twenty as possibly or 'said to be' Bollitree, and two are without any designation whatever. An additional problem with this collection of coins is that they seem to have been originally selected for their high quality. Consequently pieces in poor condition, imitations, and coins of the Later Roman Empire are discriminated against in favour of earlier and more 'interesting' coins from a collector's point of view. This bias makes it difficult to use the coins in any meaningful way to analyse the chronological distribution of coins lost on the site.

In 1923, A. G. K. Hayter published 212 coins from Weston-under-Penyard from the collections of C. J. Butcher, F. C. Cooper, the Misses Edwards, Mrs. R. L. Harkness, Mrs. E. Martell, W. Price, and W. Charles Palmer collectively in a brief summary without attributing the coins specifically to their individual owners. The Roman coins were listed only by emperor, the Iron Age pieces by metal. Consequently it is not possible to link more than a few coins in his list to specific coins in the Gloucester Museum collection donated by Barnett (Hayter 1923).

Table 42. The Iron Age coins

\begin{tabular}{|c|c|c|c|c|c|c|c|c|}
\hline \multicolumn{9}{|c|}{ Dobunnic gold } \\
\hline No & Class & Mack No & Van A No & CCI No & Reference & Pub No & Coin Seen & Photo \\
\hline 1 & Catti & 391 & $1130-1$ & 94.0141 & & & No & Yes \\
\hline \multicolumn{9}{|c|}{ Dobunnic silver } \\
\hline No & Class & Mack No & Van A No & CCI No & Reference & Pub No & Coin Seen & Photo \\
\hline 2 & $\mathrm{~A}$ & 376 & $1020-1$ & 61.0005 & P679 & 2 & No & Yes \\
\hline 3 & B & 378 & $1042-1$ & 61.0013 & P681 & 3 & No & Yes \\
\hline 4 & $\mathrm{~B}$ & 378 & $1042-1$ & 61.0011 & P675 & 4 & No & Yes \\
\hline 5 & $\mathrm{~B}$ & 378 & $1042-1$ & 68.0001 & Garr & 6 & No & Yes \\
\hline 6 & $\mathrm{C}$ & $378 \mathrm{a}$ & $1045-1$ & 61.0016 & Garr & & No & Yes \\
\hline 7 & $\mathrm{C}$ & $378 \mathrm{a}$ & $1045-1$ & 70.0002 & Garr & & No & Yes \\
\hline 8 & $\mathrm{D}$ & 379 & $1049-1$ & 61.0017 & P672 & 7 & No & Yes \\
\hline 9 & $E$ & 380 & $1074-1$ & 61.0022 & P674 & 8 & No & Yes \\
\hline 10 & $\mathrm{E}$ & 380 & $1074-1$ & None & Pnone & & No & No \\
\hline 11 & $\mathrm{E}$ & 380 & $1074-1$ & None & $\mathrm{Gaz}$ & & No & No \\
\hline 12 & $\mathrm{~F}$ & 382 & $1078-1$ & 61.0027 & P673 & 9 & $\mathrm{No}$ & Yes \\
\hline 13 & $\mathrm{H}$ & 389 & $1110-1$ & 61.0050 & Gaz & & No & Yes \\
\hline 14 & $\mathrm{~J}$ & 384 & $1137-1$ & 61.0030 & P677 & 11 & No & Yes \\
\hline 15 & $\mathrm{~J}$ & 384 & $1137-1$ & 61.0032 & P680 & 12 & No & Yes \\
\hline 16 & $\mathrm{~J}$ & 384 & $1137-1$ & 61.0033 & P676 & 13 & No & Yes \\
\hline 17 & $\mathrm{~J}$ & 384 & $1137-1$ & 61.0036 & P678 & 14 & No & Yes \\
\hline 18 & $\mathrm{O}$ & $384 d$ & $1185-1$ & 69.0052 & Garr & & No & Yes \\
\hline \multicolumn{9}{|c|}{ Plated Dobunnic quarter stater } \\
\hline No & Class & Mack No & Van A No & CCI No & Reference & Pub No & Coin Seen & Photo \\
\hline 19 & RB & 68 & $1010-2$ & None & $\mathrm{Gaz}$ & & No & No \\
\hline \multicolumn{9}{|c|}{ Bronze core of plated Dobunnic stater } \\
\hline No & Class & Mack No & Van A No & CCI No & Reference & Pub No & Coin Seen & Photo \\
\hline 20 & Uncertain & & & 92.0452 & M-WA & & No & Yes \\
\hline \multicolumn{9}{|c|}{ Quarter stater of the Corieltauvi } \\
\hline No & Class & Mack No & Van A No & CCI No & Reference & Pub No & Coin Seen & Photo \\
\hline 21 & & $396 b$ & $1231-1$ & None & P671 & 19 & No & Yes \\
\hline \multicolumn{9}{|c|}{ Trinovantes bronze } \\
\hline No & Class & Mack No & Van A No & CCI No & Reference & Pub No & Coin Seen & Photo \\
\hline 22 & Cunob & 245 & $1983-1$ & 86.0086 & & & No & Yes \\
\hline 23 & Cunob & 248 & $2097-1$ & 61.0268 & P682 & 21 & Yes & Yes \\
\hline \multicolumn{9}{|c|}{ Atrebates quarter staters } \\
\hline No & Class & Mack No & Van A No & CCI No & Reference & Pub No & Coin Seen & Photo \\
\hline 24 & Commius & 83 & $353-5$ & 61.0374 & & & No & Yes \\
\hline 25 & Verica & 112 & $466-1$ & 86.0145 & & & No & Yes \\
\hline \multicolumn{9}{|c|}{ Gallic bronze } \\
\hline No & Class & Mack No & Scheers No & CCI No & Reference & Pub No & Coin Seen & Photo \\
\hline 26 & Atrebates & & pl. 12, 315-316 & 94.1256 & Sterry & & No & Yes \\
\hline
\end{tabular}


Unfortunately, the descriptions of the coins listed by Hayter are so imprecise that his list cannot be used to suggest a chronological distribution by period.

\section{Excavations}

THE JACK EXCAVATIONS 1922

Nine coins were published by Hayter from the Jack excavations (Hayter 1923). Although it was not possible to re-examine them, they have been recorded in sufficient detail to permit an attribution to a ruler or period and assign them a date. The number of coins recovered is too small to allow quantitative analysis of periods when coins were minted or comparison with other sites but they can be used in conjunction with other groups of coins to give a general picture of coin loss at Ariconium.

Garrod and Moss excavations 1967 (HSM 23546, 23547, 23551, 23552, 5324)

Thirteen coins from the Garrod and Moss excavations have been recorded on the finds database. Nine were sent for re-examination while four were not included. The missing coins include a legionary denarius of Mark Antony which is no longer in its envelope. It was, however, referred to in the records of early Roman finds from trial trenches in the 1967 excavations. The only other coin mentioned in the 1967 excavation records, a nummus of Diocletian was included in the group sent from Gloucester Museum and is as described (Garrod and Moss 1967). The three remaining coins, all of which are silver pieces of the Dobunni, (one each of Class B, C, and O) are recorded in the Celtic Coin Index in Oxford together with an illustration. One (the Class $\mathrm{B}$ coin) has also been published in the sylloge volume of the coins in Gloucester Museum (Grinsell et al. 1973). The Class $\mathrm{O}$ coin is now in the British Museum.

The small size of the group of coins examined from this excavation precludes their use on their own in producing a meaningful analysis of their chronological distribution or comparison with other sites although they could be usefully assessed together with other groups of coins. If it can be established that the Iron Age and Roman Republican coins were found in unambiguous pre-Roman contexts, this evidence would help to confirm a pre-Roman settlement at Ariconium.

Welsh Water salvage Recording (JACKSON, HanCoCKS AND PEARSON 1999; HSM 6097)

There is one coin from the Welsh Water pipeline that was sent for examination and it can be attributed to a ruler and assigned a date but not to a mint.

\section{Fieldwalking, metal detecting, and miscellaneous}

The Dean Archaeological Group

The fieldwalking activities of the DAG yielded 77 coins (excluding a Rose farthing which was not sent for examination). Although all of the coins recovered were in an extremely poor state of preservation and some were little more than fragments, nonetheless a significant number could be attributed to fairly broad chronological categories. Five were produced either in the 1 st or 2 nd centuries AD, twenty-one between AD 260 and AD 286 (17 of which were copies), five to the years AD 330 to AD 348, twelve (all of which are copies) to the years between AD 330 and $\mathrm{AD} 360$, eight genuine coins to the years between $\mathrm{AD}$ 364 and AD 378, and one to the period from AD 388 and AD 402. Four were illegible pieces from the 4th century and nineteen were illegible coins of either the 3rd or 4th centuries $\mathrm{AD}$, while one was not from the Roman period and the final piece is probably not a coin. The material is generally in very poor condition owing to the effects of corrosion and many pieces are also worn and/or broken.

The bias of this assemblage is towards low quality coins and particularly those of the later 3rd and 4th centuries AD which is unsurprising since the coins were recovered by fieldwalking and coins from these periods are those most frequently found on Romano-British sites. While it would be dangerous to use this group on its own to create a model of the distribution of Roman coins at Ariconium, there is no doubt of its integrity. In conjunction with other coins of equivalently secure provenance from this site, it is useful in suggesting patterns of coin loss in the Roman period.

\section{HARPER 1964 (HSM 21376)}

Two coins, a sestertius of Trajan and an antoninianus of Carausius, now in Hereford Museum, were examined and catalogued. They represent too small a sample to be of use in a comparative analysis of coins by period but considered together with other coins from the site they could contribute to the elucidation of the pattern of coin loss.

\section{Mark Walters 1991 (HSM 21376)}

There are two coins in this group, neither of which was sent for examination. The first is a core of a plated Iron Age gold coin which was initially attributed to Bodvoc (Mack 395; Van A 1052-1). The coin, which has been recorded in the Celtic Coin Index, is now identified simply as a core; a more precise attribution is not possible given its poor condition. It is presumably the piece found by Martin Sterry in 1991. The second coin is a copy of an as of Claudius I. Unfortunately, there is no documentation suggesting whether the two coins were found together, near one another, or at the same time although they were found in the same year. Consequently they are of limited value on their own in interpreting the site.

Martin Sterry collection (HSM 21376 = 196 coins; HSM $23563=7$ cOINS)

The majority of these coins, 202 out of a total of 203, were found between 1989 and 1994 by Martin Sterry with a metal detector. None of the coins were sent for examination. One is recorded in the Celtic Coin Index (CCI 94.1256); seven have a provisional identification; the remainder have not been systematically catalogued. 
This is unfortunate since this is the largest assemblage from the site and, if formally identified would contribute significantly towards defining a chronological distribution of the pattern of coin loss at Ariconium.

\section{Miscellaneous 1970 (HSM 5324)}

The findspot and identification of this Iron Age Dobunnic Class $\mathrm{C}$ coin is substantiated by the fact it is recorded in the Celtic Coin Index together with an illustration. (CCI 70.0002) On its own it contributes little to our understanding the Iron Age coins although it does reinforce the predominance of Dobunnic coins among this group.

\section{Morris 1970 (HSM 23568)}

There is no indication of the number or types of coins in this group and consequently there is nothing that can be meaningfully said about them.

\section{Analysis}

\section{The Iron Age coins (Table 42)}

There are twenty-six Iron Age coins recorded from Ariconium all but four of which (Table 42: Nos 10, 11, 19 and 21) have been recorded in the Celtic Coin Index together with an illustration. Their unique CCI number has been included wherever possible in Table 42. Thirteen (12 from the Palmer Collection and one purchased from A. P. Garrod in 1970) are in Gloucester Museum and these have been published in the sylloge volume of the Bristol and Gloucester Museums' collections (Grinsell et al. 1973). No Celtic Coin Index record, illustration or publication details exist for coins 10,11, and 19; consequently their attributions cannot be verified. They were, however, published in the gazetteer of Dobunnic coins and consequently have been included here (de Jersey 1994).

Twenty (or 77\%) of the coins can be attributed to the Dobunni if we include the three unverifiable pieces: one gold Catti stater, a plated British RB quarter stater, a bronze core of a plated stater, and seventeen silver pieces. These can be subdivided and dated according to Van Arsdell's chronology as follows:

$\begin{array}{lll}\text { Class A } & 35-30 \text { BC } & 1 \\ \text { Class B } & 30-15 \text { BC } & 3 \\ \text { Class C } & 30-15 \text { BC } & 2 \\ \text { Class D } & 30-15 \text { BC } & 1 \\ \text { Class E } & 10 \text { BC-AD 10 } & 3 \\ \text { Class F } & 10 \text { BC-AD 10 } & 1 \\ \text { Class H } & \text { AD 15-30 } & 1 \\ \text { Class J } & \text { AD 30-43 } & 4 \\ \text { Class O } & 15 \text { BC-AD 30 } & 1\end{array}$

There are five non-Dobunnic coins of British origin: one quarter stater (Mack 396b, Van Arsdell 1231-1) now attributed to the Corieltauvi, two bronze coins of Cunobeline, and two Atrebatic quarter staters. The final coin is a Gallic bronze attributed by Scheers to the Atrebates and dated to $c$. 57-51 BC (Scheers 1977, 113, 483-4, pl. 12, nos 315-16).
Two points emerge in a summary analysis of these finds. The first is the dominance of coins of the Dobunni which is unsurprising since Ariconium lay within their sphere of influence although strictly speaking it was not inside their territorial boundaries (Van Arsdell 1994, 25). The second point worth noting is the presence of nearly $25 \%$ of the Iron Age coins deriving from areas well beyond Dobunnic territory.

The critical questions are how and when these coins reached Ariconium. Despite the relative abundance of material, the absence of secure contexts and systematic modern excavations make them virtually impossible to answer. One difficulty is that almost all Dobunnic coins occur in Roman contexts (Sellwood 1980, 130-1; 1984, $199,203 ; 1988)$. In the absence of stratified archaeological evidence from Ariconium, it is not easy to determine whether these Dobunnic pieces pre-date or post-date the conquest. This level of problem persists even when, as in the case of Hayling Island, excavations yield coins in secure contexts (Briggs, Haselgrove and King 1992, 34-5). Similar uncertainties arise in regard to the date when the other British Iron Age coins and the Gallic piece reached the site. The only coin minted significantly before $c .35$ $\mathrm{BC}$ is the Gallic bronze of the Atrebates and it is not clear when it arrived at Ariconium. The remaining British coins were produced between $30 \mathrm{BC}$ and AD 43 and certainly the Dobunnic pieces could have remained in circulation after the conquest. The same could plausibly apply to the non-Dobunnic British coins as well. It was perhaps for this reason that Sellwood suggested that Ariconium was a purely Roman foundation although she cites no evidence in support of this view (Sellwood 1984, 197). However, in conjunction with the substantial amount of late Iron Age/early Roman pottery and the group of early brooches (see above) these coins provide support for the argument in favour of the settlement having had Iron Age origins.

Given the nature of the existing evidence, it is no easier to construct hypotheses about possible economic activity at Ariconium on the basis of the Iron Age coins recorded to date. Van Arsdell has characterized the site as a gateway to and from Dobunnic territory without clearly specifying what he means by this term. However, he does describe Ariconium as a magnet for Dobunnic coins and possibly forming part of a trade network involving iron from the Forest of Dean (Van Arsdell 1994, 26).

It is probable but by no means entirely certain that future excavations at Ariconium could help to solve the questions of the date when it was founded and the extent to which it was functioning in the pre-Roman period. There is no doubt that the systematic recording of Iron Age coins in the Celtic Coin Index (C.C.I.) in Oxford has both added new material from Ariconium and allowed some of the older finds listed on the database to be linked to specific C.C.I. numbers. These will contribute to any future interpretation of the finds. 
Table 43. Summary of Roman coins

\begin{tabular}{|l|c|c|c|}
\hline Excavations & Coins Seen & $\begin{array}{c}\text { Coins Not } \\
\text { Seen }\end{array}$ & Total \\
\hline Jack 1923 & 0 & 9 & 9 \\
\hline Bridgewater 1963 & 0 & 0 & 0 \\
\hline Garrod and Moss 1967 & 9 & 4 & 13 \\
\hline Walters and Walters 1989 & 1 & 0 & 1 \\
\hline Welsh Water & 0 & 0 & 0 \\
\hline Total & $\mathbf{1 0}$ & $\mathbf{1 3}$ & $\mathbf{2 3}$ \\
\hline
\end{tabular}

\begin{tabular}{|l|c|c|c|}
\hline Fieldwalking/Metal Detecting & Coins Seen & $\begin{array}{c}\text { Coins Not } \\
\text { Seen }\end{array}$ & Total \\
\hline DAG 1984-1989 & 77 & 0 & 77 \\
\hline Welsh Water & 0 & 0 & 0 \\
\hline SWAG & 0 & 0 & 0 \\
\hline Garrod & 0 & 0 & 0 \\
\hline Harper & 2 & 0 & 2 \\
\hline Misc 1970 & 0 & 1 & 1 \\
\hline Morr 1970 & $?$ & $?$ & $?$ \\
\hline M-WA 1991 & 0 & 2 & 2 \\
\hline M Sterry & 0 & 203 & 203 \\
\hline Total & $\mathbf{7 9}$ & $\mathbf{2 0 6}$ & $\mathbf{2 8 5}$ \\
\hline
\end{tabular}

\begin{tabular}{|l|c|c|c|}
\hline Early Finds & Coins Seen & $\begin{array}{c}\text { Coins Not } \\
\text { Seen }\end{array}$ & Total \\
\hline Palmer Coll & 91 & 38 & 129 \\
\hline
\end{tabular}

\begin{tabular}{|l|l|l|l|}
\hline Grand Total & 180 & 257 & 437 \\
\hline
\end{tabular}

\section{The Roman coins (Tables 43 and 44)}

It should be recognised from the outset that the Roman coins from Ariconium that are currently available for analysis provide a flawed sample for determining the chronological pattern of their distribution (Table 43).

The Palmer Collection is almost certainly over represented by coins of the earlier empire and it is also unclear whether all of the coins in it actually come from the site. The majority of the fieldwalking finds recovered by the DAG cluster in the later empire and a significant number (c. 25\%) are illegible. Only a few coins have been recovered from the various excavations and some (nine from the Jack excavation and four from that of Garrod and Moss) were not available for re-examination and, as a result, their attributions may not be accurate in every detail (Table 44). Furthermore, the chronological distribution of the 203 coins found by Martin Sterry is not known since the coins have not formally been identified.

Despite these limitations, a number of general observations can be made about the Roman coin assemblage. The first is that there is a small amount of early Roman material. Two denarii produced in the late Republic survive in the Palmer Collection (nos 683,684) and their attribution to the collection is secure. A denarius of Marc Antony was also found in the course of the Garrod and Moss excavations in 1967 and while it was not re-examined, there seems no reason to doubt the identification. The Palmer Collection also has two imitation Minerva asses of Claudius I, one of which certainly belongs to this collection (no. 685) while the other is possible (no. 702). A further Claudian imitation was recovered in 1991 (Mark Walters; HSM 21376). The presence of these early pieces at Ariconium is not sufficient in itself to confirm their arrival before the conquest or even immediately after but does demonstrate that both Republican and early imperial coins reached the site.

The second observation is related to the date when coins ceased to reach Ariconium in significant numbers. Hayter commented on the small quantity of coins which were datable to the later 4th century (AD 361-95) when he published the finds from the Jack excavation and related local material (Hayter 1923). This perception is modified somewhat by the addition of the DAG fieldwalking finds. Although there are only three coins in the Palmer Collection minted after AD 360, nine of the DAG group belong in this period. On the basis of this evidence, we cannot be certain of the extent to which coin deposition may have declined in the later 4th century or whether the picture would look different if more coins were to be found and identified.

Given the bias of the Palmer Collection and the DAG finds, in particular, it is difficult to interpret the significance of the material from the later 1 st century $\mathrm{AD}$ to that of the middle of the 4th century. The difficulties can be illustrated by a brief analysis of the coins from the $3 \mathrm{rd}$ and 4 th centuries from Ariconium. Coins minted in the periods between $\mathrm{AD}$ 260 and 286, AD 330 and 348, AD 364 and 378, and in 
Table 44. Distribution of Roman coins by period

\begin{tabular}{|l|c|c|c|c|c|c|c|c|}
\hline Period & Palmer & Jack & Garrod & $\begin{array}{c}\text { Welsh } \\
\text { Water }\end{array}$ & DAG & Harper & Total & \% \\
\hline Iron Age & {$[1]$} & 0 & {$[3]$} & 0 & 0 & 0 & 4 & 2.1 \\
\hline Roman Republic & 2 & 0 & {$[1]$} & 0 & 0 & 0 & 3 & 1.5 \\
\hline 31 BC-AD 69 & 2 & 0 & 0 & 0 & 0 & 0 & 2 & 1.0 \\
\hline AD 69-96 & 4 & {$[1]$} & 0 & 0 & 0 & 0 & 5 & 2.6 \\
\hline AD 97-193 & 13 & 0 & 1 & 0 & 1 & 1 & 16 & 8.3 \\
\hline 1c-2c illeg. & 0 & 0 & 0 & 0 & 5 & 0 & 5 & 2.6 \\
\hline AD 193-235 & 6 & 0 & 0 & 0 & 0 & 0 & 6 & 3.1 \\
\hline AD 235-260 & 2 & 0 & 0 & 0 & 0 & 0 & 2 & 1.0 \\
\hline AD 260-285 & 11 & {$[4]$} & 3 & 0 & 20 & 0 & 38 & 19.6 \\
\hline AD 285-296 & 4 & {$[1]$} & 0 & 0 & 0 & 1 & 6 & 3.1 \\
\hline AD 295-315 & 5 & {$[2]$} & 1 & 0 & 0 & 0 & 8 & 4.1 \\
\hline AD 315-330 & 7 & 0 & 0 & 0 & 0 & 0 & 7 & 3.6 \\
\hline AD 330-348 & 24 & {$[1]$} & 3 & 1 & 5 & 0 & 34 & 17.6 \\
\hline AD 330-360 & 0 & 0 & 0 & 0 & 12 & 0 & 12 & 6.2 \\
\hline AD 348-360 & 7 & 0 & 0 & 0 & 0 & 0 & 7 & 3.6 \\
\hline AD 364-378 & 3 & 0 & 0 & 0 & 8 & 0 & 11 & 5.7 \\
\hline AD 388-402 & 0 & 0 & 0 & 0 & 1 & 0 & 1 & 0.5 \\
\hline 4c illeg. & 0 & 0 & 0 & 0 & 4 & 0 & 4 & 2.1 \\
\hline 3c-4c illeg. & 0 & 0 & 1 & 0 & 19 & 0 & 20 & 10.5 \\
\hline Not Roman & 0 & 0 & 0 & 0 & {$[2]$} & 0 & 2 & 1.0 \\
\hline Total & $\mathbf{9 0}[1]$ & {$[9]$} & $\mathbf{9}[\mathbf{4}]$ & $\mathbf{1}$ & $\mathbf{7 5}[\mathbf{2}]$ & $\mathbf{2}$ & $\mathbf{1 7 7}[\mathbf{1 6}]$ & \\
\hline
\end{tabular}

some instances AD 388 and 402 tend to predominate on British sites although the pattern of which group or groups are dominant is not the same at all sites. There are only two of these periods at Ariconium which have a significant number of coins: AD 260 to 285 ( 38 coins or $19.6 \%$ and AD 330 to 348 (34 coins or $17.6 \%$ ) and even these percentages are somewhat low. In part, the under-representation of later 3rd and 4th century coins results from the bias of the Palmer Collection towards pieces of the earlier empire. However, to some extent, it also reflects the fact that a high proportion of the DAG fieldwalking coins are not sufficiently legible to assign them to a specific period (Table 44). The balance might shift more strongly towards the later period if the Sterry material could be included, but in the absence of secure identifications of these coins, this cannot be established as fact.

\section{Areas of potential research and future objectives}

It is clear that Ariconium is an important site about which little is known. Its role in the Iron Age and early empire remains ambiguous but its potential significance in these periods is attested by the number of Iron Age coins recovered and the existence of Republican and early imperial coins, albeit in small quantities. Not only is it desirable to maintain a watching brief on this site but more positive action is recommended.

\section{Excavations}

There is no doubt that more extensive excavations carried out in a systematic manner would greatly aid in the interpretation of the material currently available in Ariconium while adding valuable new artefacts and information. The number of coins already recorded on the database suggests that there may be many more that could be found and if secure contexts existed, especially for the early material, the coins could contribute significantly to our understanding of the site in both chronological and functional terms.

\section{Recording finds}

It is greatly to be regretted that so few of the coins recovered through fieldwalking and by metal detector users have thus far been formally identified and catalogued. It would be extremely useful, for example, if the 203 coins found by Martin Sterry could be examined and catalogued as well as any other earlier finds that are still available to be studied. It would also be helpful if some sort of systematic programme to record future coin finds from Ariconium, could be established, particularly those recovered by fieldwalking or by metal detector users.

The practices followed by the Celtic Coin Index in this regard illustrate the advantages of systematic recording. The fact that coins from Weston-under-Penyard continue to be found but not necessarily reported to local archaeologists is attested by recent finds of Iron Age coins that have been recorded in the Index which are not on the Herefordshire Sites and Monuments Record. It is clear that the role played by the index in actively seeking to record all Iron Age coins found in Britain has resulted in a higher proportion of these finds being listed on the Index database than would have been possible without this level of initiative. 
It ought to be possible to achieve a similar level of coverage for Roman coins. One means by which this could be achieved is through regular contact with the Finds Liaison Officer for Herefordshire, Worcestershire, Warwickshire and the West Midlands. This post was established as part of the National Recording Scheme for Archaeological Objects and is funded by the Buildings, Monuments and Sites Division of the Department of Culture, Media, and Sport under their Portable Antiquities Scheme. Liaison officers are trained to identify and record coins and other objects as part of their routine duties and are expected to be in frequent communication with local archaeologists and museum curators. They also make regular contact with metal detector users in their areas and encourage them to report their finds. Since their job is to locate and record local finds, they could provide useful information about new finds from Weston-under-Penyard.

If more material from Ariconium were available for analysis, we might gain a fuller picture of how and when the town was founded, its historical evolution, and how it compares with other 'small towns' of similar size or type during the Roman period. It would also be helpful to know what influence, if any, the presence of the Roman army in the area may have had at different times on Ariconium and its immediate vicinity. The types of coins and their chronological distribution, not to mention their existence in stratified archaeological contexts, would all contribute significantly to this exercise. Without more material accurately identified and catalogued, we will continue to have only a very general notion of the town. This is a pity since it is of great potential interest.

\section{Other small finds}

\section{H. E. M. Cool}

\section{Introduction}

In total over 400 items of non-ferrous metal, glass, bone and stone items recovered from surface collection and a small amount of excavation were available for study. The following discussion and catalogue deals with all the items that can be assigned a pre-modern date either with greater or lesser certainty. Items that are not intrinsically dateable such as fragments of metal sheet, wire, rings, etc. frequently make up a large part of surface collections of this kind and these have not been presented here as little useful can be said about them. They consist of 60 assorted fragments of metal (primarily copper alloy) and two fragments of worked bone, details of which are held in archive. Selected items have been illustrated (Figs 4.37-4.41).

Some of the pieces discussed here have relatively precise spatial locations within the area of Ariconium, but the bulk of the collection lacks this information. Naturally material such as this has its limitations with respect to the sorts of questions it can answer. However, at a broad scale it is informative about the date of the occupation, about some aspects of the nature of the occupation and about the links to the rest of the province and beyond.

It has not been possible to study all the material that has been found at Ariconium. The most notable group excluded is the material from Martin Sterry's collection (Sterry 1994), but this is, to an extent, mitigated by access to drawings and photographs of some of the more important items. Furthermore where the SMR has included an identification of this material, the details are included at the end of the relevant functional sections although the descriptions provided are not detailed enough for this material to be closely identified and dated. Though some of these identifications may be incorrect, this is not thought to be too great a problem. A comparison of the identification suggested on the record and the objects catalogued here has sometimes resulted in a more precise identification, but the broad functional category identification was generally correct.

In the first part of this contribution a general overview of the material will be attempted. This is followed by a more detailed typological examination of the items, arranged by function following Crummy 1983. This provides, where possible, the date and regional affiliations the material. In the catalogue site details are given in the following order: the SMR (HSM) number; the national grid reference (where a specific location is known); the context or museum accession number as appropriate; the excavator/collector and the year recovered (or first reported). Where the item has already been published, the reference is included at the end of the entry.

\section{The date of the finds}

The bulk of the objects that can be dated and which were available for analysis belong to the Roman period. There are a small number of post-medieval and modern buckle fragments (nos 151-55), some beads (nos 61-73, 139) and a few miscellaneous metal items that seem most likely to be relatively modern. These are also some post-medieval and modern vessel glass fragments and a modern key for a clockwork mechanism (not catalogued). There are no obvious Anglo-Saxon artefacts and the only medieval objects that can be identified with any certainty are the two lead spindle whorls (nos 175-6) and a buckle (no. 151). The medieval and later objects are all of the type that can easily be lost during casual use of the site, and it seems very likely that much of the material, even where it is impossible to date it independently could well be Roman.

There are no items for which an exclusively preConquest Iron Age date can be advanced, though it should be noted that the polychrome beads (nos 76-7) appear to have a lifespan that may start in the 1 st century BC. There may, however, be at least one considerably earlier find. The copper alloy spearhead tip (no. 231) seems most unlikely to be of Roman date and the possibility must exist that this is a Bronze Age piece. This need not necessarily indicate occupation of that date on the site. Prehistoric implements, some of considerable antiquity, are noted from time to time 
on Roman sites (Henig 1984, 188) where they must have arrived due to deliberate collection. Presumably they may well have had religious, ritual or magical significance for the Romano-Britons who collected them.

Occupation during the second half of the 1 st century is indicated by several beads (nos 41-43), and the enamelled terret (no. 223). A slightly larger group of material can be dated later 1 st to the earlier 2 nd century. Many of these items are personal ornaments such as two hairpins (nos 1-2), an intaglio (no. 13), a glass bangle (no. 22) and several beads (nos 42-6). Other material of this date includes the frit melon beads (nos 37-40), a fragment of a glass jug (no. 186), five glass counters (nos 202-6), two keys (nos 233-4) and a lorica segmentata fitting (no. 224).

Material belonging to the mid to late 2 nd century and into the 3rd century is also well represented. Personal ornaments and equipment include intaglios (nos 14-5), finger rings (nos 17-9), bracelets (nos 28-9), beads (nos 85-6, 118, 127, 129-30 and 131), nail cleaners (nos 156-64) and possibly one of the bracelets (no. 32). Metal and glass vessels from this period are also represented (nos 178 and 181-4). The bone counters (nos 208-11) and the military fittings (nos 225-6) also belong to this period, though the counters may have continued in use into the 4 th century.

Late Roman material of the later $3 \mathrm{rd}$ and 4 th century can primarily be recognised amongst the personal ornaments. Hairpins (nos 3-8), finger rings (nos 20 and 235), some of the bracelets (no. 35 and probably nos $23-7$ and 34), beads (nos 78-84, 87-117, 119-26, 128, 132-3, 135-8, 140-4 and 146), and the necklace fastener (no. 147), can all be assigned to this broad period. Some of the glass vessel fragments (nos 198-201) and the pewter jug (no. 179) are also of 4th century date. It is very likely that the ivory bangle (no. 36), the samian spindle whorl (no. 170) and the polychrome counter (no. 207) indicate occupation in the later 4th century.

The bulk of these dateable items belong to the broadly defined fieldwalking sites. Some, however, do have more precise find spots. Jack's main trench (Jack 1923; HSM 16780 ) produced one item of purely 1 st century date (no. 45 ), two of the 1 st to 2 nd centuries (nos 186 and 206), ten of the later 2nd to $3 \mathrm{rd}$ centuries (Nos 17-8, 178, 183-4, and 208-212) and five of the later 3rd to 4th centuries (nos 5-8 and 35), of which one (no. 35) can be assigned to the later 4th century. Dateable finds were less prolific on other sites. Three of Patrick Garrod's trenches (Garrod 1967; HSM 23547, 23548 and 23551) each produced a single find belonging to the 1 st to 2 nd centuries (nos 22, 77 , and 224) whilst recording on the Welsh Water pipeline to the west of the scheduled area (Jackson, Hancocks and Pearson 1999; HSM 6097) produced three items of late 3 rd to 4 th century date (nos 24, 33, and 143).

\section{The nature of the occupation}

In general the range of finds found at Ariconium is typical of that found on many urban and rural sites in the south and does not hint at any particular specialisations. There are, however, indications of a military presence, of the production of copper alloy artefacts and, speculatively, of the presence of temple.

Though the lorica segmentata fitting (no. 224) is of a type that was in use in the middle of the 1 st century and could thus have been associated with a military presence as part of the initial conquest of the area; the belt plate (no. 225) and mount (no. 226) are mid 2nd to 3rd century forms. All pieces could have been in use at the same time during the mid 2nd century and might well relate to a small military detachment at Ariconium at that time. If so, it would fit the pattern noted by Bishop (1991) who suggests the 2 nd and 3rd century military finds often recovered in towns in the notional 'civilian' zone relate to the presence of soldiers carrying out policing and similar tasks.

The Palmer collection contains several fragments of casting waste (nos 276-80), a fragment that may have been a runner (no. 274) and numerous offcuts and trimmings from cast and sheet items (nos 289-300). A possible sprue came from HSM 10008 (no. 275) and there were also numerous fragments of casting waste (nos 281-8) and offcuts (nos 301-5) recovered during the DAG 1984-9 fieldwalking at a variety of sites. By itself this material is not inherently dateable, but the presence of an unfinished Colchester one-piece brooch (Gloucs. Mus. A6282; Mackreth: Catalogue no. 9) suggests that at least some may relate to mid 1 st century production of copper alloy objects. The widespread recovery of such debris, however, suggests that it may represent many different episodes of metal-working.

The possible presence of a temple is far more speculative. It may, however, be noted that the copper alloy 'spearheads' have been recovered (nos 230-32). These cannot have been functional weapons, but by analogy to other temple sites they may have been votive objects.

\section{Ariconium in context}

During the earlier Roman period, it is often possible to identify specifically south-western forms that are rarely found in the east or north of the province (see Cool 1991, fig. 17 for a typical distribution). Such a phenomenon is especially noticeable amongst personal ornaments. Unsurprisingly, Ariconium has produced a number of finds that fall into this category, showing that the site was well embedded in the regional economy, with its inhabitants sharing styles of dress and ornamentation with neighbouring communities. Regional fashion can be seen in one of the hair pins (no. 2), an earring (no. 11), finger rings (nos 17-8) and two bracelets (nos 32 and 35). The use of opaque yellow glass to make a bangle (no. 22) and bead (no. 7) might also be another manifestation of a local preference. Many of the other finds can be more widely paralleled suggesting the site was also part of the national exchange networks for much of the Roman period. The polychrome glass counter (no. 199) indicates that these 
national links must have lasted into the later 4th century, as does the ivory bracelet (no. 35) which obviously cannot be a local product.

Many of the finds are of the middling sort, reflecting a comfortable rather than a luxurious lifestyle. Some items, however, do indicate that as least some inhabitants had access to more expensive items. The escutcheon (no. 172) indicates the presence of a copper alloy vessel of some elegance, and ivory, used for a bracelet (no. 36) and possibly a counter (no. 216), has always been a luxury item.

\section{Catalogue and discussion of the small finds}

Personal ornaments other than brooches (Figs 4.37 and 4.38)

HAIRPINS (FIG. 4.37)

In total eight hairpins are known from the site, four of metal and four of bone, and all are common forms. Two of the metal ones can be dated to the 1 st to 2 nd centuries. The first (no. 1) is an example of the widespread form with a head formed of grooves cut into the top of the shank (Cool 1991, 154 Group 3A), while the second (no. 2) belongs to a type that has a more restricted distribution range in the south-west centred on the Severn estuary (Cool 1991, 164 Group 13). The two other metal pins and all the bone examples are late Roman forms which were probably most numerous in the 4th century. nos 3-4 both have faceted cubic heads (Cool 1991, 164 Group 15), nos 5 and 6 have spherical heads (Crummy 1983, 21 type 3; Greep 1995, 1117 Types B1.1 and B1.6 respectively). The more nailshaped head of No. 7 would be included by Crummy in her Group 3, but is assigned by Greep $(1995,1118)$ to his type B2.1. The final example (no. 8) has a head decorated with multiple collars (Crummy 1984, Type 3; Greep 1995, 1119 Type B2.2).

1. Hairpin; copper alloy. Head of same diameter as circularsectioned tapering shank. Head with diamond-shaped pointed finial with 3 cordons above and below barrelshaped unit. Length $91.5 \mathrm{~mm}$, section 2.5mm. HSM 23571; Gloucs. Mus. A3707; 1870 Palmer Coll.

2. Hairpin; copper alloy. Hemispherical knob head with hourglass cordon below, knob head vertically grooved; tapering shank. Length 86mm. HSM 16780; SO 64672405; Jack 1922 (Not seen, missing from Heref. Mus. Coll. and catalogued from publication: Jack 1923, 24, pl. 12 fig. 5.). Not illustrated.

3. Hairpin; copper alloy. Diamond and triangle faceted head, triangular facets are 4-sided due to diamond facets not meeting accurately; tapering oval-sectioned shank. Length $58 \mathrm{~mm}$, head section $3.5 \mathrm{~mm}$. HSM 23571; Gloucs. Mus. A1630; 1870 Palmer Coll.

4. Hairpin; copper alloy. Short diamond and triangle faceted head; circular-sectioned broken shank. Length $28 \mathrm{~mm}$, head section $3.5 \times 3 \mathrm{~mm}$. HSM 23571; Gloucs. Mus. A24294; 1964/6 Garrod.

5. Hairpin; bone. Spherical knob head, slightly pointed tip; expanded shank. Length 90mm. HSM 16780; SO 64672405; Heref. Mus. 7639/10; Jack 1922.
6. Hairpin; bone. Ovoid knob head with pointed top; expanded shank. Length 84mm. HSM 16780; SO 64672405; Heref. Mus. 7639/7; Jack 1922.

7. Hairpin bone. Flat-topped conical head; expanding shank. Length 84mm. HSM 16780; SO 64672405; Heref. Mus. 7639/12; Jack 1922.

8. Hairpin; bone. Oval-sectioned flat-toped tapering shank with 2 grooves below head. Length 80mm. HSM 16780; SO 64672405; Heref. Mus. 7639/11; Jack 1922.

Jack's excavations also produced four other recorded bone pins that have not been available for study (HSM 16780).

EARRINGS (FIG. 4.37)

Four small penannular copper alloy rings are most likely to be simple earrings. Nos 9-10 are undecorated rings with the characteristic opposed blunt and pointed terminals (Allason-Jones 1989a, 2 Type 1). This is the most numerous earring form and was in use throughout the Roman period. nos 11 and 12 have the same basic form but are decorated. In the case of no. 11 this consists of a unit of transverse grooves, a variant which Allason-Jones (1989a, 3 type 2b) notes has a concentration in the Bristol channel area. It does not appear to be closely dateable. No. 12 has zigzag decoration and a late 2 nd to early 4 th century date has been suggested for the variant (ibid. 5 type $2 \mathrm{~g}$ ).

9. Earring; copper alloy. Penannular; lentoid section; one rounded end, one blunt end. Internal diameter $11.5 \mathrm{~mm}$, section 1x2mm. HSM 23571; Gloucs. Mus. A24296; 1964/6 Garrod. Allason-Jones 1989a, 70, no. 114. Not illustrated.

10. Earring; copper alloy. Penannular; oval section; tapering from blunt end. Internal diameter $13.5 \mathrm{~mm}$, section 2x2.5mm. HSM 23571; Gloucs. Mus. A1623; 1870 Palmer Coll. Allason-Jones 1989a, 70, no. 115. Not illustrated.

11. Earring; copper alloy. Circular-sectioned penannular ring, extant terminal blunt with notched decoration, other broken. Diameter $15 \mathrm{~mm}$, section 1.5mm. HSM 23571; Gloucs. Mus. A1651; 1870 Palmer Coll.

12. Earring; copper alloy. Penannular; triangular-section; outer edge decorated along length with notches forming zigzag. Internal diameter $13 \mathrm{~mm}$, section 2mm. HSM 23571; Gloucs. Mus. A1624; 1870 Palmer Coll. Allason-Jones 1989a, 70, no. 116 .

INTAGLIOS AND FINGER RINGS (FIG. 4.37)

The Palmer collection includes two orange cornelian intaglios (nos 13 and 14). In general such intaglios can be assigned to a broad 1 st to 3 rd century date as the signet rings which would have held them were going out of use during the 3 rd century. Cornelian appears to have remained popular throughout this period (Henig 1974, 41), but the shape of the stone may well be chronologically sensitive, and it has been shown that those with convex faces (no. 13) were commoner in the 1 st to 2 nd century whilst those with flat faces (no. 14) were commoner in 2 nd to 3 rd century contexts (Zienkiewicz 1986, 121). The subjects on these two intaglios are of some interest. Fortuna (as seen on no. 13) was a very popular choice (Henig 1974, 99), but the gladiator (seen on no. 14) was a most unusual subject (ibid. 

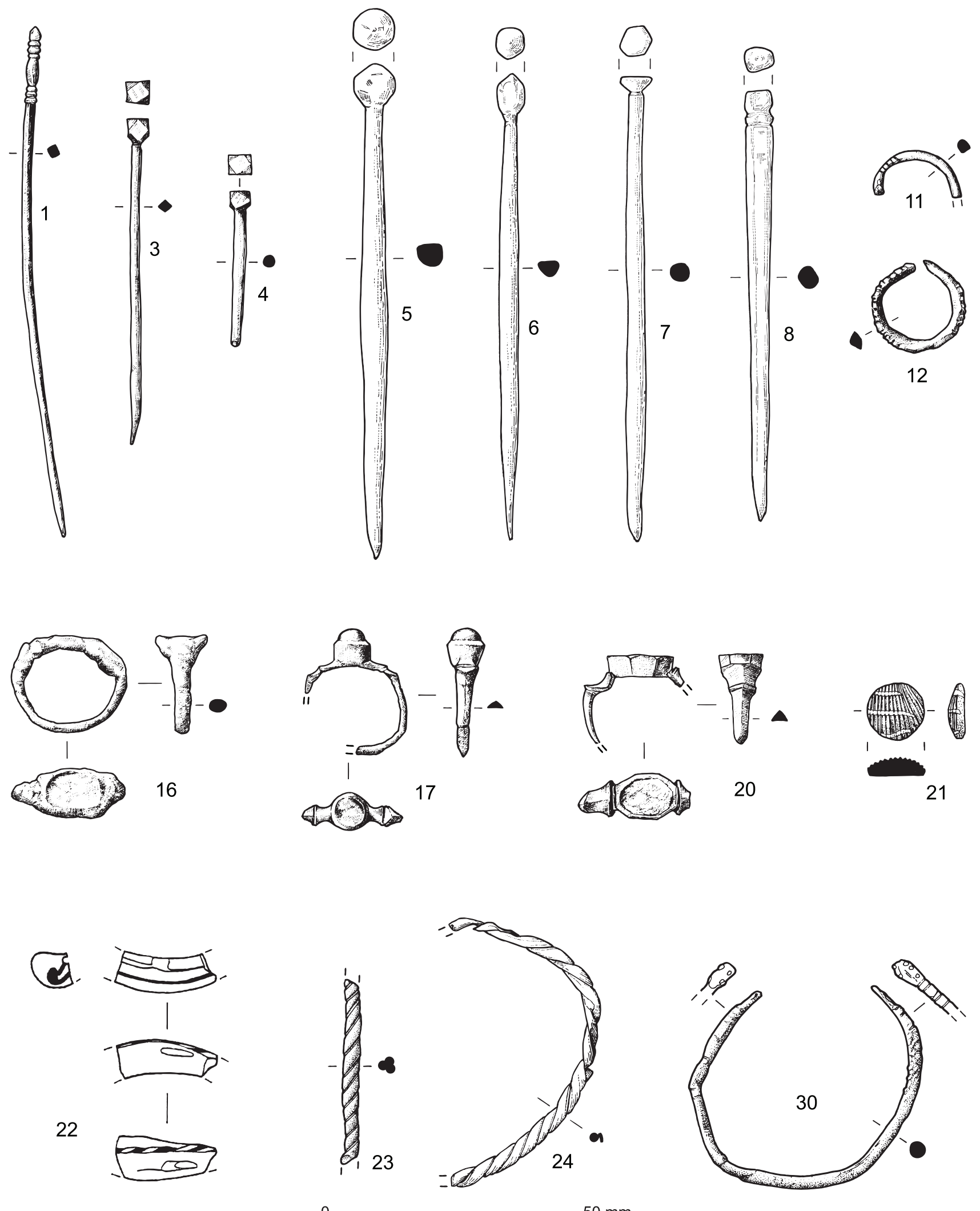

Figure 4.37. Other small finds (Personal ornaments) 
148). This suggests that at least one inhabitant or visitor to Ariconium in the 2 nd to 3 rd century could have had a more than casual interest in gladiatorial games.

No. 15 probably belonged to someone of lower social standing than the owners of nos 13 and 14 as it is part of the family of moulded glass intaglios thought to be based on radiate coinage which Henig $(1974,164)$ suggests represents the spread of the Roman habit of using intaglios to the rural peasantry during the 3 rd century.

The iron finger ring (no. 16) is an example of the type of finger ring that such intaglios could have been used in (Henig 1974, fig. 1 ring type II). That it is made of iron suggests a 1 st to 2 nd century date, and also an understanding of the Roman sumptuary laws (ibid. 47) governing the right of different classes of society to wear different metals.

Three examples of copper alloy finger rings with constricted shoulders, circular box bezels and domed blue/ green glass settings are now extant in the Ariconium finds (nos 17-19) and it is possible that a fourth was originally present. Nos 17 and 18 were found together during the 1922 excavations and the original publication indicates that three rings were found and implies that they were of the same type (Jack 1923, 24). The third cannot now be traced. In general constricted shoulder rings have a 2 nd to 3rd century date range (Cool 1983, 251). Examples closely similar to the Ariconium ones have been found at Silchester in a bank with material dated to AD 190-210 (Cotton 1947, fig. 9.5) and at Verulamium in a destruction deposit containing late 3rd century material (Cotton and Wheeler 1953, fig. 1.10). This suggests the variant may have had a late 2 nd to 3 rd century floruit. These four examples from Ariconium strengthen the possibility that this may primarily be another south-western variant. Of the 14 other examples known to this author, 11 come from the south-central and south-west regions (Silchester, Westbury (Wiltshire), Dorchester (Dorset) Ashley Camp (Hampshire) Cirencester, Woodeaton - Cool 1983, 1057 nos 34-6, 38-9, 44-6, 48-9; Uley - Woodward and Leech 1993, 173 no. 7 ) and only three from further away. The example from Verulamium already cited, one from Weeting Norfolk (Cool 1983, 1059 no. 47) and a third from Canterbury (Brockley et al. 1995, 1001 no. 199).

The other ring catalogued here has an octagonal bezel and scalloped shoulders (no. 20) and comes from a more widespread type in use during the 4 th and possibly during the 3rd centuries as well (Cool 1983, 262 type XVIA). A finger ring with a key attached (no. 235) will be discussed below.

Finally the unusual black glass setting (no. 21) has been catalogued here as it would have been an ideal size to be a finger ring setting. However, it is very difficult to parallel amongst securely stratified Roman assemblages and it is possible that it is not of Roman date.

13. Intaglio; cornelian, Convex oval with bevelled edge. Two Fortunas (or Fortuna and Concordia). One stands front and faces left (Cornucopia in left hand; right arm raised), the other faces right (cornucopia in right hand left arm lowered). Between them is an altar. Dimensions $13 \times$ $12 \times 3.5 \mathrm{~mm}$. HSM 23571; Gloucs. Mus. A1735; 1870 Palmer Coll. Henig 1974, 48 no. 339. Hills 1871, 207, no. 48 . Not illustrated.

14. Intaglio; cornelian. Flat oval with bevelled edge. Gladiator advancing towards the right, head turned to left; holding shield in left hand. Dimensions $13 \times 8 \times 1.5 \mathrm{~mm}$. HSM 23571; Gloucs. Mus. A1739; 1870 Palmer Coll. Henig 1974, 70 no. 491. Hills 1871, 207, no. 49. Not illustrated.

15. Intaglio; blue glass. Flat oval. Fragmented design perhaps intended to represent a human figure. Dimensions $7 \times 6$ $\times 2$ mm. HSM 23571; Gloucs. Mus. A1737; 1870 Palmer Coll. Henig 1974, 79 no. 573. Hills 1871, 207, no. 51. Not illustrated.

16. Finger ring; iron. Circular-sectioned hoop expanding to empty oval bezel. Broken in two pieces. Diameter 21 $\times 18 \mathrm{~mm}$. Hoop section 2, bezel section 9x2mm. HSM 23551; SO 64672389; A/67, Tr. A1, context 1, sf. 2; Garrod 1967.

17. Finger ring; copper alloy and glass. Triangular-sectioned hoop expanding slightly towards shoulder; bevel across hoop at junction with constricted shoulders; circular box bezel with domed blue/green glass setting. Approximately one-third of hoop missing. Diameter (hoop) $18 \mathrm{~mm}$. Diameter bezel $7 \mathrm{~mm}$. Hoop section $2 \times 1.5 \mathrm{~mm}$. HSM 16780; SO64672405; Heref. Mus. 7639/25; Jack 1922; Jack 1923, 24, pl. 12 fig. 4.

18. Finger ring; copper alloy and glass; bezel and shoulders only. Rectangular-sectioned shoulders; circular box bezel with domed blue/green glass setting. Diameter of bezel 7mm. HSM 16780; SO64672405; Heref. Mus. 7639/25; Jack 1922; Jack 1923, 24. Not illustrated.

19. Finger ring; copper alloy and glass. Circular box bezel with broken stumps of shoulders; domed blue/green setting. Diameter 6mm. HSM 23571; Gloucs. Mus. A1738; 1870 Palmer Coll. Hills 1871, 207, no. 52. Not illustrated.

20. Finger ring; copper alloy. Triangular-sectioned hoop expanding to scalloped shoulders with ridge against oval octagonal box bezel now filled with decayed enamel appearing creamy coloured. Majority of hoop and one shoulder missing. Diameter of bezel $10 \times 8 \mathrm{~mm}$. HSM 10008; SO64852383; DAG Fieldwalking 1984-9.

21. Setting; black glass. Plano-convex with ribbed upper surface resembling cockle shell; with 3 opaque white streaks crossing ribs. Diameter $10 \mathrm{~mm}$, thickness $3 \mathrm{~mm}$. HSM 23571; Gloucs. Mus. A1707; 1870 Palmer Coll. Hills 1871, 207, no. 52.

\section{BANGLES AND BRACELETS (Figs 4.37 AND 4.38)}

Bracelets were primarily a late Roman fashion in Britain but one noticeable exception is the annular glass ring, commonly called a bangle. These were in use during the 1 st to 2 nd centuries. Quite what their function was remains unknown as, though some were large enough to fit over the hand or foot, others are too small (Price 1988, 354). The single example from Ariconium (no. 22) will be discussed here with the caveat that it may have served quite a different purpose or have been worn in a different manner than the rest of the bracelets considered.

No. 22 is an example of Kilbride-Jones (1937/8) Type 
2 bangle, a common form clearly in use before AD 75 (Harden and Price 1971, 366; van Lith 1978-0, 119). This example, however, is most unusual because the ground colour is an opaque yellow which appears unparalleled. Opaque yellow glass was used for a relatively uncommon bangle variant (Kilbride-Jones 1937/8, 381 Type 3B), but that has a southern Scottish distribution and glossy surfaces (Price 1989, 133) unlike the matt surface seen here. Possibly this bangle is the product of a local industry and it may be relevant that opaque yellow glass was used for a bead type thought to have originated at Meare which is dated to the mid 3rd century BC to the mid 1 st century AD (Guido's 1978, 76, class 8). It is a colour rarely encountered in glass products of Roman date, though evidence of the melting of opaque yellow glass has been found in a late 3 rd to early 4th century context at Catsgore, Somerset.

Twelve fragments (nos 23-35) can be identified as copper alloy bracelets with more or less certainty. Of these five (nos 23-7) are from multi-strand cable twist bracelets, the commonest bracelet type in Britain. These were in use from at least the early 2 nd century but were most numerous in the 4th century (Cool 1983, 120).

Penannular bracelets were another category that appears to have been used prior to the 4th century, when they often had snakeshead terminals. nos 28-9 are of especial interest as they have the well-moulded head of the Asclepian snake and clearly belong to the same family of penannular snakeshead bracelets as those present in the Snettisham hoard (Johns 1997, 111-2 nos 312-6). A mid 2 nd to 3 rd century date would thus be appropriate. These two bracelets appear to have been found together. In antiquity one head had been snapped off each and the bracelets had been flattened to form a staff or wand-like object. Bracelets of this type are rare as site finds but pairs do occur repeatedly in hoards, and there are some grounds for thinking they might have been some sort of cult paraphernalia rather than fashionable jewellery (Cool 2000a). Certainly the re-use of the pair from Ariconium might suggest they had some significance to the owners other than merely as ornaments.

No. 30 is a simple variant of a snake bracelet where the heads are moulded on the upper face and flat on the underside. These were generally in use during the 2nd century (Johns 1997, 37), though it may be noted that a very similar one was found at Wilcote in a context which, while it had some redeposited early material, was in the main deposited during the period AD 315-360 (Hands 1998, 62 no. 92). The simple flattened terminal of no. 31 may also have been intended as a snakes' head but it is not sufficiently diagnostic to be closely dated, nor indeed certainly identified as a bracelet. Despite the corroded and obscured surfaces of no. 32, the typical dotted decoration that can be made out suggests it may well have come from a type of cast penannular bracelet that has a distribution centred on the southern side of the Severn Estuary, though it is slightly wider than the other examples. These have been found at Kingsholm, Gloucester, Sea Mills and Brockworth
(Cool 1983, 207 Group XXXIX). The last mentioned was found in a ditch filling during the second half of the $3 \mathrm{rd}$ century (Rawes 1981, 66, fig. 9.9).

No. 33 might also have been from a penannular bracelet but is not sufficiently diagnostic for the identification to be secure.

Expanding bracelets (such as no. 34) are primarily a late 3rd and 4th century form though they are known earlier (Cool 1983, 132 Group III). It is very striking that the only copper alloy bracelet which is undoubtedly of 4th century date on typological grounds is no. 35 . When complete it would have resembled a perforated bracelet found in a grave dated to AD 360-80 at Lankhills Winchester (Clarke 1979, 306; fig. 99.566). This belongs to a type that seems only to have been found in southern Britain (Swift 2000, 127,310 , fig. 164) and is an uncommon type of bracelet. This too seems to be predominantly a south-western type. Of the four quoted by Swift only an example from Canterbury falls outside of that region. This distribution is repeated by additional examples which have precisely the same decorative scheme as the Ariconium fragment as they have been found at Nettleton (Wedlake 1982, 210, no. 45), Lincoln (Mann 1999, 149, no. 23) and possibly Cirencester (Viner 1986, 111, no. 67). Unfortunately none of these come from closely dated contexts. Most 4th century bracelet types occur in large numbers on a wide range of sites. The absence of these common types is a curious feature of the Ariconium assemblage. Though they are rarely substantial, it could have been expected that some would have been noticed in the various periods of collection at the site, especially given the small size of many of the fragments recovered (see for example the single strands of a cable twist bracelet Nos 26 and 27).

The final bracelet (no. 36) is another uncommon find. It is an example of an ivory bracelet, which as staining at one end demonstrates would have been fastened by a copper alloy clasp. Bone bracelets such as these were never as numerous as copper alloy bracelets, but they appear to have become increasingly common in the later 4th century. The largest single collection from a British site was recovered from the Lankhills School cemetery (Clarke 1979, 313) and where the graves could be relatively closely dated, the majority post-dated the mid 4th century. They are also found in very late 4 th or 5 th century assemblages such as at Filey (Ottaway et al 2000) and Birdoswald (Summerfield 1997, 272, no. 10). Ivory bracelets, of course, are even rarer, but one was found at Barnsley Park in a context dated to c. AD 375-81 (Webster and Smith, 1982, 107, fig. 24.25), suggesting that their use might have been contemporaneous with the bone ones.

22. Bangle; glass. D-sectioned (broken); matt opaque yellow ground with voids and streaks of translucent dark brown glass internally; central marvered cable of single light translucent blue and opaque white rods (right-hand twist). External diameter c. $65 \mathrm{~mm}$ ( $8 \%$ of circumference). Section depth 6mm. HSM 23547; SO 64682377; A/67 Tr. AII, context 5, sf 5; Garrod 1967. 
23. Bracelet; copper alloy. Cable twist; 3 strand, left-hand twist; both ends broken. Length $32 \mathrm{~mm}$. Section $3 \mathrm{~mm}$. HSM 23571; SO 64202375; HSM 5324; F-DAG 87/9.

24. Bracelet; copper alloy. Cable twist, 3 strands, right-hand twist; both ends broken. Length $c$. $70 \mathrm{~mm}$. Section $3.5 \mathrm{~mm}$. HSM 6097; SO 64102371; Tr. 4, context 405; Jackson 1993.

25. Bracelet; copper alloy. Cable twist, 2 strand, left-hand twist, D-sectioned overall; both ends broken. Length $c$. $50 \mathrm{~mm}$. Section $4 \times 3.5 \mathrm{~mm}$. HSM 5324; SO 6435385; A/67 unstratified; Garrod 1967. Not illustrated.

26. Bracelet; copper alloy. 1 strand curved wire from cable twist bracelet. Length $19 \mathrm{~mm}$. HSM 23571; Gloucs. Mus. A1656; 1870 Palmer Coll. Not illustrated.

27. Bracelet; copper alloy. One strand from left-hand twist cable bracelet of originally three strands and probably oval cross-section. Length 22mm. HSM 21376; SO 64602400; DAG 1991, unstratified.

28. (see 29 below).

29. Bracelet; copper alloy. Probably D-sectioned, one end broken; other a moulded snakes' head. Outer face decorated by grooves to imitate scales. HSM 21376; SO 64502414; Sterry 1994. Two examples. Not illustrated.

30. Bracelet; copper alloy. Penannular; circular-sectioned hoop with flat oval terminals; one terminal has 5 small mouldings, other has 3 ; traces of grooves around hoop behind terminal. Hoop bent slightly out of shape. Diameter c. $42 \mathrm{~mm}$. Section diameter $2.5 \mathrm{~mm}$. HSM 21376; SO 64722401; HSM 21376; F-DAG 87/9.

31. Bracelet?; copper alloy. Oval-sectioned hoop, 1 end broken, other tapering to blunt slightly flattened terminal. Diameter c. $65 \mathrm{~mm}$ (c. $18 \%$ of circumference). Section 5.5 $\times 4 \mathrm{~mm}$. HSM 23571; Gloucs. Mus. A1683; 1870 Palmer Coll. Not illustrated.

32. Bracelet; copper alloy. Rectangular-sectioned cast curved band; both ends broken; surfaces corroded and obscured. Upper face has groove parallel to each edge with punched decoration centrally, at least one dotted lozenge possibly with ring and dot at one apex. Length $24 \mathrm{~mm}$. Section 13 $\times 2.5 \mathrm{~mm}$. HSM 5324; SO 6435385; surface find; Garrod 1967.

33. Bracelet(?); copper alloy. Rectangular-sectioned with slightly curved upper face, one end squared off, other tapering to point. Now bent into penannular ring. Present diameter 20mm. Section $4 \times 1 \mathrm{~mm}$. HSM 21368; unlocated; Heref. Mus. 9379/2. Not illustrated.

34. Bracelet; copper alloy. Circular-sectioned wire with expanding joint of at least 4 turns on one side, point covered by sheet capping. Incomplete in 3 fragments and bent out of shape. Current diameter $41 \mathrm{~mm}$. HSM 6097; SO 64102371; Tr. 4, context 405; Jackson 1993.

35. Bracelet; copper alloy. Rectangular-sectioned, widest to wrist, 2 joining fragments, outer edges broken. Groove parallel to each long edge with nicks running from edge to groove; 4 large circular perforations centrally, between the alternate 2 smaller circular perforations and a group of 9 small circular perforations arranged in a diamond of 5 rows; one broken end has neither beyond the large perforation and is possibly a chipped top/bottom butt joint. Present length $c$. $60 \mathrm{~mm}$. Section $13 \times 1 \mathrm{~mm}$. HSM 5324; SO 64302388; Gloucs. Mus. A24322; Garrod 1964/6.

36. Bracelet; ivory. Tall D-sectioned; both ends broken; $c$. one-third of circumference remaining. 1 end broken straight across and green stained, groove immediately behind break and probably snapped off at a similar groove. Diameter $70 \mathrm{~mm}$. Section $4 \times 3 \mathrm{~mm}$. HSM 16780; SO 64672405; Heref. Mus. 7639/9; Jack 1922.

An additional copper alloy bracelet is noted in the Sterry collection (HSM 21376).

Beads and necklaces (Fig. 4.38)

Four frit melon beads (nos 37-40) have been included in this section though it is doubtful whether they were personal ornaments in the same sense as the rest of the beads catalogued here. They are a very common find on 1 st to mid 2 nd century sites, especially military ones, and it has occasionally been suggested that they were horse harness decorations (Fox 1940, 132). This seems to have been confirmed by the discovery of such beads decorating a metal neck collar in a horse burial at Krefeld-Gellep (Pirling 1997, 58, grave 3960).

Most of the remaining beads have already been studied as part Mrs. Guido's definitive work on the prehistoric and Roman beads of Britain and they will be summarised according to her scheme (Guido 1978).

Three of the beads are deep blue and decorated with opaque white trails. The first (no. 41) with spirals is a Guido Group 2 whilst the others (nos 42-3) with waves are Guido Group 5a. The former is a disparate group without close dating, the latter is assigned a long date range from the Iron Age through into the post Roman period though it is suggested (Guido 1978, 63) that the strongly coloured blues are a feature of the Roman period. This would suggest that all three of these deep blue beads were of Roman date. Within well-stratified large assemblages of beads, it is noticeable that beads of Guido Group 5a tend to be found in 1st century contexts. For example at the Caerleon fortress baths with stratified groups ranging from those dated to AD 75-85 to 160-230, the five examples present do not occur in any contexts post-dating AD 110 (Brewer 1986, 147). At the fort and vicus of Castleford where the majority of the beads came from contexts of $c$. AD 140-180, the only example found came from a context of c. AD 71-86 (Cool and Price 1998, 181). A mid to late 1 st century date would thus seem most appropriate for nos 42-3 and probably also for no. 41. Certainly that would be a period when much deep blue would have been available for bead making as deep blue glass vessels were common at the time.

A similar case for a primarily 1 st century date could be made for the blue/green annular beads of Guido Group 6ii, represented by three beads (nos 44-6), and the deep blue annular beads of Guido Group 6iv (nos 48-56). Again both are present in the Caerleon and Castleford assemblages but only in the 1st century contexts (Brewer 1986, op cit.; Cool and Price 1999 op cit.).

Three other annular beads are also present. No. 47 is an example of Guido Group 6iiib, no. 57 is a Guido Group 6ix and no. 58 of the rare colourless Group 6x. It is not possible 

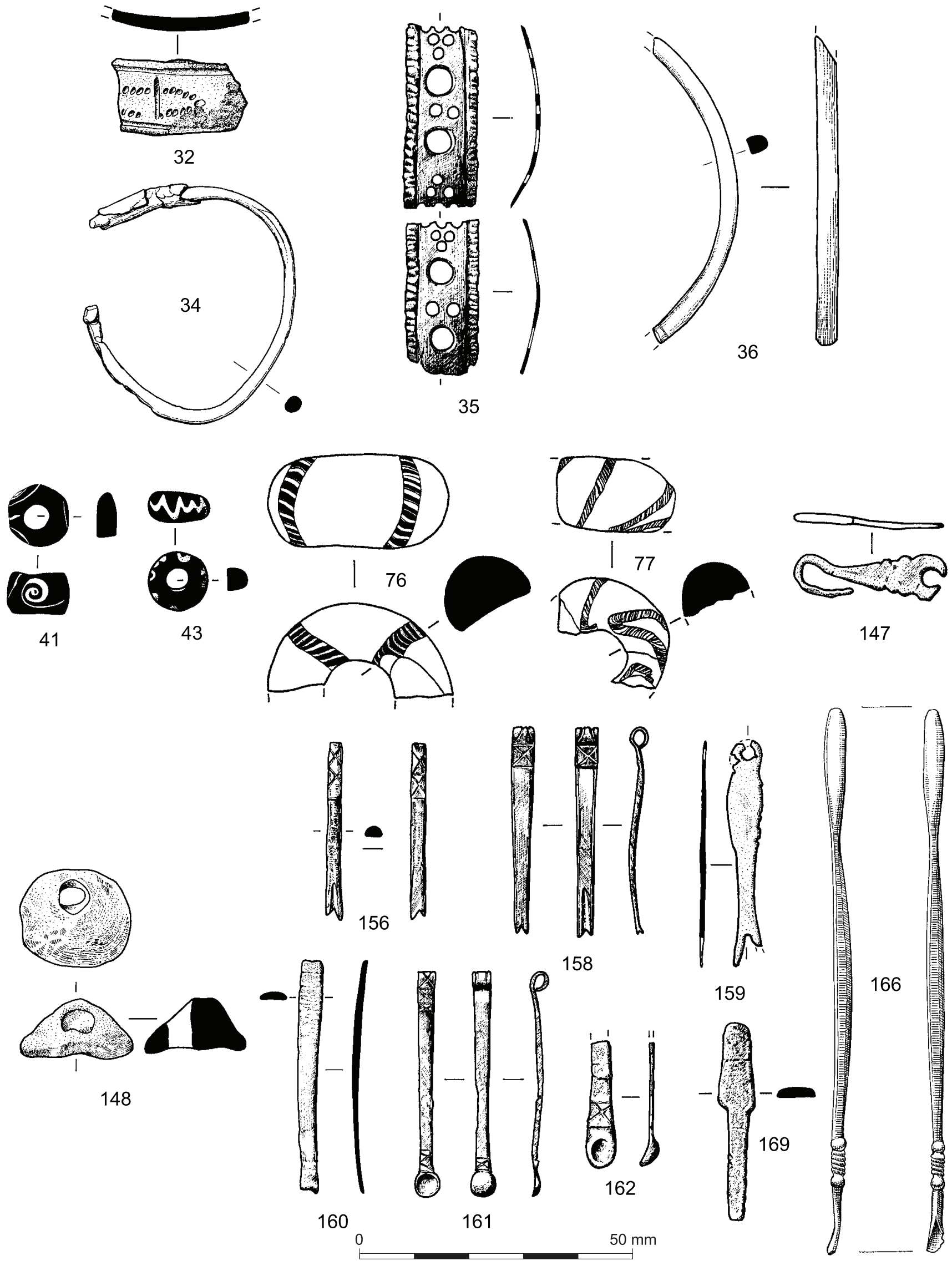

Figure 4.38. Other small finds (Personal ornaments and toilet equipment) 
to assign anything bit a very broad date to these. The only example of a colourless annular bead that Guido cites is from an Iron Age site (Guido 1978, 69). Such colourless beads have rarely been reported from Roman sites, but with the ubiquity of colourless vessel glass during the 2nd and 3 rd centuries it would be surprising if this 'colour' wasn't occasionally used for beads making at this time.

Globular monochrome beads are numerous in the Ariconium collections. There are two examples of the blue/green Group 7ii (nos 59-60), four of the deep blue Group 7iv (nos 61-64), nine of the turquoise Group 7v (nos 65-73) and one of the 'black' Group 7viii (no. 74), and to these may be added a globular bead made in dark grey stone (no. 75). The blue/green examples (nos 59-60) are almost certainly Roman, but cannot be more closely dated. Mrs. Guido included nos 61-73 in her schedules but notes for both groups that some in the schedules may not be ancient (Guido 1978, 70). All of the Ariconium examples are in very distinct bright shades and I have never seen any Roman glass vessels in these shades, nor have I encountered any similar beads in securely stratified Roman contexts. I am inclined, therefore, to consider that nos 61-73 could well be of relatively recent date though clearly as they are part of the Palmer collection this must be of the mid 19th century or earlier.

Ariconium has also produced two examples (nos 76-7) of the large annular beads decorated by polychrome cables classified by Guido as her Class 9 for which she suggests a floruit of the 1 st century $\mathrm{BC}$ to the early 2 nd century AD. No. 76 clearly belongs to her subdivision Class 9A but no. 77 is most unusual as the ground colour is an opaque yellow. Mrs. Guido's Class 9C is described as having a brown or golden brown ground, a description which would not normally include opaque yellow. The unusual use of the opaque yellow might be another indication of a local industry in the vicinity suggested in connection with the bangle no. 22 .

Sixty-five beads from the Palmer collection (nos 78-142) are currently preserved as a string of beads but there is no information about whether they were found together or whether the current arrangement stems from an attempt to keep them all safely together. One of the beads (no. 139) is a most unusual long faceted biconical form which may well be of relatively recent date. The majority of the rest are standard late Roman forms (Guido 1978, 91-102) but there are also several for which a later 2 nd century date would be appropriate.

There is a single example of a gold-in-glass bead (no. 85 ) for which a late 2 nd to early 3 rd century date can confidently be advanced (Brewer 1986, 151). The bright green pentagonal bead (no. 131) may belong to the variant lined with opaque yellow (its position on the string makes this difficult to advance with certainty). These have been found in a mid to late 2 nd century context at Caerleon (Guido 1978, 218) and in a well fill of the late 2nd to early 3rd century date at Leicester (Cooper 1999, 260, no. 76), while an example from the rampart at Malton might even suggest an early 2nd century date (Price and Cottam 1997, 130, no. 61). The types on the string represented by nos $86,118,127,129-30$ and 134 were all present in the mid 2nd century assemblage at Castleford (Cool and Price 1998, 181) and the late 2nd to 3rd century fortress drain deposit at Caerleon (Brewer 1986, 147).

In addition to the beads on the string, there are four individual finds of beads similar to those on the string (nos 143-6). Of these the hexagonal example (no. 145) could be as early as the late 1 st century, whereas the rest are likely to be of late Roman date.

Finally there is a single example of a 4th century metal fastener for a bead necklace (no. 147). These were used on bead necklaces, both those where the beads were threaded on links of wire and those which used an organic thread as on an example from a grave dated to $c$. AD 350-70 at Lankhills, Winchester. (Clarke 1979, fig. 90.363).

37. Bead; frit. Melon bead; Traces of turquoise glaze but mostly worn; wide gadroons. Diameter $18 \mathrm{~mm}$, length $16 \mathrm{~mm}$, perforation diameter 6mm. HSM 23571; Gloucs. Mus. A1773; 1870 Palmer Coll. Not illustrated.

38. Bead; frit. Melon bead; traces of turquoise glaze but mostly worn; narrow gadroons. Diameter $13 \mathrm{~mm}$, length $12 \mathrm{~mm}$, perforation diameter $7 \mathrm{~mm}$. HSM 23571; Gloucs. Mus. A1774; 1870 Palmer Coll. Not illustrated.

39. Bead; frit. Melon bead; worn appearing dark grey. Diameter $15 \mathrm{~mm}$, length $9 \mathrm{~mm}$, perforation diameter $7 \mathrm{~mm}$. HSM 23571; Gloucs. Mus. A1775; 1870 Palmer Coll. Not illustrated.

40. Bead; frit. Melon bead; Traces of turquoise glaze. Diameter $14 \mathrm{~mm}$, length $11 \mathrm{~mm}$, perforation diameter 6.5mm. HSM 23571; Gloucs. Mus. A1776; 1870 Palmer Coll. Not illustrated.

41. Bead; glass. Dark blue with 3 white spirals. Globular. Diameter $10 \mathrm{~mm}$, length $7 \mathrm{~mm}$, perforation diameter $5 \mathrm{~mm}$. HSM 23571; Gloucs. Mus. A1734; 1870 Palmer Coll. Guido 1978, 123 Group 2. Hill 1971, 207, no. 4.

42. Bead; glass. Blue with opaque white rather irregular wave. Annular. Diameter $16 \mathrm{~mm}$, length $6 \mathrm{~mm}$. HSM 23571; Heref. Mus. 7630; Jack 1922. Jack 1923, 25. Guido 1978, 129, Group 5a (not personally inspected). Not illustrated.

43. Bead; glass. Translucent deep blue with opaque white marvered wave pattern. Annular. Diameter $11 \mathrm{~mm}$, length $6.5 \mathrm{~mm}$, perforation diameter 5mm. HSM 23571; Gloucs. Mus. A1760. 1870 Palmer Coll. Guido 1978, 129, Group 5a.

44. Bead; glass. Blue/green translucent; strain cracked; wound with streaky impurities. Annular. Diameter $19 \mathrm{~mm}$, length 8mm, perforation diameter 8mm. HSM 23571; Gloucs. Mus. A1754. 1870 Palmer Coll. Guido 1978, 141, Group 6iia. Not illustrated.

45. Bead; glass. Blue/green translucent. Annular. Half extant. Diameter $16 \mathrm{~mm}$, length $7 \mathrm{~mm}$, perforation diameter $7 \mathrm{~mm}$. HSM 16780; SO 64672405; Heref. Mus. 7639/42. Jack 1922; Jack 1923, 25. Not illustrated.

46. Bead; glass. Blue/green translucent. Annular. Diameter $13 \mathrm{~mm}$, length $6 \mathrm{~mm}$, perforation diameter $6 \mathrm{~mm}$. HSM 23571; Gloucs. Mus. A1752; 1870 Palmer Coll. Guido 1978, 144, Group 6iib. Not illustrated. 
47. Bead; glass. Light green translucent; wound. Annular. Diameter $13 \mathrm{~mm}$, length $4 \mathrm{~mm}$, perforation diameter $6 \mathrm{~mm}$. HSM 23571; Gloucs. Mus. A1756; 1870 Palmer Coll. Guido 1978, 151, Group 6iiib. Not illustrated.

48. Bead; glass. Deep translucent blue; slightly oval annular. Diameter $17 \mathrm{x} 15 \mathrm{~mm}$, thickness 15 , perforation diameter 8mm. HSM 23571; Gloucs. Mus. A1757; 1870 Palmer Coll. Guido 1978, 153, Group 6iva. Not illustrated.

49. Bead; glass. Deep opaque blue; squashed globular annular. Diameter $12 \mathrm{~mm}$, thickness 8 , perforation diameter $5 \mathrm{~mm}$. HSM 23571; Gloucs. Mus. A1759; 1870 Palmer Coll. Guido 1978, 157, Group 6ivb. Not illustrated.

50. Bead; glass. Translucent deep blue. Annular. Diameter $7 \mathrm{~mm}$, length $2 \mathrm{~mm}$, perforation diameter $4.5 \mathrm{~mm}$. HSM 23571; Gloucs. Mus. A1762; 1870 Palmer Coll. Not illustrated.

51. Bead; glass. Translucent deep blue. Annular. Diameter $8 \mathrm{~mm}$, length $2.5 \mathrm{~mm}$, perforation diameter $5.5 \mathrm{~mm}$. HSM 23571; Gloucs. Mus. A1763; 1870 Palmer Coll. Guido 1978, 157, Group 6ivb. Not illustrated.

52. Bead; glass. Translucent deep blue. Annular; asymmetrical. Diameter $7 \mathrm{~mm}$, length $3 \mathrm{~mm}$, perforation diameter $4 \mathrm{~mm}$. HSM 23571; Gloucs. Mus. A1764; 1870 Palmer Coll. Guido 1978, 157, Group 6ivb. Not illustrated.

53. Bead; glass. Translucent deep blue. Annular. Diameter $7 \mathrm{~mm}$, length $2.5 \mathrm{~mm}$, perforation diameter $4 \mathrm{~mm}$. HSM 23571; Gloucs. Mus. A1765; 1870 Palmer Coll. Guido 1978, 157, Group 6ivb. Not illustrated.

54. Bead; glass. Translucent deep blue. Annular. Diameter $6 \mathrm{~mm}$, length $3 \mathrm{~mm}$, perforation diameter $3 \mathrm{~mm}$. HSM 23571; Gloucs. Mus. A1766; 1870 Palmer Coll. Guido 1978, 157, Group 6ivb. Not illustrated.

55. Bead; glass. Translucent deep blue. Annular. Diameter $6 \mathrm{~mm}$, length $3.5 \mathrm{~mm}$, perforation diameter $3 \mathrm{~mm}$. HSM 23571; Gloucs. Mus. A1767; 1870 Palmer Coll. Guido 1978, 157, Group 6ivb. Not illustrated.

56. Bead; glass. Translucent deep blue. Annular. Diameter $9 \mathrm{~mm}$, length $4 \mathrm{~mm}$, perforation diameter $4 \mathrm{~mm}$. HSM 21376; SO 64502395; DAG Fieldwalking 1984-9. Not illustrated.

57. Bead; glass. 'Black'. Annular. Diameter $12 \mathrm{~mm}$, length 4mm, perforation diameter 7mm. HSM 23571; Gloucs. Mus. A1751; 1870 Palmer Coll. Guido 1978, 164, Group 6ix. Not illustrated.

58. Bead; glass. Colourless translucent with many bubbles appearing white opaque. Annular with small central perforation. Diameter $7 \mathrm{~mm}$, length $4 \mathrm{~mm}$, perforation diameter 1.5mm. HSM 23571; Gloucs. Mus. A1761; 1870 Palmer Coll. Not illustrated.

59. Bead; glass. Translucent blue/green with many strain cracks and streaky green impurities. Globular. Diameter $15 \mathrm{~mm}$, length $11 \mathrm{~mm}$, perforation diameter $6 \mathrm{~mm}$. HSM 23571; Gloucs. Mus. A1755; 1870 Palmer Coll. Guido 1978, 167, Group 7ii. Not illustrated.

60. Bead; glass. Bright translucent blue/green. Globular. Diameter $10 \mathrm{~mm}$, length $8 \mathrm{~mm}$, perforation diameter $2 \mathrm{~mm}$. HSM 23571; Gloucs. Mus. A1753; 1870 Palmer Coll. Guido 1978, 167, Group 7ii. Not illustrated.

61. Bead; glass. Bright deep semi-transparent blue. Globular. Diameter $10 \mathrm{~mm}$, length $8 \mathrm{~mm}$, perforation diameter 3.5mm. HSM 23571; Gloucs. Mus. A1747; 1870 Palmer Coll. Guido 1978, 170, Group 7iv. Not illustrated.
62. Bead; glass. Bright deep opaque blue. Globular. Diameter $10 \mathrm{~mm}$, length $7.5 \mathrm{~mm}$, perforation diameter $2.5 \mathrm{~mm}$. HSM 23571; Gloucs. Mus. A1749; 1870 Palmer Coll. Guido 1978, 170, Group 7iv. Not illustrated.

63. Bead; glass. Bright deep opaque blue. Globular. Diameter $11 \mathrm{~mm}$, length $9 \mathrm{~mm}$, perforation diameter 3.5. HSM 23571; Gloucs. Mus. A1758; 1870 Palmer Coll. Guido 1978, 170, Group 7iv. Not illustrated.

64. Bead; glass. Opaque deep blue. Globular. Diameter $6 \mathrm{~mm}$, length 5.5mm, perforation diameter 2mm. HSM 23571; Gloucs. Mus. A1770; 1870 Palmer Coll. Guido 1978, 170, Group 7iv. Not illustrated.

65. Bead; glass. Translucent bright turquoise. Globular. HSM 23571; Gloucs. Mus. A1740; 1870 Palmer Coll. Guido 1978, 173, Group 7v. Not illustrated.

66. Bead; glass. Translucent bright turquoise; strain cracked. Globular. Diameter $13 \mathrm{~mm}$, length $11 \mathrm{~mm}$, perforation diameter 3mm. HSM 23571; Gloucs. Mus. A1741; 1870 Palmer Coll. Guido 1978, 173, Group 7v. Not illustrated.

67. Bead; glass. Translucent bright turquoise. Globular. Diameter $9 \mathrm{~mm}$, length $8 \mathrm{~mm}$, perforation diameter $3 \mathrm{~mm}$. HSM 23571; Gloucs. Mus. A1742; 1870 Palmer Coll. Guido 1978, 173, Group 7v. Not illustrated.

68. Bead; glass. Translucent bright turquoise; strain cracked and extensively chipped. Globular. Diameter $10.5 \mathrm{~mm}$, length $9 \mathrm{~mm}$, perforation diameter 2.5mm. HSM 23571; Gloucs. Mus. A1743; 1870 Palmer Coll. Guido 1978, 173, Group 7v. Not illustrated.

69. Bead; glass. Translucent bright turquoise; strain cracked. Globular. Diameter $8 \mathrm{~mm}$, length $6.5 \mathrm{~mm}$, perforation diameter 2.5mm. HSM 23571; Gloucs. Mus. A1744; 1870 Palmer Coll. Guido 1978, 173, Group 7v. Not illustrated.

70. Bead; glass. Translucent bright turquoise. Globular. Diameter $9 \mathrm{~mm}$, length $6.5 \mathrm{~mm}$, perforation diameter $3 \mathrm{~mm}$. HSM 23571; Gloucs. Mus. A1745; 1870 Palmer Coll. Guido 1978, 173, Group 7v. Not illustrated.

71. Bead; glass. Opaque turquoise. Globular. Diameter $8 \mathrm{~mm}$, length $5 \mathrm{~mm}$, perforation diameter $2 \mathrm{~mm}$. HSM 23571; Gloucs. Mus. A1746; 1870 Palmer Coll. Guido 1978, 173, Group 7v. Not illustrated.

72. Bead; glass. Opaque turquoise. Globular. Diameter 4mm, length $4 \mathrm{~mm}$, perforation diameter $1.5 \mathrm{~mm}$. HSM 21376; SO 64482399; HSM 21376; DAG Fieldwalking 1984-9. Not illustrated.

73. Bead; glass. Translucent bright turquoise. Globular. Diameter 9mm, length $7 \mathrm{~mm}$, perforation diameter $2 \mathrm{~mm}$. HSM 23571; Gloucs. Mus. A1748; 1870 Palmer Coll. Guido 1978, 173, Group 7v. Not illustrated.

74. Bead; glass. 'Black'. Globular. Diameter $13 \mathrm{~mm}$, length $12 \mathrm{~mm}$, perforation diameter 3mm. HSM 23571; Gloucs. Mus. A1750; 1870 Palmer Coll. Guido 1978, 175, Group 7 viii. Not illustrated.

75. Bead; stone. Dark grey. Globular. Diameter $7 \mathrm{~mm}$, length $5 \mathrm{~mm}$, perforation diameter $1.5 \mathrm{~mm}$. HSM 23571; Gloucs. Mus. A1768; 1870 Palmer Coll. Not illustrated.

76. Bead; glass; annular. Translucent yellow/green (lime green ) with impurities and folding marks; broad cable of opaque white and translucent deep blue rods (almost vertical right-hand twist) formed into closed loop with sides forming slightly diagonal bands across outer face 
and top and bottom pressed into edges of inner face; marvered smooth. Half extant. Diameter $35 \mathrm{~mm}$, length $18 \mathrm{~mm}$, perforation diameter $12.5 \mathrm{~mm}$. HSM 5324; SO 64352385; A/67, unstratified; Garrod 1967.

77. Bead; glass. Opaque yellow decorated with fine cable of translucent brown and opaque white rods (right-hand twist) in meandering waves marvered smooth. 2 fragments of large annular bead. Diameter c. $25 \mathrm{~mm}$. length c. $14 \mathrm{~mm}$. HSM 23546; SO 64352385; A/67 A1, context 3, sf. 12; Garrod 1967.

78 to 142 . Beads; glass. 65 beads currently threaded onto modern thread. Catalogued by type as no evidence that this was original order. (Order here as Guido 1978, 91). HSM 23571; Gloucs. Mus. A1772; 1870 Palmer Coll. Not illustrated.

78-83. 6 segmented; opaque dark blue (noted Guido 1978, 202): 3 joined segments. Diameter $4 \mathrm{~mm}$, length $7 \mathrm{~mm} ; 3$ joined segments. Diameter $3.5 \mathrm{~mm}$, length $8 \mathrm{~mm} ; 2$ joined segments. Diameter $3 \mathrm{~mm}$, length $5.5 \mathrm{~mm} ; 2$ joined segments. Diameter $3.5 \mathrm{~mm}$, length $7.5 \mathrm{~mm}$; Single segment. Diameter $3.5 \mathrm{~mm}$, length $2 \mathrm{~mm}$; Single segment. Diameter $3.5 \mathrm{~mm}$, length $2.5 \mathrm{~mm}$.

84. Segmented; opaque green (noted Guido 1978, 202): 4 joined segments. Diameter $4 \mathrm{~mm}$, length $14 \mathrm{~mm}$.

85. Gold in glass; single segment. Diameter $5 \mathrm{~mm}$, length 4mm. (noted Guido 1978, 205).

86. Long cylindrical; translucent dark blue. Diameter $4 \mathrm{~mm}$, length $7 \mathrm{~mm}$.

87-115. 29 short square-sectioned; opaque dark blue: $1 \times$ Diameter $6 \mathrm{~mm}$, length $3.5 \mathrm{~mm} ; 1 \times$ Diameter $4.5 \mathrm{~mm}$, length $4 \mathrm{~mm} ; 1 \times$ Diameter $4.5 \mathrm{~mm}$, length $3 \mathrm{~mm} ; 1 \times$ Diameter $4 \mathrm{~mm}$, length $6 \mathrm{~mm}$; $1 \times$ Diameter $4 \mathrm{~mm}$, length $5 \mathrm{~mm} ; 1 \times$ Diameter $4 \mathrm{~mm}$, length $4.5 \mathrm{~mm} ; 2 \times$ Diameter $4 \mathrm{~mm}$, length $4 \mathrm{~mm} ; 1$ $\times$ Diameter $3.5 \mathrm{~mm}$, length $4.5 \mathrm{~mm} ; 2 \times$ Diameter $3.5 \mathrm{~mm}$, length $4 \mathrm{~mm} ; 1 \times$ Diameter $3.5 \mathrm{~mm}$, length $3.5 \mathrm{~mm} ; 1 \times$ Diameter $3.5 \mathrm{~mm}$, length $2.5 \mathrm{~mm} ; 1$ $\times$ Diameter $3 \mathrm{~mm}$, length $5.5 \mathrm{~mm}$; $2 \times$ Diameter $3 \mathrm{~mm}$, length $5 \mathrm{~mm} ; 5 \times$ Diameter $3 \mathrm{~mm}$, length $4 \mathrm{~mm} ; 1 \times$ Diameter $3 \mathrm{~mm}$, length $3.5 \mathrm{~mm} ; 2 \times$ Diameter $3 \mathrm{~mm}$, length $3 \mathrm{~mm}$; $1 \times$ Diameter $3 \mathrm{~mm}$, length $2.5 \mathrm{~mm} ; 1 \times$ Diameter $2.5 \mathrm{~mm}$, length $5 \mathrm{~mm}$; $2 \times$ Diameter $2.5 \mathrm{~mm}$, length $4 \mathrm{~mm} ; 1 \times$ Diameter $2 \mathrm{~mm}$, length $4 \mathrm{~mm}$.

116-7. 2 short-diamond-sectioned, opaque dark green. $1 \times$ Diameter $4 \mathrm{~mm}$, length $5 \mathrm{~mm}$; $1 \times$ Diameter $8 \mathrm{~mm}$, length $5 \mathrm{~mm}$.

118. Short square-sectioned, translucent dark blue. Diameter $3 \mathrm{~mm}$, length $5 \mathrm{~mm}$.

119-21. 3 long square-sectioned; dark opaque blue. 1 $\times$ Diameter $3 \mathrm{~mm}$, length $6.5 \mathrm{~mm} ; 1 \times$ Diameter $3 \mathrm{~mm}$, length $8 \mathrm{~mm} ; 1 \times$ Diameter $2.5 \mathrm{~mm}$, length $6.5 \mathrm{~mm}$.

122-4. 3 short square-sectioned; opaque green. $2 \times$ Diameter $3.5 \mathrm{~mm}$, length $3.5 \mathrm{~mm}$; $1 \times$ Diameter $4 \mathrm{~mm}$, length $5 \mathrm{~mm}$.

125. Short square-sectioned; translucent dark green. Diameter $3.5 \mathrm{~mm}$, length $3.5 \mathrm{~mm}$.

126. Long square-sectioned; opaque dark green (noted Guido 1978, 214). Diameter $3 \mathrm{~mm}$, length $10 \mathrm{~mm}$.
127. Long rectangular-sectioned translucent green (noted Guido 1978, 214). Diameter $3.5 \times 2 \mathrm{~mm}$, length $6 \mathrm{~mm}$.

128. Hexagonal; translucent green/blue (peacock). Diameter $5 \mathrm{~mm}$, length $6 \mathrm{~mm}$.

129-30. 2 hexagonal; opaque green. ! × Diameter 5mm, length $7 \mathrm{~mm}$; $1 \times$ Diameter $4 \mathrm{~mm}$, length $5 \mathrm{~mm}$.

131. Pentagonal; translucent bright green (possibly lined with yellow). Diameter $7 \mathrm{~mm}$, length $9 \mathrm{~mm}$.

132-3. 2 short biconical; opaque dark blue. $1 \times$ Diameter $6 \mathrm{~mm}$, length $3.5 \mathrm{~mm} ; 1 \times$ Diameter $5 \mathrm{~mm}$, length $3 \mathrm{~mm}$.

134. Short biconical; translucent dark blue. Diameter $5 \mathrm{~mm}$, length $3 \mathrm{~mm}$.

135-6. 2 long biconical; opaque dark blue. $1 \times$ Diameter $4 \mathrm{~mm}$, length $7 \mathrm{~mm}$; $1 \times$ Diameter $3.5 \mathrm{~mm}$, length $9 \mathrm{~mm}$.

137-8. 2 oblong with round section; turquoise appearing opaque. $1 \times$ Diameter $7 \mathrm{~mm}$, length $17 \mathrm{~mm} ; 1 \times$ Diameter $7 \mathrm{~mm}$, length $18 \mathrm{~mm}$.

139. Long square-sectioned, faceted to biconical; opaque dark blue. Diameter $8 \mathrm{~mm}$, length $13 \mathrm{~mm}$. Guido 1978, 221.

140-1. 2 conical; opaque blue: $1 \times$ Diameter $4.5 \mathrm{~mm}$, length $4 \mathrm{~mm} ; 1 \times$ Diameter $3.5 \mathrm{~mm}$, length $3.5 \mathrm{~mm}$.

142. Globular (misshapen); translucent blue/green. Diameter $7 \mathrm{~mm}$, length $8 \mathrm{~mm}$.

143. Bead; glass. Opaque dark blue. Fragment of segment of segmented bead. Diameter 3mm. HSM 6097; SO 64102371; WW1, context 309 (1 $\mathrm{mm}$ residue); Jackson 1993. Not illustrated.

144. Bead; glass. Opaque dark blue. Short square-sectioned. Diameter $3 \mathrm{~mm}$, length $5 \mathrm{~mm}$, perforation diameter $1 \mathrm{~mm}$. HSM 6097; SO 64102371; WW1, context 309 (1mm residue); Jackson 1993. Not illustrated.

145. Bead; glass. Opaque green. Hexagonal. Diameter $6.5 \mathrm{~mm}$, length $7 \mathrm{~mm}$, perforation diameter $2.5 \mathrm{~mm}$. HSM 21376; SO 64502400; DAG Fieldwalking 1984-9. Not illustrated.

146. Bead; glass. Opaque blue. Short biconical. Diameter $8 \mathrm{~mm}$, length $6 \mathrm{~mm}$, perforation diameter $2.5 \mathrm{~mm}$. HSM 23571; Gloucs. Mus. A1769; 1870 Palmer Coll. Guido 1978, 219. Not illustrated.

147. Necklace fastener; copper alloy. Triangular sheet tapering to wire hook. Edges decorated with notches and broad curved broken end with central perforation. Length $28 \mathrm{~mm}$, maximum width 9mm. HSM 21368; not located; Heref. Mus. 9379; Ritchie 1970.

Other glass beads are listed from HSM 21376 (Sterry 1994) and HSM 5324 (F-GAR 1971)

\section{Pendants (Fig. 4.38)}

Three items have tentatively been identified as pendants, though if the identification is correct a better description might be good-luck charms.

The perforated lead cone (no. 148) is worn to one side as if it was worn or used suspended. It might have acted as a small net or line weight but another interpretation could be as an amulet. A similar piece was found at the neck of an inhumation of probable late Roman date at Castleford 
(Mould 1998, 124, no. 22). There is no certainty that this lead cone (no. 148) is of Roman date as the context (Bridgewater 1966, 129) contained clay pipes as well as Roman pottery of 2 nd century date. The date when the oyster shell (no. 149) was perforated is also a matter of speculation, but the popularity of oysters as a food item in the Roman period makes a Roman date a possibility.

The boar tusk (no. 150) is broken and shows no signs of working, but has been included here because boar tusks have been found with copper alloy mounts fastened together as if for suspension (Henderson 1949, 141, nos 173-4). The mounted tusks found in stratified contexts suggest a late 4th century date, and Allason-Jones (1993, 202, no. 451) discussing an unmounted example from Segontium, noted that links have been drawn both with German mercenaries, and with hunting and the veneration of Diana the goddess of hunting.

148. Pendant; lead alloy. Uneven flat-based cone with perforation close to one margin; possible evidence of wear between perforation and edge. Diameter $19 \mathrm{~mm}$, length $8 \mathrm{~mm}$, perforation diameter $5 \mathrm{~mm}$, weight $16 \mathrm{~g}$. HSM 23558; SO 64402430; AR 9, C 2; Bridgwater 1963.

149. Pendant?; oyster shell. One valve with off centre perforation. Dimensions $53 \times 57$. HSM 16780; SO 64672405; Heref. Mus. 7639/16; Jack 1922. Not illustrated.

150. Boar's tusk. Tip of sharply triangular-sectioned tusk with no evidence of working. Length. 80mm. HSM 16780; SO 64672405; Heref. Mus. 7639/1; Jack 1922. Jack 1923 , 25. Not illustrated.

\section{BuCKLES}

All five of the buckle or buckle fragments that have been recovered are of post-Roman date. The first (no. 151) is a double loop buckle of the type that is normally found in 15 th century contexts though it has occasionally been found in ones of the previous century (Hinton 1990, 508). No. 152 is a slightly later development of the same type often used as a 17th century shoe buckle though it is known earlier. One for example was found in a 15 th to mid 16th century pit at Marlowe, Canterbury (Blockley et al. 1995, 1058, no. 616). The single looped example (no. 153 ) is probably a relatively modern harness buckle. The fragmentary frame (no. 154) and buckle pin (no. 155) are not closely dateable.

151. Buckle; copper alloy. Double-looped buckle with Dsectioned frame and traces of pin groove on each side; loose wire pin wrapped around central pin bar, point missing. Length $20 \mathrm{~mm}$, width $1 \mathrm{~mm}$. HSM 5324; SO 6420/2401; F-DAG 1987. Not illustrated.

152. Buckle; copper alloy. One side of frame of double-looped spectacle buckle with central expansion decorated with cross-hatching. Width $41 \mathrm{~mm}$. HSM 23555; SO 64302420; Hask Barn Field, DAG Fieldwalking 1984-9 (Walters). Not illustrated.

153. Buckle; copper alloy. Single D-shaped loop with circularsectioned fragment; pin bar stepped down from frame with iron corrosion products possibly from pin; pin groove on upper face of frame. Length $28 \mathrm{~mm}$, width $29 \mathrm{~mm}$. HSM 21376; SO 6460/2400; F-DAG 87/9. Not illustrated.

154. Buckle frame fragment?; copper alloy. L-shaped curved strip with both ends broken. Length $41 \mathrm{~mm}$, section 9x2mm. HSM 23546; SO 64682377; A/67, Trench A1, context 2, sf. 5; Garrod 1967. Not illustrated.

155. Buckle pin?; copper alloy. Circular-sectioned tapering to point, other end expanded and bent over. Length 30mm. HSM 21376; SO 6462/2411; F-DAG 87/9. Not illustrated.

ToILeT EQUIPMENT (FIg. 4.38)

Toilet implements are common finds on Roman sites and though certain forms, most notably nail cleaners, have great potential for revealing chronological and regional patterns, at present these are not well understood.

Two of the nail cleaners (nos 156-7) belong to a relatively common type that has been found in 3rd to 4th century contexts at Nettleton (Wedlake 1982, fig. 94.8, 11 ), but was clearly in use during the late 2 nd century as examples in contexts of that date have been found at Wilcote, Oxon (Hands 1993, 38, no. 19; 1998, 60, no. 77). It has not been possible to date the other nail cleaners closely. No. 158 is a very distinctive type and shares sufficient decorative traits with the cosmetic spoons (nos 161-2) for it to be likely that they were contemporary and could have used together on chatelaines.

No. 159 is a simple and long lasting type and no. 160 has been made from a broken fragment of a bracelet, but unfortunately not one that is closely dateable. A similar lack of close dating within the Roman date applies to the tweezers (nos 163-65) and the probes (nos 166-8).

No. 169 might be part of a crude probe or spatula, but in shape it is reminiscent of a spearhead and given the presence of possible votive spears in the collections (see nos 230-32), the possibility that this was a miniature votive item cannot be excluded.

156. Nail cleaner; copper alloy. Oval-sectioned shank, broken at upper end and tapering to rectangular-sectioned notched blade. Upper part of shank decorated by diagonal crosshatched grooves. Present length $32 \mathrm{~mm}$, maximum section 2mm. HSM 5324; SO 64302388; Gloucs. Mus. A24295; Garrod 1964/6.

157. Nail cleaner; copper alloy. Circular-sectioned shank, broken at upper end and tapering to rectangular-sectioned notched and chipped blade. Upper part of shank decorated by diagonal cross-hatched grooves. Present length $37 \mathrm{~mm}$, maximum section 3mm. HSM 23571; Gloucs. Mus. A1627; 1870 Palmer Coll. Hills 1871, 206, no. 33. Not illustrated.

158. Nail cleaner; copper alloy. Rectangular-sectioned with upper end bent over to form cylindrical loop, tapering to lower end with slight notch. 2 deep grooves over top of loop; unit of 2 diagonal crossed grooves bordered top and bottom by horizontal groove on each face below loop; faint groove parallel to each edge on one face. Length $37 \mathrm{~mm}$, maximum section 4x1mm. HSM 23571; Gloucs. Mus. A1628; 1870 Palmer Coll. Hills 1871, 206, no. 32.

159. Nail cleaner; copper alloy. Flat strip with broken 
perforated disc at one end and broken fork at other. Length $42 \mathrm{~mm}$, maximum width $7 \mathrm{~mm}$. Unlocated; Heref. Mus. 9397/7.

160. Nail cleaner; copper alloy. Re-used penannular bracelet fragment; shallow D-sectioned blunt slightly expanded terminal with unit of grooves across; straightened and broken end has concave notch. Length $42 \mathrm{~mm}$, maximum section $4 \times 1.5 \mathrm{~mm}$. HSM 23571; Gloucs. Mus. A1640; 1870 Palmer Coll.

161. Cosmetic spoon; copper alloy. Rectangular-sectioned with upper end bent over to form cylindrical loop, tapering to lower end with small spoon. 3 pairs of 2 diagonal crossed grooves separated by 2 horizontal grooves decorating front face over loop and upper part of shank; 2 diagonal crossed grooves bordered top and bottom by horizontal groove above spoon bowl. Length $41 \mathrm{~mm}$, maximum section 3 $\times 1 \mathrm{~mm}$. HSM 23571; Gloucs. Mus. A1629; 1870 Palmer Coll. Hills 1871, 206, no. 34 .

162. Cosmetic spoon; copper alloy. Rectangular-sectioned strip broken one end, expanding to rounded end with spoon bowl beaten in. Heavily corroded but traces of 2 diagonal crossed grooves bordered top and bottom by horizontal groove above spoon bowl. Length $23 \mathrm{~mm}$, maximum section $4 \times 1 \mathrm{~mm}$. HSM 23571; Gloucs. Mus. A1641; 1870 Palmer Coll.

163. Tweezers; copper alloy. Rectangular sectioned strip bent in half with small upper loop, strip tapers to fine edge at jaws which are curved inwards. Light transverse ridges across outer faces. Length $91 \mathrm{~mm}$, width $5 \mathrm{~mm}$. HSM 21368; not located; Heref. Mus. 9397/3; Ritchie 1970. Not illustrated.

164. Tweezers; copper alloy. Part of one arm broken at loop and above jaw, vertical grooves over loop, unit of 2 crossed diagonal grooves between 2 horizontal grooves immediately below loop. Surfaces much corroded. Length 40mm, section 7x1mm. HSM 21376; SO64602390; DAG Fieldwalking 1984-9, Mark Walters. Not illustrated.

165. Tweezers?; copper alloy. Rectangular-sectioned strip; both ends broken but one curving over as if from hinge of tweezers. Length $23 \mathrm{~mm}$, section $3 \times 1 \mathrm{~mm}$. HSM 23571; Gloucs. Mus. A1637; 1870 Palmer Coll. Not illustrated.

166. Scoop/probe; copper alloy. Faceted hexagonal-sectioned handle expanding centrally; circular-sectioned olivary probe at one end; broken scoop at other; moulded unit between handle and scoop - rounded cordon either side of group of 4 narrow ridges. Length $97 \mathrm{~mm}$, maximum handle section 4mm. HSM 23546; SO 64682377; A/67 Trench A1, context 2, sf. 7; Garrod 1967.

167. Olivary probe; copper alloy. Circular-sectioned probe; broken shank. Length $28 \mathrm{~mm}$, maximum section $3.5 \mathrm{~mm}$. HSM 23571; Gloucs. Mus. A1638; 1870 Palmer Coll. Not illustrated.

168. Olivary probe; copper alloy. Circular-sectioned probe; shank broken. Length $29 \mathrm{~mm}$, maximum section $4 \mathrm{~mm}$. HSM 23571; Gloucs. Mus. A1643; 1870 Palmer Coll. Not illustrated.

169. Spatula; copper alloy. Rectangular-sectioned; broken shank; elongated spatula with rounded end. Length $37 \mathrm{~mm}$, maximum section $7 \times 2 \mathrm{~mm}$. HSM 21376; SO 64602400; DAG Fieldwalking 1984-9.

The Sterry metal detecting collection (HSM 21376) has two nail cleaners and a pair of tweezers listed.

\section{TEXTILE EQUIPMENT}

Five fragments of Roman pottery have been turned into spindle whorls (nos 170-74). All have perforation diameters that would be appropriate for Roman spindles rather than the thicker medieval examples (Walton Rogers 1997, 1735-6). Other than to note that the pottery spindle whorls are Roman, no closer date can be suggested for most of them, as even the original date of the pottery can be misleading. There are, for example, good grounds for believing that spindle whorls made of samian pottery are commonest during the very late 4 th to 5 th centuries (Cool 2000b, 53). It may well be, therefore, that No. 170 is another indication of very late Roman activity at Ariconium.

Moulded lead whorls such as nos 175-6 are found from time to time on sites with Roman occupation such as Usk (Manning et al. 1995, 254, no. 16) and Ribchester (Buxton and Howard-Davis 2000, fig. 77, no. 39), but well-stratified examples point to a later, medieval, 13th or 14th century floruit. Of particular importance was the discovery of one still in place on an oak spindle from a monastic drain deposit in Leicester with pottery of the 14th century (Clay 1981, 135, no. 71). Other examples from contexts of that date have been found at Brompton Bridge, N. Yorkshire (Maxwell 1996, 203, no. 16) and New Radnor, Powys (Courtney 1999, 173, no. 2).

The perforated stone disc (no. 177) has a perforation diameter of only $4 \mathrm{~mm}$ which would be small even for a Roman spindle and so the disc might have had a different purpose (see Crummy 1983, 94 for the problems of what this might have been).

170. Spindle whorl; ceramic. Slightly curved wall fragment; samian; carefully ground edge and central perforation. Half remaining. Diameter $39 \mathrm{~mm}$, thickness $6 \mathrm{~mm}$, perforation diameter 6mm. HSM 16780; SO 64672405; Heref. Mus. 7639/2; Jack 1922. Jack 1923, 25. Not illustrated.

171. Spindle whorl; ceramic. Oxidised (reddish) slightly curving body sherd; carefully ground edges and central perforation. One edge chipped. Diameter $45 \mathrm{~mm}$, thickness $7 \mathrm{~mm}$., perforation diameter 6.5mm. HSM 23571; Gloucs. Mus. A1709; 1870 Palmer Coll. Not illustrated.

172. Spindle whorl; ceramic. Oxidised (buff) slightly oval with uneven edges, carefully ground central perforation. Diameter $30 \times 27 \mathrm{~mm}$., thickness $4.5 \mathrm{~mm}$, perforation diameter 6mm. HSM 23571; Gloucs. Mus. A1708; 1870 Palmer Coll. Not illustrated.

173. Spindle whorl; ceramic. Buff, slightly curved wall fragment (F12); carefully ground edge and central perforation. Diameter $31.5 \mathrm{~mm}$, thickness $7 \mathrm{~mm}$, perforation diameter 8mm. HSM 21376; SO 64702380; DAG Fieldwalking 1984-9. Not illustrated.

174. Spindle whorl; ceramic. Reduced with black surfaces (F41); slightly curved wall fragment; carefully ground edge and central perforation. Diameter $30 \mathrm{~mm}$, thickness $9.5 \mathrm{~mm}$, perforation diameter $8 \mathrm{~mm}$. HSM 21376; SO 64702380; DAG Fieldwalking 1984-9. Not illustrated.

175. Weight? lead alloy. Biconical with wide cylindrical perforation; outer faces divided into panels by vertical ribs with small moulded pellet in each panel. Dented on one side. Diameter $24 \mathrm{~mm}$, length $20 \mathrm{~mm}$, perforation 
diameter 10mm, weight 42g. HSM 23555; SO 64302417; Hask Barn field; DAG 1989.

176. Weight? lead alloy. Much corroded but either sharply biconical as 175 above or rounded biconical. Possible traces of seating for suspension loop on upper face. Possible evidence of moulded panels as above. Diameter 25mm, length $15 \mathrm{~mm}$, perforation diameter. HSM 21376; SO 64602400; HSM 21376; DAG 1991. Not illustrated.

177. Spindle whorl or perforated disc; stone. Fine-grained dark pebble of elipsoidal cross-section. Most edges natural but one side ground to produce circular outline. Small slightly off-centre perforation. Diameter $24 \mathrm{~mm}$., maximum diameter $6.5 \mathrm{~mm}$, perforation diameter $4 \mathrm{~mm}$. HSM 23571; Gloucs. Mus. A1777; 1870 Palmer Coll. Not illustrated.

Household Utensils (Fig. 4.39)

Two metal vessels can be identified with certainty. No. 178 is an escutcheon from a footed bowl with a swing handle. Only one complete example has been recovered from a British site, found with an undated cremation at Ramsgate (Smith 1922, 94), but escutcheons such as no. 178 have been found at a number of sites. Those from dated contexts such as Benwell (Birley and Charlton 1934, 201, no. 28) and Verulamium (Waugh and Goodburn 1972, 130 , no. 130) suggest they were in use during the mid to later 2nd century. No. 179 consists of several fragments of lead alloy which have features that are consistent with them coming from a pewter jug perhaps like those from the sacred spring at Bath (Sunter and Brown 1988, 14, nos 20-21, fig. 7). If this identification is correct, then a 4th century date would be appropriate for No. 179 .

The identification of the lead alloy object, no. 180, as a vessel is more tentative. It bears a resemblance to a shallow dish or plate but with a diameter of $c .100 \mathrm{~mm}$ it would be very small for such a vessel. The 4 th century pewter dishes of this general form tend to be much larger. It has been suggested that a lead artefact of similar diameter, though slightly deeper, found at Segontium (AllasonJones 1993, 201, no. 416) might have been part of a lamp holder. Alternately it might have been some form of lid or capping such as was found at Blake St York (Cool et al. 1995, 1666, no. 6385).

A small number of vessel glass fragments of Roman date are known from Ariconium, mainly from formal excavation. This paucity undoubtedly reflects the collection method for many of the Ariconium finds. Casual collections tend not to include Roman glass as the good condition it is found in often erroneously leads people to think it modern.

The foot fragment no. 181, and probably also the body fragment no. 175 , come from a mid 2 nd century beaker with separately blown foot (see for example Cool and Price 1995, 80, no. 426, fig. 5.10). There is one example (no. 183) of a colourless cylindrical cup (Isings form 85b; Cool and Price 1995, 82). This was the commonest glass drinking vessel of the late 2 nd to mid 3rd century, often found in large numbers. The rim fragment, no. 184, is less diagnostic but might come from the family of 3rd century cups often decorated with pinched-out knobs (Cool and Price 1995, 86). No. 185 comes from a blue/green jug, but insufficient is preserved for the type to be identified. The blue/green colour suggests 1 st to 3 rd century date. The small pinched fragment, no. 186, is most likely to come from the pinched lower handle attachment of a conical jug of Isings Form 55 (Cool and Price 1995, 120). This was a very common late 1 st to mid 2 nd century form.

There are also fragments come from blue/green containers which tend to be less closely dateable within the 1 st to 3 rd century period. There is one flask (no. 187) and seven fragment from prismatic bottles (nos 188-94). The latter were very common from the later 1 st to earlier 3rd centuries (Cool and Price 1995, 179). The deep colour of no. 194 which approaches a peacock shade is most unusual on a bottle of this type, and the possibility must exist that the fragment is of more recent date.

Fourth century vessels are represented by nos 198-201 made in the typical bubble glass of that period. None of the fragments are sufficiently diagnostic for the forms to be identified with certainty.

178. Escutcheon; copper alloy. Shallow triangular plate, upper edge notched on either side of circular perforation. Diameter of vessel c. 130mm; length of escutcheon $52 \mathrm{~mm}$, depth 14mm. HSM 16780; SO64672405; Heref. Mus. 7639/26; Jack 1922.

179. Jug; lead alloy. 8 rim and neck fragments and one base fragment. Cylindrical neck bent out to horizontal rim, edge missing. Central part of slightly concave vase with lathe centring mark on both faces and two concentric grooves on underside. Surfaces heavily corroded. Outer diameter of neck c. $25 \mathrm{~mm}$, dimensions of base fragment $30 \times$ 30mm. HSM 21376; SO 64492395; DAG Fieldwalking 1984-9. Not illustrated.

180. Dish or lid?; lead alloy; 2 joining rim side and base fragment. Rim edge bent out and down; shallow side sloping in slightly and flat base. Now bent and much distorted. Diameter?c. 100mm., height 9mm. HSM 16780; SO 64672405; Heref. Mus. 7639/69; Jack 1922.

181. Beaker; glass; foot fragment. Colourless; slightly clouded surfaces. Separately blown foot, curved lower edge of foot knocked off but not obviously ground. Base diameter $55 \mathrm{~mm}$., foot thickness $3 \mathrm{~mm}$., present height $16 \mathrm{~mm}$. HSM 15983; SO63732331; Jackson 1993, context 111. Not illustrated.

182. Body fragment; glass. Colourless; slightly clouded surfaces. Convex-curved side. Dimensions $29 \times 12 \mathrm{~mm}$, wall thickness $3.5 \mathrm{~mm}$. HSM 15983; SO63732331; Jackson 1993, context 106. Not illustrated.

183. Cup; glass; rim fragment. Colourless; flaking iridescent surfaces. Vertical rim, edge fire-thickened. Rim diameter $95 \mathrm{~mm}$, wall thickness $1.5 \mathrm{~mm}$, present height $18 \mathrm{~mm}$. HSM 16780; SO 64672405; Heref. Mus. 7639/46; Jack 1922. Not illustrated.

184. Cup; glass; rim fragment. Colourless; clouded surfaces. Horizontally out-turned rim, edge fire-rounded; side sloping out slightly. Rim diameter $80 \mathrm{~mm}$, wall thickness $2 \mathrm{~mm}$, present height 8mm. HSM 16780; SO 64672405; Heref. Mus. 7639/57; Jack 1922. Not illustrated.

185. Jug; glass; handle fragment. Blue/green; outer edge of 

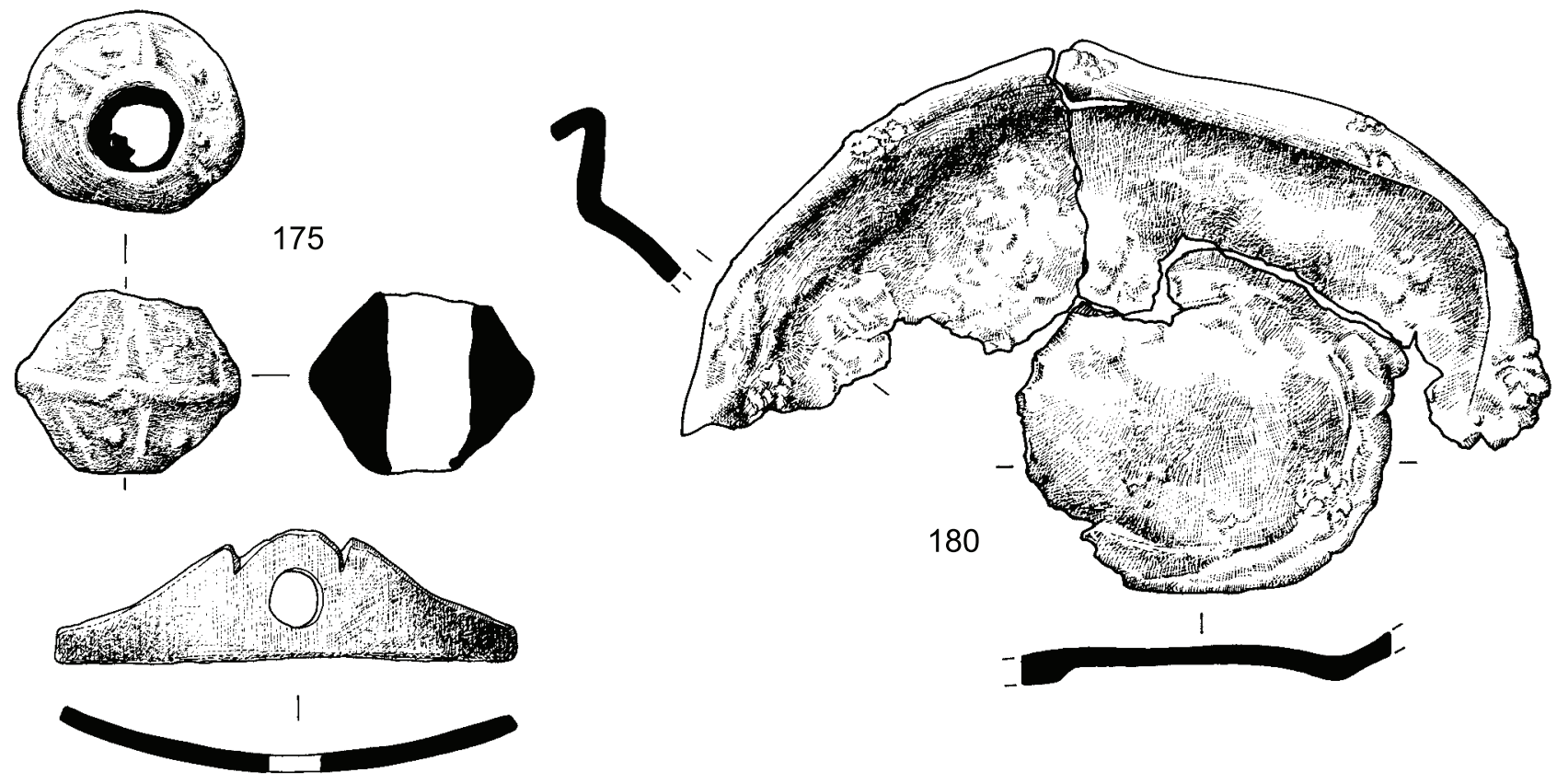

178

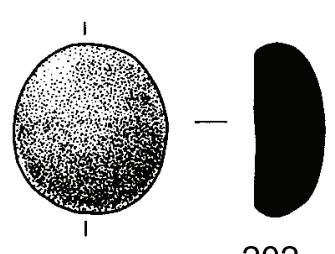

202

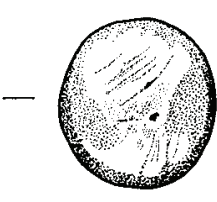

$\left(\frac{1}{1}\right.$
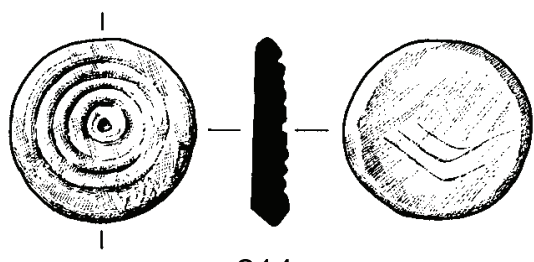

214

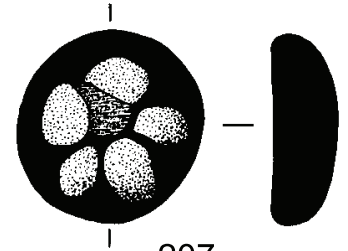

207
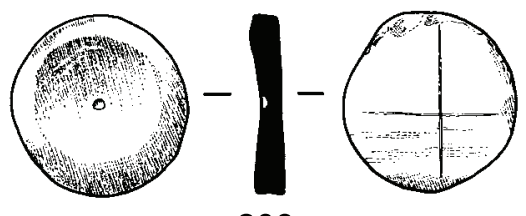

208
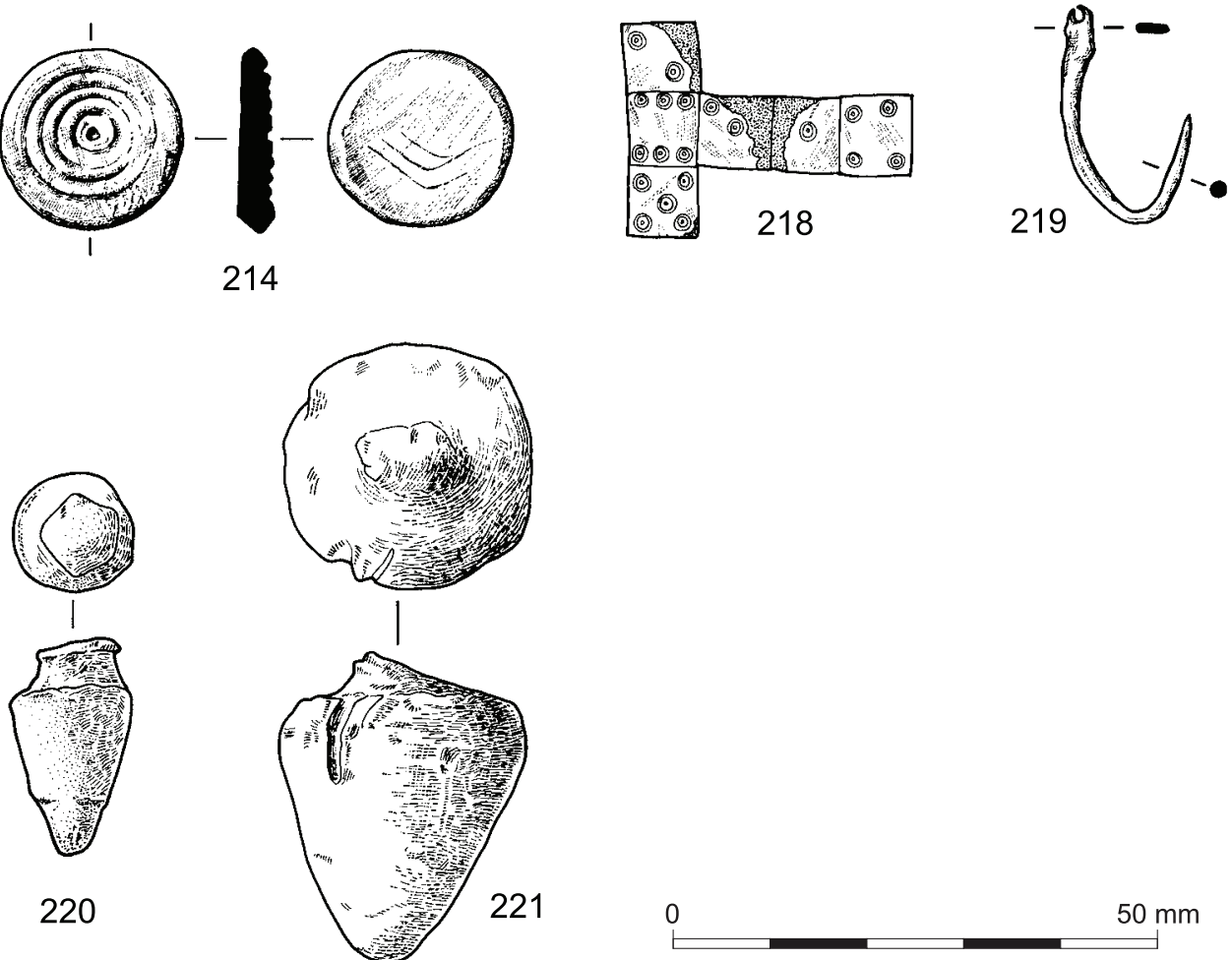

0 $50 \mathrm{~mm}$

Figure 4.39. Other small finds (Household utensils, recreational equipment and surveying and measuring equipment) 
straight handle with thick rounded ribs, 1 rib remaining. Length 23mm. HSM 16780; SO 64672405; Heref. Mus. 7639/58; Jack 1922. Not illustrated.

186. Jug; glass; handle fragment? Blue/green. D-shaped pinched projection. Dimensions 12x10mm, HSM 16780; SO 64672405; Heref. Mus. 7639/54; Jack 1922. Not illustrated.

187. Flask; glass; rim fragment. Blue/green; iridescent surfaces. Rim edge bent out, up, in and down. Rim diameter $35 \mathrm{~mm}$. HSM 16780; SO 64672405; Heref. Mus. 7639/55; Jack 1922. Not illustrated.

188. Bottle; glass; rim fragment. Blue/green; iridescent surfaces. Rim bent out, up, in and flattened; small part of neck with scar from handle attachment. Rim diameter 60mm. HSM 16780; SO 64672405; Heref. Mus. 7639/47; Jack 1922. Not illustrated.

189. Bottle; glass; handle fragment. Blue/green reeded handle fragment. Dimensions 26x16mm. HSM 16780; SO 64672405; Heref. Mus. 7639/49; Jack 1922. Not illustrated.

190. Bottle or jug; glass; handle fragment. Blue/green. Lower part of ribbon handle with pronounced edge ribs; simple lower attachment retaining fragment of shoulder. Handle section $20 \times 3 \mathrm{~mm}$. HSM 5324; SO 64352385; unstratified; Garrod 1967. Not illustrated.

191. Bottle; glass; base fragment. Blue/green. Base pattern at least 3 concentric circular mouldings. Diameter of extant outer moulding 70mm. HSM 16780; SO 64672405; Heref. Mus. 7639/48; Jack 1922. Not illustrated.

192. Bottle; glass; side fragment. Blue/green; flat. Dimensions $47 \times 34 \mathrm{~mm}$. HSM 16780; SO 64672405; Heref. Mus. 7639/51; Jack 1922. Not illustrated.

193. Bottle; glass. Blue/green; heat affected (?) side fragment. Dimensions $49 \times 38 \mathrm{~mm}$. HSM 16780; SO 64672405; Heref. Mus. 7639/43; Jack 1922. Not illustrated.

194. Bottle?; glass; side fragment. Green/blue (peacock); flat. Dimensions $35 \times 26 \mathrm{~mm}$. HSM 16780; SO 64672405; Heref. Mus. 7639/53; Jack 1922. Not illustrated.

195. Vessel; glass; body fragment. Colourless. HSM 21376; SO 64462398; DAG unstratified. Not illustrated.

196. Vessel; glass; body fragment. Blue/green. HSM 16780; SO 64672405; Heref. Mus. 7639/50; Jack 1922. Not illustrated.

197. Vessel; glass; body fragment. Blue/green. HSM 16780; SO 64672405; Heref. Mus. 7639/52; Jack 1922. Not illustrated.

198. Beaker or cup; glass; body fragment. Light greenish colourless; many small bubbles. Straight side broken at edge of base. 2 horizontal abraded bands above base. Dimensions $22 \times 18 \mathrm{~mm}$, WT 1-2mm. HSM 23552; SO64452405; A/67 Trench CXX, sf. 19; Garrod 1967. Not illustrated.

199. Body fragment; glass. Light greenish colourless; many small bubbles. Straight side. HSM 23552; SO64452405; A/67 Trench CXX, context 2, sf. 1; Garrod 1967. Not illustrated.

200. Body fragment; glass. Light greenish colourless; many small bubbles. Straight side. HSM 23549; SO64672376; A/67 Trench B II, context 2, sf. 17; Garrod 1967. Not illustrated.

201. Body fragment; glass. Light greenish colourless; some small bubbles. Convex-curved side. HSM 23550;
SO64662276; A/67 Trench B III, context 2, sf. 2; Garrod 1967. Not illustrated.

ReCreational EQuipment (Fig. 4.39)

Counters are relatively common in the assemblage. They are made of glass (nos 202-7), bone (nos 208-16) and from a fragment of pottery (no. 217). A further group was identified by Steven Willis within the ceramic assemblage and these are described at the end of the catalogue. All can be assigned to the Roman occupation and some of the glass and bone examples can be more closely dated.

'Black' and white plano-convex glass counters such as nos 202-6 are a common 1 st to early 2 nd century form. After that date, bone counters seem to have been preferred (Cool et al. 1995, 1555). At Ariconium, five of the bone counters (nos 208-212) are examples of Greep type 2 with slightly dished centres. This form was primarily in use after the mid 2nd century (Greep 1995, 1127), while the concentrically grooved Type 3 , represented here by Nos 213-6, does not appear to be chronologically sensitive within the Roman period. The material of one example of the latter (no. 216) is visually very different and could be ivory, though is should be noted that it has not been inspected by a bone specialist who would be able to confirm or refute this.

The polychrome glass counter no. 207 is a 4th century type. In discussing a set of similar polychrome counters found with a burial at Lullingstone, it was noted that the earliest had been found in a grave dated to the 1 st half of the 4th century at Krefeld Gellep and a single example had been found in a late 4th century context at Shakenoak (Cool and Price 1987, 124). Discoveries since then have suggested that the form was primarily in use during the second half of the 4th century. Several, for example were found it Wellington Row, York in the material being dumped there during the last third of the 4th century and into the 5th (unpublished). An example was also found at Uley in a context belonging to the second half of the 4th century (Woodward and Leech 1993, 177, no. 17).

The small jet die (No. 218) is a most unusual find. Examples of jet dice from Winchester found in postmedieval contexts were attributed to a medieval date (Brown 1990, 694). An example from York without any context details was published as Roman (Allason-Jones 1996, 49, no. 314), but this appears to be unique. Given the rarity of medieval material in this assemblage, a Roman date seems most likely for No. 218. The York die had traces of a yellow/white material in the ring and dots that formed the spots, and it is likely that, though there do not now appear to be any such traces on the Ariconium die, there must have been some originally. Without such a contrasting inlay, the dots would be very difficult to make out in the ordinary course of play.

Finally it seems most appropriate to include the fishhook no. 219 here. Fish tends to form a relatively small part of the Romano-British diet, and it seems likely fishing was frequently a leisure pursuit. Fish-hooks are not a 
common find in Roman finds assemblages, but no. 219 is similar to ones known from well-stratified Roman contexts (Goodburn 1974, 62, no. 84, fig. 32).

202. Counter: glass; appearing black. Irregular plano-convex; base pitted. Diameter $17 \times 15 \mathrm{~mm}$; thickness $6 \mathrm{~mm}$. HSM 23571; Gloucs. Mus. A1703; 1870 Palmer Coll.

203. Counter: glass; appearing black. Plano-convex. Diameter $14 \times 13 \mathrm{~mm}$; thickness 5.5mm. HSM 23571; Gloucs. Mus. A1704; 1870 Palmer Coll. Not illustrated.

204. Counter: glass; appearing black. Plano-convex. Diameter $17 \times 15 \mathrm{~mm}$; thickness 6mm. HSM 23571; Gloucs. Mus. A1705; 1870 Palmer Coll. Not illustrated.

205. Counter: glass; opaque white. Plano-convex. Diameter $13 \times 12 \mathrm{~mm}$; thickness 5mm. HSM 23571; Gloucs. Mus. A1706; 1870 Palmer Coll. Hills 1871, 207, no. 53. Not illustrated.

206. Counter; glass. Plano-convex with smooth base; opaque white. Diameter $16.5 \mathrm{~mm}$, thickness $6.5 \mathrm{~mm}$. HSM 16780; SO 64672405; Heref. Mus. 7639/4; Jack 1922. Not illustrated.

207. Counter: glass; appearing black. Plano-convex; smooth base. 5 opaque white dots around central red dot. Diameter 20mm; thickness 6mm. HSM 23571; Gloucs. Mus. A1702; 1870 Palmer Coll. Hills 1871, 207, no. 51.

208. Counter; bone. Flat disc with dished obverse and small central dot; reverse has graffito of 2 crossed lines. Diameter $18 \mathrm{~mm}$, thickness $3 \mathrm{~mm}$. HSM 16780; SO 64672405; Heref. Mus. 7639/15; Jack 1922.

209. Counter; bone. Flat disc with dished obverse and slight central dot. Diameter $19 \mathrm{~mm}$, thickness $4 \mathrm{~mm}$. HSM 16780; SO 64672405; Heref. Mus. 7639/16; Jack 1922. Not illustrated.

210. Counter; bone. Flat disc with dished obverse and slight central dot. Diameter $16 \mathrm{~mm}$, thickness $3.5 \mathrm{~mm}$. HSM 16780; SO 64672405; Heref. Mus. 7639/16; Jack 1922.

211. Counter; bone. Flat disc with dished obverse and slight central dot. Diameter $15 \mathrm{~mm}$, thickness $3.5 \mathrm{~mm}$. HSM 16780; SO 64672405; Heref. Mus. 7639/18; Jack 1922. Not illustrated.

212. Counter; bone. Flat disc with dished obverse and small central perforation. Diameter $19 \mathrm{~mm}$, thickness $3.5 \mathrm{~mm}$. HSM 16780; SO 64672405; Heref. Mus. 7639/19; Jack 1922. Not illustrated.

213. Counter; bone. Flat disc; obverse with central dot and 3 concentric grooves; reverse lipped on one edge. Diameter $21 \mathrm{~mm}$, thickness 3mm. HSM 16780; SO 64672405; Heref. Mus. 7639/14; Jack 1922. Not illustrated.

214. Counter; bone. Flat disc; obverse with central dot and 4 concentric grooves; reverse lipped on one edge and has graffito of 3 widely angled V markings parallel to each other . Diameter 19mm, thickness 3.5mm. HSM 16780; SO 64672405; Heref. Mus. 7639/14; Jack 1922. Jack 1923, 25 pl. 12 fig. 6.

215. Counter; bone. Flat disc; obverse with central dot and 4 concentric grooves. Diameter $24 \mathrm{~mm}$, thickness $3 \mathrm{~mm}$. HSM 16780; SO 64672405; Heref. Mus. 7639/14; Jack 1922. Not illustrated.

216. Counter; bone. Flat thick disc; dished obverse with dot and small concentric groove centrally. Diameter $18 \mathrm{~mm}$, thickness 5mm. HSM 16780; SO 64672405; Heref. Mus. 7639/18; Jack 1922. Not illustrated.
217. Counter; fired clay. Reduced black-surfaced body sherd with ground edges, diameter $25 \mathrm{~mm}$ thickness $5.5 \mathrm{~mm}$. HSM 5324; SO 64302388; Gloucs. Mus. A 24320; Garrod 1964/6. Not illustrated.

218. Die; jet. Cube damaged at one corner. Spots marked by fine single ring and dots with opposite sides adding up to 7. Length 8mm. HSM 23571; Gloucs. Mus. A1701; 1870 Palmer Coll.

219. Fish-hook; copper alloy. Wire tapering to hooked point at one end and hammered flat with broken perforation at other. Length $23 \mathrm{~mm}$, section $2.5 \mathrm{~mm}$. HSM 21376; SO 64602400; DAG Fieldwalking 1984-9.

The sites and monuments record notes an additional bone counter from HSM 21376.

SURVEYING AND MEASURING EQUIPMENT (Fig. 4.39)

No. 220 may tentatively be identified as a plumb-bob. Such surveying aids were in use during the Roman period but they tended to have a more practical method of attachment to the line such as a ring (Watkin, 1982, 58, no. 2) or a terminal for a chain (Manning et al. 1995, 243, no. 5). Whether or not this is a plumb bob, it could well be of Roman date as a very similar item was recovered from the civil settlement at Cramond (Maxwell 195, no. 12).

The lead weight no. 221 is a typical Roman steelyard weight form (see for example Crummy 1983, 101, no. 2510; Mould 1998, 122, no. 13).

220. Plumb bob; copper alloy. Cast cone with concavity around neck with flat top. Length $22.5 \mathrm{~mm}$, maximum diameter 12mm. HSM 10008; SO 64852382; HSM 10008; DAG Fieldwalking 1984-9 (Walters).

221. Weight; lead alloy. Conical with stump of attachment for suspension loop in upper face; some deep gouges on sides. Maximum diameter $26 \mathrm{~mm}$, length $34 \mathrm{~mm}$; weight 92gr. HSM 23556; SO 64102315; Hask Barn Field; DAG 1989.

WRITING EQUIPMENT (FIg. 4.40)

Styli made of copper alloy are much less common on Romano-British sites than those made of iron, and when they are found tend to have either expanded triangular or stepped erasers (see for example Wedlake 1982, fig. 103, nos 5-9 and 14). The narrow wedge-shaped eraser as on no. 222 is thus rare though a comparable stylus was recovered from a Roman context at Gatcombe (Branigan 1977, 122, no. 537). It is likely, therefore, that this is Roman but the type is too uncommon for a closer date to be suggested.

222. Stylus; copper alloy. Circular-sectioned shank tapering to simple wedge at one end and point at other. 4 notches on corners below wedge; 2 pairs of grooves on upper shank and centrally; 5 grooves above point with 4 lower ones producing 4 ribs. Length $100 \mathrm{~mm}$, maximum section $4 \mathrm{~mm}$. HSM 23571; Gloucs. Mus. A1668; 1870 Palmer Coll.

ITEMS ASSOCIATED WITH TRANSPORT

The only item that can be associated with transport is an enamelled terret now in the British Museum which was 

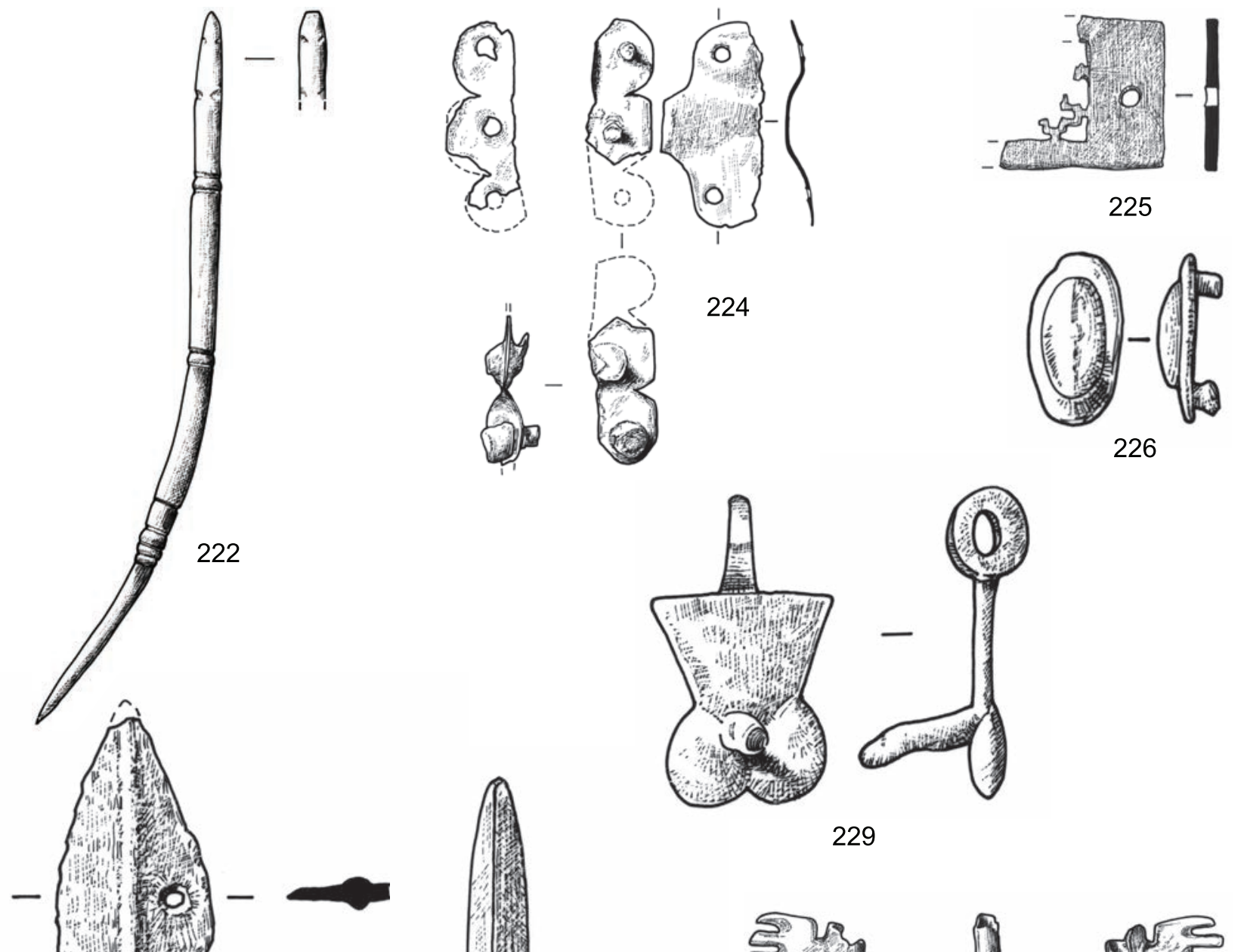

229
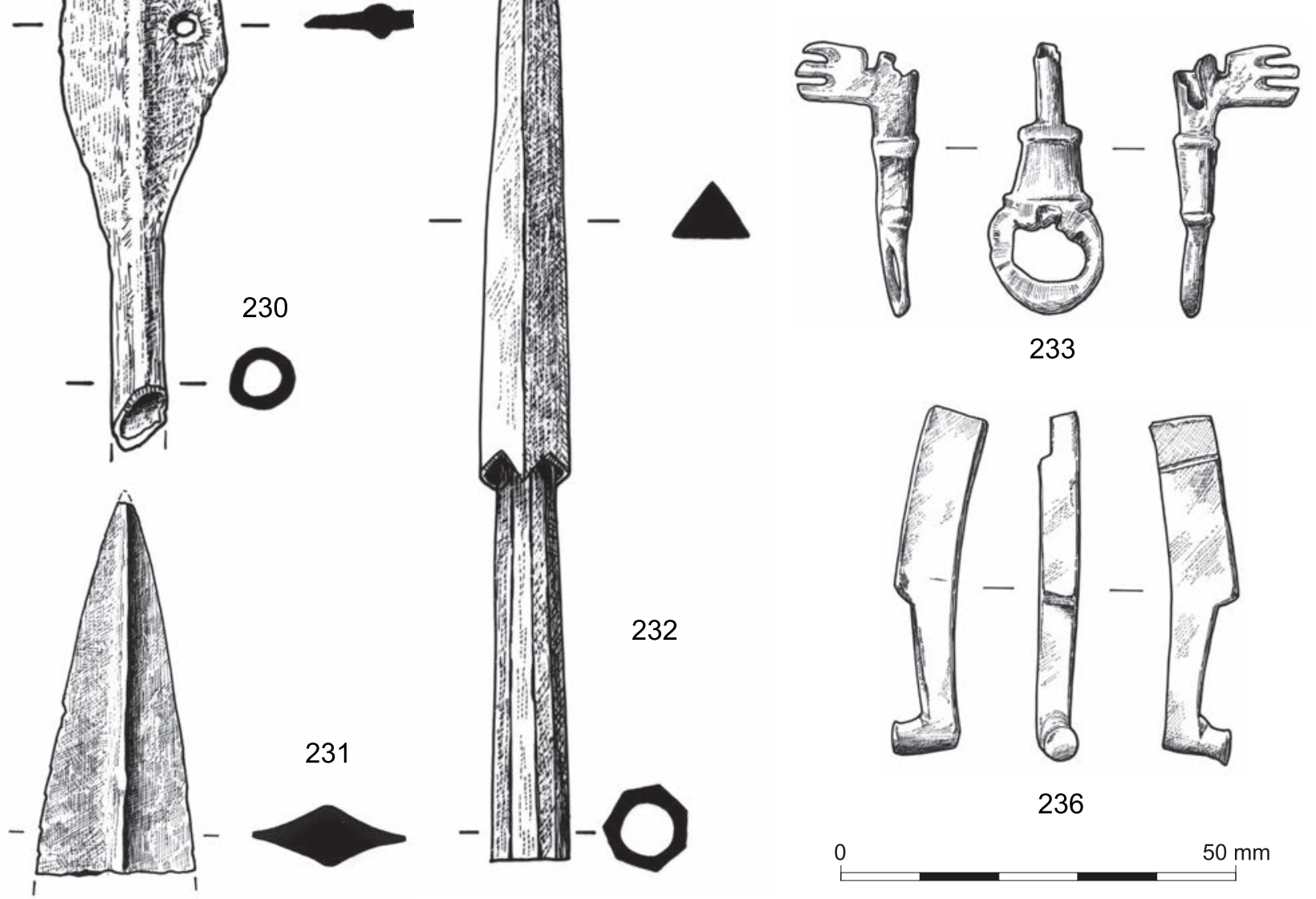

232

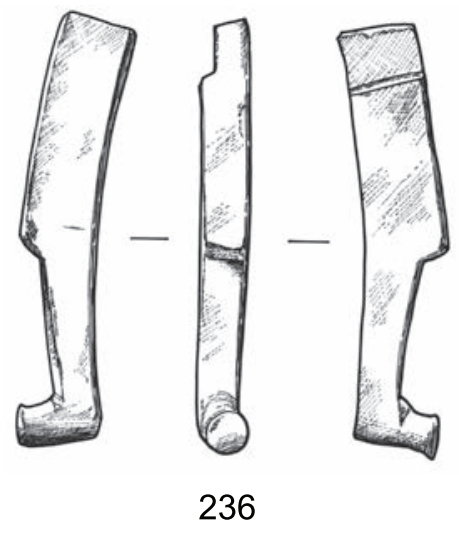

0 $50 \mathrm{~mm}$

Figure 4.40. Other small finds (Writing equipment, military equipment, religious items and keys/locks 
unavailable for study. I am most grateful to Valery Rigby for sending me the relevant entry from Dr Spratling's thesis which is quoted below. It is clearly an example of a winged terret, a type in use during the 1 st century AD (MacGregor 1976, 44).

223. Terret; copper alloy. 'Fragment of a cast bronze ring with a large circular stop, slightly hollowed out on one face; a triangular stump in the stop indicates the attachment bar was of the 'saddle' type. Running around the stop (but now obliterated at the top by wear) is a groove. The surviving section of the circular-sectioned ring has insets for red champlevé enamel, some of which has dropped out. A pair of lip-like wings is set transverse to the ring. Each wing has a groove around the outer edge and a pair of circular insets for red enamel. There are pronounced wear facets on the top of the circular stop and on the adjacent part of the inner face of the ring.' British Museum Dept of Prehistoric and Romano-British Antiquities. Accession no. 1910.10-1.4. Spratling 1972, catalogue no. 12, fig. 12. Not illustrated.

Military Equipment (Fig. 4.40)

Three certain military items have been identified at Ariconium and two other pieces could also be interpreted in this way. The fragments forming No. 224 are from a lobate hinge from the body armour known as lorica segmentata (see for example Bishop and Coulston 1993, fig. 52, no. 3). This type of hinge may be dated to the mid 1 st to mid 2 nd century. The openwork belt plate (no. 225) is typical of the style that came into use during the mid 2 nd century. It was for example the commonest belt plate type found in the fortress baths drain deposit accumulating during the period AD 160-230 (Brewer 1986, 175, nos 36-8). A similar later 2 nd to 3 rd century would also be appropriate for the vulva mount (no. 226; Bishop 1996, 71, no. 440, fig. 38).

There are also two iron weapons for which a military context could be appropriate. The arrowhead (no. 227) has four vanes and is possibly socketed (this item was not available for examination and the drawing is unclear). If this identification is correct, it might belong to one of the long socketed arrowheads for which a 3rd century date is normally suggested (Bishop and Coulston 1993,139, fig. 97, nos 2-3). The spearhead (no. 228) is not a type that is particularly chronologically sensitive within the Roman period, but it would not be out of place in a 2 nd to $3 \mathrm{rd}$ century military episode suggested by the other finds. An alternative explanation for its presence is, however, suggested below in connection with nos 230-2.

The phallic pendant (no. 229) cannot be precisely paralleled but is clearly of Roman date and is most likely to have been present as part of the military episode as such pendants are a common find on military sites.

224. Lorica segmentata lobate hinge; copper alloy. Thin sheet in 3 fragments. One side of hinge with 2 perforations, both sides of 3 lobed terminal fastened together with 3 domed rivets. Width $39 \mathrm{~mm}$, length $22 \mathrm{~mm}$. HSM 23551; SO 64672389; A/67 Trench C1, context 2, sf. 3; Garrod 1967.
225. Belt plate; copper alloy. One end of rectangular plate with central perforation in one end; broken across open fretwork pattern. Length $22 \mathrm{~mm}$, width $20 \mathrm{~mm}$. HSM 5324; SO 64352385; A/67, unstratified; Garrod 1967.

226. Vulva mount; copper alloy. Oval mount with central oval boss with narrow indentation down centre; 2 shanks on underside. Dimensions $23 \times 13 \mathrm{~mm}$. (Not seen; description from a drawing). HSM 23563; SO 64502418; Accession no. 4072; Sterry 1994.

227. Arrowhead; iron. Quadruple-vaned with broken socket. (Not seen; description from drawing). HSM 5324; SO 64502385, u/s; Walters 1989. Not illustrated.

228. Spearhead; iron. Lower-shouldered blade with broken oval-sectioned socket. (Not seen; description from drawing). HSM 9071; SO64252488; Accession no. 2973. Walters 1989. Not illustrated.

229. Phallic pendant; copper alloy. Flat circular suspension loop at $90^{\circ}$ to triangular plate with representation of male genitalia including erect phallus at base. (Not seen; description from a drawing). HSM 23563; SO64502418; Accession no. 4073; Sterry 1994.

An additional 1 st to 2 nd century copper alloy strap or belt buckle is noted from 1993 metal detecting. If correctly identified this would be most likely to be military as belts were not much used by civilians at that time.

\section{Religious items (Fig. 4.40)}

In addition to the iron spearhead (no. 228) discussed above, there are also three items which could perhaps best be described as spearheads made of copper alloy. As this material was not used to make such weapons in the Roman period, the possibility that these have some sort of ritual significance and indicate a temple site must be a distinct possibility. Certainly small spearheads have been found on undoubted temple sites such as Lamyatt Beacon (Leech 1986, 303, nos 43-54, Figs 29-30) and Uley (Woodward and Leech 1993, 131-5) where they have been interpreted as votive. It may also be noted that an iron spearhead was found below the temple at Lydney in a context that could possibly be interpreted as a foundation deposit (Wheeler and Wheeler 1932, 74, no. 3, fig. 8).

The deliberate piercing on no. 230 recalls the piercings on iron spear-shaped items termed rattles (Wheeler 1930, 108, pl. XLVIII, nos 1-3) which have rings threaded through the perforations. These have been interpreted as the sitra used in religious ceremonies. Some credence might be given to this as an example was found at Baldock in a late 4th century context which also contained a miniature, and probably votive, copper alloy spear (Manning and Scott 1986, 153, no. 523, fig. 66).

If the interpretation of no. 230 is correct then it might explain the tip of a copper alloy spearhead (no. 231) which seems more likely to be of early prehistoric origin than Roman. A chance find of such an item might be considered an appropriate offering at a temple where spears were offered. It might also explain the bizarre nature of no. 232 for which this specialist can offer no comparanda of any date. 
230. Spearhead; copper alloy. Leaf-shaped centrally ribbed blade with broken socket. Drilled hole on widest part of blade. Length c. $80 \mathrm{~mm}$. (Not seen; description from drawing). HSM 23563; SO64502418; Sterry 1994.

231. Spearhead; copper alloy. Tip of centrally ribbed blade. Length 47mm, maximum section $20 \times 7 \mathrm{~mm}$. HSM 23571; Gloucs. Mus. A1598; 1870 Palmer Coll.

232. Spearhead; copper alloy. Triangular-sectioned blade with circular-sectioned socket. Outer face of socket possibly faceted. Length $115 \mathrm{~mm}$, weight $48 \mathrm{~g}$. (Not seen; description from a drawing and notes). HSM 23563; SO64502421; Accession no. 4071; Sterry 1994.

\section{FASTENERS AND FITTINGS}

Keys and locks (Fig. 4.40)

The two small lever lock keys (nos 233-4) come from a distinctive form that was clearly in use during the later 1st and 2nd centuries given the examples from Castleford (Cool and Philo 1998, 109, nos 645 and 648) and Cirencester (Viner 1986, 239, no. 7) in contexts of that date. A key ring is also recorded from the Palmer collection (no. 235), it is likely to have been either one with a lever lock (see for example Birley 1997, 20, no. 38 ) or for a tumbler lock (ibid. 20, no. 40). These are a 3 rd to 4 th century form.

No. 236 might be the bolt from a tumbler lock. It has a stepped ridge down one side like that often seen on such bolts (see Crummy 1983, 124, nos 4133-6), though the openings for the key wards are usually much more complex.

233. Lever lock key; copper alloy. Semi-circular rectangularsectioned loop handle with mushroom-shaped central opening; rectangular-sectioned block below connecting handle to piped stem broken on one side; bit has 2 notches at outer edge and I on lower edge by stem. Length $34 \mathrm{~mm}$, width of bit and stem 3.5mm. HSM 23571; Gloucs. Mus. A1632; 1870 Palmer Coll. Hills 1871, 207, no. 35.

234. Lever lock key; copper alloy. Description as no. 210 but well developed ridge top and bottom of block and notches on outer edge of bit decorative rather than practical. Length 40mm, length of bit and stem 34mm. HSM 23571; Gloucs. Mus. A1633; 1870 Palmer Coll. Hills 1871, 206, no. 36. Not illustrated.

235. Lever lock key ring; copper alloy. Not seen. HSM 23571; Gloucs. Mus. A3707; 1870 Palmer Coll. Hills 1871, 206, no. 37. Not illustrated.

236. Lock bolt? copper alloy. Rectangular-sectioned block slightly curved; one end has angular step down; other ends in L-shaped bar with circular-sectioned terminal. Diagonal ridge on one face of bar. Length $44 \mathrm{~mm}$, Maximum section $7 \times 5 \mathrm{~mm}$. HSM 23571; Gloucs. Mus. A1684; 1870 Palmer Coll.

Box FITTINGS AND STUdS (Fig. 4.41)

The Jack excavations produced a variety of mounts and studs (nos 237-47) that would be appropriate for box fittings. Similar mounts and composite studs such as nos 246-8 are known on a casket used in a mid to late 2 nd century burial at Skeleton Green (Partridge 1981, 305), and composite studs were also used in 4th century caskets (Crummy 1983, 85, nos 2179-82). No. 250 from the same excavation may well have been a lock pin (see for example Crummy 1983, 124, no. 4142). As there are no contextual details about these finds it is not possible to say if any of them were found together, but they might have come from a single casket.

Other box fittings may be represented by the sheet fittings (nos 248-9), a composite stud (no. 251) and two small decorated bone discs (nos 252-3). These seem more likely to be inlay than bone counters such as nos 213-6 because their backs have been left unfinished. Bone inlay was often used to decorate late Roman caskets (see for example Henderson 1949, 152, no. 276), though of course such decoration continued into the medieval period and there can be no certainty that these are of Roman date. The figured sheet fragment (no. 254) may have been a box fitting as well as the back does not appear to have been intended for view. The style of cutting looks as if the piece could be of Roman date.

No. 255 is a bell-shaped stud of Allason-Jones (1985) Type 1. Bell-shaped studs are common finds on RomanoBritish sites and seem to have been in use throughout the Roman period. They seem to have served a variety of functions such as lock pins, handles etc. The other copper alloy studs and nail (nos 256-64) can all be paralleled amongst securely stratified Roman material, but without secure contexts this material is not independently dateable.

237. Mount; copper alloy. Circular domed hollow-backed mount with raised circular ridge and central dot. Diameter $33 \mathrm{~mm}$, depth 13mm. HSM 16780; SO64672405; Heref. Mus. 7639/61; Jack 1922; Jack 1923, 24, pl. 12, fig. 9.

238. Mount; copper alloy. Circular hollow-backed mount with flat flange; shallowly domed with central raised dot; lead alloy on underside of raised dot. Broken off-centre. Diameter 27mm. HSM 16780; SO64672405; Heref. Mus. 7639/59; Jack 1922.

239. Mount; copper alloy. Circular with curved flange edge and raised ring midway between edge and centre; central perforation. Edge damaged. Diameter $37 \mathrm{~mm}$. HSM 16780; SO64672405; Heref. Mus. 7639/60; Jack 1922. Not illustrated.

240. Mount; copper alloy. Circular mount with flat broken flange around outer edge; domed inner ring with central perforation. Diameter 44mm. HSM 16780; SO64672405; Heref. Mus. 7639/62; Jack 1922. Not illustrated.

241. Stud; copper alloy. Hollow-backed hemispherical head with short square-sectioned shank. Diameter $13 \mathrm{~mm}$., length 10mm. HSM 16780; SO64672405; Heref. Mus. 7639/64; Jack 1922. Not illustrated.

242. Stud head; copper alloy. Hollow-backed hemispherical dome with rounded flange; one edge damaged. Diameter 17mm. HSM 16780; SO64672405; Heref. Mus. 7639/65; Jack 1922. Not illustrated.

243. Stud head; copper alloy. Hollow-backed hemispherical dome. Diameter 16mm. HSM 16780; SO64672405; Heref. Mus. 7639/67; Jack 1922. Not illustrated.

244. Stud head; copper alloy and lead (?) alloy. Domed 
hemispherical copper alloy head with remnants of lead alloy infilling; iron corrosion products centrally, possibly from shank. One edge chipped and all much corroded. Diameter 16mm. HSM 16780; SO64672405; Heref. Mus. 7639/68; Jack 1922. Not illustrated.

245. Stud head; copper alloy and lead (?) alloy. Description as No. 244. Diameter 13mm. HSM 16780; SO64672405; Heref. Mus. 7639/68; Jack 1922. Not illustrated.

246. Stud head; lead alloy. Fragment of infill as No. 244. Diameter 13mm. HSM 16780; SO64672405; Heref. Mus. 7639/68; Jack 1922. Not illustrated.

247. Stud; copper alloy. Flat circular head; short squaresectioned shank set off-centre. Diameter $18 \mathrm{~mm}$, length $11 \mathrm{~mm}$. HSM 16780; SO64672405; Heref. Mus. 7639/63; Jack 1922. Not illustrated.

248. Box fitting (?); copper alloy. Three sheet fragments, one retaining small rivet and second rivet hole and parts of two edges at right angles to each other bent over and down. Largest fragment $26 \times 14.5 \mathrm{~mm}$, thickness $0.5 \mathrm{~mm}$. HSM 21376; SO 64492395; DAG Fieldwalking 1984-9. Not illustrated.

249. Mount; copper alloy. Rectangular strip with perforated terminal. Length $15.5 \mathrm{~mm}$, section $5.5 \times 1 \mathrm{~mm}$. HSM 21376; SO 64602400; DAG Fieldwalking 1984-9. Not illustrated.

250. Lock pin?; copper alloy. Sub-circular slightly conical head with central damaged point; broken rectangular-sectioned shank. Diameter of head $22 \mathrm{~mm}$, shank section $9 \times 2 \mathrm{~mm}$. HSM 16780; SO64672405; Heref. Mus. 7639/66; Jack 1922. Not illustrated.

251. Stud head?; copper alloy and lead (?) alloy. Broken domed head with broken flange, infill remnants of ? lead solder. Present diameter 23mm. HSM 15983; SO 63732331; WW1, context 105; Jackson 1993. Not illustrated.

252. Inlay?; bone. Oval disc with inwardly bevelled edge; flat obverse with deep central pit and concentric groove; reverse roughly finished showing cancellous tissue. Diameter $12.5 \times 11 \mathrm{~mm}$, thickness 5mm. HSM 16780; SO 64672405; Heref. Mus. 7639/20; Jack 1922.

253. Inlay?; bone. Oval disc with straight edge; flat obverse with deep central pit and 2 concentric grooves; reverse roughly finished showing cancellous tissue. Diameter 17 $\times 15 \mathrm{~mm}$, thickness $4 \mathrm{~mm}$. HSM 16780; SO 64672405; Heref. Mus. 7639/17; Jack 1922.

254. Mount?; copper alloy. Fragment of sheet with broken and cut edges; now bent in two. Lightly incised figurative scheme of seated figure facing right, holding up a laurel wreath. 2 lightly punctuated vertical lines in front of figure with ? edge of large wreath beyond them. Cut edges ignore pattern. Dimensions c. $90 \times 40 \mathrm{~mm}$. HSM 23557; SO 64762404; DAG 1989 (Walters).

255. Bell-shaped stud; copper alloy. Inverted truncated cone head with flat base and cylindrical sides adjacent to upper face; upper face has sunken field around projecting central cone, top of cone has central concavity. 2 grooves around margin of upper face and 1 on cylindrical side. Traces of (?) iron shank flush with base. Length $15 \mathrm{~mm}$., diameter 26mm. HSM 21376; SO 64502400; DAG Fieldwalking 1984-9 (Walters).

256. Stud; copper alloy. Cast flat-headed stud; thick shank and integral washer. Length $8 \mathrm{~mm}$, head diameter $10 \mathrm{~mm}$, washer diameter $8 \mathrm{~mm}$. HSM 23571; Gloucs. Mus.
A1671; 1870 Palmer Coll. Hills 1871, 206, no. 31. Not illustrated.

257. Stud; copper alloy. Cast flat head with groove around margin; blunt circular-sectioned shank. Length $10 \mathrm{~mm}$, head diameter $10 \times 9 \mathrm{~mm}$, shank section $3 \mathrm{~mm}$. HSM 23571; Gloucs. Mus. A1675; 1870 Palmer Coll. Not illustrated.

258. Stud; copper alloy. Domed sheet head; circular-sectioned bent shank tapering to point. Head diameter $17 \mathrm{~mm}$, length 32mm. HSM 23547; SO 64682377; A/67, Trench AII, context 2, sf. 1; Garrod 1967. Not illustrated.

259. Stud; copper alloy. Domed circular head, edges chipped; short oval-sectioned shank with burred end. Diameter of head 8mm, length 4mm. HSM 21376; SO 64602400; DAG Fieldwalking 1984-9. Not illustrated.

260. Stud; copper alloy. Hemispherical domed head; squaresectioned pointed shank. Length $9.5 \mathrm{~mm}$, head diameter 11,5mm, shank section 2mm. HSM 23571; Gloucs. Mus. A1673; 1870 Palmer Coll. Not illustrated.

261. Stud; copper alloy. Hemispherical domed head; broken square-sectioned shank. Diameter 16mm, thickness of head $7 \mathrm{~mm}$. HSM 21376; SO 64602400; DAG Fieldwalking 1984-9. Not illustrated.

262. Stud; copper alloy. Square-sectioned tapering shank; fragment of flat head. Length $17 \mathrm{~mm}$. HSM 21376; SO 64602400; DAG Fieldwalking 1984-9. Not illustrated.

263. Stud; copper alloy. flat circular head; very short circular sectioned shank. Head diameter $10 \mathrm{~mm}$, head thickness $1 \mathrm{~mm}$, length 2mm. HSM 21376; SO 64602400; DAG Fieldwalking 1984-9. Not illustrated.

264. Stud; copper alloy. Fragment from stud as No. 263 above. HSM 21376; SO 64602400; DAG Fieldwalking 1984-9. Not illustrated.

265. Stud; copper alloy. Circular slightly domed head with broken shank. Diameter 15mm HSM 23547; SO64682377; A/67, Trench AII, context 3, sf. 3; Garrod 1967. Not illustrated.

266. Nail; copper alloy and lead(?) alloy. Flat disc head bent at an angle to shank with a layer of ? lead solder between it and a flat copper alloy sheet capping. Circular-sectioned shank tapering to point. Length $49 \mathrm{~mm}$. Head diameter 10mm. HSM 23552; SO64452405; A/67, Robber trench, CXX, sf. 22; Garrod 1967.

OTHER FASTENINGS AND FITTINGS (FIG. 4.41)

The small clip (No. 267) is a type of fitting that is frequently found in assemblages of copper alloy from Roman sites (Cool 1990, 83, nos 51-7). They are not closely dated and their function is uncertain but they are probably some form of fastener. The small model of a cock (no. 268) appears very likely to be Roman on stylistic grounds. The recess on the underside suggests it might have been a terminal, possibly from an item of furniture. Alternately it might have allowed the attachment of the figure to a larger figural group. As the cockerel is an attribute of Mercury, it is very likely that many were part of small sculptural groups depicting this god such as that found at Verulamium where Mercury is surrounded by the figures of a ram, a tortoise and a cockerel, each separately cast (Henig 1984, 60-61, fig. 19). The ferrule (no. 269) could be of any date. 

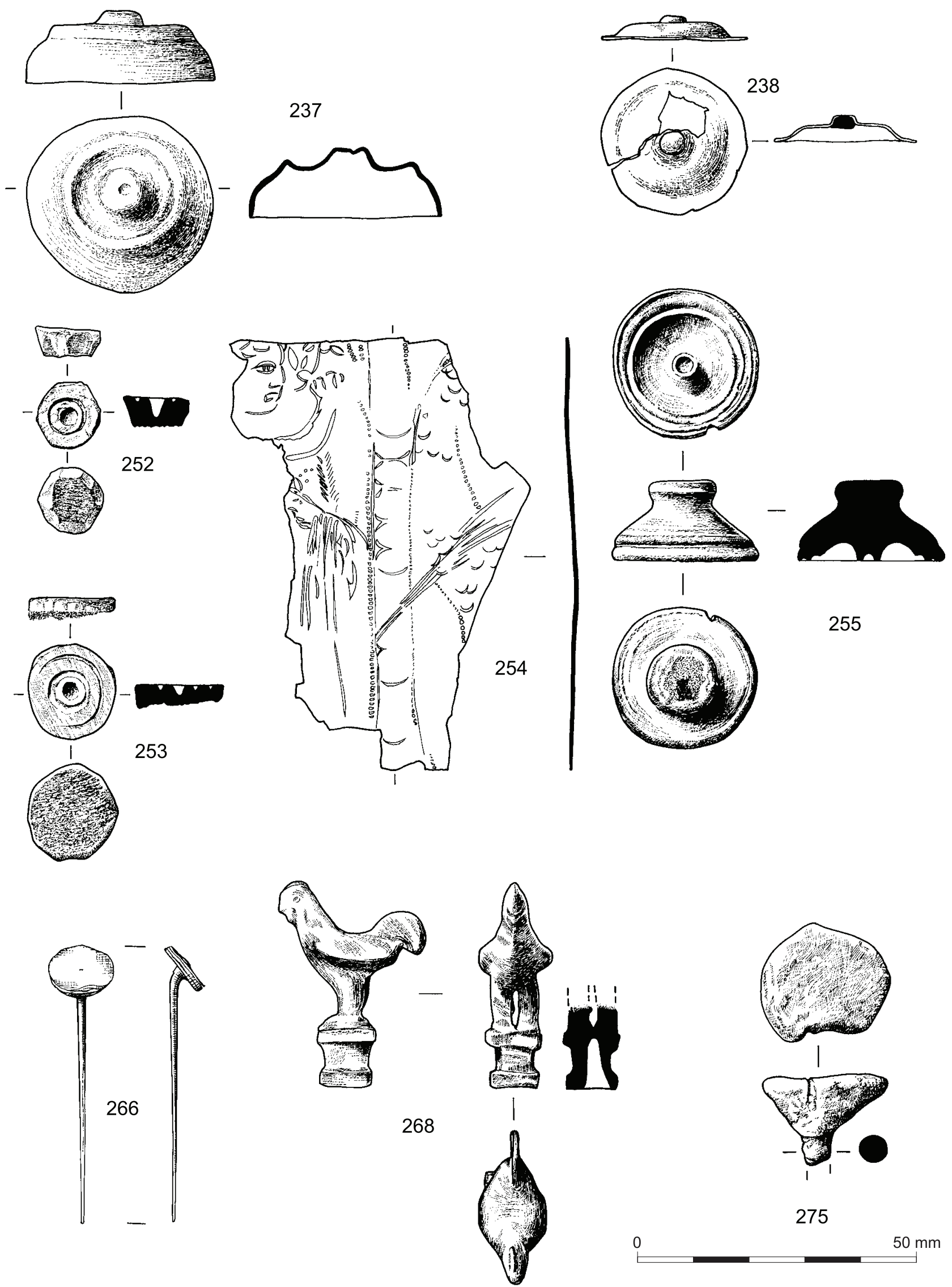

Figure 4.41. Other small finds (Box fittings and studs, other fastenings and fittings and metalworking finds) 
267. Clip; copper alloy. Diamond-shaped piece of sheet, ends folded in towards centre and then back out; the whole flattened. Length $22 \mathrm{~mm}$, width $13 \mathrm{~mm}$. HSM 23571; Gloucs. Mus. A1693; 1870 Palmer Coll. Not illustrated.

268. Terminal; copper alloy. Small figure of cock standing on small square plinth; circular recess on underside. HSM 23571; Gloucs. Mus. A1636; 1870 Palmer Coll. Hills 1871, 207, no. 54.

269. Ferrule; copper alloy. Cast rectangular strip bent into penannular ring. Outer face has 3 long ribs central one widening to terminal ends. Diameter $9 \mathrm{~mm}$, section $10 \times$ 1.5mm. HSM 23571; Gloucs. Mus. A1644; 1870 Palmer Coll. Not illustrated.

\section{STRUCTURAL FINDS}

There is a single fragment of cast window glass (no. 270) indicating the presence of glazed buildings during the $1 \mathrm{st}$ to 3 rd centuries. The sheet lead fragments could well be Roman but are not intrinsically dateable.

270. Window glass; fragment. Blue/green; cast; one edge fire rounded. Area $8 \mathrm{~cm}^{2}$; thickness $2.5 \mathrm{~mm}$. HSM 16780; SO 64672405; Heref. Mus. 7639/45; Jack 1922. Not illustrated.

271. Sheet; lead alloy. Weight 342gr. HSM 16780; SO 64672405; Heref. Mus. 7639/73; Jack 1922. Not illustrated.

272. Sheet; lead alloy. Weight 24gr. HSM 16780; SO 64672405; Heref. Mus. 7639/72; Jack 1922. Not illustrated.

273. Sheet; lead alloy. Weight 40gr. HSM 16780; SO 64672405; Heref. Mus. 7639/70; Jack 1922. Not illustrated.

\section{MetalwORKING FINDS}

The presence of an unfinished Colchester brooch has been discussed in the brooch report (Glos A6282; Mackreth: Catalogue no. 9). Other evidence of the working of copper alloys is indicated by the presence of waste debris from casting (nos 274-88) and offcuts from trimming (nos 289-306).

274. Runner? copper alloy. Triangular-sectioned rod. Length $28 \mathrm{~mm}$, section $7 \times 3.5 \mathrm{~mm}$. HSM 23571; Gloucs. Mus. A1667; 1870 Palmer Coll. Not illustrated.

275. Sprue (?); copper alloy. Irregular solid cone with broken circular-sectioned shank below. Diameter $21.5 \times$ 20mm, length 16mm. HSM 10008: SO 64802385; DAG Fieldwalking 1984-9.

276. Casting waste; copper alloy. HSM 23571; Gloucs. Mus. A1662; 1870 Palmer Coll. Not illustrated.

277. Casting waste; copper alloy. HSM 23571; Gloucs. Mus. A1663; 1870 Palmer Coll. Not illustrated.

278. Casting waste; copper alloy. HSM 23571; Gloucs. Mus. A1664; 1870 Palmer Coll. Not illustrated.

279. Casting waste; copper alloy. HSM 23571; Gloucs. Mus. A1665; 1870 Palmer Coll. Not illustrated.

280. Casting waste; copper alloy. HSM 23571; Gloucs. Mus. A1666; 1870 Palmer Coll. Not illustrated.

281. Casting waste; copper alloy. 23 fragments. HSM 21376; SO 64602400; DAG Fieldwalking 1984-9. Not illustrated.

282. Casting waste; copper alloy. 15 fragments. HSM 10676; SO 64302435; DAG Fieldwalking 1984-9. Not illustrated.

283. Casting waste; copper alloy. 1 fragment. HSM 10676; SO
64302450; DAG Fieldwalking 1984-9. Not illustrated.

284. Casting waste; copper alloy. 9 fragments. HSM 10008; SO 64752375; DAG Fieldwalking 1984-9. Not illustrated.

285. Casting waste; copper alloy. 1 fragment. HSM 10008; SO 64802371; DAG Fieldwalking 1984-9. Not illustrated.

286. Casting waste; copper alloy. 2 fragments. HSM 23555; SO 64262431; DAG Fieldwalking 1984-9. Not illustrated.

287. Casting waste; copper alloy. 2 fragments. HSM 5324; SO 64282388; DAG Fieldwalking 1984-9. Not illustrated.

288. Casting waste; copper alloy. 2 fragments. HSM 5324; SO 64202401; DAG Fieldwalking 1984-9. Not illustrated.

289. Offcut? copper alloy. Roughly dumb-belled hammered rod with chopped off ends. Length $28 \mathrm{~mm}$, maximum section 4.5x3mm. HSM 23571; Gloucs. Mus. A1642; 1870 Palmer Coll. Not illustrated.

290. Offcut; copper alloy. Cast fragment with trimming marks. Dimensions $25 \times 7 \times 2.5 \mathrm{~mm}$. HSM 23571; Gloucs. Mus. A1645; 1870 Palmer Coll. Not illustrated.

291. Offcut; copper alloy. Strip. Length $29 \mathrm{~mm}$, maximum section $3.5 \times 1$. HSM 23571; Gloucs. Mus. A1647; 1870 Palmer Coll. Not illustrated.

292. Offcut; copper alloy. Twisted rectangular-sectioned sheet. Length $c$. $40 \mathrm{~mm}$, section $3 \times 2 \mathrm{~mm}$. HSM 23571; Gloucs. Mus. A1648; 1870 Palmer Coll. Not illustrated.

293. Offcut; copper alloy. Sheet. Dimensions $18 \times 6 \times 1 \mathrm{~mm}$. HSM 23571; Gloucs. Mus. A1653; 1870 Palmer Coll. Not illustrated.

294. Offcut? copper alloy. Triangular strip folded and crushed flat. Dimensions $11.5 \times 7 \times 3 \mathrm{~mm}$. HSM 23571; Gloucs. Mus. A1660; 1870 Palmer Coll. Not illustrated.

295. Offcut; copper alloy. Triangular with trimming marks. HSM 23571; Gloucs. Mus. A1661; 1870 Palmer Coll. Not illustrated.

296. Offcut; copper alloy. Length $35 \mathrm{~mm}$, section $3 \times 1 \mathrm{~mm}$. HSM 23571; Gloucs. Mus. A1674; 1870 Palmer Coll. Not illustrated.

297. Offcut; copper alloy. Length $26 \mathrm{~mm}$, section $9 \times 3 \mathrm{~mm}$. HSM 23571; Gloucs. Mus. A1685; 1870 Palmer Coll. Not illustrated.

298. Offcut; copper alloy. Length $38 \mathrm{~mm}$, section $4 \times 2 \mathrm{~mm}$. HSM 23571; Gloucs. Mus. A1686; 1870 Palmer Coll. Not illustrated.

299. Offcut; copper alloy. Length $27 \mathrm{~mm}$, section $5 \times 3 \mathrm{~mm}$. HSM 23571; Gloucs. Mus. A1687; 1870 Palmer Coll. Not illustrated.

300. Offcut; copper alloy. Triangular strip tapering to point bent over to form hook. Length $27 \mathrm{~mm}$, maximum section 8x1mm. HSM 23571; Gloucs. Mus. A1690; 1870 Palmer Coll. Not illustrated.

301. Offcut; copper alloy. Strip. Length $37 \mathrm{~mm}$, section $5 \times$ 2mm. HSM 21376; SO 64602400; DAG Fieldwalking 1984-9. Not illustrated.

302. Offcut; copper alloy. Strip. Length $37 \mathrm{~mm}$, section $6.5 \times$ $1 \mathrm{~mm}$. HSM 21376; SO 64602400; DAG Fieldwalking 1984-9. Not illustrated.

303. Offcut; copper alloy. Strip with bevelled end. Length $42 \mathrm{~mm}$, section $6.5 \times 2 \mathrm{~mm}$. HSM 21376; SO 64602400; DAG Fieldwalking 1984-9. Not illustrated.

304. Offcut; copper alloy. Strip with hammering marks on both faces. Length $41.5 \mathrm{~mm}$, section $15 \times 2 \mathrm{~mm}$ HSM 21376 ; SO 64602400; DAG Fieldwalking 1984-9

305. Offcuts; copper alloy. 28 sheet fragments, many as thin 
strips; some folded. Largest fragment $28 \times 14 \mathrm{~mm}$. HSM 21376; SO 64602400; DAG Fieldwalking 1984-9. Not illustrated.

306. Offcut; copper alloy. Cast. Dimensions $28 \times 11 \times 2 \mathrm{~mm}$. HSM 23571; Gloucs. Mus. A1691; 1870 Palmer Coll. Not illustrated.

307. Glassy slag. 2 fragments. HSM 21376; SO 64462398; DAG unstratified. Not illustrated.

A number of other copper alloy working items were recorded at HSM 15983 during the Welsh Water salvage recording project. These included three crucible fragments and two fragments of casting waste (Starley 1995).

\section{Ceramic counters and dises}

\section{Steven Willis}

Apart from the items described above, a number of counters and discs were recorded within the ceramic assemblage. These are catalogued below.

\section{BRIDGEWATER EXCAVATIONS 1963}

1. A well-fashioned disc, c. $21 \mathrm{~mm}$ in diameter, from a vessel in Fabric R21, 3g; presumably a counter. Context 1. Not illustrated.

2. A disc, c. $21 \mathrm{~mm}$ in diameter, from a vessel in Fabric S03, $3 \mathrm{~g}$; presumably a counter. Context 1 . Not illustrated.

3. A disc, c. $25 \mathrm{~mm}$ in diameter, from a vessel in Fabric O11, 5g; presumably a counter. HSM 21360; Area A, context 1. Not illustrated.

4. A well-fashioned disc, c. $22 \mathrm{~mm}$ in diameter, from a vessel in Fabric O12, 5g; presumably a counter. HSM 23558; Area C, context 1 . Not illustrated.

5. A disc, c. $70-84 \mathrm{~mm}$ in diameter, from the wall of a vessel in Fabric R2O, 48g; presumably a counter. From 'TH 1'. Not illustrated.

Garrod and Moss excavations 1967

6. A disc, c. $45 \mathrm{~mm}$ in diameter, from the junction of the wall and base of a vessel in Fabric R29, 35g; presumably a counter. HSM 23548; Trench BI, context 2b. Not illustrated.

7. A crudely fashioned disc, c. 58-67mm in diameter, from the wall of a vessel in Fabric C11, 51g; a hole c. $7 \mathrm{~mm}$ in diameter has been drilled through the centre of the disc; possibly used as a weight. HSM 23550; Trench B III, context 2. Not illustrated.

\section{SuRfaCe COLLECTION}

8. A damaged disc, c. $26 \mathrm{~mm}$ in diameter, from a vessel in Fabric O16, 6g; presumably a counter. HSM 21376; SO 64622384; AR 100-4; DAG 1986. Not illustrated.

9. 9. A disc, c. $58-66 \mathrm{~mm}$ in diameter, from the wall of a vessel in Fabric O16, 28g; presumably a counter. HSM 21376; SO 64642381; AR 100-3; DAG 1986. Not illustrated.

\section{Worked stone}

\section{Ruth Shaffrey and Fiona Roe}

\section{Analysis and discussion}

Excavations and fieldwork have produced a wide collection of stone objects including several rotary quern fragments. Almost all of these appear to have been manufactured from a pebbly sandstone or Quartz Conglomerate of the Old Red Sandstone (ORS) which would have been readily available within a few kilometres of the site (Dreghorn 1968, 63). This corresponds well with what is already known about the exploitation of Old Red Sandstone for rotary querns as it was common for sites within close proximity of a good stone resource to have relied on it almost entirely. Gatcombe and Chew Valley Lake would be two prime examples (Horwell 1977, 99-102; Rahtz and Greenfield 1977, 202-203). Other sites where ORS was locally available almost always exploited it for example the Chesters, Woolaston and Chepstow (Fulford and Allen 1992, 186; Hughes 1996, 78).

Old Red Sandstone was not, however, merely a locally exploited material. It was used extensively further afield at sites including Sidbury, Worcester (Darlington and Evans 1992, 29), Silchester in Hampshire (Fulford 1984; 1989), Alcester in Warwickshire (Evans 1994, 231-248), Mantles Green in Buckinghamshire (Stewart 1992, 172) and many other sites in Oxfordshire, Wiltshire, Gloucestershire, South Wales, Dorset and Bedfordshire to name a few. Over 100 Romano-British sites have produced querns made from Old Red Sandstone which had been extracted from the outcrops close to the River Wye and this is likely to have been the primary route along which querns were transported. Indeed the presence of millstones on the bed and banks of the River Wye illustrate their transportation along the river in the past and fieldwork has revealed millstone quarries close to the river (Tucker 1972, 232-233). Distribution of these querns might naturally have passed through Ariconium.

Of the quern fragments recovered, at least one produced two fragments of a typically Late Iron Age 'Beehive' style rotary quern (HSM 21376; Nos 1 and 2; Fig. 4.42). The other fragments are of the typical Romano-British 'disc' type with diameters between $0.36-0.50 \mathrm{~m}$ and thicknesses between $32-65 \mathrm{~mm}$ (nos 3-7). Most of the quern fragments seen were of average dimensions and pecked all over, this being by far the most common treatment of Old Red Sandstone querns (Saunders 1998). One fragment had been deeply incised with widely spaced grooves reminiscent of the imported lava querns (no. 5). This is relatively rare for Old Red Sandstone querns occurring on roughly one in ten, although urban sites are where they are most commonly found (ibid.). The fragments seen were also in varied states of wear. All were slightly to moderately worn all over while one (no. 7) had an extremely well worn grinding surface. A complete quern of Old Red Sandstone is also recorded, although this was not seen by the author (no. 8). 

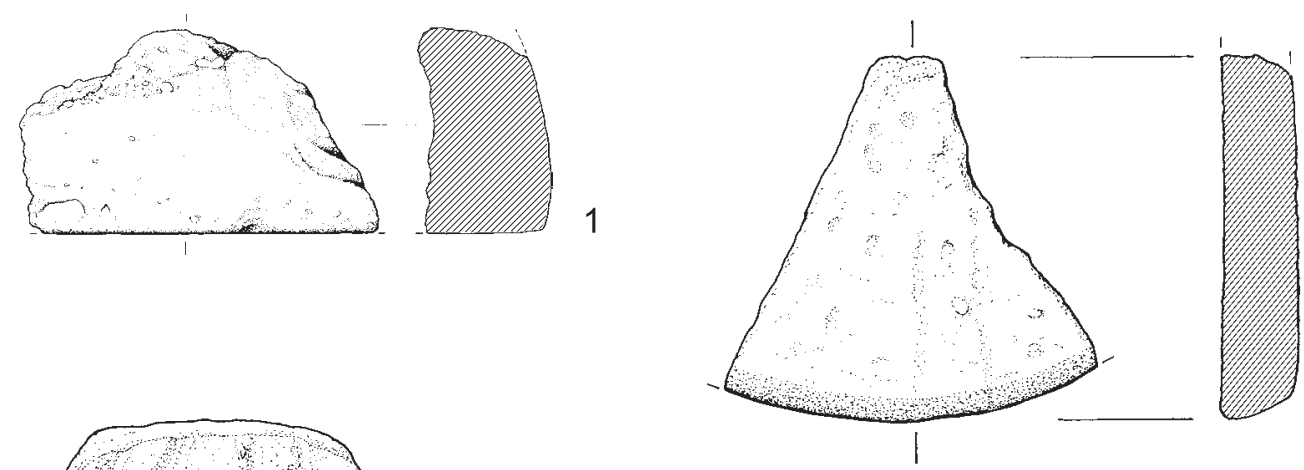

4
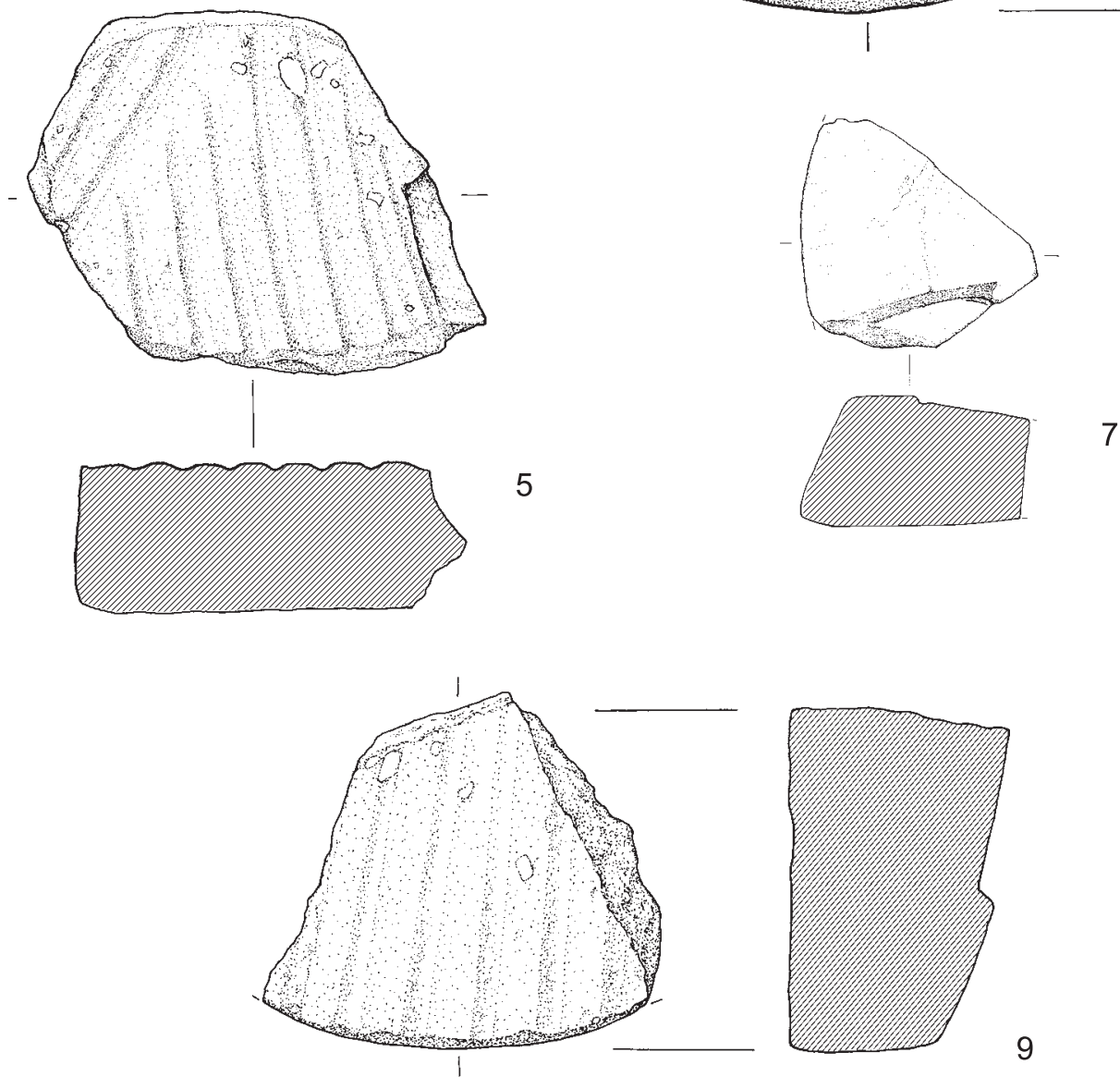

0

$200 \mathrm{~mm}$

Figure 4.42. Quernstones/millstones

One further fragment has been recorded and could well represent part of a millstone (no. 9; Fig. 4.43). This is not unexpected, however, when one considers that other millstones have been recovered from many of the larger sites including Woolaston (Fulford and Allen 1992, 201), Kenchester (Wilmott and Rahtz 1988, 150) and Usk (Welfare 1995, 236). Although Old Red Sandstone querns were manufactured in South Wales, the Bristol area and in the Mendips, present evidence indicates that the larger millstones predominantly came from the Forest of Dean/ Wye Valley area (Saunders 1998). We would therefore expect to see examples from Ariconium. The presence of one or more millstones is significant, however, for the interpretation of the site as their presence indicates a more organised and larger scale production of flour.

Several whetstones have also been recovered and appear to have largely been manufactured from local materials (nos 10-14). Previous excavators were overzealous in their preservation of possible stone implements with the result that several of the 'whetstones' are little more than broken pebbles which had been well shaped by water action. The whetstones which have been identified, however, are also mainly utilised river worn pebbles and those which had never been used may well have been intended for this purpose.

One notable example appears to be made from Kentish 
Rag (no. 15). These Kentish Rag whetstones are found widely on Roman sites, occurring for instance at Wroxeter (Williams 1988). The fragments from Ariconium suggest that the site may have been on the main trading networks for this and other widely distributed material such as Purbeck marble and Kimmeridge shale. An alternative whetstone material, perhaps for a different kind of sharpening, was the Coal Measures sandstone or finer-grained Millstone Grit used for another whetstone fragment recovered from fieldwalking (no. 16).

Other interesting stone finds include two spindle whorls (Fig. 4.44; nos 17 and 18) and two small discs, which are likely to have been gaming counters (Nos 19 and 20). Both of the gaming counters appear to be made from the Lower Old Red Sandstone Brownstones, which was available in the vicinity of the site (Dreghorn 1968, 64). These Roman gaming discs were often made from broken roofing tiles as was the case at Wroxeter (Williams 1988). At Kenchester the local Old Red Sandstone was used for roofing, and again made into discs (Wilmott and Rahtz 1988, archive $\mathrm{H}$ and fig. 7). Although not individually catalogued there is also some slender evidence for the use of the Old Red Sandstone Brownstones at Ariconium for roofing or paving (e.g. three small fragments of tile/paving were recovered from HSM 6097, context 701; Jackson, Hancocks and Pearson 1999).

\section{Catalogue}

\section{Quernstones/millstones (Figs 4.42 and 4.43)}

1. Fragment of lower stone of 'beehive style' rotary quern. $0.36 \mathrm{~m}$ diameter. Quartz Conglomerate from the Forest of Dean. HSM 21376; surface find; DAG 87.

2. Small fragment of upper stone of beehive style rotary quern, diameter $0.37 \mathrm{~m}$. Quartz Conglomerate from the Forest of Dean. HSM 21376; surface find; DAG 87.

3. Fragment of upper stone of disc type rotary quern. Estimated diameter $0.50 \mathrm{~m}$. $60 \mathrm{~mm}$ max thickness. Upper Old Red Sandstone. HSM 15983; SO 63732331; context 105; Jackson, Hancocks and Pearson 1993. Not illustrated.

4. Fragment of upper stone of disc type rotary quern. ?Pecked grinding surface. Estimated diameter $0.48 \mathrm{~m} .32 \mathrm{~mm} \max$ thickness. Upper Old Red Sandstone. HSM 6097; Trench 4, context 403; Jackson, Hancocks and Pearson 1993.

5. Small fragment of upper stone of disc type rotary quern with deep lava style grooves. Quartz Conglomerate from the Forest of Dean. HSM 21376; surface find; DAG 87.

6. Fragment of upper stone of rotary quern. Quartz Conglomerate from the Forest of Dean. HSM 21376; surface find; DAG 87. Not illustrated.

7. Fragment of upper stone of a rotary quern with evidence of the handle slot. Quartz Conglomerate from the Forest of Dean. HSM 23548; SO 64672376; Tr. B1, context 2B; Garrod 1967.

8. Complete rotary quern. Quartz Conglomerate from the Forest of Dean. (Not seen; part of Dean Heritage Centre collection). HSM 21377; surface find; 1974 (Finder not known). Not illustrated.
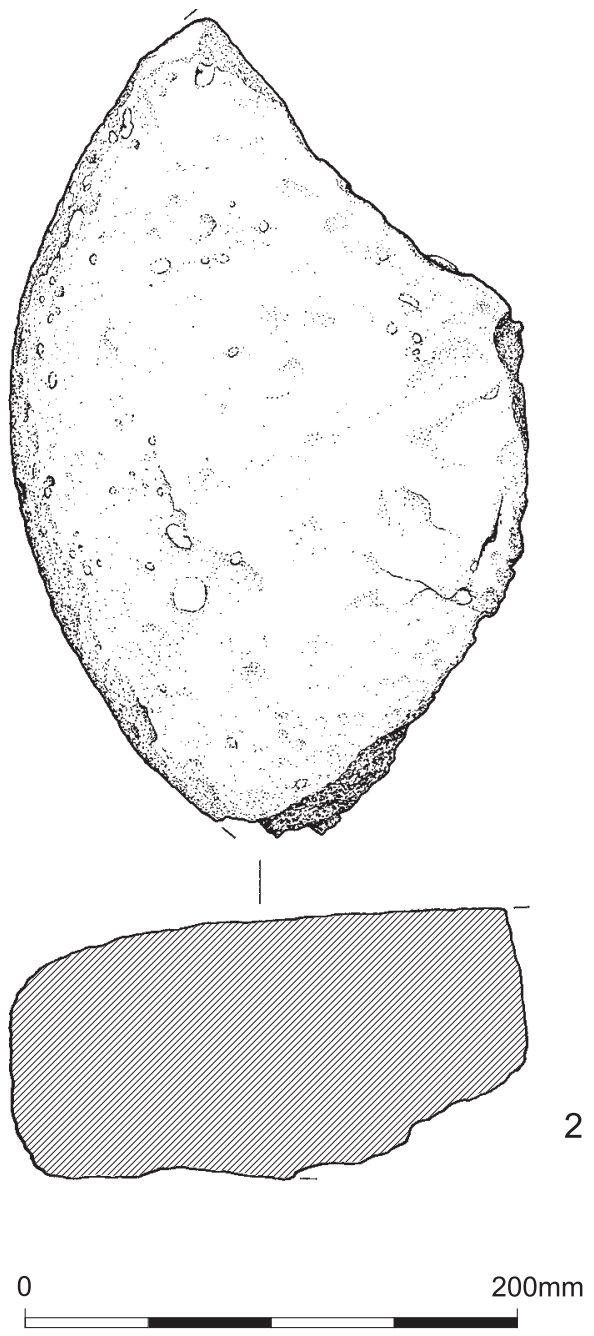

Figure 4.43. Quernstones/millstones

9. Quern or millstone with grooved grinding surface. Wear on outer edge. 96mm max thickness. Upper Old Red Sandstone Quartz Conglomerate. HSM 6097: Trench 2, context 205; Jackson, Hancocks and Pearson 1993.

\section{Whetstones (Fig. 4.44)}

10. Well used whetstone with long deep scars. Fine grained Old Red Sandstone Brownstones, obtainable locally. HSM 23552; SO 64452405; Tr. CXX, pit 1; Garrod 1967.

11. Fine whetstone with tiny scratch marks. Very fine grained. HSM 16780; SO 64672405; Heref. Mus. A7639/1299; Jack 1922. Not illustrated.

12. Whetstone, broken at one end. Fine grained micaceous sandstone, possible Lower Old Red Sandstone Brownstone. HSM 21376; surface find; DAG 87. Not illustrated.

13. Well used whetstone with well worn edges and rougher surfaces. Very fine grained grey sandstone, probably local. HSM 21376; surface find; DAG 87. Not illustrated.

14. Whetstone fragment. Old Red Sandstone. HSM 6097: Trench 11, context 1103; Jackson, Hancocks and Pearson 1993. Not illustrated. 

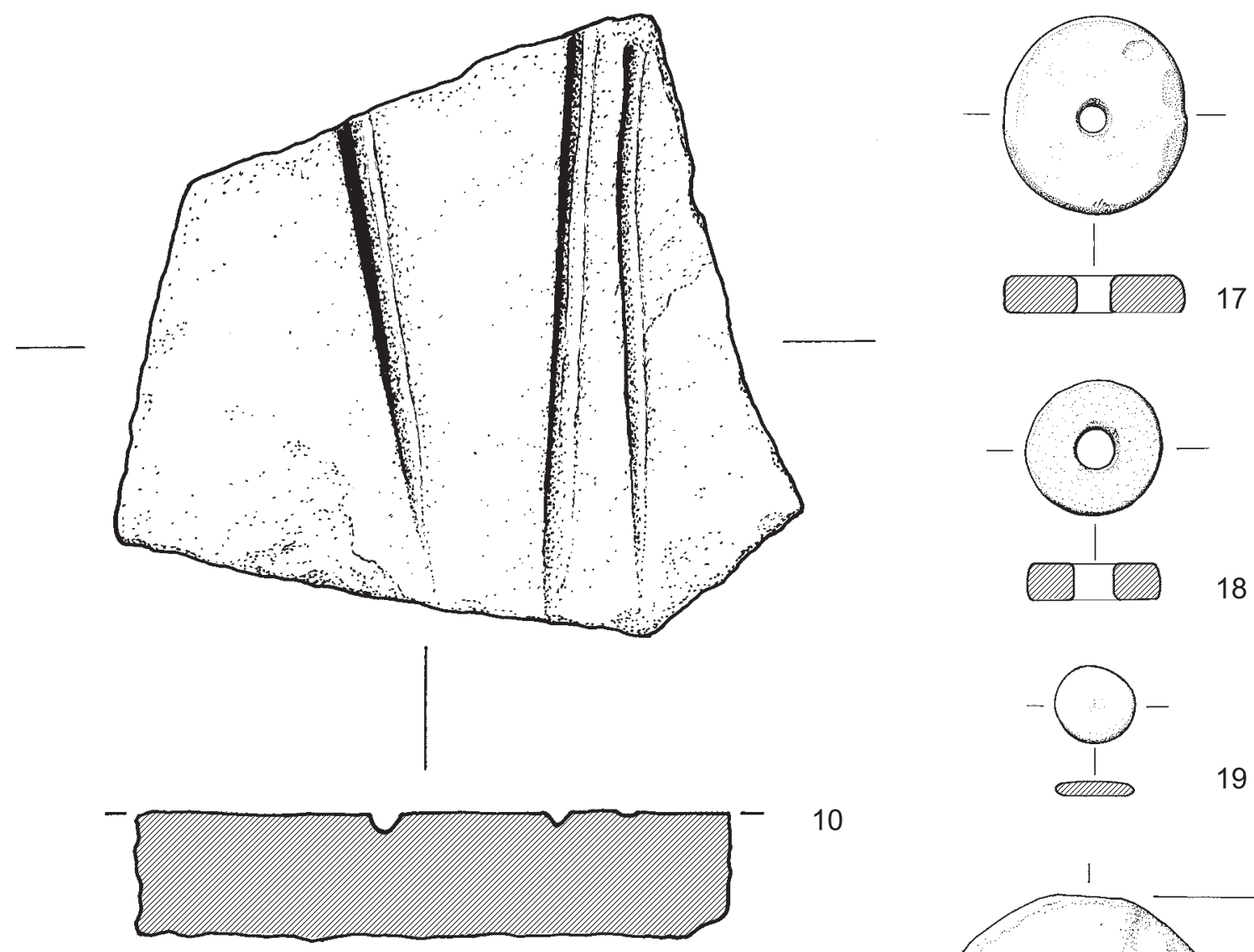

19
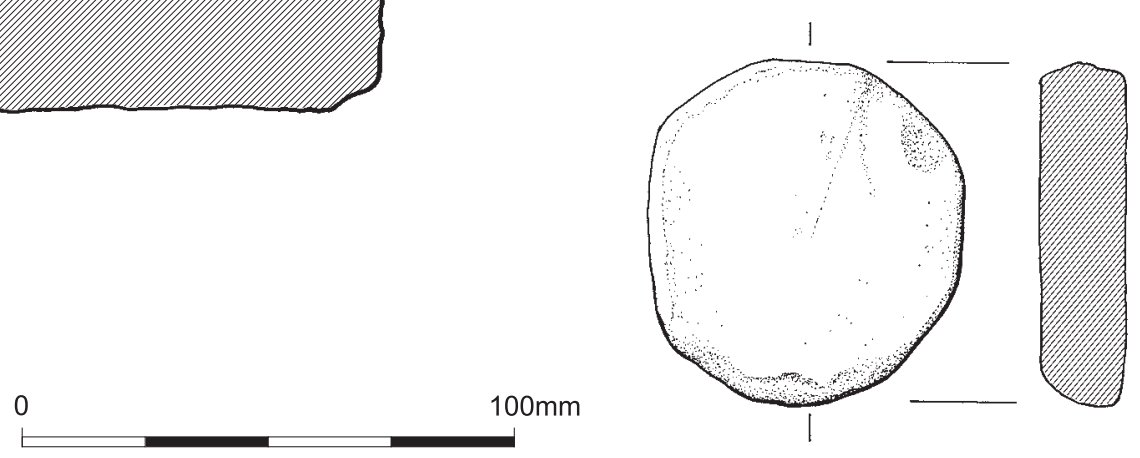

20

Figure 4.44. Other stone objects

15. Fragment of whetstone with weathered oval section. $20 \mathrm{~mm} \times 12.5 \mathrm{~mm}$. Kentish Rag. HSM 6097; surface find; Jackson, Hancocks and Pearson 1993. Not illustrated.

16. Fragment of whetstone with circular section. $24.5 \mathrm{~mm}$ $\times 24.5 \mathrm{~mm}$. Coal Measures Sandstone or fine-grained Millstone Grit. HSM 6097; surface find; Jackson, Hancocks and Pearson 1993. Not illustrated.

\section{Spindle whorls (Fig. 4.44)}

17. Spindle whorl. Very fine grained micaceous sandstone. HSM 16780; SO 64672405; Heref. Mus. A7639/3; Jack 1922.

18. Spindle whorl. Fine grained well sorted micaceous pale olive sandstone such as May Hill sandstone. HSM 23562; SO 64652385; findspot ' $Z$ '; Bridgewater 1963.

\section{Gaming counters (Fig. 4.44)}

19. Small circular gaming counter. Very fine grained calcaerous sandstone. HSM 16780; SO 64672405; Heref. Mus. A7639/5; Jack 1922.

20. Probable gaming counter. $69 \mathrm{~mm}$ diameter. Lower Old Red sandstone Brownstone. HSM 6097: Trench 10, context 1001; Jackson, Hancocks and Pearson 1993.

\section{Bracelet?}

21. Fragment of bracelet? Crinoidal limestone. HSM 23560; SO 64712407; finspot ' $Y$ '; Bridgewater 1963. Not illustrated. 


\section{Building materials}

\section{Robin Jackson}

Apart from the evidence for timber structures represented by postholes, excavated remains as well as surface scatters have included a range of building materials utilised at the site which indicate the presence of more substantial, romanised structures.

The most comprehensive evidence comes from excavations towards the northern side of the scheduled area. Jack's excavation of 1922 (1923) recorded regular coursed walling of mortared sandstone blocks set on a rubble and mortar foundation. Both ceramic and stone rooftiles were present some with nails still in place (Jack 1923, plate 3). Sandstone flags were also recorded on the floor. Wall plaster still adhered to some of the wall with a simple colour scheme of ochre, dark red and white lines. These were associated with the building he called the 'kitchen block', adjacent to which further masonry was interpreted as part of furnace, hearth or hypocaust. Associated flue tile supported the evidence for a heating system. A finely worked fragment of Bath Stone (Jack 1923, fig. 17) and window glass indicate that at least part of the building was appointed with high quality fittings and finishes.

Evidence of rubble sandstone footings and masonry from other excavations provides further evidence for buildings not soley built in timber (Garrod and Moss 1967, HSM 23552, Trench CXX and HSM 23554, Trench CII; Jackson 1993, HSM 6097, Trenches 2, 10 and 11). Of these, Garrod and Moss' Trench CXX produced the most significant evidence with a robber trench and rubble foundation being associated with a large quantity of stone rooftile, wall plaster (with a red colour scheme) and both grey and white tesserae.

Further evidence has come from surface scatters of building debris recorded from the vicinity of the two main buildings described above. In 1971, a morticed stone, a large spread of plaster (red, blue-green and white) and tesserae were recorded (HSM 4186-8; Fig. 1.3). A 'rubbish dump' (HSM 4189; Fig. 1.3) and a stone spread including two morticed stones (HSM 4185; Fig. 1.3; letter from Alan Morriss in HAN 22) were also recorded. Similarly located spreads were visible following ploughing in both 1988 and 1996 (DAG; HSM 23568).

Evidence of one or more buildings has been observed by Martin Sterry to the north of the scheduled area (HSM 23567; Fig. 1.3) in a previously unknown part of the site. Here, a significant quantity of surface finds was recorded focussed on a scatter of building rubble, painted wall plaster and tesserae.

Lastly, numerous stone and ceramic roof tiles (both tegulae and imbrex), as well as potentially Roman dated brick fragments and window glass have been noted within both excavations and surface scatters across the settlement area, although only small quantites have been retained.

\section{Ironworking residues}

\section{Ironworking debris from the Welsh Water pipeline (from Starley 1995)}

\section{Introduction}

During the course of the salvage recording on the Welsh Water pipeline a large collection of ironworking debris was recovered along with other metalworking residues. Analysis of these was undertaken at the time, elements of the report on which (Starley 1995) are reproduced here.

\section{Methodology}

Visual examination of approximately $40 \%$ of the metalworking debris recovered allowed the material to be categorised on criteria of morphology, density, colour and vesicularity. Table 45 summarises the material examined. It should be stressed that many 'classes' of ironworking slags form part of a compositional and morphological continuum. Only certain classes of material are strictly diagnostic, and can be unambiguously assigned to a single metalworking process. Others may derive from a restricted range of processes but, when found in association with the diagnostic types may provide support for the identification of these activities. Some forms of debris may originate from a very wide range of high temperature processes and are of no help in identifying crafts or industries. Class names and criteria on which they are based may vary between specialists. Those currently used by the Ancient Monuments Laboratory are defined below.

\section{Explanation and discussion of classification of ironworking debris}

On the whole, the slag examined from Ariconium was notable for its lack of vesicularity and its high density. Much of the assemblage showed flow lines and gave a dark grey streak on an unglazed porcelain tile. Although no slag

Table 45. Slag weight totals from the Welsh Water pipeline

\begin{tabular}{|l|r|}
\hline Slag type & Total weight $(\boldsymbol{g}$ ) \\
\hline tap slag & 25660 \\
\hline furnace bottoms & 4100 \\
\hline dense ironworking slag & 30270 \\
\hline possible roasted ores & 165 \\
\hline glassy/blast furnace slag & 110 \\
\hline smithing hearth bottom(s) & 4150 \\
\hline hammerscale & not quantified \\
\hline vitrified hearth/furnace & 2930 \\
\hline cinder & 900 \\
\hline iron-rich cinder & 340 \\
\hline undiagnostic ironworking & 9960 \\
\hline ferruginous concretion & 6110 \\
\hline fired clay & 345 \\
\hline iron objects & 2400 \\
\hline Total & $\mathbf{8 7 4 4 0}$ \\
\hline
\end{tabular}


was analysed the composition is undoubtedly close to the low melting point composition iron silicate (fayalite).

The most abundant 'diagnostic' waste material was tap slag. These fragments show a characteristic 'ropy' flowed morphology on their upper surface and very low vesicularity at their fracture surfaces. These provide unambiguous evidence of the smelting (i.e. primary extraction from the ore) of iron and are typical waste products of the tapped bloomery furnace, in use during the Roman period, from which the molten slag was run out from the furnace. Some of the fragments were of considerable size, thicknesses if over $100 \mathrm{~mm}$ being noted. Other fragments were of regular cylindrical form, often with two or more parallel cylinders attached and have a rough 'sand cast' surface. These appear to be runs of slag which have solidified inside the tap hole.

One example of a furnace bottom was identified. This also originates from a smelting furnace and may derive either from material that has not been fully run out from a tapped furnace, or possibly from a furnace type in which the slag is not tapped.

The greatest category of material was dense ironworking slag. This had a homogenous dense structure but not the distinctive morphology of tap slag or furnace bottoms. Much of this material was of a shattered blocky form and as such may be the broken up fragments of furnace bottoms or the thick plates of tap slag. In either case it can be assumed that at least the bulk of this material derives from iron smelting. Supportive evidence of smelting was provided by the limited quantities of probable roasted ores. Although no analyses of these were carried out they appeared (after roasting) to be largely hermatite (red streak)/magnetite (attracted to bar magnet) of sufficiently high grade to be a viable source of iron, given the furnace technology of the period.

Evidence for smithing, i.e. hot working of iron, is limited. Normally it is recognised in two main forms; bulk slags and micro slags. Of the bulk slags produced during smithing only the smithing hearth bottoms are unlikely to be confused with the waste products of smelting and are therefore considered to be diagnostic of smithing. These hearth bottoms are normally recognisable by a number of characteristic features: their plano-convex form, having a rough convex base and a smoother, vitrified upper surface which is flat, or even slightly hollowed as a result of the downwards pressure of the air blast from the tuyère. Compositionally, smithing hearth bottoms are also predominately fayalitic and form as a result of high temperature reactions between the iron, iron-scale and silica from either the clay furnace lining or sand used as a flux by the smith.

From the $87 \mathrm{~kg}$ sample of slag examined, only eight possible smithing hearth bottoms were identified and these were generally small and poorly formed. One exceptional lump weighed $2,740 \mathrm{~g}$ whilst the remainder averaged only $200 \mathrm{~g}$. The structure of the large piece was much more vesicular, with a rough upper surface and it is possible that it is a misclassified furnace bottom, although it was unlike the other example. If it is a smithing hearth bottom, its size must indicate a very substantial hearth, perhaps as might be expected for the primary consolidation of blooms after removal from the furnace.

In addition to bulk slags, iron smithing also produces micro slags of two types. Flake hammerscale consists of fish-scale like fragments of the oxide/silicate skin of the iron dislodged during working. Spheroidal hammerscale results from the solidification of small droplets of liquid slag expelled during working, particularly when two components are being fire welded together or when a slag-rich bloom of iron is first worked into a billet or bar. Hammerscale is considered important in interpreting a site not only because it is highly diagnostic of smithing but because it is often allowed to build up in the immediate vicinity of the smithing hearth and anvil. Therefore, it may give a more precise location of the activity than the bulk slags which may be transported elsewhere for disposal (Mills and McDonnel 1992).

Examination of the Ariconium sieve samples was carried out using a bar magnet. Most of these samples contained much material that was attracted to a magnet; most of this appeared to be fired clay and possibly roasted ore particles. Hammerscale was present in many of the sieve residues but the quantities were small. Much of the hammerscale was of the spheroidal rather than flake type (despite the tendency of the former to contain air bubbles and hence float away from the residue). Thus it would appear that the smithing probably only extended to the consolidation of the bloom immediately after it removal from the furnace. The large quantities of small pieced of shattered slag, caught on the coarser sieves may also derive from bloom smithing.

Four categories of debris not normally considered diagnostic are vitrified hearth lining, cinder, iron rich cinder and undiagnostic ironworking slag. However, given the restricted evidence for iron smithing on the site it is probable that most of the debris in these four categories derives from iron smelting. Material listed as vitrified hearth/furnace lining forms during either iron smelting, iron smithing or non-ferrous metal working as a result of a high temperature reaction between the clay lining of the hearth/furnace and the alkali fuel ashes or fayalitic slag. The material may show a compositional gradient from unmodified clay on one surface to an irregular cinderey material on the other.

An associated material, classed as cinder, comprises only the lighter portion of this. This is a porous, hard and brittle slag formed as a result of high temperature reactions between the alkali fuel ashes and either fragments of clay which had spalled away from the hearth/surface lining or another source of silica, such as the sand used as a flux during smithing. Iron-rich cinder is a similar material but contains a significant iron content, making it denser. More dense still are those slags classed as undiagnostic ironworking slags. The compositions of these fragments are predominantly fayalitic, but their morphology is irregular and similar materials may be produced by smelting and smithing operations. 
Undiagnostic ferruginous concretion forms as a result of the redeposition of iron hydroxides, similar to the natural phenomenon of iron panning, although the process is likely to be enhanced by the nature of the surrounding archaeological deposits, particularly iron-rich waste. Glassy slag was identified in two contexts. Although bloomery furnaces can (and occasionally did) produce light-weight glassy slags, which could be confused with blast furnace slag, the two fragments examined are probably intrusive pieces of post-medieval blast furnace slag.

The small quantity of fired clay may derive from some form of metallurgical hearth/forge, but could equally come from a domestic hearth or other pyrotechnic process. The iron 'objects' may be fragments of smelted metal not incorporated into the bloom.

\section{Conclusions}

The diagnostic components of the slag and debris from the Welsh Water work were largely restricted to iron smelting, i.e. the primary production of iron from its ore. The morphology of the slag appears to be consistent with the use of tapped (shaft) furnaces and evidence from the site included at least one possible tapping pit comparable to those excavated by Bridgewater (1965). Some probable ores were also associated with the assemblage but as these appear to have been partly processed the original nature of the ore could not be determined visually. No products of the smelt were recovered but a few 'Fe objects' may be detached parts of the blooms.
Relatively few bulk slags characteristic of iron smithing were identified, although some evidence, in the form of hammerscale in flotation tank sieve residues was identified. It is thought that only the primary consolidation/working of the bloom was carried out at this location. However, limited quantities of non-ferrous debris, suggested that some production of non-ferrous artefacts was taking place in the vicinity.

The importance of the excavated ironworking debris clearly lies beyond the limited scope of the pipeline salvage excavation. Although this produced relatively large quantities of slag $(220 \mathrm{~kg})$, these are undoubtedly only a tiny fraction of the total quantity of debris that has been reported across the site, the quantities of which are likely to already have been depleted by the re-use of slag for hardcore and as a source of iron for post-medieval blast furnaces.

\section{Petrographic and chemical analysis (Tim Young)}

In addition to the analysis discussed above, further samples were examined during the current project. The iron working residues examined were typical of those Roman sites producing iron from the Bristol Channel Orefield, in which the ores are haematite/goethite, and typically of high-grade. Since these compositions are not self-fluxing, the furnaces operate in a slightly different manner to those smelting ores of a lower degree of purity, and generally produce slags of a rather high density.

A selection of specimens (Table 46) of materials associated with iron smelting was examined petrographically

Table 46. Ironworking residues. List of examined material (iron slags)

\begin{tabular}{|l|l|l|l|r|}
\hline Ref. & Context & Interpretation & Material & Weight (g) \\
\hline A1 & HSM 6097 405 & C4 slag surface/layer & Dense tap slag & 1280 \\
\hline A2 & HSM 12666 101 & Late IA ditch? fill & Dense tap slag & 32 \\
\hline A3 & HSM 6097 203 & Post-Roman linear feature & Dense tap slag & 117 \\
\hline A4 & & & Dense tap slag & 74 \\
\hline A5 & & & Leucite-bearing low density tap slag, w. charcoal & 97 \\
\hline A6 & & & Hercynite / leucite-bearing slag tube & 97 \\
\hline A7 & & & Dense tap slag & 59 \\
\hline A8 & & & Dense tap slag & 73 \\
\hline A9 & & & Dense slag tube & 117 \\
\hline A10 & & Tap slag? Contains much iron & 150 \\
\hline A11 & HSM TR2 6097 212 & C2-C4 ? ground surface & Lining & \\
\hline A12 & & & Lining & \\
\hline A13 & HSM TR3 6097 301 & Post-Roman ditch fill & Lining & 161 \\
\hline A14 & HSM TR3 6097 304 & Roman layer & Dense tap slag & 980 \\
\hline A15 & HSM TR3 6097 405 & C4 slag surface & Massive slag with hercynite and leucite, blotchy & \\
\hline A16 & & & Bowl shaped vesicular slag, ?smithing slag & 346 \\
\hline A17 & & & Clinkery semi-tube & 57 \\
\hline A18 & HSM TR3 6097 506 & C3-4 soil layer & Massive slag with hercynite and leucite, blotchy & \\
\hline A19 & & & Hercynite / leucite bearing massive, bowl shape & 249 \\
\hline A20 & & & Dense tap slag & 294 \\
\hline A21 & & & Thin vesicular sheet, ?tap slag & 222 \\
\hline A22 & & & Leucite-bearing, massive, blotchy, ?tap slag & 95 \\
\hline A23 & & & Thin vesicular sheet, ?tap slag with leucite & \\
\hline A24 & & & Massive slag, blotchy & 66 \\
\hline A25 & & & Roasted ore & 112 \\
\hline A26 & & & Partially reduced ore & \\
\hline
\end{tabular}


Table 47. Ironworking residues. Raw wholerock major element analyses by XRF. All iron appears as FeIII

\begin{tabular}{|c|c|c|c|c|c|c|c|c|c|c|c|}
\hline & LOI & $\mathrm{SiO}_{2}$ & $\mathrm{Al}_{2} \mathrm{O}_{3}$ & $\mathrm{Fe}_{2} \mathrm{O}_{3}$ & $\mathrm{MnO}$ & $\mathrm{MgO}$ & $\mathrm{CaO}$ & $\mathrm{Na}_{2} \mathrm{O}$ & $\mathrm{K}_{2} \mathrm{O}$ & $\mathrm{TiO}_{2}$ & $\mathrm{P}_{2} \mathrm{O}_{5}$ \\
\hline \multicolumn{12}{|l|}{ Ores } \\
\hline $\begin{array}{l}\text { A25 } \\
\text { roasted }\end{array}$ & 0.87 & 1.86 & 1.06 & 95.78 & 0.44 & 0.31 & 0.20 & $<$ & 0.11 & 0.05 & 0.20 \\
\hline $\begin{array}{l}\text { A26 } \\
\text { reduced }\end{array}$ & -2.27 & 1.37 & 0.33 & 97.57 & 0.04 & 0.29 & 0.12 & $<$ & 0.02 & 0.02 & 0.24 \\
\hline \multicolumn{12}{|l|}{ Slags } \\
\hline A1 tap slag & -5.77 & 26.45 & 5.73 & 61.14 & 0.21 & 1.38 & 2.65 & $<$ & 1.85 & 0.30 & 0.29 \\
\hline A2 tap slag & -6.64 & 19.65 & 4.50 & 70.93 & 0.14 & 0.88 & 1.82 & 0.16 & 1.46 & 0.22 & 0.24 \\
\hline A3 tap slag & -6.89 & 19.20 & 2.82 & 73.64 & 0.21 & 0.66 & 1.42 & 0.55 & 1.09 & 0.19 & 0.22 \\
\hline A4 tap slag & -6.04 & 26.27 & 4.80 & 60.15 & 0.19 & 1.61 & 4.58 & $<$ & 1.71 & 0.21 & 0.38 \\
\hline A7 tap slag & -6.51 & 22.48 & 3.63 & 69.08 & 0.11 & 0.83 & 2.03 & $<$ & 1.26 & 0.21 & 0.37 \\
\hline A9 tube & -6.91 & 8.57 & 2.28 & 82.68 & 0.10 & 0.96 & 2.19 & 2.12 & 0.62 & 0.13 & 0.35 \\
\hline $\begin{array}{l}\text { A10 tap } \\
\text { slag? }\end{array}$ & -6.85 & 18.05 & 2.99 & 73.77 & 0.18 & 1.20 & 1.86 & $<$ & 1.32 & 0.17 & 0.46 \\
\hline $\begin{array}{l}\text { A18 } \\
\text { blocky }\end{array}$ & -5.54 & 19.60 & 5.14 & 67.22 & 0.13 & 1.43 & 3.40 & 0.79 & 1.72 & 0.29 & 0.28 \\
\hline $\begin{array}{l}\text { A19 } \\
\text { blocky }\end{array}$ & -5.60 & 22.57 & 4.99 & 65.78 & 0.12 & 1.10 & 2.81 & 0.45 & 1.52 & 0.24 & 0.43 \\
\hline \multicolumn{12}{|l|}{ Lining } \\
\hline A13 & 0.38 & 70.95 & 11.29 & 6.10 & 0.09 & 0.77 & 0.49 & 0.00 & 2.41 & 0.44 & 0.21 \\
\hline
\end{tabular}

and chemically in an attempt to provide information on the technology of smelting and on the provenance of the ore being smelted. This analytical investigation was designed to complement the report by Starley (1995; see above) and focussed on the types of slag which fell into Starley's 'tap slag' and 'dense ironworking slag' categories. In this study 21 slag samples (total weight $5 \mathrm{~kg}$ ) along with 3 lining samples $(0.4 \mathrm{~kg})$ and 2 ore fragments $(52 \mathrm{~g})$ were obtained (Samples A1 -A26) from the $220 \mathrm{~kg}$ of material recovered from the Welsh Water pipeline work (HSM 6097 and 12666; Fig. 1.3). A full description of this material is held in archive.

The petrography of all slag specimens (except A20) has been examined by back-scattered scanning electron microscopy, together with energy dispersive spectroscopy microanalyses of selected components. Most of the slags have a wustite + fayalite + glass mineralogy, but some tap slags show leucite and the massive blocky slags contain leucite and hercynite.

Chemical analysis of selected specimens has been undertaken by X-ray fluorescence (major elements; Table 47) and ICP-MS (minor and trace elements) of 2 ore samples (1 not from the HSM archive), 9 slags (tap slags A1, A2, A3, A4, A7; possible tap slags A9, A10; massive 'furnace' slags A18, A19) and 1 sample of furnace lining ( 2 other lining samples were sampled for trace elements only). The analyses of the slags reveal a fairly homogeneous group. The massive, blocky slags with a blotchy texture, which correspond to Starley's 'dense ironworking slag' category, do not show any significant difference in chemical composition from the tap slags, despite their textural and mineralogical differences (presence of hercynite and leucite).

Uranium occurs at $2.8-6.3 \mathrm{ppm}$ in the slags and in the two ore samples at 1.8 and $2.5 \mathrm{ppm}$; such levels are entirely consistent with a provenance for the ore in the eastern part of the Forest of Dean.

\section{Charcoal from Bridgewater's 1963 excavation}

\section{Rowena Gale}

\section{Introduction}

Bridgewater's 1963 excavation (HSM 21357-60 and 10676; Bridgewater 1965) covered one area of ironworking at the site, dating of which focuses on the 2 nd half of the 2nd century. Excavations of other areas include those of Jack in 1922 (1923), Garrod and Moss in 1967 and on the Welsh Water pipeline in 1993 (HSM 6097; Jackson, Hancocks and Pearson 1999). Charcoal residues (from industrial fuel) were found at all four sites, but only those from the 1922 and the 1993 excavations were reported on at the time, while charcoal from Bridgwater's site was placed in store. This report discusses the identification and implications of charcoal from Bridgewater's excavation. 


\section{Materials and methods}

Nine samples of charcoal were examined. The charcoal mostly consisted of large lumps of roundwood, which were structurally firm and well preserved. Similar methods to those described in the previous report (Gale 1999; HSM 6097 ) were used for the preparation and examination of the charcoal. Where possible, details of diameter and growth rates were recorded.

\section{Results}

Table 48 gives a summary of the taxa identified. The anatomical structure of the charcoal was consistent with the taxa or groups of taxa given below. It should be noted that the anatomical structure of some related taxa can not be distinguished with any certainty, for example, members of the Pomoideae (Crataegus, Malus, Pyrus and Sorbus) and Salicaceae (Salix and Populus). Classification follows that of Flora Europaea (Tutin, Heywood et al. 1964-80):

Betulaceae. Betula sp., birch

Caprifoliaceae. Viburnum sp., guelder rose and/ or wayfaring tree

Celastraceae. Euonymus sp., spindle

Corylaceae. Corylus sp., hazel

Fagaceae. Quercus sp., oak

Oleaceae. Fraxinus sp., ash

Rosaceae. Subfamilies: Pomoideae which includes Crataegus sp., hawthorn; Malus sp., apple; Pyrus sp., pear; Sorbus spp., rowan, service tree and whitebeam. These taxa are anatomically indistinguishable.

Salicaceae. Salix sp., willow and Populus sp., poplar. These taxa are anatomically similar.

Tiliaceae. Tilia sp., lime.
Site 21357-60

\section{AREA A (HSM 21360)}

The area included a furnace and associated slag-pit. Charcoal was found beneath the slag in the main pit (F4).

\section{Sample 21360 AR 9 A [2]}

The sample included a single piece of fast-grown oak (Quercus) roundwood, measuring $25 \mathrm{~mm}$ in diameter, with 6 growth rings. Bark was in situ and the stem had been cropped in the dormant season.

Sample 21360 AR 9 A [9]

The sample included 3 sections of roundwood as follows:

Oak (Quercus): length $75 \mathrm{~mm}$; diameter 20mm, 6 growth rings, felled when dormant;

Birch (Betula): diameter 40mm, 7 growth rings, bark in situ, felled when dormant;

Hawthorn/Sorbus group (Pomoideae): diameter 20mm, 11 growth rings, with evidence of tool marks.

\section{AREA B (HSM 23557)}

This area also consisted of a furnace and pit, the latter containing charcoal.

Sample 23557 AR 9 B [4]

The sample included 2 pieces of roundwood and a few smaller fragments, probably broken away from the larger pieces. The roundwood consisted of hazel (Corylus) and lime (Tilia). Hazel roundwood measured $30 \mathrm{~mm}$ in diameter, with 19 or 20 growth rings (inner rings wide, outer rings narrow). Although the lime roundwood did not include a complete cross-section, it was evident that it was wider than

Table 48. Bridgewater excavations (1963): charcoal from metal-working contexts

\begin{tabular}{|c|c|c|c|c|c|c|c|c|c|}
\hline HSM/Feature & $\begin{array}{c}\text { Betula } \\
\text { birch }\end{array}$ & $\begin{array}{c}\text { Corylus } \\
\text { hazel }\end{array}$ & $\begin{array}{l}\text { Euonymus } \\
\text { spindle }\end{array}$ & $\begin{array}{c}\text { Fraxinus } \\
\text { ash }\end{array}$ & $\begin{array}{c}\text { Pomoideae } \\
\text { hawthorn } \\
\text { group }\end{array}$ & $\begin{array}{c}\text { Quercus } \\
\text { oak }\end{array}$ & $\begin{array}{l}\text { Salicac } \\
\text { willow } \\
\text { /poplar }\end{array}$ & $\begin{array}{l}\text { Tilia } \\
\text { lime }\end{array}$ & $\begin{array}{c}\text { Viburnum } \\
\text { wayfaring/ } \\
\text { guelder }\end{array}$ \\
\hline \multicolumn{10}{|l|}{ Site 21357-60 } \\
\hline \multicolumn{10}{|l|}{ Area A } \\
\hline $\begin{array}{l}21360 \\
\text { AR } 9 \text { A [2] }\end{array}$ & - & - & - & - & - & 1 & - & - & - \\
\hline $\begin{array}{l}21360 \\
\text { AR } 9 \text { A [9] }\end{array}$ & 1 & - & - & - & 1 & 1 & - & - & - \\
\hline \multicolumn{10}{|l|}{ Area B } \\
\hline $\begin{array}{l}23557 \\
\text { AR } 9 \text { B [4] }\end{array}$ & - & 1 & - & - & - & - & - & 1 & - \\
\hline \multicolumn{10}{|l|}{ Area C } \\
\hline $\begin{array}{l}23558 \\
\text { AR C [9] }\end{array}$ & - & 4 & - & - & $3 \mathrm{k}$ & $? 1(\mathrm{v})$ & - & - & - \\
\hline $\begin{array}{l}23558 \\
\text { AR } 9 \text { C }[8] \text { F1 }\end{array}$ & - & 2 & - & - & - & 2 & - & - & 1 \\
\hline \multicolumn{10}{|l|}{ Area D } \\
\hline $\begin{array}{l}23559 \\
\text { AR } 9 \text { D [2B] }\end{array}$ & - & 1 & - & - & - & - & - & - & - \\
\hline \multicolumn{10}{|l|}{ Site 10676} \\
\hline $\begin{array}{l}10676 \\
\text { AR 9 [1] }\end{array}$ & 2 & 1 & 1 & 1 & - & 3 & 1 & - & - \\
\hline $\begin{array}{l}10676 \\
\text { AR } 9 \text { TH[1] }\end{array}$ & - & 1 & - & - & 1 & 1 & - & 1 & - \\
\hline $\begin{array}{l}10676 \\
\text { AR } 9 \mathrm{U} / \mathrm{S}\end{array}$ & 1 & 1 & - & $\therefore$ & - & 1 & - & - & - \\
\hline
\end{tabular}


the hazel and included very fast-grown wood (minimum diameter at least $60 \mathrm{~mm}$ with $9+$ growth rings).

\section{AREA C (HSM 23558)}

This area was larger and contained the remains of 2 furnaces, pits and working hollows. The charcoal occurred in the main slag pit.

\section{Sample 23558 AR C [9]}

The sample included 4 pieces of roundwood including 4 of hazel (Corylus). Two of these measured 25mm (19 or 20 growth rings, inner rings wide, outer rings narrow) and $15 \mathrm{~mm}$ ( 9 growth rings) respectively. The sample also included 3 slightly knotty pieces of the hawthorn/Sorbus group (Pomoideae), and possibly a piece of oak (Quercus). The latter was vitrified, a condition induced by exposure to temperatures exceeding $800^{\circ} \mathrm{C}$, when cell walls become plastic and recognisable cellular structure is lost (Prior and Alvin 1983).

\section{Sample 23558 AR 9 C [8] F1}

The sample consisted of 5 pieces of roundwood identified as follows:

Two of hazel (Corylus): diameter 20mm, 8 growth rings (inner rings wide) felled when dormant; diameter $11 \mathrm{~mm}$, 3 wide growth rings; bark in situ, felled when dormant; Two of oak (Quercus): diameter 10mm, 3 wide growth rings, felled when dormant; diameter $6 \mathrm{~mm}, 5$ growth rings (inner rings wide) felled when dormant;

One of wayfaring tree/guelder rose (Viburnum): diameter $7 \mathrm{~mm}, 4$ growth rings (inner rings wide).

\section{AREA D (HSM 23559)}

Area D contained 2 furnace units and other features including a rectangular hollow, cut about $18 \mathrm{~cm}$ deep into the bedrock. The latter, which was filled with dense layer of charcoal and the remains of wattle and daub, was interpreted as a fuel store.

\section{Sample 23559 AR 9 D [2B]}

This sample consisted of a single piece of hazel (Corylus) roundwood with an oblique cut across one end, probably as a result either of severance from the coppice stool or from subsequent reduction of the stem into shorter lengths. The stem diameter measured $30 \mathrm{~mm}$ and included 9 growth rings, with wide inner rings. The bark was in situ and it was evident that the stem had been cropped in the spring, after the start of the new seasons growth.

\section{Site HSM 10676}

Sample 10676 AR 9 [1]

The sample included 9 lengths of roundwood as follows:

Three oak (Quercus): diameter 20mm, 7 growth rings, bark in situ, felled when dormant; diameter $30 \mathrm{~mm}, 14$ growth rings, felled when dormant; diameter $60 \mathrm{~mm}, 14$ growth rings, felled when dormant;

Two birch (Betula): diameter 15mm, 4 growth rings; diameter $20 \mathrm{~mm}$, about 8 growth rings;
One ash (Fraxinus); diameter $25 \mathrm{~mm}, 8$ growth rings, felled when dormant;

One willow/ poplar (Salix/ Populus): diameter 20mm, 5 growth rings;

One spindle (Euonymus): diameter 10mm, 5 growth rings, felled when dormant;

One hazel (Corylus): fragment only.

Sample 10676 AR 9 TH[1]

The sample included 4 pieces of roundwood as follows:

Hazel (Corylus): diameter 18mm, 11 growth rings, bark in situ, felled when dormant;

Oak (Quercus): diameter 20mm, 9 growth rings, felled when dormant;

Lime (Tilia): diameter 40mm+, 34+ growth rings;

Hawthorn group (Pomoideae): diameter 20mm, 16 growth rings.

Sample 10676 AR 9 Unstratified

The sample included 3 pieces of roundwood:

Birch (Betula): diameter 25mm, 8 growth rings;

Oak (Quercus): diameter 10mm, 2 wide growth rings, felled when dormant;

Hazel (Corylus): diameter 15mm, 9 growth rings, felled when dormant.

\section{Discussion}

The charcoal residues occurred in pits and other features closely associated with ironsmelting, and possibly a fuel store. Evidence indicated that limited primary smithing of blooms also occurred in the vicinity. In common with the charcoal from the Welsh Water pipeline (Gale 1999), the charcoal residues described here were extremely well preserved and allowed details of roundwood dimensions, growth patterns, and often the season of felling, to be recorded.

Fuel consisted of roundwood from a range of taxa including birch (Betula), hazel (Corylus), ash (Fraxinus), oak (Quercus), spindle (Euonymus), lime (Tilia), the hawthorn/Sorbus group (Pomoideae), willow/poplar (Salix/ Populus) and wayfaring tree or guelder rose (Viburnum). Although there was insufficient material to gauge evidence of preferential selection of taxa, it may be relevant that oak and hazel occurred in more contexts than other species (Table 48).

Charred roundwood diameters measured between $6 \mathrm{~mm}$ and $60 \mathrm{~mm}$, with most pieces occurring around the $20 \mathrm{~mm}$ range. When freshly cut these stems would have been up to $40 \%$ wider. Although growth rates varied, the stems mostly included the wide growth rings characteristic of coppice growth. The morphology of the roundwood (i.e. straight and rod-like) was also indicative of coppice wood. By implication, most of the fuel wood was probably supplied from managed woodland. The age of felling ranged between 2 and 60 years but the highest incidence occurred around 8-9 years. There was insufficient evidence to indicate specific cycles of felling for individual taxon. Evidence of the season of felling indicated that cropping 
was mostly carried out in the dormant period, before the onset of leaf growth. It is likely that the wood would then have been left to season before conversion to charcoal.

The character of this fuel is comparable to that from ironworking areas recorded on the Welsh Water pipeline (Gale 1999), from which roundwood was identified as maple (Acer), alder (Alnus), birch (Betula), hazel (Corylus), ash (Fraxinus), the hawthorn group (Pomoideae) and oak (Quercus). There was no evidence of the use of oak (Quercus) heartwood, usually the preferred fuel for metallurgy (J. Cowgill, pers comm.) from either site. Charcoal from Jack's 1922 excavation was identified (by A. H. Lyell) as oak, birch, elder (Sambucus), willow and hazel, and the brief report refers to 'sticks', which infers that this material was also narrow roundwood.

The consistent use of narrow roundwood in the Roman period is of particular interest in this region. Fuel residues from ironworking sites, operating at the roughly the same time but located in other parts of the Forest of Dean, at Millend Lane, Blakeney (Gale 2000) and The Chesters villa, Woolaston (Fulford and Allen 1992), testify to similar practices. The results appear to reflect regional preferences or traditions, although they could represent evidence for of the overexploitation and depletion of woodland resources.

In the Roman period, local woodlands would have been supplying the charcoal trade not only for industrial purposes but also for domestic heating and cooking. Charcoal was in common use in Roman communities in Britain for numerous domestic purposes (Allason-Jones 1989b). In addition, timber and wood (e.g. fuel for brickmaking) would have been required for construction work in the Roman town and for other activities. The economic importance of the iron industry in this region, which was fuelled from managed woodland, almost certainly shaped the woodland element of the environment and probably ensured its survival throughout the following millennia. A not insignificant local trade in woodland products (charcoal, timber and wood) continued in the medieval period, when, in addition to supplying charcoal for the major ironworking industry of the area, timber and wood were exported from the Forest of Dean to be sold in Bristol (Power and Postan 1933).

\section{Environmental evidence}

\section{Elizabeth Pearson}

\section{Introduction}

Until salvage recording in 1993 (Jackson, Hancocks and Pearson 1999), much of the archaeological evidence recorded from Ariconium has resulted from chance finds or antiquarian and pre-modern field intervention. During this time there has been no policy of wet-sieving samples for environmental remains, therefore the environmental evidence has been mostly restricted to larger visible items (such as large mammal bone or large charcoal fragments) hand-collected during fieldwork. Consequently, plant remains, molluscs, insects, and small animal bone (recoverable by wet-sieving and flotation of soil samples) have not been recovered and analysed in detail until recently. No work has been undertaken on interpretation of the evolving local landscape through pollen and sediment studies, although there is considerable potential for such work on this site. The following is a summary of the evidence to date.

\section{Summary of evidence}

\section{Human burials}

Human skeletons were discovered in 1804 when a road crossing the site at Bury Hill was widened (RCHME 1932; HSM 23565). These are the only skeletons reported and were not studied in detail. Consequently, there is currently no information on the demographic make-up of the settlement's population.

\section{Animal bone}

Numerous bones of ox, pig and sheep, antler of red deer, and horn cores of Bos longifrons (Celtic shorthorn ox) were found in association with Roman remains during excavations by Jack (1923). A small assemblage of animal bone recovered during excavations by Garrod and Moss in 1967 has been analysed (Jackson 2000).

During salvage recording on the Welsh Water pipeline, a quantity of animal bone (including worked bone) was recovered (Jackson, Hancocks and Pearson 1999). This was a small, poorly preserved assemblage $(2.35 \mathrm{~kg})$ recovered from various context types. It was dominated by large ungulate bone (horse, cattle or red deer size), with some sheep or goat, horse and bird bones present. As various parts of the carcass were represented (no particular anatomical part being predominant in any one context), there was no indication of waste from an industrial process. Rather the assemblage resembles mixed domestic waste including butchered bones. A small number of animal bones (included burnt bone) were recovered during evaluation of the Ryeford Bypass (Napthan, Ratkai and Pearson 1995), on which notes were made.

In general, the information acquired from animal bone assemblages to date has been limited. No interpretation was included on the bone from Jack's excavations in 1923, and because assemblages from the Garrod excavations and the Welsh Water pipeline were small, it was not possible to comment on aspects of animal husbandry such as relative species importance, culling patterns and stature.

\section{Plant and other remains}

Reports on charcoal fragments from Bridgewater's excavations (Gale, see above) and from the Welsh Water pipeline (Gale 1999) have been prepared. Analysis has 
indicated the use of fuel from narrow roundwood supplied from managed woodland, and there is evidence for similar use of narrow roundwood from Roman sites in other parts of the Forest of Dean. This possibly indicates a regional practice which differs from the more usual tradition demonstrated in other parts of the country where oakwood was preferred (Gale, see above). The analyses have allowed details of roundwood dimensions, growth patterns, and often the season of felling.

Plant remains have been discovered as early as 1785 , during the enclosing and levelling of part of the site at Bury Hill. Here, charred wheat was discovered within vaults, in addition to other antiquities. As a result of excavations in 1922, a short species list was produced for 'sticks' of charcoal recovered, and a small quantity of oyster and other mollusc shells were also noted (Jack 1923).

During the Welsh Water pipeline salvage recording in 1993, deposits were routinely sampled for environmental remains and a total of 21 samples were taken, of which 11 were selected for full analysis (HSM 6097; Jackson, Hancocks and Pearson 1999). Only sparse quantities of environmental remains were recovered from the majority of samples, consisting of fragmented animal bone, charred cereal and beetle remains. However, richer assemblages were recovered from a pit fill and from waterlogged deposits in a channel (possibly a leat), near the stream at Pond Cottage.

The pit fill produced remains of charred fine sieving waste from processing of a spelt wheat crop which may have been burnt when crop waste was used as fuel for a fire or kiln. The sample from the channel was remarkably rich in waterlogged organic remains. These included species likely to have grown around the watercourse and in the surrounding area. These indicated a very open environment which appears to have included much disturbed ground, for instance cornfields or gardens. Of particular interest were a seed of coriander (Coriandrum sativum) and several seeds of celery (Apium graveolens) both of which are rare finds and are cultivars likely to have originated in gardens.

During the evaluation of the Ryeford Bypass, to the south (HSM 22965; Napthan, Ratkai and Pearson 1995), one sample was taken from a ditch adjacent to a Roman road, in which occasional of seeds preserved by anaerobic conditions survived. Peat deposits are also thought to exist adjacent to the Tackford Brook. Although trenching was not possible at this location on account of the large number of land drains, peaty deposits were thought to exist in view of the 'springy' nature of the ground. 


\section{Section 5. Archaeological synthesis}

\section{The character of the settlement}

Discussion of the character of the settlement derives principally from the analysis of the evidence described above. It is recognised that there are considerable limitations, in that only small areas have been excavated and that coverage across the potential full extent of the settlement is highly variable. The latter has had the effect that there is only a minimal amount of data from the eastern side of the settlement where the presence of modern properties and areas of pasture has limited opportunities for fieldwork. Conversely, the regular ploughing of the scheduled area allied to its recognition as a focus of settlement has led to a considerable bias in favour of this area.

An additional factor is that erosion has clearly affected some areas (Section 6). This will have influenced survival and depth of deposits and therefore ploughsoil distributions. In particular this is liable to have affected distributions of material on hillslopes and the uppermost (and thereby latest) Roman deposits.

\section{A military presence?}

Before discussion of the morphology of the settlement, one key issue relevant to both its origins and development is the question of whether a Roman military presence can be identified.

The location of Ariconium at an important junction in the Roman road network and at a convenient distance from military sites at Gloucester, Kenchester, Stretton Grandison and Monmouth argues in favour it being the location of an early fort. In the light of this, the enclosures to the north have been suggested to represent military installations established shortly after AD 43 to police the iron industry (Walters and Walters 1989; Walters 1992). The supply of iron to the western part of Britain would have been important, especially in respect of supplies for the 1st century military campaigns into Wales and in the building of major towns like the Colonia at Gloucester. It is also known that an imperial monopoly was held over certain mineral resources and this has been demonstrated in the case of the Wealden iron industry (Cleere 1975). However, the situation regarding the operation of this monopoly is ambiguous. Rights to extract and work minerals were granted to private entrepreneurs and there is no direct evidence of military or imperial involvement in the organisation of the Forest of Dean industry (Fulford and Allen 1992, 206). In the light of the reinterpretation of the northern enclosures at Ariconium as a native settlement and the later date of the few military items from the main site, it is concluded that there is an absence of firm evidence for early Roman military activity. Similar arguments have put forwards revising the supposed military origins of Kelvedon and other 'small towns' in Essex (Eddy 1995) and it is becoming increasingly evident that the commonly held view that 'small towns' had military origins is not an accurate one (Burnham 1995, 12).

The discovery of mid 2nd to 3rd century items with military associations (Cool: Catalogue nos 224-9) from the main settlement area reflects the pattern of many towns in the 'notional' civilian zone. Here, such items may indicate the presence of a small military detachment with a 'policing' role (Bishop 1991) or, alternatively, they may have been the possessions of soldiers in transit, visiting officials or residents who had once served in the army (de la Bédoyère 1991; Black 1994).

\section{Settlement morphology}

The morphology of the late Iron Age settlement cannot be readily determined from the available evidence, however, the Roman settlement pattern is better understood and some general observations about the layout of the 'small town' can be made.

The Roman settlement appears to have developed on and around one or more focus of late Iron Age activity. Examination of the Antonine Itinerary (Margary 1955) suggests that the site occupied an important junction in the Roman road network (Fig. 5.1), elements of which almost certainly had Iron Age and probably earlier origins as long distance routes.

The settlement area spreads along and around several of these roads with the internal street system developing haphazardly between them as has been observed at Baldock (Stead and Rigby 1986; Burleigh 1995) and other 'small towns' located at road junctions (Burnham and Wacher 1990, 23-4; Burnham 1995, 9). A central occupation area and several industrial zones can be defined; however, it is evident that the settlement was not densely populated, rather it was fairly widely dispersed and probably polyfocal. This settlement form probably reflects two factors. Firstly, that the basic land requirements of the population could be readily satisfied and, secondly, that in the absence of social, 


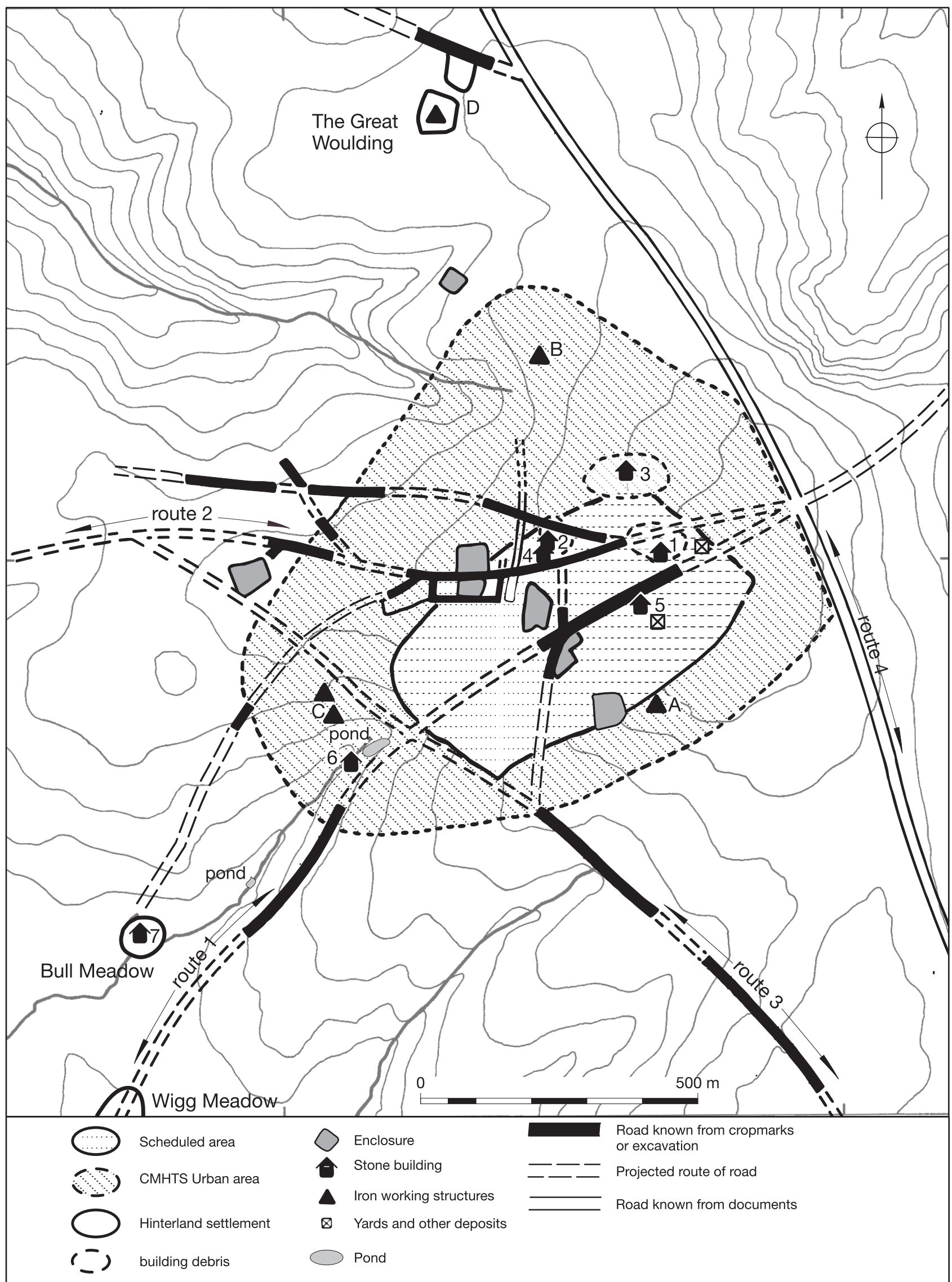

Figure 5.1. Summary of buried remains. Reproduced by permission of Ordnance Survey on behalf of HMSO. (C) Crown Copyright 2011. All rights reserved. Ordnance Survey Licence number 100051813 
economic or administrative pressures there was no necessity for the settlement to develop a centralised, compact urban core. In many respects, therefore the settlement has more in common with the characteristics of an Iron Age oppida than the traditional model of a Roman town thus reflecting 'native' rather than romanised traditions of 'urbanism'.

Within the study area, it has been possible to estimate the extents of the main settlement as well as the location of hinterland settlements to the north and to the south-west (Fig. 5.1). Evidence for domestic activity spreads across a wide area within the main settlement. Some of this material represents domestic rubbish dumped over disused industrial zones (Bridgewater 1965); however, it is clear that the area of domestic occupation was probably quite extensive. The 'core' of this occupation area spread across the south and west facing slopes of the hill, along the routes running west and south-west. At the peak of settlement in the 2 nd and 3 rd centuries several stone/stone founded houses were present in this domestic 'core', reflecting the widely observed trend of timber buildings being replaced by stone/stone-founded ones from the mid 2nd century onwards (Burnham 1985, 9).

Several roads converge where these more romanised buildings stood. Numerous finds of domestic artefacts and small personal items have been recovered from this location. The spread of domestic finds extends down the west facing slopes of the hill. Here, excavation has been limited but cropmarks show small enclosures extending alongside the roads probably representing roadside properties bounded by ditches. It is likely that many of these enclosures would have contained timber houses and ancillary buildings with associated yards and pits, and the limited excavated evidence appears to support this observation. This postulated development, of property boundaries and enclosed compounds with associated buildings rather than a pattern of narrow strip development along frontages, reflects an increasingly observed pattern within 'small towns' (Burnham 1995, 9).

Some of the enclosures are liable to have provided a focus for small-scale commercial enterprises, while during the early Roman period ironworking also may have been located within or immediately adjacent to domestic enclosures. However, from the 2 nd century onwards, distinct ironworking zones developed, presumably reflecting increasing specialisation and nucleation of production. The focus for this intensive ironworking activity initially lay to the north of the occupied core and then later shifted to the south-west.

Within the urban area it has already been suggested that occupation may not have been intense and it is possible that some enclosures and other apparently less well-defined areas of the settlement may have supported gardens, small agricultural plots, animal pens or rubbish disposal areas. Towards the settlement fringes, areas such as these are liable to have merged with the surrounding field systems as has been observed at 'small towns' such as Water Newton and Dragonby (Burnham and Wacher 1990, 29).
Within the region the settlement's morphology and character most closely resembles that of Worcester, another 'small town' and major iron smelting centre where occupation also seems to have been widely dispersed around an important road junction and river crossing (Burnham and Wacher 1990, 232-3, fig. 74; Dalwood and Edwards 2004).

\section{Roads and tracks}

Ariconium is situated at an important Roman road junction (Figs 5.1 and 5.2). These communication routes provided a network for the supply and distribution of the raw materials and finished products of the ironworking industry as well as for more general trade and exchange linking the site to other Roman settlements in the region.

Evidence for character and dating of these roads derives from two sources, excavated remains and cropmark evidence. These provide evidence of both surviving surfaces and large negative features where the original iron slag surfaces have been mined away for resmelting in the 17 th century.

Major roads headed south and east along the eastern margins of the Forest of Dean, towards Lydney and Gloucester (Margary 1955, routes 614 and 611). To the south and west, further routes head towards and into the Forest and down its western side towards Monmouth, Usk and Caerleon (Margary 1955, routes 612a and 615). To the north, a further route heads towards Blackwardine (Margary 1955, route 613), crossing the road linking Stretton Grandison, Kenchester and Clyro (Margary 1955, route 63 ).

Two further important routes are also postulated running north-west on a more direct route towards Kenchester and east towards Newent. Whilst these can be identified as Roman routes, it is probable that many of them originated as Iron Age and probably earlier long distance communication routes.

\section{Route 1}

The most extensively recorded road is that running to the south-west towards Wigg Meadows and on towards Hope Mansell (Figs 5.1 and 5.2). This can be equated with Margary's route 615 (1955) and is believed to link Ariconium with the ore sources on the north-west side of the Forest of Dean. It may also have connected with a route crossing the River Wye to Whitchurch and heading towards Monmouth. To the east of Ariconium this may have continued towards Newent where further extensive evidence for ironworking has been recorded.

Successive investigations have been undertaken along the line of this route (HSM 22053, Jack 1923; HSM 840, Bridgewater 1959; HSM 23554, Garrod and Moss 1967; HSM 840, Topping 1993; and HSM 22965, Napthan, Ratkai and Pearson 1995). This was a well-constructed road having a compact slag and stone surface, surviving up 


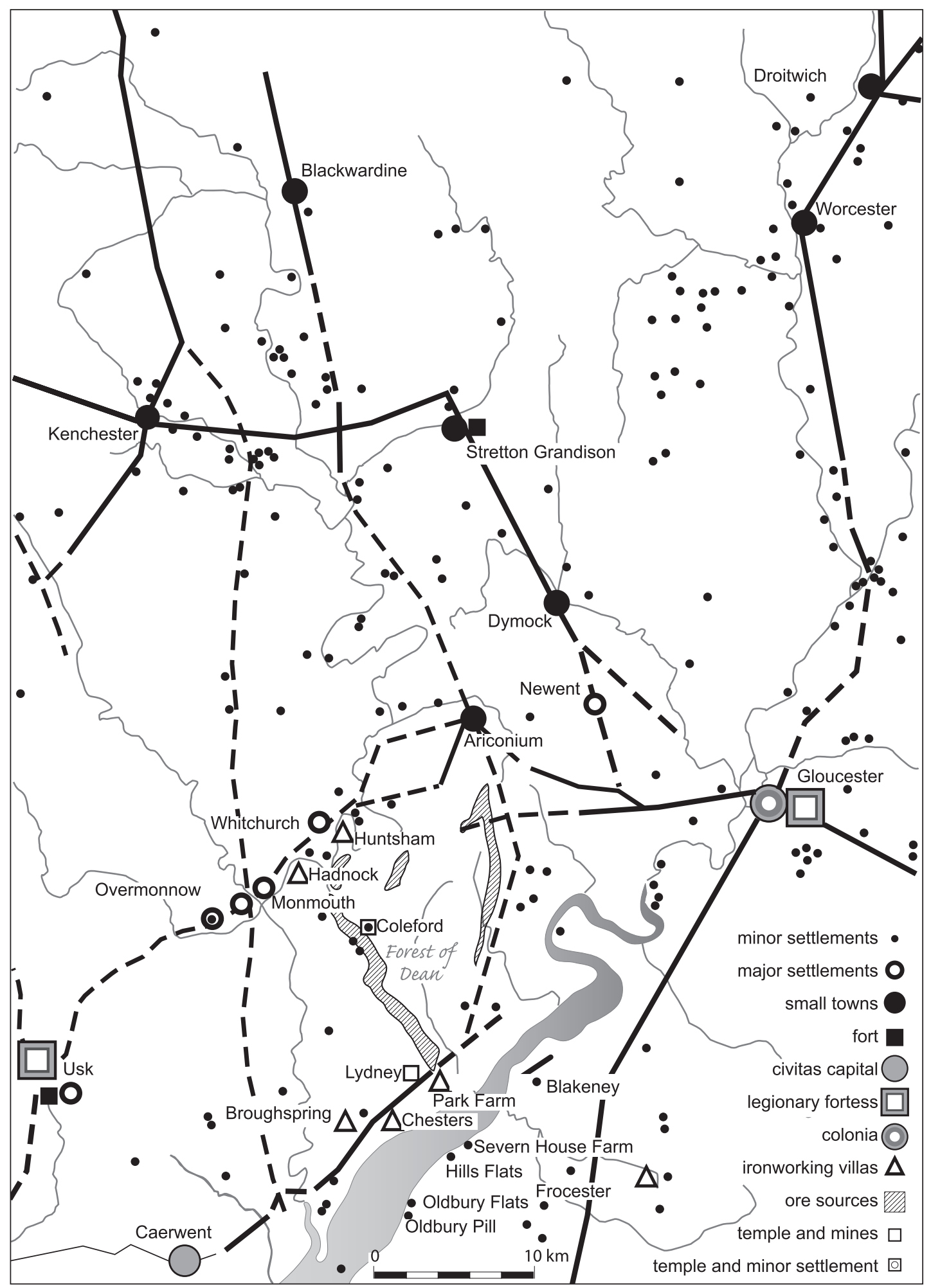

Figure 5.2. Sites in the region. Reproduced by permission of Ordnance Survey on behalf of HMSO. (C) Crown Copyright 2011. All rights reserved. Ordnance Survey Licence number 100051813

to $0.10 \mathrm{~m}$ thick and being recorded as between $3 \mathrm{~m}$ and $5 \mathrm{~m}$ in width. Wider sections have been observed where wetter ground was crossed (Bridgewater 1959, Wigg 7), while at several locations roadside ditches have been identified (Garrod and Moss 1967; Napthan, Ratkai and Pearson
1995). 'Ridges' surviving down the sides of the surface in two of Bridgewater' trenches (1959; Wigg I and II) have been suggested as the remains of a later resurfacing and probably reflect heavy wear of the central section.

Although dating evidence is not extensive the route is 
believed to have been in use since the late Iron Age or earlier; associated material ranging from the $1 \mathrm{st}$ through to the 4th century and including late Iron Age/early Roman material and a strong 3/4th century presence (Bridgewater 1959; Wigg III; Napthan, Ratkai and Pearson 1995; Trench 11). Surface observation of a broad spread of iron slag near Pond Cottage (Holland 1932) and cropmark evidence (Cox 1995; roads N-M and F-E; Fig. 1.5) also appears to represent this route.

\section{Route 2}

A section of this route was investigated by Jack (1929; HSM 21367). Here, a 3.65m wide unditched, slag surface was recorded and can be equated with a cropmark (Cox 1995; road C-D; Fig. 1.5).

This runs towards Ross-on-Wye (Fig. 5.1, Route 2) and can be equated with Margary route $612 \mathrm{a}$. It may have turned south and run towards Whitchurch and Monmouth (Fig. 5.2). This would have provided a link to any river based distribution network along the River Wye and also would have provided access to charcoal supplies from woodland focussed around Penyard Hill.

\section{Route 3}

On the south side of the settlement, Bridgewater (1959; HSM 21361) recorded sections of a third road which ran south-east from the town (Fig. 5.1, Route 3). This crossed Route 4 and headed through Huntley, past May Hill and on towards Gloucester (Margary 1955: route 611; Fig. 5.2). The road was also well-constructed, again using slag and stone. It had a compact, heavily made central agger and measured some $3 \mathrm{~m}$ wide.

This was an important trading route linking Ariconium and the quarries at May Hill to the colonia at Gloucester and thereby to the south and east. This probably had Iron Age (or earlier) origins, being the most probable route for the contacts evidenced at the site with the south and east at this time.

\section{Route 4}

A further major road (Fig. 5.1, Route 4), often referred to as the Dean Road, is believed to lie under the current B4224 through Bromsash. This is recorded in the Antonine Itinerary and has been traced running north towards Ashton, near Leominster (Margary 1955, route 613) and probably on to Blackwardine (Fig. 5.2). To the south, this important route linked Ariconium to charcoal supplies from the Forest of Dean, ore sources at the Wigpool Syncline (only some $4 \mathrm{~km}$ to the south-east) and the temple and postulated harbour on the Severn Estuary at Lydney (Margary 1955, route 614 ).

Although known as a Roman road, as with Route 3, this is liable to have had Iron Age or earlier origins.

\section{Lesser routes and internal tracks}

Other lesser routes are known from cropmarks. These appear to be metalled with stone or iron slag since they show as parchmarks (Figs 1.5 and 5.1). Several probably represent back-lanes running behind properties fronting the more substantial roads. Others form internal links between roads and areas of settlement and there are likely to have been many further tracks spread throughout the settlement 'core' and leading from the main roads towards farmsteads in the town's hinterland. Two examples of the latter are known, one a hollow-way linking the settlement to the north with the Dean Road, the other paralleling Route 1 but running down the north side of the stream towards the small settlement to the south-west.

\section{Post-medieval route}

A post-medieval road was recorded by Bridgewater (1959; HSM 21362) to the south-west of Eccleswall Court. This was on a south-west to north-east alignment and is believed to represent a road constructed to carry Roman iron slag waste for re-smelting at Linton during the 18th century.

\section{Domestic remains}

\section{High status and other stone-founded buildings}

Evidence of stone/stone-founded buildings has come from a number of locations towards the northern end of the scheduled area. These probably fronted onto or lay in enclosed plots alongside or slightly set back from Routes 1 and 2 (Fig. 5.1, Buildings 1-6).

\section{BUILDING 1}

Jack's 'kitchen block' and 'heated rooms' represent the most substantial structures excavated to date (HSM 16780; Jack 1923; Fig. 5.1, Building 1). The two rooms of the 'kitchen block' suggested the presence of a range of buildings about $24 \mathrm{~m}$ long running parallel to one of the roads (Route 2). Mortared sandstone walls although heavily robbed, survived in places to a height of three courses, and along with stone diamond shaped and oblong tiles and other building debris indicated a building of some substance. A surface spread of morticed stones and other rubble may also relate to this building (HSM 4185; Morris 1971).

There are indications that the building was of some pretension. The southern wall's internal surface was plastered and painted with a scheme of ochre, dark red and white lines. The 'heated rooms' featured a $5.5 \mathrm{~m}$ length of wall with a hearth, furnace or 'hypocaust' set against it and associated evidence of burning and box flue tile. A fragment of cast window glass suggests that at least some of the building had been glazed (Cool: Catalogue no. 270) and, along with a finely worked masonry fragment of Bath Stone, indicates that at least part of the building was appointed with high quality fittings and furnishings. The 
finds also include some expensive, luxury items, including an escutcheon and an ivory object (Cool: Catalogue nos 178 and 36). Dating suggests that the building/s had a relatively extended period of use from the 2 nd through into the 4th century.

\section{BUILDING 2}

A second building, sharing some similar characteristics, has been identified some $200 \mathrm{~m}$ to the west (Garrod and Moss 1967; Trench CXX; HSM 23552; Fig. 5.1, Building 2). This building, consisting of an unmortared stone footing, robber trench and pit associated with stone tiles, nails and loose stone rubble was also clearly substantially constructed. Grey and white tesserae and red coloured painted wall plaster recovered from these features indicate a structure of a similar degree of pretension to Building 1, either at this location or immediately adjacent. Surface spreads of tesserae, morticed stone and painted plaster have also been recorded in the vicinity (HSM 4186-8, Morris 1971; DAG, HSM 23568).

Dating evidence, though poor, is again suggestive that this building was of 2 nd century construction and that it was at least partly demolished and robbed in the later 3rd or early 4 th century.

\section{BuILDING 3}

Finds of tesserae, painted wall plaster and rubble have also been reported further to the north (Martin Sterry, pers comm.; HSM 23567; Fig. 5.1, Building 3). These indicate the location of another building of some pretension. Some evidence exists to suggest that this might have been the site of a temple or shrine (see below).

\section{BuILDINGS 4-6}

The presence of further stone-founded buildings can be suggested within the main settlement. These were probably of simple construction, perhaps having been timber-framed buildings resting on stone foundation courses. In this area sandstone is readily available and this may have been a typical construction method for middle-range properties.

The first of these (Fig. 5.1, Building 4) is indicated by a 'shapeless mass of masonry' suggestive of a stone structure in the vicinity (Jack 1923, HSM 21097). Elsewhere within the domestic core, a further example survives in the form of the stone footings fronting a metalled surface identified by Garrod and Moss (HSM 23554; Fig. 5.1, Building 5). Further afield, near to Pond Cottage, two wall footings and a nearby dump of masonry rubble represent the site of further building, possibly a watermill (Fig. 5.1, Building 6; HSM 6097, Trenches 2, 10 and 11; Jackson, Hancocks and Pearson 1993).

BuILDING 7

To the south-west of the main settlement, a wall line and associated building debris were recorded at the 3rd to 4th century site at Bull Meadow. This appears to represent a fairly substantial stone-founded building with a tiled roof
(Fig. 5.1, Building 7; HSM 15983; Jackson, Hancocks and Pearson 1993).

These more substantial buildings date from the 2nd century onwards and three of them were clearly fairly well appointed with tessellated floors and painted plaster on the walls. The absence of buildings of stone or of part stone construction prior to the 2 nd century is fairly typical for Roman sites (de la Bédoyère 1991, 118). Similarly the association of several of the buildings with tessellated floors and painted plastered walls reflects romanised building styles which were becoming more commonplace in reasonably well appointed town houses as the $2 \mathrm{nd}$ century progressed (de la Bédoyère 1991, 28; Burnham 1995, 9).

At Ariconium these were occupied until perhaps the later 3rd or earlier 4th century and in the case of Building 1 , occupation probably extended well into the 4th century. The building near Pond Cottage (Building 6) and that at the hinterland settlement (Building 7) may not have been constructed until the 3rd century and their occupation also probably extended well into the 4th century. In the latter case, this might represent a high status residence of the type often found concentrated around market centres during this period (Burnham 1995, 13).

The examples identified may only represent a small proportion of stone-founded structures within the settlement core. It is evident, from reports of the 18th century clearance of the site, that a considerable quantity of building stone was removed and that many walls were 'dug out'. Pillars, door jambs and walls form a frequent component of antiquarian descriptions of the remains uncovered throughout the 18th and 19th centuries and, whilst these should be treated with caution, they do appear to indicate that a considerable number of stone-founded buildings might once have been present. This point is emphasised by more recent accounts of ploughing encountering stone obstructions and the observation of worked masonry and other building debris following ploughing.

\section{Timber buildings}

Some of the less substantial stone foundations discussed above (Fig. 5.1, Buildings 4, 5 and 6) may have supported timber-framed buildings. Otherwise only slight evidence of timber structures has been identified, although, elements of post-built structures have been found (HSM 23551, Garrod and Moss 1967, Trench CI; HSM 6097 and 15983, Jackson, Hancocks and Pearson 1993).

A roundhouse has been tentatively identified at the Late Iron Age and early Roman farmstead enclosure to the north at The Great Woulding on the basis of several postholes and short length of curvilinear gully (HSM 9071, Walters and Walters 1989). A second roundhouse has been tentatively identified within the settlement core (HSM 23551, Garrod and Moss 1967).

Despite this limited evidence, timber buildings would certainly have been commonplace within the 'small 
town' and, as at the majority of Roman settlements, all structures are liable to have been timber built in the 1st century (de la Bédoyère 1991, 16) with roundhouses the predominant type. These reflected native building traditions and probably persisted into the 2 nd century or later in the surrounding countryside. From the end of the 1 st century or early in the 2 nd, simple rectangular houses and buildings probably started to be constructed within the main settlement forming the bulk of domestic and workshop accommodation as has been observed within other 'small towns' (Burnham and Wacher 1990, 17).

The generally limited evidence probably reflects a combination of poor survival, generally ephemeral character, and the fact that excavation has focussed upon areas where building debris and other evidence of higher status occupation have been recorded.

\section{Yards and boundaries}

A range of other features including metalled surfaces, mortar spreads and gullies and ditches provide evidence of yards, drainage and plot boundaries. These date from the 1 st century through to the later 3 rd or early 4 th century. Although the evidence does not allow the reconstruction of any properties, it is clear from cropmarks that there were a number of rectilinear compounds or enclosures bounded by ditches or gullies.

These features focus along the roads running west and south-west from the settlement (Routes 1 and 2), while several others are scattered beyond the main settlement focus (Fig. 5.1). The character of activity within these enclosures is uncertain and some of the outlying enclosures may represent industrial areas or small fields and animal pens. However, the concentration and dating of domestic finds in surface collections from the areas of the site in which the remainder occur suggests that these are liable to have enclosed 2 nd to 3 rd century domestic buildings.

These enclosures and associated structures appear to be relatively spacious and there is no evidence to indicate the development of narrow-fronted strip buildings along the main street frontages as has regularly been observed in many Roman 'small towns' (Burnham and Wacher 1990, 27). Some may remain to be identified in the area where the stone founded buildings focus; however, beyond these, larger enclosed plots seem to be the norm and it would be surprising if the higher status buildings did not similarly enjoy the luxury of large plots.

\section{Mansio?}

It is likely that Ariconium would have had a mansio or inn. Many 'small towns' along the road network developed such buildings from the 2 nd century onwards and these may be seen as reflecting the development of official functions at these middle order settlements (Burnham 1995, 12-13). Given Ariconium's location at a major junction on the routes between Gloucester $(20 \mathrm{~km})$, Kenchester $(32 \mathrm{~km})$,
Monmouth $(20 \mathrm{~km})$ and Lydney $(21 \mathrm{~km})$ and its mention in the Antonine Itinerary it seems probable that one was present here. The location of Building 1 (Fig. 5.1) and the fact that it appears to have been the best appointed in the settlement suggest that this could have fulfilled such a function.

\section{Watermill?}

Salvage recording in 1993 recovered a Roman millstone from a dump of rubble to the north of the stream running west from Pond Cottage (Shaffrey and Roe: Catalogue no. 9; Fig. 5.1, Building 6; HSM 6097, Trench 2). Close to the stream, another trench (Trench 3 ) produced evidence of a canalised watercourse which had been infilled or silted up during the later 3rd to 4th century (Jackson, Hancocks and Pearson 1999). This was interpreted as a channel or leat. Although no dating evidence was recovered, recording in the 1930s, identified three ponds and the remains of two dam structures along the stream (Anon 1932). These could be of later date but a Roman origin should not be excluded especially for the ponds.

To the south of the stream, stone footings have been interpreted as the foundations for one or more timberframed buildings (HSM 6097, Trenches 10 and 11). Adjacent to one of these footings, a clay-lined pit contained charred cereal crop processing waste, suggesting perhaps that this building was a grain store.

Taken together this evidence is strongly suggestive of a watermill. Roman watermills have been rarely recorded in Britain (M. P. P. 1988; Watts 2002, 50-55), although large millstones of a size indicating that they would have been power driven have been widely reported (Watts 2002, 58). Locally Roman mills have identified at the Chesters villa (Fulford and Allen 1992, 201) and just to east of Kenchester (Wilmott and Rahtz 1988, 72). These sites along with Ariconium share the two most commonly represented elements, leats and millstones; however, the presence of a possible millpond, dam and of one or more associated stone founded buildings is unusual since such elements have rarely been encountered (M. P. P. 1988; Watts 2002).

\section{Temple/shrine (?) and other religious activity}

Although no temple or shrine has been firmly identified there are indications that the most northerly scatter of building debris might represent the site of such a building (Fig. 5.1, Building 3; HSM 23563 and 23567). Apart from evidence for a building of some status, this area has produced a number of probable votive or cult items, including a sherd from a face pot, two penannular snakeshead bracelets and two bronze spearheads (Cool: Catalogue nos 28-9, 230 and 232).

The presence of the face pot may indicate an association with the smith god. The latter, who may be equated the classical god Vulcan, held an elevated position in Celtic 
society (Ross 1967, 379-80) and is liable to have been a particularly important deity for the local population many of whom would have been ironworkers. The putative shrine/temple and these items were situated close to a major ironworking area (Fig. 5.1, Ironworking area B). Further, deposits in this area produced a concentration of decorated samian possibly representing a ritual deposit sealing several furnaces (Willis, Section 4, Analytical Group 5). This might be seen as an offering to the smith god, made as production ceased in this area to either encourage success in future ironworking or give thanks for the iron from the old furnaces.

Elsewhere on this site, other items potentially associated with religious activity include a small model of a cock on a fitting or terminal possibly associated with Mercury (Cool: Catalogue No. 268). A figure of Diana reportedly from the site has also been recorded (VCH 1908). These items may have been associated with small household shrines or other aspects of religious beliefs as would have been tightly interwoven into the fabric of everyday life at the settlement.

\section{Cemetery evidence}

Evidence of burials is surprisingly absent. The only report of graves dates to 1804 when several skeletons were uncovered during the widening of a road (Brayley and Britton 1805). The location of this is unclear. The 1838 tithe shows roads broadly following the routes of several of the earlier Roman ones and since Roman cemeteries were typically in roadside locations, it seems probable that the road widening affected a cemetery lying on one of the routes leading out of the town.

One other potentially relevant find is the fragment of Roman tombstone recorded within the fabric of the chancel of the church at Upton Bishop (HSM 6630). Upton Bishop lies only a few kilometres from Ariconium, which is the most likely source currently known for this item.

\section{Ironworking remains}

Excavation provides the most reliable indicator of ironworking since there was an almost ubiquitous use of iron slag for surfacing of roads and yards and consequently plots of ironworking debris show spreads extending across the whole settlement. Evidence for three areas of ironworking at the main settlement and a further focus at the enclosures to the north can be identified from the excavation record (Fig. 5.1, Ironworking areas A-D).

\section{Ironworking area A}

This lies in the 'core' of the main settlement and has been identified from excavation at two locations.

The first area included a row of three shaft furnaces pre-dating a 2nd century stone building (Fig. 5.1, located as Building 2; HSM 23552; Garrod and Moss 1967). These were virtually identical, shallow sub-oval depressions with traces of fired clay superstructures around their sides. They were associated with a probable smithing or roasting hearth which contained a fill rich in ash, cinders and what was described as fine metallic silt, the latter probably representing a deposit rich in hammerscale. These lay in and around a working hollow and were associated with a couple of postholes representing a timber structure. No direct dating evidence was recovered, although the overlying building dated to the 2nd century and residual material included some late Iron Age/Transitional pottery. This suggests that the furnaces date to the 1 st century AD, and that they potentially pre-dated the Roman conquest.

A second location, to the south, produced evidence of two hearth/oven structures (Fig. 5.1, Ironworking area A; HSM 23548 and 23550; Garrod and Moss 1967). Dating was again poor, but a limited amount of 1 st century material and large quantities of late Iron Age/Transitional pottery in overlying layers suggest that they are broadly contemporary with the furnaces described above.

\section{Ironworking area $B$}

A second focus of activity lies to the north of the settlement's domestic 'core' (Fig. 5.1, Ironworking area B; HSM 21360 and 23557-9; Bridgewater 1965). This is the most comprehensively investigated ironworking area to date.

A total of six shaft furnace bases were identified along with slag pits, working hollows and some evidence of associated timber structures. Of the latter the most significant was a structure interpreted as a charcoal store, samples from which clearly indicated that this contained fuel suitable for using in furnaces (Gale, Section 4). Along with in situ masses of iron slag with attached runners, this evidence demonstrates beyond doubt that these were associated with smelting. Smithing may also be suggested on the basis of the presence of slag with coal inclusions, the latter fuel being associated with smithing rather than smelting.

Pottery indicates that a start date of $c$. AD 135 should be assigned to this ironworking area. This continued in use for about 100 years until the early to mid 3rd century, the end date being provided by a distinct abandonment layer (Willis, Section 4, Analytical Group 6). The latter has been interpreted as resulting from a period of dumping of domestic debris and potentially includes evidence for the 'closure' of this area through ritual deposition of decorated samian.

\section{Ironworking area $C$}

This lies to the south-west of the domestic 'core', where salvage recording recorded an extensive concentration of ironworking debris and associated features (Fig. 5.1, Ironworking area C; HSM 6097, Trench 8/14; Jackson, Hancocks and Pearson 1999).

Intercutting hollows, tap slag and remnants of associated 
fired clay superstructures provided evidence of at least one shaft furnace and tapping pits while a specialised industrial feature contained large quantities of slag waste and fuel charcoal from coppiced woodland (Gale 1999). Metalled surfaces, pits, postholes and ditches were interpreted as associated yards, buildings, storage/disposal features and drainage features or property divisions.

Large quantities of iron slag indicated that ironsmelting was a primary function of this area. The morphology of some of the slag indicated that limited smithing was also undertaken probably relating to consolidation of the bloom (Starley 1993; Starley, Section 4). Activity appears most likely to have developed during the later 2 nd century with clear evidence indicating that this continued through to the end of the 3 rd century and well into the 4th century.

\section{Ironworking area $D$}

A fourth area which appears to have been associated with ironworking lies to the north within the cropmark enclosures investigated by Walters and Walters (1989) at The Great Woulding (Fig. 5.1, Ironworking area D; HSM 9071).

Although no furnaces have been identified, the quantities of iron slag recorded in the ditches of both enclosures seem unlikely to have been transported this far from the main settlement. In particular the more irregular, southerly enclosure seemed associated with ironworking waste having produced 'bloomery slag', 'tapped bloomery slag' and 'smithing slag' along with vitrified clay (Walters and Walters 1989).

Both enclosures appear to be of Iron Age origin; activity within the southern enclosure perhaps having ended by the mid 1 st century AD and in the northern enclosure only extending until the end of the 1st century AD. The latest feature in this area, a hollow-way between the enclosures and linking them to the nearby road, may have remained in use into the early 2 nd century.

\section{Other industrial activity}

Although Ariconium is likely to have supported a range of other specialist crafts and small-scale industrial enterprises, evidence is slight and apart from the watermill is limited to artefactual evidence.

Evidence for bronze working can be identified at two locations. At the main settlement, the presence of casting waste, a possible runner, and numerous offcuts and trimmings from cast and sheet items provides evidence for production of copper alloy objects (Cool: Catalogue nos 274-306). This argument appears to be strengthened by the presence of an unfinished casting of a Colchester one-piece brooch (Mackreth: Catalogue no. 9). The distribution of these items is rather dispersed; however, concentrations appear to exist to the south-west and within the domestic 'core'.

More definite evidence for bronze working comes from the outlying settlement at Bull Meadow (Fig. 5.1; HSM 15983). This comprised crucible and hearth lining fragments from a non-ferrous alloy melting furnace and copper alloy dribbles (waste products of non-ferrous casting; Starley 1995) along with a part melted item (Mackreth: Catalogue no. 88). In this case the activity could be dated to the 3 rd to 4 th century AD.

Other activities represented which are likely to have been undertaken on a moderate scale include glass working (glass slag), textile production (spindle whorls and a lead loom weight), construction (plumb bobs) and fishing or bird catching (net weights).

\section{Hinterland settlement}

Small farming settlements and villa clusters were often located close to towns and were especially common around 'small towns', suggesting that the latter were more closely integrated into the rural economy than the larger towns and cities (Dark and Dark 1997, 118). In the immediate hinterland of Ariconium, there is evidence for three outlying settlements within the study area all of which are situated close to, or on the road network. These would probably have been primarily agricultural production sites but may have been involved in woodland management and charcoal burning and may also have provided seasonal labour for the ironsmelting industry.

\section{The Great Woulding}

The first of these settlements lies about $1 \mathrm{~km}$ to the north where two enclosures have been shown to be of 1 st to early 2nd century date (Fig. 5.1; HSM 9071; Walters and Walters 1989). These have been discussed previously and appear to have been associated with ironsmelting in the late Iron Age to early post-conquest period.

Although the trenching was limited, re-assessment of the evidence (Section 2) suggests that Iron Age activity occurred in both enclosures. The southern enclosure appears to have been deserted at the end of the Iron Age possibly reflecting a decline in fortunes as the main Roman settlement developed to the south. This decline seems to have continued, since by the early part of the 2 nd century the settlement had largely been abandoned.

\section{Bull Meadow}

This lies to the south-west of the main settlement and developed during the 3 rd century with occupation extending well into the 4th century (Fig. 5.1; HSM 15983; Jackson, Hancocks and Pearson 1999). This focussed around a relatively high status stone-founded building lying a slight distance west of the main road (Building 7). A minor route running parallel to the main one may have directly linked this settlement to Ariconium. Copper alloy working waste suggested that its economic function also encompassed small-scale industrial activity. 


\section{Wigg Meadow}

A second site lies to the south-west, about $1 \mathrm{~km}$ from the main settlement on the line of a major road (Fig. 5.1; HSM 22965). Although dating evidence is poor this seems to have been of mainly $3 \mathrm{rd}$ to 4 th century date.

\section{Wigg 3}

A final hinterland settlement lies just beyond the study area and is also situated on this main road about $1 \mathrm{~km}$ on from that at Wigg Meadow. This was a 2 nd to 4 th century settlement and included a building of some substance (Bridegewater 1959; Wigg 3).

\section{Settlement chronology}

\section{Earlier prehistoric activity}

The site has only produced a very limited amount of evidence for earlier prehistoric activity. Flint finds indicate a low level of activity in the area but no firm evidence for settlement and it is entirely possible that these represent no more than stray losses. One item is of slightly greater interest, the tip of a small bronze spearhead of possible Bronze Age origin (Cool: Catalogue no. 231). Although this might imply early activity, a strong possibility exists that this reflects the recognised Roman practice of making use of antique objects for religious, ritual or magical purposes.

\section{The late Iron Age settlement}

\section{The evidence (Fig. 5.3)}

The earliest evidence for occupation of the site dates to the late Iron Age. Previous discussions about potential Iron Age origins for Ariconium had been limited by the absence of unequivocal evidence or of any fully collated data. The current project has gone some way to addressing these problems, although, firm excavated evidence remains elusive.

One particular problem lies in differentiating late preRoman Iron Age from early Roman occupation, a problem which is commonly encountered on transitional period sites. The subsequent development of the Roman 'small town' has also inevitably truncated much of the area of Iron Age occupation. Despite these limitations, areas of potential late Iron Age activity have been identified alongside two (Roman) roads believed to have Iron Age origins linking the site to the Herefordshire basin, the Severn Estuary, the Forest of Dean and Gloucestershire.

The Great Woulding

To the north of the later Roman settlement, strong evidence for Iron Age occupation exists at the two enclosures at The Great Woulding (Fig. 5.3). Assessment of these (Section 2) suggests that they probably represent farmstead enclosures, typical of Iron Age and Roman rural settlements in the region (Whimster 1989).

Dating of the infilling of the southern enclosure and of one of the overlapping northern enclosures is based on the small number of artefacts seen during the course of the Ariconium project and on the published artefacts and descriptions from the interim (Willis, Section 4). This suggests that both were of at least late pre-Roman Iron Age date and that the southern enclosure had fallen out of use by the conquest, although it is evident that the northern enclosure ditch was recut and continued in use until about the end of the 1 st century AD. The presence of a possible roundhouse supports the early dating and probable domestic function of this enclosure.

Both of the late Iron Age ditches produced quantities of iron slag including material consistent with the use of tapped furnaces. The southern, more irregular enclosure appeared to be particularly associated with iron slag and it is suggested that this enclosure may have had a specialist ironworking function while the northern enclosure supported domestic occupation. A trackway between the enclosures, although used into the Roman period, probably has Iron Age origins and linked the site eastwards to a major north-south route.

\section{HASK BARN}

The second area to produce evidence of Iron Age activity lies within the later settlement core and to the south of Hask Barn (Fig. 5.3). This has produced large quantities of both residual and unstratified late Iron Age material, plotting of which covers a fairly broad area. Within this area a small number of potentially late Iron Age features have been recorded, including a couple of 'hearths' with associated iron slag to the north and to the south a group of shaft furnace bases (Fig. 5.3, ?Ironworking; Fig. 1.3, HSM 23548, 23550 and 23552).

Neither group of features can be firmly dated due to the absence of associated artefacts but both groups were at the base of excavated sequences and pre-dated early Roman deposits. Furthermore, the area where the 'hearths' were recorded produced significant quantities of late Iron Age/Transitional period pottery from overlying Roman contexts. This material supports the identification of a late Iron Age focus at this location. Considerable quantities of typologically late Iron Age and Transitional pottery amongst the material examined has left little doubt that there was significant activity in this vicinity during the late pre-Roman Iron Age, if not before.

Additional supporting evidence comes from surface finds of Iron Age pottery, especially those recorded from the area of the trenches described above. These have been recovered and retained by various individuals and consequently have not been available for this study. However, they are reported to include a fine duck stamped vessel (usually a middle Iron Age decorative motif) and a high proportion (c. 15\%) of vessels with linear and oblique incised lines around their shoulders and occasionally 


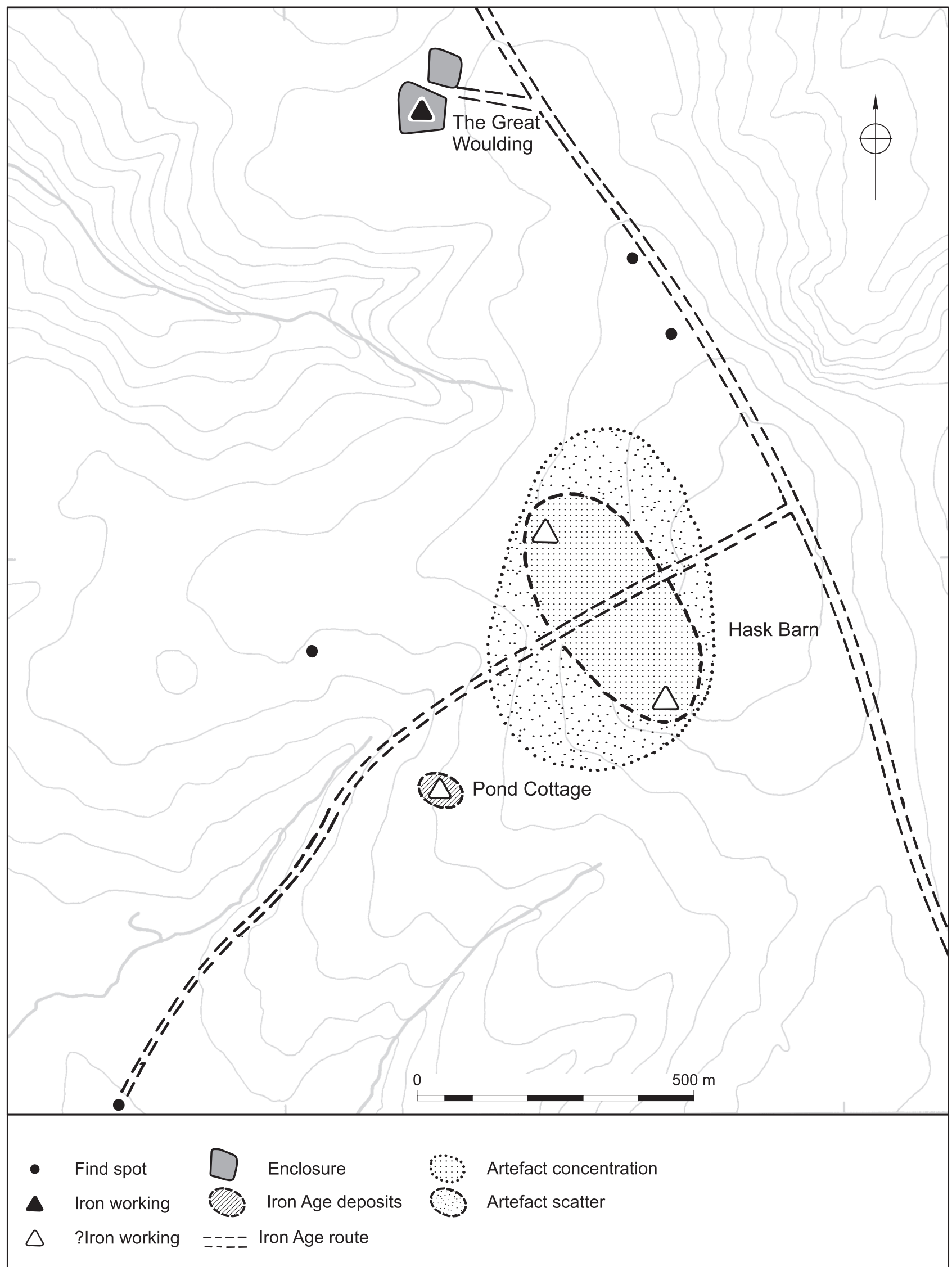

Figure 5.3. The late Iron Age settlement 
stabbed decoration below (Patrick Garrod pers. comm.). This pottery has affinities with material from Sutton Walls to the north and the Cotswolds hillforts to the south and east. Walters (1992) has also identified this as an area where surface collection has produced considerable quantities of late Iron Age pottery, on the basis of which he has suggested this as the location of a pre-Roman ironworking settlement.

Other artefactual evidence, including brooches, coins and two fragments from 'beehive' querns, also points to late Iron Age occupation in this area. Important collections of pre-conquest brooches have been recovered (Section 4, Mackreth: Catalogue nos 1-4, 14-15, 18, 20-22 and possibly 10, 16, 17 and 19) as well as a significant quantity of Iron Age coins (Section 4, King: Table 42). Although there are problems relating to use and circulation of some of these into the Roman period, the quantities of this material allied to the strong ceramic presence build a firm case for significant late pre-Roman Iron Age activity within the area of the later settlement 'core'.

\section{Pond Cottage}

Further limited evidence for deposits of Iron Age date has been recorded to the south-east of Pond Cottage (Fig. 5.3; HSM 12666; Jackson, Hancocks and Pearson 1999). Although observation was restricted to the width of a stripped pipeline easement, two ditches produced a small quantity of late Iron Age/Transitional period pottery, briquetage and tapping slag. In the absence of Roman material, which is widely present in the vicinity, these artefacts are strongly indicative of a late pre-Roman Iron Age date for these ditches. The presence of iron slag is again of particular interest indicating an early association with ironworking.

\section{Character}

Iron Age origins of the settlement at Ariconium have been considered previously by amongst others Stanford (1981), Webster (1981) and Walters (1982). Iron Age origins would certainly not be unusual since about a third of Roman 'small towns' can be suggested to have had pre-Roman origins (Burnham 1986).

The settlement appears to have had no clear nucleus, comprising several foci situated on or adjacent to communication routes leading north, south and southwest. Of the foci, that to the north at The Great Woulding is defined by two enclosures lying either side of a track, one supporting domestic occupation the other providing a focus for ironworking. The location of the latter, to the south of the domestic focus, reflects a pattern observed for Iron Age smelting sites which have been noted to occupy peripheral areas of sites often to the south or west of occupation areas (Hingley 1997, 12-13).

A more extensive area of activity (Hask Barn) underlies the core of the later Roman 'small town' and is situated across the line of a route heading to the south-west.
Stratified remains have not been firmly identified but surface finds cover an area of over 20ha. An association with iron production is likely and the range of finds is indicative of high status occupation. Two potential ironworking foci again lie towards the periphery of the spread of material defining this area and it is possible that one or more enclosures were present lying to either side of a central track. Further activity (at Pond Cottage), seemingly lying just beyond this focus, has been identified to the south-west and although limited to two ditches has produced further evidence of ironworking.

The pottery in use was of predominantly local origin with unelaborated jars and bowls in Limestone tempered ware as would be typical for a Late Iron Age site in this area (Willis, Section 4). However other elements of the assemblage are of note. These include a range of dark surfaced wares representing a distinct Late Iron Age 'Aylesford-affinity' ceramic phase. Elaborated beakers, jars and bowls are present in this tradition in quantities notable at a site this far to the west. Furthermore, early to middle 1st century Gallo-Belgic fineware imports are present, comparable to examples from Bagendon and its hinterland, but which are rare elsewhere in the region especially to the west of the Severn.

The brooches show a similar range of contacts with the south-east and the continent with the introduction of brooches certainly made on the continent before the end of the 1st century BC (Mackreth, Section 4). As a group from west of the Severn they are exceptional and suggest that Ariconium attracted traders carrying goods from the continent and the south-east. Similarly the coins form a surprising large collection, twenty-six having been catalogued in this report and a further two having been since reported as metal detecting finds (Martin Sterry, pers comm.). The majority of these are Dobunnic issues and of the regional tribal centres only Bagendon (Gloucestershire) has produced more coins (King, Section 4). Thus Ariconium was clearly a centre of some economic importance when these coins were in circulation. An important element of the assemblage is represented by the five non-Dobunnic coins, showing contacts to the east and south-east with the Corieltauvi, Atrebates and the Trinovantes/Catuvellauni. A further contact is represented by the identification of briquetage indicating that the site was a consumer of salt from Droitwich (Worcestershire).

These finds strongly indicate a centre of some considerable status and economic importance. Clearly the economy would have been primarily agricultural but it is evident that the settlement developed an extensive range of regional contacts to the south and east, with clear evidence of exchange over $40 \mathrm{~km}$, and beyond. Van Arsdell (1994) called the site a gateway to and from Dobunnic territory, describing it as a 'magnet' for Dobunnic coins and suggesting that it possibly formed part of a trade network involving iron from the Forest of Dean. Although it can be argued that this area may not have been under Dobunnic political control (Ray 2003), it certainly seems to have 
fallen within the sphere of social and cultural influence of the Dobunni and the distribution/trading network associated with that tribe.

The cultural products linking the site to the Dobunni and the south and east are readily visible within the archaeological record. However, consideration should also be given to archaeologically 'invisible' products which would reveal other elements of the contact and trade network involved. For instance, slaves, dogs, cattle, wool and other agricultural surplus may all have been important items. The regions to the north and west, traditionally associated with tribes such as the Cornovii and Silures, are areas from which only limited quantities of cultural material are recovered from Iron Age occupation sites (Cunliffe 1991, 186, 189; Davies and Lynch 2000, 199). Despite this, Malvernian pottery, Droitwich briquetage and Dobunnic coins have all been recovered from Welsh sites, particularly in south-east Wales within the territory associated with the Silures (Davies and Lynch 2000, 205-7). It has also recently been argued that Dobunnic tribal entrepreneurs established an early trading post near the Roman fort at Wroxeter, where Dobunnic coins and Malvernian pottery have been recovered from the earliest levels (White 2003). It has been suggested that the populations of Wales and the northern Welsh Marches might have expressed wealth and social position through a different means than cultural material, cattle being one possibility (Cunliffe 1991, 394-98). Such 'invisible' products are liable to have been exchanged for the 'visible' products found in these areas and some of them must have passed through Ariconium.

The economic status and widespread trading links evidenced at Ariconium can be argued to have resulted from wealth generated by involvement in an iron production industry based in and around the Forest of Dean. It appears to have been a production site and possibly had a more specialist function as a tribal centre, providing control over the production and distribution of iron regionally, as has been argued for the salt industry at Droitwich (Woodiwiss 1992, 185). This may also explain its apparent status and role as a focal point for the exchange of other goods in the local area. However, there is a danger here of creating circular arguments and it is equally possible that iron production became centralised at Ariconium as an extension of an already existing focal role.

The apparently dispersed non-nucleated character, considerable economic links and potential political status of Ariconium in many ways echo the function and roles of other small pre-Roman centres such as that identified at Baldock, Hertfordshire (Burleigh 1995). Although no linear dykes or defensive boundaries have been identified, their presence should not be excluded among the extensive cropmarks present (Fig. 1.5) and the site in many ways is comparable to those sites classed as oppida. In any case, the traditional classification of oppida has been challenged in recent years (Woolf 1993; Burnham et al. 2001, 68-9). Criticism has particularly focussed upon the exclusion of sites which 'lack fortifications and/or are located outside the supposed heartland of the oppida civilisation' and yet in other ways fulfil the functions of a focal site.

As a potential socio-economic centre, the location of Ariconium towards the western limits of the area defined as the tribal territory of the Dobunni (Cunliffe 1991, fig. 8.1) is of some considerable interest. As discussed earlier, cultural material indicates a strong affinity with the Dobunni if not actual inclusion within their territory. Cunliffe's model of Dobunnic territory (Cunliffe 1991, 170-75) argues that it was divided into two discrete spheres of social or economic contact, one to the north centred on Bagendon (Gloucestershire) and one to the south possibly centred on Camerton (Somerset). Secondary tribal centres and markets are postulated at Meare, Worcester, Wappenbury, Dyke Hills, Mildenhall and Salmondsbury. These all lie within the suggested tribal territory or close to its southern and eastern borders, the latter sites perhaps facilitating trade and other contact with adjacent tribes. The location of Ariconium suggests that it was well positioned to develop a role as a Dobunnic tribal centre for what is now south Herefordshire. This would fill a gap on the western margins of their sphere of influence and provide a point of articulation with the Silures to the west.

The development of a specialist production function at Ariconium might also be seen as part of a wider late pre-Roman Iron Age Dobunnic development, ironworking perhaps mirroring the large-scale production and distribution of both Droitwich salt and Malvernian pottery (Peacock 1968; Morris 1985; Morris 1996). These have been argued to reflect late Iron Age social and commercial development along the lines of that more commonly associated with communities to the south and east (Woodiwiss 1992, 185). Traditionally the Dobunni, along with the Durotriges and the Corieltauvi, have been seen as 'peripheral' to an Iron Age 'core' occupying south-eastern England (Cunliffe 1991, 130). Situated on the fringes of this 'periphery', Ariconium and these other sites might be expected to show little coin use, centralisation of production or contact and cultural affinity with the south-east and the Continent. However, the evidence emerging does not readily support this model, suggesting a more complex pattern than has been previously realised. In this revised pattern, Ariconium and these other Dobunnic centres should perhaps be viewed within the context of the wider cultural and economic developments more traditionally seen as characterising the late Iron Age tribal groups of southern and eastern England.

\section{The early Roman settlement (c. AD 50 to 100)}

\section{The evidence (Fig. 5.4)}

Evidence for early Roman activity in many ways reflects that for the Iron Age in that only a very limited quantity of excavated data is available. More than one area of activity is again evident and threre is a considerable overlap with Iron Age areas discussed above. 


\section{The Great Woulding}

During this period, the enclosures at The Great Woulding were remodelled, the southern one apparently being abandoned and the ditch defining the northern one being re-cut. Iron production may have continued, but activity only lasted until the end of the 1 st or the early 2 nd century $\mathrm{AD}$ at the latest. A partially metalled hollow-way, which had fallen into disuse by the early 2 nd century, occupied the line of the postulated earlier Iron Age track linking the site to the major north-south road, running to south Lydney and north towards Blackwardine.

\section{THE MAIN SETTLEMENT}

This lay about $1 \mathrm{~km}$ to the south of The Great Woulding, developing on the site of the late pre-Roman Iron Age focus at Hask Barn and around the junction of four Roman roads, themselves probably largely based on Iron Age predecessors. A group postholes and gullies of probable 1 st century date and possibly associated with a roundhouse were recorded in this area. In addition, although the ironworking furnaces and hearths described above have been assigned to the late Iron Age, an early Roman date should not be excluded, especially for the hearths lying to the south-east. Here, a considerable assemblage of Roman material dating to before $c$. AD 100 was recovered as residual material in 2 nd to 3 rd century deposits.

More extensive evidence comes from the artefact assemblages, the distributions of which have been used to define a settlement area covering some 30ha. Pottery has been commonly recovered and indicates a 'seamless' continuity in consumption and occupation through the 1st century AD (Willis, Section 4). Brooches show a similar continuity with the Aucissa-Hod Hill element of the assemblage indicating a date range of AD 40-45/50 (Mackreth, Section 4). Other brooches clearly demonstrate a 1st century Roman presence, but the material is typical of groups occurring across southern Britain. Limited numbers of coins and other finds, particularly of personal ornaments, provide additional evidence of occupation. The spread of early Roman material is slightly greater than that for the pre-conquest settlement but occupies much the same location, namely the south and west facing slopes of the hill.

\section{Character}

No formal layout or occupation core can be discerned and the settlement pattern was again probably dispersed with at least two focal areas based around enclosures lying on, or set back from, an irregular street pattern.

Although reduced in size, the enclosed farmstead at The Great Woulding probably differed little in character from its Iron Age predecessor. Ironworking may have continued; however, the southern enclosure was abandoned and since this appears to have been the focus of earlier iron production the scale of operations may have reduced.

In contrast, the main settlement seems to have expanded slightly from its Iron Age predecessor. The curvilinear gullies, possibly associated with a roundhouse, are consistent with continuing native occupation of the settlement. Large quantities of slag in stratified deposits indicate that ironworking remained an important activity. This impression of continuity is supported by the presence among the personal ornaments of items which have a definable south-western style. These show that the site was well embedded into the regional economy, its inhabitants sharing styles of dress and ornamentation with neighbouring communities (Cool, Section 4).

Typically, no abrupt change can be seen in the ceramic assemblage at the transition from Iron Age to Roman (Willis, Section 4). An apparent first wave of 'romanisation' by $c$. AD 50 was followed by a second period of change which becomes evident by $c$. AD 70. By this time samian vessels were reaching the site in some quantity along with other continental wares and regional wares. Typically Iron Age pottery declined in use, replaced by locally produced Early Severn Valley wares which dominate the assemblages from this point onwards. Important 1st century forms mirror the early types recognised by Timby from eastern Gloucestershire (1990). Although this was clearly a relatively small settlement, developing out of its Iron Age predecessor, levels of samian strongly indicate that Ariconium remained a site of some status. During this period and well into the following century, samian supply remained high, generally exceeding that of other middle rank settlements. Especially notable is the supply of decorated vessels which appears higher than that to the 'small town' of Kenchester and indeed compares favourably with larger Roman towns such as Cirencester and Verulanium. Sherds of Dressel 20 amphora also suggest a comparably high level of supply and use.

The site therefore maintained the relatively high regional standing it had held during the late pre-Roman Iron Age. As before, this wealth is likely to have derived from the production and possibly control of the distribution of iron from the Forest of Dean, supported by the trading of other goods for which Ariconium probably represented an important local market. It seems likely that the impetus for this continuity and status came, not from external influences (military or other imperial) but rather, as a consequence of a local native elite (?Dobunnic) population rapidly articulating with, and taking advantage of, the expanded economic opportunities that the conquest brought. Further evidence for continuity comes from the fact that the settlement form appears to reflect an 'organic' growth of the pre-Roman settlement. As such it reflects the situation of many Roman 'small towns' having more in common with pre-Roman oppida and other focal settlement forms than romanised urban developments (Millett 1995; Hingley 1997; Burnham et al. 2001).

Lastly, despite the wider economic contacts and character of the settlement, it should be borne in mind that agriculture and the local rural economy would have remained of prime importance for the inhabitants. 


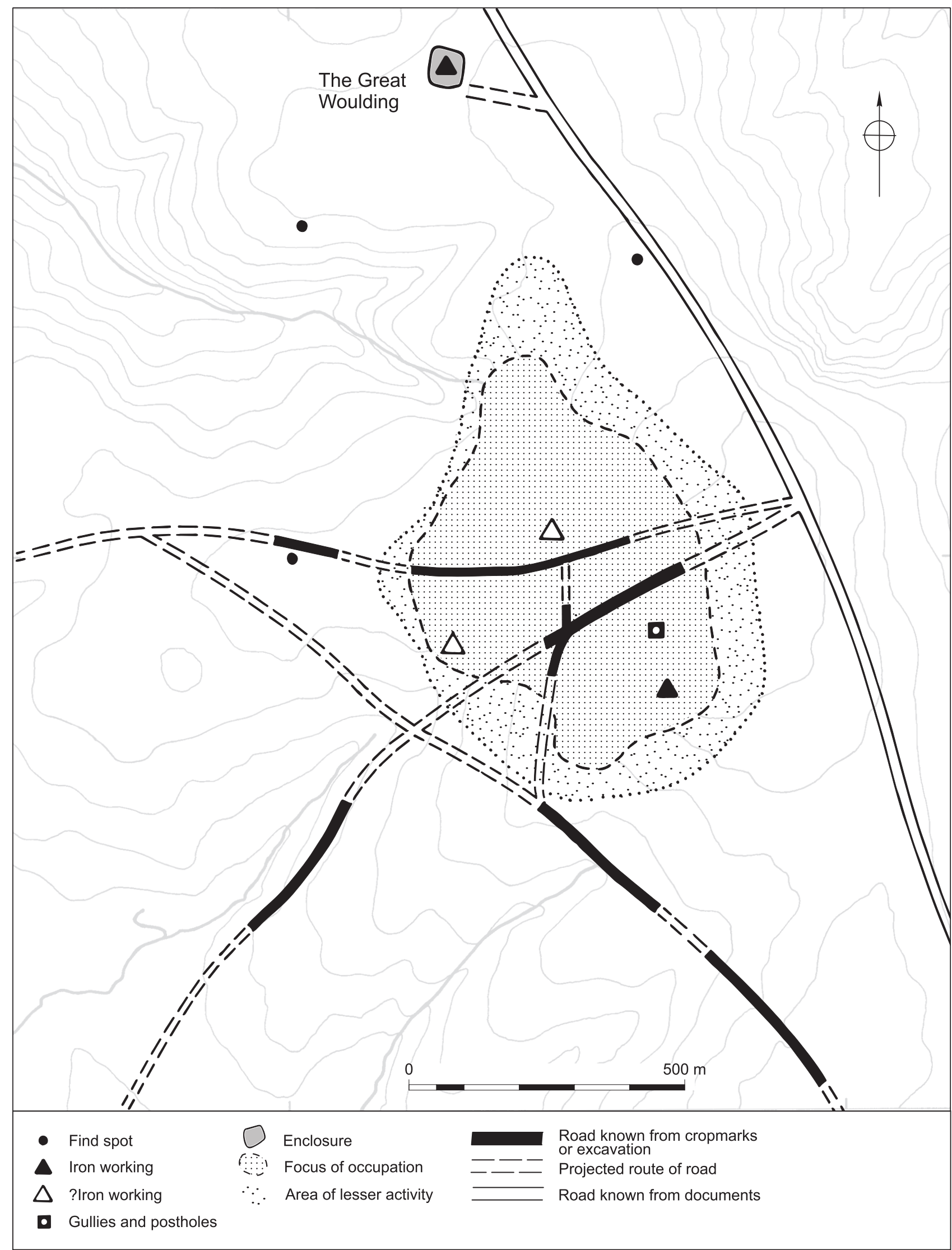

Figure 5.4. The early Roman settlement (c AD 50 to 100). Reproduced by permission of Ordnance Survey on behalf of HMSO. (C) Crown Copyright 2011. All rights reserved. Ordnance Survey Licence number 100051813 


\section{The Roman 'small town' (c. AD 100 to 250)}

\section{The evidence (Fig. 5.5)}

The evidence for this period is extensive and for the first time some idea of the layout of the settlement can be discerned. The Iron Age and early Roman core, situated on the south and west facing slopes of the hill formed a focus for domestic occupation. Three buildings of some pretension have been identified; one suggested as an inn (mansio), a second potentially representing a temple or shrine and a third which was possibly the town house of a local elite family. A number of other stone founded buildings in this vicinity probably had timber framed superstructures while from cropmark evidence, several enclosures are known. The latter probably represent plots of land beside or behind the main roads converging on the settlement and are likely to have contained domestic properties, ancillary buildings, yards and workshops. Other cropmarks suggest an irregular pattern of tracks and streets across the settlement area running from the main routes into the 'small town'.

A considerable quantity of 2 nd and earlier 3rd century domestic pottery and other finds have been recorded within the area occupied by the buildings and enclosures and support the other evidence for the extent and scale of the domestic focus. Beyond this, two distinct ironworking zones developed. To the north, extensive spreads of iron slag and a group of shaft furnaces provide evidence of an ironworking area, developed during the first half of the 2nd century and extending in use through to the early to mid 3 rd century. To the south-west, around two road junctions, a second area with extensive evidence for ironworking developed, either at the end of the 2nd century or early in the 3rd. Indications of copper alloy working and the identification of the probable site of a mill attest further to the industrial/productive character of this latter area.

Further afield the enclosures at The Great Woulding appear to have been abandoned by the middle of the 2nd century; however, towards the end of the 2 nd century or early in the 3rd century two new outlying settlements developed to the south-west, at Wigg Meadow and Bull Meadow. The latter supported a stone-founded building of some pretension and has produced evidence of copper alloy working, providing some evidence of the character of outlying settlements in the immediate vicinity.

\section{Character}

In most Roman 'small towns' the 2nd century was a period of expansion (Burnham and Wacher 1990, 314; Burnham $1995,12)$ and Ariconium is no exception, probably really only becoming recognisable as a 'small town' during this period. Developments such as the construction of stone or stone founded buildings are typical in 'small towns' and have been widely observed from the 2nd century onwards to replace purely timber-framed ones (Esmonde Cleary 1989, 68).
Distinct functions emerge for different parts of the settlement area with a domestic focus and two industrial areas. As in previous phases, there is no evidence for any element of organised planning of the internal street network, with an irregular pattern of tracks, back lanes and access routes linking the domestic and industrial areas as well as gardens and small fields within and around the margins of the settlement.

Despite expanding, the 'small town' does not seem to have enjoyed the high status of the earlier settlement. The modest levels of finewares and the character of numerous other finds are consistent with a middle order settlement, typical of roadside or industrial 'small towns' (Burnham 1995, 10; Willis, Section 4). Certainly the levels and patterns of supply of samian are comparable to those from Droitwich (Dickinson 1992a) and Sidbury, Worcester (Dickinson 1992b). In particular, it is notable that the proportions of decorated to plain samian fall throughout the 2 nd century to levels more consistent with ordinary roadside settlements.

The contrast with earlier patterns of supply indicates that in relative terms Ariconium fell in status during the 2nd century, although there remain some indications of more wealthy inhabitants. The ivory items and the escutcheon from a copper alloy vessel, an expensive object of some elegance are of note in this respect. The stone building excavated by Jack (1923) was associated with a possible hypocaust system, window glass, painted wall plaster and a tesselated floor. This was clearly a town house of some pretension and this building has been suggested above as having been an imperially owned inn (mansio). However, there are no other known public buildings, indeed only a couple of other buildings show any signs of higher status. Along with the potential mansio, these are the type of town houses recognised at many 'small towns' and which may have been the urban residences of local elites (Burnham and Wacher 1990, 19-20). Otherwise, the majority of buildings are liable to have been simple, rectilinear timber structures with at the most stone foundations.

In contrast with evidence for some decline in status, it is evident that Ariconium remained a major regional iron production centre throughout this period with output possibly at its highest level (see below). A wider range of activities and functions are also evident from the late 2nd century and into the 3rd, including copper alloy working and possibly large-scale processing of grain as indicated by the construction of a watermill. The levels of exchange and redistribution of goods are also likely to have increased in line with increasing commercial activity across the province, the growth of which was 'precocious' (Esmonde Cleary 1989, 81).

The expansion of the settlement, the emergence of town houses, the growth of the ironworking industry and other craft production and the wide range of economic contacts all provide evidence of the development of Ariconium as a 'small town' with marketing and administrative functions. This development can be seen as typical, the state revenue 


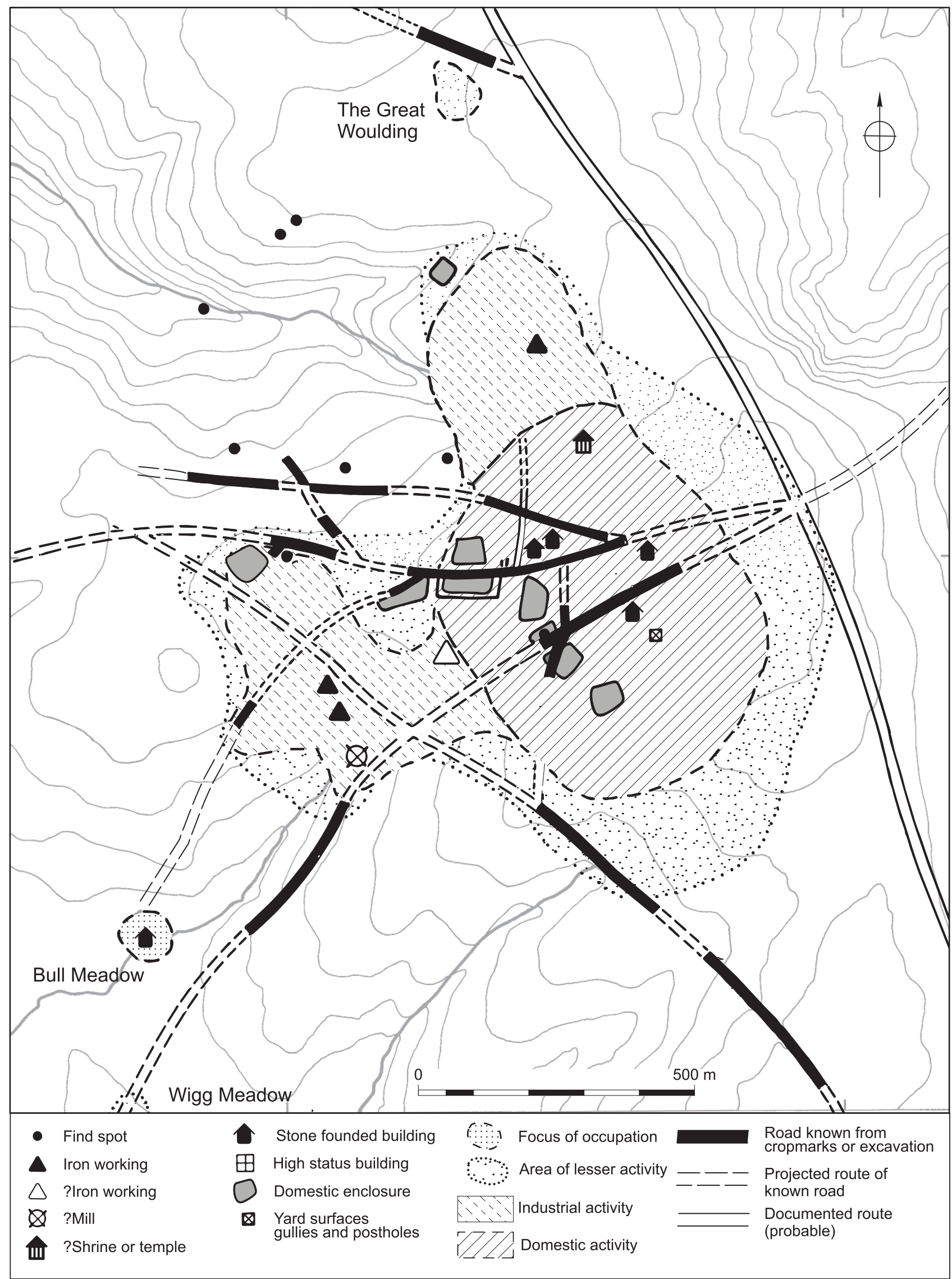

Figure 5.5. The Roman 'small town'(c. AD 100 to 250). Reproduced by permission of Ordnance Survey on behalf of HMSO. (C) Crown Copyright 2011. All rights reserved. Ordnance Survey Licence number 100051813 
and expenditure cycle providing a major stimulus for urban growth and roles for local elites as local administrators (Esmonde Cleary 1989, 72-4; Burnham and Wacher 1990, 43-4).

Lastly, the importance of agriculture, hinterland settlement and the rural economy to the 'small town' should not be underestimated. In particular the construction of a watermill and possibly of an associated storage and processing building can be seen as an element of the role the 'small town' is likely to have fulfilled in the process of marketing, processing and redistribution of local agricultural surplus. Two hinterland settlements also developed, at Bull Meadow and Wigg Meadow (Figs 5.1 and 5.5). These and other rural hinterland settlements were undoubtedly closely integrated with the 'small town', providing seasonal labour for ironworking, food, charcoal (for the furnaces) and a range of other products. For the rural population the 'small town' would have provided a market for the exchange and redistribution of local, regional, inter-regional and even interprovincial products.

\section{The Roman 'small town' (c. AD 250 to 400)}

\section{The evidence (Fig. 5.6)}

Evidence for occupation in the second half of the $3 \mathrm{rd}$ century and the 4 th remains relatively extensive. Although the northern industrial area had been abandoned and was now used for rubbish dumping, the south-western area of the 'small town' continued to thrive. Here, the mill leat remained in use until the late 3rd or early 4th century, while ironsmelting activity extended well into the 4th century. Artefactual evidence suggests that considerable levels of activity continued until at least $c$. AD 350, while the presence of a single sherd of shell gritted ware raises the potential that occupation may have continued beyond this date.

The northern side of the focus of domestic occupation diminished slightly (compare Fig. 5.5 with 5.6), perhaps reflecting the abandonment of the adjacent industrial area. Some contraction of occupation along the roads running to the west can also be deduced from a reduction in the spread of domestic artefacts. However, the suggested mansio appears to have remained in use until the mid 4th century while other stone founded buildings survived at least until the end of the 3rd century. The robbing of one of the latter in the late 3 rd century (Building 2), although indicating its decline, suggests that the stone was needed elsewhere. This implies that buildings were still being constructed and the stone rubble wall foundation also recorded at this location might represent a replacement of the earlier building.

Material evidence for the earlier part of this period is relatively plentiful; however, the picture for the second half of the 4th century is less certain due to characteristic problem of dating later Roman artefacts. Ceramic evidence suggests that the 'small town' fell into a marked decline in the 4th century and that it may have largely been abandoned by about AD 350 (Willis, Section 4). In contrast, although not present in any great quantities, coin issues include those dating from the period AD 364-378, while the latest issue recorded can be dated AD 388-402 (King, Section 4). This reflects the usual pattern of use and loss of coinage during the second half of the 4 th century with peaks at both of these times (Esmonde Cleary 1989, 93), and thereby indicates a level of continuing occupation and economic activity in contrast to that provided by the ceramics. Further evidence derives from the small finds assemblage examined (Cool, Section 4). Personal ornaments of later $3 \mathrm{rd}$ and 4 th century date are well represented, with the ivory bangle, samian spindle whorl and polychrome counter (Cool: Catalogue Nos 36, 170 and 207) all datable to the second half of the 4 th century.

Beyond the town, both settlements to the south-west also continued as centres of occupation, until at least the middle of the 4th century at Bull Meadow (Fig. 5.6) when the stone building appears to have been demolished. Both here and at Wigg Meadow, pottery supply and consumption appears to have ceased by the mid 4th century.

\section{Character}

Although perhaps not on the same scale as during the 2nd and earlier 3rd century, Ariconium maintained a robust economy and considerable size until at least the end of the 3rd century. The south-western part of the 'small town' and the hinterland settlements were active until the middle of the 4th century and perhaps beyond. The settlement core, although in decline, also appears to have retained some high status occupation into the latter half of the 4th century as indicated by the ivory counter, which would have been an item of some luxury and expense.

Most 'small towns' like Ariconium saw growth throughout 2 nd century but the pattern was more mixed in the 3rd and beyond (Burnham and Wacher 1990, 314) with a more widespread reduction in commercial activity during the later $3 \mathrm{rd}$ and 4 th century. This may reflect a settling back after 'precocious early growth' rather than any real decline and, while the occupied areas of 'small towns' may have remained fairly constant, as with larger towns, there may have been a decrease in the density of occupation (Esmonde Cleary 1989, 68 and 81). At Ariconium, although some decline in the overall size of the settlement is obvious from the end of the 3rd century, the reduction in evidence for properties and in the volumes of material recovered might be explained by such a decrease in occupation density.

The ironworking industry remained active until the middle of the 4th century. However, thereafter Ariconium and its ironworking industry saw a marked recession; reflecting the widespread decline of the most visibly romanised sectors of the economy such as the major industries (Esmonde Cleary 1989, 135-6). Throughout Ariconium had been a major iron production centre, probably deriving much of 


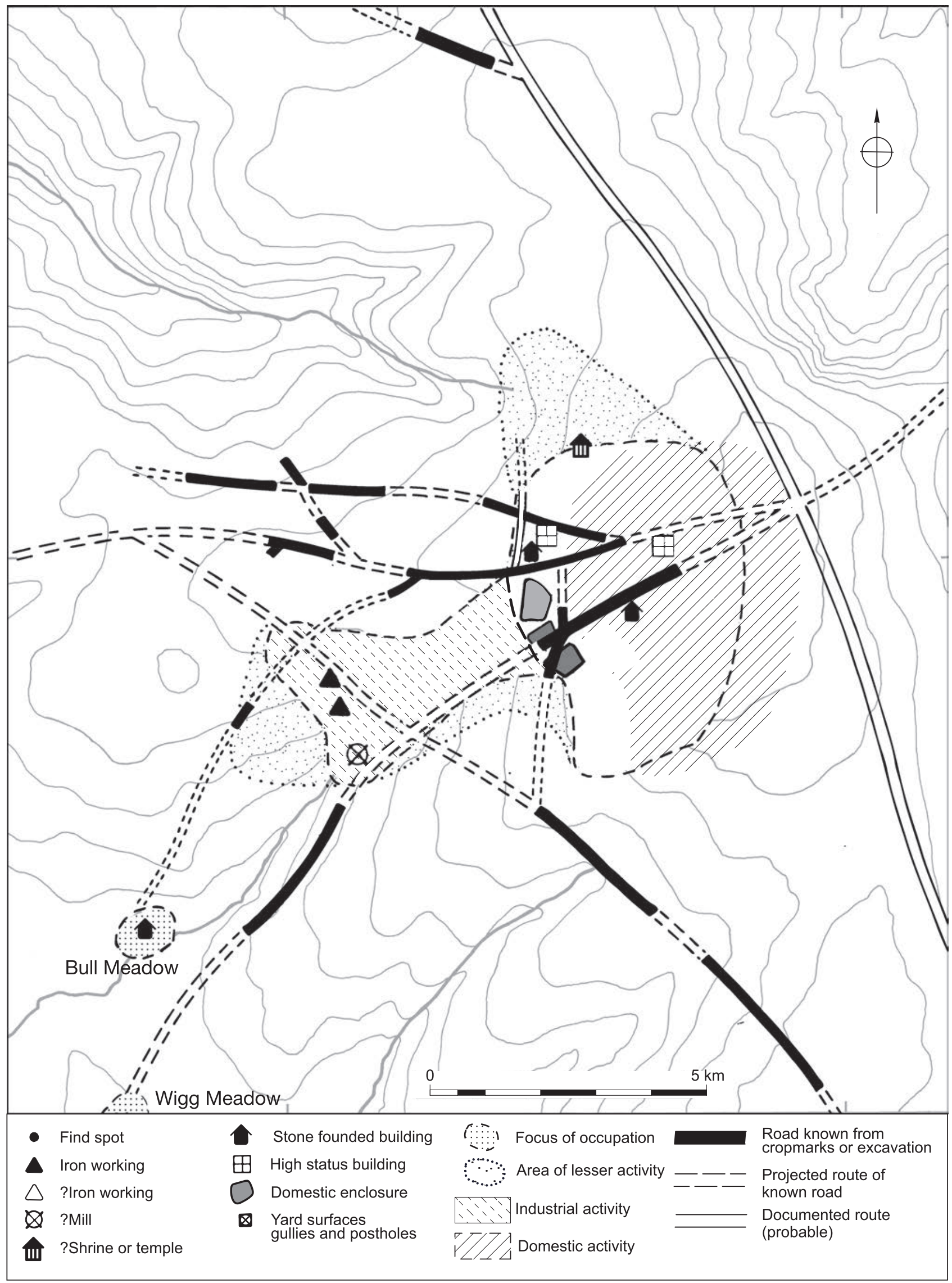

Figure 5.6. The Roman 'small town' (c. AD 250 to 400). Reproduced by permission of Ordnance Survey on behalf of HMSO. (C) Crown Copyright 2011. All rights reserved. Ordnance Survey Licence number 100051813 
its wealth and impetus from this important commodity. As a result, the economy must have been especially vulnerable to the impact of the collapse of widespread demand for iron from other towns and the military. As a consequence, little would have remained to sustain its function as a local market centre or productive base.

One area of importance may have survived into the mid 4th century and beyond, and that was as an administrative centre. The late Roman period saw growing decentralisation of the taxation system and an increasing reliance on payment in kind levied through compulsory requisitions. This process may have led to an increased importance for the 'small towns' at the centres of the sub-divisions (pagi) of the broader administrative units, the civitates. While still administered from the level of civitas capitals, requisitions appear increasingly to have been collected through government installations such as mansiones in 'small towns' (Millet 1990, 149). Control over this system (and perhaps local markets) has been suggested to have been a function fulfilled by local elites under imperial patronage. It has even been suggested, given the correlation of 'small towns' and late pre-Roman Iron Age centres, that these local elites may have been the descendants of earlier tribal leaders (Millet 1990, 150). This role of 'small towns' in local administration may have grown in importance during the 4th century. At Ariconium, status as the administrative centre of a pagus under the control of a local elite family might provide an explanation for its continued recognition, function and possible status until the end of the 4th century and, as discussed below, beyond the Roman period.

\section{Post-Roman occupation}

Evidence for activity into the 5th and 6th centuries at Ariconium relies solely on documentary sources. Placename evidence indicates some continuity of occupation at or near the Roman settlement and possibly centred on Eccleswall Court (HSM 21372; Fig. 1.3).

The emergent early medieval sub-kingdom of Ergyng or Archenfield also indicates a continued role for the settlement, the name being well established as deriving from Ariconium (cf. Copplestone-Crow 1989; Gelling 1992). This evidence has supported the development of a model for post-Roman political development in the West Midlands. The very limited documentary evidence has been used to argue that the British population of Herefordshire, together with Shropshire, Worcestershire and Gloucestershire, remained relatively stable during this period (Pretty 1989, 174). This population is suggested as having owed allegiance to hereditary ruling families, whose importance had been masked during the Roman occupation under which they had served as administrators. The stability of these small kingdoms was reflected in a degree of military strength, which continued at least up to the Battle of Dyrham (near Bath) in AD 577. This model sees the local elites of Roman Britain emerging as dynastic rulers of small kingdoms or sub-kingdoms based upon late Roman towns (such as Wroxeter) and 'small towns', such as Ariconium, Kenchester and Leintwardine. The administrative and judicial territories (pagi) which had been based upon these Roman towns and 'small towns' became the territories of these small kingdoms.

The argument that the Roman 'small town' of Ariconium and its territory formed the basis for one such small kingdom, rests with the place-name evidence and its location within south Herefordshire (Pretty 1989, 174; Dark 1994, 155 and fig. 40). Although, there is a danger that the argument is rather circular, this is supported by suggestion that Ariconium may have served as a late Roman administrative centre for its surrounding territory (pagus). Discussion about the potential post-Roman character has been further extended in the light of dedications to Dyfrig (Saint Dubricius) in conjunction with the later Anglo-Saxon area of Archenfield. These have been taken to suggest that a late Roman see may have existed at Ariconium and developed into a territorial bishopric and possible political unit (Davies 1978, 157; Dark 194, 155). One final strand of evidence may come from the later settlement at Weston-under-Penyard which at Domesday is recorded as Westune meaning 'west settlement' (Thorn and Thorn 1983; Copplestone-Crow 1989). This place-name may indicate that the settlement lay west of a recognised focus or feature in the landscape, which given its location to the west of Ariconium suggests that the latter might have remained a recognised or remembered important place. If this was the case, by the later 14th century any association with Ariconium had evidently been superseded by the importance of Penyard Hill and castle which lay to the east, since in 1376 there is the first documented appearance of the name Weston-under-Penyard (Weston subtus Penyard; Copplestone-Crow 1989).

In the light of the absence of material archaeological evidence of 5 th and 6th century date, it is difficult to place too much reliance on these lines of argument. However, as at many known and other postulated post-Roman settlements it is unlikely that much evidence would survive given the very limited material culture in use at this time. Furthermore, the most likely focus of any sub-Roman occupation lies at Eccleswall Court, which is situated several hundred meters away from the core of the Roman town. This location has not been subject to any fieldwork. It is therefore possible that any material evidence for postRoman settlement has yet to be revealed and this is an area which would certainly warrant attention in the future.

\section{Trade and exchange}

The iron industry undoubtedly underpinned the economy of Ariconium and is discussed in detail below. This industry would have created considerable wealth, providing a strong economic base as reflected in the quality, quantity and range of artefacts recovered. 
During the Iron Age artefacts demonstrate cultural affinities and trading links with the east and south-east and especially with the area traditionally identified as that of the Dobunni, while it has been argued above that 'invisible' products might have been traded with communities to the west and north. The pattern was, however, undoubtedly complex since, in contrast with Limestone tempered wares and Dobunnic coins, remarkably little pottery from the Malvernian industry has been encountered considering the comparative closeness of this production centre (c. $35 \mathrm{~km})$. This may reflect that it was unable to compete with the more local Limestone tempered wares, but could also be interpreted as an indicator of a cultural distinctiveness, differentiating the site and perhaps the wider Forest of Dean area from other parts of 'Dobunnic territory'. A similar reason may lie behind the paucity of Droitwich and Cheshire briquetage, only the former having been recorded and that at only one location. Certainly an Iron Age site with the range of contacts evidenced here would be expected to produce a reasonable quantity of briquetage. Alternatively, this may partly result from its generally limited representation in ploughsoil assemblages, and for the earlier excavations, the possibility of confusion with daub which may not always have been retained.

After the Roman conquest the range of contacts widens as might be expected, to include a variety of local, regional and inter-provincial sources. Inter-provincial trade is represented by pottery from Spain (amphorae), Gaul (Samian, Terra Nigra, Black slipped ware, Glazed ware, Sandy white ware and mortaria) and the Lower Rhineland (Colour coat from Cologne). Regional contacts with Dorset (Black burnished ware), Oxfordshire (Colour coat and mortaria), the Nene Valley (Colour coat), Verulanium (mortaria), Mancetter-Hartshill (mortaria), Caerleon (mortaria) and Worcestershire (Malvernian ware) are all represented along with locally produced Severn Valley ware. Other items include personal items derived from both local and regional sources, while the presence of ivory objects demonstrates links with a much wider imperial trade network.

As a local centre of some size at an important road junction Ariconium is likely to have played a role beyond that of a consumer of these items. Food, fuel and other products of the local rural economy would have been exchanged while the occupants of the town, apart from ironworking, were involved in bronze working, glass working and textile production, probably all for local consumption. A possible redistribution role has been identified in relation the nearby quarries at May Hill from which sandstone querns were widely distributed. Locally produced pottery such as Severn Valley wares and Limestone tempered wares may have similarly been marketed through Ariconium. These are fairly typical patterns of supply and trade for local markets centred in Roman 'small towns'; however, some unusual patterns can be determined in the supply and consumption of goods at the site with Malvernian wares continuing to be poorly represented.
The use of coinage at Ariconium is well attested by the quantities recovered and this use and the wider function of coinage in the Roman period is likely to have been a complex issue here as at other sites (see Esmonde Cleary 1989, 91-99). At minimum, coinage was needed for much of the Roman period for payment of state taxes and earlier discussion has covered the manner in which agricultural surplus was probably exchanged for coinage at 'small towns'. However, arguments have also been made (ibid., 95) that coinage, especially in the later Roman period, was used as a medium for everyday commercial transactions and such a use seems likely at Ariconium given the range of goods and services attested in the artefactual record.

\section{The ironworking industry}

\section{Introduction}

Ariconium has long been recognised as a major Roman ironworking centre, the charcoal stained character of the local soils and iron slag waste having been noted since the early part of the 19th century (e.g. Brayley and Britton $1805)$. Subsequent 19 th century accounts emphasised this association, the site being variously described as a 'Roman Birmingham' (Fosbroke 1821) and a 'Merthyr Tidfil of the Romans' (Bull 1882). Throughout the 20th century this theme recurred and it is evident that the principal economic function of the settlement was ironworking. This has led to its characterisation as one of a group of specialised 'small towns' which have an industrial function (Burnham and Wacher 1990).

\section{Ironworking structures}

Structural evidence indicates that the form of the furnaces used was similar throughout, these being free-standing shaft furnaces (Cleere 1976, 132-8; Sim and Ridge 2002). At Ariconium, these typically survive within complexes of shallow rock cut depressions and hollows, with a slight ridge of clay forming all that remains of the original furnace superstructure (Bridgewater 1965; Jackson, Hancocks and Pearson 1999; Jackson 2000). Such ridges of clay often survive in a crescent around the back of a shallow pit at the base of a furnace, the latter usually fronting onto a tapping pit or hollow (Section 2; Figs 2.2, 2.3, 2.5 and 2.11). The size of the surviving bases varies but indicates that internal diameters were between $0.30 \mathrm{~m}$ and $0.50 \mathrm{~m}$. Internal clay surfaces are fired to pale grey and white and external surfaces to red brown. These are associated with tap slags, which in several instances have survived in situ in the associated tapping pits with the runners still attached to a mass of slag.

These structures can be closely paralleled at other Forest of Dean ironworking sites such as the Chesters villa (Fulford and Allen 1992) where shaft furnaces had internal diameters in the range of $0.30 \mathrm{~m}$ to $0.40 \mathrm{~m}$. At Chesters, evidence of re-lining was noted using local 
clays. A similar practice may be suggested by one of the furnaces investigated by Bridgewater (1965; Area A; Figs 2.2 and 2.3), although at the time the thickness of the clay was interpreted as possibly representing a reworking of an earlier feature. Comparable structures have also been recorded at other major ironworking centres such as those on the Weald and in Northamptonshire (Cleere 1970; Jackson and Ambrose 1978), all of which can be classified according to Cleere's typology as Group B slag tapping furnaces (Cleere 1976).

As at Chesters and other local sites, the absence of tuyères for the insertion of bellows is somewhat puzzling. At Chesters this was particularly unusual since the evidence suggested that they were contained within an open-sided building and it is unlikely that the structures were tall enough to exploit natural draughts (Fulford and Allen 1992). It is not evident whether the furnaces were within buildings at Ariconium, but it seems likely that some form of shelter would have covered them since to work efficiently it is believed that it would have been necessary to keep the furnaces dry (Salter 2000). A relevant factor might be the location of the ironworking areas. These mostly occupy south or south-west facing slopes thus facing the prevailing wind. As long as any buildings covering the furnaces were open-sided, a good natural draught would have been available which possibly reduced the need for forcing air into the furnaces through bellows.

Evidence for associated structures is limited. The most notable include the charcoal store identified by Bridgewater (1965; Section 2; Figs 2.2, 2.3 and 5.1, Ironworking area B), the charcoal from which has been analysed (Gale, Section 4), and the possible ore roasting hearth from the Garrod and Moss excavations (Fig. 2.5, 'furnace D'). A charcoal store has also been identified at Chesters (Fulford and Allen 1992), while ore roasting hearths have often been recorded, as at Bardown, on the Weald (Cleere 1976) and at Wakerley, Northamptonshire (Jackson and Ambrose 1978). Post and stake-holes have been recorded suggesting that timber-built structures were present (see Figs 2.5 and 2.11) probably providing shelter, storage and other ancillary functions but unfortunately none are reconstructable. Areas of metalling, ditches and gullies indicate the provision of yards and drainage, as well as providing some evidence of the industrial areas having been divided up into separate working areas or enclosures.

\section{Origins and development of the industry}

Iron Age

Evidence indicates that the industry at Ariconium had its origins in the late Iron Age and three possible locations for activity have been discussed previously. The recovery of pre-Roman iron smelting residues from the most firmly dated of these at Pond Cottage (Fig. 5.3; HSM 12666; Jackson, Hancocks and Pearson 1999) is of great significance, for there is little evidence from this region for the technology of smelting in the pre-Roman Iron
Age. The single specimen examined (Young, Section 4: Sample A2) is very small, but is entirely consistent in morphology, microstructure and chemical composition with being a small piece of tap slag flow similar to the Roman examples examined (from HSM 6097). This specimen was not amongst the material reported on by Starley (1995). The only other pre-Roman site in the region (and smelting Forest of Dean iron ore) for which we have technical data is Frocester Court, Gloucestershire (Tim Young unpublished data), where similarly small specimens suggest slag tapping technology from at least the 3 rd century BC.

Further evidence of ironworking during the Iron Age may derive from two other locations although the evidence is equivocal. Firstly, the ditch fills of the 1st century enclosures at The Great Woulding included 'smelting slag', 'bloomery slag', 'smithing slag', 'vitrifed clay' and 'tapped bloomery slag' (Fig. 5.3; HSM 9071; Walters and Walters 1989). The latter suggests the use of shaft furnaces and at least one of the enclosure ditches associated with 'tapped bloomery slag' can be dated to the late Iron Age. The late Iron Age focus within the main settlement at Hask Barn also appears to have had an association with ironworking since the shaft furnaces identified here are also likely to date to this period (Fig. 5.3; HSM 23552, 23546 and 23547; Garrod 1967).

Taken together the evidence is indicative of iron production at more than one location at the site during the first half of the 1st century AD and possibly earlier.

\section{Roman}

Evidence for Roman ironworking has been recovered from a wide area of the 1 st to early 2 nd century settlement. This appears to have been focussed around the settlement core and to its immediate west. Some activity may have continued at The Great Woulding site to the north (HSM 12666), but this seems to have been abandoned by the early part of the 2nd century perhaps reflecting nucleation of settlement and industrial activity at the main site.

During the early part of the 2nd century, a new ironworking area was established to the north of the domestic core (Fig. 5.1, Ironworking area B; HSM 21360 and 23557-9; Bridgewater 1965). This probably reflects a reorganisation of the settlement which saw production concentrated in a defined zone. This industrial area zone remained in use until about the middle of the 3rd century $\mathrm{AD}$ when the area appears to have been given over to the disposal of domestic rubbish (Bridgewater 1965). Abandonment might reflect further reorganisation or result from some other factor affecting production such the drying up of a water supply, competition from elsewhere or simply that the area had become too unpleasant and cluttered with slag waste for the industry to continue effectively. However, ironworking remained an important activity with a new industrial area created to the south-west towards the end of the 2nd century and continued in use through the 3rd century and into the 4th (Fig. 5.1, Ironworking area C; HSM 6097; Jackson, Hancocks and Pearson 1999). 


\section{Post-Roman mining for iron}

There is no evidence for post-Roman ironworking at Ariconium. However, Bridgewater (1965) suggested that deposits had been disturbed by post-medieval mining for iron for resmelting at the Linton ironworks which were established in 1680 (TWNFC 1954, 171). These were part of a major post-medieval Forest of Dean industry. This used "iron works of great Antiquity and vast heaps of cinders" while "in the Forest of Dean ... the Iron is made at this day of Cinders, being the rough and offal thrown by in the Romans time" (Yarranton 1696). Ariconium, only $2 \mathrm{~km}$ distant, would have been the nearest supply to Linton and a post-medieval road surfaced with slag runs has been recorded running towards Linton (Bridgewater 1959).

\section{The source of the iron ore and the distribution of smelting}

\section{Tim Young}

Two samples of iron ore have been analysed to provide evidence of origin. The broad features of the samples clearly indicate an origin with the Bristol Channel Orefield, but details of their trace element geochemistry provide strong evidence for an ore source within the eastern side of the Forest of Dean. The latter include those closest to Ariconium in the area of the Wigpool Syncline (approximately 4km away; Fig. 5.2). This has long been recognised as the most probable source of iron ore for Ariconium (cf. Jack 1923) and is linked to the settlement by a major Roman road, the Dean Road (Fig. 5.1, Route 4).

The exploitation of the ores of the Bristol Channel Orefield has been characterised, from pre-Roman times, by the movement of large quantities of ore away from the major sources (the Forest of Dean and Glamorgan) for smelting in other areas. In the Roman period smelting has been documented over a wide area from the edges of the Cotswolds, the Severn Vale from South Gloucestershire to Worcester, across the southern parts of Worcestershire and Herefordshire, and down through Gwent, west of the Wye. Doubt has been cast on the sourcing of all the ore for the widespread smelting in this part of the region from the Forest of Dean (Bick 1990), but the analytical studies support derivation from Dean. Increasing evidence for a similar pattern of activity in medieval times is supported by finds of Forest of Dean iron ore on quays around the lower Severn.

Within this context there is an apparent divide between on the one hand the widely distributed smelting, occurring on rural settings, and which, in some areas at least, formed a component of the villa economy, and on the other hand the smelting focussed in 'urban' settings more or less close to the ore sources (Worcester, Monmouth, Ariconium). Very little is known in sufficient detail about these two styles of activity to generate a model to explain them. There is no evidence, so far, of any significant difference in technology between the centralised smelting and that in the rural areas. A likely scenario is that a proportion of ore was shipped to regions with local fuel supplies. It remains uncertain whether rural smelting (e.g. at Frocester Court) took place on a regular basis, or whether they were sporadic activities, perhaps associated with local demand (e.g. building projects). In either case, it also remains uncertain whether the smelting was undertaken by the estates themselves, or whether there were itinerant ironmakers.

\section{Technology, mass balance modeling and yield calculations}

\section{Tim Young}

Iron-making residues from this study have formed a 'testbed' for a new approach to mass-balance modelling, as a tool for investigating furnace efficiency. The modelling approach has been developed in two studies by Thomas and Young (1999a and 1999b). The operation of the Ariconium furnaces has been investigated by producing a mass-balance model of the average tap slag, a furnace lining specimen (Sample A13), an ore fragment (A26) and a typical charcoal ash. The modelling suggested that $1 \mathrm{~kg}$ of raw goethite ore would have generated $0.34 \mathrm{~kg}$ of iron and $0.54 \mathrm{~kg}$ slag from reaction with $0.15 \mathrm{~kg}$ of furnace lining and $0.02 \mathrm{~kg}$ of fuel ash. This gives an efficiency of $44 \%$ (calculated as weight of iron produced/weight of iron in the ore), which would appear to be fairly typical of Roman bloomeries.

Although the mass balance approach is still the subject of research, and attempts are being made to test the modelling in reconstruction furnaces, the results of the model can be used as a basis for speculation on production figures. The rate of recovery of raw bloom into finished bar iron is not well understood, but in experimental work Crew (1991) obtained average yields of 45\% (raw bloom to billet) and $22 \%$ (raw bloom to final bar). On this basis $1 \mathrm{~kg}$ goethite ore might have generated $150 \mathrm{~g}$ billet or $75 \mathrm{~g}$ bar iron. If these figures are correct it would suggest a production of $280 \mathrm{~g}$ billet or $140 \mathrm{~g}$ bar iron per $1 \mathrm{~kg}$ slag (which would have been derived from $1.85 \mathrm{~kg}$ ore).

Tap slag cakes of this period (including those from Ariconium) usually indicate rather passive accumulation (with no sign for instance of the upturning of slag flows commonly encountered in large medieval cakes). It is likely, therefore, that they accumulated progressively during a single smelt, with clearance of the tapping pit at the end of the smelt, and that a conversion from tap slag cake weight to bloom weight is possible. However, slags tapped from a bloomery furnace usually develop cracks as they cool rapidly; the slag masses tend to fragment along these cracks on disposal and even relatively large lumps of tap slags may only be partial cakes. Cracked tap slags often become further fragmented during excavation. The most complete cakes give an indication of the weight of slag produced in a smelt, and in the case of some fieldwalking material from Ariconium available (maximum fragment weight $5.6 \mathrm{~kg}$, in 
a case where the fragment represents just over half of the complete cake), this appears to have been between 6 and $10 \mathrm{~kg}$, corresponding to raw blooms of 3.8 to $6.3 \mathrm{~kg}$, billets of 1.7 to $2.8 \mathrm{~kg}$, finished bar of 0.8 to $1.4 \mathrm{~kg}$ and ore usage of 11 to $19 \mathrm{~kg}$. A few (undated, but usually assumed to be Roman) compacted blooms have been recovered from the Forest of Dean area, and have weights between 2 and $2.5 \mathrm{~kg}$ (pers obs.). These are at the small end of the scale of blooms from Britain of Roman age (Tylecote 1986), but are of an appropriate size for smelts producing 6-10kg slag cakes. Elsewhere in Britain compacted blooms of 7-10kg seem more common in Roman contexts.

In contrast to the relatively small cakes from Ariconium, some slag cakes from the Roman smelting site at Chesters (Fulford and Allen 1992), were very much larger; measuring up to $18 \mathrm{~kg}$, suggesting raw blooms of $11 \mathrm{~kg}$, billets of $5 \mathrm{~kg}$, finished bars of $2.5 \mathrm{~kg}$ and ore charges of $40 \mathrm{~kg}$. This would suggest the production of compacted blooms within the $7-10 \mathrm{~kg}$ range. These large flows are associated with furnaces apparently having an internal diameter of close to $40 \mathrm{~cm}$, somewhat larger than the size reconstructed by Bridgewater from the rather scanty remains at Ariconium (Bridgewater 1965; HSM 21360 and 23557-9; Fig. 5.1, Ironworking area B) but comparable with those recorded elsewhere at the site by Garrod and Moss (1967; HSM 23552; Ironworking area A) and along the Welsh Water pipeline (HSM 6097; Jackson, Hancocks and Pearson 1999; Ironworking area C).

These rather limited data hint at a possible variation in smelting technology, at very least in furnace size, between sites in the area, and between industrial areas across the settlement as well as perhaps through time.

\section{Woodland management and charcoal supply}

\section{Rowena Gale}

The origins of ironworking in the region have been observed to extend back to the Iron Age and evidence of fuels from prehistoric metalworking sites in the area is particularly relevant, given the apparent preferences for the use of narrow roundwood by the Roman ironmasters. This may indicate a regional practice. The character and type of timber and wood used for industrial and other activities would have influenced the prevailing woodland environment and landuse in the Iron Age and later periods.

The evidence from charcoal residues indicates that woodlands were managed in the Roman period. Associated woodland industries would have provided timber and wood for construction work, fencing, and other activities, including faggots for domestic fuel and some industrial activities (e.g. brick-making, bread-making). The Roman charcoal trade, supplied with raw materials from local woodlands, would have provided fuel not only for industrial purposes (e.g. ironworking), but also for domestic heating and cooking towns (charcoal was in common use in Roman communities in Britain for numerous domestic purposes;
Allason-Jones 1989). Large-scale charcoal production probably made considerable inroads in this richly wooded area. Other woodland products which were probably produced locally but for which, as yet, there is no evidence, include tan-bark and wood tar.

The size, character and economy of the Roman 'small town' of Ariconium would have had a direct impact on the use and management of woodland resources. Evidence from charcoal residues from metalworking fuels indicates the existence of managed woodlands. It seems likely that control of woodland resources would have been essential at this time to service both the 'small town' and a flourishing iron industry. In addition, the associated woodland industries would have offered a significant commercial opportunity. The economic importance of the iron industry in this region, fuelled from managed woodland, almost certainly shaped the woodland element of the environment at this time and probably ensured its survival throughout the following millennia.

\section{Coal supply}

Coal was used by the Romans as an industrial fuel and is usually assumed, where associated with the iron industry, to have been used in the smithing process (Cleere 1976). It has been recorded in industrial contexts at Ariconium by Bridgewater (1965) who suggested such an association. Given the general paucity of evidence for smithing to produce finished items, it seems most probable that this was used for the primary working of the blooms, probably immediately following their removal from the furnace. However, caution should be exercised with the interpretation of coal since it was also present in the trenches excavated in 1922 by Jack (1923) where a domestic association seems more probable.

Similar uses of coal can be seen at other sites around the Forest of Dean. At Monmouth it was associated with a smithing hearth (Walters 1992, 59) while at the Chesters villa it seemed to be predominantly associated with domestic building ranges (Fulford and Allen 1992). The probable source for this coal is the outcrops in the Forest of Dean and it seems likely that small quantities were transported along with the charcoal and iron ore being brought onto the site from that area.

\section{Iron production, supply and output}

\section{Introduction}

Estimates of the output of the ironworking industry and the associated demands on raw material sources are problematic, due to variations in estimates of potential output and requirements for these furnaces, allied to the limited firm data available from the site. Despite this, it is felt that the production of some tentative estimates is a valid exercise, but with a strong caveat that the resultant figures should be treated with considerable caution.

Both smelting and primary smithing can be identified 
and it is evident that the end product was finished bars of forgeable iron. Thus the raw material requirements were iron ore and charcoal. Demand for the latter is likely to have been especially high since it would be required not only as fuel for smelting of the ores to produce iron blooms, but also for the primary smithing process to consolidate the blooms into billets and lastly the billets into bars.

\section{Rates of production}

Estimates of the ratios between raw materials and products vary widely. Some have been presented above (Young: Technology, mass balance modelling and yield calculations) and are supported by experimental work and estimates from other sources (e.g. Crew 1991). In this report, it is assumed that the smelting of 1 tonne of ore in a shaft furnace will require 1 tonne of charcoal. The resultant products will be approximately $540 \mathrm{~kg}$ of slag and $330 \mathrm{~kg}$ of unconsolidated (raw) bloom. Primary smithing of the bloom will produce a billet of approximately $150 \mathrm{~kg}$ which will result in a final product of $75 \mathrm{~kg}$ of forgeable iron.

The potential output of individual shaft furnaces can be calculated from the size of slag cakes. At Ariconium these suggest that an individual firing might produce a finished iron bar weighing between 0.8 and $1.4 \mathrm{~kg}$. However, these seem to be on the small side and may reflect a collection bias.

Cleere (1974) has suggested that a shaft furnace with an internal diameter of between 0.30 and $0.50 \mathrm{~m}$ (i.e. one comparable to those recorded at Ariconium) could produce about $10 \mathrm{~kg}$ of bloom after $7-8$ hours of operation. On the basis of the figures given earlier this would convert to an iron bar weighing $2.2 \mathrm{~kg}$. A team of three would be required to operate the furnace and at full production a single furnace could produce up to 6 tonnes of iron (bloom) annually. This assumes two firings per day for about 300 days per year (figures derived from Cleere 1974, 184 and 191). The lifespan of a furnace can be calculated at a maximum of 30 operations and consequently a number of rebuilds would be required during the course of a year (Cleere 1976). On this basis, moderate-sized Wealden enterprises were estimated to be producing 40-50 tonnes of bloom (9 to 11 tonnes of iron) per annum. Larger sites such as Beauport Park and Oaklands may have producing as much as between 140 to 210 tonnes of bloom per annum (32 to 48 tonnes of iron; bracketed figures have been converted according to the conversion ratios established for this study).

At Chesters a less intensive seasonal production is suggested with a workforce also engaged in woodland management and farming (Fulford and Allen 1992). Thus smelting fitted into the gap between spring sowing and late summer harvest, or alternatively could have been in autumn and winter; although some conflict might exist in this model with periods of coppicing and charcoal burning. Slag weights of unconsolidated blooms from Chesters suggest that a single furnace firing would produce about $11 \mathrm{~kg}$ of bloom and a finished bar weighing up to $2.5 \mathrm{~kg}$, figures which are comparable to those from the Wealden sites. One the basis of 100 days of operation per year this provides an annual output of 1 tonne of bloom or approximately 0.25 tonnes of finished iron.

Estimates of the areas of coppiced woodland needed to maintain the substantial charcoal fuel supplies, which would have been required, are similarly problematic. At Chesters it has been estimated that a hectare of coppiced woodland would produce something in the region of 1 tonne of charcoal per year (Figueiral 1992). A single furnace producing about $680 \mathrm{~kg}$ of iron per annum might therefore require slightly over 9ha of woodland to satisfy its charcoal needs for smelting alone. Estimates of charcoal requirements for the preliminary roasting of the ores and the smithing processes following smelting to produce first the billet and then the finished iron bar are even more problematic. Much depends on how rapidly each stage follows its predecessor, since if there is a gap between each operation, then the whole consolidation and smithing process could require several times as much charcoal as the original smelting.

\section{Estimated output for Ariconium}

Ariconium had a highly specialised industrial function like the Wealden sites, however, as argued above, it seems to have been a civilian-run enterprise that probably developed from a native, pre-Roman ironworking tradition. There is also some evidence that indicates that individual outputs from some furnaces may have been smaller than those suggested for either the Wealden sites or the Chesters villa. Seasonal production may also have been a factor, as has been suggested at Chesters (Fulford and Allen 1992), and this would reduce overall outputs to below the levels suggested on the Wealden sites where year-round production has been argued (Cleere 1975).

For the purposes of this study it is assumed that production at a major Forest of Dean site like Ariconium would have been more intensive than at Chesters but perhaps not year round. Consequently estimates will be made on the basis of each furnace producing between 2 and 3 tonnes of bloom per annum, giving an annual output of between 450 and $680 \mathrm{~kg}$ of finished iron per furnace. This would utilise between 6 to 9 tonnes of charcoal and iron ore in the smelting process and produce something between 3.25 and 4.90 tonnes of slag. Significantly more charcoal would be needed for the primary smithing.

Several approaches can be taken using these figures to make estimates of the potential fuel demand and iron production output for the settlement over the 350 years or so during which ironsmelting was carried out.

The first approach uses the estimated volume of slag waste, although estimates of the original thickness of slag rich deposits and the weights present are highly conjectural; slag distributions having been affected by erosion, ploughing and depletion by 17 th and 18 th century extraction. However, on the basis of comparison with more 
extensively excavated sites Walters has suggested that up to 475,000 tonnes of slag might have been present (Walters 1992). If correct these would provide a total output of about 66,000 tonnes of finished iron. Given an estimated lifespan for major production of 300 years, annual output might therefore have been in the order of 220 tonnes of finished iron. At the estimated production rate of between $440 \mathrm{~kg}$ and $680 \mathrm{~kg}$ per annum per furnace this would indicate that between 325 and 500 furnaces were in operation at any given time. These figures are probably flawed since Walters based his estimates on a 12 ha area, which would suggest he was allowing for almost 4 tonnes of iron for every $1 \mathrm{~m}^{2}$ of the site. This seems rather high even allowing for the fact that the spread suggested by the current survey indicates a greater site area of some 80ha.

An alternative approach is to consider the relative frequency of furnaces in excavated areas and estimate the total furnace population at any given time. The most comprehensively investigated ironworking area is that excavated by Bridgewater (1965) where 6 furnaces were recorded across an area of $550 \mathrm{~m}^{2}$. The total area covered by slag and charcoal rich soils in this 2 nd to early/mid 3rd century industrial zone covers an estimated $52,500 \mathrm{~m}^{2}$ and therefore the total population of furnaces might be in the region of 575. Across the whole settlement area a total of ten shaft furnaces have been identified to date. The excavated area has been estimated to be in the order of $0.5 \%$ of the maximum settlement area. Although this represents a maximum extent of settlement and the excavated proportion cannot be shown to be a representative sample, as a guide it suggests that a total population of 2000 furnaces may be present. Naturally at any one time the entire settlement area would not have been covered. Evidence suggests, however, at least a fifth of the total settlement area was taken up with ironworking activity at any given time which would provide a figure of up to 400 operational furnaces. If allowance is made for up to $75 \%$ of the production areas being taken up by access routes, storage facilities, ancillary structures and waste heaps then a more realistic estimate might be that an average of between 100 and 145 furnaces might have been in operation at any one time.

These furnace density estimates are considered more reliable than the slag weight estimates, but it must be remembered that the excavated sample might not be representative. Allowing for this, and using the lowest figures, the potential output is still considerable. The average annual output of finished iron would have been between 45 and 100 tonnes (200 to 435 tonnes of unconsolidated bloom), a figure comparing very favourably with the estimated output of the larger Wealden production sites such as Bardown. Between 600 and 1300 tonnes of ore would be required and for fuelling the smelting furnaces alone a similar quantity of charcoal would have been used. Significant further quantities of charcoal would have been needed for preliminary roasting of the ore and after smelting for the primary smithing to produce first the billet and then the finished iron. Even if these additional processes only use an equivalent amount of charcoal it can be estimated that a massive commitment of between 1200 ha and 2600 ha of coppiced woodland would have been necessary to provide the required fuel.

\section{Patterns of iron production at Ariconium and within the Forest of Dean (Fig. 5.2)}

Based upon the likely demands for iron and the overall character and scale of settlement at Ariconium, production during the Late Iron Age and early Roman period is unlikely to have been on any great scale. Activity seems to have been dispersed, perhaps occurring within more than one enclosure. Other sites in the region such the closely comparable industrial 'small town' at Worcester, the sites of the later villas at Hadnock, Huntsham and Frocester, the hillfort at Symonds Yat and the promontory fort at Sudbrook Camp may also have been iron production centres during this period. It has been suggested in this report that the early status and wealth of Ariconium may result not only from its productive capacity but also from the control of the distribution of ore and iron from the Forest of Dean to sites such as these.

Production appears to have increased in the later 1st century not only at Ariconium, but also at Monmouth, where a new ironworking centre developed, and at many lesser settlements which were also involved in production (Walters 1992, 151). These probably initially reflected the demands of the military expansion into Wales. Later in the 1 st century and moving into the 2 nd century, continuing expansion is liable to result more from the growing requirements of the civilian population, the burgeoning economy and in particular the growth of the towns at Gloucester, Kenchester, Cirencester and Caerwent. During the first half of the 2nd century, the Forest of Dean industry may also have been involved in supply for the construction demands of Hadrian's Wall (Fulford and Allen 1992). Alternatively it may have covered the civilian market of the Wealden industry, the output of which had been absorbed by the requirements for the wall's construction.

At Ariconium this period saw the development of a distinct and extensive northern ironworking area while at Monmouth production also expanded, turning this into a major ironworking centre. Further important production sites also developed at Newent, Worcester and perhaps at Dymock, Whitchurch and Coleford as well (Walters 1992; Jackson 2004).

The later 2nd and 3rd century appears therefore to have been a major period of expansion for the industry as described by Fulford and Allen (1992, 205). The period is characterised by a mixture of larger nucleated settlements to the north and west of the Forest, and villas and other minor industrial settlements to the south and east. This expansion coincides with the increased use of the western seaways to service the northern frontier and the Welsh garrisons from the early 2 nd century onwards.

During the 3 rd century at Ariconium, although the 
northern industrial area fell into disuse in AD 230/250, a new smelting area developed to the south-west. This continued in use through into the 4 th century and seems to indicate that production and demand was still considerable. At Monmouth, an early 3rd century shift of operations also occurred with production focused at Overmonnow to the south of the earlier production centre (Walters 1992, 104). In Worcester, iron production may have shifted from the 2nd to 3rd century Deansway site towards the Farrier Street and Broad Street sites to the north where 3rd to 4th century ironworking is evidenced (Dalwood, Buteux and Darlington 1994; Jackson 2004). Of the larger centres only Newent seems to have ceased to operate during this period. In contrast several villas or other important rural centres were established at existing sites such as Hadnock and Huntsham (Fulford and Allen 1992) as well as at Blakeney (Barber and Holbrook 2000). New sites were established at Broughspring, Park Farm (Lydney), the Chesters and at the suburban villa to the east of Kenchester (Fulford and Allen 1992; Wilmott and Rahtz 1985). Ironworking is also evidenced at the villa complex at Frocester at this time (Standing 2000). In addition, a range of minor sites also seem to have developed ironworking associations, in particular those along the fringes of the Severn Estuary such as at Whitescourt (Awre), Severn House Farm, Hills Flats, Oldbury Flats and Rumney Great Wharf (Allen and Fulford 1987, 278). Several of these have hints of Iron Age origins but seem to have flourished from the 3rd century onwards. This late production period has been suggested as possibly compensating for the demise of the Wealden industry (Cleere 1974; Fulford and Allen 1992).

At Ariconium ironworking continued into the 4th century but fell into a period of decline, production apparently having ceased by $c$. AD 350 . Overmonnow, outside Monmouth, seems to have suffered a similar decline. In contrast, a number of the higher status sites such as the temple complex at Lydney and several of the local villas appear to have been at their peak reflecting what has been described as the 'heyday' of the villa in Britain (Esmonde Cleary 1999). Despite this late flourish, by the later 4 th century iron production appears to have largely ceased at all these sites, a decline noted to coincide with the re-organisation of the northern frontier (Fulford and Allen 1992). More widely it also reflects the general decline of demand from the military, the towns, and the provincial economy in the late 4 th century.

\section{The organisation and wider context of the iron industry}

The scale of iron production is clearly the factor which marks out Ariconium, and the Forest of Dean region as whole, throughout the Roman period. Within this region, Ariconium can be recognised as the major production centre, although many other large and small centres have been identified. Within the province as whole, only the scale of production in the Wealden area appears to have been comparable with that of the Forest of Dean, although the industries of Northamptonshire and East Yorkshire were also important.

There is, however, no indication of direct military or imperial control of the Dean industry (Fulford and Allen 1992) whereas the Classis Britannica played a major role in the organisation of the Wealden industry (Cleere 1974).

Pre-Roman influences may be significant. A pattern of increasingly centralised and specialist production would not be out of place in the Late pre-Roman Iron Age and one possibility is that this important resource was shared between tribal groupings flanking the Forest, perhaps between elements of the Dobunni and the Silures. Certainly some of the key sites such as Ariconium and Lydney appear to have been important Late Iron Age centres suggesting that the Roman pattern developed from the Late Iron Age one. The location and size of the temple of Nodens and associated complex and mines at Lydney has been taken to imply that this could have fulfilled a crucial role in the control of mining and distribution of ores from the Forest (Fulford and Allen 1992). Further postulated temple sites at High Nash, Coleford and Littledean Hall may have fulfilled similar or subsidiary roles to that of the Lydney complex. The potential importance of the smith god has already been discussed above and ironworking is liable to have been integrated into native religious beliefs, as a mystical process in which 'rocks were converted into powerful cultural artefacts' such as swords and ploughshares, items associated respectively with death and regeneration (Hingley 1997). The 'magic' of the ironworking process, the importance of the smith god and other aspects of religious belief within the iron industry reflect pre-Roman traditions and the temple at Lydney appears to have been Iron Age in origin.

It is therefore suggested that Late Iron Age tribal leaders may have developed control of iron production either through the priestly caste or even in their own right as agents of the gods. The local Iron Age religious and political elites may subsequently have maintained their importance into the Roman period, both through their position in native society and through the Roman state system as administrators of local taxation and as entrepreneurs licensed by the state and overseeing the production and distribution of iron.

One particularly distinguishing factor of the Forest of Dean industry is the tradition of smelting iron at some remove from the sources of ore and the general paucity of evidence for stages of production beyond smelting and primary bloom smithing. The patterns of production and distribution of ironsmelting sites around the fringes of the Forest may have been influenced by control of the ore sources, mining and distribution by a centralised authority or local elites or alternatively by pre-Roman practices or possibly a combination of both. The distribution of ores and the finished product must also have been an important issue and it is notable that Ariconium and the Forest of Dean as a whole were furnished with an extensive road network. 
Most major centres lay on or near major routes and at no great distance from either the River Severn or the River Wye, which would also have been important corridors for transportation of heavy and bulk goods (Fulford and Allen 1992).

One problem remaining for modelling the patterns of distribution of the Forest of Dean industry is that sourcing of ores remains uncertain especially for sites such as Worcester and some of those in the Severn Valley above the estuary (McDonnell and Swiss 2001).

A further significant factor in examining the distribution of production sites, is access to coppiced woodland and charcoal supplies. It has been suggested earlier that equal weights of charcoal and ore would be used in a shaft furnace, but that subsequent processing would require at least as much charcoal again. Not only does this indicate that much more charcoal would be needed than ore, but it should also be taken into account that charcoal is vastly more bulky than either iron ore or than finished iron. Therefore although other factors must all have had an influence, an equally if not more important consideration might have been the availability of fuel. The production and supply of this must have been an important industry in own right and one which would have had considerable influence over the whole regional environment and economy. 


\section{Section 6. Management of the monument}

\section{Management, erosion and landuse}

\section{Management and protection}

Protection for the site is currently divided between that offered by scheduling to a 'core' area which is administered by English Heritage and that offered to the remainder through the development control processes, and managed through the relevant local authority maintained, planning advisory service, Herefordshire Archaeology.

The area covered by the scheduled ancient monument was designated in 1961 and recognises the national significance of the site (Here and Worc no. 154; Ancient Monuments and Archaeological Areas Act 1979). This provides strong protection from damage through development and also requires permission to be granted for archaeological excavation, removal of surface artefacts and metal detecting. Subsoiling and drainage improvement works are also covered. However, the site has been in agricultural use since the time of scheduling and, consequently is not protected from ploughing or subsequent soil erosion both of which are areas of considerable concern as discussed below. In addition, as at numerous sites, the policing of metal detecting is problematic and some activity has affected and undoubtedly continues to affect the scheduled area.

Despite these limitations, scheduling does otherwise offer relatively strong protection Beyond this, protection is offered through the development control process, mainly through the use of Planning Policy Statement 5 (PPS5) and the Local Plan, supported by other regulations and guidelines such as those relating to the utilities. PPS5 is probably the most important forming the basis for most development control decisions relating to archaeology and having its principles enshrined in, or reflected by, most other relevant regulatory documents. At Ariconium, the implementation of these protective measures is managed by Herefordshire Archaeology and guided by the assessment of the town undertaken by the CMHTS (Dalwood 1995), supplemented by more detailed and recent data held by the Herefordshire County Sites and Monuments Record.

The level of protection offered through PPS5 is, however, less comprehensive than that offered by scheduling in that no protection exists against damage by changes in agricultural practice, land drainage works, metal detecting or removal of surface finds either by structured fieldwalking or sporadic surface collection. In addition, as with scheduling, no protection is offered from continuing plough damage and associated soil erosion.

\section{Erosion studies: models and background}

At Ariconium the impact of arable farming has long been recognised while more recently, erosion has been specifically identified as a threat to deposits. The deterioration and causes of deterioration of archaeological monuments have been matters of concern for many years, and have been the subject of numerous articles and surveys. The most comprehensive has been The Monuments at Risk Survey of England (MARS; Darvill and Fulton 1998) which has collated and analysed data on the impact of various agents of damage and destruction across a wide sample of the surviving archaeological resource in England. The results of the MARS project provide a theoretical framework for examining the processes of decay and erosion, and providing conclusions and recommendations about ongoing damage and destruction of archaeological monuments.

MARS has presented a model for a 'life-cycle' for a monument in which it passes through some or all of the following stages: "construction, use, re-use, adapted use, desertion, dereliction (?monumental status), decomposition, deterioration and disappearance". In considering the survival and condition of deposits at any site and the agents affecting them, it is the later stages of this 'lifecycle' which are of most relevance (Darvill and Fulton 1998, 16-18). Naturally the character and durability of the original structures and associated material culture affect the rates of decay and deterioration but in principal the basic process is broadly the same. This process has been described in detail (ibid., 16-18) but can be summarised as follows. Initially there is rapid decay as remains are first affected by use and then initial post-desertion processes of weathering and collapse. These will be followed by a stabilisation of the rate of decay which will continue but in a more gradual way. Naturally there are variations, particularly on a local or micro-scale, however, where only natural processes occur the profile of a curve of decay of a monument should theoretically be "of smooth inverse exponential form" (Darvill and Fulton 1998, 18).

This natural profile is interrupted on most sites by periods of human intervention which serve to accelerate the rate of decay. On lowland sites, such as Ariconium, MARS postulates that the steepening of decay curves (i.e. periods of accelerated decay) will coincide with major periods of agricultural intensification such as the enclosure movement of the 17 th and 18 th centuries. Arable cultivation 
is widely recognised as one of the most extensive and destructive threats to archaeological deposits, damage arising from successive phases of ploughing and ground preparation in an annual cycle. Ploughing will typically be to a depth of between $150 \mathrm{~mm}$ and $350 \mathrm{~mm}$ but will in practice occasionally bite deeper due to variable ground surfaces, incorrectly set ploughshares and uneven soil depths resulting from both widespread and localised erosion. The latter can be a particular problem, the effects of which can be exacerbated by the timing of ploughing and ground preparation. These expose and weaken the structure of the topsoil and often lead to erosion during periods of rainfall. Since these processes usually occur in times of the year which coincide with the periods of heaviest rainfall, the effects can be especially damaging.

Changing agricultural methods over the years have also contributed to the extents of such destruction. Later prehistoric, Roman, medieval and post-medieval changes in approaches to cultivation have all been identified as factors which have increasingly affected monuments, while since the turn of the 20th century the introduction of increasingly heavy and powerful machinery has accelerated the rates and degree of damage by arable farming. The latter has led to the expansion of arable farming into previously untouched areas, to the creation of larger fields and to the use of machinery which cuts through sub-surface obstructions such as archaeological features which in the past the plough would have ridden over.

Most recently the frequently changing cropping cycles in response to European agricultural subsidies have added to problems caused by erosion with complex responses having been observed to follow from an initial destabalising impact (Bell and Boardman 1992). In particular, a major phase of erosion has affected British arable landscapes since the late 1970s and is a response to intensification of farming and a shift to winter cereals, change which has been driven by economic forces (namely EEC subsidies; Bell and Boardman 1992). Observation of these processes has led to MARS' conclusion that "Cultivation is the single biggest hazard facing monuments, accounting for $10 \%$ of wholesale monument loss and $30 \%$ of piecemeal loss". Its impact is especially great for early field systems and large single monuments (38\% of recorded destruction; Darvill and Fulton 1998, 236-7). This impact does not generally result from any one particular arable episode, being more typically due to the cumulative effect of the damage to deposits by repeated cycles of ploughing and associated soil erosion. To these can be added the additional damage caused through compaction (by the movement of heavy machines on wet soils) and the associated development of mineral pans which require sub-soiling (at depths below the normal ploughzone) to break them up. In summary, it has been observed that on average arable fields erode about one to two years in every ten and this clearly poses an ongoing and significant threat to archaeological remains.

\section{The impact of erosion at Ariconium}

\section{Introduction}

Detailed study of the impact of erosion was identified at assessment as being beyond the scope of the project due to lack of relevant and existing data. In particular, further data relating to the current state of preservation of deposits (known to vary widely but only quantifiable in isolated areas at given times), character of the surface assemblage (believed to be changing through time) and former landuse and cropping, is likely to be required before the full potential of this information can be realised. However, discussion is made below of the existing evidence of erosion and avenues for further research are identified.

\section{Soil erosion: the ADAS survey}

The undertaking by ADAS of a survey of erosion at Bollitree Farm has provided a fortuitous and possibly unique opportunity to study independently collected specialist data relating to erosion. In conjunction with archaeological evidence, this data has enabled assessment of the potential extents and impact of erosion on archaeological deposits at this particular site and approaches to mitigating its effects.

Over the five year duration of the survey, erosion of varying degrees was recorded widely (ADAS Field numbers 1, 2, 4, 6 and 10; Fig. 3.1), generally occurring between October and January in circumstances where no crop cover was present following late harvested potatoes or beet. As described in Section 3 erosion was severe in some areas.

These findings are supported and emphasised by the guidelines and information provided in a series of documents on 'Controlling soil erosion' produced by the Ministry of Agriculture, Fisheries and Food (MAFF 1999a, b, c and d). These guidelines indicate that the site lies within what is defined nationally as a "most at risk area" for erosion by water (MAFF 1999a, appendix B). This risk may increase since occurrences of 'threshold' situations for erosion may be increasing as a result of climate changes associated with global warming since this is believed likely to result in spells of severe rainfall becoming more common (MAFF 1999a).

\section{Evidence of soil erosion and plough damage from buried remains}

The impact of erosion at Ariconium has been most clearly demonstrated by the work undertaken along the route of the Welsh Water pipeline (HSM 6097; Jackson, Hancocks and Pearson 1999). Here, observation of the stripped pipeline easement and subsequent pipetrenching quite clearly recorded the impact of erosion on significant archaeological deposits. The contrast in preservation and character of overlying deposits between those in upslope areas and towards the base of the hillslope was dramatic. Deposits near the crest of the hillslope were only buried 
beneath thin topsoil and had clearly been damaged by ploughing. Only deeper natural cut features survived and the natural sandstone had been scored by ploughing. Moving downslope, topsoil became thicker, the subsoil survived and increasing depths of underlying deposits (interpreted as colluvial in nature) were present. In the shallow valley bottom, well-preserved and stratified Roman deposits were preserved beneath up to $1.00 \mathrm{~m}$ of topsoil, subsoil and colluvial accumulation. A schematic section produced shows the variability encountered (Fig. 3.2), the erosion observed strongly supporting the ADAS survey results for this land parcel (ADAS Field 2).

Elsewhere across the monument, excavation has indicated that the depth of material overlying and protecting the Roman deposits is variable. Photographs of Jack's trenches (1923, plate 1) show only a thin cover over building remains while the wall recorded by Garrod and Moss only lay some $0.20 \mathrm{~m}$ below the surface. Along with recorded instances of ploughs striking masonry, this suggests that walls may be consistently buried beneath only a shallow ploughsoil of $0.20-25 \mathrm{~m}$ in depth. Such deposits are probably the most robust and a tendency for ploughing to ride up over them may have helped to preserve them, while to some extent they may have provided barriers to downslope erosion rather in the manner of groynes on a beach. Elsewhere, indications are that less robust deposits (e.g. postholes, gullies and furnace bases) may have been affected; reflecting the pattern observed on the pipeline with between 0.20 and $0.75 \mathrm{~m}$ of overlying deposits present. Such variations of accumulation on slopes are likely to result from erosion and redeposition of ploughsoils leading to the infilling of hollows and build up of material in downslope areas adjacent to hedgelines.

\section{Artefactual evidence of plough damage and soil erosion}

The composition and character of the artefact assemblages, along with observations made during their collection, provide further evidence for the impact of plough damage and soil erosion.

Regular observations of fresh material being brought to the surface have been made since the 19th century. These effectively demonstrate that each ploughing results in some damage to buried remains. Perhaps most concerningly, over the last twenty odd years this situation appears to have worsened. Recorded plough depths of 0.30 to $0.40 \mathrm{~m}$ in the 1980 s are clearly sufficient to have affected significant deposits. The situation appears to have worsened from 1991 onwards with the introduction of potato cropping. New damage was recorded in the form of disturbed building debris scattered in the ploughsoil and numerous fresh surface finds (DAG 1991a; DAG 1993a). In 1993, a field just beyond the scheduled area (HSM 23563; Fig. 1.4) was ploughed for first time in over ten years for cereal crop and then the following year for potatoes (DAG 1994a). These two events revealed large quantities of newly disturbed finds and building debris from an area of the site which had previously been unknown and apparently relatively undisturbed.

These reports are of considerable concern and further data from finds assemblages adds to this. Fieldwalkers from DAG have suggested that the composition of surface assemblages has changed, with a decreasing number of later finds being recorded and a corresponding increasing presence of earlier material in collections. In 1988 (letter to English Heritage), Bryan Walters observed that "3rd and especially 4th century pottery now rarely appears on the surface (if it ever did)" and that "possibly 99\% of the pottery now ploughed up is of 1 st and 2 nd century date". Walters suggested that 3rd and 4th century deposits had been ploughed out and that 1 st and 2 nd century ones were being eroded; a suggestion supported by the observation in 1990 that nearly all the retrievable finds were of 1 st and 2nd century date (Sindrey 1990, 31-32). Firm evidence of changes in the composition of the assemblage is hard to demonstrate from the available data since areas of collection have not been consistent. However, a comparison of the percentage of later material to earlier material from surface collections of small finds does seem to demonstrate a distinct contrast between the 19th collections and later ones (Fig. 6.1). Since it has been observed that in the early collections there is a bias in favour of large early coin issues and against less aesthetically pleasing, later coin issues, this is a particularly telling observation. From the ceramic evidence, the presence of much of the later samian in surface collections may indicate that these collections often include a disproportionate amount of such material since later deposits are those most likely to have been disturbed.

\section{Metal detecting}

One further potential impact comes from metal detecting, a plot of the distribution of which shows a wide spread of affected areas (Fig. 2.14).

Information from two detectorists with links to DAG, Martin Sterry and Terry James, has been of particular support to this study. They have been working the fields around the monument from 1991 onwards using detectors with a range of about $0.25-0.30 \mathrm{~m}$. At greatest penetration this would clearly affect the upper parts of archaeological deposits and result in removal of artefacts from context. However, the great majority of finds are retrieved from the top $0.10-0.15 \mathrm{~m}$ and appear to have probably been brought into range by ploughing (Martin Sterry, pers comm.) and thus damage to extant deposits through metal detecting is probably minimal.

Metal finds have also been reported through DAG from the monument area, however, these probably only represent a fraction of the true amount of material taken off the site. Although some result from permitted surface collection, others certainly result from illegal surface collection and metal detecting. 

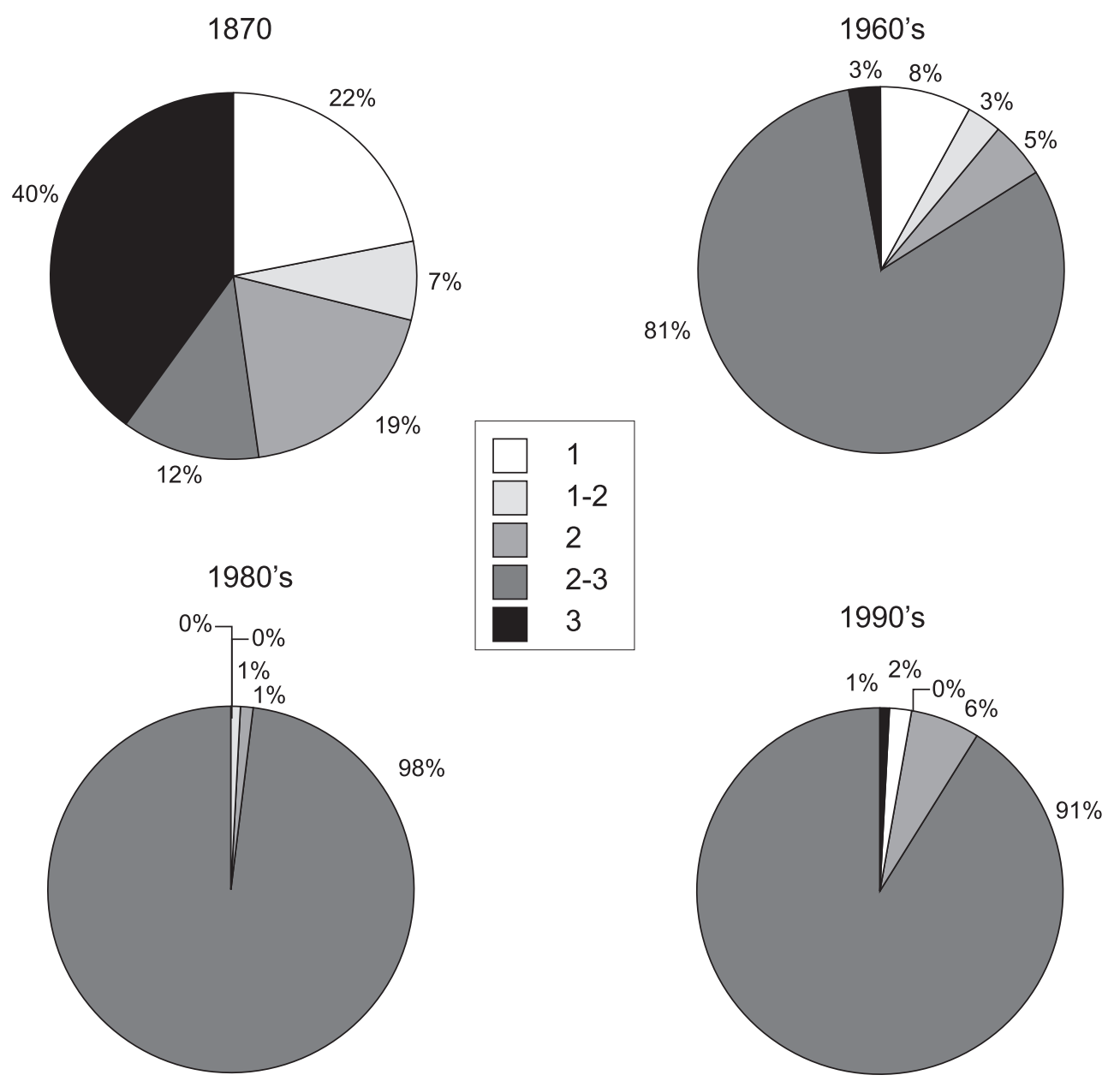

Figure 6.1. The changing composition of surface finds by phase

In either case, removal of material from any part of the site will have had a detrimental affect on the survival and composition of assemblages.

\section{A model for the history of landuse and erosion at Ariconium}

As stated earlier, MARS has produced a model for the lifecycle of an archaeological site from construction and use through desertion, decay and potentially ultimately disappearance. The following discussion attempts to apply this model to Ariconium.

\section{Pre-20th century decay and erosion}

The early stages of construction, use, re-use and desertion have been considered earlier. Following desertion the site appears likely to have followed a fairly natural decay curve for well over 1000 years.

Early references such as Camden and Stukeley suggest that the settlement was destroyed by an earthquake, a popular explanation at the time for the destruction of Roman towns. This is not likely to have been the case, but it is interesting to note in passing that earthquakes were recorded in Herefordshire in 1571, 1775, 1863, 1868, 1896, 1897, 1924 and 1999, the worst of which in 1775 damaged more than 2000 buildings (Hereford Times June 24 1999). It is therefore possible that at some time earthquake damage may have affected standing remains at the site.

Some damage must have occurred at specific locations as a result of digging for iron slag waste for re-smelting in the 17th century as suggested by Bridgewater (1963). Certainly the post-medieval Forest of Dean ironworking industry is documented as having made extensive use of Roman iron slag (Cohen 1954, 171). Linton, the location of a major late 17 th century ironworks, is linked to the site today by a footpath. Investigations along the line of this have suggested that it was a slag surfaced route, constructed in about 1700 (Bridgewater 1959; Second route) and it therefore can be concluded that Ariconium was being "mined" for slag during this period.

The first major acceleration of the decay of deposits across a wide area is likely to date from the mid 18th century when the land was levelled and enclosed. Prior to this, it had been in a rough state, with heaps of rubbish 
overgrown with briars, suggesting that it had not previously been under arable cultivation. Certainly no suggestion of medieval arable use has come to light. Very few medieval finds have been recorded and no evidence of ridge and furrow cultivation has been recorded. This is unsurprising since large areas of the Herefordshire are believed to have remained in a semi-cleared state until the 16th and 17 th centuries with much "barren, bushy or broomy pasture" (Thirsk 1967, 99).

The years 1640 to 1750 are seen as a period in which this pattern was transformed in response to agricultural innovations and the growing demands of the rapidly increasing urban populations (Thirsk 1985, 159). At this time, Merrick cleared and enclosed the land occupied by Ariconium. It was clearly taken into arable use as Merrick recorded soil colour changes and that often during ploughing the plough would strike ruins. He recovered "vast" quantities of stone from digging these ruins out as well as numerous artefacts. This must therefore be seen as the first identifiable period of accelerated decay. Apart from the damage being caused directly by the digging out of ruins, ploughing itself must have caused widespread damage to what were clearly immediately sub-surface remains protected only by a shallow turfline and soil cover.

Reports of discoveries throughout the 19th century illustrate that it was being regularly ploughed. The readiness with which finds could be picked up after ploughing and the darkness of the soils is a recurrent theme and clearly demonstrates that extant archaeological deposits were being disturbed by each cycle of cropping. This in turn suggests that a stable ploughsoil was not established and the most likely cause for this can be concluded to be periodic localised or more general erosion of the soil cover following ploughing, thus bringing fresh deposits into the range of the ploughshares.

The causes of erosion have been summarised above and are considered to be relevant to consideration of the situation in the later 18 th and 19 th centuries. Soil type and slope would have been similar while patterns of rainfall are unlikely to have differed significantly from the present day. However, heavy machinery would not have operated thus reducing the problems of compaction and removing tramlines and wheelings.

In these circumstances, fields with shallow slopes (HSM $10008,21378,22050,23565)$ are unlikely to have been affected by erosion to any great degree once a ploughsoil had been established.

Conditions were, however, ripe for erosion in some of the other fields with greater slopes (especially HSM 10676, 21377, 23563, 23566 and 23569; Figs 1.4 and 3.1) and for these the critical remaining factor is crop cover and overall copping regime. The ADAS survey showed that this was the most important (and controllable) factor in triggering erosion. The combination of a late lifted crop (e.g. potatoes) and late drilling for the subsequent crop was observed to be especially harmful. Although we have no records of the crop regime Merrick introduced or the subsequent cropping pattern, Herefordshire was at this time dominated by a corn-livestock economy. Sheep represented the main livestock while the arable system was based upon a rotation in which wheat was the major cereal crop but where barley and roots were also important (Phillip Dodd 1980, 212). In 1801, the Ross area is notable for producing almost as much barley as wheat, although records of 1820 for Weston-under-Penyard indicate that wheat yields were high. More significantly it is also recorded that the occupier was experimenting with the cultivation of swedes (Phillip Dodd 1980). Root crops had been increasingly cultivated from the late 18th century (Mingay 1984) and although turnips were traditionally grown within rotations, swedes were grown by larger farmers. At Weston-under-Penyard sheep were recorded as being folded on swedes, probably as part of a fold-course agricultural system, a practice known to make fields susceptible to erosion in winter (Evans 1992). It is therefore evident that local practice included situations where a late root crop was followed in a rotation by a spring sown cereal crop. This is highly likely to have given rise to conditions in which erosion would have been triggered by high rainfall in the winter months.

There is unfortunately no certain way of demonstrating that such circumstances occurred at Ariconium or if erosion resulted. However, the presence of quantities of 18th and 19th century pottery in colluvial (hillwash) deposits would appear indicate that erosion and corresponding deposition were occurring from this period onwards.

\section{0th century decay and erosion}

Arable use is documented throughout the 20th century, all excavators targeting trenches to areas of black soil where surface finds were being recorded following ploughing. Notably, the 1967 excavations were initiated as a result of concerns about a national ploughing competition being held at the site. Corn is the most regularly recorded crop, although in 1980 an English Heritage field monument warden noted rape, barley and wheat being grown in rotation. This also recorded ploughing to a depth of 300-400mm.

Throughout this period it is therefore clear that the site continued to be affected and that deposits were newly disturbed on a regular basis. Spreads of freshly disturbed building material (in HSM 21376) demonstrate that substantial damage was still occurring to surviving subsurface structures within the core area of the monument as recently as 1971. Even more recently, in 1993 the ploughing of a rarely cultivated field (HSM 23563) produced rubble, tesserae and painted wall plaster.

In addition to the ongoing process of damage through ploughing and any associated erosion, several alterations in landuse and cropping cycles are liable to have exacerbated the rates of erosion. One clear example is the impact of removal of field boundaries as can be seen from a comparison of modern field boundaries with those of the 1838 tithe (Fig. 6.2). In particular the field to the north 

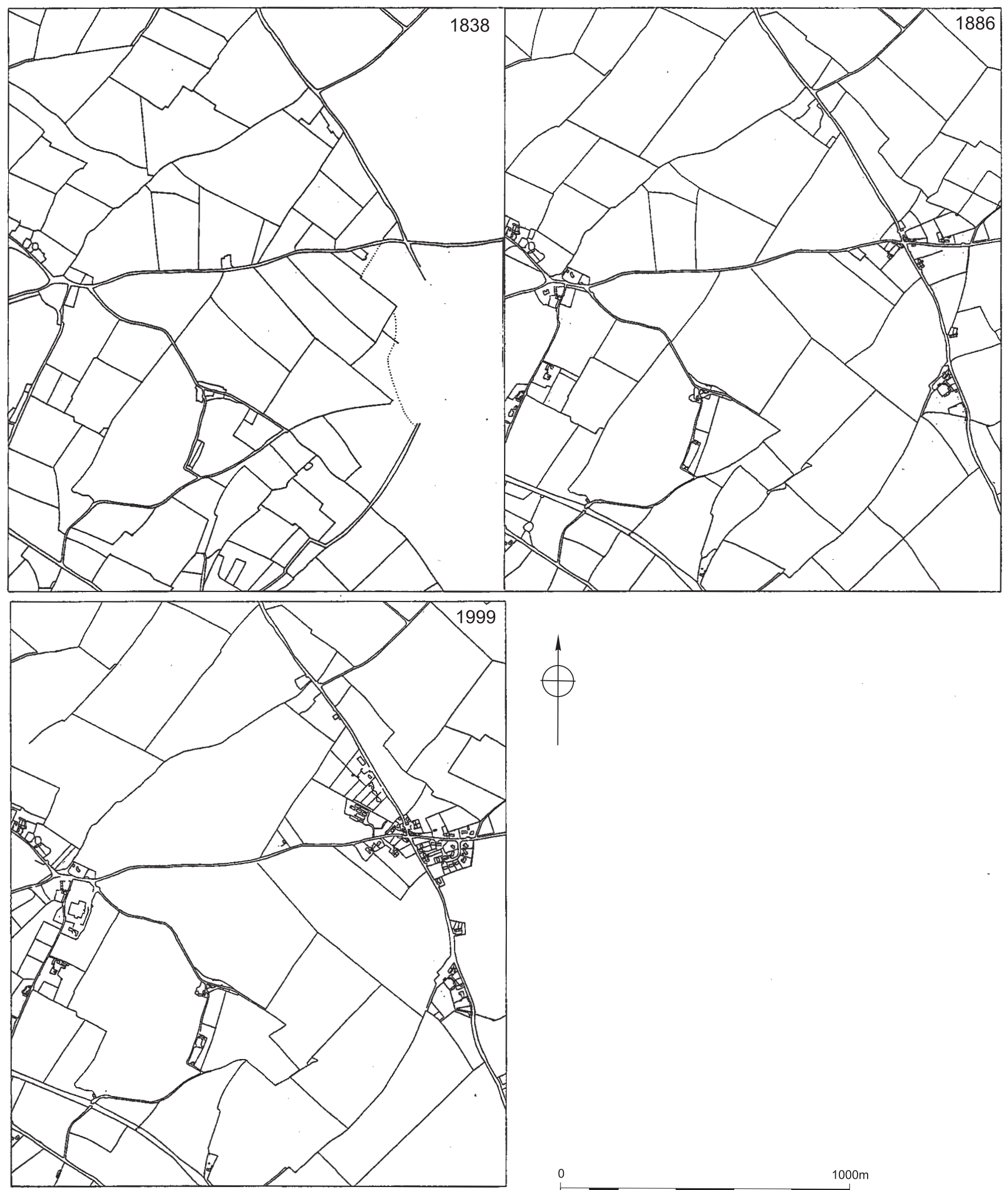

$1000 \mathrm{~m}$

Figure 6.2. Cartographic evidence for field boundary removal. Reproduced by permission of Ordnance Survey on behalf of HMSO. (C) Crown Copyright 2011. All rights reserved. Ordnance Survey Licence number 100051813

(HSM 10176/23564) appears to have suffered having been five fields in 1838 and also 1965 but only three by 1967 and one by 1989. The ADAS report highlights the potential impact of boundary removal, especially where they crossed the top of a valley slope in a field and thus cut water run-off before it hit the steeper slopes below.

A second example is the changing cropping regimes, which have become increasingly common in response to 


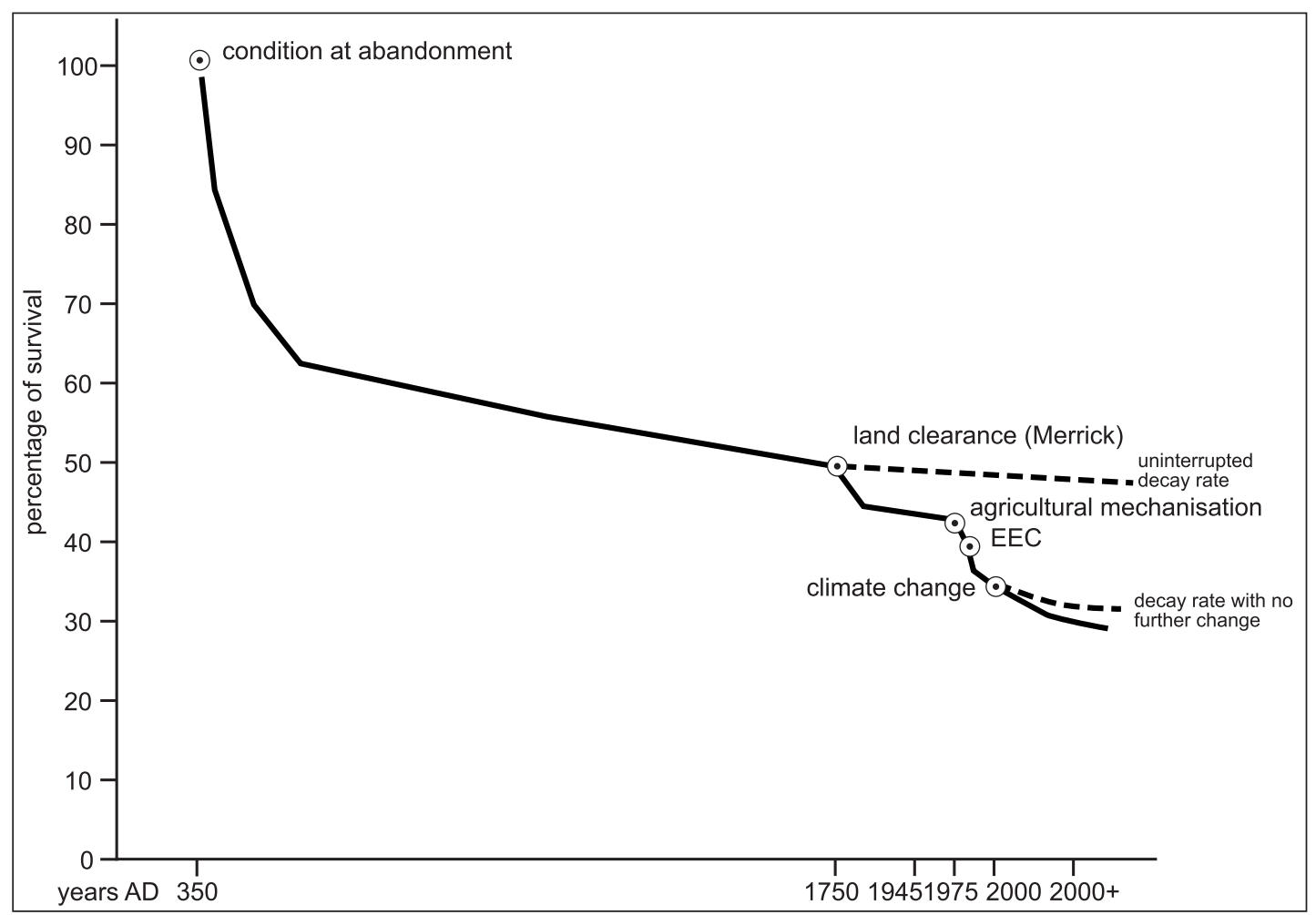

Figure 6.3. Decay profile for deposits at Ariconium (based upon MARS; Darvill and Fulton 1998)

changing economic forces and in particular EEC subsidies. One particular example is the introduction of potato cropping in the late 1980s (DAG 1991; Lloyd 1999). This resulted in much deeper ploughing and thus new damage to surviving deposits. In addition, this also introduced heavier machinery and thus greater compaction which in conjunction with this being a late harvested crop has led to greater erosion of topsoil and in turn the exposure of previously unaffected deposits to plough damage.

The combined impact of these changes on archaeological deposits and in particular the increasingly rapid and damaging changes of the latter half of 20th century must have had a considerable detrimental effect upon surviving remains. A suggested decay profile for the site has been produced based upon the evidence presented above and using the model in the MARS report (Fig. 6.3; Darvill and Fulton 1998, 16-27). (It should be noted that on this profile the percentage survival has been approximated rather than calculated).

An assessment of the circumstances and potential erosion risk has been produced for each field at the site (Lloyd, Section 3). MAFF criteria (MAFF 1999b), the results of the ADAS survey and archaeological evidence have all been used. Using an O.S. map base and contour plot this information has been used to create a plan mapping areas of potential high, moderate and low risk (of soil erosion; Fig. 6.4). This should be used to inform any management decisions made regarding control of soil erosion (see below).

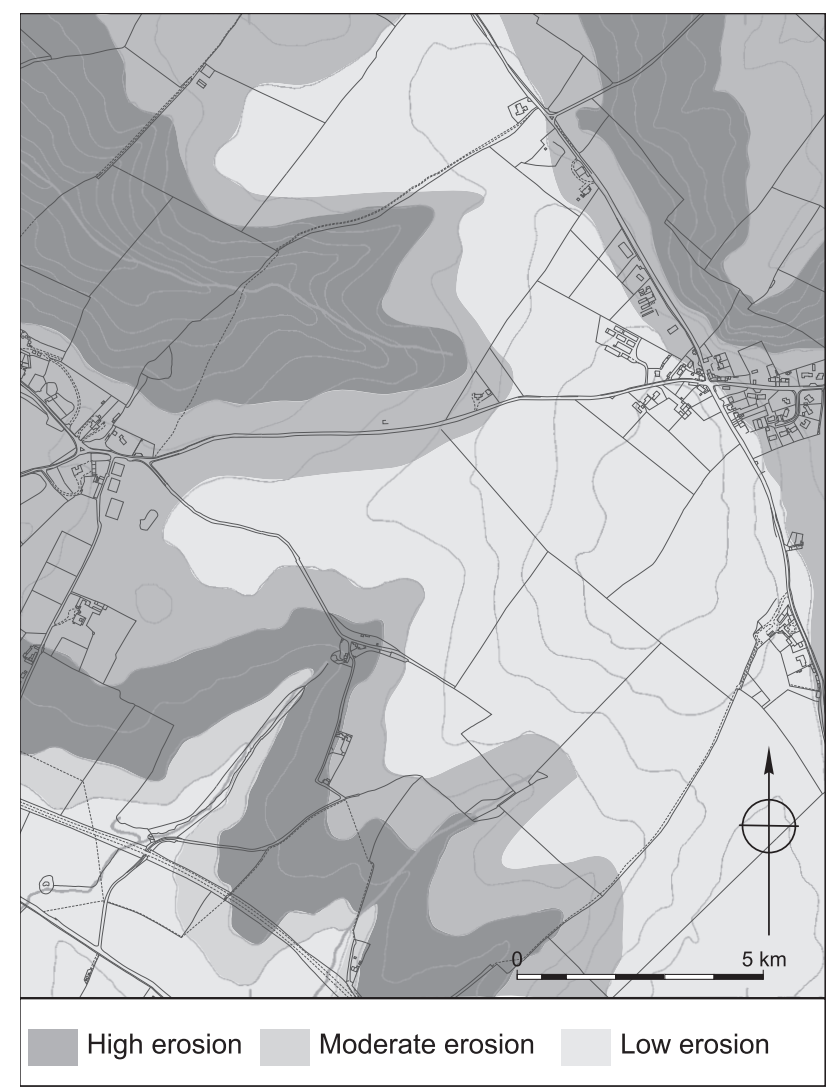

Figure 6.4. Areas of potential erosion. (C) Crown Copyright 2011. All rights reserved. Licence number 100051813 


\section{Options for controlling future erosion}

Tony Lloyd, ADAS

\section{Key factors}

A number of key factors were noted as contributing to erosion, namely soil type, slope, rainfall, crop cover and soil management/cultivations and these are discussed in more detail below.

Obviously nothing can be done about the type of soil. The soils at Bollitree Farm contain a high proportion of fine sand and silt and are considered to be in the 'moderate erosion risk' category. There may be a case for increasing the organic matter content with dressings of farmyard manure - because this will tend to increase the stability of the soil aggregates, generally improve the structure and thus allow water to penetrate into the soil (so avoiding run-off). However, it has been found in practice that there is little relation between erosion and organic matter content and that other factors are far more important; besides this, manure would have to be imported onto this all arable farm.

Slope does have an important effect on whether erosion occurs and its severity. In general, slopes over $3^{\circ}$ are susceptible and greater care is needed to avoid erosion on steeper sloping land. There has to be sufficient rainfall to initiate erosion but the amount will be affected by other factors such as slope, soil structure, crop cover and timing. The data from the survey at Bollingtree Farm (and other farms in the survey) suggest that an intensity of approximately $5 \mathrm{~mm}$ /hour can be considered as 'threshold' values. Having said this, the soil must be sufficiently wet beforehand for this to cause run-off. Rainfall events were generally greater than $25 \mathrm{~mm}$ in the previous day(s) on the fields where erosion occurred. Although rainfall is outside anyone's control, it does appear that most of the erosion-initiating rain occurred during the period October to January and thus any management techniques to reduce the risk should be concentrated then.

Crop cover is one factor that can be controlled by the farmer. As can be seen from the results, a dense crop cover over the soil does appear to have a major impact on reducing the erosion risk. This can be such as wheat stubble or even sugar beet tops. In many cases the land was subsequently cultivated in February/ March and no high rainfall event occurred during the period when the following crop was establishing a ground cover. The worst situation, as regards erosion risk, is where potatoes or sugar beet are lifted late and the subsequent crop is drilled late. The result is that the land is cultivated, perhaps compacted in places, and there is no ground cover to protect the soil.

The other factor, directly under the farmer's control, is soil management. It might be considered that sowing/ planting crops across, rather than with, the slope may control erosion. Unfortunately this will be of limited use at Bollitree Farm as slopes are often complex and thus failed attempts at following contours can result in water being channelled, forming rills and gullies. Besides this, it is often safer to operate machinery with the slope while sugar beet and potato harvesters only work effectively with the slope. Thus working with the slope is only likely to be successful on gentle, uniform slopes for cereal crops.

Any land which is compacted either in the topsoil or just below plough depth will be more vulnerable to erosion because these layers will reduce water infiltration and thus increase run-off. This survey found that, on some fields, erosion was concentrated around compacted wheelings, headlands and tramlines. It is interesting to note that on one field headlands were cultivated to relieve compaction and that in 1993/94, tramlines were not installed until late winter in two fields - this may partly explain why no erosion occurred.

As regards future control of erosion at Bollitree Farm, it may be that some control measures have already put in place since the end of the survey. However, one must consider the various options that are available.

\section{Cropping}

The surest way to prevent erosion is to grass the field down (reversion); however this is unlikely to be practical on this farm. Another possibility is to only grow wheat or rape crops on very susceptible fields - as this would allow early harvest and subsequent sowing of the next crop in early autumn. However, this is unlikely to be welcome on this farm where root crops form part of the rotation. It should also be noted that growing continuous crops such as cereals can lead to agronomic problems such as disease build up. It appears likely that the farm will wish to continue with its present rotation. Therefore the following options should be considered:

- If arable crops continue to be grown, every effort should be made to keep a crop cover or to keep crop residues on the soil surface during the winter period.

- Any wheat crops should be sown early enough to ideally achieve a minimum of $25 \%$ crop cover before early winter.

- Where root crops are harvested late, their crop remains should be left until as late as possible before cultivating for spring crops.

- Following cereal harvesting, leave land in stubble (and even incorporate trash i.e. chopped straw - this will also tend to increase organic matter levels over time). It should be noted, however, that this can never entirely remove the risk; the survey showed that erosion could happen in late spring/early summer before the spring sown crop had established sufficiently to cover the soil surface.

- Wheat crops sown immediately after late harvesting of a root crop should be avoided if possible as they will be unlikely to establish sufficiently during the period of greatest rainfall risk. 
- It should be noted that valley floors in fields can receive large amounts of run-off from higher areas and thus be eroded. This only to a certain extent occurred in Field 1 during the survey period. If this was found to be an important problem, then an area of grass in the valley bottom might be beneficial.

Finally, a more drastic approach is to remove very susceptible areas from agricultural production altogether and plant with trees. However, although this may be a suitable option for controlling soil erosion, tree planting is liable to damage archaeological deposits and in any case unless this can be justified economically, it is likely that keeping down to grass would be just as satisfactory.

\section{Cultivations}

Several simple measures will tend to reduce erosion risk:

- Remove compaction before planting/sowing a crop and avoid operations that could cause further compaction (though there are inherent problems in the processes of removing compaction).

- Avoid working the soil too much and leave seedbeds as coarse as practicable.

- Drill without tramlines or avoid using tramlines until the spring.

- Avoid rolling in the autumn, especially if wet because this can smear the top of the soil and reduce water infiltration.

- Where row crops are grown, such as potatoes, tied ridging can reduce water flow down the rows and reduce run-off.

- Incorporation of chopped cereal straw ('trash') could be considered. This will in the long term increase organic matter levels which will contribute to the formation of good soil structure. However, as stated before, increasing organic matter levels is unlikely to have a major effect.

\section{Other options}

More drastic options for controlling erosion could be considered. These include introduction of ditch or hedge breaks on slopes. If this is not possible then one might consider establishing grass contour strips on slopes; as a guide strips $5-15$ metres wide positioned every $50-150$ metres down a slope can be effective on most erosion susceptible areas.

\section{Summary and recommendations}

The site is currently offered protection through a number of measures, however, these do not provide adequate or indeed any real protection from the ongoing and extensive destruction of deposits through the type of soil erosion and crop regime which has been documented. This problem is exacerbated by the evident fact that the current scheduled area falls a considerable way short of covering the extents of significant archaeological deposits.

One potential avenue for improving protection would be through extending scheduling to include areas currently falling outside of the monument and seeking a management agreement covering the redefined area. The latter would provide a more active measure of protection than the basic scheduling which is a rather passive form of legislation (Breeze 1993) or than development control measures which are threat specific and effectively only a reactive measure. Alternatively an agi-environment scheme negotiated through Natural England might offer a means of ensuring that protective land management practices were established for the whole site area. Measures incorporated in such an agreement should be based upon the ADAS recommendations and the improved understanding of the extents of the settlement which this project has produced. 


\section{Section 7. Concluding remarks}

The Ariconium Project was developed in response to the poor state of understanding and the difficulties of managing this important Roman industrial 'small town'. Previously unpublished sources have been assessed and analysed and in conjunction with published evidence have been used to create a model for the chronological and morphological development of the settlement at Ariconium. Processes of soil erosion and problems of management have also been examined leading to a discussion that will inform future management of the site. Lastly suggestions for future research are made.

\section{Summary of archaeological and historical evidence}

Although only very limited excavated remains of Iron Age date have been identified, the site has produced significant quantities of late Iron Age and Transitional period pottery along with important collections of earlier 1st century brooches and coins. These indicate that settlement has its origins in the late pre-Roman Iron Age. Three potential areas of activity have been identified. A pair of ditched enclosures to the north formed one focus, a second and possibly relatively extensive focus lies under the later town while a third small area lies immediately to its southwest. All three have produced evidence indicative of early ironworking although no furnaces have been certainly identified. Artefactual assemblages demonstrate a wider range of trading links than would be expected this far west in Dobunnic territory and indicate that the population was engaged with late Iron Age social, cultural and economic developments taking place in Gloucestershire and the south-east. Together this evidence is indicative of an important Dobunnic tribal centre pre-dating the Roman 'small town' and having much in common with those sites defined as oppida. It is argued that this settlement owed its considerable status to control of the production and distribution of Forest of Dean iron.

During the first 50 years after the Roman conquest, the main late pre-Roman Iron Age focus expanded considerably, however, the enclosures to the north seem to have been abandoned by the early 2 nd century. The range of contacts and comparatively high status of the settlement seen in the late Iron Age were maintained throughout this period, the supply of finewares in particular reflecting its continuing importance. Ironworking again appears to be the main activity and it seems that the native population was able to rapidly articulate with the new economic opportunities the Roman conquest brought. During the 2nd and 3rd centuries the settlement's extent seems to have reached its peak. However, in comparison with its earlier importance its development was more typical of small roadside towns elsewhere in southern England. Several substantial stone-founded town houses were constructed along a number of roads which converge at this location. A mansio and a temple may have been among these buildings which were otherwise probably the town houses of local elites responsible for the administration and collection of state taxes in the surrounding area. These buildings occupied the north side of the settlement while a number of enclosures spreading along the roads to the south and west are likely to have enclosed timber-built houses, yards and ancillary buildings. Some of these probably provided a focus for small-scale industries such as copperworking, although ironsmelting clearly remained the main industry. The focus of this activity became well-defined, shifting to the north where a major new ironworking area developed during the earlier 2 nd century.

From the mid-3rd century onwards the extent of the settlement appears to have slightly reduced. A new ironworking centre developed to the south-west, probably to replace the one to the north which was abandoned at this time. This new area was active well into the 4th century and apart from ironworking also supported a watermill. The status of the 4th century settlement remains uncertain, however, at least one of the major stone-founded town houses appears to have remained occupied well into the 4th century. Artefactual evidence indicates that relatively extensive occupation continued until at least $c$. AD 350. Beyond this date, the heavy reliance of the site on ironworking and integration within the provincial economy made its function as an industrial and market centre particularly vulnerable to economic changes in the later part of the 4th century. Only a handful of artefacts are dated later than this and include some high status items. It is suggested that the settlement may have retained an elite presence and function as an administrative and political focus.

Although there is no excavated or artefactual evidence for 5 th or 6 th century occupation, the survival of the name Ariconium in the early medieval kingdom of Erynyg or Archenfield has been taken to imply some form of continuity of settlement at Ariconium itself. Such a settlement is unlikely to have retained its urban character, although, like the Roman 'small town' in the latter half of the 4th century, it may have retained some political function 
as a focal point for a 5 th and 6 th century sub-kingdom. One indicator of continued settlement in the immediate vicinity exists in the local place-name 'Eccleswall' meaning 'spring of the Christian community'. Eccleswall Court lies to the immediate south-east of the Roman settlement in an area which has received little or no attention from fieldwalking or excavation. This should perhaps be considered as the potential location of any 5 th or 6th century occupation.

The economic basis for the settlement was an iron industry based upon ores from the Forest of Dean and using supplies of charcoal from what must have been extensive and carefully managed coppiced woodland. Relatively small shaft furnaces characterised by tapping pits and waste products, including tapping slags, seem to have been in use from the late pre-Roman Iron Age onwards. The site formed part of an extensive network of iron producing settlements distributed around the fringes of the Forest of Dean. Within this network, Ariconium was probably the most important production centre complementing a range of other settlements of varying size. Production seems to have been focussed upon smelting with only very limited evidence for smithing beyond that required to finish the blooms. In this respect the settlement reflects the pattern observed at other major iron producing centres in the region such as Worcester. In the absence of any evidence for imperial or other centralised management of the industry (beyond perhaps some control of the ore source itself), it is argued that the organisation and technology of the industry might have been influenced by pre-Roman factors. This valuable resource might have been shared between enterprises situated around the Forest or was possibly controlled by the late pre-Roman Iron Age Dobunnic tribal elite. It is suggested that a primary determining factor for the location of smelting centres may not have been the ore sources but the supply fuel (in the form of charcoal) from managed woodlands. This is based upon the observation that charcoal is a much bulkier and less readily transportable material than iron ore. In this respect the organisation of the Forest of Dean iron industry differs from that of the Weald where at least some production was under imperial control and where smelting was undertaken in close proximity to the ore sources. Finally it is noted that this pattern also differs from the organisation of the exploitation of other mineral resources in the western parts of the province such as gold (Wales), lead (Mendips) and salt (Droitwich).

There is no evidence for early medieval activity and apart from a thin scatter of medieval finds the area appears to have remained little used until the late 17th to 18 th century. At this time iron 'cinders' from Ariconium were probably amongst those extracted from Roman sites throughout the Forest of Dean for re-smelting at ironworks such as those at nearby Linton. In the mid 18th century the site first came to antiquarian attention due to the clearance for agriculture of the unenclosed and overgrown land that it occupied. Over the subsequent 250 years the area has largely been in arable use as reflected in reports of surface finds throughout this period.
Small-scale excavations and extensive surface collections have only affected a small area of the overall settlement and what is currently known must be a poor reflection of its true character and development. In particular the nature of the earliest occupation and the character of any subRoman settlement are areas where future research should concentrate, along with any evidence which might support an understanding of the development and organisation of the ironworking industry on which the settlement's economy was founded.

\section{Erosion and management}

A related element of the project was to examine processes of soil erosion resulting from former and current landuse at the monument with the aim of facilitating more effective future management of the surviving resource. Archaeological data has been considered in conjunction with the results of an ADAS survey of erosion across the settlement area. These have demonstrated that the over about the past 350 years, changes in landuse have caused considerable damage to archaeological remains, damage which has clearly continued and in some respects accelerated since the scheduling of part of the site.

It is argued that the condition of remains is liable to have remained fairly stable following its initial abandonment and decay until the mid 18th century clearance of the site. This involved much removal of walls and clearance of 'rubbish heaps' and clearly caused extensive damage. Through the 19th and first half of the 20th century further erosion of deposits occurred as a result of the 'digging out' of obstructions to ploughing as well as ploughing itself. However, after the initial impact of ploughing and clearance, damage is liable to have been localised. A limited amount of small-scale development will also have impacted on localised areas of deposits; however, over the past 50 years the main impact on surviving deposits has resulted from soil erosion arising from changing agricultural practice. This seems to have has accelerated since the 1960s. In particular practices such as the removal of field boundaries, the use of heavy machinery and the introduction of new crops (e.g. potatoes) have created conditions where severe erosion of soils has occurred on many areas of the site bringing further deposits into the range of damage by the plough.

It is suggested that an appropriate land management regime to limit the effects of hillslope erosion would be one where either crop cover is maintained or crop residues are kept on the soil surface during the winter months. In addition efforts should be made to reduce compaction and use of machinery as far as possible until the spring. Options for implementation of these measures through an agri-environment scheme should be explored by the Field Monument Warden, Herefordshire Archaeology and Natural England in consultation with the landowner. 


\section{Areas for future research}

Inevitably during the course of such a project particular shortfalls in understanding and avenues for future research are identified. Five such areas can be highlighted:

\section{Erosion}

There exists a high potential for soil erosion to be affecting archaeological deposits at the site. Unfortunately, with the exception of the data from the pipeline and limited support from information derived from surface assemblage composition, it has not proved possible to quantify or demonstrate in any way the actual impact that this has had, and will potentially continue to have, on surviving deposits. Future research could potentially improve the understanding of the impact that such erosion has had and continues to have.

One approach might be to undertake more extensive surface collection from across the monument allied to selected and limited investigation of surviving deposits in areas which have not been tested before and more particularly in areas adjacent to those where excavation has previously occurred. This would enable fuller comparisons to be made of the composition and condition of artefact assemblages and also comparison of levels of deposit survival with those of earlier excavations. In conjunction with further analysis and soil micromorphology to determine the character of overlying layers (i.e. whether they are 'dark earth', colluvium or dumped deposits), this would provide key information for developing an understanding of the impact of soil erosion at this site. It would also potentially provide a model for the testing and control of erosion on other sites situated in comparable geological and topographical locations.

\section{Early origins}

Ariconium has been demonstrated as a site of considerable status in the Late Iron Age and potentially was an important tribal centre. The character of such sites and their evolution into Roman 'small towns' are poorly understood and in particular this applies to sites west of the River Severn.

Current evidence is based upon the composition of what are largely residual or unstratified artefact collections. In view of the importance of such settlements to our understanding of the pre-Roman and transitional period and the paucity of stratified remains, the identification and testing of any areas of early activity should be viewed as a high priority.

\section{Post-Roman activity}

The models for the continued status of Ariconium as an administrative or central place for a post-Roman subkingdom are relatively robust in terms of 5th and 6th century studies of western Britain; however, it must be remembered that the evidence upon which they are based is only very slight. This is a poorly understood period and any site with the potential to support the development of an understanding of the character of 5th and 6th century occupation, political structures and continuity of importance of former Roman towns should be regarded as one with a high priority for further research.

Consequently, the area around Eccleswall Court which has been postulated as a potential focus for such occupation should be regarded as a particularly sensitive one, along with any areas which produce evidence of activity of later Roman or sub-Roman date. In the light of the likely limited evidence which may survive of any such occupation, the design of any research project formulated or indeed any mitigation strategies responding to proposed development of any sensitive areas should be especially carefully considered and implemented.

\section{The environment}

\section{Elizabeth Pearson}

The majority of fieldwork was carried out before wetsieving and flotation of samples for environmental remains was commonplace, and therefore opportunities for recovering biological remains have been limited. The full potential for recovery of environmental remains and research is therefore largely unknown. As the area is located on soils overlying permeable sandstone, survival of organic deposits preserved by waterlogging is not generally expected. However, salvage recording in 1993 demonstrated survival of organic remains including wellpreserved plant macrofossils and timbers alongside a stream. Moreover, it seems likely that peat exists in the stream valleys, particularly in the light of ground conditions noted adjacent to the Tackford Brook during work on the Ryeford Bypass. Analysis of all organic remains (for example, pollen, plant macrofossil and insect remains) would be invaluable for adding to this information. Pollen and insect analysis is likely to provide information on the landscape over a wider area, while plant macrofossils providing information on living conditions and activities in the town may be recovered from pits, ovens and floor surfaces associated with occupational areas.

Much information has been gathered on the industrial functions of the town, but little is known of local agricultural practice. Small assemblages of charred cereal crop remains and animal bone have been recorded but further and more substantial assemblages are required to provide information on crop regimes, animal husbandry, butchery and food waste disposal patterns in the town. The record of a primitive breed of domestic cattle (Celtic shorthorn oxen) which is sometimes found on sites of this period is also of interest.

Hillwash and alluvial deposits have been noted beneath the topsoil, sealing Roman archaeological features. It would be interesting to establish the date of such deposits as they provide evidence of intensive landuse. Determination of 
the source of the soils and the nature of their deposition may indicate whether their presence is related to local changes in landuse (particularly clearance and agricultural or industrial activity), and the rapidity of these events. A combination of work on sediments with pollen and other remains from organic deposits is likely to be one of the key approaches to investigating the relationships between landscape and the local population. Particular areas of interest are, for example, the effects of industrial activity on the surrounding woodland, the supply of timber for fuelling the ironworking industry, and the nature of woodland management which was presumably required. It may be difficult to detect the effect of the metalworking industry on woodland using pollen analysis as it may have been intensively managed by coppicing to maintain a steady supply of timber. Phases of woodland clearance would therefore not necessarily be evident. However, analysis of pollen from peat deposits in the local area may be useful for estimating the extent and location of woodland, arable and pastoral land, in order to investigate the supply of valuable products to the town. Further analysis of charcoal associated with metalworking features would be useful for developing understanding of woodland management practices.

Lastly analysis of heavy metals in sediments has proved useful in investigating levels of atmospheric pollution from metalworking elsewhere in the country. Such techniques would be worth considering in order to detect, for example, bursts of pollution. Various techniques have been successful for investigating pollution from tin and copper working or mining. However, in the case of ironworking, it may be necessary to test for minerals associated with iron ore (Tony Brown, pers comm.).

In conclusion, as few environmental remains have been recovered from Ariconium, any environmental material would be of considerable interest. Apart from information on diet, living conditions and agricultural economy, an especially important area of research would be to support the development of an understanding of the considerable impact that the ironworking industry would have had on the local environment. Future excavation should include a policy of sampling and wet-sieving deposits in order to recover plant, insect, molluscs and small animal remains in conjunction with hand-collection of larger items. Where appropriate, specialist sampling for soil and pollen analysis may be required. Special emphasis should be placed on the identification of any sites producing information relating to coppicing, charcoal burning and fuel use and on the development of sampling strategies which produce information relating to the industrial economy of this 'small town' and its relationship to the rural economy.

\section{Ironworking industry}

Despite Ariconium's status as an important Roman industrial 'small town' and the wider importance of the Forest of Dean ironworking industry, understanding of the origins, development and organisation of the industry both at the site and inter-site level are poorly understood. Since this was probably the most important iron producing centre in England, after the Weald, and since its character and development clearly differ from that of the Weald, any research which improved understanding would be of great value. Ariconium might shed considerable light on a number of aspects of the organisation of the industry. How was iron smelting organised within the settlement? How was the fuel supply industry organised? What evidence is there for the form in which iron left the site? Was ore traded through the settlement? What changes to the industry and its technology occurred through time?

Two aspects of the industry may be of particular interest. Rowena Gale has observed that the excellent preservation of the charcoal from Ariconium has provided a rarely available source of data. Evidence suggests a regional preference for the use of charcoal from narrow roundwood to fuel the metalworking industry. Similar practices have been recorded from other Roman sites in the Forest of Dean as at Mill End Lane, Blakeney (Gale 2000) and The Chesters villa, Woolaston (Fulford and Allen 1992). It seems likely that during the course of time, similarly preserved charcoal deposits will be excavated from other local sites. Only by future work on similar material, especially those from metalworking deposits, will the question of regional uses of woodland resources be resolved. The area around Ariconium has enormous potential to further this study, particularly given its longstanding importance in the British ironmaking industries, and to indicate the environmental effects of industrial activities from pre-Roman times to the medieval period.

Tim Young has also commented on the great potential of Ariconium for research into early ironmaking. The details of the technology employed in the region prior to the Roman invasion are almost unknown, while considerable uncertainty exists about Roman smelting too. Areas of significance include structural details of the furnaces, the detailed interpretation of slag types and proportions generated by both primary and secondary processes, details of the fuel (charcoal species and size; source of coal in smithing; control of fuel type choice in smithing), and evidence for blowing technology (in smelting and smithing). Current and future research into the mechanisms of bloomery operation (both theoretical and experimental) will help improve the interpretation of bloomery slag assemblages. Retrieval of 'complete' slag assemblages associated with furnaces sufficiently well-preserved to yield detailed information on structural, blowing and tapping arrangements, are an essential part of this research. Such questions will only be answered by excavation targeting the better preserved ironworking sites, with controlled techniques aimed at generating metallurgical data. Ariconium might well be able to make a major contribution to these research goals, as well as being a potential beneficiary of the improved level of interpretation. 
Beyond this specific site, the character, extent, origins and development of the nationally important Forest of Dean iron industry are poorly understood, in particular for the Iron Age and Roman periods. Many sites are known, however, few have had even the minimum of structured archaeological survey. Many others which have enjoyed some levels of investigation suffer from the same problems which have been addressed by this project for Ariconium; namely that no detailed synthetic study has been undertaken and that available information resides in a diverse range of sources and is often unpublished or largely unanalysed. A significant aim for research in and around the Forest of Dean should therefore be to seek to redress this situation and develop an understanding of this nationally important collection of early industrial sites. In particular, it is hoped that the research undertaken by Gloucestershire County Council on the Forest of Dean will highlight the importance and potential of this area.

\section{Abbreviations}

ADAS Agriculture and Development Advisory Service

AML Ancient Monuments Laboratory

CAS County Archaeological Service

CCI Celtic Coin Index

CMHTS Central Marches Historic Towns Survey

DAG Dean Archaeology Group

GCMAG Gloucester City Museum and Art Gallery

GIS Geographical Information System

Heref. Mus. Hereford Museum and and Art Gallery

HSM Numbers prefixed with 'HSM' are the primary reference numbers used by the Herefordshire County Sites and Monuments Record

MARS Monuments at Risk Survey

NMR National Monuments Record

OD Ordnance Datum

SMR Sites and Monuments Record

SWAG South Worcestershire Archaeology Group 


\section{Bibliography}

Allason-Jones, L. (1985) Bell-shaped studs? In M. C. Bishop (ed.), The production and distribution of Roman military equipment: Proceedings of the Second Roman military equipment research seminar. British Archaeological Reports (International Series), 275, 95-108. Oxford.

Allason-Jones, L. (1989a) Ear-rings in Roman Britain. British Archaeological Reports (British Series), 201. Oxford.

Allason-Jones, L. (1989b) Women in Roman Britain. British Museum. London.

Allason-Jones, L. (1993) Small finds. In P. J. Casey, J. L. Davies and J. Evans, Excavation at Segontium (Caernarfon) Roman Fort (1975-1979), Council for British Archaeology Research Report, 90, 165-210. York.

Allason-Jones, L. (1996) Roman Jet in the Yorkshire Museum.

Allen, D. F. (1961) A study of the Dobunnic coinage. In E. M. Clifford, Bagendon: a Belgic oppidum, 75-149.

Allen, D. F. (1972) The fibula of CRICIRV. Germania 50, $122-32$.

Allen, J. R. L. (1996) A possible medieval trade in iron ores in the Severn Estuary of south-west Britain. Medieval Archaeology 40, 226-230. Maney, Leeds.

Allen, J. R. L. and Fulford, M. G. (1987) Romano-British settlement and industry on the wetlands of the Severn Estuary. Antiquaries Journal LXVII (2), 237-289. Maney, Leeds.

Allen, J. R. L. and Fulford, M. G. (1996) The distribution of south-east Dorset Black Burnished category 1 pottery in south-west Britain. Britannia 27, 223-81. London.

Allen, M. J. (1991) Analysing the landscape: a geographical approach to archaeological problems. In A. J. Scofield (ed.) Interpreting artefact scatters: contributions to ploughzone archaeology. Oxbow Monograph, 4, 39-58. Oxford.

Anon, (1932) Spring annual meeting. Transactions of the Woolhope Naturalists Field Club 27 (3), 1xxix-1xxxii.

Atkinson, D. (1942) Report on Excavations at Wroxeter (The Roman City of Viroconium) in the County of Salop, 1923-1927. Oxford.

Barber, A. J. and Holbrook, N. (2000) A Roman ironsmelting site at Blakeney, Gloucestershire: excavations at Millend Lane 1997. Transactions of the Bristol and Gloucestershire Archaeological Society 118, 33-60.

Bell, M. and Boardman, J. (eds) (1992) Past and present soil erosion: archaeological and geographical perspectives. Oxbow Monograph, 22. Oxford.

Bick, D. (1990) Early iron ore production from the Forest of Dean. Journal of the Historical Metallurgy Society 24, 39-42.

Biddle, M. (1990) Object and Economy in Medieval Winchester. Winchester Studies, 7, ii.

Biek, L. and Kay, P. J. (1982) Evidence of glass melting. In R. Leech, Excavations at Catsgore 1970-1973: a Romano-Celtic village. Western Archaeological Trust Monograph, 2, 132-3.

Birley, A. (1997) Security: the keys and locks. Vindolanda Research Report, New Series IV (ii).
Birley, E. and Charlton, J. (1934) Third report on the excavation at Housesteads. Archaeolia Aeliana, Fourth Series XI, 185-205.

Bishop, M. C. (1991) Soldiers and military equipment in the towns of Roman Britain. In V. A. Maxfield and M. J. Dobson (eds) Roman Frontier Studies (1989).

Bishop, M. C. (1996) Finds from Roman Aldborough. Oxbow Monograph, 65. Oxford.

Bishop, M. C. and Coulston, J. C. N. (1993) Roman Military Equipment from the Punic Wars to the Fall of Rome.

Black, E. W. (1994) Villa owners: Romano-British gentlemen and officers. Britannia XXV, 99-110. London.

Blockley, K. (1985) Marshfield, Ironmongers Piece, excavations 1982-3, an Iron Age and Romano-British settlement in the South Cotswolds. British Archaeological Reports (British Series), 141. Oxford.

Blockley, K. (1989) Prestatyn 1984-5. An Iron Age farmstead and Romano-British industrial settlement in North Wales. British Archaeological Reports (British Series), 210. Oxford.

Blockley, K., Blockley, M., Blockley, P., Frere, S. S. and Stow, S. (1995) Excavations in the Marlowe car park and surrounding areas. Archaeology of Canterbury, V.

Böhme, A. (1972) Die fibeln der Kastelle Saalburg und Zugmantel, Saalburg Jahrbuch. Bericht des Saalburg Museums, 29.

Boon, G. C. (1969) Belgic and Roman Silchester: the excavations of 1954-8, with an excursus on the early history of Calleva. Archaeologia 102, 1-81.

Boon, G. C. (1988) British coins from Wales. In D. M. Robinson (ed.) Biglis, Caldicot and Llandough: three late Iron Age and Romano-British sites in south-east Wales. Excavations 1977-79, British Archaeological Reports (British Series), 188. Oxford.

Booth, P. M. (1991) Inter-site comparisons between pottery assemblages in Roman Warwickshire: ceramic indicators of site status. Journal of Roman Pottery Studies 4, 1-10.

Booth, P. M. (1996) The Oxford Archaeological Unit Roman pottery recording system: an introduction. Unpublished reference guide.

Booth, P. M. (1997) The pottery. In P. M. Booth, Asthall, Oxfordshire: Excavations in a Roman 'Small Town', 1992. Thames Valley Landscapes Monograph, 9, 105-34. Oxford Archaeological Unit, Oxford.

Booth, P. M. and Willis, S. H. (eds) (1997) Research framework for the study of Roman pottery in western Britain. In S. H. Willis (ed.) Research Frameworks for the Study of Roman Pottery in Britain. The Study Group for Roman Pottery.

Brailsford, J. W. (1962) Hod Hill, volume one, Antiquities from Hod Hill in the Durden Collection. London.

Braithwaite, G. (1984) Romano-British face pots and head pots. Britannia XV, 99-132. London.

Branigan, K. (1977) The excavation and study of a RomanoBritish villa estate 1967-76. British Archaeological Reports (British Series), 44. Oxford. 
Brayley, E. W. and Britton, J. (1805) The beauties of England and Wales 6.

Breeze, D. J. (1993) Ancient monuments legislation. In J. Hunter and I. Ralston (eds) Archaeological resource management in the UK: an introduction, 44-55. Alan Sutton, Stroud.

Brewer, R. J. (1986) The beads and glass counters, and other objects of bronze. In Zienkiewicz 1986, 146-56, 172-89.

Bridgwater, N. P. (1959) Ancient buried roads in south Herefordshire: part 1. Tranactions of the Woolhope Naturalists Field Club 36 (2), 218-27.

Bridgwater, N. P. (1965) Romano-British iron-working near Ariconium. Transactions of the Woolhope Naturalists Field Club 38 (2), 124-135.

Briggs, D., Haselgrove, C., King, C. (1993) Iron Age and Roman coins from Hayling Island temple. British Numismatic Journal $62,1-62$.

Brodribb, C. C., Hands, A. R. and Walker, D. R. (1971) Excavations at Shakenoak Farm, near Wilcote, Oxfordshire, Part II: Sites $B \& H$, A. Privately printed.

Brodribb, C. C., Hands, A. R. and Walker, D. R. (1973) Excavations at Shakenoak Farm, near Wilcote, Oxfordshire, Part IV: Site C. Privately printed.

Brown, A. E. (ed.) (1995) Roman small towns in Eastern England and beyond. Oxbow Monograph, 52. Oxford.

Brown, D. (1990) Dice, a games-board and playing pieces. In Biddle 1990, 692-706.

Bryant, S., Morris, M. and Walker, J. S. F. (1986) Roman Manchester, a frontier settlement. The Archaeology of Greater Manchester, 3. Manchester.

Bull, H. G. (1882) Credenhill camp, Magna Castra and the Roman stations and towns in Herefordshire. Tranactions of the Woolhope Naturalists Field Club 10, 236-261.

Bulleid, A. and Gray, H. S. G. (1911) The Glastonbury Lake Village, a full description of the excavations and relics discovered, 1892-1907. Taunton.

Burleigh, G. (1995) The plan of Romano-British Baldock, Hertfordshire. In A. Brown (ed.) 1995, 177-82.

Burnham, B. C. (1986) The origins of Romano-British 'small towns'. Oxford Journal of Archaeology 5 (2), 185-203.

Burnham, B. C. and Wacher, J. (1990) The 'small towns' of Roman Britain. Batsford, London.

Burnham, B., Collis, J., Dobinson, C., Haselgrove, C. and Jones, M. (2001) Themes for urban research. In S. James and M. Millett (eds) Britons and Romans: advancing an archaeological agenda. Council for British Archaeology Research Report, 125, 67-76. York.

Bushe-Fox, J. P. (1913) Excavations on the site of the Roman town at Wroxeter, Shropshire, in 1912. Reports of the Research Committee of the Society of Antiquaries of London, 1. Oxford.

Bushe-Fox, J. P. (1949) Fourth Report on the excavations of the Roman fort at Richborough, Kent. Reports of the Research Committee of the Society of Antiquaries of London, 16. Oxford.

Buteux, V. and Evans, J. (2004) Iron Age and Roman pottery. In Dalwood and Edwards, 240-80.

Buxton, K. and Howard-Davis, C. (2000) Bremetenacum. Excavations at Roman Ribchester 1980, 1989-1990. Lancaster Imprints, 9. Lancaster.

Cameron, H. and Lucas, J. (1973) Tripontium. Second interim report on excavations by the Rugby Archaeological Society at Cave's Inn, near Rugby. Transactions of the Birmingham and Warwickshire Archaeological Society 85, 93-144.
Campion, G. F. (1938) Roman relics found at Broxtowe. The Thoroton Society of Nottinghamshire, excavation section. Third Annual Report for the year 1938, 6-18.

Casey, P. J. and Davies, J. L. (1993) Excavations at Segontium (Caernarfon) Roman Fort, 1975-1979. Council for British Archaeology Research Report, 90. York.

Chapman, H. (1985) Small finds. In G. Parnell (1985) The Roman and medieval defences and the later development of the inmost ward, Tower of London; excavations 1955-77. Transactions of the London and Middlesex Archaeological Society 36, 60-5.

Clarke, G. (1979) The Roman cemetery at Lankhills. Winchester Studies, 3: pre-Roman and Roman Winchester, Pt II.

Clay, P. (1981) The small finds - non-structural. In J. E. Mellor and T. Pearce The Austin Friars Leicester. Council for British Archaeology Research Report, 35, 130-45. York.

Clay, P. and Pollard, R. (1994) Iron Age and Roman occupation in the West Bridge area, Leicester, Excavations 1962-1971. Leicester.

Cleere, H. F. (1970) Bardown and Holbeanwood. Sussex Archaeological Society Occasional Paper 1.

Cleere, H. F. (1975) The Roman iron industry of the Weald and its connections with the Classis Britannica. Archaeological Journal (1974) 131, 171-99. London.

Cleere, H. F. (1976) Ironmaking. In D. Strong and D. Brown (eds) Roman Crafts, 127-43.

Clifford, E. M. (1961) Bagendon: A Belgic Oppidum. A record of the excavations 1954-56. Cambridge.

Cohen, I. (1954) History of iron working in and near the Forest of Dean. Transactions of the Woolhope Naturalists Field Club XXXIV (pt III), 161-77.

Cooke, W. H. (1882) Collections towards the history and antiquities of the county of Herefordshire in continuation of Duncumb's History 3.

Cool, H. E. M. (1983) A study of the Roman personal ornaments made of metal, excluding brooches, from southern Britain. Unpublished PhD Thesis, University of Wales.

Cool, H. E. M. (1990) Silver and copper-alloy objects (other than brooches). In S. Wrathmell and A. Nicholson Dalton Parlours Iron Age settlement and Roman villa. Yorkshire Archaeology, 3, 79-92.

Cool, H. E. M. (1991) Roman metal hair pins from southern Britain. Archaeological Journal (1990), 147, 148-82. London.

Cool, H. E. M. (2000a) The significance of snake jewellery hoards. Britannia 31, 29-40.

Cool, H. E. M. (2000b) The parts left over: material culture into the fifth century. In T. Wilmott and P. Wilson (eds) The Late Roman Transition in the North. British Archaeological Reports (British Series), 299, 47-65. Oxford.

Cool, H. E. M., Lloyd-Morgan, G. and Hooley, A. D. (1995) Finds from the Fortress Archaeology of York 17/10.

Cool, H. E. M. and Philo, C. (eds) (1998) Roman Castleford excavations 1974-85. Volume I: the small finds. Yorkshire Archaeology, 4.

Cool, H. E. M. and Price, J. (1987) The glass. In G. W. Meates The Roman villa at Lullingstone, Kent. Volume II the wall paintings and finds. Kent Archaeological Society Monograph Series, 3, 110-42.

Cool, H. E. M. and Price, J. (1995) Roman vessel glass from excavations in Colchester, 1971-85. Colchester Archaeological Report, 8.

Cool, H E M, and Price, J. (1998) The vessels and objects of glass. In Cool and Philo (eds) 1998, 141-94. 
Cooper, N. (1999) The small finds. In A. Connor and R. Buckley Roman and Medieval Occupation in Causeway Lane. Leicester Archaeology Monograph, 5, 239-82.

Copplestone-Crow, B. (1989) Herefordshire place-names. British Archaeological Reports (British Series), 214.

Cotton, M. A. (1947) Excavations at Silchester 1938-9. Archaeologia XCII, 121-68.

Cotton, M. A. and Wheeler, R. E. M. (1953) Verulamium 1949. Transactions of the St Albans and Hertfordshire Architectural and Archaeological Society (1953), 13-97.

County Archaeological Service (1995) Ariconium Project Proposal (P1079). Unpublished typescript, Worcestershire County Council.

Courtney, P. (1999) Metalwork. In N. W. Jones, Excavations within the medieval town at New Radnor, Powys, 1991-92. Archaeological Journal (1988) 155, 134-206. London.

Cox, C. (1995) Ariconium Project, Weston-under-Penyard, Hereford and Worcester. Unpublished aerial photographic assessment, Air Photo Services.

Cracknell, P. M. (1990) A group of marked brooches from Gloucester. Britannia 21, 197-206.

Cracknell, S. and Mahany, C. (1994) Roman Alcester: Southern extramural area, 1964-1966. Excavations, Part 2: Finds and discussion, Roman Alcester Series: Volume 1. Council for British Archaeology Research Report, 96. York.

Crew, P. (1991) The experimental production of prehistoric bar iron. Historical Metallurgy 25, 21-36.

Crickmore, J. (1984) Romano-British urban settlements in the West Midlands. British Archaeological Reports (British Series), 127. Oxford.

Crummy, N. (1983) The Roman small finds from excavations in Colchester 1971-9. Colchester Archaeological Report, 2.

Crummy, N. (1985) The Brooches. In Pryor et al. (1985), 164-166.

Cunliffe, B. (1971) Excavations at Fishbourne, 1961-1969, Volume II, The Finds. Reports of the Research Committee of the Society of Antiquaries of London, 27.

Cunliffe, B. (1987) Hengistbury Head, Dorset, Volume I, The prehistoric and Roman settlement, 3500 BC-AD500. Oxford Committee for Archaeology Monograph, 13.

Cunliffe, B. (1991) Iron Age communities in Britain (3 edn.). Routledge.

Curle, J. (1911) A Roman frontier post and its people: The fort of Newstead in the Parish of Melrose. Glasgow.

D.A.G. (1988) Dean Archaeology Group Newsletter 1.

D.A.G. (1989a) Dean Archaeology Group Newsletter 5.

D.A.G. (1989b) Dean Archaeology Group Newsletter 7.

D.A.G. (1989c) Dean Archaeology 2.

D.A.G. (1990a) Dean Archaeology Group Newsletter 10.

D.A.G. (1990b) Dean Archaeology Group Newsletter 11.

D.A.G. (1990c) Dean Archaeology 3.

D.A.G. (1991a) Dean Archaeology Group Newsletter 14.

D.A.G. (1991b) Dean Archaeology Group Newsletter 16.

D.A.G. (1991c) Dean Archaeology 4.

D.A.G. (1993a) Dean Archaeology Group Newsletter 20.

D.A.G. (1993b) Dean Archaeology 6.

D.A.G. (1994a) Dean Archaeology Group Newsletter 24.

D.A.G. (1994b) Dean Archaeology Group Newsletter 26.

D.A.G. (1994d) Dean Archaeology 7.

D.A.G. (1995) Dean Archaeology 8.

Dalwood, H. (1994) Archaeological assessment of Weston-underPenyard, Hereford and Worcester (CMHTS). Hereford and
Worcester County Council, Archaeological Service, internal report, 353.

Dalwood, H., Buteux, V. and Darlington, J. (1994) Excavations at Farrier Street and other sites north of the City Wall, Worcester 1988-92. Transactions of the Worcestershire Archaeological Society (3 Series) 14, 75-114.

Dalwood, H. and Edwards, R. (2004) Excavations at Deansway, Worcester 1988-89, Council for British Archaeology Research Report, 139. York.

Dannell, G. B. and Wild, J. P. (1987) Longthorpe II, The military works depot: an episode in landscape history, Britannia Monograph Series, 8.

Dark, K. R. (1994) Civitas to kingdom: British political continuity 300-800. Leicester University Press.

Darling, M. J. (1977) Pottery from early military sites in western Britain. In J. Dore and K. Greene (eds) Roman Pottery Studies in Britain and Beyond. British Archaeological Reports (Supplementary Series), 30, 57-100. Oxford.

Darlington, J. and Evans, J. (1992) Roman Sidbury, Worcester: Excavations 1959-1989. Transactions of the Worcestershire Archaeological Society (3 Series) 13, 5-104.

Darvill, T. and Fulton, A. K. (1998) MARS: The Monuments at Risk Survey of England, 1995. Bournemouth University and English Heritage.

Davies, B. J., Richardson, B. and Tomber, R. S. (1994) A dated corpus of early Roman pottery from the City of London. Council for British Archaeology Research Report, 98.

Davies, J. L. and Lynch, F. (2000) The Late Bronze Age and Iron Age. In F. Lynch, S. Aldhouse-Green and J. L. Davies (eds) Prehistoric Wales. Sutton.

Davies, W. (1978) Early Welsh microcosm: studies in the Llandaff charters.

Dawson, M. (ed) (2005) An Iron Age Settlement at Salford, Bedfordshire. Bedfordshire Archaeology Monograph 6. Bedfordshire Archaeological Council.

de la Bedoyere, G. (1991) The buildings of Roman Britain. Batsford.

Deru, X. (1996) La Céramique Belge dans le Nord de la Gaule. Département d'Archéologie et d'Histoire de l'Art de l'Université catholique de Louvain. Louvain-la-Neuve.

Dickinson, B. (1992a) Samian. In Woodiwiss (1992), 58-61.

Dickinson, B. (1992b) The samian. In Darlington and Evans (1992), 57-61.

Dool, J. and Wheeler, H. (1985) Roman Derby: Excavations -1968-1983. Journal of the Derbyshire Archaeological and Natural History Society 105.

Down, A. (1974) Chichester Excavations II. Chichester.

Down, A. (1978) Chichester Excavations III. Chichester.

Down, A. (1979) Chichester Excavations IV, the Roman villas at Chilgrove and Upmarden. Chichester.

Down, A. (1989) Chichester Excavations VI. Chichester.

Dreghorn, W. (1968) Geology explained in the Forest of Dean and Wye Valley. David and Charles, Newton Abbot.

Duval, A. (1974) Un type particulier de fibule gallo-romaine précoce: la fibule "d'Alésia". Antiquités Nationale, 6, $67-76$.

Eddy, M. (1995) Kelvedon and the fort myth in the development of Roman small towns in Essex. In A. E. Brown (ed.) (1995), 119-28.

Elsdon, S. M. (1997) Old Sleaford Revealed. Nottingham Studies in Archaeology, 2. Oxbow, Oxford.

English Heritage (1991a) Exploring our past: strategies for the 
archaeology of England. Historic Buildings and Monuments Commission for England, London.

English Heritage (1991b) Management of Archaeological Projects. Historic Buildings and Monuments Commission for England, London.

English Heritage (1996) Archaeology Review 1995-6. Historic Buildings and Monuments Commission for England, London.

Esmonde Cleary, S. (1987) Extra-mural areas of Romano-British towns. British Archaeological Reports (British Series), 169.

Esmonde Cleary, S. (1989) The ending of Roman Britain. Batsford.

Esmonde Cleary, S. (1999) Roman Britain: civil and rural society. In J. Hunter and I. Ralston (eds) The Archaeology of Britain, 157-75. Routledge.

Evans, C. Jane, Jones, L. and Ellis, P. (2000) Severn Valley Ware production at Newlands Hopfields: excavation of a Romano-British kiln site at North End Farm, Great Malvern, Worcestershire in 1992 and 1994. British Archaeological Reports (British Series), 313.

Evans, Jeremy (1988) All Yorkshire is divided into three parts; social aspects of later Roman pottery distributions in Yorkshire. In J. Price and P. R. Wilson, with C. S. Briggs and S. J. Hardman (eds), Recent Research in Roman Yorkshire, Studies in honour of Mary Kitson Clark (Mrs. Derwas Chitty). British Archaeological Reports (British Series), 193, 323-37. Oxford.

Evans, Jeremy (1993) Pottery function and finewares in the Roman north. Journal of Roman Pottery Studies 6, 95-118.

Evans, Jeremy (1994a) Discussion of the pottery in the context of Roman Alcester. In Cracknell and Mahany (eds) 1994, 144-9.

Evans, Jeremy (1994b) Worked stone and Quernstones. In Cracknell and Mahany (eds) (1994), 231-248.

Evans, Jeremy (1996) The Roman pottery. In G. Hughes The Excavation of a Late Prehistoric and Romano-British Settlement at Thornwell Farm, Chepstow, Gwent, 1992. British Archaeological Reports (British Series), 244, 46-64. Oxford.

Evans, Jeremy (1997) Romano-British pottery: social and economic aspects. Unpublished paper given at the second international Roman Archaeology Conference, University of Nottingham (April 1997).

Evans, Jeremy (2001) Material approaches to the identification of different Romano-British site types. In S. James and M. Millet (eds). Britons and Romans. Advancing an Archaeological Agenda. Council for British Archaeology Research Report, 125. York.

Evans, Jeremy (2002) The Alchester (A421) Roman and Saxon pottery. In P. M. Booth, J. Evans and J. Hiller Excavations in the extramural settlement of Roman Alchester, Oxfordshire, 1991. Oxford Archaeology Monograph Series, 1.

Evans, Jeremy (forthcoming) The Binchester Roman pottery. In I. M. Ferris and R. F. J. Jones Binchester Roman Fort. English Heritage Monograph series.

Evans, Jeremy, and Millett, M. J. (1992) Residuality Revisited. Oxford Journal of Archaeology 11/2, 225-40.

Feugère, M. (1985) Les fibules en Gaule Méridionale de la conquête à la fin du Ve siècle après $J$-C. Revue Archéologique de Narbonnaise Supplément, 12, Paris.

Figueiral, I. (1992) The fuels. In Fulford and Allen (1992), 188-91.

Fitts, R. L., Haselgrove, C. C., Lowther, P. C. and Willis, S. H.
(1999) Melsonby revisited: Survey and excavation 1992-95 at the site of the discovery of the "Stanwick", North Yorkshire, hoard of 1843. Durham Archaeological Journal 14/15, 1-52.

Ford, D. and Rees, H. (1984) The Iron Age and later pottery from Beckford. Unpublished typescript, Hereford and Worcester County Council.

Fosbroke, T. D. (1821) Ariconensia.

Fox, A. (1940) The legionary fortress at Caerleon, Monmouthshire: excavations in Myrtle Cottage Orchard 1939. Archaeologia Cambrensis XCV, 102-52.

France, N. E. and Gobel, B. M. (1985) The Romano-British temple at Harlow. Gloucester.

French, C. A. I. (1994) The Haddon farmstead and a prehistoric landscape at Elton: the archaeology along the A605 EltonHaddon Bypass, Cambridgeshire. Cambridge.

Frere, S. (1962) Excavations at Dorchester on Thames. Archaeological Journal 119, 114-49. London.

Frere, S. (1972) Verulamium excavations, Volume I. Reports of the Research Committee of the Society of Antiquaries of London, 28. Oxford.

Frere, S. (1984) Verulamium excavations, Volume III. Oxford University Committee for Archaeology Monograph, 1.

Frere, S. and St. Joseph, J. K. (1974) The Roman Fortress at Longthorpe. Britannia 5, 1-129.

Fulford, M. G. (ed.) (1984) Silchester: Excavations on the Defences 1974-80. Britannia Monograph, 5.

Fulford, M. G. (1989) The Silchester Amphitheatre. Excavations of 1979-1985. Society for the Promotion of Roman Studies, London.

Fulford, M. G. and Allen, J. R. L. (1992) Iron-making at The Chesters villa, Woolaston, Gloucestershire: survey and excavation 1987-91. Britannia XXIII, 159-206.

Fulford, M. G. and Huddleston, K. (1991) The Current State of Romano-British Pottery Studies: A Review for English Heritage. English Heritage.

Gale, R. (1999) The charcoal. In Jackson, Hancocks and Pearson (1999), 29-30.

Gale, R. (2000) The fuels. In Barber and Holbrook (2000), $51-4$.

Garrod, A. P. and Heighway, C. M. (1984) Garrod's Gloucester: Archaeological observations 1974-81. Western Archaeological Trust, Gloucester.

Garrod, A. P. and Moss, P. (1967) Ariconium, Herefordshire. West Midlands Archaeology 10, 25-6.

Gelling, M. (1992) The West Midlands in the early Middle Ages.

Gillam, J. P. (1968) Types of Roman Coarse Pottery Vessels in Northern Britain. Oriel Press Ltd.

Gillam, J. P. (1976) Coarse fumed ware in North Britain and beyond. Glasgow Archaeological Journal 4, 57-80.

Goodburn, R. (1974) The objects, 42-88. In S. S. Frere and J. K. St. Joseph (1974) The Roman fortress at Longthorpe. Britannia 5, 1-129.

Gould, J. (1967) Excavations at Wall, Staffordshire, 1964-6, on the site of the Roman forts. Transactions of the Lichfield and South Staffordshire Archaeological and Historical Society 8, 1-40.

Greep, S. J. (1995) Objects of bone and antler. In Blockley et al. (1995), 1112-52.

Greene, K. T. (1979) Report on the Excavations at Usk 19651976: The Pre-Flavian Fine Wares. University of Wales Press, Cardiff. 
Green, C. S. (1987) Excavations at Poundbury, Volume I: The settlements. Dorset Natural History and Archaeology Society Monograph Series, 7. Dorchester.

Grinsell, V., Blunt, C. E. and Dolley, M. (1973) Sylloge of the British Isles, 19. Bristol and Gloucester Museums, London.

Guido, M, (1978) The Glass Beads of the Prehistoric and Roman Periods in Britain and Ireland. Reports of the Research Committee of the Society of Antiquaries of London, 35 .

Gurney, D. (1986) Settlement, religion and industry on the Roman fen edge, Norfolk. East Anglian Archaeology, 31. Gressenhall.

Gwilt, A. and Haselgrove, C. (eds) (1997) Reconstructing Iron Age Societies. Oxbow Monograph, 71. Oxbow, Oxford.

Haigh, J. G. B. (1993) A new issue of AERIAL - Version 4.20. Aerial Archaeology Research Group News 7.

Halkon, P. (1992) Romano-British face pots from Holme-onSpalding Moor and Shiptonthorpe, East Yorkshire. Britannia XXIII, 222-24.

Hands, A. R. (1993) The Romano-British Roadside Settlement at Wilcote, Oxfordshire I Excavations 1990-92. British Archaeological Reports (British Series), 232. Oxford.

Hands, A. R. (1998) The Romano-British Roadside Settlement at Wilcote, Oxfordshire II Excavations 1993-96. British Archaeological Reports (British Series), 265. Oxford.

Hannan, A. (1993) Excavations at Tewkesbury, 1972-74. Transactions of the Bristol and Gloucestershire Archaeological Society 111, 21-75.

Hanson, W. S., Daniels, C. M., Dore, J. N. and Gillam, J. P. (1979) The Agricolan supply base at Redhouse, Corbridge. Archaeologia Aeliana 5, 1-88.

Harden, D. B. and Price, J. (1971) The glass. In B. Cunliffe (1971) Excavations at Fishbourne, 1961-1969 Volume II: the finds. Report of the Research Committee of the Society of Antiquaries of London, 27, 317-68.

Hart, C. E. (1971) The industrial history of Dean with an introduction to its industrial archaeology. Newton Abbot.

Hartley, K. F. (1977) Two major potteries producing mortaria in the 1 st AD. In J. Dore and K. Greene (eds) Roman Pottery Studies in Britain and Beyond. British Archaeological Reports (Supplementary Series), 30, 5-17. Oxford.

Hartley, K. F. (1985) Mortaria. In Wilmott and Rahtz (1985), $142-5$.

Hartley, K. F. (1996) Mortaria. In D. L. Brown (1996) The Roman 'small town' at Leintwardine: excavations and other fieldwork 1971-1989. Transactions of the Woolhope Naturalists Field Club 48 (3), 543.

Hartley, K. F. (1998) The incidence of stamped mortaria in the Roman Empire, with special reference to imports to Britain. In J. Bird (ed.) (1998) Form and Fabric: Studies in Rome's Material Past in Honour of B. R. Hartley. Oxbow Monograph, 80, 199-217. Oxbow, Oxford.

Haselgrove, C. C. (1985) Inference from ploughsoil artefact samples. In C. C. Haselgrove, M. J. Millett and I. M. Smith (eds) Archaeology from the Ploughsoil: Studies in the collection and interpretation of field survey data, 7-29. Sheffield.

Haselgrove, C. C. (1997) Iron Age brooch deposition and chronology. In Gwilt and Haselgrove (1997), 51-72.

Hattatt, R. (1982) Ancient and Romano-British brooches. Milborne Port.

Hattatt, R. (1989) Ancient Brooches and other artefacts, A fourth selection of brooches with some other antiquities from the author's collection. Oxbow, Oxford.
Hawkes, C. F. C. and Hull, M. R. (1947) Camulodunum. First Report on the Excavations at Colchester 1930-1939. Reports of the Research Committee of the Society of Antiquaries of London, 14.

Hayter, A. K. G. (1923) The coins and pottery. In Jack (1923), 9-23.

Herefordshire Field Name Survey (undated) Weston-underPenyard. Woolhope Naturalists Field Club.

Henderson, A. M. (1949) Small objects in metal, bone, glass etc. In J. P. Bushe-Fox (1949) Fourth Report on the Excavations of the Roman Fort at Richborough, Kent. Reports of the Research Committee of the Society of Antiquaries of London, $16,106-60$.

Henig, M. (1974) A corpus of Roman engraved gemstones from British sites. British Archaeological Reports (British Series), 8 (1st edn.). Oxford.

Henig, M. (1984) Religion in Roman Britain. Batsford, London. Hill, J. D. (1995) The pre-Roman Iron Age in Britain and Ireland: an overview. Journal of World Prehistory 9/1, 47-98.

Hills, G. M. (1871) On a series of antiquities collected at Ariconium, near Ross. Herefordshire, by William Charles Palmer, Esq, of Bollitree'. Journal of the British Archaeological Associaition XXVII, 203-18.

Hinchliffe, J. and Green, C. S. (1985) Excavations at Brancaster, 1974 and 1977. East Anglian Archaeology Report, 23. Gressenhall.

Hingley, R. (1997a) Iron, ironworking and regeneration: a study of the symbolic meaning of metalworking in Iron Age Britain. In Gwilt and Haselgrove (1997), 9-18.

Hingley, R. (1997b) Resistance and domination: social change in Roman Britain. In D. Mattingley (ed.) Dialogues in Roman imperialism: power, discourse and discrepant experiences in the Roman Empire. Journal of Roman Archaeology 23, 81-102.

Hinton, D. A. (1990) Buckles and buckle-plates. In M. Biddle (1990) Artefacts from medieval Winchester. Part II: Object and economy in medieval Winchester. Winchester Studies, 7, 506-26. Oxford.

Hobley, B. (1973) Excavations at "The Lunt" Roman military site, Baginton, Warwickshire, 1968-71 (Second Interim Report). Transactions of the Birmingham and Warwickshire Archaeological Society 85, 7-92.

Horwell, D. (1977) Stone Objects. In K. Branigan (ed.) Gatcombe Roman Villa. British Archaeological Reports (British Series), 44, 99-102. Oxford.

Hughes, G. (1996) The Excavation of a Late Prehistoric and Romano-British Settlement at Thornwell Farm, Chepstow, Gwent, (1992). British Archaeological Reports (British Series), 244. Oxford.

Hume, A. (1863) Ancient Meols; or, some account of the antiquities found near Dove Point, on the sea-coast of Cheshire. Abraham Hume, London.

Hull, M. R. and Hawkes, C. F. C. (1987) Pre-Roman Bow Brooches, Corpus of Ancient Brooches in Britain. British Archaeological Reports (British Series), 168. Oxford.

Hurst, D. and Rees, H. (1992) Pottery fabrics; a multi-period series for the County of Hereford and Worcester. In Woodiwiss (ed.) (1992), 200-9.

Hurst, D. (1994) Potential for artefactual studies. In Dalwood (1994), 7-8.

Hurst, D. (ed.) (1999) Pottery fabrics: a multi-period series for the Counties of Herefordshire and Worcestershire. Worcestershire 
County Council Archaeological Service, internal report 445 (updated 1999). Worcester .

Hurst, H. R. (1985) Kingsholm. Cambridge.

Hurst, H. R. (1986) Gloucester, the Roman and later defences: Excavations on the east defences and a reassessment of the defensive sequence. Gloucester Archaeological Reports, 2. Gloucester.

Jack, G. H. (1923) Excavations on the site of Ariconium. Woolhope Naturalists Field Club Monograph.

Jackson, D. A. and Ambrose, T. M. (1978) Excavations at Wakerley. Britannia IX, 115-242.

Jackson, D. and Dix, B. (1987) Late Iron Age and Roman settlement at Weekley, Northants. Northamptonshire Archaeology 21, 41-93.

Jackson, R. and Hancocks, A. (1998) Ariconium: Updated project design and assessment report. Worcestershire County Council Archaeological Service, internal report, 589.

Jackson, R., Hancocks, A. and Pearson, E. (1999) Salvage recording on the Lea and Weston-under-Penyard Sewage Transfer: archive report. Worcestershire County Council Archaeological Service, internal report, 474.

Jackson, R. (2000) Ariconium, Herefordshire - The 1967 Garrod and Moss excavations: archive report. Worcestershire County Council Archaeological Service, internal report, 838.

Jackson, R. (2004) Production: Roman ironworking. In Dalwood and Edwards (2004), 98-103.

Jackson, R. P. J. and Potter, T. W. (1996) Excavations at Stonea, Cambridgeshire, 1980-85. London.

Jarrett, M. J. and Wrathmell, S. (1981) Whitton, An Iron Age and Roman farmstead in South Glamorgan. Cardiff.

de Jersey, P. (1994) A gazetteer of findspots. In van Arsdell (1994).

Johns, C. (1997) The Snettisham Roman Jeweller's hoard. British Museum Press, London.

Jones, R. J. A. and Evans, R. (1975) Soil and crop marks in the recognition of archaeological sites by aerial photography. In D. R. Wilson (ed.) Aerial Reconnaissance for Archaeology. Council for British Archaeology Research Report, 12.

Kenyon, K. M. (1940) Excavations at Viroconium 1936-7. Archaeologia 88, 175-227.

Kenyon, K. M. (1948) Excavations at the Jewry Wall Site, Leicester. Reports of the Research Committee of the Society of Antiquaries of London, 15. Oxford.

Kenyon, K. M. (1954) Excavations at Sutton Walls, Herefordshire, 1948-1951. Archaeological Journal 110, 1-87.

Kilbride-Jones, H. E. (1937-38) Glass armlets in Britain. Proceedings of the Society of Antiquaries of Scotland 72, 366-95.

Lambrick, G. (1980) Excavations in Park Street, Towcester. Northamptonshire Archaeology 15, 35-118.

Lee, F. and Lindquist, G. with Evans, Jeremy (1994) RomanoBritish coarse pottery. In Cracknell and Mahany (1994), 3-92.

Leech, R. (1981) The excavation of a Romano-British farmstead and cemetery on Bradley Hill, Somerton, Somerset. Britannia 12, 177-252.

Leech, R. (1982) Excavations at Catsgore, 1970-1973, A RomanoBritish village. Western Archaeological Trust Excavation Monograph, 2. Bristol.

Leech, R. (1986) The excavation of a Romano-Celtic temple and a later cemetery on Lamyatt Beacon, Somerset, Britannia XVII, 259-328.
Lucas, R. N. (1993) The Romano-British villa at Halstock, Dorset, excavations 1967-1985. Dorset Natural History and Archaeological Society Monograph Series, 13.

MacGregor, M. (1976) Early Celtic Art in North Britain.

Mackreth, D. F. (1973) Roman Brooches. Salisbury.

Mackreth, D. F. (1996) Orton Hall Farm, a Roman and early Anglo-Saxon farmstead. East Anglian Archaeology, 76. Manchester.

McCarthy, M. R. (1990) A Roman, Anglian and medieval site at Blackfriars Street, Carlisle: Excavations 1977-9. Cumberland and Westmorland Antiquarian and Archaeological Society Research Series, 4. Kendal.

McDonnell, G. and Swiss, A. (2001) Ironworking residues. In Dalwood and Edwards (2004), 368-77.

MAFF (1999a) Controlling soil erosion: an advisory booklet for the management of agricultural land. MAFF Publications (PB3280).

MAFF (1999b) Controlling soil erosion: a manual for the assessment and management of agricultural land at risk of water erosion in lowland England. MAFF Publications (PB4093).

MAFF (1999c) Controlling soil erosion: a field guide for an erosion risk assessment for farmers and consultants. MAFF Publications (PB4092).

MAFF (1999d) Controlling soil erosion:an advisory leaflet for preventing erosion caused by grazing livestock in lowland England. MAFF Publications (PB4091).

Mann, J. E. (1999) Other artefacts. In C. Colyer, B. J. J. Gilmour and M. J. Jones (1999) The Defences of the Lower city The Archaeology of Lincoln VII.2. Council for British Archaeology Research Report, 114, 146-69. York.

Manning, W. H., Price, J. and Webster, J. (1995) Report on the excavations at Usk 1965-1976. The Roman Small Finds.

Manning, W. H. and Scott, I. R. (1986) The iron objects. In I. M. Stead and V. Rigby (1986) Baldock. The Excavation of a Roman and Pre-Roman Settlement, 1968-72. Britannia Monograph, 7, 145-62. London.

Marsh, G. (1981) London's samian supply and its relationship to the development of the Gallic samian industry. In A. C. Anderson and A. S. Anderson (eds) (1981) Roman Pottery Research in Britain and North-West Europe. British Archaeological Reports (British Series), 123, 173-238. Oxford.

May, J. (1996) Dragonby. Report on excavations at an Iron Age and Romano-British settlement in North Lincolnshire, Vol.1 and 2. Oxbow Monograph, 61. Oxbow, Oxford.

Maxwell, G. (1974) Objects of bronze. In A. Rae and V. Rae (1974) The Roman fort at Cramond, Edinburgh, excavations 1954-1966. Britannia, V, 193-5.

Maxwell, R. (1996) Domestic objects, 201-3. In P. Cardwell (1996) Excavation of the hospital of St Giles by Brompton Bridge, North Yorkshire. Archaeological Journal 152, 109-245.

Millett, M. J. and Graham, D. (1986) Excavations on the RomanoBritish Small Town at Neatham, Hampshire, 1969-1979. Hampshire Field Club with the Farnham and District Museum Society, Gloucester.

Millett, M. (1990) The Romanization of Britain. Cambridge University Press.

Millett, M. (1995) Strategies for Roman small towns. In A. Brown (ed.) (1995), 29-38.

Mills, A. and McDonnel, J. G. (1992) The identification and analysis of the hammerscale from Burton Dassett, 
Warwichshire. Ancient Monuments Laboratory Report, 47/92.

Mingay, G. E. (ed.) (1989) The agrarian history of England and Wales, Volume VI 1750-1850. Cambridge University Press.

Morris, E. L. (1983) Salt and ceramic exchange in western Britain during the First millennium BC. Unpublished PhD thesis, University of Southampton.

Morris, E. L. (1985) Prehistoric salt distributions: two case studies from western Britain. Bulletin of the Board of Celtic Studies $32,336-79$.

Morris, E. L. (1996) Artefact production and exchange in the British Iron Age. In T. C. Champion and J. R. Collis (eds) (1996) The Iron Age in Britain and Ireland: recent trends, 41-66.

Mould, Q. (1998) The lead alloy artefacts. In Cool and Philo (1998), 121-8.

MPP(Monument Protection Programme) (1988) Monument Class Description: Watermills (Romano-British). English Heritage.

Napthan, M., Ratkai, S. and Pearson E. (1995) Evaluation of the proposed Ryeford bypass, Weston-under-Penyard (Stage 3). Hereford and Worcester County Council Archaeological Service, internal report, 405.

Neal, D. S., Wardle, A. and Hunn, J. (1990) Excavation of the Iron Age, Roman and medieval settlement at Gorhambury, St Albans. English Heritage Archaeological Report, 14. London.

O’Neil, H. (1952) Whittington Court Roman villa, Whittington, Gloucestershire. Transactions Bristol and Gloucestershire Archaeological Society 71, 13-87.

Orton, C. R. (1982a) Mathematics in Archaeology. Cambridge University Press.

Orton, C. R. (1982b) Computer simulation experiments to assess the performance of measures of quantity of pottery. World Archaeology 14 (1), 1-20.

Orton, C. R. (1989) An introduction to the quantification of assemblages of pottery. Journal of Roman Pottery Studies $2,94-7$

Orton, C. R., Tyers, P. A. and Vince, A. G. (1993) Pottery in Archaeology. Cambridge.

Ottaway, P., Brickstock, R., Carrott, J., Cool, H. E. M., Dobney, K., Gajowski, R., Garside-Neville, S., Gaunt, G. D., Hall, A., Issitt, M., Jaques, D., Large, F. and Monaghan, J. (2000) Excavations on the site of the Roman signal station at Carr Naze, Filey, 1993-94. Archaeological Journal 157, 79-199. London.

Oswald, F. (1952) Excavation of a traverse of Margidunum. Nottingham.

Page, W. (ed.) (1908) The Victoria history of the counties of England: A history of Herefordshire I.

Palmer, R. and Cox, C. (1993) Uses of aerial photography in archaeological evaluations. Institute of Field Archaeologists Technical Paper, 12. IFA, Birmingham.

Partridge, C. (1979) Excavations at Puckeridge and Braughing, 1975-79. Hertfordshire Archaeology 7, 28-132.

Partridge, C. (1981) Skeleton Green, a Late Iron Age and RomanoBritish site. Britannia Monograph Series, 2.

Partridge, C. (1989) Foxholes Farm, a multi-period gravel site. Hertfordshire Archaeological Trust Monograph. Hertford.

PCRG (Prehistoric Ceramics Research Group) (1995) The Study of Later Prehistoric Pottery: General Policies and Guidelines for Analysis and Publication. Prehistoric Ceramics Research Group Occasional Papers, 1 and 2.

Peacock, D. P. S. (1967) Romano-British pottery production in the Malvern district of Worcestershire. Transactions of the Worcestershire Archaeological Society (3 Series) 1, 15-28.

Peacock, D. P. S. (1968) Petrological study of certain Iron Age pottery from western England. Proceedings of the Prehistoric Society 34, 414-427.

Peacock, D. P. S. (1977) Ceramics in Roman and medieval archaeology. In D. P. S. Peacock (ed.) Pottery and early commerce, 21-33. Academic Press, London.

Peacock, D. P. S. and Williams, D. F. (1986) Amphorae and the Roman economy, an introductory guide. Longman.

Petch, D. F. (1960) Excavations at Lincoln, 1955-58, the southern defences of the legionary fortress and the upper colonia, at the sub-deanery and the Old Bishop's Palace. Archaeological Journal 97, 40-70. London.

Phillip Dodd, J. (1980) Hereford agriculture in the mid-nineteenth century. Transactions of the Woolhope Naturalists Field Club XLIII (ii), 203-22.

Pirling, R. (1997) Das Römisch-Fränkische Graberfeld von Krefeld-Gellep 1975-1982. G.D.V. Series B, 17. Stuttgart.

Pitt Rivers, A. H. L. F. (1888) Excavations in Cranborne Chase, Volume II. Privately printed.

Pollard, R. J. (1988) The Roman Pottery of Kent. Kent Archaeological Society Monograph, 5. Kent Archaeological Society, Maidstone.

Potter, T. W. (1979) Romans in north-west England, Excavations at the Roman forts of Ravenglass, Watercrook and Bownesson-Solway. Cumberland and Westmorland Antiquarian and Archaeological Society Research Series, 1. Kendal.

Power, E. and Postan, M. M. (1933) Studies in English Trade in the fifteenth century. Routledge and Keegan Paul Ltd, London.

Price, J. (1988) Romano-British glass bangles from East Yorkshire. In J. Price and P. R. Wilson (eds) (1988) Recent Research in Roman Yorkshire. British Archaeological Reports (British Series) 193, 339-66.

Price, J. (1989) Glass. In M. G. Jarrett and D. H. Evans (1989) Excavation of two palisaded enclosures at West Whelpington. Archaeologia Aeliana (5 ser), XVII, 132-3.

Price, J. and Cottam, S. (1997) The Roman Glass. In L. P. Wenham and B. Heywood (1997) The 1968 to 1970 excavations in the vicus at Malton, North Yorkshire. Yorkshire Archaeology Report, 3, 118-31.

Prior, J. and Alvin, K. L. (1983) Structural changes on charring woods of Dichostachys and Salix from Southern Africa. International Association of Wood Anatomists Bulletin 4 (4), 197-206.

Pryor, F., French, C., Crowther, D., Gurney, D., Simpson, G. and Taylor, M. (1985) Archaeology and environment in the Lower Welland Valley. The Fenland Project, No. 1. East Anglian Archaeology Report, 27.

Ragg, J. M., Beard, G. R., George, H., Heaven, F. W., Hollis, J. M., Jones, R. J. A., Palmer, R. C., Reeve, M. J., Robson, J. D. and Whitfield, W. A. D. (1984) Soils and their use in midland and western England. Soils survey of England and Wales, 12.

Rahtz, P. A. and Greenfield, E. (1977) Excavations at Chew Valley Lake, Somerset. Department of the Environment Archaeological Report, 8. HMSO.

Ravetz, A. (1964) The fourth-century inflation and Romano-British coin finds. Numismatic Chronicle (Series 7) 4, 201-31.

Rawes, B. (1981) The Romano-British site at Brockworth, Gloucestershire. Britannia XI, 45-77.

Rawes, B. (1984) The Romano-British site on the Portway, near 
Gloucester. Transactions of the Bristol and Gloucestershire Archaeological Society 102, 23-72.

RCHME (1934) An inventory of the historical monuments in Herefordshire 1: northwest.

RCHME (1979) Compiled plot of aerial photographs, SO 62 SW. Unpublished document in HER.

Redknap, M. and Young, T. P. (1998) The iron industry of southeast Wales in the 13th century. In N. Nayling (1998) The Magor Pill Medieval Wreck. Council for British Archaeology Research Report, 115, 112-115.

Rees, H. (1990) Coarse pottery. In D. L. Brown (1990) The Romano-British settlement at Blackwardine (HSM 737). Transactions of the Woolhope Naturalists Field Club 46 (3), 391-406.

Rees, H. (1992) Pottery (from the Old Bowling Green site). In Woodiwiss (1992), 35-57.

Richardson, K. M. (1940) Excavations at Poundbury, Dorchester, Dorset. Antiquaries Journal 20, 429-448. Maney, Leeds.

Rigby, V. (1988) Discussion: an assessment of the Gallo-Belgic wares in the Cirencester/Bagendon region. In S. Trow (1988) Excavations at Ditches hillfort, North Cerney, Gloucestershire, 1982-3. Transactions of the Bristol and Gloucestershire Archaeological Society 106, 61-3.

Rigby, V. (1991) Gaulish imports and related wares. In N. Holbrook and P. T. Bidwell (1991) Roman finds from Exeter. Exeter Archaeological Reports, 4. Exeter County Council and The University of Exeter, Exeter.

Riha, E. (1979) Die Römischen fibeln aus Augst und Kaiseraugst. Forschungen in Augst, 3.

Riley, D. N. (1987) Air Photography and Archaeology. London.

Rivet, A. L. F. (1970) The British section of the Antonine Itinerary. Britannia 1, 34-82.

Rivet, A. L. F. and Smith, C. (1979) The place-names of Roman Britian. Batsford.

Rodwell, K. A. (1988) The prehistoric and Roman settlement at Kelvedon, Essex. Council for British Archaeology Research Report, 63 (Chelmsford Archaeological Trust Report, 6). London.

Ross, A. (1967) Pagan Celtic Britain; studies in iconography and tradition.

Rush, P. (1997) Symbols, pottery and trade. In K. I. Meadows, C. R. Lemke and J. Heron (eds) (1996) TRAC 96: Proceedings of the Sixth Annual Theoretical Roman Archaeology Conference, Sheffield 1996, 55-64. Oxbow, Oxford.

Saville, A. (1984) The Iron Age in Gloucestershire: a review of the evidence. In A. Saville (ed.) Archaeology in Gloucestershire. Cheltenham Art Gallery and Museums and the Bristol and Gloucestershire Archaeological Society, Cheltenham.

Saunders, R. L. (1998) The use of Old Red Sandstone in Roman Britain. A Petrographical and Archaeological Study. Unpublished PhD thesis, University of Reading.

Scheers, S. (1977) Traité de Numismatique Celtique, ii. La Gaule Belgique, Paris.

Sealey, P. R. (1985) Amphorae from the 1970 Excavations at Colchester Sheepen. British Archaeological Reports (British Series), 142. Oxford.

Sellwood, L. (1980) Notes on nine ancient British coins from Bath. British Numismatic Journal 50, 128-131.

Sellwood, L. (1984) Tribal boundaries viewed from the perspective of numismatic evidence. In B. Cunliffe and D. Miles (eds) (1984) Aspects of the Iron Age in Central Southern Britain, 191-204. Oxford.

Sellwood, L. (1988) The celtic coins. In D. R. Walker (1988)
Roman Coins from the Sacred Spring at Bath, 279-280. Oxford.

Sim, D. and Ridge, I. (2002) Iron for the eagles: the iron industry of Roman Britain. Tempus.

Sindrey, G. (1990) Roman Dean - The Forest of Dean in the Roman period. Dean Archaeology Group Occasional Publication, 1, 31-2.

Smith, R. (1922) A guide to the antiquities of Roman Britain in the Department of British and Medieval Antiquities.

Spratling, M. G. (1972) Southern British decorated bronzes of the late pre-Roman Iron Age. Unpublished $\mathrm{PhD}$ thesis, University of London.

Society for the Promotion of Roman Studies (1985) Priorities for the preservation and excavation of Romano-British sites. London.

Standing, I. J. (2000) Ironworking residues. In E. Price (2000) Frocester: a Romano-British settlement, its antecedents and successors, Volume 2 The finds. Gloucester and District Archaeological Research Group, 92-4.

Stanford, S. C. (1991) The archaeology of the Welsh Marches (2 Edn.). Ludlow.

Starley, D. (1995) The assessment of slag and other metalworking debris from Ariconium (Weston-under-Penyard), Hereford and Worcester 1993. Ancient Monuments Laboratory Report $61 / 95$.

Stead, I. M. (1975) A Roman pottery theatrical face-mask and a bronze brooch blank from Baldock, Herts. Antiquaries Journal 55, 397-8.

Stead, I. M. (1980) Rudston Roman villa. The Yorkshire Archaeological Society.

Stead, I. M. and Rigby, V. (1986) Baldock, The excavation of a Roman and pre-Roman settlement, 1968-72. Britannia Monograph Series, 7.

Stead, I. M. and Rigby, V. (1989) Verulamium: the King Harry Lane site. English Heritage Archaeological Report, 12.

Stewart, I. J. (1992) Querns. In P. A. Yeoman and I. J. Stewart (1992) A Romano-British Villa Estate at Mantles Green, Amersham, Buckinghamshire. Records of Buckinghamshire 34, 172 .

Summerfield, J. (1997) The small finds. In T. Wilmott (1997) Birdoswald. English Heritage Archaeology Report, 17, 269-361.

Sunter, N. and Brown, D. (1988) Metal vessels. In B. Cunliffe (ed.) (1988) The Temple of Sulis Minerva at Bath. Volume 2: the Finds from the Sacred Spring. Oxford University Committee for Archaeology Monograph, 16, 9-21.

Sunter, S. and Woodward, P. J. (1987) Romano-British Industries. In P. J. Woodward (1987) Purbeck: Excavations at Norden, Nigel Sunter, Excavations at Ower and Rope Lake Hole. Dorset Natural History and Archaeological Society Monograph Series, 6.

Swift, E. (2000) Regionality in dress accessories in the late Roman West. Monographies Instrumentum, 11. Millau.

Timby, J. R. (1990) Severn Valley Wares: a reassessment. Britannia 21, 243-51.

Timby, J. (1998) Excavations at Kingscote and Wycomb, Gloucestershire, a Roman estate centre and small town in the Cotswolds, with notes on related settlements. Cirencester.

Thirk, J. (ed.) (1967) The agrarian history of England and Wales, Volume IV 1500-1640. Cambridge University Press.

Thirk, J. (ed.) (1985) The agrarian history of England and Wales, Volume VI 1640-1750. Cambridge University Press.

Thomas, G. R. and Young, T. P. (1999a) A graphical method 
to determine furnace efficiency and lining contribution to Romano-British bloomery iron-making slags (Bristol Channel Orefield, UK). In S. M. M. Young, P. D. Budd, R. A. Ixer and A. M. Pollard (eds) Metals in Antiquity. British Archaeological Reports (International Series) 792, 223-226. Oxford.

Thomas, G. R. and Young, T. P. (1999b) Bloomery furnace mass balance and efficiency. In A. M. Pollard (ed.) (1999) Geoarchaeology: exploration, environments, resources. Geological Society of London Special Publication, 165, 155-164.

Thorn, F. and Thorn, C. (1983) Domesday Book: Herefordshire. Chichester.

Tomber, R. S. (1985) Pottery. In Wilmott and Rahtz (1985), 99-142.

Tomber, R. S. and Dore, J. (1998) The National Roman Fabric Reference Collection: A Handbook. Museum of London Archaeology Service, London.

Topping, J. (1993) Salvage recording at Wig Meadows, Westonunder-Penyard. Hereford and Worcester County Council Archaeological Service, internal report, 182.

Trow, S. D. (1988) Excavations at Ditches hillfort, North Cerney, Gloucestershire, 1982-3. Transactions of the Bristol and Gloucestershire Archaeological Society 106, 19-85.

Tucker, D. G. (1972) Millstone making at Penallt, Monmouthshire. Industrial Archaeology 8, 229-36.

Turner, R. (1999) Excavations of an Iron Age settlement and Roman religious complex at Ivy Chimneys, Witham, Essex, 1978-183. East Anglian Archaeology, 88.

Turner, T. (1923) Report upon the iron ore, slag and nails. In Jack (1923), 27-31.

Tutin, T. G., Heywood, V. H., Burges, N. A., Moore, D. M., Valentine, D. H., Walters, S. M. and Webb, D. A. (eds) (1964-80) Flora Europaea, 1-5. Cambridge.

Tylecote, R. F. (1986) The prehistory of metallurgy in the British Isles. The Institute of Metals, London.

Tyers, P. A. (1996) Roman Pottery in Britain. Batsford, London. van Arsdell, R. (1989) Celtic Coinage of Britain. London. van Arsdell, R. (1994) The Coinage of the Dobunni. Oxford.

van Es, W. A. and Verlinde, A. D. (1977) Overijssel in Roman and early medieval times. Berichten van de Rijksdienst voor het Oudheidkundig Bodemonderzoek 27, 7-89.

van Lith, S. M. E. (1978-79) Römisches Glas aus Valkenburg Z.H. Oudeidkundige mededelingen uit het Rijksmuseum van Oudheden te Leiden LIX-LX, 1-150.

Viner, L. (1986) Objects of copper alloy. In A. McWhirr (1986) Houses in Roman Cirencester. Cirencester Excavations, III, 106-111.

Wainwright, G. J. (1971) Durrington Walls: Excavations 19661968. Reports of the Research Committee of the Society of Antiquaries of London, 29.

Wainwright, G. J. (1979) Gussage All Saints: an Iron Age settlement in Dorset. Department of the Environment Archaeological Reports, 10.

Walters, B. (1999) The Forest of Dean iron industry: 1st to 4th centuries $A D$. Dean Archaeology Group Occasional Publication, 4 (1 and 2).

Walters, B. and Walters, M. (1989) Ariconium military site excavation interim report. In Dean Archaeology Group (1989c), 33-45.

Walton Rogers, P. (1997) Textile Production at 16-22 Coppergate. The Archaeology of York, 17/11.

Watkins, A. (1929) Archaeology. Transactions of the Woolhope Naturalists Field Club 26 (3), 228-231.
Watkins, M. J. (1982) The small finds. In C. M. Heighway and A. J. Parker (1982) The Roman Tilery at St Oswald's Priory, Gloucester. Britannia XIII, 58-60.

Watson, M. B. (1963) Iron Age site on Bridge Hill. Archaeologia Cantiana 78, 185-8.

Watt, S. (ed.) (2003) West Midlands Archaeology 44 (2001).

Watts, M. (2002) The archaeology of mills and milling. Tempus.

Waugh, H. and Goodburn, R. (1972) The non-ferrous objects. In S. S. Frere (1972), 114-62.

Webster, G. (1955) Further excavations at the Roman fort, Kinvaston, Staffordshire. Transactions and Proceedings of the Birmingham Archaeological Society 73, 100-8.

Webster, G. (1960) The discovery of a Roman fort at Waddon Hill, Stoke Abbott, 1959. Proceedings of the Dorset Natural History and Archaeological Society 82, 88-108.

Webster, G. (1981) Final report on the excavations of the Roman fort at Waddon Hill, Stoke Abbott, 1963-69. Proceedings of the Dorset Natural History and Archaeological Society 101, 51-90.

Webster, G. (1989) Deities and religious scenes on RomanoBritish pottery. Journal Roman Pottery Studies ii, 1-29.

Webster, G. and Smith, L. (1982) The excavation of a RomanoBritish Rural establishment at Barnsley Park, Gloucestershire, 1961-1979, Pt II, c. A.D. 360-400+. Transactions of the Bristol and Gloucestershire Archaeological Society 100, 65-189.

Webster, P. V. (1976) Severn Valley Ware: a preliminary study. Transactions of the Bristol and Gloucestershire Archaeological Society 94, 18-46.

Webster, P. V. (1995) The pottery. In E. Taylor (1995) Report on the excavation of Huntsham Romano-British villa and Iron Age enclosure 1959-1970. Transactions of the Woolhope Naturalists Field Club 48 (2), 253-69.

Wedlake, P. V. (1958) Excavations at Camerton, Somerset. Privately printed.

Wedlake, W. J. (1982) The Excavation of the shrine of Apollo at Nettleton, Wiltshire, 1956-1971. Reports of the Research Committee of the Society of Antiquaries London, 40.

Welfare, A. (1995) The Milling Stones. In W. H. Manning, J. Price and J. Webster (1995) Report on the Excavations at Usk: The Roman Small Finds. University of Wales, Cardiff.

Wheeler, R. E. M. (1943) Maiden Castle, Dorset. Reports of the Research Committee of the Society of Antiquaries of London, 12.

Wheeler, R. E. M. (1930) London in Roman Times. London Museum Catalogue, 3. London.

Wheeler, R. E. M. and Wheeler, T. V. (1928) The Roman Amphitheatre at Caerleon, Monmouthshire. Archaeologia 78, 111-218.

Wheeler, R. E. M. and Wheeler, T. V. (1932) Report on the Excavations of the Prehistoric, Roman and post-Roman site in Lydney Park, Gloucestershire. Reports of the Research Committee of the Society of Antiquaries of London, 9.

Wheeler, R. E. M. and Wheeler, T. V. (1936) Verulamium, a Belgic and two Roman cities. Reports of the Research Committee of the Society of Antiquaries of London, 11.

White, P. (2003) The impact of potato growing on archaeological sites in Herefordshire: a preliminary study. In Watt (2003), 63-7.

White, R. (2003) Wroxeter and the Civitas Cornoviorum. In Watt (2003), 9-13.

Williams, A. (1948) Canterbury excavations in 1948. Archaeologia Cantiana 61, 1-45. 
Williams, R. L. and Zeepvat, R. J. (1994) Bancroft. A Late Bronze Age/Iron Age settlement, Roman villa and temple-mausoleum. Buckinghamshire Archaeological Society Monograph Series, 7.

Williams, R. J., Hart, P. J. and Williams, A. T. L. (1995) Wavendon Gate, a Late Iron Age and Roman settlement in Milton Keynes. Aylesbury.

Willis, S. H. (1993) Aspects of pottery assemblages of the Late Iron Age/First century AD in the East and North-East of England. Unpublished PhD thesis, University of Durham.

Willis, S. H. (1994) Roman imports into late Iron Age British societies: towards a critique of existing models. In S. Cottam, D. Dungworth, S. Scott and J. Taylor (eds) (1994) TRAC 94: The proceedings of the 4th Theoretical Roman Archaeology Conference, Durham 1994, 141-50. Oxbow.

Willis, S. H. (1996) The Romanization of pottery assemblages in the east and north-east of England during the first century AD: a comparative analysis. Britannia 27, 179-221.

Willis, S. H. (1997) Samian: beyond dating. In K. I. Meadows, C. R. Lemke and J. Heron (eds) (1997), TRAC 96: The proceedings of the 6th Theoretical Roman Archaeology Conference, Sheffield 1996, 38-54. Oxbow.

Willis, S. H. (1998a) Iron Age and Roman pottery. In L. Main (1998) Excavation of a timber round-house and broch at the Fairy Knowe, Buchlyvie, Stirlingshire, 1975-8. Proceedings of the Society of Antiquaries of Scotland 128, 321-31.

Willis, S. H. (1998b) Samian pottery in Britain: exploring its distribution and archaeological potential. Archaeological Journal 155, 82-133. London.

Wilmott, A. R. (1980) Kenchester (Magnis): a reconsideration. Transactions of the Woolhope Naturalists Field Club XLIII, (part 2).

Wilmott, A. R. and Rahtz, S. P. Q. (1985) An Iron Age and Roman settlement outside Kenchester (Magnis), Herefordshire.
Excavations 1977-79. Transactions of the Woolhope Naturalists Field Club 45, 36-185.

Williams, D. F. (1988) Roman Honestones and other worked stone from Wroxeter, Shropshire. Ancient Monuments Laboratory Report 88/89.

Wilson, D. R. (1982) Air Photo Interpretation for Archaeologists. London.

Woodiwiss, S. G. (ed.) (1992) Iron Age and Roman salt production and the medieval town of Droitwich. Council for British Archaeology Research Report, 81. York.

Woods, P. J. and Hastings, B. C. (1984) Rushden: The early fine wares. Northampton.

Woodward, A. and Leach, P. (1993) The Uley Shrines. Excavation of a ritual complex on West Hill, Uley, Gloucestershire: 1977-9. English Heritage Archaeological Report, 17.

Woodward, P. J., Davies, S. M. and Graham, A. H. (1993) Excavations at the Old Methodist Chapel and Greyhound Yard, Dorchester, 1981-1984. Dorset Natural History and Archaeological Society Monograph, 12.

Woolf, G. (1993) Rethinking the oppida. Oxford Journal of Archaeology 12 (2), 223-34.

Yarranton, A. (1696) England's improvement by land and sea.

Yeoman, P. A. and Stewart, I. J. (1992) A Romano-British villa estate at Mantles Green, Amersham, Buckinghamshire. Records of Buckinghamshire 34, 107-82.

Young, C. J. (1977) The Roman Pottery Industry of the Oxford Region. British Archaeological Reports (British Series), 43.

Zienkiewicz, J. D. (1986) The engraved gemstones. In Zienkiewicz (1986), 117-41.

Zienkiewicz, J. D. (1986) The legionary fortress baths at Caerleon. Volume II: the finds.

Zienkiewicz, J. D. (1992) Pottery from excavations on the site of the Roman Legionary Museum, Caerleon 1983-5. Journal of Roman Pottery Studies 5, 81-109. 


\section{Appendices}

\section{Appendix 1. Sources}

The following sources were consulted:

\section{Primary archives and material}

Herefordshire County Sites and Monuments Record Hereford City Museum and Art Gallery collections (Jack 1922 finds; Bridgewater 1965)

Gloucester City Museum collections (Palmer collection and others)

British Museum collections

Dean Heritage Centre collections

National Museum of Wales, Cardiff, collections

DAG fieldwork archives (fieldwalking and metal detecting finds 1984 onwards)

SWAG fieldwork archive (fieldwalking 1986)

Garrod and Moss 1967 excavation archive

Cambridge University collection of aerial photographs

National Library of aerial photographs

ADAS Cambridge aerial photographs

\section{Antiquarian reports, excavation reports, other fieldwork reports and finds references}

Anon 1932

Brayley and Britton 1805

Bridgwater 1959

Bridgwater 1965

Bull 1882

Cooke 1882

Copplestone-Crow 1989
DAG 1988

DAG 1989a

DAG 1989b

DAG 1989c

DAG 1990a

DAG 1990b

DAG 1990c

DAG 1991a

DAG 1991b

DAG 1991c

DAG 1993a

DAG 1993b

DAG 1994a

DAG 1994b

DAG 1994d

DAG 1995

Dalwood 1994

Fosbroke 1821

Garrod and Moss 1967

Herefordshire Field Name Survey nd Jack 1923

Jackson, Hancocks and Pearson 1999

Jackson 2000

Journal of the British Archaeological Association, XXVII, 203-18

Napthan, Ratkai, and Pearson 1995

Walters 1999

Walters and Walters 1989

Watkins 1929 


\section{Appendix 2. Fieldwork/HER Index}

\begin{tabular}{|c|c|c|c|c|c|c|}
\hline$H S M$ & NGR & Source & Field ref & Type & Nature of evidence & Comments \\
\hline 841 & Unlocated & SMR & N/A & Finds (Neolithic axe/IA coins) & Indeterminate & \\
\hline 842 & N/A & CMHTS & Various & $\begin{array}{l}\text { Component (Roman urban form) - } \\
\text { used by EH for scheduled part of } \\
21376\end{array}$ & Indeterminate & \\
\hline 3896 & SO 64572362 & $\begin{array}{l}\text { Jackson, Hancocks } \\
\text { and Pearson } 1999\end{array}$ & 21378 & Watching brief finds & Artefacts & $\begin{array}{l}\text { U/S pot - Roman (1) post- } \\
\text { med (1) }\end{array}$ \\
\hline 4185 & SO 64672408 & $\begin{array}{l}\text { Morris 1971 } \\
\text { (HAN 22) }\end{array}$ & 21376 & $\begin{array}{l}\text { Observation - morticed stones and } \\
\text { rubble }\end{array}$ & Domestic building? & $\begin{array}{l}\text { With } 16780 \text { suggests } \\
\text { building }\end{array}$ \\
\hline 4186 & SO 64462408 & $\begin{array}{l}\text { Morris 1971 } \\
\text { (HAN 22) }\end{array}$ & 21376 & Observation - morticed stone & Domestic building? & $\begin{array}{l}\text { With } 4187 \text { and } 4188 \\
\text { suggests building }\end{array}$ \\
\hline 4187 & SO 64462408 & $\begin{array}{l}\text { Morris 1971 } \\
\text { (HAN 22) }\end{array}$ & 21376 & Observation - plaster spread & Domestic building? & $\begin{array}{l}\text { With } 4186 \text { and } 4188 \\
\text { suggests building }\end{array}$ \\
\hline 4188 & SO 64462408 & $\begin{array}{l}\text { Morris 1971 } \\
\text { (HAN 22) }\end{array}$ & 21376 & Observation - tesserae & Domestic building? & $\begin{array}{l}\text { With } 4186 \text { and } 4187 \\
\text { suggests building }\end{array}$ \\
\hline 4189 & SO 64622391 & $\begin{array}{l}\text { Morris 1971 } \\
\text { (HAN 22) }\end{array}$ & 21376 & Observation - rubbish dump & Artefact concentration & \\
\hline 5324 & SO 64302390 & SMR & 5324 & $\begin{array}{l}\text { Land parcel with cropmark. } \\
\text { Fieldwalking finds. }\end{array}$ & Artefact concentration & $\begin{array}{l}\text { Bridgewater 2; DAG C; } \\
\text { ADAS } 3 \text { (pt). Large volumes } \\
\text { of finds - some Garrod finds } \\
\text { possibly from } 21376\end{array}$ \\
\hline 6093 & SO 64002400 & $\begin{array}{l}\text { Jackson, Hancocks } \\
\text { and Pearson } 1999\end{array}$ & 22049 & Cropmark and watching brief & Artefacts & U/S post-med pot (2) \\
\hline 6094 & SO 64722343 & $\begin{array}{l}\text { Jackson, Hancocks } \\
\text { and Pearson } 1999\end{array}$ & 22050 & Cropmark and watching brief & Artefact & U/S post-med pot (1) \\
\hline 6097 & SO 64082376 & $\begin{array}{l}\text { Jackson, Hancocks } \\
\text { and Pearson } 1999\end{array}$ & 21377 & $\begin{array}{l}\text { Salvage recording and watching } \\
\text { brief }\end{array}$ & $\begin{array}{l}\text { Industrial activity. } \\
\text { Possible domestic } \\
\text { structure/s }\end{array}$ & $\begin{array}{l}\text { Extensive Roman activity } \\
\text { and artefacts from series of } \\
\text { trenches }\end{array}$ \\
\hline 9071 & SO 64292484 & $\begin{array}{l}\text { Walters and } \\
\text { Walters } 1989\end{array}$ & 23544 & $\begin{array}{l}\text { Excavation and cropmark } \\
\text { (enclosure) }\end{array}$ & Domestic enclosure & $\begin{array}{l}\text { Excavation - ditches of } \\
\text { enclosure plus associated } \\
\text { features }\end{array}$ \\
\hline 9818 & SO 64452380 & SMR & 9818 & Land parcel with cropmark & Indeterminate activity & $\begin{array}{l}\text { Shows possible ditched } \\
\text { track, fragmented ditches - } \\
\text { possibly enclosures }\end{array}$ \\
\hline 10008 & SO 64752380 & SMR & 10008 & Land parcel with cropmark & Indeterminate activity & $\begin{array}{l}\text { Bridgewater 5; DAG G; } \\
\text { ADAS 5. Fragmented } \\
\text { ditches - possibly roads or } \\
\text { enclosures }\end{array}$ \\
\hline 10010 & SO 64062350 & SMR & 23569 & Cropmark (road) & Communication & $\begin{array}{l}\text { Cox route M-N (Margary } \\
\text { route } 615 \text { ) }\end{array}$ \\
\hline 10090 & & SMR & & Cropmark (road) & Communication & Unlocated record \\
\hline 10113 & SO 64002412 & SMR & 23564 & Cropmark (road) & Communication & $\begin{array}{l}\text { Cox route A-B. Possibly } \\
\text { Margary } 612 \mathrm{a}\end{array}$ \\
\hline 10672 & SO 64902295 & $\begin{array}{l}\text { Jackson, Hancocks } \\
\text { and Pearson } 1999\end{array}$ & 22052 & Watching brief & Artefacts & U/S post-med pot (4) \\
\hline 10673 & SO 64722312 & $\begin{array}{l}\text { Jackson, Hancocks } \\
\text { and Pearson } 1999\end{array}$ & 22051 & Cropmark and watching brief & $\begin{array}{l}\text { Artefact/indeterminate } \\
\text { activity }\end{array}$ & $\begin{array}{l}\text { U/S post-med pot (1). } \\
\text { Fragmentary ditches - } \\
\text { possibly roads or enclosures }\end{array}$ \\
\hline 10674 & SO 65062310 & SMR & 22052 & Cropmark & Indeterminate activity & Fragmentary cropmarks \\
\hline 10676 & SO 64402430 & SMR & 10676 & $\begin{array}{l}\text { Land parcel with cropmark. } \\
\text { Fieldwalking \& u/s finds from } \\
\text { area of field around Bridgewaters' } \\
\text { excavations. }\end{array}$ & $\begin{array}{l}\text { Artefact concentration } \\
\text { and enclosure }\end{array}$ & $\begin{array}{l}\text { Bridgewater 9; ADAS 1 (pt). } \\
\text { 300+ U/S Roman finds. } \\
\text { Small enclosure with pit }\end{array}$ \\
\hline 12549 & N/A & SMR & 23564 & Placename & N/A & "Kill Dane" \\
\hline 12573 & N/A & SMR & Various & Surface finds & N/A & $\begin{array}{l}\text { Various non-specific reports } \\
\text { of artefacts from the } \\
\text { settlement area - Crickmore } \\
\text { 1984; Hayter 1923; Allen } \\
\text { 1961 }\end{array}$ \\
\hline 12666 & SO 64252399 & $\begin{array}{l}\text { Jackson, Hancocks } \\
\text { and Pearson } 1999\end{array}$ & 23553 & $\begin{array}{l}\text { Salvage recording and watching } \\
\text { brief }\end{array}$ & Indeterminate activity & $\begin{array}{l}\text { Roman and Iron Age } \\
\text { features/deposits. Also } \\
\text { 14/15th century sherds (7) }\end{array}$ \\
\hline 15980 & SO 63452455 & $\begin{array}{l}\text { Jackson, Hancocks } \\
\text { and Pearson } 1999\end{array}$ & N/A & Watching brief & Artefacts & U/S post-med pot (19) \\
\hline 15981 & SO 63852445 & $\begin{array}{l}\text { Jackson, Hancocks } \\
\text { and Pearson } 1999\end{array}$ & N/A & Watching brief & Artefacts & $\begin{array}{l}\text { U/S pot - Roman (1), post- } \\
\text { med (6) }\end{array}$ \\
\hline 15982 & SO 63902420 & $\begin{array}{l}\text { Jackson, Hancocks } \\
\text { and Pearson } 1999\end{array}$ & 23564 & Watching brief & Artefacts & $\begin{array}{l}\text { U/S pot - Roman (1), post- } \\
\text { med (2) }\end{array}$ \\
\hline
\end{tabular}


Appendix 2. Fieldwork/HER Index, continued

\begin{tabular}{|c|c|c|c|c|c|c|}
\hline HSM & NGR & Source & Field ref & Type & Nature of evidence & Comments \\
\hline 15983 & SO 63732331 & $\begin{array}{l}\text { Jackson, Hancocks } \\
\text { and Pearson } 1999\end{array}$ & N/A & $\begin{array}{l}\text { Salvage recording and watching } \\
\text { brief }\end{array}$ & Domestic - ?enclosure & $\begin{array}{l}\text { Roman settlement remains } \\
\text { and finds }\end{array}$ \\
\hline 15984 & SO 63702324 & $\begin{array}{l}\text { Jackson, Hancocks } \\
\text { and Pearson } 1999\end{array}$ & N/A & Watching brief & Negative & No finds \\
\hline 16780 & SO 64672405 & Jack 1923 & 21376 & Excavation & Domestic building & $\begin{array}{l}\text { Main trench - remains of } \\
\text { substantial domestic } \\
\text { building. Many finds }\end{array}$ \\
\hline 16781 & SO 64122371 & Jack 1923 & 5324 & Excavation & Indeterminate & $\begin{array}{l}\text { Trench } 4 \text { - No finds. Black } \\
\text { earth. }\end{array}$ \\
\hline 20148 & SO 63702300 & $\begin{array}{l}\text { Fagan and Hurst } \\
1994\end{array}$ & 20148 & $\begin{array}{l}\text { Land parcel-A40 Desktop and } \\
\text { walkover }\end{array}$ & N/A & $\begin{array}{l}\text { Wigg Meadow on route of } \\
\text { Roman road }\end{array}$ \\
\hline 21095 & SO 64092374 & Jack 1923 & 5324 & Excavation & Indeterminate & $\begin{array}{l}\text { Trench } 5 \text { - black earth, No } \\
\text { finds. }\end{array}$ \\
\hline 21096 & SO 63652375 & Jackson 1996 & N/A & Watching brief & Negative & $\begin{array}{l}\text { On swimming pool - no } \\
\text { finds/features }\end{array}$ \\
\hline 21097 & SO 64462400 & Jack 1923 & 21376 & Excavation & ?Domestic building & $\begin{array}{l}\text { Trench } 1-\text { shapeless } \\
\text { masonry } 0.18 \mathrm{~m} \text { below } \\
\text { surface. Some finds. }\end{array}$ \\
\hline 21098 & SO 64112369 & Jack 1923 & 21376 & Excavation & $\begin{array}{l}\text { Indeterminate } \\
\text { occupation }\end{array}$ & $\begin{array}{l}\text { Trench } 2-\text { many finds. Dark } \\
\text { earth layers. } 0.75 \mathrm{~m} \text { to } \\
\text { natural }\end{array}$ \\
\hline 21099 & SO 64122366 & Jack 1923 & 21376 & Excavation & Negative & $\begin{array}{l}\text { Trench } 3 \text { - no finds. Red } \\
\text { earth. }\end{array}$ \\
\hline 21353 & SO 23056355 & $\begin{array}{l}\text { Fagan and Hurst } \\
1994\end{array}$ & 21353 & $\begin{array}{l}\text { Land parcel - A40 Desktop and } \\
\text { walkover }\end{array}$ & Artefacts & $\begin{array}{l}\text { Single sherds of Roman, } \\
\text { med and post-med pot }\end{array}$ \\
\hline 21355 & SO 63752310 & $\begin{array}{l}\text { Fagan and Hurst } \\
1994\end{array}$ & 21355 & $\begin{array}{l}\text { Land parcel - A40 Desktop and } \\
\text { walkover }\end{array}$ & Negative & No finds \\
\hline 21360 & SO 64402430 & Bridgewater 1963 & 10676 & Excavation & Industrial activity & $\begin{array}{l}\text { Area } \mathrm{A} \text { - ironworking } \\
\text { furnaces }\end{array}$ \\
\hline 21361 & SO 64382359 & Bridgewater 1959 & 21378 & Excavation - road & Communication & $\begin{array}{l}\text { Slag surface. } 0.35-0.40 \mathrm{~m} \\
\text { down. No dating. On route } \\
\text { of Roman road HSM } 21371 \\
\text { (Margary route } 611 \text { ) }\end{array}$ \\
\hline 21362 & SO 64852366 & Bridgewater 1959 & 10008 & Excavation - road & Communication & $\begin{array}{l}\text { Slag surface. } 0.25 \mathrm{~m} \text { down. } \\
\text { Post-med finds. Has junction } \\
\text { with HSM } 21361 / 21371 \text { but } \\
\text { is later. Heads towards } \\
\text { Eccleswall }\end{array}$ \\
\hline 21363 & SO 63942342 & $\begin{array}{l}\text { Holland (Anon } \\
\text { 1932) }\end{array}$ & $\begin{array}{l}21377 \& \\
23569\end{array}$ & Observation (worked stone/dam) & Industrial structure & $\begin{array}{l}\text { This has worked stone in it } \\
\text { and is marked on } 6 " \mathrm{O} / \mathrm{S} \\
\text { map }\end{array}$ \\
\hline 21364 & SO 64152365 & $\begin{array}{l}\text { Holland (Anon } \\
\text { 1932) }\end{array}$ & $\begin{array}{l}21377 \& \\
23569\end{array}$ & Observation (worked stone/dam) & Industrial structure & $\begin{array}{l}\text { Stone structure by Pond } \\
\text { Cottage }\end{array}$ \\
\hline 21365 & SO 63982344 & $\begin{array}{l}\text { Holland (Anon } \\
\text { 1932) }\end{array}$ & $\begin{array}{l}21377 \& \\
23569\end{array}$ & $\begin{array}{l}\text { Observation (dam and slag road } \\
\text { surface). Road probably is } \\
\text { Margary route } 615 \text { (HSM 21383) }\end{array}$ & $\begin{array}{l}\text { Industrial structure and } \\
\text { communication }\end{array}$ & $\begin{array}{l}\text { Location a bit ambiguous - } \\
\text { the road is 'below' the } \\
\text { stream but 'above' the dam }\end{array}$ \\
\hline 21366 & SO 63522350 & Walters 1988 & N/A & Evaluation & Negative & $\begin{array}{l}\text { Test pit excavated in } \\
\text { advance of proposed A40 } \\
\text { Bypass - location not certain }\end{array}$ \\
\hline 21367 & Unlocated & Jack 1929 & 21376 & Excavation - road & Communication & $\begin{array}{l}\text { Road - Cox route E-F. } \\
\text { Precise location not certain. } \\
\text { Possibly HSM } 21383 \\
\text { (Margary 615) }\end{array}$ \\
\hline 21368 & Unlocated & DAG? (Ritch) & N/A & Surface finds & Artefacts & Unlocated finds \\
\hline 21369 & Unlocated & CMHTS & Uncertain & Excavation (Garrod 1967) & N/A & $\begin{array}{l}\text { One of two numbers given to } \\
\text { Garrod } 1967 \text { excavation - } \\
\text { now known to be } 8 \text { trenches }\end{array}$ \\
\hline 21370 & Unlocated & CMHTS & Uncertain & Excavation (Garrod 1967) & N/A & $\begin{array}{l}\text { One of two numbers given to } \\
\text { Garrod } 1967 \text { excavation - } \\
\text { now known to be } 8 \text { trenches }\end{array}$ \\
\hline 21371 & Various & Margary 1955 & Various & Road (extrapolated) & Communication & $\begin{array}{l}\text { Margary route } 611 . \text { Tested at } \\
\text { HSM } 21361\end{array}$ \\
\hline 21372 & SO 65042372 & CMHTS & N/A & Placename (Eccleswall) & N/A & \\
\hline 21376 & SO 64502414 & CMHTS & 21376 & $\begin{array}{l}\text { Land parcel with cropmark. } \\
\text { Fieldwalking finds }\end{array}$ & Artefact concentration & $\begin{array}{l}\text { Bridgewater 6; DAG C; } \\
\text { ADAS 4. Very significant } \\
\text { quantities of Roman finds. }\end{array}$ \\
\hline 21377 & SO 63902370 & CMHTS & 21377 & Land parcel with cropmark & N/A & $\begin{array}{l}\text { Bridgewater } 14 \& 15 \\
\text { ADAS } 2\end{array}$ \\
\hline
\end{tabular}


Appendix 2. Fieldwork/HER Index, continued

\begin{tabular}{|c|c|c|c|c|c|c|}
\hline HSM & NGR & Source & Field ref & Type & Nature of evidence & Comments \\
\hline 21378 & SO 64552375 & CMHTS & 21378 & $\begin{array}{l}\text { Land parcel with cropmark. } \\
\text { Fieldwalking finds }\end{array}$ & Artefact concentration & $\begin{array}{l}\text { Bridgewater 3; DAG F; } \\
\text { ADAS 3. Many U/S finds } \\
\text { incl. 250+ sherds Roman } \\
\text { pot. }\end{array}$ \\
\hline 21379 & Unlocated & $\begin{array}{l}\text { CMHTS (RCHME } \\
\text { 1979) }\end{array}$ & Various & Cropmarks (plots) & N/A & No specific location \\
\hline 21380 & Unlocated & $\begin{array}{l}\text { CMHTS (Merrick - } \\
\text { Cooke 1882) }\end{array}$ & Various & Documentary & $\begin{array}{l}\text { Domestic buildings. } \\
\text { Corndrier? Artefact } \\
\text { concentration }\end{array}$ & $\begin{array}{l}\text { Documentary record of } \\
\text { clearance and enclosure of } \\
\text { the site in the } 18 \text { th century } \\
\text { by Merrick. Lots of finds } \\
\text { and walls reported - } \\
\text { possibly focus on } 21376\end{array}$ \\
\hline 21381 & Unlocated & $\begin{array}{l}\text { CMHTS (Brayley } \\
\text { and Britton 1805) }\end{array}$ & Various & Documentary & $\begin{array}{l}\text { Stone } \\
\text { building/structure - } \\
\text { domestic or } \\
\text { agricultural. Also } \\
\text { burials }\end{array}$ & $\begin{array}{l}\text { Further reports of Merrick's } \\
\text { clearance (HSM 21380). } \\
\text { Also records that during } \\
\text { road building in } 1804 \text { a wall, } \\
\text { finds and inhumations were } \\
\text { recorded. }\end{array}$ \\
\hline 21382 & Various & Margary 1955 & Various & Road (extrapolated) & Communication & Margary Route 614 \\
\hline 21383 & Various & Margary 1955 & Various & Road (extrapolated) & Communication & $\begin{array}{l}\text { Margary route } 615 \text {. Tested at } \\
\text { HSM } 21365 \text { and possibly at } \\
\text { HSM } 21367\end{array}$ \\
\hline 21384 & Various & Margary 1955 & Various & Road (extrapolated) & Communication & Margary Route 612a \\
\hline 21385 & Unlocated & Bevan 1980 & 21378 & Excavation & Negative & $\begin{array}{l}\text { Excavation to investigate } \\
\text { cropmark of building - no } \\
\text { finds/features }\end{array}$ \\
\hline 22049 & SO 64002400 & SWAG 1986 & 22049 & Land parcel. Fieldwalking finds & Artefact scatter & $\begin{array}{l}\text { Bridgewater 1; DAG A; } \\
\text { ADAS } 3(\mathrm{pt}) \text {. U/S Roman } \\
\text { pot } c .50 \text { items. Also post- } \\
\text { med }\end{array}$ \\
\hline 22050 & SO 64702345 & CMHTS & 22050 & Land parcel & N/A & Bridgewater 4; ADAS 8 \\
\hline 22051 & SO 64702315 & CMHTS & 22051 & Land parcel & N/A & Same as HSM 23565 \\
\hline 22052 & SO 64852300 & CMHTS & 22052 & Land parcel & N/A & \\
\hline 22053 & SO 64022378 & Jack 1923 & 21376 & Excavation & $\begin{array}{l}\text { Indeterminate } \\
\text { occupation }\end{array}$ & $\begin{array}{l}\text { Trench } 6 \text { - many finds. } \\
\text { Black earth over yards. } \\
\text { Possible wall footing. } 0.45 \mathrm{~m} \\
\text { below surface }\end{array}$ \\
\hline 22965 & SO 63702230 & Napthan et al. 1995 & 20148 & Excavation (A40) & $\begin{array}{l}\text { Communication and } \\
\text { domestic occupation }\end{array}$ & $\begin{array}{l}\text { Evaluation on line of Roman } \\
\text { Road HSM } 21383 \text { (Margary } \\
\text { Route } 615 \text { ). Surfacing, } \\
\text { buried Roman soil, ditch } \\
\text { complex, finds - possible } \\
\text { roadside settlement }\end{array}$ \\
\hline 23544 & SO 64252470 & Bridgewater 1963 & 23544 & Land parcel and fieldwalking finds & Artefact scatter & $\begin{array}{l}\text { Bridgewater } 12 . \text { Some } \\
\text { Roman finds }-25+\text { sherds }\end{array}$ \\
\hline 23546 & SO 64682377 & Garrod 1967 & 10008 & Excavation & $\begin{array}{l}\text { Indeterminate } \\
\text { occupation }\end{array}$ & $\begin{array}{l}\text { Trench AI - Many finds. } \\
\text { Roman layers. No features }\end{array}$ \\
\hline 23547 & SO 64682377 & Garrod 1967 & 10008 & Excavation & $\begin{array}{l}\text { Indeterminate } \\
\text { occupation }\end{array}$ & $\begin{array}{l}\text { Trench AII - Many finds. } \\
\text { Roman layers. No features }\end{array}$ \\
\hline 23548 & SO 64672376 & Garrod 1967 & 21378 & Excavation & Industrial activity? & $\begin{array}{l}\text { Trench BI - Many finds. } \\
\text { ?Roman hearth and layers. }\end{array}$ \\
\hline 23549 & SO 64672376 & Garrod 1967 & 21378 & Excavation & $\begin{array}{l}\text { Indeterminate } \\
\text { occupation }\end{array}$ & $\begin{array}{l}\text { Trench BII - Many finds. } \\
\text { No features. Roman layers. }\end{array}$ \\
\hline 23550 & SO 64662376 & Garrod 1967 & 21378 & Excavation & Industrial activity & $\begin{array}{l}\text { Trench BIII - Many finds. } \\
\text { Roman layers, hearth, pit \& } \\
\text { posthole. }\end{array}$ \\
\hline 23551 & SO 64672389 & Garrod 1967 & 21376 & Excavation & $\begin{array}{l}\text { Indeterminate } \\
\text { occupation }\end{array}$ & $\begin{array}{l}\text { Trench CI - Many finds. } 3 \\
\text { phases of Roman incl. } \\
\text { features, metalling and ?wall } \\
\text { footing. }\end{array}$ \\
\hline 23552 & SO 64452405 & Garrod 1967 & 21376 & Excavation & $\begin{array}{l}\text { Industrial activity. } \\
\text { Domestic occupation }\end{array}$ & $\begin{array}{l}\text { Trench CXX - Many finds. } \\
\text { Two ?Roman phases. } \\
\text { Ironworking furnaces and } \\
\text { assoc'd features. Substantial } \\
\text { stone foundations, building } \\
\text { debris and pit. Robber and } \\
\text { trampled horizon. }\end{array}$ \\
\hline 23553 & SO 64302355 & Ariconium project & 23553 & Land parcel & N/A & Bridgewater 16 \\
\hline
\end{tabular}


Appendix 2. Fieldwork/HER Index, continued

\begin{tabular}{|c|c|c|c|c|c|c|}
\hline HSM & NGR & Source & Field ref & Type & Nature of evidence & Comments \\
\hline 23554 & SO 64612394 & Garrod 1967 & 21376 & Excavation & $\begin{array}{l}\text { Indeterminate } \\
\text { occupation }\end{array}$ & $\begin{array}{l}\text { Trench CII - Few finds. } \\
\text { Roman metalling, ?wall } \\
\text { footing \& features. }\end{array}$ \\
\hline 23555 & SO 64252417 & DAG (M Walters) & 10676 & Surface finds & Artefact scatter & Located finds from DAG \\
\hline 23556 & SO 64102415 & DAG & 10676 & Surface finds & Artefact scatter & Located finds from DAG \\
\hline 23557 & SO 64402430 & Bridgewater 1963 & 10676 & Excavation & Industrial activity & $\begin{array}{l}\text { Area B - Ironworking } \\
\text { furnaces }\end{array}$ \\
\hline 23558 & SO 64402430 & Bridgewater 1963 & 10676 & Excavation & Industrial activity & $\begin{array}{l}\text { Area } \mathrm{C} \text { - ironworking } \\
\text { furnaces }\end{array}$ \\
\hline 23559 & SO 64402430 & Bridgewater 1963 & 10676 & Excavation & Industrial activity & $\begin{array}{l}\text { Area D - ironworking } \\
\text { furnaces }\end{array}$ \\
\hline 23560 & SO 64712407 & Bridgewater 1963 & 21376 & Fieldwalking & Artefact concentration & $\begin{array}{l}\text { Roman u/s finds. Findspot } \\
\text { 'Y' - from near Jack's } \\
\text { Trench HSM } 16780\end{array}$ \\
\hline 23561 & SO 64762404 & Bridgewater 1963 & 21376 & Fieldwalking & Artefact concentration & $\begin{array}{l}\text { Roman u/s finds. Findspot } \\
\text { ' } \mathrm{X} \text { ' - from north side of } \\
\text { field }\end{array}$ \\
\hline 23562 & SO 64652385 & Bridgewater 1963 & 21376 & Fieldwalking & Artefact concentration & $\begin{array}{l}\text { Roman u/s finds. Findspot } \\
\text { ' } Z \text { ' - from south of field }\end{array}$ \\
\hline 23563 & SO 64602418 & Ariconium project & 23563 & Land parcel and fieldwalking finds & Artefact scatter & Bridgewater 8 \\
\hline 23564 & SO 64102420 & Ariconium project & 23564 & Land parcel and fieldwalking finds & Artefact scatter & $\begin{array}{l}\text { Bridgewater } 10 \& 11 \\
\text { ADAS } 1(\mathrm{pt})\end{array}$ \\
\hline 23565 & SO 64952345 & RCHME & 23565 & $\begin{array}{l}\text { Land parcel (also documentary - } \\
\text { buried remains) }\end{array}$ & N/A & $\begin{array}{l}\text { ADAS 9. NB buried remains } \\
\text { at Bury Hill so location } \\
\text { dodgy since this is a vague } \\
\text { term }\end{array}$ \\
\hline 23566 & SO 65102395 & Ariconium project & 23566 & Land parcel & N/A & ADAS 10 \\
\hline 23567 & SO 64602418 & Sterry 1994 & 23563 & Observation (building debris) & Domestic building & \\
\hline 23568 & SO 64662405 & $\begin{array}{l}\text { DAG } 1988 \& \\
01 / 1996\end{array}$ & 21376 & Observation (building debris) & Domestic building & \\
\hline 23569 & SO 63952360 & Ariconium project & 23569 & Land parcel & N/A & $\begin{array}{l}\text { ADAS 6; Bridgewater } 15 \\
\text { (pt) }\end{array}$ \\
\hline 23570 & SO 63912369 & Ariconium project & 21377 & Finds concentration & Artefact concentration & Roman u/s finds \\
\hline 23571 & Unlocated & Ariconium project & Various & $\begin{array}{l}\text { Surface finds - only located to } \\
\text { Ariconium }\end{array}$ & Artefact scatter & $\begin{array}{l}\text { Palmer collection. Formerly } \\
\text { numbered HSM 5324, } \\
\text { however, clearly not that } \\
\text { well located thus newly } \\
\text { numbered. }\end{array}$ \\
\hline
\end{tabular}




\section{Appendix 3. Aerial photographic assessment}

\section{Chris Cox}

\section{Archaeological assessment}

The study area contains evidence of multi period archaeological features alongside natural and modern features which are shown as an overview for reference purposes by Figure 1.5.

\section{Results}

The following areas of archaeological interest have been identified from the available photographic coverage:

\section{NGR: $\quad 064602400$ \\ HSM No: $\quad 00842,05324,21376$ \\ Site location: Roman town of Ariconium \\ Principal aerial photographs:}

CUCAP: BM 90-91, CH 81, TH 67-68, VM 52-58, ABR 89-93, BVP 22-23. Various colour prints held by Herefordshire SMR; NLAP 6423/3.

An extensive complex of cut and metalled linear features shows over the entire scheduled area and well beyond. The archaeological features at Ariconium can be seen as positive and negative crop marks in cereals, and present a great challenge to the aerial photographic interpreter. The site consists of a series of linear features which represent the remains of ploughed and robbed road and trackways. These features were probably metalled, with either stonework or compacted slag (as described by Dalwood 1995). They show as discreet areas of either dark or light toned crop. The dark toned areas represent cut or robbed road surface, and the light areas compacted soil or metalling. They confuse with similar appearing areas of naturally deeper soil, and only those which show a coherent pattern and appear to be 'edged' have been mapped for this assessment. Three main alignments have been identified.

The road running from A-B (HSM 10113-21376) skirts Aricon, and emerges as a dark toned sinuous crop marked feature. A further roadway, with well-defined side ditches and partially metalled surface extends from C-D (HSM 6093-HSM 21376). To its south, a well-defined metalled roadway extends from E-F (HSM 0842 into 21376). These features represent the major alignments of roadways into the industrial and settlement area at Ariconium. Further small lengths of metalled track can be seen throughout the area. Long linear features, appearing as a single 'ditch' may be further smaller tracks or boundaries between industrial and settlement features.

The most substantial roadway, C-D, has definite evidence of side ditches and abutting enclosures and linear ditches. An area of darker soil at G may have been be the focus of iron smelting operations, and appears very disturbed. No further interpretation can be made from the existing photographs.

The entire area is one of great archaeological potential, but its interpretation is confused by the extent of former industrial activity and the rather ill-defined nature of the crop marked evidence.

NGR: $\quad 064002400$
HSM No: $\quad 6093$
Site location: West of Well Cottage, Weston
Principal aerial photographs:
CUCAP: TH66, HSM 6093 colour print copy 1235

This site consists of two parallel ditches and associated cut features which are part of the system of Roman roads, and a continuation of linear feature $\mathrm{C}-\mathrm{D}$ described above.

NGR: $\quad$ SO6390024100

HSM No: $\quad$ 10113, 10676

Site location: West of Hask Barn, Weston

Principal aerial photographs:

Various colour prints and colour enlargement held by Herefordshire SMR.

Two parallel ditches reveal the course of a road running from A-B into the area of Ariconium Roman town. The relationship of the ditches to a contiguous area of deeper soil may be coincidental, since the entire area contains very amorphous crop marked evidence of soil depth changes. However, the ditch continuations may be lost in this area, from which metalled surfacing materials may have been removed. The field contains two small streams, which have been mapped, and a valley, the dip slopes of which have been indicated on the 1:2500 plan. Linear ditches have been located and mapped. An isolated but well defined ditched enclosure lies nearby, and is recorded as HSM 10676.

The enclosure, centring SO 642250, could not be properly rectified and positioned due to a lack of suitable control points on the available aerial photographs. It may be associated with the nearby iron smelting sites, and have enclosed a small farmstead or outlying settlement. There is some confined evidence for one cut internal feature which may have been a large pit. An area of deeper soil to its south may be a focus of industrial or settlement activity.

NGR: $\quad 064502370-$ SO65002300

HSM No: $\quad$ 21378, 6094, 10672-10674, 10008

Site location: Bury Hill-Eccleswall 
Principal aerial photographs:

CUCAP: CAX 3-8. Various colour prints held by Herefordshire SMR. NLAP 6423/1, 5, 7.

Buried features in this area show as positive marks in crops, and as very low contrast crop reversal marks. Photographs taken by Baker (SO6423/ 1, 5, 7) show extremely intricate and complex geological features underlying the topsoil. Areas of deeper soil and cut archaeological features show in superimposition. The area contains a series of defined trackways, with no present evidence of metalling, plus a collection of fragmentary ditched features and possible enclosures. A well-defined curvilinear embanked feature was recorded running from $\mathrm{H}-\mathrm{I}$. This feature may be natural, as it seems to fade out at the southern end of the field containing the SAM. However, its interpretation remains open to speculation.

Enclosures recorded by the HSM were not wholly visible, and could only be tentatively identified. However, a series of possible small rectilinear enclosures, or fragments of enclosures, are in evidence. Areas of deeper soil may be indicative of further buried evidence. The entire field contains tantalising hints at the presence of very complex buried remains, which never show themselves fully as crop or soil marks. A long linear feature traverses the area, and seems to fit with the present field boundaries. It may be a removed boundary of no great antiquity. A former boundary, also represented on the modern OS 1:2500 plan runs from $\mathrm{K}$ to $\mathrm{L}$, and has been recorded by the HSM. It may be a more ancient feature, re-used as a path or boundary in modern times.

Crop marked linear ditches are still in evidence at the southern extent of the study area, indicating that the known area of archaeological activity extends at least as far south as Goomstool Barn, where colour photograph (film 5: frame 26) from the SMR records very faint linear ditches centring SO6480022700 which have not been mapped for this assessment as the relevant map extract was not available.

\section{NGR: $\quad$ SO6464402320 \\ HSM No: 09818 \\ Site location: Stroud Cottages - Greenway \\ Principal aerial photographs}

CUCAP VM 56, Various colour prints held by Herefordshire $\operatorname{SMR}(21 / 4)$.

Linear ditches and areas of deep soil represent a continuation of features recorded in the western adjacent field. They are probably associated with the Ariconium settlement and transport network.

NGR: $\quad$ O64102350
HSM No: $\quad 10010$
Site location:
Principal aerial photographs:
CUCAP: HX 70

A small ditched enclosure recorded in grass immediately south of the hamlet at Bury Hill may be the remains of a small moated site. The enclosure appears in association with ditched features which may be the remains of former watercourses. To its south lies a wide ditched and embanked linear feature $\mathrm{M}-\mathrm{N}$. This may have bounded the burial ground which is indicated at this location on the 1:2500 OS plan.

Areas of deep soil in this vicinity and to the west centring SO640236 may show the location of further iron smelting sites associated with Ariconium. Traces of possible linear ditches were recorded in this area.

$\begin{array}{ll}\text { NGR: } & \text { O63802430 } \\ \text { HSM No: } & \text { N/A - }\end{array}$

Site location: Site O, East of Bollitree Castle

Principal aerial photographs:

Background of colour print (H\&W SMR) showing HSM 10113.

A pasture field adjacent to HSM 10113 contains some amorphous areas of darker toned crop indicative of deeper or disturbed soil. These may represent further smelting sites. Very slightly embanked features were seen on the ADAS vertical photographs. These were not seen on any other prints, and may be the remains of medieval headlands. No further evidence of medieval ploughing was seen in that area. The features are mapped at 1:2500 scale.
$N G R$ :
064252498
HSM No:
9071, 10007
Site location: Fidler's cross
Principal aerial photographs:
CUCAP: CDQ 27-30, CDR 2-6, Various colour prints held by Herefordshire SMR; NLAP 6424/1-3.

A complex of well-defined, rectilinear ditched enclosures appear as positive crop marks. The features lie in superimposition on similar alignments. Traces of possible extensions to the sites are visible as very tenuous ditches. The sites also extend as single linear ditches into the northern adjacent field. The whole field has a very mottled appearance, similar to the natural background encountered throughout the study area, which may mask the appearance of further ditches. The sites in this field area probably more extensive than shown by the photographic evidence.

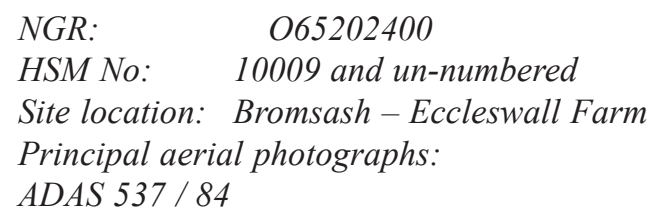

An enclosure listed at HSM 10009 could not be seen. However, the area contains a system of sinuous linear features which traverse the fields to the immediate East of the Bromsash - Eccleswall road. These features are the remains of removed field boundaries which were still extant when the 1:2500 plan was compiled. They resemble features recorded at the adjacent site of the town (Ariconium), but align with, and are part of, the post enclosure field systems. They may preserve the alignment 
of former roads. They are not mapped, as all features are recorded by the Ordnance Survey.

\section{Conclusions}

The above features represent the focus of settlement and industrial activity at Ariconium. The actual extent of the core settlement cannot be determined, although certainly covers the entire area between Aricon, Bromsash, Eccleswall Court, Stroud Cottages and Bollitree Castle, with outlying features recorded at Fidler's Cross, to the east of Bollitree Castle and south-west of Goomstool Barn.

The existing oblique aerial photographs concentrate heavily on the scheduled area, and do not represent an ideal collection of photographs from which to derive accurate rectified interpretations. The peripheral areas are not very well recorded, and may benefit from a localised programme of intensive aerial reconnaissance with the precise objective of defining the extent of the industrial / urban area and its interface with the surrounding countryside. The density of features certainly reduces to the south and east of Bury Hill and to the north of Aricon, where isolated enclosures are seen, which may be contemporary farmsteads, although no dating evidence can be postulated on the basis of aerial photographic evidence.

Temporal and spatial links between the 'farmsteads' and urban areas are tenuous, and at present are assumed rather than proven by this assessment.

\section{Aerial photographic sources}

Cambridge University Collection of Aerial Photographs

Oblique Photographs

$\begin{array}{ll}\text { CH 77-90 } & \text { 17th June } 1949 \\ \text { HX 70-72 } & \text { 25th May } 1952 \\ \text { BM 90-91 } & \text { 18th July } 1948 \\ \text { TH 66-68 } & \text { 13th June 1956 } \\ \text { VM 52-58 } & \text { 2nd July 1957 } \\ \text { ABR 89-93 } & \text { 1st July 1960 } \\ \text { AIO 41-42 } & \text { 10th April 1964 } \\ \text { ADM 96-99 } & \text { 24th June 1966 } \\ \text { ARF 97 } & \text { 29th October 1966 } \\ \text { BVP 20-23 } & \text { 4th August 1975 } \\ \text { CAX 3-8 } & \text { 4th August } 1976 \\ \text { CDQ 2-6, 26-30 } & \text { 29th July 1977 } \\ \text { CDR 2-6 } & \text { 29th July 1977 }\end{array}$

No vertical coverage
National Library of Aerial Photographs

Oblique Photographs

(INCORPORATING SOME CUCAP PRINTS)

SO6323/1 25th June 1952

SO6423/1-8 1st January 1959

SO6423/9 1st January 1957

SO6423/10 18th July 1948

SO6423/11-12 17th June 1949

SO6423/13 25th June 1952

SO6423/14-16 2nd July 1957

SO6423/17 1st July 1960

SO6423/18 24th June 1966

SO6423/19 1st August 1975

SO6423/20-21 4th August 1975

SO6423/23 25th June 1952

SO6423/24-25 4th August 1978

SO6424/1-3 20th June 1989

SO6425/1 4th August 1978

Vertical photographs

$106 \mathrm{G} / \mathrm{UK} / 1652$

2026-2030

3026-3030 11th July $1946 \quad 1: 10000$

$541 / 114$

4027-4031 28th July $1948 \quad 1: 10000$

$58 / 2113$

28-29

20th February 1957 1:10000

$58 / 5516$

87-89

17th October $1962 \quad 1: 10000$

OS66007

27-330

52-356 18th March 1956

\section{Herefordshire County Council SMR}

OBLIQUE PHOTOGRAPHS

DAG Aerial Survey 1989-19...?

Colour prints, films 20, 21, and 5, incorporating some display mounted enlargements.

\section{ADAS Cambridge}

VERTICAL PHOTOGRAPHS

$\begin{array}{llll}449 & 158-163 & \text { 9th April 1990 } & 1: 10000 \\ 497 & 38-45 & \text { 28th March 1991 } & 1: 8000 \\ 537 & 84-88 & \text { 15th May 1992 } & 1: 10000\end{array}$




\title{
Appendix 4. Detailed results from ADAS erosion survey
}

\author{
Tony Lloyd
}

\section{Period: 1989-90}

Field 1

Field observations

Slope $\quad 4-24^{\circ}$

Date of erosion 8-10 November 1989

Rainfall initiating erosion $\quad 44.8 \mathrm{~mm}$ over 3 days (max intensity: $7 \mathrm{~mm} / \mathrm{hr}$ )

Crop cover at time of erosion West side: Wheat after potatoes; ground cover $5 \%$

East side: Wheat after potatoes; ground cover $0 \%$

Cultivations prior to erosion West side: ploughed and drilled (with tramlines) up/down slope on 9/10/89 East side: ploughed and drilled 15/11/89

\section{Erosion event}

NATURE OF EROSION

1 large valley rill (up to $0.25 \mathrm{~m}$ deep) on $5^{\circ}$ slope and 80 valley side rills on slopes of $4-24^{\circ}$. (1\% of field affected). Estimated volume of soil lost $18.2 \mathrm{~m}^{3}$.

In addition to this, water from field 4 (and some from Field 3 ) entered this field and created a deep gulley $(200 \mathrm{~m}$ long, $0.5-3 \mathrm{~m}$ wide and $0.2-1.2 \mathrm{~m}$ deep). Estimated volume eroded from this gully was $66 \mathrm{~m}^{3}$.

NATURE OF DEPOSITION

Various fans at the base of slopes.
OFF-SITE EFFECTS

Flooding and soil deposition on neighbour's field.

REASON FOR EROSION

The deep valley rill was caused by compaction in wheelings which caused water to build up at the intersection of two slopes at the head of the steep valley in this field. This water gouged the deep rill down the valley and formed a 'lake' at the bottom. Overflow from this passed to a neighbour's field.

The smaller rills occurred because of steep slope, compaction by wheelings and lack of ground cover.

\section{Field 3}

\section{Field observations}

\section{Slope}

Crop cover over winter

Cultivations

\section{Up to $3^{\circ}$}

Sugar beet tops (100\% ground cover) until ploughed for wheat in early December ' 89 Ploughed and drilled (with tramlines) up/down slope in early December '89

\section{Erosion event}

No erosion occurred - although water ran off this field to Field 1 during November, no measurable amount of soil was transported because of crop cover. Following ploughing there was insufficient rain to cause erosion.

\section{Field 4}

Field observations

Slope

Crop cover at time of erosion

Cultivations during winter

$$
5-7^{\circ}
$$

Potatoes (during harvesting); subsequently cultivated on 17/11/89 for wheat Ploughed and drilled (with tramlines) up/down slope in early December ' 89

\section{Erosion event}

NATURE OF EROSION

Water and some soil (possibly $20 \mathrm{~m}^{3}$ ) ran off this field to Field 1 and created a deep gulley (see notes for Field 1).
OFF-SITE EFFECTS

Flooding and some soil deposition on the road.

REASON FOR EROSION

Compaction caused by late lifting of potatoes allowed run-off. 
Fields 2 and 6

Field observations

Slope $\quad$ Up to $18^{\circ}$ in field 2 and up to $12^{\circ}$ in Field 6

Erosion Event

No erosion occurred - wheat stubble left over winter $(100 \%$

ground cover) and land not cultivated until the spring.

Rainfall after that insufficient to cause erosion.

\section{Field 5}

\section{Field observations}

Slope

Crop cover over winter

Up to $3^{\circ}$

Cultivations over winter

Winter wheat after potatoes. 10\% ground cover in mid-November 1989

Ploughed and drilled (with tramlines) up/down slope in mid-late October 1989

\section{Erosion event}

No erosion occurred - although only light ground cover, the shallow slopes must have prevented erosion.

\section{Period: 1990-91}

\section{Field 1}

\section{Field observations}

Slope $\quad 7-24^{\circ}$

Date of erosion 24-30 October '90

Rainfall initiating erosion $\quad 51 \mathrm{~mm}$ over 7 days (max intensity: $5 \mathrm{~mm} /$ hour)

Crop cover at time of erosion Winter oilseed rape (following winter wheat)

Ground cover $\quad<5 \%$ - just germinated

Cultivations prior to erosion Ploughed across slope in early September; drilled (with tramlines) up/down slope and rolled in mid-September

\section{Erosion event}

NATURE OF EROSION

15 rills and estimated volume of soil eroded was $11.2 \mathrm{~m}^{3}$.

NATURE OF DEPOSITION

Surface wash and sediment in rills $\left(8.9 \mathrm{~m}^{3}\right.$ accounted for).

OFF-SITE EFFECTS

None.

REASON FOR EROSION EVENT

Accumulated rain causing rills in tramline wheelings; also water running along adjacent road and through hole in bank into field.

\section{Field 3}

Field observations

Slope $2-10^{\circ}$

\section{Erosion event}

No erosion occurred - wheat stubble left over winter and headlands and tramlines cultivated to relieve compaction. 


\section{Field 4}

\section{Field observations}

Slope $\quad 2^{\circ}$

Date of erosion 3-9 April 1991

Rainfall initiating erosion $\quad 35.8 \mathrm{~mm}$ ( $\max$ intensity $3.6 \mathrm{~mm} / \mathrm{hr}$ ) over 6 days

Crop cover at time of erosion Sugar beet after wheat. Ground cover 0\% (not emerged)

Cultivations prior to erosion Ploughed and drilled up/down slope in late March 1991

\section{Erosion event}

NATURE OF EROSION

2 rills $(<1 \%$ of field affected) on $2 \%$ slope. Estimated volume of soil eroded was $7 \mathrm{~m}^{3}$.

NATURE OF DEPOSITION

None deposited in field.

OFF-SITE EFFECTS

All soil deposited in road.

REASON FOR EROSION EVENT

After sugar beet was drilled, rain caused surface capping and run-off. This accumulated and ran down the headland wheelings into road where it was deposited.

\section{Field 10 north and south}

\section{Field observations}

Slope

Date of erosion

Rainfall initiating erosion

Crop cover at time of erosion

Cultivations prior to erosion $2-12^{\circ}$

24-30 October '90

$35.8 \mathrm{~mm}$ (max intensity $3.6 \mathrm{~mm} / \mathrm{hr}$ )

Wheat (after potatoes). Ground cover $0 \%$

Ploughed, drilled (with tramlines) in October '90

\section{Erosion event}

NATURE OF EROSION

226 rills, including 1 surface channel $2 \mathrm{~m}$ wide ( $80 \%$ of field affected). Estimated volume of soil eroded was $79 \mathrm{~m}^{3}$.

NATURE OF DEPOSITION

16 fans of various sizes, with an estimate of $42.5 \mathrm{~m}^{3}$ deposited.

\section{Period 1991-92}

\section{Field 1}

Field observations

Dates of erosion

$31 / 10 / 91$ to $3 / 11 / 91$ (event 1 )

$8 / 1 / 92$ to $9 / 1 / 92$ (event 2 )

Rainfall initiating erosion

$42.4 \mathrm{~mm}$ over 4 days (event 1 )

$74 \mathrm{~mm}$ over 2 days (event 2)

Crop cover over winter

Cultivations prior to erosion
OFF-SITE EFFECTS

Water and some soil went through hedge to a neighbour's field; this formed extensive gullies on the ploughed land down a $7^{\circ}$ slope.

REASON FOR EROSION EVENT

Little or no crop cover and steep slopes.

\section{Erosion event 1}

NATURE OF EROSION

228 rills (10\% of field affected) on area of $24 \%$ slope. These were approx. $40 \mathrm{~m}$ long, $0.05 \mathrm{~m}$ wide and $0.05 \mathrm{~m}$ deep. Estimated volume of soil eroded was $28.5 \mathrm{~m}^{3}$.

NATURE OF DEPOSITION

$10 \mathrm{~m}$ long washes of soil at base of steep slope but volume could not be measured.

\section{OFF-SITE EFFECTS}

None

REASON FOR EROSION EVENT

Accumulated rainfall from 28/9/91 to 16/11/91 (108mm) together with steep slopes and little ground cover. Sandstone at just below $1 \mathrm{~m}$ depth held water up in the soil profile and, when saturated, run-off occurred. 


\section{Erosion event 2}

NATURE OF EROSION

The rills recorded in event \#1 became 20\% larger plus a further large rill formed at the base of the valley. The additional amount of soil eroded was $9.9 \mathrm{~m}^{3}$. Thus the total amount eroded in both events was $38.4 \mathrm{~m}^{3}$.

NATURE OF DEPOSITION

Washes were noted at the base of each rill but volume could not be measured. There was also one fan of soil deposited down slope, covering an area of $36 \mathrm{~m}^{2}$ to a depth of $0.2 \mathrm{~m}$ (a volume of $0.72 \mathrm{~m}^{3}$ ).

OFF-SITE EFFECTS

None

REASON FOR EROSION EVENT

Further heavy rainfall and ground cover still low

\section{Field 2}

\section{Field observations}

Slope up to $12^{\circ}$

Erosion events

No erosion occurred - Sugar beet was harvested in early December 1991 and tops left on the soil surface $(90 \%$ cover) until ploughing for potatoes in February. There was insufficient rain to cause erosion then and potatoes were planted in mid-April 1992.

Fields 3, 7 and 8

Field observations

Slope

Crop cover over winter

up to $3 \%$

Winter wheat. Ground cover $0 \%$ in October ' $91,10 \%$ in December ' $91,30 \%$ by February '92

Cultivations

Ploughed across slope in early Oct '91 and drilled (with tramlines) up/down slope on $16 / 10 / 91$

\section{Erosion events}

No erosion occurred - although there was sufficient rainfall to cause erosion in Field 1, the slopes in these fields were not steep enough.

\section{Field 10}

\section{Field observations}

Slope

Dates of erosion

Rainfall initiating erosion

Crop cover over winter

Cultivations $7-12^{\circ}$

$28 / 5 / 92-1 / 6 / 92$

$22 \mathrm{~mm}$ over 4 days (max. intensity $4.4 \mathrm{~mm} /$ hour)

Wheat stubble (100\% cover) until February '92 when land was ploughed for sugar beet. At time of erosion event sugar beet leaves gave a $90 \%$ surface cover

Ploughed up/down slope in late March '92 and drilled up/down in late April '92. Tramlines placed across slope at right angles to sugar beet rows

\section{Erosion event}

NATURE OF EROSION

8 rills in sugar beet crop but volume could not be measured

- however assessed from deposition measurements.

NATURE OF DEPOSITION

6 wheelings with sediment washed into them, one fan and some deposition into a ditch. Estimated volume was $34.6 \mathrm{~m}^{3}$.

\section{OFF-SITE EFFECTS}

None.

REASON FOR EROSION EVENT

Rainfall and a capped soil surface led to run-off, despite the $90 \%$ ground cover. Tramlines at right angles to the sugar beet rows broke the slopes up into $24 \mathrm{~m}$ increments - but this only prevented run-off on slopes less than $7^{\circ}$. 


\section{Period 1992-93}

\section{Field 1}

\section{Field observations}

Slope

Crop cover over winter

Cultivations

up to $24^{\circ}$

Wheat stubble until mid-March '93; then planted with potatoes

For potatoes: ploughed across slope on 15/3/93 then potatoes planted up/down slope

\section{Erosion events} on $5 / 4 / 93$

No erosion occurred - wheat stubble prevented any erosion.

\section{Field 2}

\section{Field observations}

Slope

Dates of erosion

Rainfall initiating erosion

Crop cover over winter

Cultivations

\section{Erosion event 1}

NATURE OF EROSION

30 rills ( $30 \%$ of field affected) on $7^{\circ}$ slope, eroding $6 \mathrm{~m}^{3}$ of soil.

NATURE OF DEPOSITION

Not deposited in field.

OFF-SITE EFFECTS

Soil washed into ditch.

REASON FOR EROSION EVENT

Accumulated rainfall in shallow soil over sandstone rock. The profile quickly became saturated and with no ground cover, run-off occurred. $7^{\circ}$

$24 / 11 / 92$ to $25 / 11 / 92$ (event 1 )

$13 / 1 / 93$ (event 2)

$30.4 \mathrm{~mm}$ over 2 (event 1$)$

$24.4 \mathrm{~mm}$ in one day (event 2)

Winter wheat (after potatoes). Ground cover from wheat: $0 \%$ in December '92 and 10\% by February '93

Ploughed across slope and drilled (with tramlines) in early December '92

\section{Erosion event 2}

NATURE OF EROSION

255 small rills affecting $50 \%$ of the field. The volume eroded at this event was $21.2 \mathrm{~m}^{3}$; thus the total volume eroded for both events was $27.2 \mathrm{~m}^{3}$.

NATURE OF DEPOSITION

Approx. $10.8 \mathrm{~m}^{3}$ of soil was deposited down slope in the field.

OFF-SITE EFFECTS

Balance of soil, not deposited in the field, was washed into the stream.

REASON FOR EROSION EVENT

As for Erosion event 1 - accumulated rainfall in shallow soil over sandstone rock. The profile quickly became saturated and with no ground cover, run-off occurred.

\section{Field 6}

\section{Field observations}

Slope $10^{\circ}$

Dates of erosion $24 / 11 / 92$ to $25 / 11 / 92$ (event 1 ) 13/1/93 (event 2)

Rainfall initiating erosion $30.4 \mathrm{~mm}$ over 2 days (event 1 )

Crop cover over winter $24.4 \mathrm{~mm}$ in one day (event 2)

Cultivations Winter wheat (after potatoes). Ground cover from wheat: 0\% in December '92 and $10 \%$ by February ' 93

\section{Erosion event 1}

NATURE OF EROSION

7 large rills (up to $0.5 \mathrm{~m}$ wide and $0.3 \mathrm{~m}$ deep) affecting $15 \%$ of the field. Volume of soil eroded $8.6 \mathrm{~m}^{3}$.

Ploughed across slope and drilled (with tramlines) in early December '92

NATURE OF DEPOSITION

Not deposited in field.

OFF-SITE EFFECTS

All soil washed into the stream. 
REASON FOR EROSION EVENT

Accumulated rainfall in shallow soil over sandstone rock. The profile quickly became saturated and with no ground cover, run-off occurred

\section{Erosion event 2}

NATURE OF EROSION

7 rills (one being $0.75 \mathrm{~m}$ wide) with $11 \mathrm{~m}^{3}$ soil eroded. Thus the total volume of soil lost in the two events was $19.6 \mathrm{~m}^{3}$.
NATURE OF DEPOSITION

None deposited on the field.

OFF-SITE EFFECTS

All soil was washed into the stream.

REASON FOR EROSION EVENT

As for Erosion event 1 - accumulated rainfall in shallow soil over sandstone rock. The profile quickly became saturated and with no ground cover, run-off occurred.
Fields 3, 4, 5, 7 and 8

Field observations

Slopes

$3-10^{\circ}$

\section{Erosion events}

No erosion occurred - these were all fields where wheat stubble remained until March '93. Then they were cultivated for peas, potatoes or sugar beet. However there was insufficient rain after cultivations to cause erosion.

\section{Field 10}

\section{Field observations}

Slope $\quad 3^{\circ}$

\section{Erosion events}

No erosion occurred - sugar beet was harvested in December 1992 (thus 100\% cover until then) and the land was cultivated for wheat on 25/1/93. There was insufficient rain after that for erosion to occur.

\section{Period 1993-94}

Field 1

\section{Field observations}

Slope $\quad 7-24^{\circ}$

Dates of erosion $\quad 10 / 10 / 93$ to $13 / 10 / 93$ (event 1 )

$\begin{array}{ll} & 13 / 1 / 94 \text { (event } 2 \text { ) } \\ \text { Rainfall initiating erosion } & 53.8 \mathrm{~mm} \text { over } 4 \text { days (event } 1 \text { ) }\end{array}$

$29.4 \mathrm{~mm}$ over previous week (event 2)

Crop cover over winter Winter wheat (after potatoes). Ground cover: $0 \%$ in October ' 93 and 10\% by February '94

Cultivations

Ploughed and drilled (with tramlines) up/down slope in late September/early October '93

\section{Erosion event 1}

NATURE OF EROSION

210 rills affecting $80 \%$ of the field. Volume of soil eroded $78.7 \mathrm{~m}^{3}$.

NATURE OF DEPOSITION

One fan $\left(740 \mathrm{~m}^{2}\right)$ deposited in field with volume of soil being $74 \mathrm{~m}^{3}$.

OFF-Site EFFECTS

Balance of soil washed into neighbour's field.

REASON FOR EROSION EVENT

Accumulated rainfall, steep slopes and little ground cover. One large rill acted as a drain, channelling water from the road to a 'lake' in the field.

\section{Erosion event 2}

NATURE OF EROSION

Existing rills (from event 1) eroded a further $52 \mathrm{~m}^{3}$ of soil. Thus a total of $130.8 \mathrm{~m}^{3}$ was lost during both events.

NATURE OF DEPOSITION

The deposition fan from event 1 grew in size with a further $13.5 \mathrm{~m}^{3}$ being deposited. Thus a total of $87.5 \mathrm{~m}^{3}$ was deposited in the field from both erosion events.

OFF-SITE EFFECTS

Further soil was washed into the neighbour's field.

REASON FOR EROSION EVENT

As for Erosion event 1 - accumulated rainfall, steep slopes and little ground cover. One large rill acted as a drain, channelling water from the road to a 'lake' in the field. 
Field 3

\section{Field observations}

Slope $\quad 3^{\circ}$

Crop cover over winter $\quad$ Winter wheat (after peas). Ground cover: $0 \%$ in October '93 and 10\% by February '94

Cultivations

Ploughed and drilled across slope in late September/ early October '93. Tramlines inserted up/down slope in February '94

\section{Erosion events}

No erosion occurred - although little crop cover (during periods when rainfall caused erosion in Field 1), the slope was insufficient. Also there were no tramlines present to channel water down slope during the wet period.

\section{Field 4}

\section{Field observations}

Slope

Crop cover over winter

$3^{\circ}$

Cultivations

Winter wheat (after potatoes). Ground cover: $0 \%$ in October ' 93 and $<5 \%$ in December '93

Ploughed and drilled up/down slope in late October/ early November '93. Tramlines inserted up/down slope in March '94

\section{Erosion events}

No erosion occurred - although little crop cover (during periods when rainfall caused erosion in Field 1), the slope was insufficient. Also there were no tramlines present to channel water down slope during the wet period.

\section{Fields 2, 6 and 10}

\section{Field observations}

Slope

\section{Erosion events}

No erosion occurred - wheat stubble remained until ploughed out in March 1994 for sugar beet (in Fields 2 and 6) and potatoes (in Field 10). There was insufficient rain after that to cause erosion.

\section{Fields 7 and 8}

\section{Field observations}

Slope $3^{\circ}$

Crop cover over winter Winter wheat (after sugar beet). Ground cover: 100\% in October '93 (sugar beet) but

Cultivations $0 \%$ in December '93 and $15 \%$ in February '94 (wheat)

\section{Erosion events}

No erosion occurred - there was $100 \%$ ground cover during the first period of heavy rain in October ' 93 and there was insufficient rain on the fairly shallow slopes to initiate erosion from the second period of fairly heavy rain in January '94. 


\section{Appendix 5. Concordance of pottery fabric codes used in the report with WAS fabric series codes \\ (Rees and Hurst 1992; Hurst 1999)}

\begin{tabular}{|c|c|c|}
\hline $\begin{array}{l}\text { Fabric code in } \\
\text { present report }\end{array}$ & Common/conventional name or source & $\begin{array}{l}\text { WCC Archaeological Service } \\
\text { fabric series code }\end{array}$ \\
\hline \multicolumn{3}{|l|}{ Amphorae } \\
\hline A11 & $\begin{array}{l}\text { Baetican amphora fabric, principally assoc. } \\
\text { with the Dressel } 20 \text { form, but also used to } \\
\text { produce the Haltern } 70\end{array}$ & Fabric 42.1 \\
\hline A12 & $\begin{array}{l}\text { Southern Spanish amphora fabric, possibly } \\
\text { from the Cadiz region }\end{array}$ & Fabric 42.5 \\
\hline A13 & $\begin{array}{l}\text { Amphora fabric, probably South Gaulish and } \\
\text { assoc. with the Gauloise 4/Pélichet } 47 \text { form }\end{array}$ & Fabric 42.3 \\
\hline \multicolumn{3}{|c|}{ Black Burnished wares } \\
\hline B11 & \begin{tabular}{l|l} 
Black Burnished ware 1 (SE Dorset) \\
\end{tabular} & Fabric 22 \\
\hline \multicolumn{3}{|c|}{ Heavily calcareous tempered wares } \\
\hline $\mathrm{C} 11$ & \begin{tabular}{l|l} 
Palaeozoic limestone tempered ware \\
\end{tabular} & Fabric 4.1 \\
\hline \multicolumn{3}{|l|}{ Finer fabrics } \\
\hline F11 & Oxfordshire red/brown colour coated ware & Fabric 29 \\
\hline F13 & Central Gaulish black slipped ware & CF. Fabric 44 \\
\hline F15 & Lower Rhineland (Cologne) colour-coated ware & CF. Fabric 45 \\
\hline F16 & Central Gaulish black slipped ware, grey fabric & CF. Fabric 44 \\
\hline F17 & Nene Valley colour-coated ware & Fabric 28 \\
\hline F18 & Central Gaulish glazed ware & Fabric 102 \\
\hline F19 & North Gaulish sandy white ware & Not represented \\
\hline F20 & North Gaulish Terra Nigra & Fabric 25 \\
\hline $\mathrm{F} 21$ & $\begin{array}{l}\text { Local fine greyware, with burnished (dark) } \\
\text { surface; an emulation of F20? }\end{array}$ & Not represented \\
\hline F22 & $\begin{array}{l}\text { Oxfordshire Brown colour-coated ware, dark } \\
\text { brown variant of F11 }\end{array}$ & Fabric 29 \\
\hline F23 & $\begin{array}{l}\text { Pale brown/buff fine fabric, probably an early } \\
\text { Severn Valley ware variant }\end{array}$ & Subsumed under Fabric 12 \\
\hline \multicolumn{3}{|c|}{ Heavily tempered Roman fabrics (handmade) } \\
\hline G11 & Malvernian metamorphic ware & Fabric 3 \\
\hline \multicolumn{3}{|c|}{ Mortaria fabrics } \\
\hline M01 & North Gaulish (Noyon) mortarium fabric & Fabric 36 \\
\hline M10 & Verulamium Region white ware mortarium fabric & Fabric 35 \\
\hline M21 & Oxfordshire parchment ware mortarium fabric & Fabric 40 \\
\hline M22 & $\begin{array}{l}\text { Oxfordshire white colour-coated ware mortarium } \\
\text { fabric }\end{array}$ & Fabric 30 \\
\hline M23 & $\begin{array}{l}\text { Oxfordshire red/brown colour-coated ware } \\
\text { mortarium fabric }\end{array}$ & Fabric 29 \\
\hline M25 & Oxfordshire white ware mortarium fabric & Fabric 38 \\
\hline M30 & Mancetter-Hartshill mortarium fabric & Fabric 32 \\
\hline M40 & Caerleon ware mortarium fabric & Fabric 110 \\
\hline M50 & $\begin{array}{l}\text { Mortarium fabric, probably from } \\
\text { Cotswolds/Gloucester area }\end{array}$ & Not represented \\
\hline \multicolumn{3}{|c|}{ Oxidized fabrics (Severn Valley ware) } \\
\hline $\mathrm{O} 10$ & Oxidized Severn Valley ware, general category & Fabric 12 \\
\hline $\mathrm{O} 11$ & Oxidized Severn Valley ware variant & Subsumed under fabric 12 \\
\hline $\mathrm{O} 12$ & Oxidized Severn Valley ware variant & Subsumed under fabric 12 \\
\hline $\mathrm{O} 13$ & Oxidized Severn Valley ware variant & Subsumed under fabric 12 \\
\hline $\mathrm{O} 14$ & Oxidized Severn Valley ware variant & Subsumed under fabric 12 \\
\hline $\mathrm{O} 15$ & Oxidized Severn Valley ware variant & Subsumed under fabric 12 \\
\hline O16 & Oxidized Severn Valley ware variant & Subsumed under fabric 12 \\
\hline $\mathrm{O} 17$ & Oxidized Severn Valley ware variant & Subsumed under fabric 12 \\
\hline $\mathrm{O} 18$ & Oxidized Severn Valley ware variant & Subsumed under fabric 12 \\
\hline O19 & Oxidized Severn Valley ware variant & Subsumed under fabric 12 \\
\hline $\mathrm{O} 20$ & Oxidized Severn Valley ware variant & Subsumed under fabric 12 \\
\hline $\mathrm{O} 21$ & Oxidized Severn Valley ware variant & Subsumed under fabric 12 \\
\hline $\mathrm{O} 22$ & Oxidized Severn Valley ware variant & Subsumed under fabric 12 \\
\hline $\mathrm{O} 23$ & Oxidized Severn Valley ware variant & Subsumed under fabric 12 \\
\hline
\end{tabular}


Appendix 5 continued

\begin{tabular}{|c|c|c|}
\hline $\begin{array}{l}\text { Fabric code in } \\
\text { present report }\end{array}$ & Common/conventional name or source & $\begin{array}{l}\text { WCC Archaeological Service } \\
\text { fabric series code }\end{array}$ \\
\hline $\mathrm{O} 24$ & Oxidized Severn Valley ware variant & Subsumed under fabric 12 \\
\hline \multicolumn{3}{|c|}{ Oxidized fabrics (Oxfordshire wares) } \\
\hline $\mathrm{O} 30$ & $\begin{array}{l}\text { Oxfordshire coarse white ware variant (with } \\
\text { translucent quartz) }\end{array}$ & Subsumed under fabric 38 \\
\hline $\mathrm{O} 31$ & Oxfordshire coarse white ware & Subsumed under fabric 38 \\
\hline $\mathrm{O} 32$ & Oxfordshire white colour-coated ware & Fabric 30 \\
\hline $\mathrm{O} 34$ & Oxfordshire parchment ware & Fabric 40 \\
\hline $\mathrm{O} 35$ & Oxfordshire fine white ware & Subsumed under fabric 38 \\
\hline $\mathrm{O} 36$ & Oxfordshire coarse red ware & Not represented \\
\hline $\mathrm{O} 37$ & $\begin{array}{l}\text { Oxfordshire white colour-coated ware type or } \\
\text { possibly a Severn Valley ware variant (Red } \\
\text { fabric, cream slip) }\end{array}$ & Not represented \\
\hline \multicolumn{3}{|c|}{ Other oxidized fabrics } \\
\hline $\mathrm{O} 38$ & ? early Severn Valley ware variant & Subsumed under fabric 12 \\
\hline \multicolumn{3}{|l|}{$\begin{array}{l}\text { Unoxidized } \\
\text { fabrics: }\end{array}$} \\
\hline $\mathrm{R} 20$ & Unoxidized 'coarse' Severn Valley ware variant & Subsumed under fabric $12 \mathrm{R}$ \\
\hline R21 & Unoxidized 'fine' Severn Valley ware variant & Subsumed under fabric $12 \mathrm{R}$ \\
\hline $\mathrm{R} 22$ & Unoxidized Severn Valley ware variant & Subsumed under fabric $12 \mathrm{R}$ \\
\hline $\mathrm{R} 23$ & Gritty micaceous grey ware & Not represented \\
\hline $\mathrm{R} 24$ & $\begin{array}{l}\text { Unoxidized 'fine' fabric, possibly a Severn } \\
\text { Valley ware variant }\end{array}$ & ? Subsumed under fabric $12 \mathrm{R}$ \\
\hline R25 & Coarse fabric with grey-brown surfaces & CF. fabric 8 \\
\hline R26 & $\begin{array}{l}\text { Distinctive coarse unoxidized ware, with } \\
\text { burnished surfaces }\end{array}$ & $\begin{array}{l}\text { Some similarity to fabrics } 7,8 \\
\text { and } 12.3\end{array}$ \\
\hline R27 & Fine unoxidized fabric with pale grey surfaces & Not represented \\
\hline R28 & $\begin{array}{l}\text { Unoxidized fabric with fine quartz and } \\
\text { sandstone/siltstone inclusions }\end{array}$ & Fabric 7 \\
\hline R29 & $\begin{array}{l}\text { Distinctive coarse unoxidized ware, with } \\
\text { burnished surfaces }\end{array}$ & CF. fabric 8 \\
\hline R30 & $\begin{array}{l}\text { Unoxidized finer ware with smooth or } \\
\text { burnished surfaces }\end{array}$ & CF. fabric 8 \\
\hline R31 & $\begin{array}{l}\text { Unoxidized coarse fabric with fine-grained } \\
\text { sandstone/siltstone inclusions, similar to } \\
\text { R26/R29 }\end{array}$ & CF. fabric 8 \\
\hline R32 & $\begin{array}{l}\text { Unoxidized coarse fabric, with quartz grain } \\
\text { temper; can be highly burnished. }\end{array}$ & CF. fabric 8 \\
\hline R33 & Pale grey coarse fabric & ? Subsumed under fabric $12 \mathrm{R}$ \\
\hline R34 & $\begin{array}{l}\text { Distinctive unoxidized coarse ware with } \\
\text { abundant inclusions }\end{array}$ & Some similarity to fabric 12.3 \\
\hline \multicolumn{3}{|l|}{ Samian fabrics } \\
\hline S01 & $\begin{array}{l}\text { South Gaulish Samian - } \\
\text { La Graufesenque }\end{array}$ & Subsumed under fabric 43 \\
\hline S02 & $\begin{array}{l}\text { Central Gaulish Samian - } \\
\text { Les Martres-de-Veyre }\end{array}$ & Subsumed under fabric 43 \\
\hline S03 & Central Gaulish Samian - Lezoux & Subsumed under fabric 43 \\
\hline S04 & East Gaulish Samian & Subsumed under fabric 43 \\
\hline S05 & East Gaulish Samian - Trier & Subsumed under fabric 43 \\
\hline S06 & East Gaulish Samian - Rheinzabern & Subsumed under fabric 43 \\
\hline S07 & East Gaulish Samian - Argonne & Subsumed under fabric 43 \\
\hline S08 & South Gaulish Samian - Montans & Subsumed under fabric 43 \\
\hline
\end{tabular}




\section{Appendix 6. List of the illustrated pottery from the analytical groups}

(by form and fabric - fuller details are recorded in the catalogue of Illustrated Pottery accompanying Figures 4.1-4.19)

\section{Analytical Group 1}

\begin{tabular}{|l|l|l|}
\hline Fabric & Form & Drawing number \\
\hline C11 & Jar & Fig. 4.2 no. 7 \\
\hline C11 & Jar & Fig. 4.2 no. 8 \\
\hline C11 & Jar & Fig. 4.2 no. 10 \\
\hline C11 & Very large bowl & Fig. 4.3 no. 10 \\
\hline O12 & Jar & Fig. 4.8 no. 3 \\
\hline O15 & Dish & Fig. 4.10 no. 13 \\
\hline O16 & Beaker & Fig. 4.11 no. 2 \\
\hline O17 & Bowl & Fig. 4.12 no. 4 \\
\hline R20 & Storage jar & Fig. 4.16 no. 1 \\
\hline R21 & Jar & Fig. 4.17 no. 3 \\
\hline R21 & Beaker & Fig. 4.17 no. 19 \\
\hline R27 & Beaker & Fig. 4.18 no. 1 \\
\hline S01 & Bowl & Fig. 4.19 no. 2 \\
\hline
\end{tabular}

\section{Analytical Group 2}

\begin{tabular}{|l|l|l|}
\hline Fabric & Form & Drawing number \\
\hline C11 & Lid & Fig. 4.3 no. 14 \\
\hline O17 & Bowl & Fig. 4.12 no. 3 \\
\hline R28 & Jar & Fig. 4.18 no. 3 \\
\hline S01 & Bowl & Fig. 4.19 no. 6 \\
\hline
\end{tabular}

\section{Analytical Group 3}

\begin{tabular}{|l|l|l|}
\hline Fabric & Form & Drawing number \\
\hline \multicolumn{2}{|l|}{ BI Context $2 a$} & Fig. 4.2 no. 9 \\
\hline C11 & Jar & Fig. 4.2 no. 11 \\
\hline C11 & Jar & Fig. 4.2 no. 12 \\
\hline C11 & Jar & Fig. 4.2 no. 15 \\
\hline C11 & Jar & Fig. 4.3 no. 5 \\
\hline C11 & Cup & Fig. 4.4 no. 10 \\
\hline F20 & Bowl & Fig. 4.8 no. 11 \\
\hline O11 & Bowl & Fig. 4.9 no. 3 \\
\hline O14 & Jar & Fig. 4.9 no. 4 \\
\hline O14 & Jar & Fig. 4.11 no. 7 \\
\hline O16 & Tankard & Fig. 4.17 no. 30 \\
\hline R26 & Bowl & Fig. 4.18 no. 9 \\
\hline R29 & Bowl & Fig. 4.18 no. 10 \\
\hline R29 & Bowl & Fig. 4.18 no. 14 \\
\hline R30 & Beaker & Fig. 4.18 no. 17 \\
\hline R31 & Cup & Fig. 4.2 no. 6 \\
\hline BI Context $2 b$ & Jar & Fig. 4.2 no. 13 \\
\hline C11 & Jar & Fig. 4.2 no. 20 \\
\hline C11 & Storage jar & Fig. 4.2 no. 23 \\
\hline C11 & Storage jar & Fig. 4.18 no. 11 \\
\hline C11 & Fig. 4.18 no. 12 \\
\hline R29 & Bowl & Fig. 4.18 no. 13 \\
\hline R29 & Bowl & Fig. 4.18 no. 16 \\
\hline R30 & Butt Beaker & Fig. 4.3 no. 2 \\
\hline R30 & Bowl & Fig. 4.18 no. 4 \\
\hline BII context 2 & Fig. 4.18 no. 15 \\
\hline C11 & Storage jar \\
\hline R28 & Beaker & \\
\hline R30 & Bowl & \\
\hline & & \\
\hline & & \\
\hline
\end{tabular}

\begin{tabular}{|l|l|l|}
\hline Fabric & Form & Drawing number \\
\hline BII context 3 & Fig. 4.2 no. 5 \\
\hline C11 & Jar & Fig. 4.2 no. 14 \\
\hline C11 & Jar & \multicolumn{2}{|l|}{} \\
\hline BIII context 2 & Fig. 4.3 no. 3 \\
\hline C11 & Storage jar & Fig. 4.3 no. 8 \\
\hline C11 & Bowl & Fig. 4.17 no. 5 \\
\hline R21 & Bowl & Fig. 4.18 no. 7 \\
\hline R29 & Jar &
\end{tabular}

\section{Analytical Group 4}

\begin{tabular}{|c|c|c|}
\hline Fabric & Form & Drawing number \\
\hline B11 & Jar & Fig. 4.1 no. 1 \\
\hline $\mathrm{C} 11$ & Very large bowl & Fig. 4.3 no. 11 \\
\hline $\mathrm{C} 11$ & Very large bowl & Fig. 4.3 no. 12 \\
\hline F18 & Beaker & Fig. 4.4 no. 6 \\
\hline F19 & Beaker & Fig. 4.4 no. 8 \\
\hline M25 & Mortarium & Fig. 4.7 no. 3 \\
\hline O11 & Jar & Fig. 4.8 no. 2 \\
\hline $\mathrm{O} 11$ & Bowl & Fig. 4.8 no. 12 \\
\hline $\mathrm{O} 12$ & Beaker & Fig. 4.8 no. 19 \\
\hline O14 & Flagon & Fig. 4.9 no. 2 \\
\hline O14 & Beaker or Bowl & Fig. 4.9 no. 10 \\
\hline $\mathrm{O} 14$ & Beaker & Fig. 4.9 no. 11 \\
\hline $\mathrm{O} 14$ & Bowl & Fig. 4.9 no. 17 \\
\hline $\mathrm{O} 14$ & Dish & Fig. 4.9 no. 23 \\
\hline O14 & Dish & Fig. 4.9 no. 24 \\
\hline O14 & Dish & Fig. 4.9 no. 26 \\
\hline O15 & Beaker & Fig. 4.10 no. 8 \\
\hline O15 & Jar/Bowl & Fig. 4.10 no. 9 \\
\hline O15 & Bowl & Fig. 4.10 no. 10 \\
\hline O16 & Beaker & Fig. 4.11 no. 4 \\
\hline O16 & Bowl & Fig. 4.11 no. 10 \\
\hline O16 & Bowl (or Cup) & Fig. 4.11 no. 14 \\
\hline O16 & Dish & Fig. 4.11 no. 15 \\
\hline O18 & Storage jar & Fig. 4.13 no. 5 \\
\hline $\mathrm{O} 23$ & Bowl & Fig. 4.15 no. 1 \\
\hline O36 & Bowl & Fig. 4.15 no. 5 \\
\hline R20 & Storage jar & Fig. 4.16 no. 2 \\
\hline $\mathrm{R} 20$ & Storage jar & Fig. 4.16 no. 3 \\
\hline R21 & Jar & Fig. 4.17 no. 1 \\
\hline R21 & Jar & Fig. 4.17 no. 2 \\
\hline R21 & Beaker & Fig. 4.17 no. 17 \\
\hline R21 & Beaker & Fig. 4.17 no. 18 \\
\hline R21 & Bowl & Fig. 4.17 no. 22 \\
\hline R21 & Bowl & Fig. 4.17 no. 23 \\
\hline $\mathrm{R} 28$ & Jar & Fig. 4.18 no. 2 \\
\hline R29 & Jar & Fig. 4.18 no. 5 \\
\hline R29 & Jar & Fig. 4.18 no. 6 \\
\hline S02 & Bowl & Fig. 4.19 no. 11 \\
\hline S02 & Dish & Fig. 4.19 no. 13 \\
\hline
\end{tabular}




\section{Analytical Group 5}

\begin{tabular}{|l|l|l|}
\hline Fabric & Form & Drawing number \\
\hline O12 & Beaker & Fig. 4.8 no. 20 \\
\hline O15 & Jar & Fig. 4.10 no. 2 \\
\hline R21 & Jar & Fig. 4.17 no. 10 \\
\hline R21 & Jar & Fig. 4.17 no. 13 \\
\hline S03 & Bowl & Fig. 4.19 no. 17 \\
\hline
\end{tabular}

\section{Analytical Group 6}

\begin{tabular}{|l|l|l|}
\hline Fabric & Form & Drawing number \\
\hline B11 & Jar & Fig. 4.1 no. 3 \\
\hline B11 & Jar & Fig. 4.1 no. 6 \\
\hline B11 & Bowl & Fig. 4.1 no. 13 \\
\hline B11 & Dish & Fig. 4.1 no. 24 \\
\hline F15 & Beaker & Fig. 4.4 no. 5 \\
\hline M25 & Mortarium & Fig. 4.7 no. 4 \\
\hline O11 & Jar & Fig. 4.8 no. 3 \\
\hline O11 & Bowl & Fig. 4.8 no. 10 \\
\hline O13 & Jar & Fig. 4.8 no. 23 \\
\hline O13 & Tankard & Fig. 4.8 no. 24 \\
\hline O15 & Storage jar & Fig. 4.10 no. 5 \\
\hline O15 & Storage jar & Fig. 4.10 no. 6 \\
\hline R20 & Jar & Fig. 4.16 no. 6 \\
\hline R20 & Storage jar & Fig. 4.16 no. 5 \\
\hline R21 & Jar & Fig. 4.17 no. 4 \\
\hline R21 & Jar & Fig. 4.17 no. 9 \\
\hline R21 & Jar & Fig. 4.17 no. 11 \\
\hline R21 & Jar & Fig. 4.17 no. 12 \\
\hline R21 & Jar & Fig. 4.17 no. 14 \\
\hline
\end{tabular}

\section{Analytical Group 7}

\begin{tabular}{|l|l|l|}
\hline Fabric & Form & Drawing number \\
\hline B11 & Jar & Fig. 4.1 no. 4 \\
\hline B11 & Jar & Fig. 4.1 no. 5 \\
\hline B11 & Jar & Fig. 4.1 no. 8 \\
\hline B11 & Jar & Fig. 4.1 no. 9 \\
\hline B11 & Bowl & Fig. 4.1 no. 12 \\
\hline B11 & Dish & Fig. 4.1 no. 20 \\
\hline B11 & Dish & Fig. 4.1 no. 21 \\
\hline B11 & Dish & Fig. 4.1 no. 22 \\
\hline B11 & Dish & Fig. 4.1 no. 23 \\
\hline F11 & Bowl & Fig. 4.4 no. 1 \\
\hline F13 & Beaker & Fig. 4.4 no. 4 \\
\hline G11 & Jar & Fig. 4.5 no. 1 \\
\hline M10 & Mortarium & Fig. 4.6 no. 4 \\
\hline M25 & Mortarium & Fig. 4.7 no. 6 \\
\hline O11 & Jar & Fig. 4.8 no. 1 \\
\hline O11 & Tankard & Fig. 4.8 no. 8 \\
\hline O11 & Tankard & Fig. 4.8 no. 9 \\
\hline O12 & Jar & Fig. 4.8 no. 14 \\
\hline O12 & Jar & Fig. 4.8 no. 15 \\
\hline O12 & Storage jar & Fig. 4.8 no. 16 \\
\hline O12 & Jar or Bowl & Fig. 4.8 no. 17 \\
\hline O12 & Tankard & Fig. 4.8 no. 21 \\
\hline O14 & Flagon & Fig. 4.9 no. 1 \\
\hline O14 & Storage jar & Fig. 4.9 no. 5 \\
\hline O14 & Jar & Fig. 4.9 no. 7 \\
\hline O14 & Tankard & Fig. 4.9 no. 13 \\
\hline O14 & Tankard & Fig. 4.9 no. 14 \\
\hline O14 & Tankard & Fig. 4.9 no. 15 \\
\hline
\end{tabular}

\begin{tabular}{|l|l|l|}
\hline Fabric & Form & Drawing number \\
\hline O14 & Bowl or Dish & Fig. 4.9 no. 20 \\
\hline O14 & Bowl & Fig. 4.9 no. 21 \\
\hline O14 & Dish & Fig. 4.9 no. 22 \\
\hline O14 & Dish & Fig. 4.9 no. 25 \\
\hline O15 & Jar & Fig. 4.10 no. 1 \\
\hline O15 & Storage jar & Fig. 4.10 no. 3 \\
\hline O15 & Storage jar & Fig. 4.10 no. 4 \\
\hline O15 & Bowl & Fig. 4.10 no. 12 \\
\hline O16 & Tankard & Fig. 4.11 no. 6 \\
\hline O16 & Tankard & Fig. 4.11 no. 7 \\
\hline O17 & Jar & Fig. 4.12 no. 1 \\
\hline O17 & Jar & Fig. 4.12 no. 2 \\
\hline O18 & Storage jar & Fig. 4.13 no. 3 \\
\hline O18 & Bowl & Fig. 4.13 no. 6 \\
\hline O18 & Dish & Fig. 4.13 no. 8 \\
\hline O19 & Bowl & Fig. 4.14 no. 2 \\
\hline O24 & Beaker & Fig. 4.15 no. 3 \\
\hline R21 & Jar & Fig. 4.17 no. 6 \\
\hline R21 & Jar & Fig. 4.17 no. 8 \\
\hline R21 & Jar & Fig. 4.17 no. 15 \\
\hline R21 & Dish & Fig. 4.17 no. 25 \\
\hline R21 & Dish & Fig. 4.17 no. 26 \\
\hline
\end{tabular}

\section{Analytical Group 8}

\begin{tabular}{|l|l|l|}
\hline Fabric & Form & Drawing number \\
\hline F11 & Bowl & Fig. 4.4 no. 2 \\
\hline O23 & Beaker & Fig. 4.15 no. 2 \\
\hline R20 & Flagon & Fig. 4.16 no. 7 \\
\hline
\end{tabular}

\section{Analytical Group 9}

\begin{tabular}{|l|l|l|}
\hline Fabric & Form & Drawing number \\
\hline B11 & Bowl & Fig. 4.1 no. 19 \\
\hline O14 & Cup & Fig. 4.9 no. 12 \\
\hline O14 & Bowl & Fig. 4.9 no. 16 \\
\hline O16 & Bowl & Fig. 4.11 no. 9 \\
\hline R21 & Jar & Fig. 4.17 no. 7 \\
\hline R26 & Beaker & Fig. 4.17 no. 27 \\
\hline
\end{tabular}




\section{Appendix 7. Samian Catalogue}

\section{Samian pottery from Bridgewater's excavations 1963}

All Areas, Context 1: Analytical Group 7.

(Where the specific area within Bridgewater's trench is known, this is noted)

Rim, SG La Graufesenque, Drag. 18, RE 0.05, c. AD 55-80. 1 rivet hole with rivet in situ

Base, CG Lezoux, Drag. 18/31, c. AD 120-150. Area B

Base, CG Lezoux, Drag. 18/31, c. AD 120-150. Burnt. Area C

Rim, CG Lezoux, Drag. 33, RE 0.08, c. AD 120-160

Base, CG Lezoux, bowl, c. AD 120-200. Area A

Base, CG Lezoux, bowl or dish, c. AD 120-200

Rim, CG Lezoux, bowl or dish, RE 0.03, c. AD 120-200. Burnt

Body, CG Lezoux, form not identifiable, c. AD 120-200. Area C

Body, CG Lezoux, form not identifiable, c. AD 120-200. Different vessel; Area C

Base, CG Lezoux, bowl, c. AD 140-200. Burnt

Rim, CG Lezoux, bowl or dish, RE 0.04, c. AD 140-200

Rim, CG Lezoux, Drag. 33, RE 0.15, c. AD 140-200

Rim, CG Lezoux, Drag. 15/31, RE: 0.06, c. AD 150-180. Area C

Base, CG Lezoux, Drag. 31, c. AD 150-200

Base, CG Lezoux, Drag. 31, c. AD 150-200. Different vessel from the item above

Rim, CG Lezoux, Drag. 31 or 31R, RE: 0.12, c. AD 150-200

Rim, EG, Drag. 31 or 31R, RE: 0.04, c. AD 150-225/250. Area B

\section{All Areas, Context 2: Analytical Group 6}

(Where the specific area within Bridgewater's trench is known, this is noted)

2 conjoining base sherds, CG Les Martres, Drag. 18/31, c. AD 100-130. Area A

Rim, CG, Lezoux, probably Drag. 18/31R, RE: 0.05, c. AD 120-150. Area D

Rim, CG Lezoux, Drag. 33, RE: 0.08, c. AD 120-200. Area C

Rim, CG Lezoux, Drag. 33, RE: 0.10, c. AD 140-160. Area D

1 rim and 2 body sherds, all conjoining, CG Lezoux, Drag. 31, RE: 0.06, c. AD 150-200. Area D

$1 \mathrm{rim}, 1$ base and 1 body sherd, base and body sherds conjoin, CG Lezoux, Drag. 31R, RE: 0.22, c. AD 160-200. Burnt. Area D

Body, CG Lezoux, Drag. 31R, c. AD 160-200. Area D

\section{Area C. Context 6: part of Analytical Group 5}

1 rim and 1 body sherd, same vessel but not conjoining, CG Lezoux, Drag. 18/31, RE: 0.08, c. AD 120-140

\section{Area C. Context 'H': part of Analytical Group 5}

Body, CG Lezoux, bowl or dish, c. AD 120-140

Rim, CG Lezoux, probably a cup, RE: 0.05 , c. AD 120-200
Area D Context 2A: part of Analytical Group 5

Rim, CG Lezoux, probably Drag. 37, RE: 0.07, c. AD 120-160

Body, CG Lezoux, Drag. 37, c. AD 140-200

$1 \mathrm{rim}$ and 1 base sherd, probably from the same vessel, CG Lezoux, Drag. 31R, RE: 0.03, c. AD 160-200

Area D Context 5: part of Analytical Group 5

Base, CG Lezoux, Drag. 18/31, c. AD 130-150. Trimmed round

Area D Context 7: part of Analytical Group 5

2 rim sherds and 3 body sherds all conjoining, CG Lezoux, Drag. 38, RE: 0.20, c. AD 140-200. Burnt

Base, CG Lezoux, Drag. 31R, c. AD 160-200. Conjoining sherds from Area D, context 9; 1 cleat hole.

Rim, CG Lezoux, Drag. 37, RE: 0.18, c. AD 160-200. Burnt. Conjoining sherds from Area D, context 9

\section{Area D, Context 9: part of Analytical Group 5}

3 rim sherds, CG Lezoux, Drag. 31R, RE: 0.21, c. AD 160-200. Burnt. Conjoining sherd from Area D, context 7; 3 cleat holes

1 rim and 2 body sherds, CG Lezoux, Drag. 37, RE: 0.08, c. AD 160-200. Burnt. Conjoining sherd from Area D, context 7. Style of Mercator (Bridgewater 1965, 135)

\section{Samian pottery from Garrod and Moss' excavations 1967}

\section{Trench A I, Context 1}

Body, SG La Graufesenque, Drag. 37, c. AD 80-100

Body, CG Les Martres, Drag. 37, c. AD 100-130

\section{Trench A I, Context 2: part Analytical Group 4}

Rim, SG La Graufesenque, small Drag. 24/25, RE: 0.07, c. AD $55-70$

Rim, SG La Graufesenque, Drag. 18, RE: 0.04, c. AD 70-100

Body, SG La Graufesenque, Drag. 37, c. AD 70-100

Rim, SG La Graufesenque, probably Drag. 37, RE: 0.04, c. AD 70-100. 1 rivet hole.

Body, CG Les Martres, Drag. 37, c. AD 100-130

Body, CG Les Martres, Drag. 37, c. AD 100-130. Different vessel from the above.

Rim, CG Lezoux, Drag. 33, RE: 0.07, c. AD 100-130

Body, CG Lezoux, Drag. 37, c. AD 140-200

Trench A II, Context 4: part of Analytical Group 4 Body, SG La Graufesenque, probably Drag. 29, c. AD 55-80 
Trench A II, Context 5: part Analytical Group 4

Rim, SG La Graufesenque, perhaps Drag. 18, RE: 0.04, c. AD $70-100$

Body, SG La Graufesenque, Drag. 37, c. AD 70-100

Rim, CG Les Martres, Drag. 37R, RE: 0.03, c. AD 100-130. This is a dish rather than a bowl.

Trench A II, Context 6: part of Analytical Group 1

Body, SG La Graufesenque, Drag. 30, c. AD 70-100

Body, SG La Graufesenque, Drag. 37, c. AD 70-100

Trench B II, Context 2: part of Analytical Group 3

Rim, CG Lezoux, Curle 15, RE: 0.03, c. AD 120-160

Rim, CG Lezoux, probably Drag. 37, RE: 0.03, c. AD 120-200

Trench B III, Context 2: part of Analytical Group 3

Body, SG La Graufesenque, Drag. 37, c. AD 70-100. Different vessel from sherd in context 5

Rim, CG Lezoux, Drag. 45, RE: 0.04, c. AD 170-200

\section{Trench B III, Context 5: Analytical Group 2}

Body, SG La Graufesenque, Drag. 37, c. AD 70-100

Body, SG La Graufesenque, probably from a small bowl or dish, c. AD 70-100

\section{Trench B III, Unstratified}

Body, CG Lezoux, Drag. 37, c. AD 140-200

\section{Trench C I, Context 1}

Body, SG La Graufesenque, Drag. 29, c. AD 55-70

Body, SG La Graufesenque, Drag. 37, c. AD 70-100

Body, SG La Graufesenque, Drag. 37, c. AD 70-100. Different vessel from the above item

Body, CG Les Martres, Drag. 37, c. AD 100-130

Body, CG Lezoux, Drag. 37, c. AD 120-140

Body, CG Lezoux, Drag. 37, c. AD 140-200

\section{Trench C I, Context 2}

Body, CG Lezoux, Drag. 37, c. AD 140-200

Body, EG Trier, Drag. 45, c. AD 220-260

\section{Trench C I, Context 9}

Body, SG La Graufesenque, Drag. 37, c. AD 70-100

\section{Trench C I, Context 13}

Rim, SG La Graufesenque, Drag. 27, RE: 0.07, c. AD 70-100

\section{Trench C II, Context 1}

Body, SG La Graufesenque, form not identifiable, c. AD 55-70. Fragment of stamp present

Body, CG Les Martres, Curle 11, c. AD 100-130

Body, CG Lezoux, Drag. 30, c. AD 120-140

\section{Trench C XX, Context 1}

Body, SG La Graufesenque, Drag. 37, c. AD 70-100

Body, CG Les Martres, Drag. 30, c. AD 100-130

Base, CG Les Martres, Drag. 33, c. AD 100-130. Stamped

Body, EG Rheinzabern, Drag. 31R, c. AD 150-225

\section{Samian surface finds collected by Bridgewater: Field ref. HSM 21376}

1 rim and 1 body sherd, SG La Graufesenque, Drag. 24/25, RE 0.07 , c. AD 40-70. Probably from the same vessel. c. SO 64672384

Rim, SG La Graufesenque, Drag. 15/17, RE 0.05, c. AD 55-80.

Rim, SG La Graufesenque, Drag. 18, RE 0.02, c. AD 55-100. SO 64702407

Body, SG La Graufesenque, cup, c. AD 55-100. c. SO 6467 2384

Rim, SG La Graufesenque, Déch. 67, RE 0.06, c. AD 65-100.

Body, SG La Graufesenque, Drag. 27, c. AD 70-100.

Base, SG La Graufesenque, probably from a platter, c. AD 70-100.

Body, SG La Graufesenque, Drag. 37, c. AD 90-110.

2 body sherds, SG La Graufesenque, Drag. 18/31, c. AD 90-110. c. SO 64672384

Body, CG Les Martres, form not identifiable, c. AD 100-130.

Body, CG Lezoux, form not identifiable, c. AD 120-140.

Body, CG Lezoux, Drag. 18/31, c. AD 120-140. SO 6470 2407

Base, CG Lezoux, Drag. 18/31R, c. AD 120-140. SO 6470 2407

Rim, CG Lezoux, probably Drag. 18/31R, RE: 0.05, c. AD 120-150. c. SO 64672384

Body, CG Lezoux, probably Drag. 18/31R, c. AD 120-150.

Body, CG Lezoux, Drag. 27, c. AD 120-160.

Base, CG Lezoux, bowl, c. AD 120-200. c. SO 64672384

Base, CG Lezoux, bowl or dish, c. AD 120-200. c. SO 6467 2384

Body, CG Lezoux, form not identifiable, c. AD 120-200. c. SO 64672384

Rim, CG Lezoux, Drag. 33, RE: 0.07, c. AD 120-200.

Body, CG Lezoux, Drag. 30 or 37, c. AD 120-200. Burnt.

Body, CG Lezoux, form not identifiable, c. AD 120-200.

Body, CG Lezoux, bowl or dish, c. AD 140-200. SO 6470 2407

Rim, CG Lezoux, probably Drag. 37, RE 0.04, c. AD 140-200. SO 64742404

Base, CG Lezoux, bowl, c. AD 140-200. SO 64742404

Body, CG Lezoux, plain bowl, c. AD 140-200. c. SO 6467 2384

Rim, CG Lezoux, bowl or dish, RE: 0.03, c. AD 140-200. c. SO 64672384

Base, CG Lezoux, cup, c. AD 140-200. c. SO 64672384

Rim, CG Lezoux, from bead rimmed vessel, RE: 0.02, c. AD 140-200. c. SO 64672384

Rim, CG Lezoux, Curle 23, RE: 0.07, c. AD 140-200.

Body, CG Lezoux, form not identifiable, c. AD 140-200.

Body, CG Lezoux, thin walled decorated form, probably $c$. AD 140-200.

Rim, CG Lezoux, Drag. 31 or 31R, RE 0.04, c. AD 150-200. SO 64702407 
Rim, CG Lezoux, Drag. 31 or 31R, RE: 0.07, c. AD 150-200. c. SO 64672384

Body, CG Lezoux, Drag. 38 or Curle 23, c. AD 150-200. c. SO 64672384

Body, CG Lezoux, Drag. 31, c. AD 150-200.

Rim, CG Lezoux, Drag. 31, RE: 0.15, c. AD 150-200.

Rim, CG Lezoux, Drag. 31R, RE 0.09, c. AD 160-200. SO 64742404

Body, CG Lezoux, Drag. 31R, c. AD 160-200. SO 64742404

Base, CG Lezoux, bowl, c. AD 160-200. SO 64742404

Body, CG Lezoux, Drag. 30, c. AD 160-200. c. SO 64672384

Body, CG Lezoux, Drag. 31R, c. AD 160-200.

Body, EG Rheinzabern, Walters 79, c. AD 160-225. c. SO 6467 2384

Rim, CG Lezoux, Drag. 45, RE: 0.06, c. AD 170-200. c. SO 64672384

\section{Samian surface finds from systematic gridded fieldwalking by DAG, October 1986:}

Field ref. HSM 21376 (part of Analytical Group 8)

Rim, SG La Graufesenque, Drag. 18, RE: 0.05, c. AD 40-70. SO 64592388

Body, SG La Graufesenque, form not identifiable, c. AD 40-100. SO 64672377

Body, SG La Graufesenque, Drag. 36 or 42, c. AD 70-100. SO 64542396 or 64622384

Body, SG La Graufesenque, form not identifiable, c. AD 70-100. SO 64622384

Body, SG La Graufesenque, form not identifiable, c. AD 70-100. SO 64592388

Body, CG Les Martres, probably Drag. 36, c. AD 100-130. SO 64542396 or 64622384

Body, CG Les Martres, Drag. 30, c. AD 100-130. SO 6459 2388

Body, CG Lezoux, Drag. 18/31, c. AD 100-130. SO 6459 2388

Body, CG Lezoux, Drag. 33, c. AD 120-140. SO 64532399

Body, CG Lezoux, form not identifiable, probably $c$. AD 120-140. SO 64522401

Body, CG Lezoux, probably Drag. 18/31R, c. AD 120-150. SO 64522401

Body, CG Lezoux, form not identifiable, c. AD 120-200. SO 64672377

Body, CG Lezoux, Drag. 18/31R or 31R, c. AD 120-200. SO 64672377

Rim, CG Lezoux, Drag. 33, RE: 0.07, c. AD 120-200. SO 6467 2377

Rim, CG Lezoux, probably Drag. $18 / 31$ or $18 / 31$ R, RE: $0.04, c$. AD 120-200. SO 64642381

Body, CG Lezoux, bowl, c. AD 120-200. SO 64592388

Body, CG Lezoux, form not identifiable, c. AD 120-200. SO 64572392

Rim, CG Lezoux, Drag. 35, RE: 0.10, c. AD 140-200. SO 6465 2379

Rim, CG Lezoux, Drag. 37, RE: 0.03, c. AD 140-200. SO 6465 2379

Base, CG Lezoux, form not identifiable, c. AD 140-200. SO 64652379

Rim, CG Lezoux, Drag. 31 or 31R, RE: 0.03, c. AD 150-200. 1 rivet hole. SO 64592388

\section{Samian surface finds from various fieldwalking exercises by the DAG: Field ref. HSM 21376}

This catalogue records the samian from various surface collections undertaken by DAG within this field. Most of the material is precisely located within the field but it is not known how systematically organised these particular collections were. The catalogue includes a cluster of finds groups from around SO 6449 2398. The material grouped here was collected in October 1987 and April 1989, and possibly at other times.

Body, SG La Graufesenque, form not identifiable, c. AD 40-70. SO 64502393

Body, SG La Graufesenque, form not identifiable, c. AD 40-100. SO 64502397

Body, SG La Graufesenque, form not identifiable, c. AD 40-100. SO 64462399

Rim, SG La Graufesenque, Drag. 15/17, RE: 0.03, c. AD 55-100. SO 64472397

Rim, SG La Graufesenque, form not identifiable, RE: 0.06, $c$. AD 70-100. SO 64602400

Body, SG La Graufesenque, form not identifiable, c. AD 70-100. SO 64702390

Body, SG La Graufesenque, form not identifiable, c. AD 70-100. SO 64702390

Body, SG La Graufesenque, form not identifiable, c. AD 70-100. SO 64702390

Body, SG La Graufesenque, Drag. 29 or 37, c. AD 70-100. SO 64472399

Body, SG La Graufesenque, Drag. 29 or 37, c. AD 70-100. SO 64462399

Body, SG La Graufesenque, Drag. 37, c. AD 70-100. SO 6460 2400

Body, SG Montans, form not identifiable, probably c. AD 70-100. SO 64462399

Rim, CG Les Martres, probably Drag. 18/31, RE: 0.05, c. AD 100-130. SO 64702390

Body, CG Les Martres, Drag. 30, c. AD 100-130. SO 6470 2390

Body, CG Les Martres, form not identifiable, c. AD 100-130. 1 cleat hole. SO 64702390

Rim, CG Les Martres, form not identifiable, RE: 0.05, c. AD 100-130. SO 64462399

Body, CG Les Martres, Drag. 30, c. AD 100-130. Burnt. SO 64602400

Rim, CG Les Martres, Drag. 30 or 37, RE: 0.04 c. AD 100-130. SO 64602400

Rim, CG Lezoux, bead rimmed vessel, RE: 0.04, c. AD 120-140. SO 64602400

Rim, CG Lezoux, from bead rimmed vessel, RE: $0.03, c$. AD $120-140$. SO 64702390

Rim, CG Lezoux, probably Drag. 27, RE: 0.08, c. AD 120-160. SO 64472397

Body, CG Lezoux, form not identifiable, c. AD 120-160. SO 64502393

Body, CG Lezoux, form not identifiable, c. AD 120-160. SO 64462398

Body, CG Lezoux, possibly Drag. 18/31R or 31R, c. AD 120-200. SO 64702390

Base, CG Lezoux, form not identifiable, c. AD 120-200. SO 64702390 
Body, CG Lezoux, form not identifiable, c. AD 120-200. SO 64702390

Rim, CG Lezoux, Drag. 18/31R or 31, RE: 0.03, c. AD 120-200. SO 64702390

Base, CG Lezoux, Drag. 18/31R or 31R, c. AD 120-200. SO 64702390

Rim, CG Lezoux, Drag. 18/31R, 31 or 31R, RE: 0.06, c. AD 120-200. SO 64702390

Body, CG Lezoux, Drag. 37, c. AD 120-200. Burnt. SO 6470 2390

Body, CG Lezoux, Drag. 37, c. AD 120-200. SO 64702390

Rim, CG Lezoux, from bead rimmed vessel, RE: 0.03, c. AD 120-200. SO 64702390

Rim, CG Lezoux, from bead rimmed vessel, RE: 0.04, c. AD 120-200. Burnt. SO 64702390

Rim, CG Lezoux, probably Drag. 33, RE: 0.07, c. AD 120-200. SO 64502394

Base, CG Lezoux, cup, c. AD 120-200. SO 64602400

Base, CG Lezoux, form not identifiable, c. AD 120-200. Burnt. SO 64602400

Body, CG Lezoux, form not identifiable, c. AD 120-200. SO 64702390

Base, CG Lezoux, form not identifiable, c. AD 120-200. SO 64702390

Body, CG Lezoux, form not identifiable, c. AD 120-200. SO 64702390

Body, CG Lezoux, form not identifiable, c. AD 120-200. SO 64702390

Body, CG Lezoux, form not identifiable, c. AD 120-200. SO 64702390

Body, CG Lezoux, form not identifiable, c. AD 120-200. SO 64702390

Body, CG Lezoux, form not identifiable, c. AD 120-200. SO 64702390

Body, CG Lezoux, form not identifiable, c. AD 120-200. SO 64502393

Body, CG Lezoux, form not identifiable, c. AD 120-200. SO 64502393

Body, CG Lezoux, form not identifiable, c. AD 120-200. SO 64502393

Body, CG Lezoux, form not identifiable, c. AD 120-200. SO 64502394

Body, CG Lezoux, form not identifiable, c. AD 120-200. SO 64502394

Rim, CG Lezoux, bead rimmed vessel, RE: 0.03, c. AD 120-200. SO 64462398

Body, CG Lezoux, form not identifiable, c. AD 120-200. SO 64462398

Rim, CG Lezoux, Drag. 33, RE: 0.05, c. AD 120-200. SO 6450 2397

Body, CG Lezoux, form not identifiable, c. AD 120-200. SO 64502397

Body, CG Lezoux, Drag. 38, c. AD 130-200. SO 64702390

Rim, CG Lezoux, Drag. 38 or 44, RE: 0.05, c. AD 130-200. SO 64702390

Rim, CG Lezoux, probably Drag. 15/31, RE: 0.03, c. AD 140-200. SO 64702390

Body, CG Lezoux, Drag. 37, c. AD 140-200. SO 64602400

Body, CG Lezoux, form not identifiable, c. AD 140-200. SO 64702390

Base, CG Lezoux, form not identifiable, c. AD 140-200. SO 64702390
Body, CG Lezoux, form not identifiable, c. AD 140-200. SO 64702390

Body, CG Lezoux, bowl or dish, c. AD 140-200. SO 6470 2390

Body, CG Lezoux, form not identifiable, c. AD 140-200. SO 64462398

Rim, EG probably Argonne, Drag. 31 or 31R, RE: 0.05 , c. AD 140-230. SO 64602400

Body, EG, form not identifiable, c. AD 140-260. SO 6470 2390

Body, CG Lezoux, probably Drag. 31, c. AD 150-200. SO 6447 2399

Rim, CG Lezoux, Drag. 31 or 31R, RE: 0.05, c. AD 150-200. SO 64602400

2 conjoining body sherds, CG Lezoux, Drag. 31, c. AD 150-200. SO 64502395

Rim, EG Rheinzabern, Drag. 33, RE: 0.10, c. AD 150-230. SO 64602400

Body, EG Rheinzabern, form not identifiable, c. AD 150-230. SO 64462398

Rim, EG Rheinzabern, form not identifiable, RE: 0.01, c. AD 150-230. SO 64502394

Rim, CG Lezoux, Walters 79, RE: 0.02, c. AD 160-200. SO 64702390

Rim, CG Lezoux, Walters 79, RE: 0.05, c. AD 160-200. SO 64702390

Body, probably EG Trier, Drag. 31R, c. AD 160-230. SO 6460 2400

Body, CG Lezoux, bowl or dish, c. AD 170-200. SO 6460 2400

Body, EG Rheinzabern, Drag. 45, c. AD 170-230. SO 6460 2400

\section{Samian surface finds collected by Bridgewater: Field ref. HSM 21378}

Rim, SG La Graufesenque, Drag. 29, RE 0.05, c. AD 55-80. Body, SG La Graufesenque, Drag. 29, c. AD 55-80.

Rim, SG La Graufesenque, Ritt. 12 or Curle 11, RE 0.06, c. AD 55-85.

Body, SG La Graufesenque, Drag. 18, c. AD 70-100.

Rim, SG La Graufesenque, Drag. 37, RE 0.05, c. AD 70-100.

Rim, SG La Graufesenque, probably Drag. 37, RE 0.03, c. AD 70-100.

Body, SG La Graufesenque, form not identifiable, probably $c$. AD 70-100. Burnt

Body, SG La Graufesenque, Drag. 37, c. AD 90-110. Burnt.

Rim, CG Les Martres, Drag. 33, RE 0.05, c. AD 100-130.

Body, CG Les Martres, Drag. 37, c. AD 100-130.

Body, CG Lezoux, Drag. 30, c. AD 120-140.

Rim, CG Lezoux, Drag. 42, RE: 0.02, c. AD 120-140.

Base, CG Lezoux, bowl, c. AD 120-140.

Body, CG Lezoux, form not identifiable, c. AD 120-140.

2 body sherds, CG Lezoux, Curle 11, c. AD 120-160. Both burnt.

Rim, CG Lezoux, bowl or dish, RE: 0.03, c. AD 120-160.

Base, CG, probably Lezoux, Drag. 37, c. AD 120-160. Burnt.

Body, CG Lezoux, Drag. 30, c. AD 120-200.

Body, CG Lezoux, Drag. 37, c. AD 120-200.

Body, CG Lezoux, Drag. 37, c. AD 120-200.

Body, CG Lezoux, Drag. 37, c. AD 120-200. 
Rim, CG Lezoux, from bead rimmed vessel, RE: $0.03, c$. AD 120-200.

Body, CG Lezoux, form not identifiable, c. AD 120-200.

Base, CG Lezoux, Drag. 18/31R, c. AD 130-150. Stamped: MALLIACVS; 2 rivet holes.

Rim, CG Lezoux, bowl or dish, RE: 0.02, c. AD 140-200.

Rim, CG Lezoux, probably from a beaker, RE: 0.08, c. AD 140-200.

Body, CG Lezoux, form not identifiable, probably c. AD 140-200. Burnt.

Rim, CG Lezoux, Drag. 31 or 31R, RE: 0.06, c. AD 150-200.

Base, EG, probably Drag. 33, c. AD 150-260.

Rim, EG, Drag. 54, RE: 0.13, c. AD 150-260. 1 cleat hole.

Rim, CG Lezoux, Drag. 31R, RE: 0.05, c. AD 160-200.

Rim, CG Lezoux, Walters 79, RE: 0.02, c. AD 160-200.

Body, CG Lezoux, Drag. 45, c. AD 170-200
Samian surface finds collected by DAG: Field ref HSM 21378

Rim, SG La Graufesenque, Drag. 18, RE: 0.09, c. AD 40-70. SO 64552375

Rim, CG Les Martres, Drag. 18/31R, RE: 0.06, c. AD 100-130. SO 64552375

Body, CG Les Martres, Drag. 30, c. AD 100-130. SO 64552375

Body, CG Les Martres, Drag. 37, c. AD 100-130. SO 64552375

Rim, CG Lezoux, Drag. 35, RE: 0.09, c. AD 120-200. Burnt. SO 64552375

Samian surface finds collected by Bridgewater: Field ref HSM 10676

Rim, CG Lezoux, Drag. 18/31, RE 0.06, c. AD 120-140.

Rim, CG Lezoux, probably Drag. 37, RE 0.07, c. AD 120-200.

Rim, CG Lezoux, Drag. 18/31R, RE 0.08, c. AD 130-150.

Rim, CG Lezoux, Drag. 18/31R, RE 0.03, c. AD 140-160.

Body, CG Lezoux, Drag. 38, c. AD 140-200. 


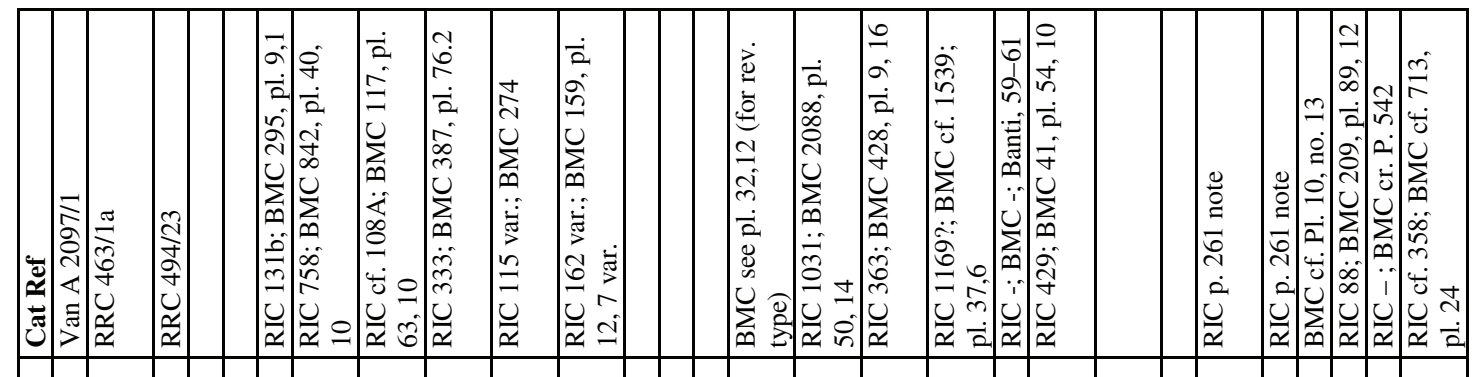

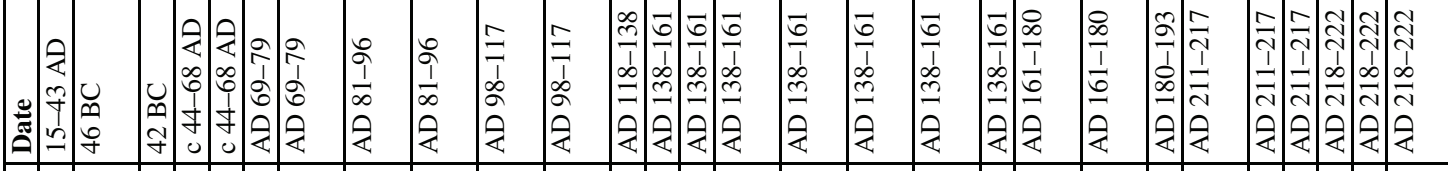

击

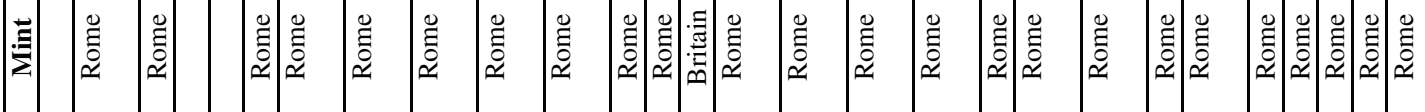

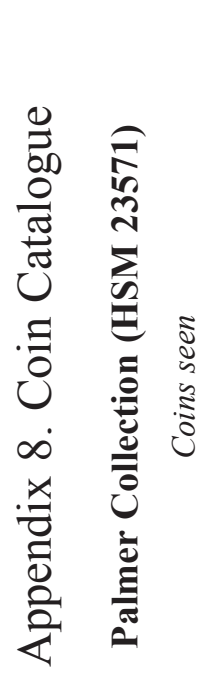

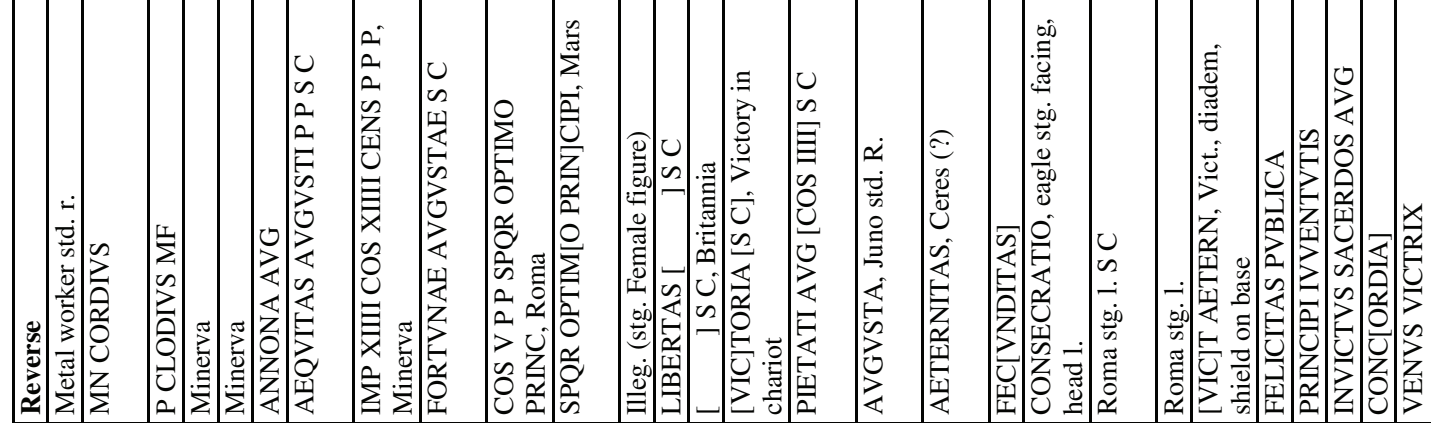

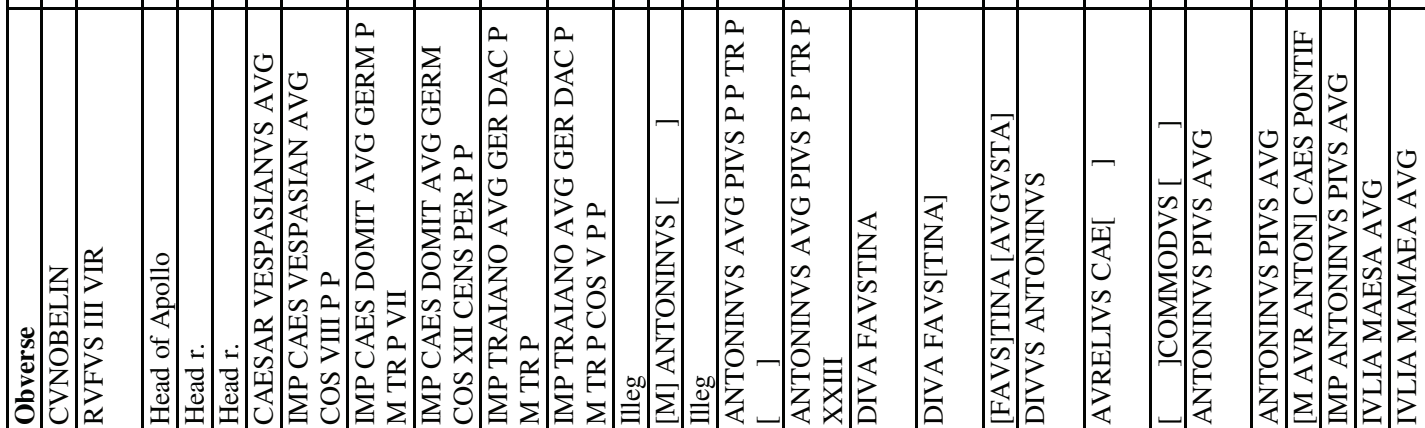

苛

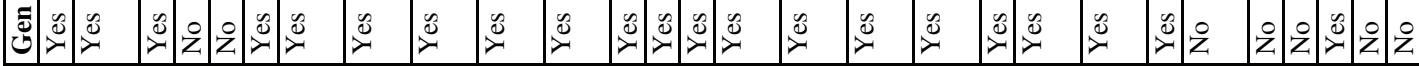

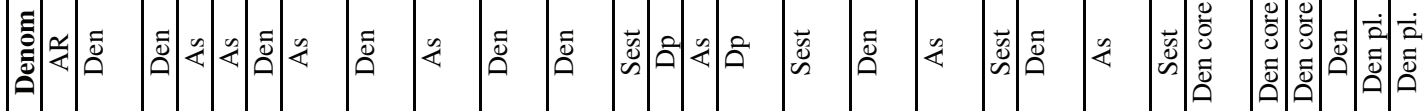

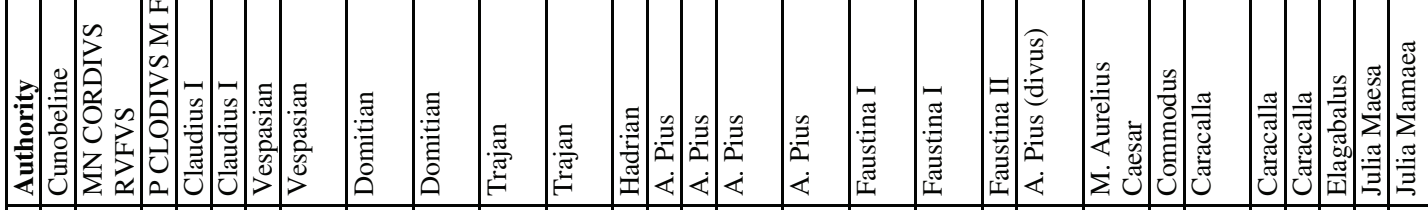

ฉ.

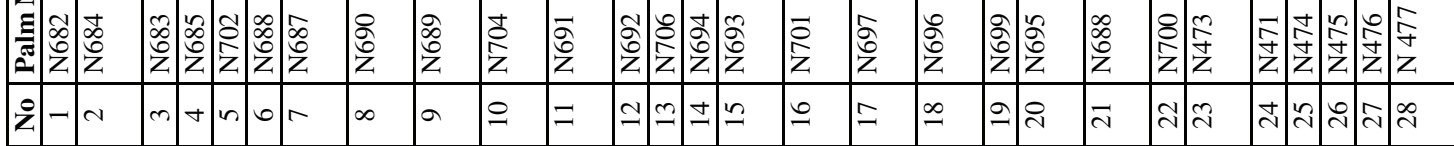




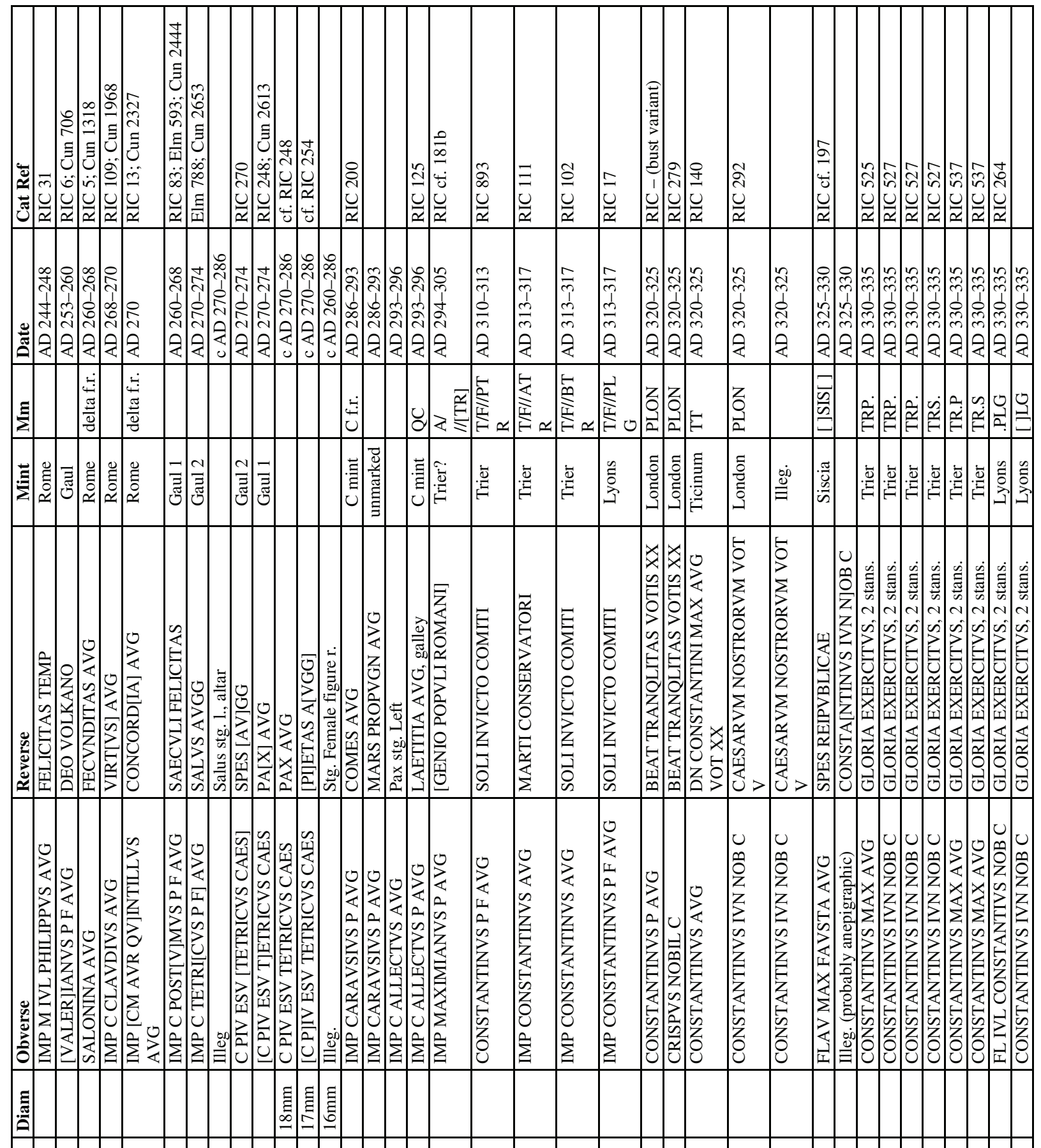

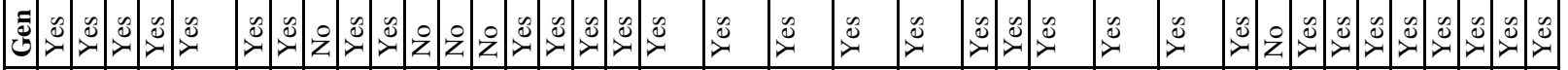

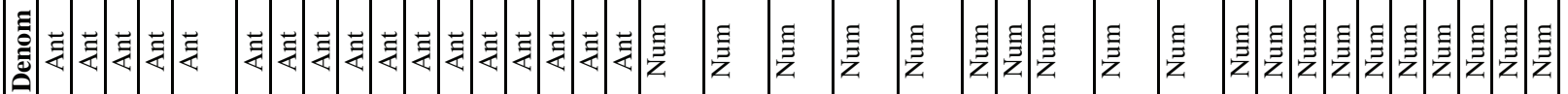

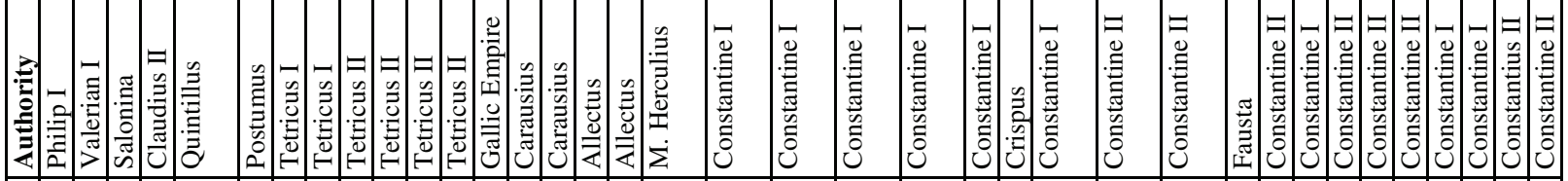

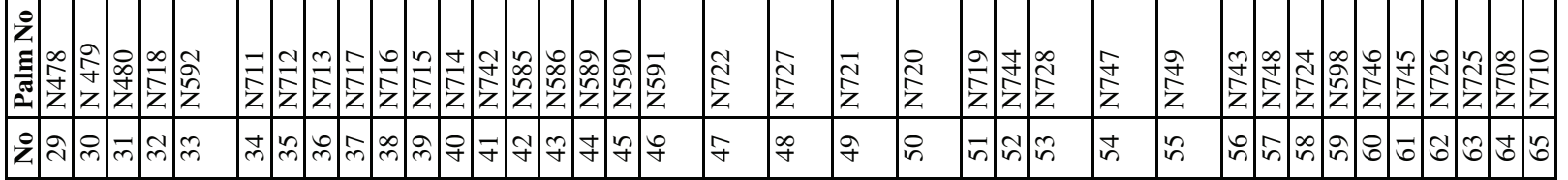




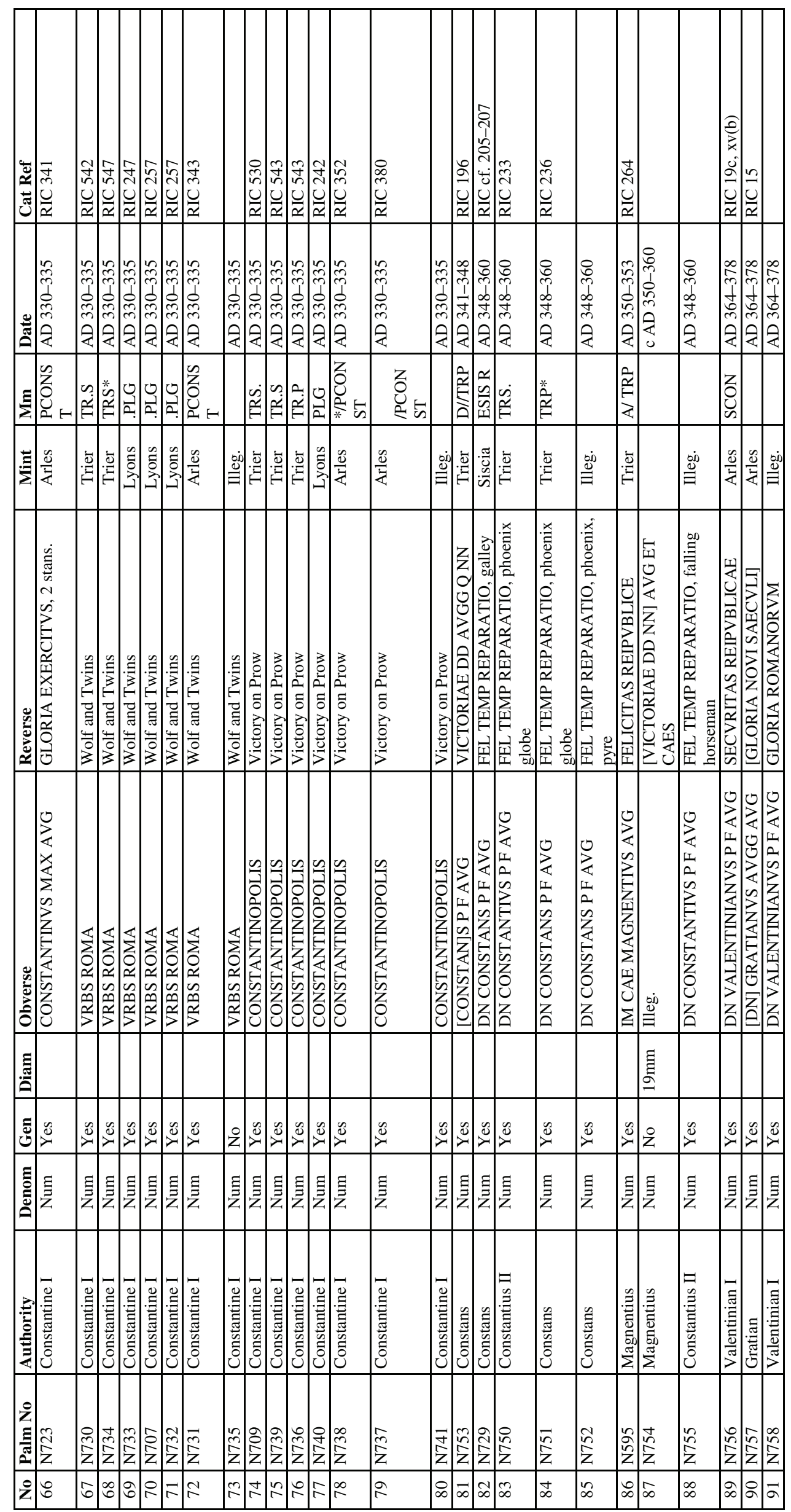




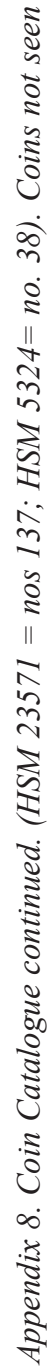

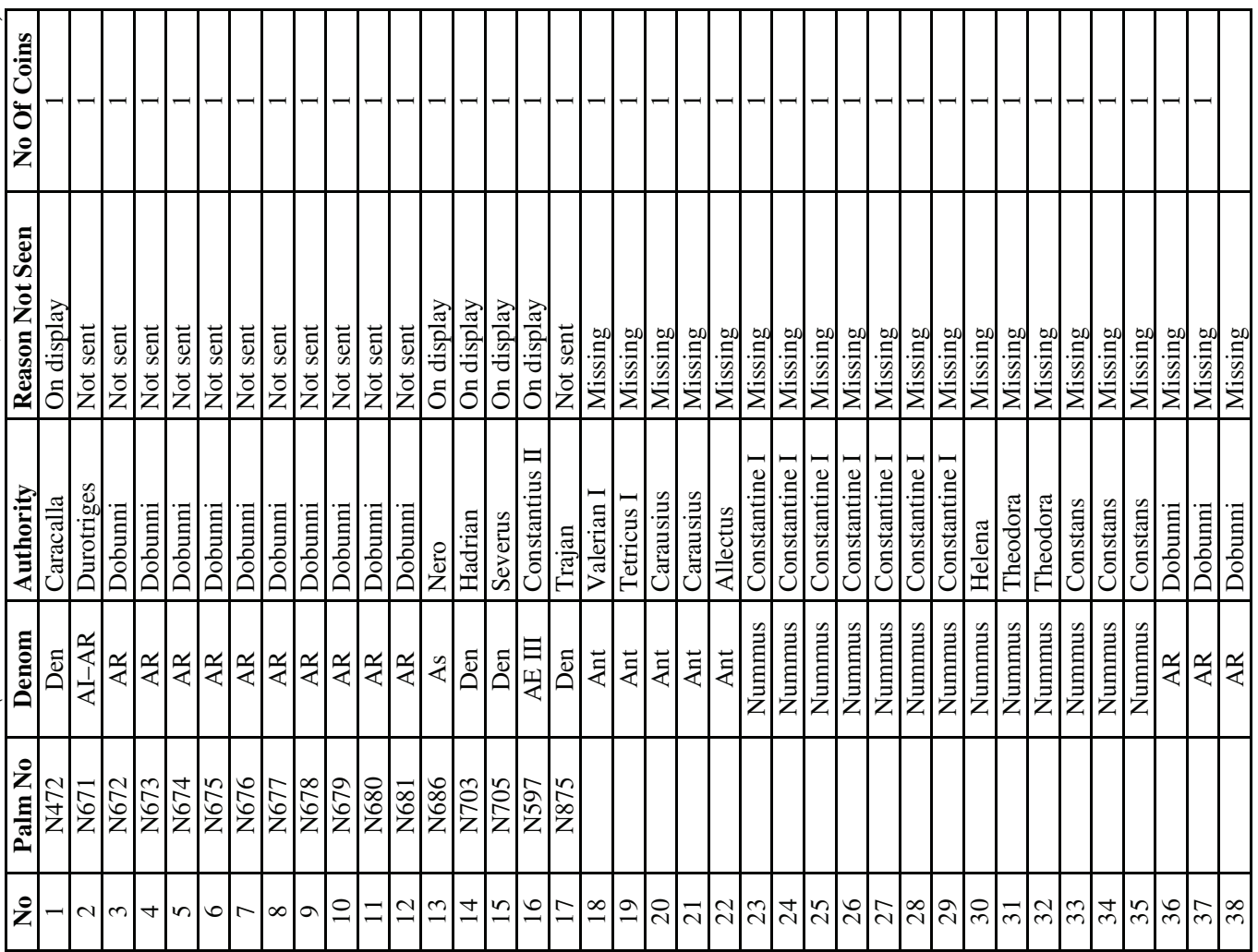




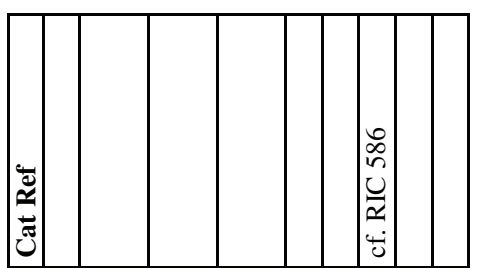

管

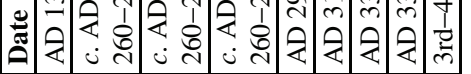

$$
5
$$

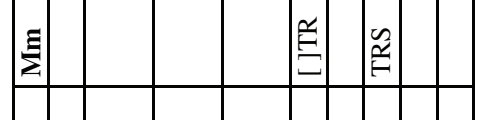

芒泀
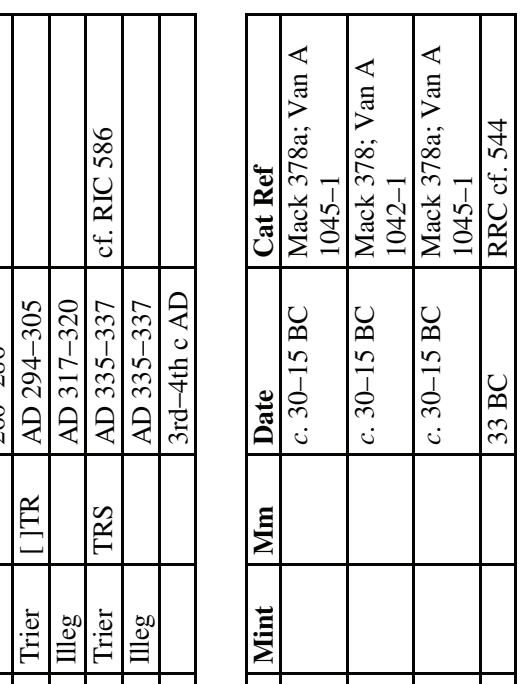

iิ

$\frac{8}{2}$

in

ข

กุ

放

$\frac{2}{3}$

है

ฐँ

章

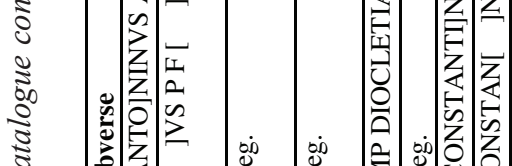

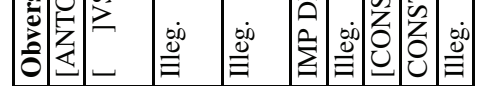

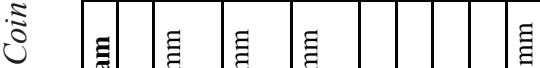

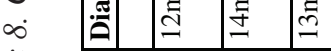

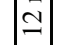

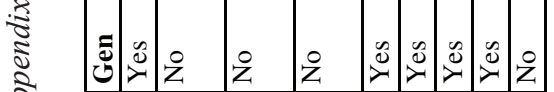

केष

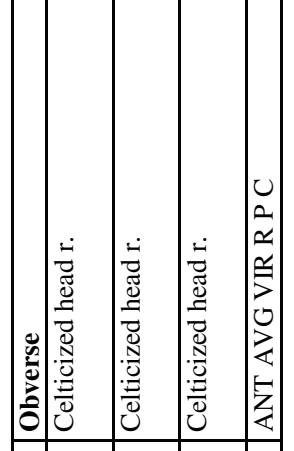

ธ

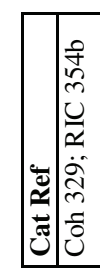

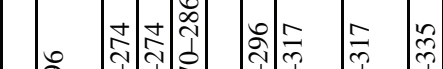

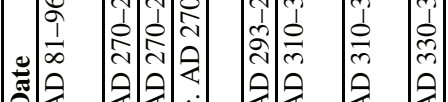

$\checkmark \quad$ 窇

妾

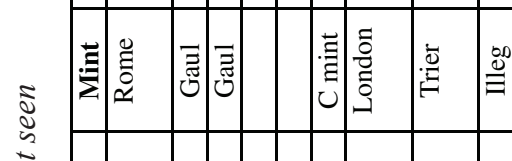

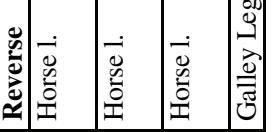

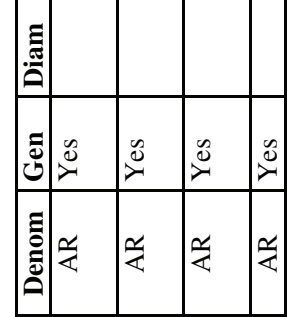

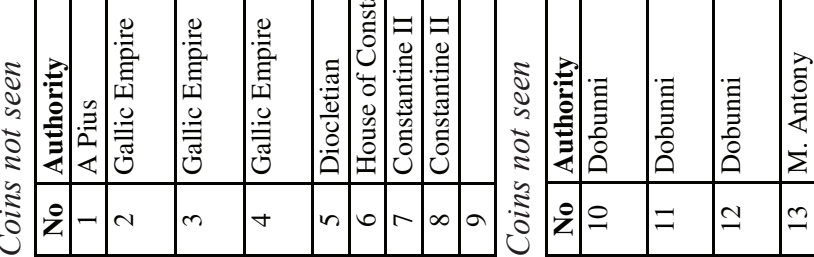

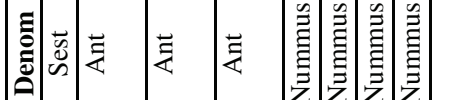

F
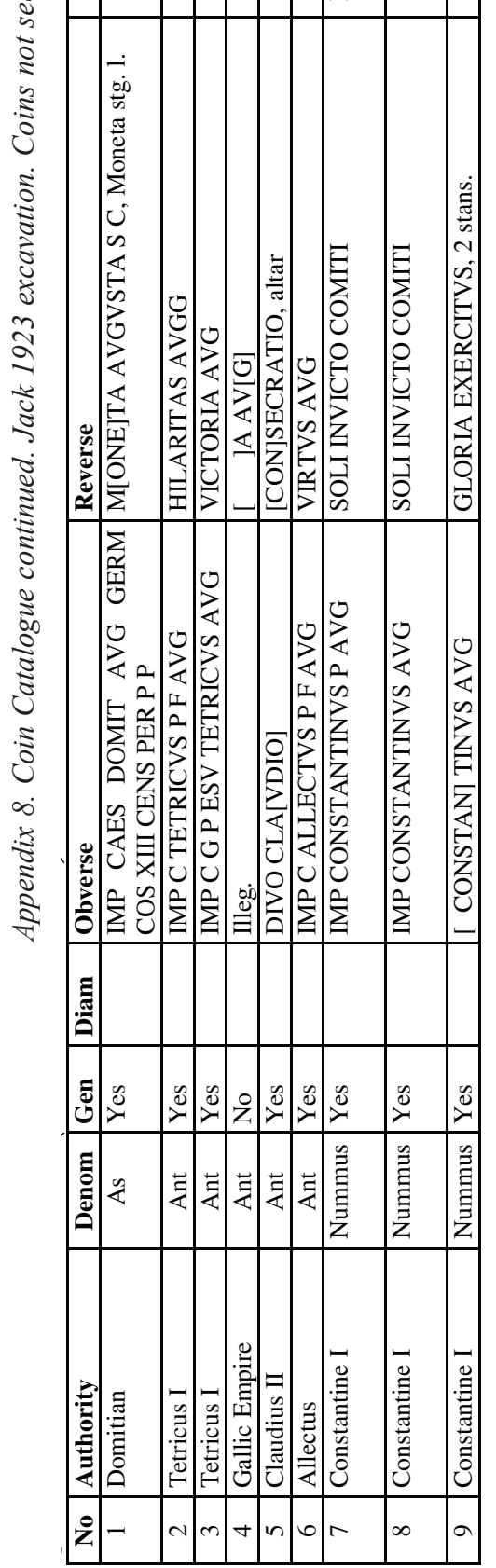

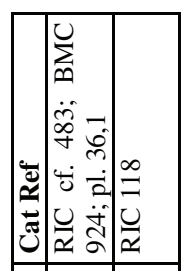

$\Xi$ กิ

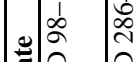

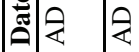

旗

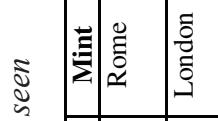

ปิ

à

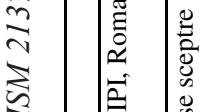

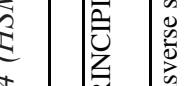

艺

ఏ.

¿

$\approx$

0
0
0
0
0
0
0
0
0
0
0
0
0
0
0
0
0
0
0
0
0

足会

造

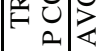

毞魚近

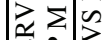

武它氛

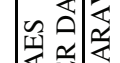

记

会主文主

离

$\approx \approx$

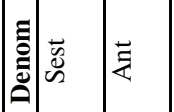

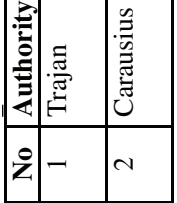




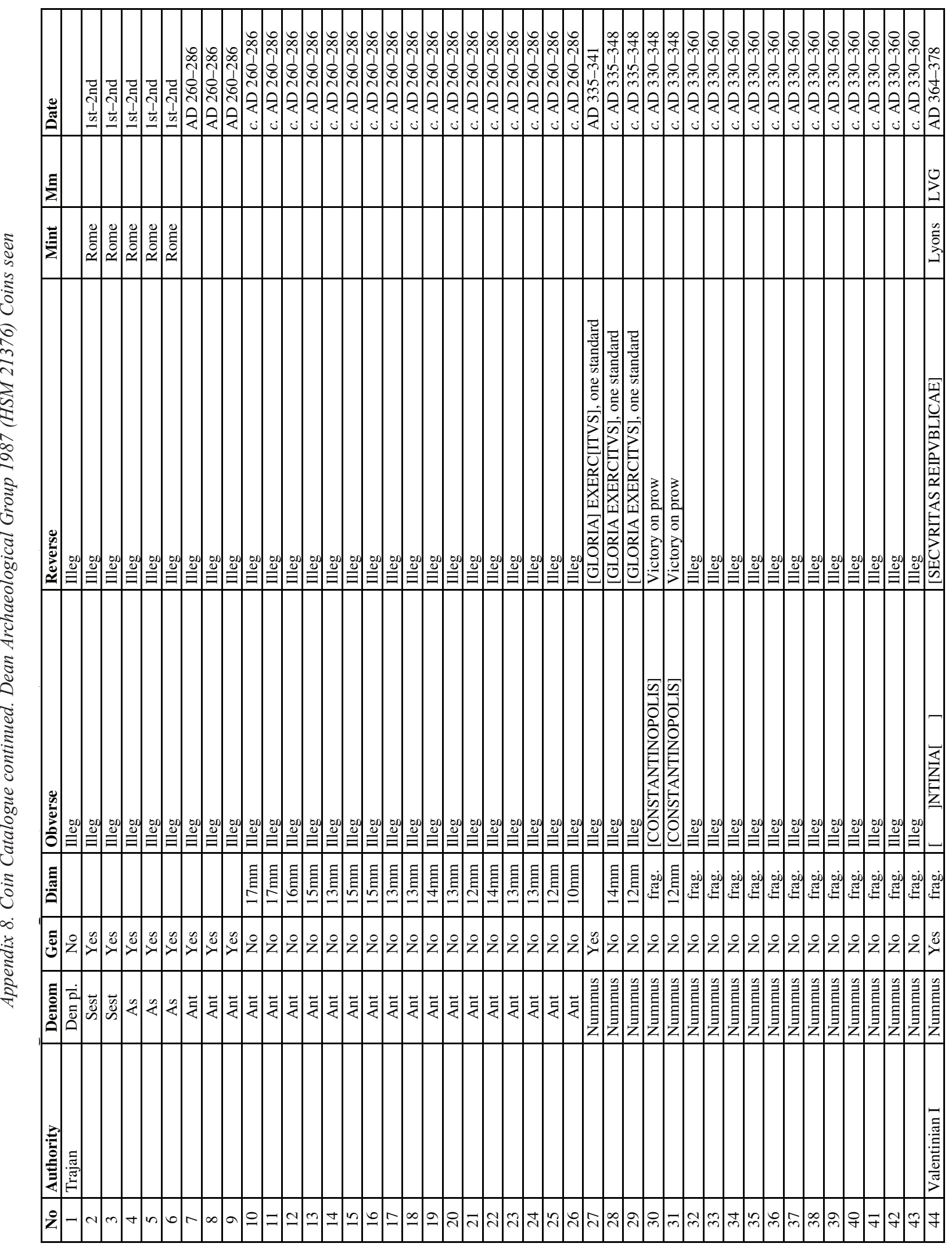




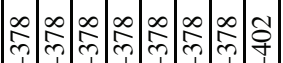

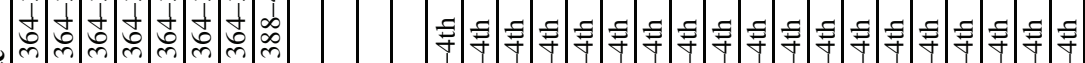

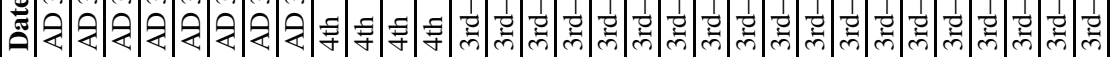

灵

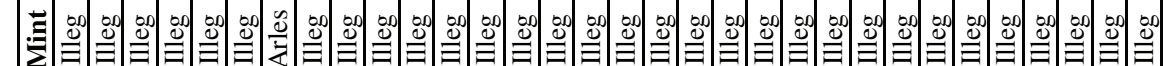

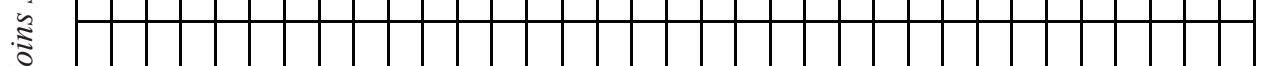

已

จ

$\grave{n}$

है

国国国国国

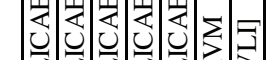

$\infty$

$\stackrel{\infty}{2}$

క

$\frac{8}{3}$

क.

$\frac{8}{8}$

$\frac{\sqrt{2}}{3}$

ฐ

๑

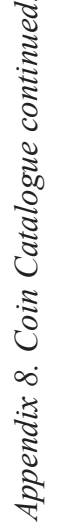

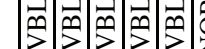

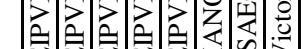

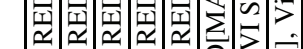

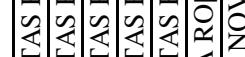

:

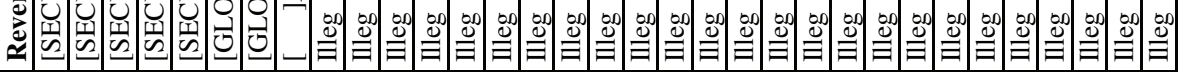

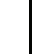

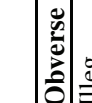

育

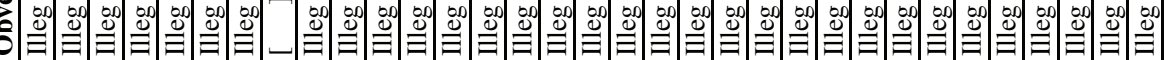

范

50

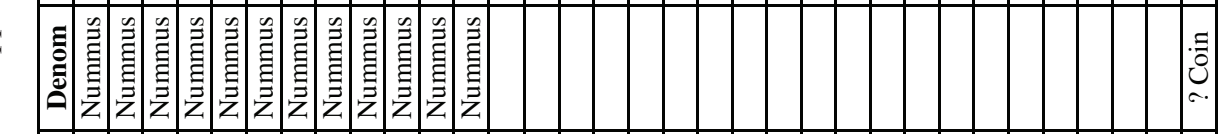

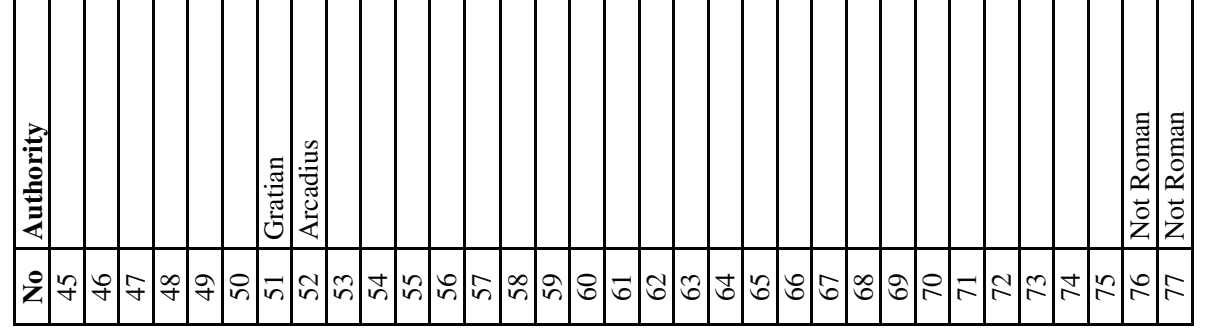

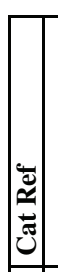

चे

m

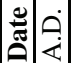

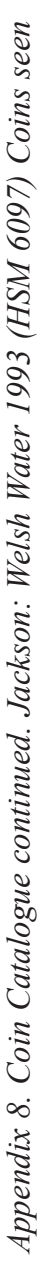

政

望些

$\varangle$

产

-

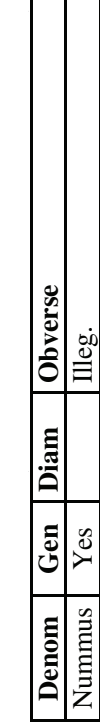




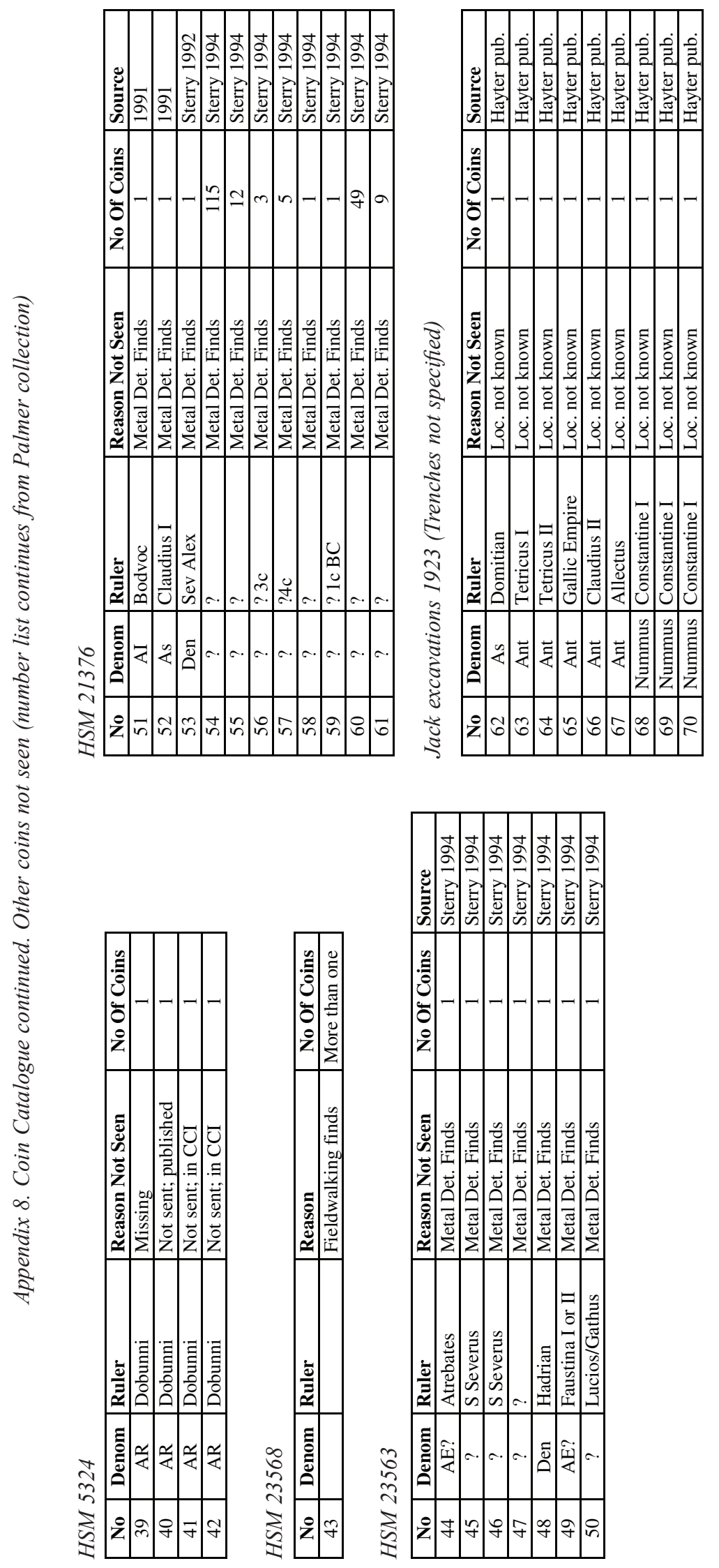




\section{Index}

Illustrations are indicated by page number in italics. Places are in Herefordshire unless specified otherwise.

administration 188,195

agger 15,173

Alcester (Warks) 77, 99, 102, 105, 107, 108

amulet $141,144-5$

animal bone 167

antiquarian investigations 7-8

Antonine Itinerary 7, 30, 169, 173, 175

Archenfield 30, 188

Ariconium (field) 32, 37

armour 135, 151, 152

arrowhead 152

Ashton 173

Atrebates 129, 131, 180

bangles see bracelets/bangles

Barnett, T. G. 128

beads

Iron Age 134, 141, 142, 143-4

Roman 135, 140-4, 141

post-Roman 134, 142, 144

Beckford (Worcs) 102

belt plate 135, 151, 152

bishopric 188

Blackwardine 171, 173

Blakeney (Glos) 195

boar's tusk 145

Bollitree Farm 7, 31-40, 32, 36

boundaries 175

box fittings 153-4, 155

bracelets/bangles

copper alloy 135, 137, 139, 140, 141, 175

glass $135,137,138-9$

ivory $135,136,139,140,141,174$

stone 160

bricks 161

Bridgets 32, 39

Bridgewater, N. P., excavations by 8

charcoal 164-7

description 14-17, 15, 16

pottery

assemblage $41,42,43$

fabrics $75-7$

forms $80-2,83$

samian 89-90, 91, 92-3, 94

briquetage 24, 95, 180, 189

British Archaeological Association 8

British Archaeological Society 8
Bromsash 1, 32, 37-8

brooches

assemblage 110

description

Alésia-Hod Hill Sequence 119, 122-4, 123

Almgren 101 123, 125

Colchester 110-13, 112

Colchester Derivatives 115, 117-21, 119

Durotrigan 121

Early Iron Age? 127-8

Headstud and related 119, 121-2

Langton Down 115, 116-17

Late La Tène: La Tène II 112, 113-14; Nauheim 114; Nauheim Derivatives 112, 114

Pennannular 126-7, 127

Plate 123, 126

Rosette 114-16, 115

Trumpets $123,124-5$

unclassified/fragments/unidentifiable 121, 122, 127 , 128

discussion 128, 180, 182

Broughspring 195

buckles 134, 145, 152

building materials 161

building stone 161, 173, 174

buildings

description

Garrod and Moss excavations 17, 18

Jack excavations 13, 13

pipeline recording 23, 24, 25, 26

Walters and Walters excavations 22

discussion 173-5, 182, 184

Bull, Dr 8

Bull Meadow 8, 24-5, 177, 184, 186

burials 7, 167, 176

Butcher, C. J. 129

Caerleon (Newport) 171

Camden, William 7, 200

Catuvellauni 180

celery (Apium graveolens) 168

cemetery 176

Central Marches Historic Towns Survey 2, 197

channel/leat 22, 175, 186

charcoal 164-7, 173, 192, 193, 196

charcoal store $15,16,176,190$

Chesters villa (Glos) 189-90, 192, 193, 195 
chronology see settlement chronology

clip, copper alloy 154, 156

Clutterbuck 32, 40

coal 17,192

coins

analysis

Iron Age 128, 129, 131

Roman 132-3

assemblage 128, 129, 132

collections

fieldwalking etc. 130-1

Garrod and Moss excavations 130

Jack excavations 130

Palmer Collection 128-30

pipeline recording 130

discussion 180, 189

future research 133-4

Coleford (Glos) 194, 195

Cooper, F. C. 129

copper alloy working 135, 156-7, 177, 184, 189

coppicing 166, 193, 196

coriander (Coriandrum sativum) 168

Corieltavi 129, 131, 180

counters

bone $135,148,149,150$

fired clay $149,150,157$

glass $135,148,149,150$

ivory $136,149,186$

stone $159,160,160$

crucible fragments 177

Davies, James 8

Dean Archaeological Group, fieldwork by 10, 21, 28

coins 130,132

pottery $43,77-8,82-3,84,91-4$

Dean Road 173, 191

Diana 7, 176

die, jet $148,149,150$

discs

bone $153,154,155$

ceramic 157

stone 159

ditches

Jack excavations 14

pipeline recording 24

Ryeford Bypass evaluation 27

Walters and Walters excavations 20, 21, 21, 22, 178

Dobunni

coins of $129,131,180$

territory 180-1, 189, 195

Droitwich (Worcs)

pottery $43,95,99,101,105,107,108$

salt 180

Dyfrig (Dubricius), St 188

Dymock (Glos) 194

earrings $135,136,137$ earthquake 7, 200

Eccleswall 30, 32, 38, 188

Edwards, Misses 129

enclosures

domestic 171, 175

The Great Woulding

description 20, 21-2, 21

discussion 177, 178, 179, 180, 182, 184

English Heritage 197

environmental remains

Bridgewater excavations 17

Jack excavations 14

pipeline recording 25-6

summary 167-8

Ergyng 30, 188

erosion and deposition history

erosion across settlement area, case studies 34

Field 1 (Hask) 35

Field 2 (Bollitree) 35-6, 36

Field 3 (Ariconium) 37

Field 4 (Bromsash) 37-8

Field 5 (Eccleswall) 38

Field 6 (Bridgets) 36, 39

Field 7 (Middle) 39

Field 8 (Pond) 40

Field 9 (Clutterbuck) 40

Field 10 (Linton) 40

Fields HSM 9071, 9818, 2356340

soil erosion

background 31

Bollitree Farm, nature of 31, 32

data presentation 33

methods 31-3

and monument management 197-205

results 33-4

escutcheon 136, 147, 148, 174

excavations and fieldwork

history of

antiquarian 7-8

20th-century 8-10, 9, 10, 11

summary and analysis 12

Bridgewater 1959 and 1963 14-17, 15, 16

buried remains 12

evaluation 1995 27;

extent and integrity of sources 12

Garrod and Moss 1967 17-20, 18, 19, 20

Holland 193214

information sources 12

Jack 1922 12-14, 13

Jack 192914

pipeline recording 22-6, 23, 24, 25, 26, 27

stratified artefactual assemblages 12

Walters and Walters 1989 20-2, 21

watching brief 1993 26-7

fieldwalking etc.

aerial photographs $28-30$

fieldwalking $27-8$ 
metal detecting finds 28,29

place-name evidence 30

poorly located finds 30

surface observations 28

see also erosion and deposition history

ferrule 154, 156

finger rings 135, 136-8, 137

fish-hook 148, 149-50

fishing 177

flagstones 161

flint 178

Forest of Dean

coal 192

iron ore 171, 173, 180, 191, 195, 196

road to 171,173

fortlets 21-2, 108, 169

Fosbroke, Thomas Dudley 8

Frocester Court villa (Glos) 190, 191, 194, 195

fuel see charcoal

furnaces

description

Bridgewater excavations 15, 16-17, 16

Garrod and Moss excavations 17, 18, 19, 20

discussion 176, 177, 178, 184, 189-90, 194

Garrod and Moss, excavations by 8

coins 130, 132

description 17-20, 18, 19, 20

pottery $41,42,43,72-4,79-81$

geology see topography and geology

glass vessels 135, 147-9

glass working 177, 189

Gloucester (Glos) 171, 173

The Great Woulding

discussion 174, 177, 178, 180, 182, 190

excavations 8, 20-2, 21

Hadnock villa 194, 195

hairpins 135, 136, 137

Harkness, R. L. 129

Harper, 130

Hask (field) 32, 35

Hask Barn 178-80, 182, 190

Hayter, A. G. K. 129, 130

hearths 17, 18, 176, 178, 182, 190

Herefordshire Archaeology 197

Hills Flats (Glos) 195

hinterland see under settlement character

Holland, Revd E. R. 8, 14

hollow-ways 22, 173, 177, 182

Horsley, John 7

Huntsham villa 194, 195

hypocaust $13,173,184$

inlay, bone 153, 154, 155

insect remains 168

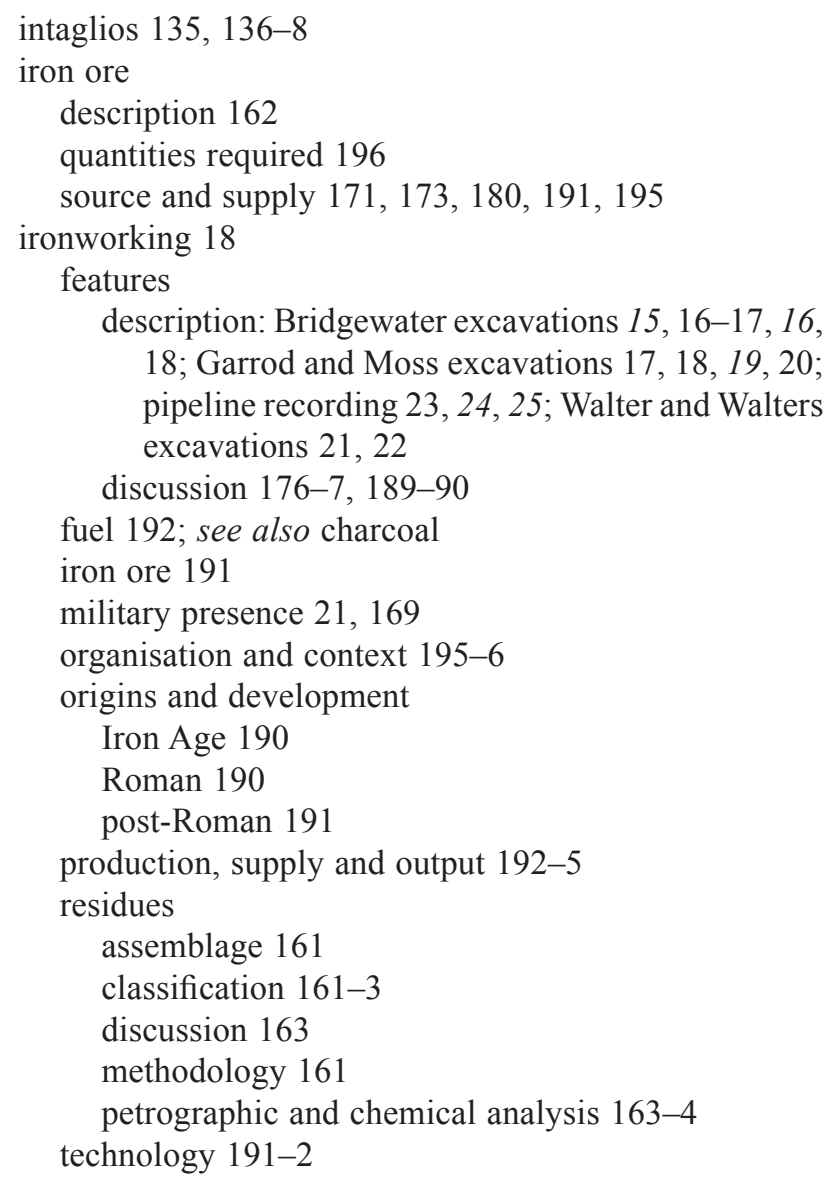

Jack, G. H., excavations by coins 130

description 8, 12-14, 13

pottery $41,42,43$

James, Terry 199

Kenchester 85, 105, 109, 158, 159

keys 135, 151, 153

kitchen block 13, 13, 173-4, 184

lead sheet 156

leat see channel/leat

Linton

field 32,40

ironworks 15, 173, 191, 200

Littledean Hall (Glos) 195

location 1, 2, 3

lock bolt 151,153

lock pin 154

lorica segmentata fitting 135, 151, 152

Lydney (Glos) 171, 173, 195

mansio $175,184,186$

Martell, E. 129

Matthews, Dr 7

May Hill (Glos/Herefs) 173, 189

Mercury 154, 176

Merrick, Thomas Hopkins 7, 8, 17, 37, 38, 201 
metal detecting 28, 199-200

metalworking see copper alloy working; ironworking Middle Field 32, 39

military finds 22, 108, 135, 151, 152

mill 175, 184, 186

mill-ponds 14

millstones $158,158,159,175$

mollusca 168

Monmouth (Mon) 171, 173, 192, 194, 195

monument management

controlling erosion 204-5

erosion impact 198-200, 200

erosion models and background 197-8

landuse and erosion history model 200-3, 202, 203

management and protection 197

Morris, 131

Moss see Garrod and Moss

mounts 135, 153, 155; see also vulva mount

nail, copper alloy 154,155

nail cleaners $135,141,145-6$

necklace fastener $135,141,144$

Newent (Glos) 194, 195

offcuts, copper alloy 135, 156

Oldbury Flats (Glos) 195

oppida 181

oyster shell, perforated 145

oysters 168

pagi 188

Palmer, M. C. 8

collection 30, 128-30, 132

paving stones 159

pendants $141,144-5,151,152$

phallic pendant 151,152

pipeline fieldwork

coins 130

description 8, 22-6, 23, 24, 25, 26, 27

pits see slag pits

place-name 30, 188

Planning Policy Statement 5197

plant remains 168

plough damage 197, 198-9, 201, 203

plumb-bob 148, 150

Pond Cottage 180, 190

Pond Field 32, 40

ponds 175

pottery, Iron Age and Romano-British 41

assemblages 41-3

discussion

functional types, fine wares and pottery function 95-9, 95, 96, 97, 98

pottery and site chronology 100-2, 180, 182, 184

religious activity $175-6$

status, character and identity 107-10

supply and trade 102-7, 103, 106, 180, 182, 189 taphonomy 99-100

fabric codes and descriptions 44

amphorae 44

black burnished wares 44, 48-50, 49

face pot 110,110

finer fabrics 44, 53, 53

greywares 46-7, 62-6, 63, 65

heavily calcareous tempered wares 44, 50-3, 51, 52

heavily tempered Roman fabric 44, 53-4, 53

mortaria 44-5, 54, 54, 55, 83-5

oxidized fabrics 45-6, 54-62, 56, 57, 58, 59, 60, 61,62

samian 48, 66, 67, 85

Bridgewater excavations 89-90, 91

distribution $86,87,88$

Garrod and Moss excavations 90-1

surface collections 91-5

groups

quantification by fabric 72

Group 1 72-3

Group 273

Group 3 73-4

Group 4 74, 75

Group 5 75-6

Group 6 76-7

Group 77

Group 8 77-8

Group 9 78, 79

quantification by form 79

Group 179

Group 2 79, 80

Group 3 80, 81

Group 4 80, 81

Group 5 80, 82

Group 6 80, 82

Group 7 82, 83

Group 8 82-3, 84

Group 9 83, 84

methodology 43

residuality $78-80$

typologies

greywares 72

Severn Valley ware 72

vessel forms 66

amphorae 66-8

beakers 69

bowls 70-1

bowls (very large) 71

cups 69-70

dishes and platters 71

flagons/jugs 68

jars 68-9

lids 71

mortaria 71

storage jars 69

storage jars/bowls 69

tankards 70 
see also briquetage; crucible fragments pottery, post-Roman 48 pottery stamps 66,67

Price, W. 129

probes $141,145,146$

project

aims and objectives $2-4$

databases 7

methodology

aerial photographic data 6

artefactual analysis 5

buried remains 5

dating 5

environmental analysis 5-6

erosion and deposition data 6

map based analysis 6

sources 4-5

synthesis and discussion 6

monument management 197-205

project design 1

querns $157-8,158,159,159,180,189$

religious activity 175-6, 195

ritual deposit 176

road network $169,170,171-3,172,195-6$

roads, fieldwork 8

Bridgewater 1959 14-15

evaluation 199527

Garrod and Moss 1967 17-18

Holland 193214

Jack 1922 and 1929 13, 14

watching brief 26

see also street system

Ross-on-Wye 173

roundhouses $18,22,174-5,178,182$

Rumney Great Wharf (Glam) 195

Ryeford Bypass 8, 27

setting, glass 137,138

settlement character 169

buildings

domestic $173-5$

mansio 175

mill 175

temple/shrine 175-6

cemetery 176

hinterland 177

Bull Meadow 177

The Great Woulding 177

Wigg 3177

Wigg Meadow 177

industry

ironworking 176-7

other 177

military presence? 169

morphology 169-71, 170 roads and tracks $171-3,172$

settlement chronology

prehistoric 178

late Iron Age

character $180-1$

evidence 178-80, 179

early Roman (c. AD 50-100)

character 182

evidence 181-2, 183

Roman 'small town' (c. AD 100-250)

character 184-6

evidence 184,185

Roman 'small town' (c. AD 250-400)

character 186-8

evidence 186,187

post-Roman 188

Severn, River 196

shrine see temple/shrine

Silures 181, 195

slag

glass 157,177

iron $161-4$

mining of 15, 173, 191, 200

slag pits $15,16,176$

small finds

assemblage 134

catalogue

box fittings and studs $153-4,155$

fasteners and fittings $151,153,154-6,155$

household utensils 147-9, 148

metalworking 156-7

military equipment 151,152

personal ornaments 136-45, 137, 141

recreational equipment $148,149-50,157$

religious items $151,152-3$

structural 156

surveying and measuring equipment 148,150

textile equipment $146-7,148$

toilet equipment $141,145-6$

transport, items associated with 150-2

writing equipment 150,151

dating 134-5

discussion

nature of occupation 135

site in context 135-6

see also stone objects

soil erosion see under erosion and deposition history

soils 31,204

South Worcestershire Archaeological Group 10, 28, 94

spatula 141,146

spearheads

prehistoric $134-5,178$

Roman 135, 151, 152-3, 175

spindle whorls

Roman 135, 146, 147, 159, 160, 160

post-Roman 134

spoons, cosmetic 141,146 
sprue 135,156

statuette, bronze 7, 176

status 107-10, 182, 184, 186, 188

Sterry, Martin 130, 132, 133, 199

stone objects

analysis and discussion 157-9

catalogue $158,159-60,159,160$

street system 169, 173, 182, 184

studs 153-4, 155

Stukeley, William 7, 200

stylus 150, 151

Sudbrook Camp (Mon) 194

Symonds Yat 194

temple/shrine 110, 135, 174, 175-6, 184

terminal 154, 155, 156, 176

terret $135,150-2$

tesserae 161, 174, 184

textile production 177,189

tiles

ceramic 161

stone 161

timber 22

toilet equipment $141,145-6$

tombstone 176

topography and geology 1,31

trade

Iron Age 180-1

Roman 135-6, 182, 184, 188-9

pottery $102-7,182$

stone objects 159,173

Trinovantes 129, 131, 180

tweezers 145,146
Upton Bishop, church 176

Usk (Mon) 171

vessels, metal 135, 136, 147, 148; see also glass vessels

Vulcan 175-6

vulva mount 151,152

wall plaster, painted $161,173,174,184$

Walters and Walters excavations

coins 130

description 8, 20-2, 21

pottery 42

water storage tank 22

Watkins, Alfred 14

weights?, lead 141, 144-5, 146-7, 148, 150

Weston-under-Penyard 188

whetstones 158-9, 159-60, 160

Whitchurch 171, 173, 194

Whitescourt (Glos) 195

Wigg 3178

Wigg Meadows, fieldwork description $8,14,15,26-7$

discussion 178, 184, 186

Wigpool Syncline 173, 191

window glass 156, 161, 173, 184

woodland management 166-7, 177, 192, 193, 196

Woolhope 102

Woolhope Archaeological Section 21

Worcester (Worcs) 171, 194, 195, 196

working hollows 15, 16, 17, 19, 176

Wye, River 196

yards 175 